HEAT FLOW AND TECTONICS OF THE LIGURIAN SEA BASIN AND MARGINS

by

JOHN P. JEMSEK

Submitted to the

Department of Earth, Atmospheric, and Planetary Sciences

Massachusetts Institute of Technology

and the

Department of Geology and Geophysics

Woods Hole Oceanographic Institution

on January 25,1988

in partial fulfillment of the requirements

for the degree of Doctor of Philosophy

Abstract

Heat flow, tectonic subsidence and crustal thickness distributions in the Ligurian Basin are best explained by asymmetric 1ithospheric thinning mechanisms. Over 150 heat flow measurements are made on several transects between Nice, France and Calvi, Corsica on continental slope and rise settings. Thermal gradient determinations are improved using an optimization technique. Piston core data and surface sediment $3.5 \mathrm{kHz}$ reflectivity patterns help constrain thermal conductivity obtained from over 100 in situ stations. P1io-Quaternary stratigraphy is revised using new seismic reflection profiles: a boundary fault system associated with postrift margin uplift, a Pleistocene-age Var Fan construction, and recent diapirism of Messinian salt are indicated. After assessing local therma1 disturbances (mass-wasting, microtopography, and salt refraction), positive heat flow corrections are made for multi-lithologic sedimentation histories and glacial paleotemperatures. Using boundary-layer cooling models, equilibrium heat flow estimates support geologic evidence for 01igocene and early Miocene rifting. Heat flow maxima correlate well with two "oceanic" sub-basins, suggesting that the southeastern trough near Corsica is $\sim 5$ Myr younger, consistent with the southeastern progression of volcanism and back arc rifting in the Western Mediterranean. Tectonic subsidence-crustal thickness trends indicate lithospheric stretching, with heat flow supporting asymmetric sub-crustal 1ithospheric thinning during the conjugate margin formation.

Thesis advisor: Richard P. Von Herzen

Title: Senior Scientist, Wood Hole Oceanographic Institution 

Extended Abstract

We report 176 new heat flow measurements which are distributed on several transects across the Ligurian Basin and margins between Nice, France and Calvi, Corsica. Improved heat flow instrumentation provides in situ thermal conductivity data at points where equilibrium temperatures are known for over 100 gradient determinations. Analytical studies of the in situ continuous-heating method indicate uncertainties of $5 \%$, comparable to those of needle-probe measurements on piston cores. Gamma ray attenuation logs of sediment cores predict vertical variations in conductivity and indicate possible instrumental bias for discretelyspaced thermistor arrangements. Piston core data and $3.5 \mathrm{kHz}$ reflection records demarcate regions of predominantly hemipelagic sediment on the slopes and turbiditic sediment on the Var fan. Mean conductivity values correlate well with surficial sediment patterns and morphology, so that conductivity may be reliably estimated for thermal gradient stations without in situ conductivity. To automate as well as improve equilibrium temperature estimates, the Golden Section Search method is used to optimize effective origin times for heating incurred on probe impact. Numerical modeling of probe thermal structure indicates that an initial temperature perturbation in sediments surrounding the probe may account for observed nonlinearities in standard temperature versus reciproca1time plots. This technique has the largest effect on equilibrium values where high velocities are necessary for successful probe entry.

Heat flow measurements for the entire basin have a weighted mean of $70 \pm 28 \mathrm{~mW} \mathrm{~m}^{-2}$. Systematic regional variations are characterized by an overall asymmetric trend in heat flow, with heat flow averaging about $20 \%$ to $50 \%$ higher on the Corsican side. Significant scatter in regional heat flow values is mainly attributed to variability in the thermal gradients. Sites with very low scatter $( \pm 5-10 \%)$ are located on the continental rise and on the lower Var fan levee. High variability on the continental slope is attributed to environments and processes of canyon formation: microtopography and mass-wasting. To a lesser extent, central basin values are perturbed by narrow salt structures and shallow faults. A reliability assessment suggests that heat flow averages are altered for sites where diapirism produces isolated high values. Contrary to the situation for most young oceanic crust, the sediment cover is extensive so that variability due to hydrothermal circulation is neglibible.

New high-resolution (100-300 $\mathrm{Hz})$ seismic records enable a revised P1io-Quaternary stratigraphy for the basin and a reassessment of the causes of margin uplift. We infer a Pleistocene age for the Var fan development, which is about 1 Myr younger than previous estimates. Recent margin subsidence has been affected by a "boundary fault" system at the base-of-slope, with up to $1 \mathrm{~km}$ uplift near the Cote d'Azur region of southern France. The uplift is consistent with Messinian and Glacial paleostrand line positions and suggests that an erosional-rebound phase occurring within the Alpine folded-and-thrusted complex is responsible for the vertical movement. The boundary fault system is the main 
Extended Abstract (cont.)

seaward dislocation for the uplift is associated with reactivated basement faults residing near the transition to highly-attenuated crust $(<10 \mathrm{~km})$. We associate the timing and geometry of the Var fan development with this uplift.

In order to determine equilibrium lithospheric heat flow, we account for the effects of deposition of up to $5 \mathrm{~km}$ of sediments in the central basin. Sedimentation rates are reconstructed from the shallow and deep seismic data and physical properties are inferred from piston core and borehole data located within the northwestern Mediterranean. We develop a multi-layer compaction and sedimentation model to simulate the thermal effects of the complex Miocene sedimentation history, including the effects of salt deposition and marginal erosion during the Messinian. Sensitivity analyses of the sedimentation model reveal that composite media effects between the sediment layer and basement are similar in magnitude to the effects of compaction. Basement burial rate is the overall determining factor of the heat flow alteration, rather than surface sedimentation rate. Overpressuring in pre-Messinian sediments may decrease the heat flow by an additional 10\%. Sedimentation corrections range from $30 \%$ for the Var levee to zero for the Corsican upper margin. Paleoclimatic corrections of $8-10 \mathrm{~mW} \mathrm{~m}^{-2}$ are a1so deemed necessary for the Mediterranean Sea basins, assuming about a $4{ }^{\circ} \mathrm{C}$ change in bottom water temperature since the late Pleistocene. Uncertainties in corrected heat flow averages due to environmental corrections are genera1ly $<10 \%$, which is smaller than data variability in most cases. Differences in sedimentation rates cannot account for local variations between stations ( $\sim 2 \mathrm{~km}$ spacing), but somewhat reduces regional deviations between sites. The final corrected basin heat flow retains an asymmetric pattern, consistent with the asymmetric continental heat flow values observed on the conjugate borderlands.

Corrected values of 102 to $120 \mathrm{~mW} \mathrm{~m}^{-2}$ for northwestern and southeastern central basin sites, respectively, are consistent with boundary-layer cooling estimates for basin opening between 18-25 Myr ago. These results, integrated with calculations of basement subsidence and recent crustal thickness measurements, require a nonuniform spatiotemporal development for the Ligurian Basin. Heat flow correlates well with two basement troughs oriented parallel to the basin axis. Two modes of asymmetric 1ithospheric thinning account for the basin development: an intrabasinal rift jump (pure shear) and low-angle detachment faulting (simple shear). Some progression in rifting ages across the basin is suggested by younger volcanics on the CorsicanSardinian block and the general southeastern arc-trench migration for the Western Mediterranean. The NW and SE margin heat flow and crustal data are consistent with asymmetric nonuniform 1 ithospheric extension similar to that predicted by detachment faulting models. Thus, the asymmetric development of the Ligurian is envisioned to be quite similar to the drilling and seismic stratigraphic evidence for the multiplerifting history of the Tyrrhenian Basin (Mascle and Rehau1t, 1988). 
Extended Abstract (cont.)

With our detailed environmental analysis, we may place more confidence in tectonic models derived from heat flow than low-amplitude magnetic anomaly patterns which favor a symmetric basin opening. Lateral heat flow appears to be suppressed for marginal basins, despite their generally narrow widths. Back arc extension in the Liguro-Provencal Basin is deemed important to the subsidence history of the basin. Negative residual basement depths of almost $1 \mathrm{~km}$ are explained by an anomalously cool upper mantle maintained by the limited influence of deep asthenospheric upwelling behind subduction zones. We speculate that "normal" high heat flow observed in marginal basins is an artifact of higher mantle thermal conductivity for highly-depleted mantle, created by plate recycling and hydrous melting in the back arc setting. 
Table of Contents

Abstract . . . . . . . . . . . . . . . . . . . 1

Table of Contents . . . . . . . . . . . . . . . 6

List of Figures... . . . . . . . . . . . . . . . 10

List of Tables . . . . . . . . . . . . . . . . 14

Preface.......................... 15

Acknowledgements . . . . . . . . . . . . . . . 17

Chapter 1. Introduction . . . . . . . . . . . . . . 21

Chapter 2. Geological setting of the Ligurian Basin: . . . . . 29

Shallow structure and stratigraphy

2.1 Regional geological evolution . . . . . . . . . . 31

2.2 Surface geology . . . . . . . . . . . . . . 38

Physiography . . . . . . . . . . . . . . . . 38

Echo character associations of the North Corsican Basin 41

Observations of the Cote d'Azur margin and central basin 50

Implications of morphology and surface geology . . . . . 53

2.3 General stratigraphy . . . . . . . . . . . . . 54

2.4 Shallow structure .. . . . . . . . . . . . 59

Var fan construction . . . . . . . . . . . . 61

Margin uplift and the boundary fault system . . . . . 62

Lateral variability and genesis of salt structures . . . . 71

Implications of P1io-Quaternary geology . . . . . . . 82

Chapter 3. Geothermal survey . . . . . . . . . . . . 85

3.1 Field program .... . . . . . . . . . . . . 87

Logistics . . . . . . . . . . . . . . 87

Navigation . . . . . . . . . . . . . . . 91

Instrumentation and data acquisition . . . . . . . . 92

3.2 Data reduction ... . . . . . . . . . . . . 96

Temperature gradient measurement . . . . . . . . 97

Therma1 conductivity measurement .......... 103

3.3 Heat flow results . . . . . . . . . . . . . 108

Heat flow calculation ................ 108

Observed heat flow patterns and comparison to other data . 110

Chapter 4. Environmental disturbances and heat flow corrections . . 115

4.1 Causes of local heat flow variations . . . . . . . . 117

Topographic effects . . . . . . . . . . . . . 118

Effect of sedimentary processes . . . . . . . . 120

Effect of bottom water temperature variations . . . . 128

Effect of subsurface structures ........... 134

Reliability of measurements . . . . . . . . . 138 
Table of Contents (cont.) $\quad$ Page

4.2 Corrections for sedimentation and erosion . . . . . . . 140

Sedimentation and compaction mode1... . . . . . . 140

General sensitivity study . . . . . . . . . . . 147

1) Effect of pore water flow . . . . . . . . . 148

2) Effect of thermal blanketing . . . . . . . . 152

3) Effect of compaction constants . . . . . . . 154

4) Multi-layer sediment systems . . . . . . . . 157

Parameter estimation: Northwestern Mediterranean Basin 162

Sedimentation correction results . . . . . . . . . . 174

4.3 Corrections for paleoclimatic temperature variations . . . 175

Inference of late Pleistocene bottom water temperatures 175

Paleoclimatic model results . . . . . . . . . . . . 179

4.4 Corrected heat flow results . . . . . . . . . . . 182

Chapter 5. Structural and thermal evolution . . . . . . . . 189

5.1 Basin structure .................. 191

Tectonic subsidence ................ 192

Deep seismic data . . . . . . . . . . . . 199

Gravity anomalies . . . . . . . . . . . . . 202

Magnetic anomaly patterns ............ . 204

Basin asymmetry ................ . . 208

Summary of basin structure . . . . . . . . . . . . 211

5.2 Rifting processes and geophysical models . . . . . . . 212

Crustal stretching . . . . . . . . . . . . 213

Lithospheric doming . . . . . . . . . . . . 215

Me1t segregation and emplacement ........... 217

1) Underplating . . . . . . . . . . . 218

2) Dikes................... . . 219

3) Mantle melting and isostasy .......... . 220

5.3 Central basin evolution .............. . . 224

Cooling of oceanic lithosphere: an overview . . . . . 225

Therma1 age estimates .............. . 232

1) Sensitivity of age estimates . . . . . . . . 233

2) Heat flow vs. age ............... 235

Rift jump mode1 .................. 238

Latera1 heat loss . . . . . . . . . . . . . 246

Residual depth anomaly of back arc basins . . . . . 250

Chapter 6. Conc1usion . . . . . . . . . . . . . . 261

References . . . . . . . . . . . . . . . . . 269

Biographical Note . . . . . . . . . . . . . . . 297 
Table of Contents (cont.) Page

Appendix 1. Heat flow and lithospheric thinning in the Ligurian 301

Basin (N.W. Mediterranean) - by J. Jemsek, R. Von

Herzen, J. P. Rehault, D. L. Williams, and J. Sclater

A1.1 Abstract . . . . . . . . . . . . . . 303

A1.2 Introduction . . . . . . . . . . . . . . . 303

A1.3 Geologic setting . . . . . . . . . . . . . . . 304

A1.4 Heat flow and subsidence results.......... . 306

A1.5 Discussion . . . . . . . . . . . . . . . . 313

A1.6 Acknowledgements . . . . . . . . . . . . . . 314

Appendix 2. Measurement of in situ sediment thermal conductivity: 315 Continuous-heating method with outrigged probes -

by J. Jemsek and R. Von Herzen

A2.1 Abstract . . . . . . . . . . . . . . . . . 317

A2.2 Introduction .................... 318

A2.3 Measuring thermal conductivity in situ with continuous- 323 heating

Outrigger probe instrumentation and data acquisition 325

Analytical development of the in situ technique .... . 331

1) Temperature history of a probe subjected to . . . 331 frictional heating

2) Applying the transient line heat source . . . . 335

A2.4 Analysis of instrumental error ............ . 339

Effect of heater output ............. . 339

Effect of heater origin time . . . . . . . . . . 340

Effect of thermal contact resistance . . . . . . . 342

Effect of estimating thermal diffusivity . . . . . . . 343

Use of a biaxial probe design ............ 352

A2.5 Field testing .................. 357

Comparison of in situ measurements to core sample values 357

Reliability of mean conductivity estimates . . . . . 362

1) GRAPE-derived conductivity data ....... 363

2) Effect of thermistor spacing ........... 365

Improving heat flow estimates with in situ conductivity . 371

A2.6 Summary ................... 374

A2.7 Acknowledgements .............. . . 376

Appendix 3. Equilibrium temperature estimation using the Golden 377 Section Search: Numerical simulations of probe thermal response

A3.1 Abstract . . . . . . . . . . . . . . 378

A3.2 Introduction .................. . 379

A3.3 Cylindrical decay function theory . . . . . . . . 380

A3.4 Golden Section Search method ............. 385

A3.5 Heat flow applications ............ . . 386 
Table of Contents (cont.)

A3.6 Numerical mode1 .................. 395

Explicit finite difference formulation ........ 396

Simulation of analytical solutions . . . . . . . . . 400

Physical models of the time advance. . . . . . . . . 402

A3.7 Discussion . . . . . . . . . . . . . . . . . . 407

Equilibrium temperature estimation . . . . . . . . . 407

Thermal contact resistance . . . . . . . . . . . . 409

Probe thermal response: evidence from continuous-heating 410

A3.8 Sumnary ... . . . . . . . . . . . . . 411

Appendix 4. Heat flow data tables and plots ......... 415

Appendix 5. Seismic profiles and heat flow results . . . . . 459 
Fig. 1.1 Map of the western Mediterranean region.

Fig. 2.1 Paleogeographic and structural sketch map of the Western Mediterranean from the late 01igocene ( $30 \mathrm{Ma}$ ) to the present.

Fig. 2.2a Simplified physiographic map of the NW Mediterranean.

Fig. 2.2b Bathymetric map of the Ligurian Basin.

Fig. 2.3 Map of echo character distribution in the Northwest Corsica Basin.

Fig. 2.4 Exemplary $3.5 \mathrm{kHz}$ profiles of echo facies.

Fig. 2.5 Plot of $3.5 \mathrm{kHz}$ profile, mean piston core thermal conductivity values, and downcore plots showing conductivity stratification.

Fig. 2.6 Example of salt structures in $3.5 \mathrm{kHz}$ and singlechanne1 profiles.

Fig. 2.7a Multi-channe1 reflection seismic section in the deep Liguro-Provencal Basin.

Fig. 2.7b Multi-channe1 reflection seismic section from the eastern Menorca continental margin.

Fig. 2.8 Location map of Ligurian Sea heat flow data and single-channel profiles.

Fig. 2.9 Interpreted single-channel profile from Cote d'Azur margin.

Fig. 2.10 Temperature history for the Messinian evaporite unit.

Fig. 2.11 Burial temperatures for the Messinian evaporite unit.

Fig. 3.1 Location map of Ligurian Sea heat flow groups.

Fig. 3.2 Histogram of mean thermal conductivities by region.

Fig. 3.3a-c Histograms of observed heat flow by region.

Fig. 4.1 Heat flow with time due to sudden erosion. 
List of Figures (cont.) Page

Fig. 4.3 Heat flow versus time since dissipation of anomalous 132 bottom water.

Fig. 4.4 Nusselt number of surface heat flow versus total sediment 150 thickness for high sedimentation rates.

Fig. 4.5 Effect of thermal blanketing on heat conduction through 153 a layer over a halfspace.

Fig. 4.6 Heat flow versus time for various compaction parameters 155 $\phi_{0}$ and $\lambda$.

Fig. 4.7 Burial rate profiles for compaction models. 156

Fig. 4.8 Sediment layer bulk conductivity versus time. 158

Fig. 4.9 Surface heat flow alteration, sedimentation rate and 160 basement depth histories in the central Ligurian Basin.

Fig. 4.10 Heat flow alteration and sedimentary evolution for the 163 upper margin.

Fig. 4.11 Porosity versus depth for NW Mediterranean sediment. 164

Fig. 4.12 Heat flow depression due to different sediment mode1s. 166

Fig. 4.13 Heat flow alteration and sedimentary evolution of sites 173 on the Menorca Rise, western Balearic Basin.

Fig. 4.14 Anomalous heat flow resulting from variations in late 181 Quaternary bottom water temperatures.

Fig. 4.15 Contour map of the Ligurian Basin corrected heat flow. 183

Fig. 5.1 Contour map of total tectonic subsidence. 198

Fig. 5.2 Comparison of two Ligurian Basin crustal cross-sections. 200

Fig. 5.3 Free air gravity contour map of Ligurian Basin. 203

Fig. 5.4 Magnetic anomaly contour map of Ligurian Basin. 205

Fig. 5.5 Sensitivity of heat flow and subsidence age estimators. 234

Fig. 5.6 Corrected mean heat flow vs. age for marginal basins. 237

Fig. 5.7 Subsidence values vs. oceanic crustal thickness. 254 
List of Figures (cont.) $\quad$ Page

Fig. 5.8 Unloaded mantle depths vs. (age $)^{1 / 2}$ for major ocean and 255 marginal basins.

Fig. 5.9 Relative change in ridge crest elevation due to upper 258 mantle temperature changes.

Fig. A1.1. Map of Ligurian Sea with heat flow and multichanne1 305 locations.

Fig. A1.2. Schematic crustal section of Ligurian Basin. 307

Fig. A1.3. Tectonic subsidence vs. crustal thinning. 311

Fig. A2.1. The WHOI outrigger heat flow pogo probe. 319

Fig. A2.2. Diagram of WHOI outrigger fin and probe assembly. 322

Fig. A2.3. Cross section of thermal probes. 326

Fig. A2.4. P1ot of digital temperature record. 329

Fig. A2.5. P1ot of temperature vs. the reciprocal of time. 333

Fig. A2.6. P1ot of modified temperature, $\theta-\theta_{1}-b t_{-1} \quad 337$ vs. $G(\alpha, \tau)$.

Fig. A2.7. Conductivity uncertainty due to initial time. 341

Fig. A2.8. Water content vs. needle-probe conductivity values. $\quad 346$

Fig. A2.9. P1ot of thermal diffusivity versus conductivity. $\quad 347$

Fig. A2.10. Conductivity uncertainty due to $\alpha$. 348

Fig. A2.11. Conductivity uncertainty due to $\tau$. 350

Fig. A2.12. Conductivity uncertainty due to thermal diffusivity. 351

Fig. A2.13. Difference in temperature for the probe mode1 vs. $\quad 354$ the off-axis model.

Fig. A2.14. Conductivity obtained assuming different probe radii. 356

Fig. A2.15. P1ot of the harmonic mean conductivity for needle- 359 probe and in situ data.

Fig. A2.16. Comparison of conductivity-depth profiles of piston 361 core and pogo probe stations. 
List of Figures (cont.) Page

Fig. A2.17. P1ot of needle-probe conductivity values versus bu1k 366 density.

Fig. A2.18. Downcore plot of GRAPE-derived conductivity profile 367 and needle-probe conductivity values

Fig. A2.19. Correlograms show the percent change in mean 369 conductivity from the true mean.

Fig. A2.20. Measured heat flow values as a function of therma1 gradient and in situ thermal conductivity.

Fig. A3.1. Plot of temperature vs. inverse time showing convex upward decay and effect of time shift.

Fig. A3.2. Time advance and resultant slope of $T-t^{-1} \mathrm{fit}$.

Fig. A3.3. Plot of linear correlation coefficient against time shift value.

Fig. A3.4. Outline of the numerical setup of the probe model.

Fig. A3.5. Nondimensional plot of radial temperatures vs. time. 403

Fig. A3.6. Initial conditions for probe and disturbed zone. $\quad 404$

Fig. A3.7. Effect of an increasing disturbed zone radius on 406 time shift and equilibrium temperatures.

Figs. A4.1 - A4.17. In situ temperature and thermal conductivity 424 versus depth.

Figs. A4.18 - A4.21. Temperature versus depth plots and linear regression results for stations without in situ conductivity.

Figs. A4.22 - A4.24. Plots of thermal conductivity versus depth 448 for piston cores.

Fig. A5.1 Track lines of seismic profiler data used for structural 461 control of heat flow data.

Fig. A5.2 Track lines of DELTARHO II seismic/SeaBeam survey.

Figs. A5.3 - A5.26 Seismic sections of the profiles used in heat 463 flow analysis. 
2.1 Echo character types of the North Corsican Basin. . . . . . 42

3.1 Ligurian Basin regional heat flow. . . . . . . . . . 88

4.1 Physical constants for sedimentation corrections. . . . . 146

4.2 Summary of corrected heat flow, subsidence, and crusta1 . . 171 thickness.

4.3 Bottom water paleotemperature estimates. . . . . . . 178

5.1 Mineralogy, density and isostasy of the uppermost mantle. . 223

5.2 Lithospheric constants . . . . . . . . . . . . . 227

5.3 Heat flow and depth-age relations $<80$ Myr lithosphere . . . 229

5.4 Reliable mean heat flow estimates of marginal basins . . . . 336

A1.1 Preliminary heat flow and subsidence data. . . . . . . 309

A2.1 Characteristic time constants for thermal probes. . . . . . 324

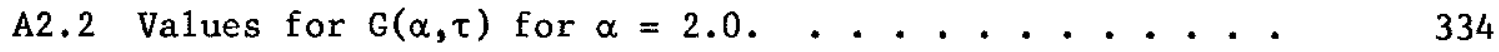

A2.3 Selected piston core and in situ thermal conductivity data. 360

A2.4 Deviations of mean conductivity due to discrete sampling. . . 370

A3.1 Time-shifting results for individual outrigger probes. . . 391

A3.2 Reference states of physical parameters used in numerical 397 solutions.

A4.1 Ligurian Sea heat flow stations. ...........418

A4.2 Ligurian Sea piston core stations. . . . . . . . . . 447

A4.3 Other Ligurian Sea heat flow and piston core stations. . . 452

A4.4 Sedimentation, subsidence and corrected heat flow of . . . 454 Ligurian Basin stations.

A5.1 Heat flow stations presented in seismic profiles. . . . . 463 
Preface

Geothermal studies of the young marginal basins of the western Mediterranean were initiated by J. Sclater and R. Von Herzen. The proposed work had two objectives: 1) to investigate the relations of heat flow, depth and age in the oceanic regime of the marginal basin, and 2) to examine relationships between heat flow, subsidence, extensional faulting, and crustal thickness on the adjacent passive margins. The first phase of this study was conducted in collaboration with U. of Cambridge scientists (K. Louden, I. Hutchison and J. Duschenes) and consisted of a heat flow and seismic refraction survey of the Balearic and Tyrrhenian Basins; the heat flow results have been presented by Hutchison et a1. (1985) in which my contribution was the reduction of the WHOI data (seismic results are given by Duschenes et a1, 1986).

The subject of this thesis, the heat flow and tectonics of the Ligurian Basin, is the second phase of the Mediterranean project. Three campaigns were performed: two heat flow cruises and one high-resolution single-channel seismic profiler experiment. R. Von Herzen coordinated the first heat flow cruise in 1982 with J. P. Rehault, D. L. Williams, J. Sclater, S. Pelletier and myself participating. I was responsible for the maintenance of the probe hardware, data reduction, and the formulation of the heat flow results. My thesis proposal was essentially a continuation of the Ligurian Basin geothermal study and laid the groundwork for additional heat flow and seismic data collection. J. P. Rehault, M. Dougherty, S. Pelletier and myself made the second suite of heat flow measurements in 1984, with the heat flow operations coordinated by myself. Single-channel data were collected in 1985 by J. P. Rehault and myself.

The main objective of this thesis is to present and analyze Ligurian Basin heat flow observations in 1 ight of simple thermal mode1s for marginal basin formation. Before tectonic interpretations of rapidly infilling sedimentary basins were made, a thorough understanding of the local geologic environment was necessary. This environmenta1 analysis was made using bathymetry, piston core data, $3.5 \mathrm{kHz}$ echo records, 60-300 $\mathrm{Hz}$ single-channel reflection profiles, and deep seismic data. From these data, I determined surface sediment thermal conductivity patterns and general sediment thickness distributions, and revised previous P1io-Quaternary sedimentary and tectonic evolutionary schemes for the Ligurian Basin (Chapter 2). Data reduction procedures included modifications due to the incomplete nature of some in situ therma1 conductivity and thermal gradient measurements (Chapter 3 ). After determining the reliability of heat flow values, I applied a multi-layered sedimentation and compaction mode1 to estimate the effect of the complex depositional history for the Mediterranean. A paleoclimatic correction in addition to sedimentation corrections were used to determine the final values. These corrected data constrain an equilibrium heat flow contour map for the Nice-Calvi swath of the 
Preface (cont.)

Ligurian Basin (Chapter 4). The asymmetric heat flow distribution is related to the total tectonic subsidence, suggesting a nonuniform spatiotemporal development for the basin. Thermal and elevation data constrain the main rifting processes encountered in the basin, but petrology and thermal (half-space cooling) models were also incorporated in the final basin evolution scheme (Chapter 5 ).

The chapters comprising the main body of the thesis were conceived and written by myself. Dick Von Herzen and Jean-Pierre Rehau1t will contribute further in various publications to be produced from the four main chapters. Three independent papers are given in the appendices, mostly in support of the methods of data reduction. The paper presented in Appendix 1 (Jemsek, Von Herzen, Rehault, Williams, and Sclater, 1985) provides preliminary theories on the thermal evolution of the Ligurian Basin. All authors participated in some aspect of the field program. I performed the data reduction and most of the heat flow and subsidence analyses. J. P. Rehault provided sediment thickness data and preliminary drafts of the map and cross-section figures. R. Von Herzen wrote most of the original manuscript. The final paper was rewritten and revised by myse1f. The methods paper (Jemsek and Von Herzen, 1988) discusses the in situ thermal conductivity measurements and Ligurian Basin sediment properties and is presented in Appendix 2. This paper was written by myself. $R$. Von Herzen conceived the instrumentation design and provided critical reviews and suggestions on the organization and content of the paper. Acknowledgements are stated at the end of the paper. A related technical report was also prepared by Jemsek, Von Herzen, and Andrew (1985). Appendix 3 developed out of efforts to optimize the heat flow results of marine geothermal data. I address the physical justification of correcting probe thermal data by automated time-shifting. All the work presented in the current version are my own. Discussions with $\mathrm{C}$. Fang on data reduction techniques and S. F. Daly on numerical computations were valuable in the development of this paper. C. Fang and R. Von Herzen made helpful suggestions on the manuscript. Appendices 4 and 5 include detailed presentation of the data in the form of summary tables, summary plots, and seismic reflection profiles.

Financial support was obtained through NSF grants OCE 84-09170, OCE 80-25181, and OCE 80-24287. The costs of the field program were shared by the French government via CNRS and the U. of Paris. A monetary gift from Gulf $0 i 1$ Co was also recieved. The Education office of the M.I.T./W.H.O.I. Joint Program in 0ceanography assisted in finances as we11. Special thanks goes to my parents for their part in seeing the thesis to its completion. 
Acknowledgements

I extend my gratitude to Dick Von Herzen, who influenced the thesis in numerous ways and helped me realize my possibilities during the course of my graduate research. Sean Solomon oversaw the beginning of my M.I.T. graduate research and continued to provide guidance during my stay at Woods Hole. John Sclater introduced me to my eventual thesis project and occasiona11y provided unconditional enthusiasm and praise from U. of Texas. Jean-Pierre Rehault has been the host and co-chief scientist for all field aspects of the study and served as my mentor on Mediterranean geology; he and his family made my sojourns to France a special experience which I hope to share again.

The final version of the thesis was improved with reviews by Dick Von Herzen, Jean-Pierre Rehau1t, A1 Uchupi, Glenn Jones, Jim Cochran, Sean Solomon, and Henry Dick. Additional comments by Tanya Furman, Jack Casey, Hans Schouten, Neil Slowey, Marty Dougherty and Nafi Toksoz are also appreciated. I thank A. Malinverno, Jim Cochran and Cristophe Pinet for providing preprints of their work.

I received support from many coworkers during my stay at Woods Hole. Foremost was Dick Von Herzen who contributed his laboratory facilities and heat flow expertise. Skip Pelletier made sure the field instrumentation was performing adequately. Paul Andrew, Sean Tavares, and Jim Broda assisted in peripheral hardware developments. I thank Ian Hutchison for contributing his sedimentation correction program and Peter Schweitzer for donating his plotting software and statistical expertise. Steve Daly and Bernard Celerier offered insights into many of the geothermal problems encountered. My fellow heat flow colleagues, Marty Dougherty, Changle Fang, and Matt Cordery, offered assistance during data analysis. Discussions with Brian Tucholke, Cindy Ebinger, Kim Klitgord, Marie Aubry-Berggren, Car1 Bowin, Gilbert Bellaiche and the reviewers proved helpful during the development of this work. Administrative assistance given by Jake Peirson, Abby Jackson, Mary Athanis, Roy Smith, Pam Foster, Annie Kauffman and Alice Tricca is also deeply appreciated.

During the Ligurian Sea oceanographic expeditions, the captain and crew of the $R / V$ Catherine-Laurence performed admirably under the sometimes formidable weather conditions. The group at the Laboratoire de Geodynamique Sous-Marine, Villefranche-sur-mer was also immensely supportive during the field program; I especia1ly thank Yves Descatoire, Jacqueline Corbelle, and Emmanual Blarez. Their hospitality complemented the charm of the French Riviera. 
Acknowledgements (cont.)

This thesis is a culmination of laboratory developments and field experiments, and the more sedentary activities of proposal writing, data analysis, numerical modeling, literature reviews, etc. What may not be apparent is that the final product, this thesis sealed with 2 " wide binder clips or preferrably a gold staple, entailed more than simply writing up the results. It required an attitude (namely determination) sustained by the moral and physical support of nearly every concerned citizen that crossed my path. I am truly indebted to my friends and coworkers: those who have occasionally provided a roof over my head, delectable delights, warm spirits, and thoughtful conversation. They include Steve Daly, Mark Traverso, Tim Genta, Jim Hoeffler, Changle Fang, Matt Cordery, Candy Lane, Colin Baker, E1len Gray, Karl Coyner, Paul Huang, Natalie Trousof, Marty Dougherty, Robin Coen, Bernward Hay, Alice Tricca, Annie Kauffman, Tanya Furman and Peter Meyer to name a few. But most of a11, I thank my family for all that they have done. 
This work is dedicated in memory of Jean Baranowski-Marks. As an office-mate, she was sunshine amongst the clouds. 
$-20-$ 
$-21-$

Chapter 1

Introduction 
Our understanding of continental margins is great1y improved since the realization that principles developed for the thermal evolution of the deep ocean floor also apply to marginal continental lithosphere. According to plate tectonic theory, the thermal lithosphere is defined as the rigid, conductive outer shell of the Earth and includes the crust and uppermost mantle material. The asthenosphere is the low viscosity medium beneath the lithosphere which convects heat upward and is consequently nearly isothermal. The fundamental similarity between continental margin formation and sea-floor spreading is that they are both induced by an extensional stress regime created in part by the divergence of two lithospheric plates, i.e., rifting. During rifting, the 1ithosphere thins by two simple necking processes: brittle faulting in the upper crust and ductile flow in the lower lithosphere. In order to conserve mass, the asthenosphere moves upward to replace the 1ithosphere removed by thinning processes. Consequently, the entire column of material at the rift has an average temperature that is much higher than normal, so that higher elevations are maintained due to thermal expansion effects (Pratt model of compensation). Crusta1 attenuation or stretching causes isostatic compensation of the low-density crust with high-density mantle which leads to lower elevations (Airy mode1 of compensation).

In the ocean basins, magma production by pressure-release me1ting proceeds to accrete crust in almost a steady-state manner at mid-ocean ridges, so that the most apparent change in the ocean lithosphere is due to the cooling and contraction of the 1ithosphere with age. Sclater and coworkers (e.g., Parsons and Sclater, 1977) have characterized the 
thermal evolution of young oceanic lithosphere by boundary layer theory, resulting in simple square root of age laws for heat flow and depth. The subsidence rates determined for the oceans also appear to reproduce the general subsidence history for many rifted margins (e.g., Sleep, 1971). Thus, the first-order correlation of oceanic and continenta1 subsidence suggests that oceanic and continental rifts maintain thin lithosphere. Since the details of basin formation (faulting and crustal thinning mechanisms, subsidence, doming, volcanism, partial melting, etc.) are related to the nature of the initial thermal anomaly, heat flow measurements are an obvious tool to study sedimentary basin formation.

On1y a few attempts have been made to match models of sedimentary basin formation with geothermal and subsidence data. Royden et a1. (1983) found excellent agreement between heat flow, subsidence and geologic data in the 10-20 Ma Pannonian basin system in which heat flow correlated with rates of thermal subsidence for a number of extensional geometries. Hutchison et al. (1985) primarily used heat flow and age determinations to show that a progression of opening has occurred in the western Mediterranean basins.

The primary objective of this work is to interpret the thermal regime and tectonic evolution of the central basin and adjacent margins of the Ligurian Basin, also located in the western Mediterranean (Figure 1.1). Sea-floor spreading, continental extension and back arc rifting are involved in the basin development. The rifted margins of the Ligurian Basin are one of the few geologically youthful examples with sufficient sediment cover to enable reliable heat flow measurements. 


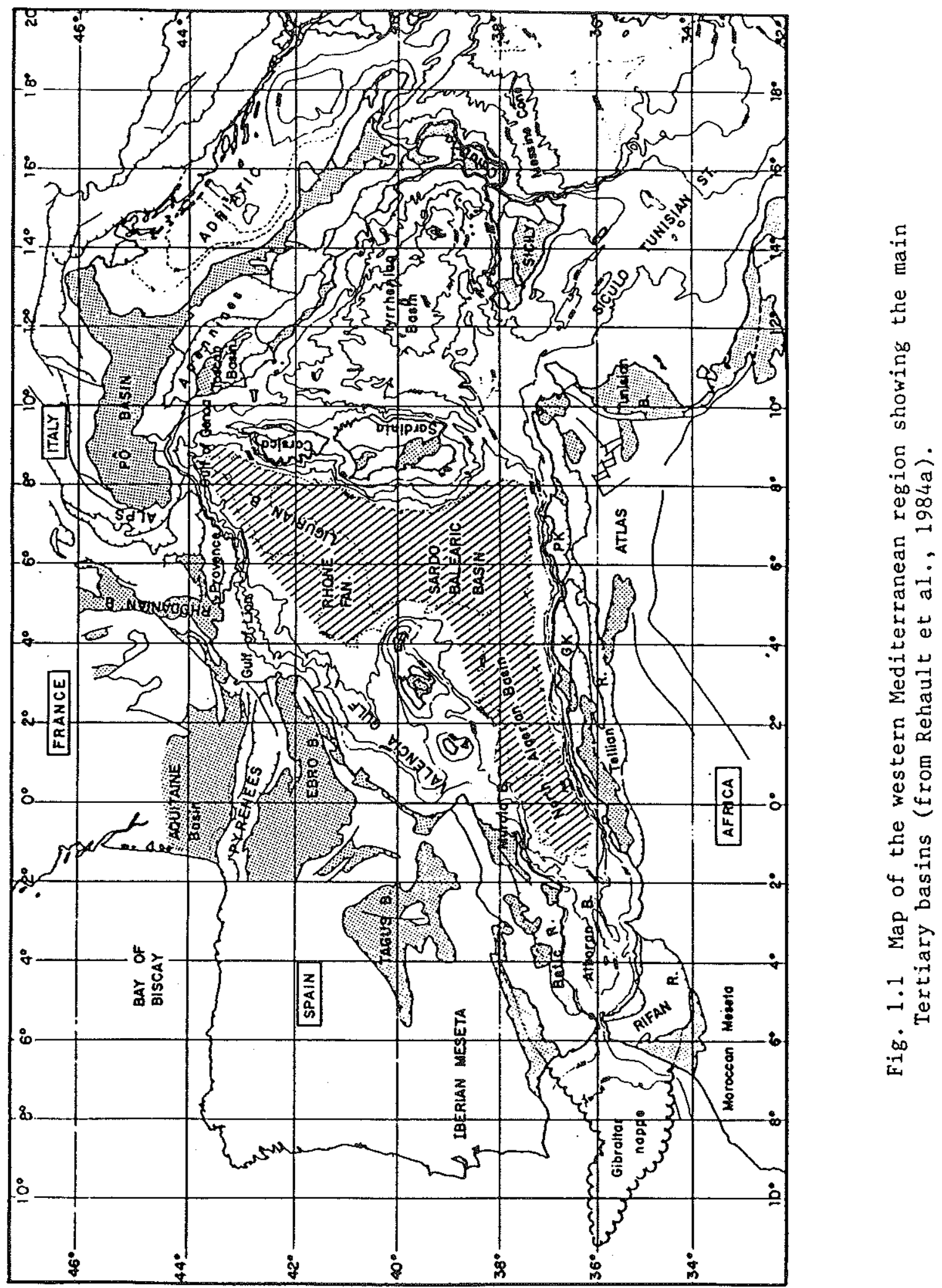


The abundant geologic and geophysical data in this area provide an exce11ent background for geothermal and subsidence analysis.

Several different mode1s of rifting and lithospheric heating may be used to explain observations of subsidence, heat flow and crustal thinning. The "active mantle" hypothesis of Sengor and Burke (1978) considers the thermal anomaly as the causal event leading to rifting. This implies that the early phase of rifting is characterized by thermal doming and general uplift (Sleep, 1971; Falvey, 1974). Crustal thinning beneath the margin (Sheridan et a1., 1979; Avedik et a1., 1982; Le Douaran et al., 1984) and normal faulting in the upper crust (Montadert et a1., 1979; Avedik et a1., 1982; Le Pichon and Barbier, 1987) support models involving extensional thinning of the 1ithosphere during rifting. McKenzie (1978) originally formulated the uniform extension (simple stretching) model in which the amount of extension is constant with depth through the whole lithosphere. Uniform extension implies "passive" rifting by horizontal plate motions instead of "active" vertical thinning of the lithosphere by thermal mechanisms. In order to explain early subsidence histories from well data, Royden and Keen (1980) developed the modified (nonuniform, two-layer, depth-dependent) extensional model in wich the upper and lower lithosphere thin by different amounts. Proposed mechanisms for nonuniform thinning include removal of the lower lithosphere by asthenospheric convection (Buck, 1986; Keen, 1984; Steckler, 1985) or by asymmetric 1ithospheric fau1t block geometries (Wernicke, 1985; Royden et al., 1983). 
Heat flow on the southern French and northern Corsican margins is a result of four factors: a) equilibrium heat flow into the base of the 1ithosphere, estimated to be roughly equivalent to that beneath old continents and oceans (Sclater et a1., 1980), b) heat flow resulting from lithospheric thinning during rifting (this flux increases with amount of extension and decays with time), c) heat flow due to the radioactive heat production in the rifted continental crust (Foucher and Sibuet, 1980); and d) modification of the basement heat flow by sediment deposition, compaction, structural heterogeneity, and radiogenic heat content of the overlying sediments. Surface heat flow is further modified by horizontal conduction of heat from extended crust to the relatively cooler less extended continental block (Alvarez et a1., 1984; Cochran, 1983; Steckler and Watts, 1980) and the effects of a prolonged duration of rifting (Cochran, 1983; Jarvis and McKenzie, 1980).

Tectonic interpretation of heat flow measurements on the thin oceanic-type crust of the central Ligurian Basin reduces to a simpler problem since the total radiogenic heat contribution is small. With borehole chronostratigraphy and radiometric age determinations of regional volcanics (e.g., Rehault et al., 1984a), a meaningful comparison can be made between observed heat flow and age with that predicted by therma1 models for major ocean basin lithosphere. Using sediment-unloading models, the basement depth versus age relationship can also be tested. Complications arise due to the fact that spreading centers and magnetic anomalies are not we11-established in the the western Mediterranean. Moreover, the sediment-unloaded basement depths are up to $1 \mathrm{~km}$ deeper than that predicted for normal oceanic crust of 
the same age (Appendix 1), similar to the negative residual depths of the western Pacific marginal basins.

This thesis is comprised of four main chapters. In Chapter 2, we review the geologic evolution and tectonic setting of the western Mediterranean, with special emphasis on the late Quaternary sedimentary development in the Ligurian Basin. The surficial geology is examined using $3.5 \mathrm{kHz}$ echo character studies to better understand the sediment patterns of the distal regions of the Var Fan and to map the thermal conductivity of the surface sediment. We relate margin uplift, the Var abyssal fan development, and salt diapirism to seismic stratigraphy and shallow structure derived from new reflection data. In Chapter 3 , the heat flow cruise operations and data processing are discussed. The data analysis draws heavily from the error analysis of in situ thermal conductivity measurement using continuously heated line source (Appendix 2 ), and the optimization of equilibrium temperature determinations (Appendix 3). The heat flow is predictably scattered on the upper margins where numerous gullies exist and mass-wasting is active. The continenta1 rise environments give the most uniform surface heat flow in the basin, with resolution equal to detailed site measurements on we11-sedimented regions of old seafloor.

With the extensive heat flow and seismic coverage used in our study, we are able to test concepts of thermal and tectonic evolution. However, the geophysical significance of the heat flow data is not immediately obvious unless the environmental influences on measurements are taken into consideration. In Chapter 4, piston core, $3.5 \mathrm{kHz}$ seismic, structural, and oceanographic data are all considered in detail 
to minimize data uncertainties and assess the reliability of using heat flow to evaluate 1ithospheric-scale processes. Corrections of up to $\sim 30 \%$ are required to compensate for the effect of moderately high average sedimentation rates $\left(\sim 300 \mathrm{~m} \mathrm{Myr}^{-1}\right)$ in north central basin. Based on transfer function, oxygen isotopic, and amino acid racemization studies of foraminifera data, we establish evidence that a $8-10 \mathrm{~mW} \mathrm{~m} \mathrm{~m}^{-2}$ paleoclimatic correction is necessary for Mediterranean heat flow data. A contour map of the final heat flow values show a very clear asymmetric trend across the basin, indicating that the 1ithosphere thickness is substantially greater beneath the Provencal margin compared to the Corsican margin.

In Chapter 5, we interpret this asymmetric distribution in terms of basin structure derived from subsidence and crustal thickness, and to simple ha1f-space cooling models which predict heat flow versus age relationships. Within the context of back arc tectonics, the simplest explanation of these asymmetric patterns is that a major rift jump occurred $\sim 21$ Ma during the transition from graben and continental trough formation to crustal accretion. The we11-defined heat flow distribution provides a unique constraint on marginal basin formation which is in disagreement with previous models of basin opening (e.g., Burrus, 1984; Rehau1t, 1981; Bayer et a1., 1973), but is consistent with the younger Tyrrhenian back arc basin which has experienced progressive rifting toward the island arc (Kastens, Mascle et al., 1987; Mascle and Rehault, 1988). 
Chapter 2

Geologic Setting of the Ligurian Basin; Shallow Structure and Stratigraphy 
Heat flow and basement subsidence of small oceanic basins are a1tered in varying degrees by syn-rift and post-rift sedimentary processes. For instance, sediment deposition not only creates a load on the underlying 1ithosphere, but also depresses the thermal structure due to the advective and composite media effects of thermal blanketing of the basement. In this chapter, we review geologic evidence for the development of the Ligurian Basin and present new observations of the complex sedimentary and structural evolution.

The geology and tectonics of the Western Mediterranean Basin and associated borderlands support an 01igocene-Miocene rifted-drifted basin formation in a probable back arc basinal setting (Biju-Duval et al., 1978; Biju-Duva1, 1984; Rehault et a1., 1984a, 1985). However, P1iocene and Quaternary stratigraphy and structures derived from and new $3.5 \mathrm{kHz}$ and $50-300 \mathrm{~Hz}$ single-channel seismic reflection profiles indicate a "neotectonic phase" within the basin. We demonstrate that the $3.5 \mathrm{kHz}$ echo character provides constraints on the thermal conductivity distribution and seafloor morphology. This is critical to heat flow determinations for thermal gradient stations without in situ conductivity or nearby piston cores. Additional1y, basin stratigraphy, derived from multichanne1 reflection and refraction data and the new shallow reflection profiles, allows for the detailed corrections to heat flow data (presented in Chapter 4) for the effect of rapid sedimentation. The late Miocene (Messinian) and P1io-Quaternary phase of basin evolution is modified by complex sedimentation patterns, basement faulting, bathyal fan development, and salt diapirism. The Messinian Event or "Salinity Crisis" has been we11-studied by drilling and seismic 
investigations (c.f. Cita, 1982), and our new reflection data is insufficient to improve our understanding of the evaporite sequence. We are able to revise previous conceptions of P1io-Quaternary evolution (e.g., Rehault et al., 1984a; Mauffret et al., 1981; Stanley et a1., 1974). In particular, we discount the role of regional compression as a major factor in the appreciable P1io-Quaternary uplift of $1 \mathrm{~km}$ in the Nice region. A boundary fault system at the base of the slope is found to accompany elevated marine terraces. We present a heuristic mode1 which accounts for the present Var fan morphology and construction, as we11 as the distributions of the evaporites and salt structure geometry in the basin. These observations support our interpretation of the heat flow data introduced in later chapters.

\subsection{Regional geological evolution}

Three Tertiary fold-and-thrust belts surround the Ligurian Basin: the Pyreneo-Provencal, the Alpine, and the Apennine (Figure 1). This arrangement supports an intra-orogenic setting for the Ligurian Basin and probably resulted in the fragmented geological provinces observed along the borderlands (e.g., Moullade, 1978). The northern coast consists of the Hercynian-age ( $300 \mathrm{Ma}$ ) Maures-Estere1 Massif and the French-Italian Maritime Alps, both resulting from plate convergence during Cretaceous-Eocene times. A Hercynian massif dominates western and central Corsica and has a geological affinity with the Maures-Estere1 Massif (Nairn and Westpha1, 1968). Northeastern Corsica (Alpine Corsica) consists of an ophiolitic complex thrust above the Hercynian autochthonous unit during the Alpine orogeny. 

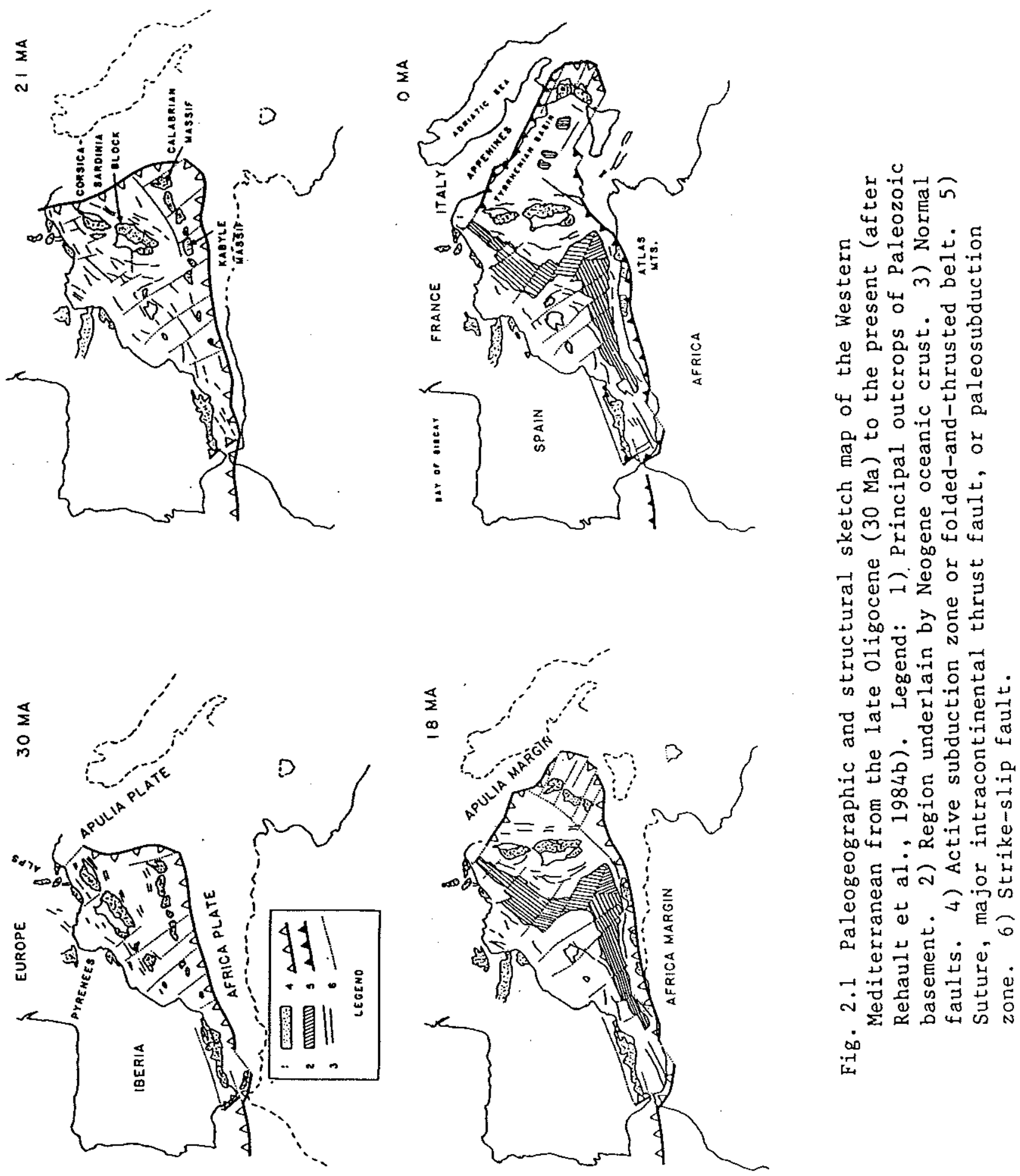
Subsequent to the Eocene collisional phase, north-northwest subduction of the African-Apulian plate probably occurred beneath the European plate (Figure 2.1). Early 01igocene movement of the African-Apulian plate away from the European plate is consistent with seafloor-spreading magnetic lineations and fracture zone patterns in the North Atlantic Ocean (Schouten et al., 1987). 0ligocene rifting of the Corsica-Sardinia continental block and Kabyle and Calabria massifs away from the European margin was accompanied by regional uplift in the Alps and erosion of the Mesozoic basement in the center of the Valencia Trough (Stanley and Mutti, 1968; Mauffret et a1., 1978, 1981). At the same time grabens were formed in the Gulf of Lion Shelf (Cravette et a1., 1974) and in the Sardinian Rift (Cherchi and Montadert, 1982), and are probably related to other European grabens (Rhine and Rhone grabens). Observations of these grabens and of submarine grabens on the Cote d'Azur margin show infilling by continental or shallow marine conglomerates and sandstones of 01igocene age (Estocade, 1978).

0ligocene continental rifting of the western Mediterranean region was succeeded by an early Miocene rifting-drifting (Figure 2.1). The timing of oceanic spreading is mainly inferred from $\mathrm{K}-\mathrm{Ar}$ dating and paleomagnetic measurements of Sardinia calc-alkaline volcanics (Montigny et al., 1981). These measurements indicate that a $30^{\circ}$ counterclockwise rotation of Sardinia took place between $21 \pm 1$ and $18 \pm 1 \mathrm{Ma}$. Modeling of a large magnetic anomaly in northeast Sardinia also supports $a \sim 30^{\circ}$ rotation (Galdeano and Ciminale, 1987). 
The estimate of the drifting chronology between Corsica and Europe is dependent on the kinematics of the Ligurian Basin opening and the amount of decoupling between the Sardinian and Corsican blocks. From geometrical arguments, Corsica probab1y had a net rotation which is $10^{\circ}$ sma11er than Sardinia (Burrus, 1984; Rehau1t et a1., 1984a,b), in agreement with structural field studies that show that Corsica and Sardinia are not offset by a large amount (Arthaud and Matte, 1977). However, Burrus (1984) cites magnetic anomaly evidence that the additional rotation of Sardinia resulted near the end of the drifting phase, rather than during the rifting phase (Rehault et a1., 1984b). This discrepancy implies that the Ligurian Basin stopped spreading either about $20 \mathrm{Ma}$ or $18 \mathrm{Ma}$.

Cessation of drifting coincides with a middle Burdigalian collision (17 Ma) in the Apennines (Apulian margin with the Corsican, Sardinian, and Calabrian blocks) and in the Rif arc of North Africa (African margin and Kabylian block; Figure 2.1). Development of the Gulf of Genoa on the eastern margin of the Ligurian Basin, was undoubtedly dependent on the kinematics of this Apennine collision. Submergence of the Gulf of Genoa region (Fanucci and Firpo, 1981) may be related to back arc extension in the Tyrrhenian Basin (e.g., Malinverno and Ryan, 1986; Rehault et a1., 1987). Post-middle Tortonian (11 Ma) extensional tectonics to the east of the Ligurian Basin and Northeastern Corsica is evidenced by the Tuscany geothermal province in Italy (Puxeddu, 1984).

Sediment infilling of the western Mediterranean basins proceeded during the Miocene and coincided with the overall subsidence of the region. A middle to upper Miocene compressional phase is indicated by 
thrust faults on the island of Mallorca (Bizon et al., 1978) and by Miocene faults in the Maritime Alps (J. P. Rehault, personal communication, 1985). A marked discontinuity took place in the late Miocene sedimentary record as a result of the Messinian salinity crisis (Cita, 1982). During the P1io-Quaternary when the pre-Messinian sedimentation conditions resumed, a contemporaneous tectonic phase may have affected the more recent evolution of the basin and margins. Horizontal compressional stresses have been invoked to explain seismicity, margin uplift, and reverse faulting on the Cote d'Azur margin (Mauffret et a1., 1981; Rehault et a1., 1984a, Rehault and Bethoux, 1984). New reflection data discussed in Section 2.4, however, indicate that a noncompressional uplift mechanism is $1 \mathrm{ikely}$. Accompanying these observations are deformations of the P1io-Quaternary sediment by the plastic flow of Messinian salt.

Magmatism in the northwestern Mediterranean borderlands is generally of calc-alkaline composition (e.g., Girod and Girod, 1977; Bellon, 1981). Sardinian andesitic and ignimbritic series provide a continuous chronologic record, with $\mathrm{K}-\mathrm{Ar}$ dates of the calc-alkaline volcanism extending from $34 \mathrm{Ma}$ to $16 \mathrm{Ma}$ (Montigny et a1, 1981). On the Provence coast near Antibes, 26 Ma calc-alkaline volcanics (andesitic conglomerates) are found (Be1lon and Brouse, 1971).

01igocene and Miocene volcanics sampled on the margins have a more varied chemistry and mineralogy, but tend to be more restricted in time. Deep Sea Drilling Project Site 123 in the Valencia Trough produced $\sim 24$ Ma rhyodacites with an evolved calc-alkaline affinity (Riviere et al., 1981). On the southwestern Corsican margin (west of 
the Gu1f of Bonifacio), an outcrop of $\sim 17$ Ma porphyritic basalt composed of $40 \%$ plagioclase and $60 \%$ alteration products (Bellon et al., 1985) and a metabasalt outcrop (Be1laiche et al., 1979) are found. Both of these samples have a magmatic evolution which excludes an alkaline or shoshonitic affinity. However, the geochemical data cannot resolve whether these samples are due to oceanic spreading (tholeiitic) or orogenesis (calc-alkaline basalt or arc tholeitic). A $18 \pm 0.5 \mathrm{Ma}$ basalt with distinct alkaline affinity (tristanite) is found on a basement outcrop $\sim 400 \mathrm{~m}$ above the Ligurian Basin continental rise (Rehault et a1., 1988). Superimposed on the 01igocene-Miocene volcanism are late Neogene and Quaternary alkaline volcanics in the Valencia Trough, eastern Sardinia, Massif Central and Tuscany archipelago (Girod and Girod, 1977). These deposits are volumetrically sma11 and are unrelated to large-scale tectonic movement in the Liguro-Provencal Basin. Using geochemical discriminant graphs and normative mineral diagrams (e.g., Miyashiro, 1975), we may infer tectonic settings for the northwest Mediterranean magmatism discussed above. Calc-alkaline volcanism is almost exclusively found prior to the drifting stage (>21 Ma) which strongly suggests that incipient island arc rifting produced the initial Ligurian and Valencia Trough system by tectonic thinning of continental crust and upper mantle. Latter stages of Miocene volcanism (21-16 Ma) include several volcanic series (alkaline, tholeiitic, and calc-alkaline) and represent early back arc spreading in the central basin, and continued arc magmatism on Sardinia. These diverse geochemical rock types, in addition to the diffuse magnetic anomaly pattern (Galdeano and Rossigno1, 1977), are consistent with west Pacific marginal basin 
1ithospheric evolution models (cf. Lawver and Hawkins, 1978).

An ambiguity in the tectonic setting of the southwestern Corsican margin basalts exists since their affinity may be either calc-alkaline, arc tholeiitic or mid-ocean ridge tholeiitic (Bellaiche et al., 1979; Bellon et al., 1985). Their emplacement either coincides with 1) the main spreading phase associated with the rotation of the CorsicanSardinian block, or 2) a short secondary extensional phase experienced between Corsica and Sardinia subsequent to the microplate rotation (Burrus, 1984; Rehault et a1., 1984a,b,1985; Thomas and Genneseaux, 1986). The first scenario suggests an offshore connection with the Sardinia calc-alkaline volcanic series, and the second a leaky transform fault zone with tholeiitic magmatism. A large amplitude (>200 $\gamma$ ) magnetic anomaly is elongated perpendicular to the margin in this region and may result from excessive volcanism along a transform zone.

In summary, calc-alkaline volcanism and especia1ly the spatiotemporal sequence of divergent and convergent tectonics strongly suggest a back arc basin formation for the western Mediterranean basins (Liguro-Provencal and Balearic Basins). According to the reconstruction of Rehault et a1. (1984a,1985), the paleoarc-trench system has migrated to the southeast to its present position in the Calabrian region, the Tyrrhenian back arc basin being a direct consequence of this migration (Figure 2.1). Although, a back arc origin for the Ligurian Basin is probable (e.g., Burrus, 1984; Rehault et a1., 1984a), a we11-developed remnant arc is lacking on Provence, and Tertiary volcanics representing the island arc unit are completely absent on Corsica. An alternative interpretation is that the Ligurian Basin is a boundary basin (cf. 
Taylor and Karner, 1983) which formed as a result of the collision and reorganization of the Apulian and Eurasian plates without subduction taking place (Tapponnier, 1977).

\subsection{Surface geology}

Physiography. Two main physiographic provinces shape the Ligurian Basin: 1) continental slopes, and 2) the Var Fan (Provencal rise; Figure 2.2a,b). The shelves of the Ligurian Basin are narrow or absent. Numerous submarine canyons incise the margin with the canyon walls maintaining a $15^{\circ}$ slope. Most notable on the French-Italian margin are, from west to east, the Stoechades, St. Tropez, Cannes, Var, Roya, and Genoa canyons. Calvi, Ile Rousse and St. Florent canyons are prominent on the northern Corsican margin. The canyon positions may be linked to basement structures (Rehault, 1981; Pautot et a1., 1984), with some probably being a manifestation of 01igocene-Miocene graben systems (e.g., Stoechades and Genoa canyons) and others controlled by offshore alpine structures (e.g., Var, Roya, and St. Florent canyons). Canyon formation accelerated during catastrophic sea-leve1 drops experienced in the Messinian (e.g., Cita, 1982), but they have also undergone important periods of erosion during the P1io-Quaternary (Be1laiche et a1., 1978; Guillocheau et a1., 1983). The continental slope is steepest on the northwest Corsican and the western Cote d'Azur margins (over $10^{\circ}$ ) but is more gentle on the eastern, Italian margin of the Ligurian Basin.

Just as the Rhone Fan dominates the sedimentary environment in the Gulf of Lion and Provencal Basin, the Var and other smaller fans on the Nice margin coalesce to form a broad continental rise influencing 


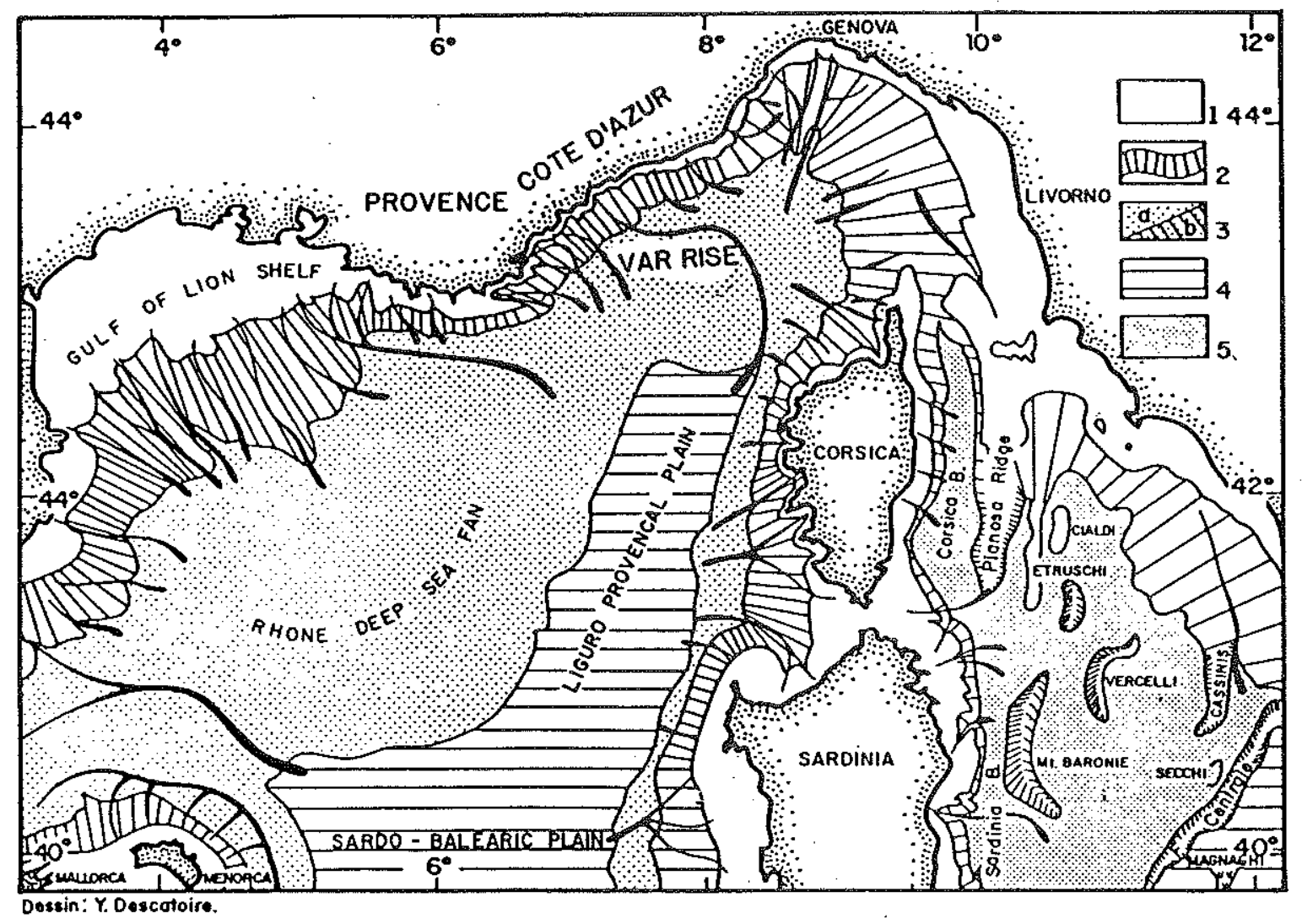

Fig. 2.2a Simplified physiographic map of the NW Mediterranean, including the Liguro-Provencal Basin. 1) continental shelf; 2) slope; 3) rise and coalescent deep-sea fans; 4) bathyal plain; 5) North Tyrrhenian Basin (from Rehault et a1., 1985). 


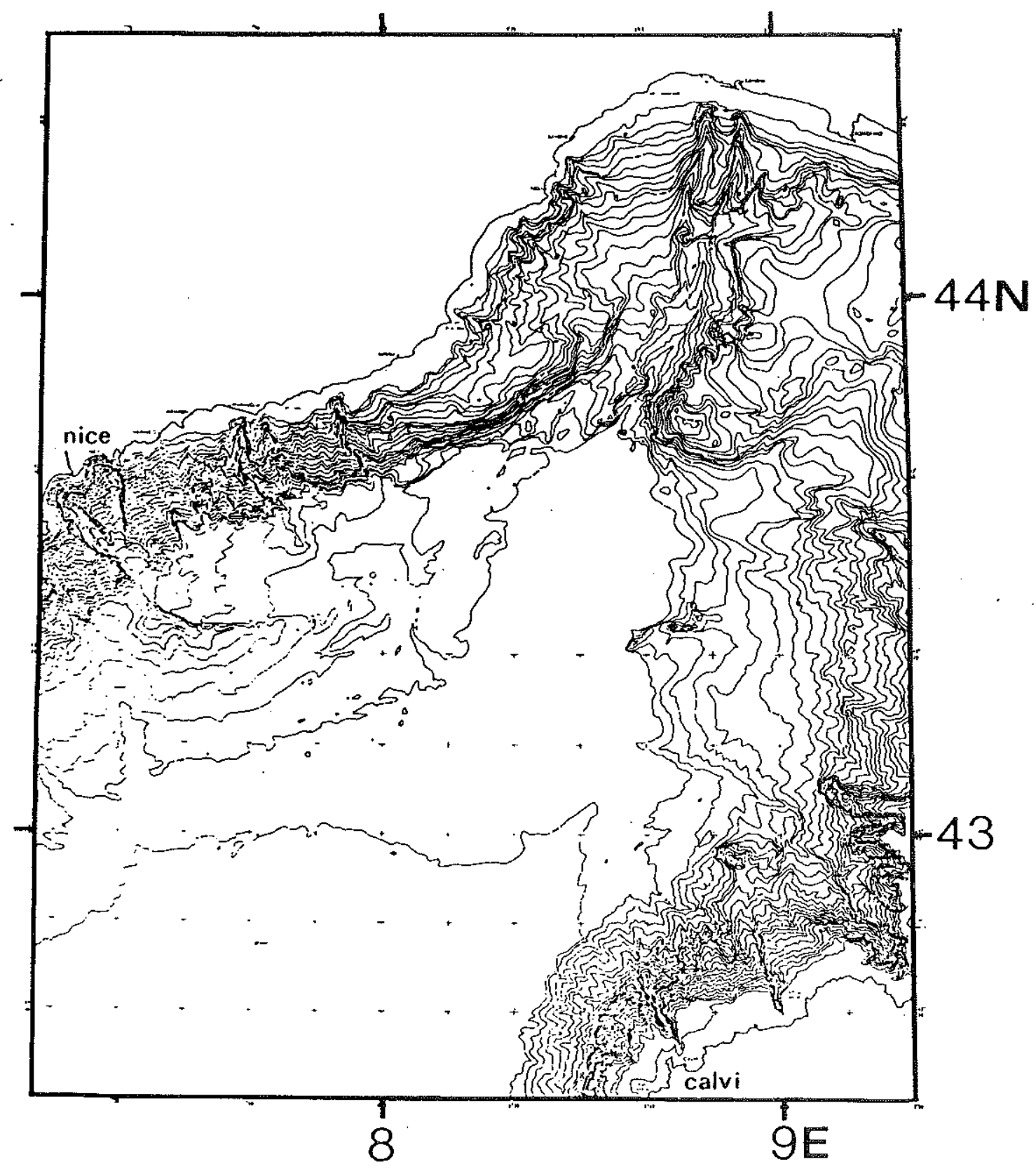

Fig. 2.2b Bathymetric map of the Ligurian Basin with $100 \mathrm{~m}$ contour interval (from Pautot and Rehault, 1986; UTM projection). 
sedimentation throughout the central basin (Figure 2.2a,b). Depending on the proximity of the Nice continental slope, the Var channel cutting across the Cote d'Azur continental rise creates a 200 to $600 \mathrm{~m}$ levee. At the base of the Nice slope, the Var channel hooks sharply in a counterclockwise direction. The channel meanders southeast across the central basin to the lowermost northern Corsican margin before turning southwest to the Balearic bathyal plain. Thus, a true bathyal plain is missing between between Nice and Calvi.

Echo character of the North Corsican Basin. Reflectivity patterns of $3.5 \mathrm{kHz}$ profiles, supplemented with bathymetry, piston core and single-channel seismic data, are used to understand the surficial sediment type and late Quaternary sediment dispersal pattern (e.g., Swift, 1985). These data have been incorporated into an echo character map of the North Corsican Basin (Figure 2.3). Although eight echo character types are present (Figure 2.4), only two echo 'facies' or 'associations' are identified for the purpose of extracting bulk physical property data from the echo data. The associations include a canyon-fan and a hemipelagic-slope facies and are mainly distinguished by the echo character of the bottom reflector (Table 2.1). An outcrop facies also is inferred from the analysis of complementary seismic reflection data.

As in the Rhone deep-sea fan (Coutellier et a1., 1984), the echo character of the North Corsican Basin is useful in relating the morphology to one of two main sedimentary processes: turbidity current deposits and mass gravity flows. A strong relationship between the echo character, physiography, sedimentation and bulk physical properties is 


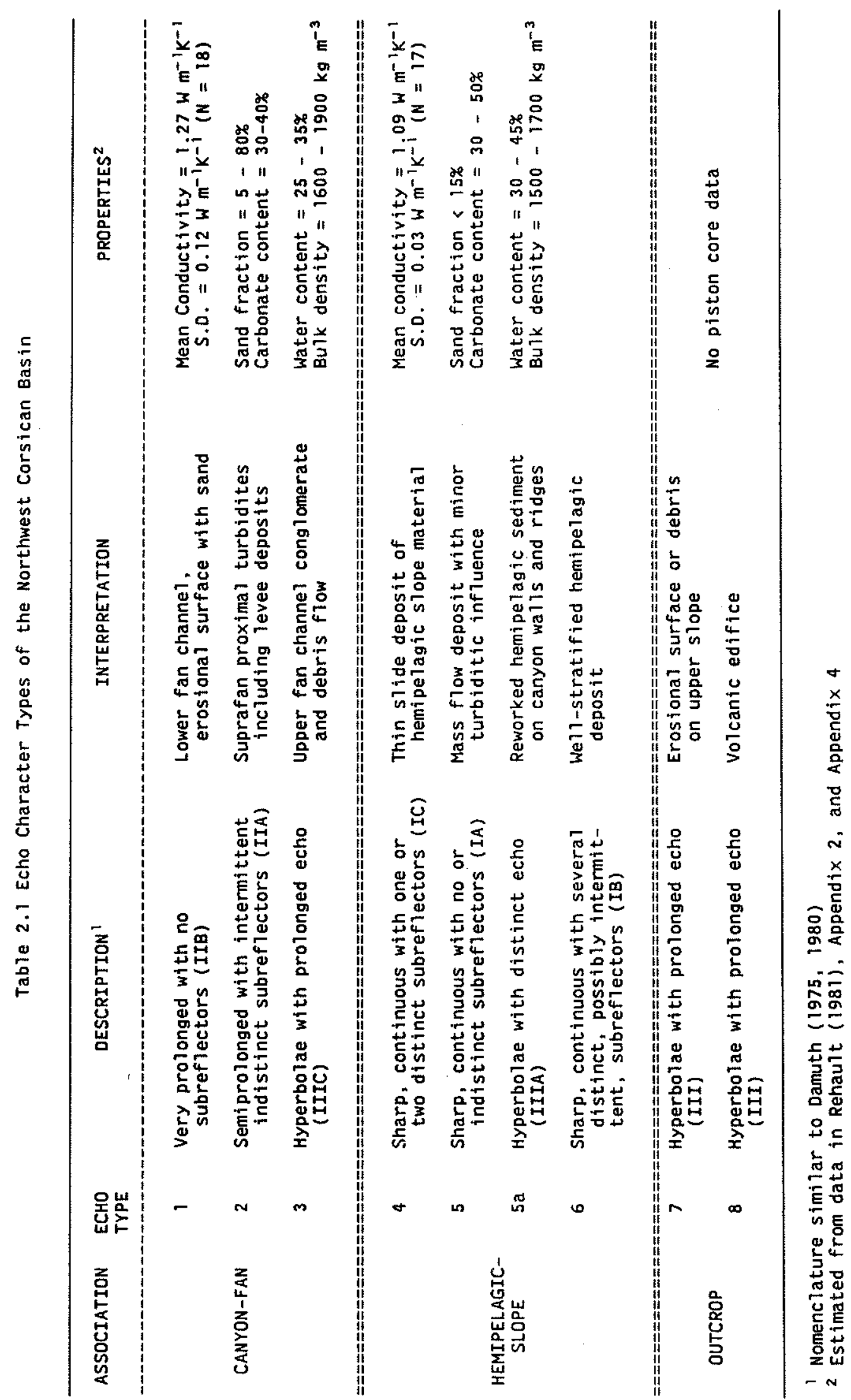




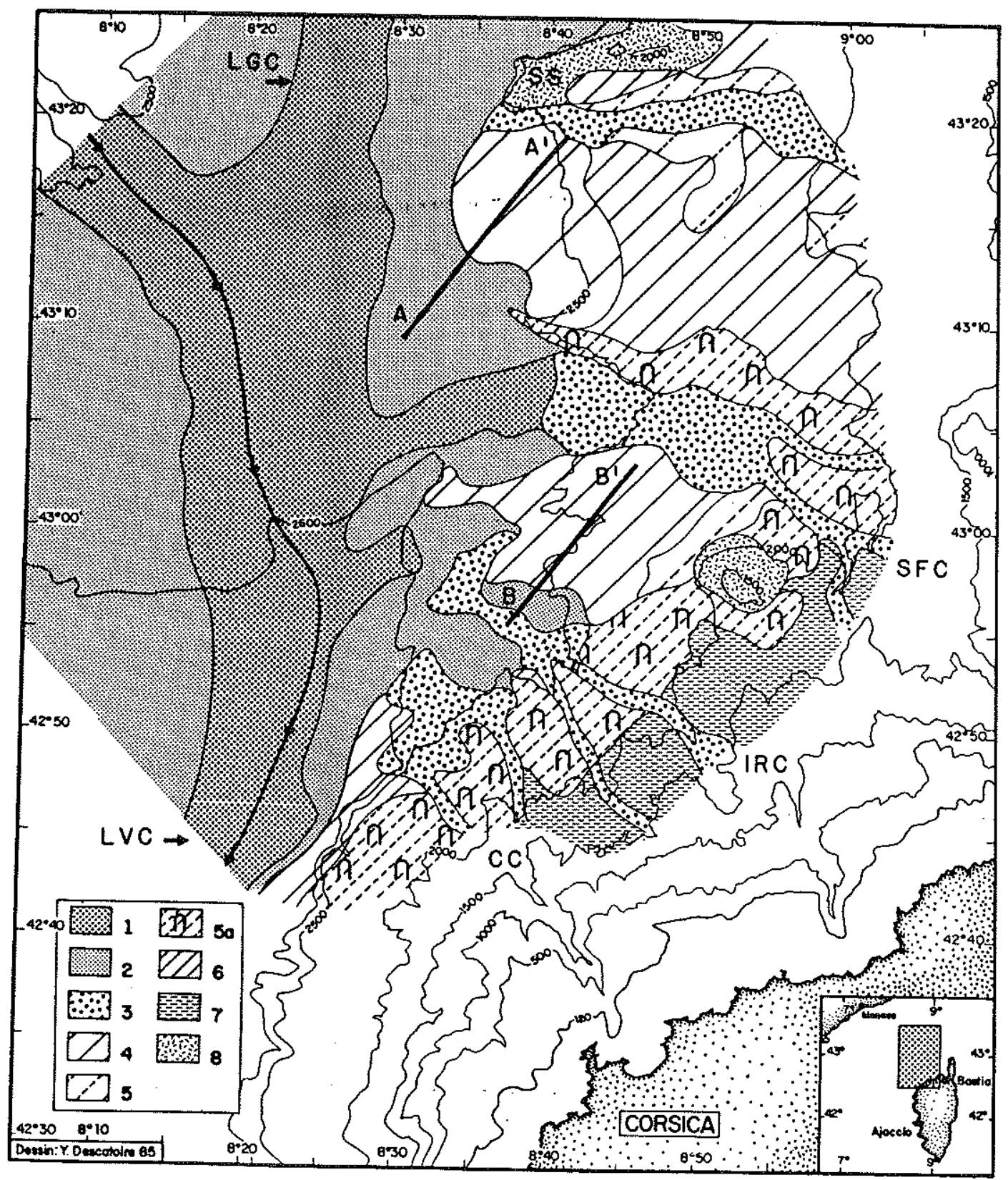

Fig. 2.3 Map of echo character distribution in the Northwest Corsica Basin. Echo types given in legend (see Table 2.1) are grouped into three echo character associations: canyon-fan (1, 2, and 3 ), hemipelagic slope $(4,5,5 \mathrm{a}$, and 6$)$, and outcrop (7 and 8 ). Physiographic features noted: LVC - Lower Var Channel (thalweg marked), LGC - Lower Genoa Channe1, SS - Spinola Spur, SFC - St. Florent Canyon, IRC - Ile Rousse Canyon, CC - Calvi Canyon. Sea Beam bathymetry shown in meters. 


\section{ECHOCHARACTER ASSOCIATION}
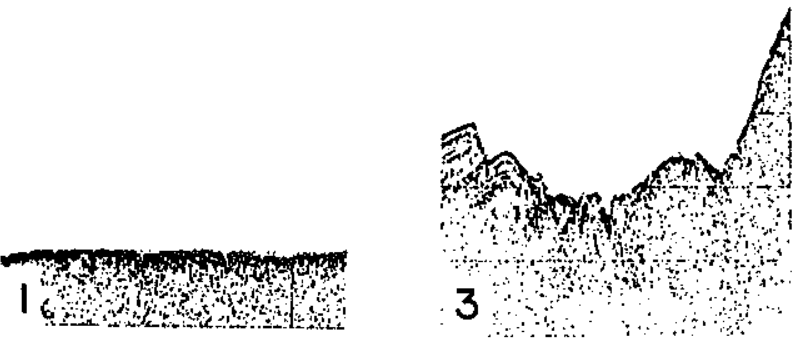

CANYON-FAN
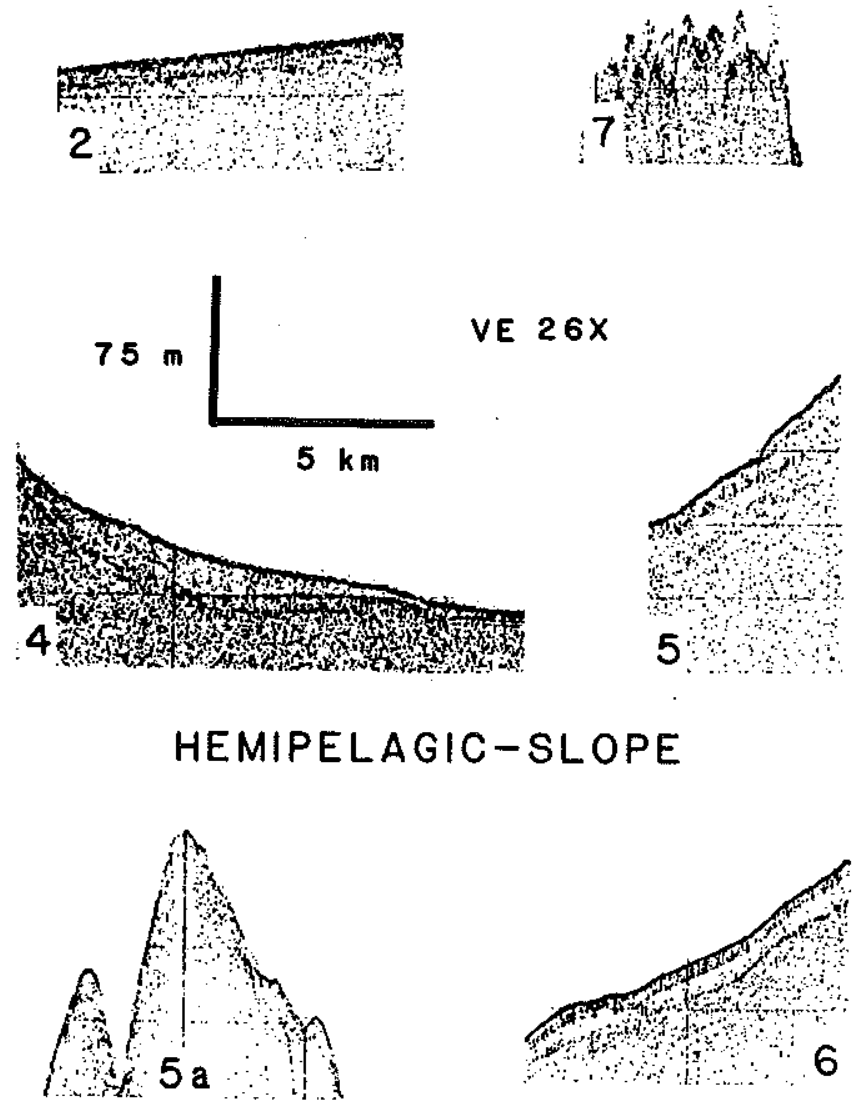

Fig. 2.4 Exemplary $3.5 \mathrm{kHz}$ profiles of echo facies. The echo facies pertain to regions shown in Figure 2.3 and described in Table 2.1. For convenience, echo type 7 is included with the canyon-fan association. 
also established. In the heat flow analysis, the echo character map given in Figure 2.3 mainly serves as a basis for estimating the sediment thermal conductivity for thermal gradient stations without coincident in situ thermal conductivity measurements.

Profiles were obtained during the 1982 DELTARHO II expedition conducted by J. P. Rehault and G. Bellaiche (U. of Paris, Villefranche-sur-mer), and include SeaBeam, $3.5 \mathrm{kHz}$, and single-channel seismic profiler data. The survey net is composed of over 30 paralle1 lines, 30 to $60 \mathrm{~km}$ in length, spaced about 1.5 to $3.0 \mathrm{~km}$ apart (see Figure A5.2). The NE-SW orientation of the profiles provides sections perpendicular to the canyons on the lower slope. This arrangement tends to give a polarized view of the reflectivity in a region which is inundated by NW-SE canyons. Echo types given in Figure 2.4 are related to the examples and nomenclature of Damuth $(1975 ; 1980)$ in Table 2.1. The hemipelagic-slope facies have sharp or distinct echo reflectors which are $<2 \mathrm{~ms}$ in length, and the canyon-fan facies have a prolonged echoes typically > $2 \mathrm{~ms}$. Thus, the initial echo reflection represents the acoustic properties of the upper few meters of sediment.

The canyon-fan facies covers the lower Var channel and levee system and the north Corsican margin canyon floors. Single-channel data suggest that the present canyon morphology of the Corsican margin has been constant throughout the P1io-Quaternary and is similar to the Provencal margin canyons. The Ile Rousse and Calvi canyons (Figure 2.3) do not transfer an appreciable amount of sediment to the lower margin and are minor tributaries to the lower Var fan system. A notable northward offset in echo type 1 region (lower fan channel) from the St. 
Florent channel thalweg suggests a recent shift in the sedimentation patterns. Lateral migration of submarine channels are not uncommon as indicated by paleochannel deposits located in profiles near the lower Var channe1 (Pautot et al., 1984); they could be triggered by sediment ponding or by upheavals due to salt diapirism (see below).

As suggested by piston core data and echo character, the intercanyon highs are blanketed by hemipelagics. Near the base-of-slope and on the continental rise, echo types 4 and 6 prevail indicating a stratification by a combination of hemipelagic deposition and minor onlapping of turbidites from the lower channel of the Var. Further upslope, echo types 5 and 5 a occur in physiographic settings which are relatively isolated from terrigenous transport avenues. The canyon walls are probably composed of mass flow deposits and inundated by tributary channels to the main canyon channe1; the resultant steep wa11s typically have echo type $5 \mathrm{a}$.

Sedimentation rates in the Ligurian Basin determined from piston cores are variable, and depend on the influence of turbidity currents. In a piston core on a $60 \mathrm{~m}$ knoll in the central basin, the mean sedimentation was $150 \mathrm{~m} \mathrm{Myr}^{-1}$ for the last $0.06 \mathrm{Myr}$ (Rotschy et al., 1972). Therefore, in regions of steady hemipelagic sedimentation the Holocene sediment thickness is probably not more than 1 to $2 \mathrm{~m}$ in the basin. A value of $300 \mathrm{~m} \mathrm{Myr}^{-1}$ is probably more typical of turbidite-rich sequences in the central basin (Gennesseaux and Thommeret, 1968). These surficial sedimentation rates are consistent with average sedimentation rates calculated from decompacted sediment thicknesses (see below). In comparison, average rates for various sites 
in the Western Mediterranean Basin range from $10^{2}$ to $10^{4} \mathrm{~m} \mathrm{Myr}^{-1}$ (Stanley, 1977). Since the penetration of the echogram is generally not greater than $40 \mathrm{~ms}$, two-way travel time, the thickness sampled is about $30 \mathrm{~m}$. Therefore, the age of the deeper echo reflectors is probab1y less than $0.2 \mathrm{Ma}$. This estimate is based on the assumption that there is little reworking of sediment and that deposition occurs by suspension settling mechanism. In actuality, over half of the Mediterranean slope and basin sediment may be reworked to some degree (Stanley, 1985).

Some average bulk physical properties related to acoustic impedance correlate fairly well with variations in echo character, but only in a qualitative sense (c.f. Tucholke, 1980). Acoustic impedance is a function of bulk density, which in turn may be empirically related to thermal conductivity (See Appendix 2). According1y, a clear relationship exists between the surface sediment thermal conductivity and echo character (Table 2.1). Hemipelagic-slope regions have a much narrower range of thermal conductivity and have a 15 percent lower mean value than the canyon-fan regions. The hemipelagic-slope facies also tends to have lower bulk density, less sand fraction, and slightly higher water and carbonate contents.

An example of the conductivity stratification and echo character is given in Figure 2.5 (Profile AA' of Figure 2.3). The slope region has a more transparent acoustic structure with continuous subreflectors (echo type 4) compared with the suprafan levee (echo type 2). The base-of-slope feature is interpreted as an apron of reworked hemipelagic sediment emplaced by a thin slide. The Var channel increases the terrigenous input on the basin side of the profile, and the layered 

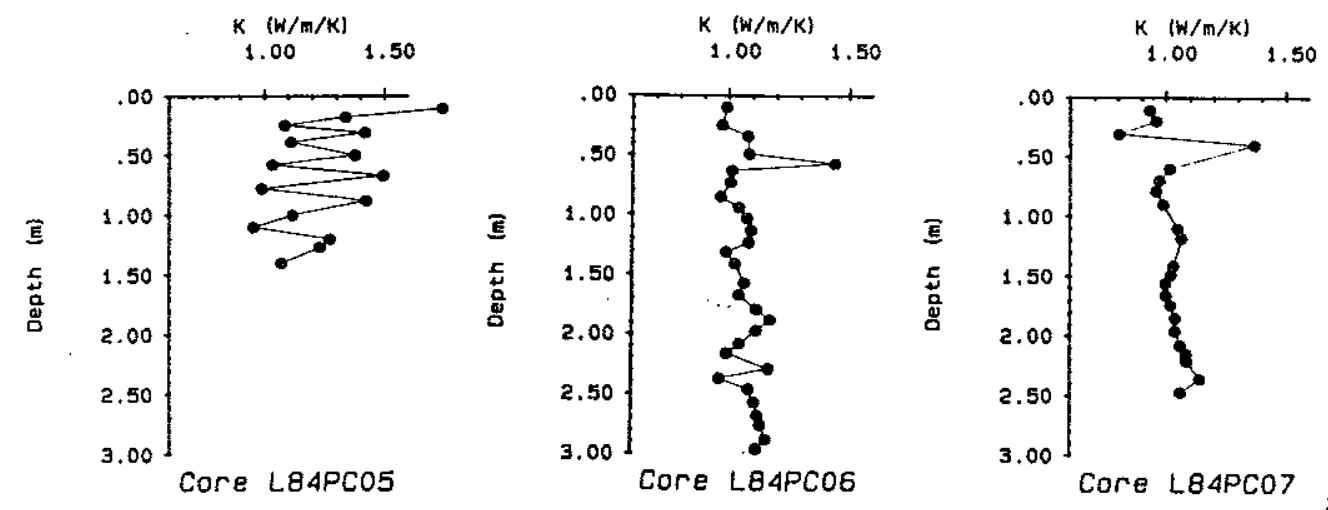

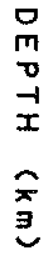

(projected)

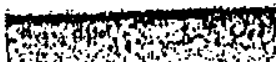

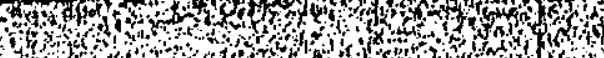
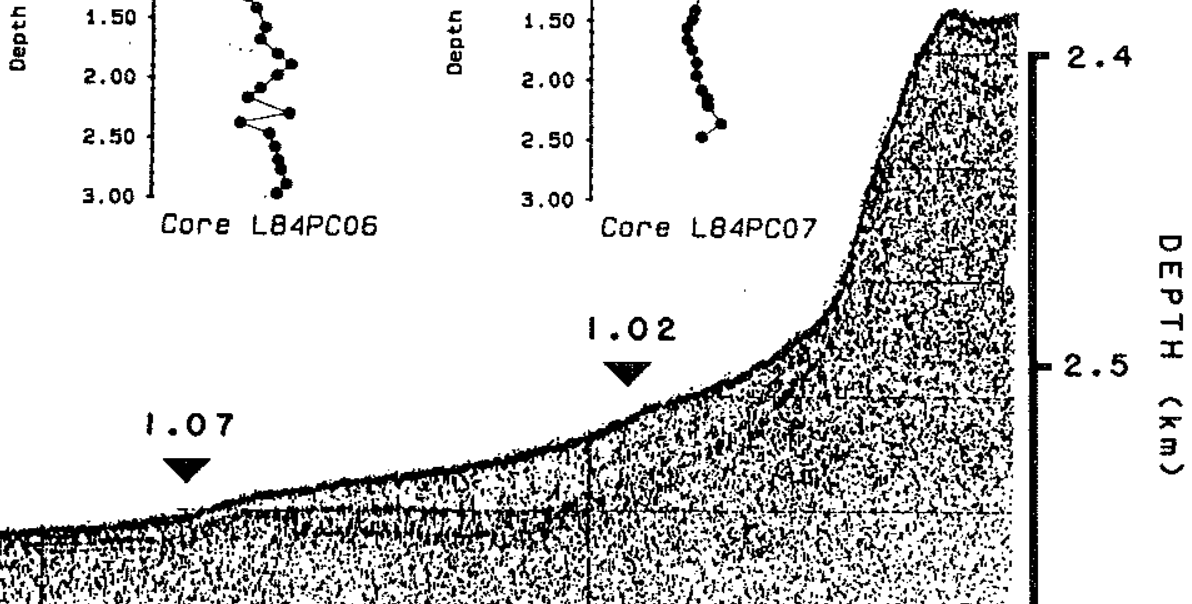

$2 \mathrm{~km}$

2.6

Fig. 2.5 Plot of $3.5 \mathrm{kHz}$ profile, mean piston core thermal conductivity values $\left(\mathrm{W} \mathrm{m}^{-1} \mathrm{~K}^{-1}\right)$, and downcore plots showing conductivity stratification. Profile is located in section AA of Figure 2.3. Note lateral change in conductivity from hemipelagic on the lower slope/rise to dominantly turbiditic sediment on the lower Var fan. 
conductivity structure is indicative of turbidite deposition. From the echo character, a sharp transition to the structureless hemipelagic sediment at the base may be inferred. In this area, sandy layers consistently have conductivities of about $1.4 \mathrm{~W} \mathrm{~m}^{-1} \mathrm{~K}^{-1}$, while the hemipelagic layers are about $1.0 \mathrm{~W} \mathrm{~m}^{-1} \mathrm{~K}^{-1}$.

Lateral conductivity variability in the canyon-fan system is attributed to smal1-scale topography in the bathyal region. Knolls of several to tens of meters relief are common above salt domes in the central basin and may account for isolated values of lower than normal conductivity due to the restriction of turbiditic sand-1aden deposition on their crests. Conversely, sediments near the submarine channels are almost entirely composed of sand which have high therma1 conductivity.

Complementary single-channel data allow echo types 7 and 8 to be identified as actual sedimentary or basement outcrops. Basement structures designated as echo type 8 have magnetic anomalies and are associated with volcanic intrusions (Rehault, 1981). Echo type 7 occurs on the midslope of the Corsican margin which has thin or no recent sediment cover. Erosion is probably due to downslope transport processes which are enhanced by the basement declivity, and possibly by uplift mechanisms and contour currents.

Contour currents are thought to influence some Western Mediterranean margins (Mauffret et al., 1982). Recent deployment of bottom current meters at $1800 \mathrm{~m}$ in the Gulf of Lion suggest that deep cyclonic contour currents do exist and have wintertime velocities of up to $3 \mathrm{~mm} \mathrm{~s} \mathrm{~s}^{-1}$, sufficient to erode hemipelagic sediment (Millot and Monaco, 1984). However, submersible studies in the Ligurian Basin show little evidence 
for appreciable reworking of the surface sediment by contour currents (G. Be11aiche, personal communication, 1985).

The topographic kno11s and ridges in the central basin are created by diapirism (Stanley et a1., 1974a; Pautot et a1., 1984; A1inat et a1., 1970). Figure 2.6 illustrates the direct correlation of $10 \mathrm{~m}$ knolls with the underlying salt diapirs. The $3.5 \mathrm{kHz}$ record shows deformation in the upper tens of meters of sediment where the topographically elevated seafloor maintains a hemipelagic-slope echo character. According to calculated sedimentation rates, deformation or salt diapirism has occurred recently. Since fresh fault scarps are identified near some of the diapirs (Figure 2.6), local rates of deformation must exceed sedimentation rates. This observation is similar to that made by Stanley et a1. (1974a) in the South Balearic bathyal plain.

Observations of the Cote d'Azur margin and Ligurian basin. The DELTARHO II survey Included two profiles that crossed the Var Rise (Figure A5.2) and allows a brief description of the nature of surficial sediments. The echo types are intermediate between types 2 and 6 ; in other words, they are representative of moderately thick-bedded turbidites with continuous subreflectors. Piston core studies indicate that turbidite sequences on the Var fan are commonly $30 \mathrm{~cm}$ thick (Foucault et al., 1986), somewhat below the resolution of the $3.5 \mathrm{kHz}$ records. Shallow normal faults which strike N40E give rise to a peculiar bench-1ike topography across the southeast portion of the Var fan (Pautot et a1., 1984). From the single-channel profile, the benches 


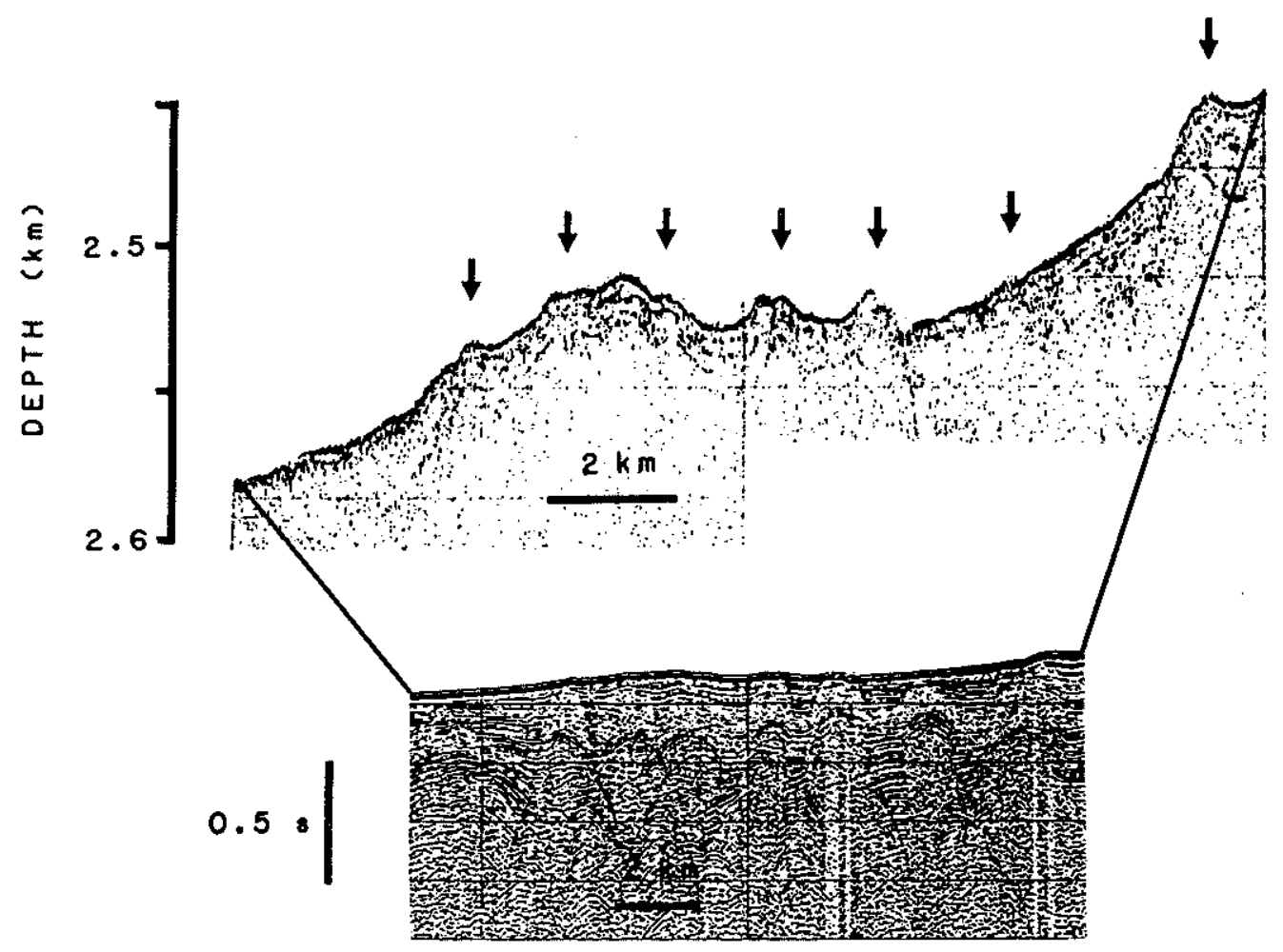

Fig. 2.6 Example of salt structures in $3.5 \mathrm{kHz}$ and single-channel profiles. Location is section BB' in Figure 2.2. Arrows are placed over the salt structure axes. 
appear to be rotated sediment blocks, a disruption that mainly influences the P1io-Quaternary section.

Salt intrusions in the Var fan region form 10 to $30 \mathrm{~km}$ long ridges or series of elongate diapirs which are aligned in a $\mathrm{N} 40 \mathrm{E}$ direction (Rehault, 1981). This morphology contrasts with the circular geometry of salt intrusions in the North Corsican Basin, where the intrusions appear to be pillow formations (c.f. Trusheim, 1960). The Var salt structures seem to be more penetrative (early diapir stage) and actually outcrop at the surface to form knolls. Some kno1ls have cap-rock of sulfur-bearing minerals related to the decomposition of the intruded evaporites (Bellaiche and Pautot, 1968; Alinat et al., 1970) and may indicate upward pore water migration associated with the diapirism.

Canyon and channel regions on the Nice margin have surfaces which are intensely reworked by mass-wasting events, with the echo type of the channels similar to type 1 or 3 of the North Corsican Basin (Pautot et a1., 1984). Recent submarine landslides documented on the Var upper canyon suggest that canyon cutting is recent, estimated to be late Quaternary age (Guillocheau et a1., 1983; Gennesseaux et al., 1980; Malinverno et a1., 1987). The Var canyon walls have gullies and spurs which set up small drainage basins with mass-wasting processes independent of the main channel activity (Malinverno et a1., 1987).

Bathymetry of the Cote d'Azur margin as compared with that of the Corsican margin reflects the greater sediment cover due to the Var paleo-de1ta system (Pautot, 1981). It is apparent that the east side of the Var Canyon has an especially we11-developed slope platform, i.e., a 
rather broad intercanyon high with subsidiary spur and gully systems which are relatively undisturbed by mass-wasting on the bordering canyon wa11s.

Geotherma1 implications of morphology and surface geology. The Ligurian Basin physiographic setting and sedimentary processes described above indicate two basic superficial environments:

1) Intercanyon highs on the upper margins. Piston core and $3.5 \mathrm{kHz}$ data indicate that hemipelagic sedimentation takes place on the intercanyon areas. Hemipelagic sediments generally provide a penetrable seafloor for pogo-probing and give a good indication of the average sediment conductivity. However, heat flow measurements are likely to be perturbed by sma11-scale topography and mass-wasting induced by subsidiary gully systems. These abundant fine-scale geomorphologic features are difficult to quantify due to the resolution available with the conventional survey tools used in the studies (e.g., surface-tow 3.5 $\mathrm{kHz}$ and $12 \mathrm{kHz}$ seismics; piston coring).

2) Continental rise. The entire bathyal region may be considered as an extension of the $\operatorname{Var}$ fan system which is composed of turbidite-rich sediment with a larger sand content than found on the intercanyon regions (Table 2.1). Bathymetry, $3.5 \mathrm{kHz}$ echo character, and piston core data constrain the general conductivity patterns and forecast areas which are 1ikely to be incised by submarine channels, recent faulting, and kno1ls and ridges caused by sa1t structures. Outside anomalous topographic features, the mean sediment conductivity maintains a fair1y constant value due to the uniform layering of turbidite sequences. The North Corsican Basin margin contributes little sediment to the central 
basin and consequently maintains a low sand content in the sediment occupying the fringes of the base-of-slope regions. The late Quaternary phase of diapirism is difficult to quantify but may have important transient effects on the surficial heat flow.

\subsection{Genera1 stratigraphy}

Seismic data indicate that the central basin of the western Mediterranean has undergone a temporally variable but spatially ubiquitous sedimentation history. Tectonic subsidence and sediment loading have resulted in $2.5 \mathrm{~km}$ of water overlying 5 to $6 \mathrm{~km}$ of sediment (Figure 2.7a). Three main units exist (Rehault et a1., 1984a; 1985):

1) $3 \mathrm{~km}$ thick infrasalt series, an early to mid-Miocene layer composed of turbiditic shales and marls (Burdigalian to Tortonian, 22 to $6.1 \mathrm{Ma}$ );

2) a Messinian evaporite sequence ( 6.1 to $5.0 \mathrm{Ma}$ ) composed of a 0.5 to $0.7 \mathrm{~km}$ thick lower evaporite layer, a 0.6 to $1 \mathrm{~km}$ thick salt layer (mother bed of Mediterranean diapirs), and a 0.5 to $1 \mathrm{~km}$ thick upper evaporite section (the top of this unit is the "M" reflector, an excellent chronostratigraphic surface); 3) a 0.7 to $1.5 \mathrm{~km}$ thick P1io-Quaternary unit of hemipelagic marls and turbiditic sediment which has been subsequently deformed by halokinesis and faulting. Deep Sea Drilling Project (DSDP) legs 13 and 42 have not drilled beyond the upper evaporite unit in the deep basin (on1y on the margins) so that the physical properties and internal sedimentation rates of the Miocene section are not as well-constrained as the P1io-Quaternary section. However, the infrasalt and evaporite series has been mapped in the 


\section{BASIN STRATIGRAPHY}

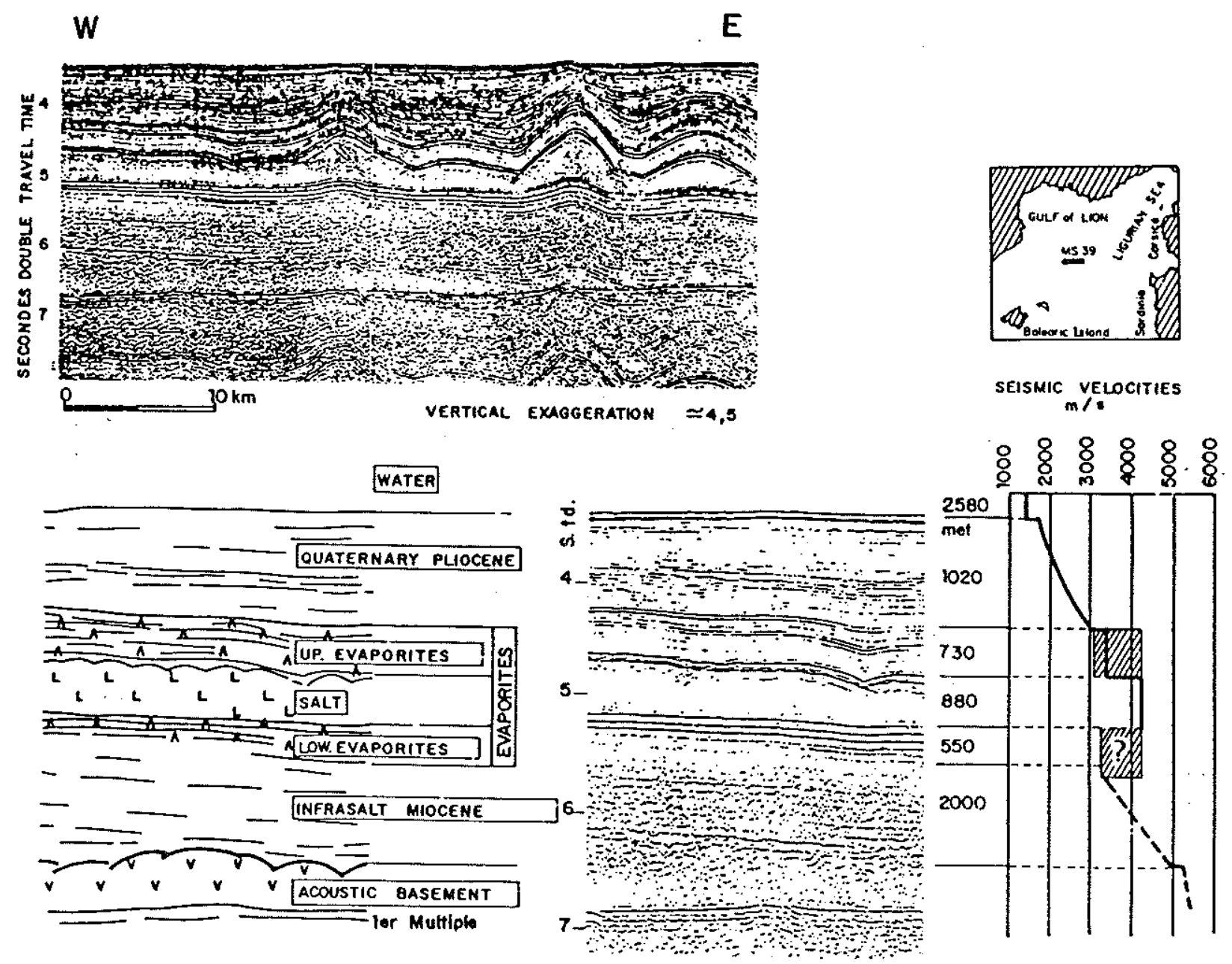

Fig. 2.7a Multi-channel seismic reflection section in the deep Liguro-Provencal Basin showing acoustic facies and seismic velocities (from Rehault et al., 1984a). Seismic profile MS 39 is from Finetti and Morelli (1973) and the velocity determination is by Montadert et al. (1978). 
Ligurian Basin and shows that this unit filled the deeper sub-basins and buried most of the basement topography in Ligurian Basin (Rehault et a1., 1985).

The stratigraphy of the continental margins is derived from DSDP and commercial borehole samples, submarine outcrops, and seismic studies (Figure 2.7b). Upper 01igocene sediment in the upper Stoechades canyon indicates fault-controlled subsidence as early as $28 \mathrm{Ma}$ (Estocade, 1978). We11 data in the Gulf of Lion shelf show that Aquitanian and Burdigalian (24-17 Ma) sediments have accumulated above basement (Cravette et a1., 1974) and that their deposition coincides mainly with therma1 subsidence (Steckler and Watts, 1980; Bessis, 1986). Due to the steep basement interface, the total sediment thickness is much thinner on the margins than in the deep basin. The reduced thickness is also due to the displacement of up to a kilometer of drift Miocene sediment during the Messinian salinity crisis (Ryan, 1976; Ryan and Cita, 1978; Cita et a1., 1978; Steckler and Watts, 1980; Bessis, 1986). The post-Messinian subsidence rates are probably of the same order as the pre-Messinian rates (Steckler and Watts, 1980; Bessis, 1986; Ryan, 1976). Therefore, the pronounced erosion and canyon cutting on the margins supports the premise that the Messinian Event is a result of a major sea-leve1 drop, which allowed sha1low water evaporites to be deposited in the central basin (c.f. Cita, 1982).

The we11-known "M" reflector, representing the top of the Messinian evaporite sequence in the deep basin and lower margins, marks the Messinian erosional surface on the upper margins. Seismic profiles show that the upper evaporite layer extends farther up the margin than the 


\section{MARGIN STRATIGRAPHY}

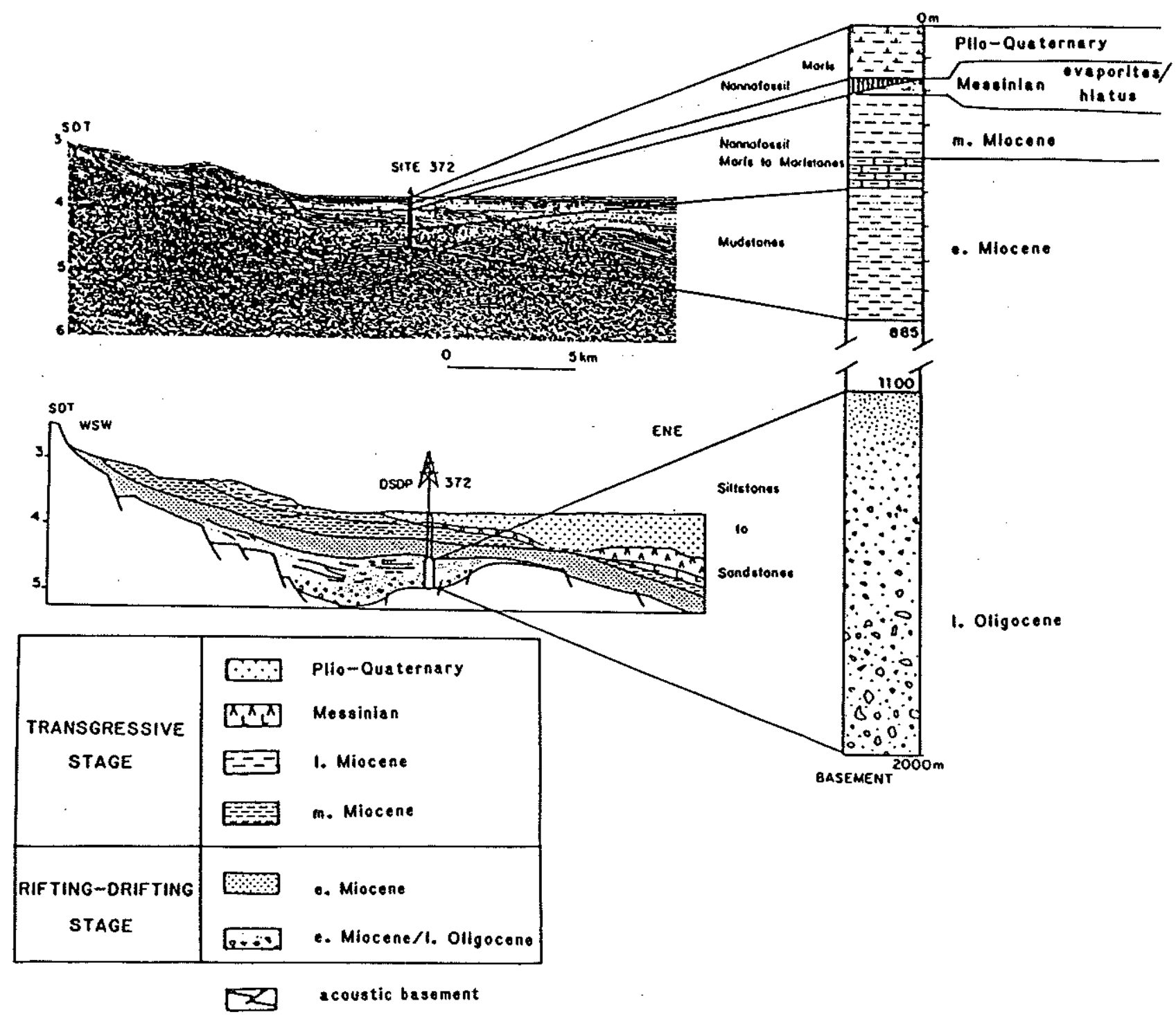

Fig. 2.7b Multi-channel seismic reflection section from the eastern Menorca continental margin with acoustic facies and DSDP site 372 lithostratigraphic section (modified from Rehault et a1., 1984a). Seismic line is from Mauffret et a1. (1978). 
underlying salt unit and rests, in places, on the erosional surface (Montadert et a1., 1978). Eventually, the upper evaporites pinch out at leve1s that are around $3.8-4.1$ seconds two-way trave1 time (twtt) on the Balearic margins, and correspond to depths which strongly support the deep-basin hypothesis for the salinity crisis (Ryan, 1976). Erosional products of the Messinian Event are found on some margins (Ryan, Hsu et a1., 1973) and appear as a sediment wedge beneath some margins (Montadert et a1., 1978). Such sedimentary wedges are found below the upper evaporites and may influence the Messinian bathymetry thus restricting the thickest salt deposits to the central basin. P1io-Quaternary sedimentation rates in the Liguro-Provencal Basin are somewhat constrained by available borehole data from Deep Sea Drilling Project (DSDP) sites in the South Balearic Basin (Sites 124, $133,134,371$, and 372 from Cita et a1., 1978). The early P1iocene is condensed throughout most of the basin for the following reasons (Cita et al., 1978): 1) the Pliocene flooding of the basin trapped sediment on the sediment-deficient shelves, 2) the sediment supply decreased as a result of high erosion rates during the Messinian, and 3) contour currents removed sediment and caused occasional hardground deposits. Late Pliocene deposits remain condensed on the lower margins but moderate accumulation rates ( $>50 \mathrm{~m} \mathrm{Myr}^{-1}$ ) took place in the deep basin. By Pleistocene time, turbidite deposition predominates everywhere, with accumulation rates generally lower on the slope and shelf. Concerning the P1io-Quaternary acoustic facies, the Pliocene unit is transparent in the lower sections and becomes more stratified in the upper P1iocene. The Quaternary unit is well-stratified due to the 
increased sediment supply created during the glacial/interglacial cycles and the subsequent downslope transport activity via turbidity currents. Plio-Quaternary sediments are fairly thin on the Ligurian Basin margins ranging from $0 \mathrm{~m}$ on the Corsican slope to $500 \mathrm{~m}$ on the Cote d'Azur slope below Nice. This reduced thickness compared to the central basin results from sediment bypassing to the deep basin via canyons incised during the Messinian, and to the minor erosive influence of probable contour currents in the Western Mediterranean as suggested by hardground deposits on the Sardinia slope (Site 133, 134; Ryan, Hsu et a1., 1973) and outcropping of pre-Quaternary sediment on the western Corsican slope (Mauffret et al., 1982) and northwestern Corsican margin (Profile 9, Appendix 5).

\subsection{Sha1low structure}

The shallow structure and stratigraphy near the heat flow stations have been analyzed using new single-channel reflection data. All the lines have been interpreted for the purpose of making sedimentation corrections and estimating the reliability of the heat flow data. Structural features such as faults and salt domes have been noted and their structural implications to the basin evolution are discussed in the following sections. Positions of the profiles complementing the heat flow data along with pertinent structural data are presented in Figure 2.8 and the cross-sections are displayed in Figures A5.3-A5.26. A11 sediment-unloaded, water-loaded depths referred to in this section are simply calculated using the Crough (1983) method. 


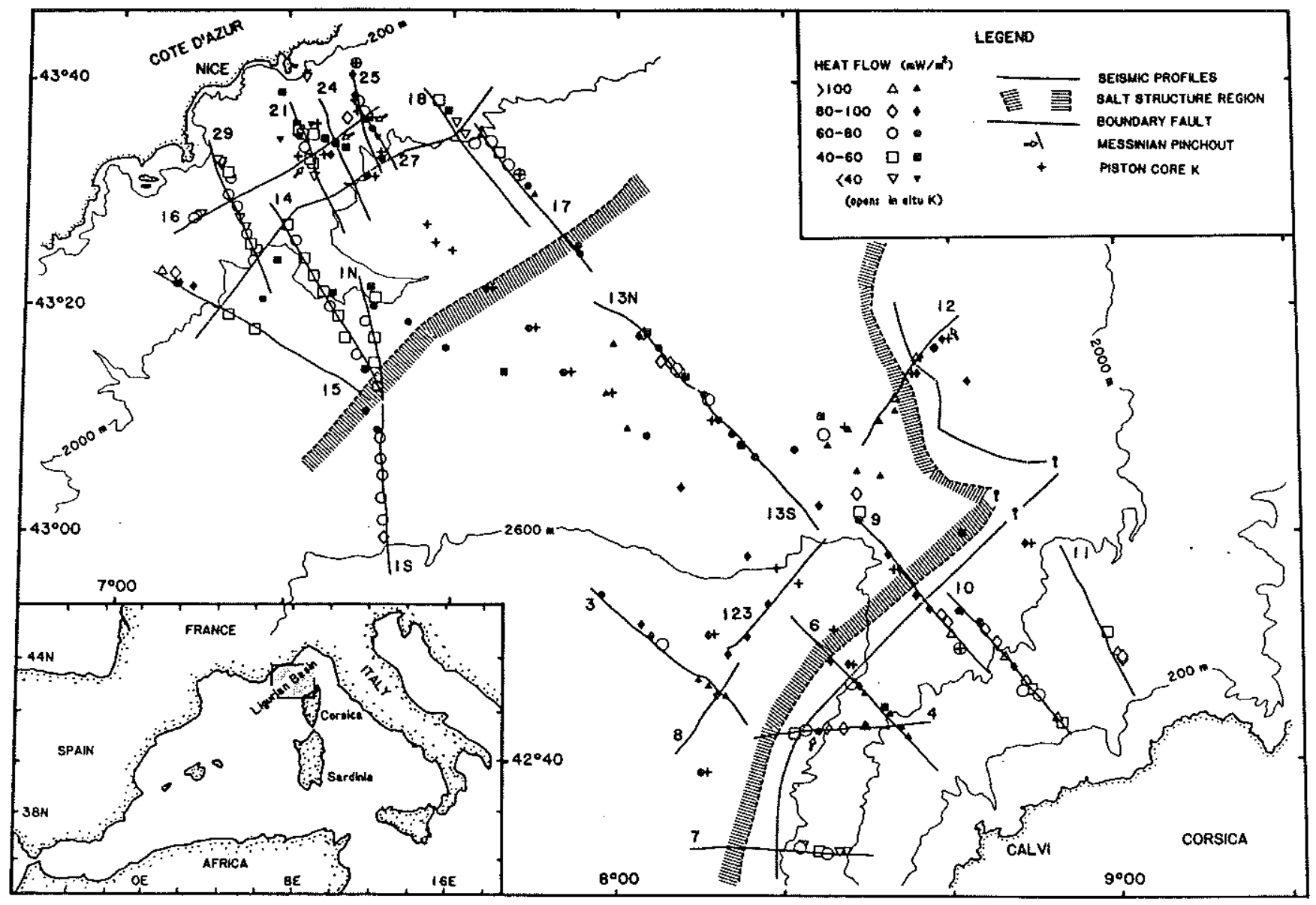

Fig. 2.8 Location map of Ligurian Sea heat flow data and pertinent single-channel profiles. All heat flow data in Ligurian Sea is shown including results from Foucher et al. (1976) and Rehault (1981), Della Vedova and Pellis (1981), and Burrus and Foucher (1986). Seismic data is illustrated in Appendix 5. Positions of main structural features such as the outline of the region of main salt deformation, the boundary fault, and the Messinian evaporite pinch out. Bathymetry shown in meters (From Pierrot, 1972; UTM projection). 
Var fan construction. An outstanding problem in the Ligurian Basin sedimentary evolution is the development of the Var deep-sea fan. It is uncertain whether there was a pre-Messinian analog to the Var fan, even though the present Var fan dominates the basin floor bathymetry. The absence of salt structures below the lower Cote d'Azur margin suggest that less salt may have been deposited there, yet seismic data indicate that a large Miocene sedimentary thickness exists there. We believe a Miocene analogue of the Var Fan is consistent with these observations. Implications of the Messinian paleobathymetry and lack of Messinian structures beneath the Var cone are discussed later in this chapter. Using the acoustic facies scheme outlined above for the P1io-Quaternary, the lower Pliocene is transparent in nature and rests on the $M$ reflector. Seismic profiles crossing the Var fan indicate that a wel1-stratified wedge-shaped unit, denoted here as the 'Var unit', produces the cone. Assuming an interval velocity of $2.0 \mathrm{~km} \mathrm{~s}^{-1}$ (Finetti and More11i, 1973; Montadert et al., 1978), the Var unit has a thickness of $1000 \mathrm{~m}$ on the shallowest point on the levee, $500-600 \mathrm{~m}$ at the basin axis, and about 300-400 $\mathrm{m}$ near the Corsica rise below Ca1vi. The Var unit rests on a transparent acoustic unit which is about $200 \mathrm{~m}$ thick (e.g., Profile 1 and TR0/12, Appendix 5). No continuous internal P1io-Quaternary reflector defines the transition from the structureless early P1iocene unit to the wel1-stratified late Pleistocene sediments. With respect to the regional tectonic setting, the age of the Var unit may be established as mid-P1iocene $(\sim 3.5 \mathrm{Ma})$ if it reflects the rejuvenation of the mountainous borderlands (see Mauffret et a1., 1973 and reference therein), or Pleistocene $(\sim 2.0 \mathrm{Ma})$ if it is induced by 
climatic or glacio-eustatic factors. Assuming a Pleistocene age for the Var unit, average decompacted sedimentation rates near the levee, centra1 basin, and Corsica rise, are $450 \mathrm{~m} \mathrm{Myr}^{-1}, 300 \mathrm{~m} \mathrm{Myr}^{-1}$, and $200 \mathrm{~m} \mathrm{Myr}^{-1}$, respectively. These rates would decrease by half if the earlier mid-Pliocene age for the Var unit lower boundary is chosen. However, a mid-P1iocene age would cause the average sedimentation rate for the underlying transparent unit to be $130 \mathrm{~m} \mathrm{Myr}^{-1}$, more than twice as high as the early Pliocene in the Southern Balearic DSDP holes (Cita et a1., 1978). Thus, an ear1y Pleistocene age for the Var Fan development is more in agreement with the borehole and acoustic stratigraphic data.

Traced upslope onto the Nice slope, the Var unit is about $400 \mathrm{~m}$ thick and maintains a 100 m unstratified P1iocene unit above the $M$ reflector (Figure 2.9). Since the greatest thickness of the Var unit wedge is at the base-of-slope where the levee has formed, the Var fan development is probably more closely associated with a deep-sea cone formation at the mouth of the Var canyon than with a de1taic construction on the upper slope. The idea that the Var unit is composed of sediment originating from the North is reinforced by the onlapping nature of the Var unit onto the Corsican rise (Profile 12; Appendix 5). Where the Corsican rise is essentially absent, the sheets of Var sediment juxtapose the basement rock since the northwestern Corsican slope has thin or no P1io-Quaternary cover (Profile 5, 6, 7; Appendix 5). Margin uplift and the boundary fault system. We describe a major fault system in the Ligurian Basin which has a profound effect on the margin uplift since at least the Messinian. The fault displaces the M 


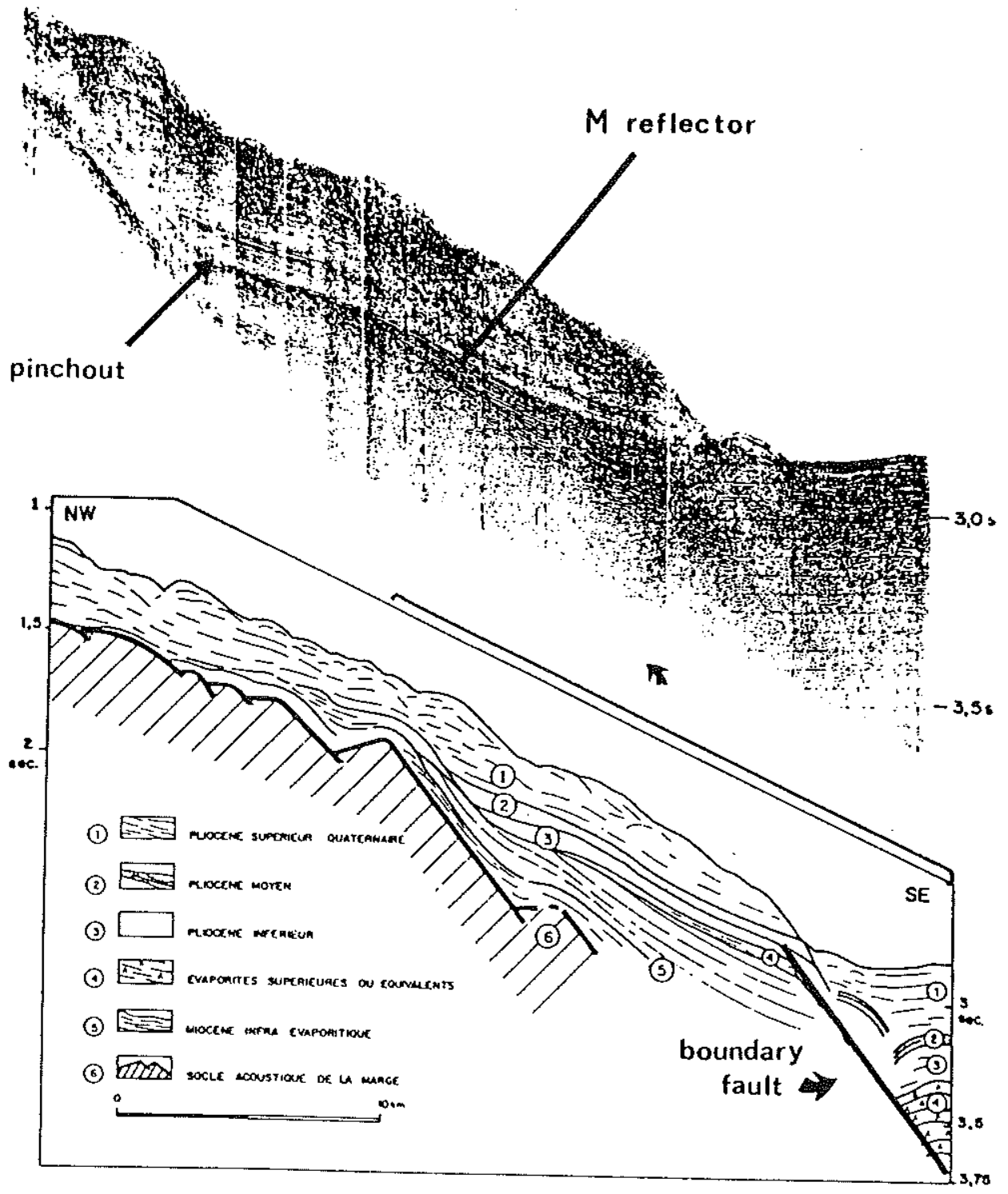

Fig. 2.9 Interpreted single-channel profile from Cote d'Azur margin (modified from Rehault, 1981) showing the Messinian evaporite sequence (M-reflector), pinchout and erosional surface. The Plio-Quaternary stratigraphy consists of a transparent P1iocene unit beneath a well-stratified Quaternary section which is referred to as the Var Unit (see text). The boundary fault has offset the Messinian by almost a kilometer. Location is given as Profile 28 in Figure A5.1. 
reflector going from the central basin onto the continental slope. A similar feature on the western Sardinian margin is termed a "boundary fault" by Ryan, Hsu et a1. (1973); it may account for large throws in the Messinian evaporite layer observed in several localities in the Western Mediterranean Basin (Montadert et a1., 1978; Mauffret et a1., 1981). The boundary fault should not be confused with the Western Mediterranean margin classification of Mauffet et a1. (1973) ("abrupt" and "gradual" margins) which refers mainly to the margin's basement topography across the base-of-slope transition zone. This apparent normal fault is consistently found beneath the base-of-slope inflection point on every profile in the Ligurian Basin (Figure 2.8), but it on1y has an appreciably large throw ( $200 \mathrm{~m}$ ) on the Cote d'Azur margin where is exceeds $1000 \mathrm{~m}$ just below Nice. The boundary fault is generally accompanied by degradation of the $M$ reflector intensity which could be attributed to shear deformation or possibly by dissolution of the evaporite 1ayer (e.g., Profile 12, Appendix 5). Because the sediment drape thickness generally exceeds the vertical displacement, no fault scarp is produced. We note that where the Cote d'Azur canyons intersect the boundary fault zone, SeaBeam bathymetry shows ova1-shaped topographic depressions (Pautot et a1., 1984). Such depressions may direct1y result from the turbidity currents scouring boundary fault zone, which in all likelihood consists of tectonized and easily erodable sediment.

The boundary fault on the Nice portion of the Cote d'Azur margin is accompanied by apparent reverse drag folding on the hanging wall (e.g., Profiles 15 and 17, Appendix 5). Several different mechanisms can 
contribute to this "antithetic-type" folding such as sediment loading, differential compaction, flowage of Messinian salt toward the deep basin, or norma1 faulting of the basement with incipient antithetic faulting of the sediment cover. Correcting for the sediment load assuming local isostasy (c.f. Crough, 1983), up to $700 \mathrm{~m}$ displacement still remains across the fault zone (e.g., Profiles 15 and 17 ). Additional compaction of the thicker basinal sediment due to deposition of the P1io-Quaternary sediment may account for no more than 50 to $100 \mathrm{~m}$ of this offset, depending on the thickness of the Miocene section. Seismic sections indicate a thin or absent salt layer adjacent to the margin. Moreover, salt deformation (elongated diapirs and salt ridges) is only found within $15 \mathrm{~km}$ seaward, which is probably too great a distance to induce a displacement at the base-of-slope. Therefore, uplift of the Cote d'Azur margin relative to the basin must have been accompanied by normal faulting of the basement during the late Pliocene and Pleistocene. The $100-200 \mathrm{~m}$ displacement of the $\mathrm{M}$ reflector on the Corsican Margin, as we11 as the other margins of the western Mediterranean, may be more easily be explained by nonepeirogenic mechanisms such as compaction of the Miocene series.

Along the littoral zone of the French-Italian Maritime Alps, marine P1iocene beds have a1titudes of $\sim 350 \mathrm{~m}$ in the Var river basin; paleobathymetric studies suggest that these beds were deposited in \%30 m water depth (Irr, 1984, p. 407; Clauzon, 1978). Additiona1 evidence for uplift is given by marine Quaternary terraces elevated over $120 \mathrm{~m}$ in coastal basins (Moullade, 1978) and a shallow shelf break depth of $110 \mathrm{~m}$ (Fierro et a1., 1973). The altitude and number of the 
P1io-Quaternary terraces along the southeast France coast1ine is greatest between Nice and Monaco where the Alpine axis juxtaposes the margin (Moullade, 1978; Irr, 1984, p. 408).

In comparison, the neritic zone and the coastal region of northwestern Corsica show evidence for substantially less uplift in the late Quaternary. Levels for the highest Corsican marine terraces and shelf break are 40 to $70 \mathrm{~m}$ less than the Nice shore. The Maures-Estere1 region, which is located west of the subalpine region of the Cote d'Azur, has marine terraces similar to the northwest Corsica coast (Mou1lade, 1978). Therefore, the marine terrace data are consistent with maximum rates of uplift being limited to the Maritime Alpine borderland.

E1sewhere on the Ligurian Sea coast1ines, the minimum Quaternary uplift indicated by the relict shoreline deposits is still much greater than the 10 to $30 \mathrm{~m}$ uplift observed on the southeastern U.S. Atlantic Coasta1 Plain, a region mainly influenced by glacio-eustatic effects (Cronin, 1981). The elevated Mediterranean shorelines must mainly be attributed to crustal displacements which may inc1ude local tectono-isostatic effects due to epeirogenic uplift or erosional/glacial unloading on 1and, and regional effects due to compression and deformation at the Mediterranean margins via in-plane 1ithospheric stress (e.g., Karner, 1986; Cloetingh et a1., 1985) or hydro-isostatic and sediment loading within the basin. The boundary fault system is a likely slip dislocation surface to accommodate these movements.

According to the deep basin-desiccation model for the Messinian evaporite deposition, the shallow water to subaerial conditions would 
1imit the thickest salt deposits to the deepest portions of the existing basin (c.f. Cita, 1982). Difficulties with the "bu11's eye" depositional model (Ryan, Hsu, et a1., 1973) are that: 1) the upper evaporite surface on the lower margins has been loca11y reworked in the Ligurian Basin (e.g., lower section of Profile 11) and elsewhere in the Western Mediterranean (Montadert et al., 1978), and 2) thin evaporite deposits may occur in bathymetrically isolated sub-basins in the western Mediterranean (e.g., Gulf of Valencia Trough and North Corsican Basin). Nevertheless, the evaporite pinchout circumscribing the central basin is probably a good representation of the strandline at the end of the Messinian and should be at a fairly uniform level in the absence of post-Messinian tectonic perturbations.

Examining the evaporite pinchout locations around the Ligurian Basin, the pinchout level is decidedly shallower and lies closer to the present coast of the Cote d'Azur margin compared to the north Corsican margin situation. The pinchout is wel1-preserved on the Nice slope platform above the large-throw boundary fault (e.g., Profiles 21, 24 , 25,27 , Appendix 5). It is within a horizon of 2.0 to $2.4 \mathrm{~s}$ two-way trave1 time, located approximately $12 \mathrm{~km}$ from the coast1ine (Figure 2.8). The sediment-unloaded water depth is about 1.4 to $1.7 \mathrm{~km}$ with the shallowest pinchout found adjacent to the eastern wall of Var canyon. Corsican margin pinchouts are only found on two profiles (Profiles 4 and 12; Appendix 5) at depths of $\sim 3.5 \mathrm{~s}$ or $2.6 \mathrm{~km}$ sediment-unloaded water depth, similar to other margins in the western Mediterranean (Ryan, 1976). The distance of the pinchout to the Corsican coastline is larger at $25 \mathrm{~km}$ (Figure 2.8). If we use the Corsican margin Messinian 
stratigraphic markers to model the Nice margin neotectonics, then about $1 \mathrm{~km}$ of uplift and a $2^{\circ}$ seaward tilting produces the Nice margin geometry. Thus, the pinchout level and strandline separation is consistent with uplift of the Cote d'Azur margin and adjacent subalpine borderland as a single block, with the boundary fault being the main seaward dislocation.

The upper evaporite surface below the Cote d'Azur margin is slightly elevated compared to the central basin. Between the boundary fault and the first appearance of the salt ridges $20 \mathrm{~km}$ seaward, the sediment-unloaded elevation decreases by about $400 \mathrm{~m}$. This suggests that 1) the Var rise was tilted $1^{\circ}$ as a result of basement flexure or faulting, or 2) a Messinian fan of similar relief existed. Late Quaternary tilting of the upper Var fan would enhance the sma11 growth faults that bound the down-dropped side of the tilted bathymetric steps which compose the southeast levee. Post-Messinian tilting is consistent with $1-2^{\circ}$ tilting calculated for the Nice margin, and would account for the $1 \mathrm{~km}$ discrepancy between the Corsican and Nice pinchout leve1s. However, this suggests that the marine Pliocene formations near Nice are preserved at elevations several hundred meters above the previously reported outcrops (Irr, 1984) or that the observed P1iocene beds are deposited $300 \mathrm{~m}$ deeper in the upper bathyal zone.

At the junction between prominent salt structures and flat-1ying evaporites (see Figure 2.8), the upper evaporites have a sediment-unloaded depth of $\sim 2.8 \mathrm{~km}$ on both the French and Corsican sides, deepening to $\sim 3.0 \mathrm{~km}$ in the center of the basin. The greater depth of the upper evaporites in the central basin where oceanic crust 
exists may indicate greater post-Miocene thermal subsidence in the central basin, greater compaction of the infrasalt series, or a gentle paleobathymetric trend. Although halokinesis is pervasive in this region, compared to the elevation change on the margins, we maintain that the central basin subsidence has not been seriously affected by differential P1io-Quaternary vertical movements.

We infer that uplift in the French-Maritime Alpine borderland is due to an active erosion-isostatic rebound phase (c.f. Stephenson and Lambeck, 1985) within the young denuding Alpine mountain belt. Since the margin side of the boundary fault and the onshore regions have been uplifted by similar amounts, the entire width of the margin must essentially behave as a competent crustal block. The boundary fault serves as the main dislocation between the subsiding basin and eroding mountain belt. This large vertical displacement may normally take place as flexural deformation if the basement faults were not available for reactivation at the base of the margin. This scheme implies a dominantly nonepeirogenic source for the vertica1 movements.

Observations of P1io-Quaternary norma1 faulting at the boundary fault is contrary to the present regional compression indicated by focal mechanism studies in the Ligurian Basin (e.g., Rehault and Bethoux, 1984), but these earthquakes do not have we11-constrained focal depths. In terms of the bending of an elastic plate, the seismicity could be a manifestation of plate flexure due to simple vertical loading processes (e.g., Stein et al., 1979). The deviatoric stresses could be generated by recent unloading in the Alps (erosion or deglaciation), loading by basin sediments, or by uncompensated basement topography. It should be 
emphasized that the uplift implied by the boundary fault is not consistent with the hypothesized Pliocene foundering of the deep basin (Stanley et a1., 1974b; Mauffret et a1., 1973) nor with shortening of the basement beneath the margin by reverse faulting (Rehault, 1981; Rehault et a1., 1984a; Mauffret et a1., 1981).

A model for the Cote d'Azur "neotectonics" must account for both onland and offshore structures. The Var coastal valley is a $20 \mathrm{~km}$ wide, $50 \mathrm{~km}$ long basin which has been filled with P1iocene marine beds (Clauzon, 1978). Other Cote d'Azur coastal river valleys have P1iocene deposits as well (see Moullade, 1978 and references therein), but there is a conspicuous change in the apparent uplift of basins located on either side of the Var valley. Two subalpine structural units, the Castellane Arc and Nice Arc, are located on the western and eastern banks of the Var valley, respectively, and their juxtaposition is probably responsible for the Var valley. Irr (1984) and others infer that a NNW-SSE trending fault beneath the valley has caused the Nice and Roya Arcs to the east to be elevated $400 \mathrm{~m}$ higher than the western bank. Both the Var Valley and the Var submarine canyon were deeply incised during the Messinian desiccation and marginal erosion, with the Var fault providing important structural control.

We define the Ligurian Alpine wedge to be composed of the borderland segments of the Nice and Roya Arcs and the adjacent margin. The boundary fault at the base of the slope, the Var canyon (Var fault) to the west, and undefined eastern and northern borders delineate the extent of the Ligurian Alpine block. This block has been uplifted a total of at least $700 \mathrm{~m}$ within the 1 ittoral to bathya1 zone, compared to 
about $300 \mathrm{~m}$ of uplift on the juxtaposed borderlands and margin sections. The timing of the uplift is either late Pliocene or Quaternary. We speculate that the uplift results from erosional-rebound isostatic movement enhanced by the repeated loading of Alpine glaciers. The Cote d'Azur Rise morphology, including the Var Fan channel and levee orientations, are undoubtedly influenced by the segmentation of the up1ifted margin.

Latera1 variability and genesis of salt structures. Using the nomenclature of Trusheim (1960), intruded and deformed salt bodies in the western Mediterranean basins include gentle sa1t anticlines, pillow formations, diapirs with rim synclinal sedimentary features, and salt walls. We show that specific salt structures are restricted to different regions of the deep basin, and that their formation is dependent on several gross geologic factors such as salt thickness, overburden thickness, geothermal structure, faulting, and deviatoric stresses (e.g., Mauffret et a1., 1973). New seismic reflection and heat flow data presented in Chapters 3 and 4 in addition to recent studies of salt creep allow us to conjecture why contrasting styles of salt structures occur within the Ligurian Basin.

Three main salt diapiric provinces are clearly identified in the Liguro-Provencal Basin from seismic profiles presented in Appendix 5 and previous studies (Finetti and More11i, 1973; Mauffret et al., 1973; Rehault, 1981, Pautot et a1., 1984). As described below, dissimilarity in the salt structure geometry exists for the lower Cote d'Azur margin (flat-1ying or gentle salt anticlines), the northern central basin (salt ridges) and southern central basin (dense pattern of narrow salt domes 
or salt pillows). The three provinces are outlined below:

Province A: On the continental rise of the Cote d'Azur, salt

tectonics beneath the Var levee generally consist of smal1-amplitude salt anticlines subparallel to the basin axis (e.g., Profiles 15 and 1N). A similar situation occurs on the Rhone Fan off the Gulf of Lion margin. Pautot et al. (1984) suggest that the negative correlation between diapirism and thick $(>1 \mathrm{~km})$ fan deposits results from the stiffer bulk elasticity of the overburden below the levee.

Province B: Farther seaward, near the morphologic transition of the Var levee to the suprafan, elongate diapirs and sa1t walls appear which are $\sim 1-2 \mathrm{~km}$ wide (Profiles $13 \mathrm{~N}$ and 1 ). These structures parallel the basin axis (N4OE) within a 20 to $40 \mathrm{~km}$ wide zone in the Var region; near the Gulf of Lion, the salt diapirs tend to align parallel to the periphery of the crescent-shaped Rhone fan (Pautot et a1., 1984). Dua1 $1 \mathrm{~km}$ wide salt ridges are separated by $4 \mathrm{~km}$ as shown on Profile $13 \mathrm{~N}$ (Appendix 5). This particular salt wall overlies seismicity which indicate N130E stresses so that basement faulting may be a source of instability (Rehault and Bethoux, 1984), but many of the lineated salt structures are not accompanied by recent faulting.

Province C: The southeastern half of the basin is occupied by sma11 circular structures ( $<0.5 \mathrm{~km}$ diameter) which we interpret as incipient diapirs or pillow formations (e.g., Profiles 3 and 8 ). The question of whether these "Ligurian-type" salt structures are actually penetrative (diapirs) or not is unresolved due to their poor seismic definition. For instance, seismic diffraction by sma11-offset faults in the upwarped overburden makes the amplitude of the salt relief unclear (Burrus and 
Foucher, 1986). The "Ligurian-type" structures are also noteworthy because of their small spacing (1-2 km), narrow geometry, and wide extent. Mauffret et a1. (1973) and others believe that Pliocene tectonics has induced the buoyancy-driven salt flow, but the wavelength of the pillow structures is probably too small to be controlled by basement faulting.

The treatise by Jackson and Talbot (1986) gives a framework by which the western Mediterranean salt tectonics may be reassessed. Central to their analysis is that a minimum pre-existing relief on one of the salt layer interfaces is necessary for the initiation of buoyancy-driven diapirism. In this manner, differential loading of the salt unit seems to be a far more effective mechanism to initiate pillow formation than simple density inversions alone. Thus, for diapirism to progress either the initial relief of the salt surface must be large $(>150 \mathrm{~m})$ or some near-surface gravity-driven mechanism must be invoked.

Halokinesis induced by differential loading is particularly applicable to the north portion of the Ligurian Basin. For instance, tilting of the Cote d'Azur Rise and formation of the Var Cone produce lateral stresses which could orient the salt ridges in Province $B$. In the Var levee (Province A), gravitational slumping of the massive P1io-Quaternary unit occurs along sha11ow faults which probab1y sole near the upper evaporite layer (see Appendix 5; Pautot et a1., 1984). Messinian topographic relief caused by the thick base-of-slope sediment wedge on the Cote d'Azur Rise may also enhance salt flow away from the margin. Thus, P1io-Quaternary structures are consistent with some 
gravity-induced lateral spreading mechanism for the Messinian salt structures near the Cote d'Azur lower margin.

Another method to achieve halokinesis is by strain induced by regional tectonic stress. This mechanism is generally thought to be applicable in the Western Mediterranean Basin due to the present regiona1 state of compression (Mauffret et al., 1981) or to Pliocene extensional faulting (Mauffret et al., 1973; Stanley et a1., 1974). From our study of the Plio-Quaternary stratigraphy and margin uplift in the Ligurian Basin, we doubt that regional stretching or shortening of the crust, as suggested by Mauffet and coworkers, can account for most of the structures. Some salt walls in Province $B$ are linked to reactivated basement faults (Rehault and Bethoux, 1984), but most basement faulting is restricted to the boundary fault system (Figure 2.8) which is attributed to passive margin up1ift, not regional tectonic movements. Shallow faults in Province $\mathrm{C}$ are associated with fractures above incipient salt intrusion and do not represent basement movement. We believe that differential loading by the Var levee, tilting of the French-Italian Maritime Alpine margin, and pre-existing Messinian relief can explain most of the linear salt structures in the north central basin (Provinces B).

In Province $A$ where salt anticlines and elongate pillows form beneath the Var levee, differential loading maintains latera1 stresses similar to the salt ridges of Province $B$. The relatively mild halokinesis may be an outcome of facies changes in the Messinian unit, as well as in the overburden. Viscosity changes may be expected from large sedimentalogical changes incurred in submarine fan facies. The 
Messinian analog of the Var Fan probably had a smaller percentage of salt and higher sand and anhydrite contents in the proximal versus the distal facies. Consequently, the bulk creep properties of the Province A source layer would be significantly more viscous than the pure salt deposits likely to be found in the Province B. Pautot et a1. (1984) suggest that the overburden is also significantly stiffer within the Var levee, but the timing of initial salt movement does not coincide with the deposition of the main Var sediment.

For the Ligurian-type structures of the southern central basin (Province $\mathrm{C}$ ), diapirism is mainly driven by buoyancy mechanisms since differential loading from above can only play a minor role in the salt flowage. Moreover, the circular geometry of the formations is consistent with the lack of significant lateral stresses. Buoyancy has not genera11y been regarded as a major factor (Rehau1t, 1981; Pautot et a1., 1984) because the P1io-Quaternary thickness is only 500 to $700 \mathrm{~m}$ over most of the province, a thickness which is barely sufficient to produce density contrasts for instability (Ta1bot and Jackson, 1986). If a layer of dense evaporites composed of anhydrite or dolomite $\left(2500-2800 \mathrm{~kg} \mathrm{~m}^{-3}\right)$ over1ies the salt 1ayer $\left(2100-2200 \mathrm{~kg} \mathrm{~m}^{-3}\right.$; see Schreiber et a1., 1973), then a sufficiently large density inversion for instability may be achieved. This situation is highly probable for the western Mediterranean since a $500 \mathrm{~m}$ thick evaporite overlies the salt layer (Montadert et a1., 1978). The fact that the Ligurian-type structures do not appear to penetrate far into the P1io-Quaternary section is consistent with theoretical neutral buoyancy estimates. Ultimately, the relatively unknown stratigraphy between anhydrite and 
salt within the Messinian controls the interna1 density structure of the evaporite sequence.

Wavelengths of 1-2 $\mathrm{km}$ for the Ligurian-type structures contrasts with dominant wavelengths of 7-26 km for Gulf Coast diapirs (Jackson and Talbot, 1986). We suggest that the small wavelength may be created by the deposition and compaction conditions experienced in the central basin during the Messinian. Elevated pore pressures are expected within the infrasalt series due to the low porosity and rapid burial rates of the evaporitic unit. Release of excessive pore pressures may initially take place by secondary diapiric phenomena in the shaly substratum. Extensional fractures would occur above these upwarped zones creating permeable avenues for pore water to rise to hydrostatic levels. Using the normal1y-pressured compaction model presented in Chapter 4, about $600 \mathrm{~m}$ of pore water per unit area would be expelled from the Miocene unit with a present compacted thickness of $3 \mathrm{~km}$ below $2 \mathrm{~km}$ of Messinian evaporites. Therefore, a dynamic model for release of excessive pore pressures may be an excellent mechanism to produce initial salt relief which later provides points of amplification for pillow growth.

Strain rate, temperature, and water are important to salt deformation as we11 (Carter and Hansen, 1983; Urai et al., 1986). As discussed above, $600 \mathrm{~m}$ of formation water may have passed through the Messinian salt during its deposition; an additional $50 \mathrm{~m}$ of water would have to pass through during the P1io-Quaternary assuming normal compaction of the Miocene infrasalt series. Urai et al. (1986) have shown that water promotes recrystallization and solution-transfer creep, both which dramatically lower the stress sensitivity of strain rate to 
that approaching a Newtonian solid. Thus, water-weakening decreases the yield strength predicted by dislocation creep laws and is a important factor in low-stress conditions. Ideally, the role of formation waters within the salt unit, as well as possible overpressuring in the infrasalt series, should be included in theoretical studies of Mediterranean diapirism.

Despite the large surface heat flow asymmetry, the temperature history for the Messinian evaporite sequence is nearly the same for the three salt provinces (Figure 2.10). We have forward modeled the Messinian evaporite temperature versus time using the known sedimentation rates and observed heat flow values (corrected for Glacial paleoc1imatic temperature changes) for Sites B, C1 and D1 (see Chapter 3, Figure 3.1) for Provinces A, B, and C, respectively. The sediment petrophysical properties used for the Plio-Quaternary and Miocene shale units and for the Messinian evaporites are models $B$ and $E$, respectively (Table 4.1).

For the deep basin provinces $B$ and $C$, the present temperatures for the upper and lower Messinian boundaries are estimated to be $\sim 60^{\circ} \mathrm{C}$ and $\sim 100^{\circ} \mathrm{C}$, respectively. These estimates are much lower than that suggested by Erickson et a1. (1977). The temperature uncertainties are mainly introduced by the lower Messinian boundary depth (reflector pick and velocity calculation) and the thermal conductivity structure of the evaporite unit (taken to be $5.0 \mathrm{~W} \mathrm{~m}^{-1} \mathrm{~K}^{-1}$ ). According to Figure 2.10, the thermal history of the Messinian evaporite varies most rapidly between the depositional period 6-5 Ma and during the rapid burial phase 2-0 Ma. During the P1iocene (5-2 Ma), temperatures are predicted to 


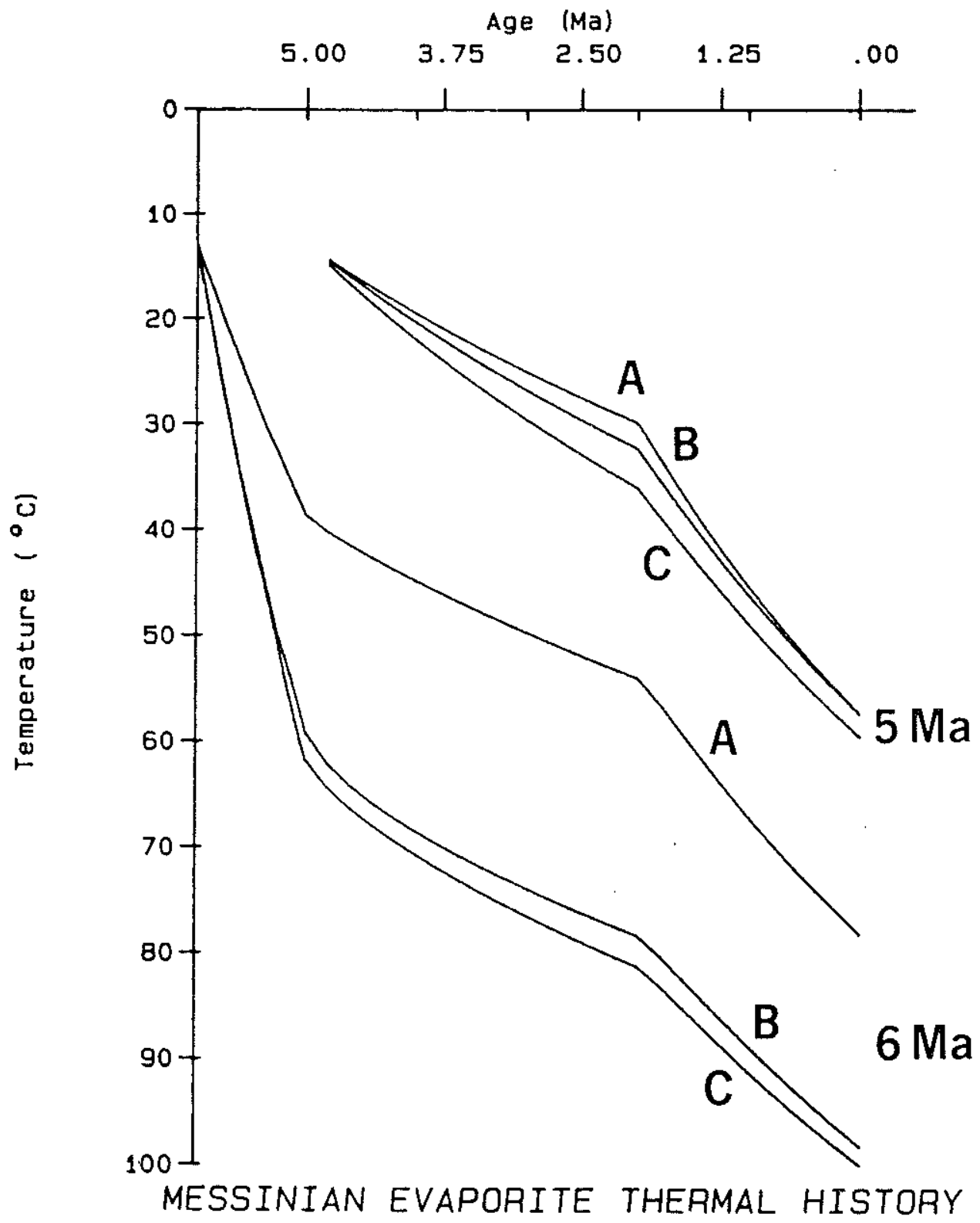

Fig. 2.10 Temperature versus time for the lower and upper surfaces of the Messinian evaporite unit. Locations $A, B$ and $C$ are given in text. See text for further details. 
remain $70-80^{\circ} \mathrm{C}$ and $20-30^{\circ} \mathrm{C}$ for the upper and lower Messinian, respectively. In contrast to the central basin, the Cote d'Azur margin section is relatively cooler with the lower Messinian predicted to be about $20^{\circ} \mathrm{C}$ cooler for Province $\mathrm{A}$. In addition to a Messinian facies changes, the lower formation temperature may inhibit the development of penetrative salt structures in this region by increasing the internal strength of the source unit.

Differences in the depth of burial beneath the P1io-Quaternary overburden compensates for the NW to SE increase in corrected heat flow from $\sim 100 \mathrm{~mW} \mathrm{~m}^{-2}$ in Province $\mathrm{B}$ to $\sim 125 \mathrm{~mW} \mathrm{~m}^{-2}$ in Province $\mathrm{C}$ (see Chapter 4). Therefore, temperature does not appear to be an important factor for the regional variability in salt structure shape. However, the intrusion distance is probably dependent on depth of burial and salt thickness. From temperature depth plots of the three provinces (Figure 2.11), buoyancy forces are most likely to be active in Province B which maintains the largest burial depth for the lower Messinian. Province B also has the largest wavelength and the most penetrative structures in the basin.

High heat flow is important to diapirism since temperature decreases the yield strength of salt, similar to water-weakening (Carter and Hansen, 1983). Erickson et a1. (1977) have noted that the higher heat flow in the western compared to the eastern Mediterranean explains the predominance of halokinesis in the western basins and the relatively flat-1ying evaporites in most portions of the central eastern basin. Using the Deep Sea Drilling Project results for the Ionian Sea site 374 and a sedimentation-thermal model appropriate for old lithosphere (see 


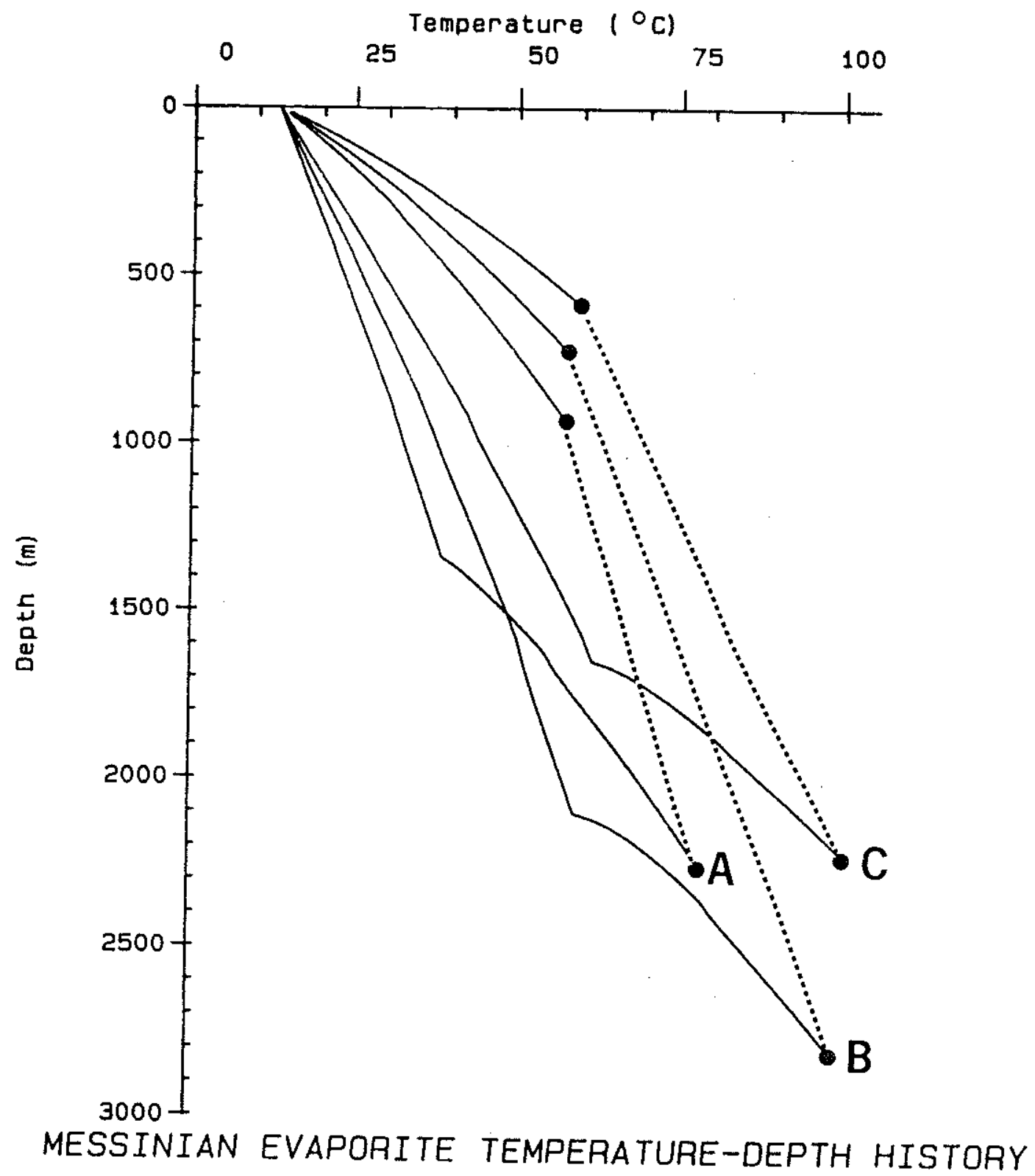

Fig. 2.11 Burial temperatures for the lower and upper surfaces of the Messinian evaporite unit. Locations as in Figure 2.10. Dashed line is present geothermal profile and solid lines are temperature-depth paths of each surface. See text for further details. 
Chapter 4), the eastern Mediterranean Messinian evaporite layer has upper and lower boundaries with temperatures of $\sim 30^{\circ} \mathrm{C}$ and $40-50^{\circ} \mathrm{C}$, respectively. These values are about $50 \%$ lower than the Liguro-Provencal estimates. In lieu of compositional changes between the eastern and western evaporite sequences, it appears that the Mediterranean salt requires minimum temperatures of at least $50^{\circ} \mathrm{C}$ to activate salt flow.

A late Pliocene or early Quaternary age for the beginning of the salt movement is consistent with concordant folding of the lower P1iocene and Messinian upper evaporites seen, for example, in Profile 12 on the Corsican margin and Profile 15 on the Cote d'Azur margin (Appendix 5). Seismic resolution of the salt structures is insufficient to determine better account of the salt growth history, especially since the Ligurian Basin salt structures are at an early stage of diapiric evolution and generally do not form rim synclinal deposits. However, formation of topographic kno1ls overlying some salt structures indicate that recent rates of salt movement exceed the local sedimentation rates of $0.1-0.3 \mathrm{~mm} \mathrm{yr}^{-1}$. Activity is also apparent in the North Corsica Basin where salt deformation seems to be closely linked with fault scarps and offsets in echo reflectors (Figure 2.6).

We suggest that the thermal and pore pressure history of the deep basin sediment are important parameters in the dynamics of salt deformation in the Liguro-Provencal Basin. Increase in salt temperature triggered by high $\mathrm{Pleistocene}$ sedimentation rates coincides with evidence for early Quaternary deformation. According to Figure 2.10, the early Pleistocene is characterized by over half of the source unit 
maintaining temperatures $>50^{\circ} \mathrm{C}$ with the lower Messinian approaching temperatures of $70-90^{\circ} \mathrm{C}$. Recent diapirism also is in agreement with continued temperature increases, and so increased ductility, of the Messinian layer due to the more rapid burial rates experienced during the last $2 \mathrm{Ma}$. The deep basin pore pressure evolution is linked to the compaction history of the lower Miocene substratum. The upward migration of formation waters associated with normal compaction is restricted to some extent by the impermeable Messinian evaporites. Excess pore pressures may have been released by faulting or diapiric episodes in the substratum, source and overburden. Such dynamic processes could easily have produce the pre-existing relief which is necessary for diapirism to proceed by buoyancy processes. Continued upward pore water migration during the late Quaternary may produce excess heat above salt structures (Keen, 1983), which may cause a transient perturbation to the near-surface thermal environment (see Chapter 4).

Implications of the P1io-Quaternary geology. Heat flow and subsidence calculations will depend in varying degrees to recent crusta1 movement and sedimentation patterns. From borehole data, we infer that the age of the Var fan is approximately Pleistocene. The start of rapid construction is probably about $2.0 \mathrm{Ma}$, which coincides with the commencement of Alpine glaciation. The "Var Unit" can be traced throughout the Ligurian Basin and so is a consistent acoustic stratigraphic unit to implement for basin-wide the sedimentation rate calculations. A Pleistocene, as opposed to a mid-Pliocene age, leads to systematically larger sedimentation corrections to the heat flow data, 
especially since the heat flow is more sensitive to the post-Miocene rates than to the mid to late Miocene rates (see Chapter 4 ).

To improve our understanding of the subsidence on the margins, reference levels of the Messinian evaporite pinchout, and 1ittoral and neritic features of Pleistocene and Recent age are investigated. We identify a circum-base-of-slope basement fault which has been reactivated in a normal sense. This "boundary fault" is the main dislocation surface in the flexural system composed of the basin and borderlands. On the basis of these paleobathymetric data, the cote d'Azur margin has been uplifted by almost one kilometer. The uplift is consistent with erosion-isostatic rebound phase within the Alps. An additional secondary mechanism may also be invoked to explain the smaller up1ift (less than $200 \mathrm{~m}$ ) observed on the other Mediterranean margins. Thus, the main Alpine uplift implies that the subsidence along the Cote d'Azur margin may be too shallow landward of the normal fault. Seaward of the boundary fault, the subsidence is affected little by the borderland up1ift. We suggest that a causal relationship exists between the Alpine uplift along boundary faults and the Var fan development and morphology .

The Messinian salt features delineate the region inundated by diapirism (Figure 2.8). Heat flow and shallow seismic reflection observations lead us to redefine the development of these salt structures. Tilting of the Cote d'Azur continental rise and the Var Fan build-up created differential loading of the salt in the north part of the Ligurian Basin. This loading provides an excellent mechanism by which linear salt structures are produced. Basement faulting oriented 
parallel to the margins also enhances the N40E direction for some salt walls. The small circular salt structures in the south central basin ("Ligurian-type diapirs") are unaffected by near-surface stresses caused by margin uplift. We suggest that their high spatial density results from Messinian relief caused by abnormal pore pressure evolution within the Miocene substratum and the consequent deformation associated with the release of the overpressuring. Actual pillow formation is accelerated during the late Pliocene to present due to the rapid burial and geothermal warming of the salt. Cooler formation temperatures and Messinian facies changes restrict diapirism beneath the Var levee. Since the role of salt structures on the surface heat flow is not certain (see Chapter 4), it is prudent to consider different salt provinces and erosional surfaces as heat flow subregions which have undergone similar histories. Further discussion of salt structural development and the interaction of structures with the surficial thermal regime is discussed in Chapters 4 and 5. 
$-85-$

Chapter 3.

Geothermal Survey of the Ligurian Basin 
A total of one-hundred and seventy-six heat flow measurements were collected in the central basin and margins of the Ligurian Sea. Over 100 of these heat flow stations are accompanied by in situ thermal conductivity measurements using the technique developed in Appendix 2. The stations are generally located within a broad swath between Nice, France and Calvi, Corsica. A shorter transect parallel to the trough axis (N40E) increases the number of measurements off the Corsican margin. Heat flow data on the margins enable a comparison between the geothermal character of thicker less extended continental crust to that of the highly-attenuated or oceanic crust of the central basin. Additionally, about a dozen piston core stations were made across the basin. Needle-probe measurements of conductivity and water content measurements on the cores supplemented the in situ conductivity data set in areas where $f e w$ in situ values are obtained. Some cores were taken as part of an experiment to calibrate and estimate the reliability of the in situ conductivity measurements (Appendix 2).

The pogo-probing survey technique was employed with the WHOI outrigger-type heat flow probe. Spacing between the heat flow measurements is generally 1 to $2 \mathrm{~km}$, except where environmenta1 conditions warranted otherwise. Areas directly overlying diapirs in the central basin are generally avoided. Coverage on the Var Fan is 1imited to areas outside of the main channels which consist of impenetrable sands. On the margins, measurements are concentrated on intercanyon highs which have a sufficiently thick cover of mainly hemipelagic sediment. We attempted to avoid measurements on canyon wa1ls and steep slopes since mass-wasting and basement outcrops are more prevalent. 
The heat flow data are grouped into 6 main regions based on geographical distribution, physiography, and crustal structure (Figure 3.1). Further division of the data set into 17 'sites' emphasizes local variability and the strong dependency of heat flow values on the sediment structure. Generally, each site occupies a roughly uniform stratigraphic section and has similar geothermal structure. Region A is located on the upper continental slope of the Cote D'Azur, landward of the boundary fault at the base of the slope. The upper northwest Corsican margin (region $F$ ) is defined as the portion of the margin which has a basement depth shallower than $3.0 \mathrm{~s}$ two way travel time ( $t w t t)$. Regions $B$ and $E$ are located on the lower margins of France and Corsica, respectively; their seaward limits are defined by the first appearance of significant salt structures. Oceanic crust occurs beneath region $\mathrm{C}$ in the north central basin, and transitional or oceanic crust under1ies the south central basin shown as region $D$. The results of the heat flow measurements are sumnarized in Table 3.1 .

\subsection{Field program}

For completeness, details of the field operations, navigation, and instrumentation used in the Ligurian Basin campaigns are presented below. Many aspects of the WHOI heat flow system used in this study are described in Appendix 2 and in reports of field experiments made elsewhere (e.g., Von Herzen et al., 1982; Detrick et al., 1986).

Logistics. In September 1982, heat flow measurements were made on the abyssal plain and lower continental margin of the Ligurian Basin; preliminary results are presented in Appendix 1. Due to the success of 


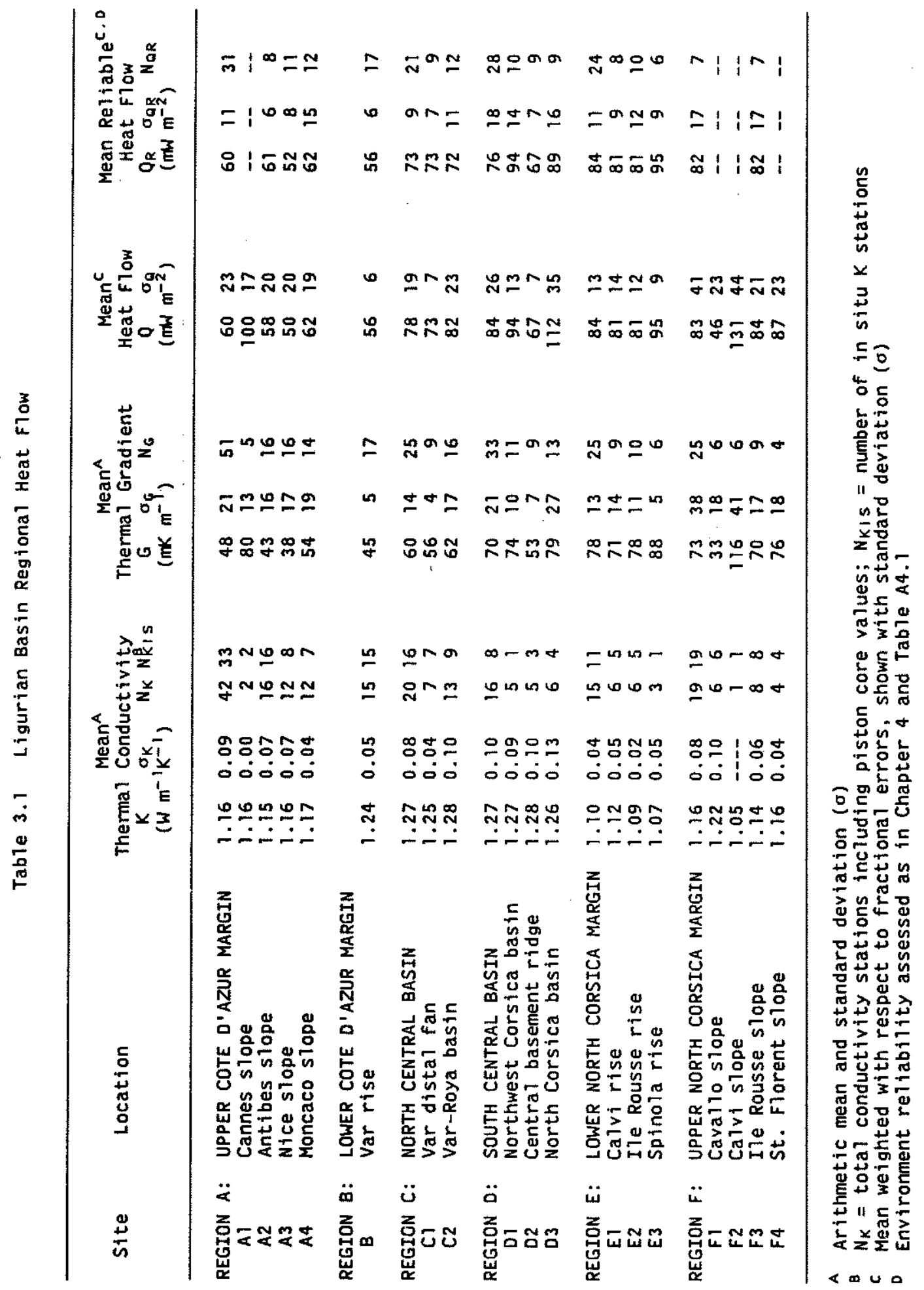




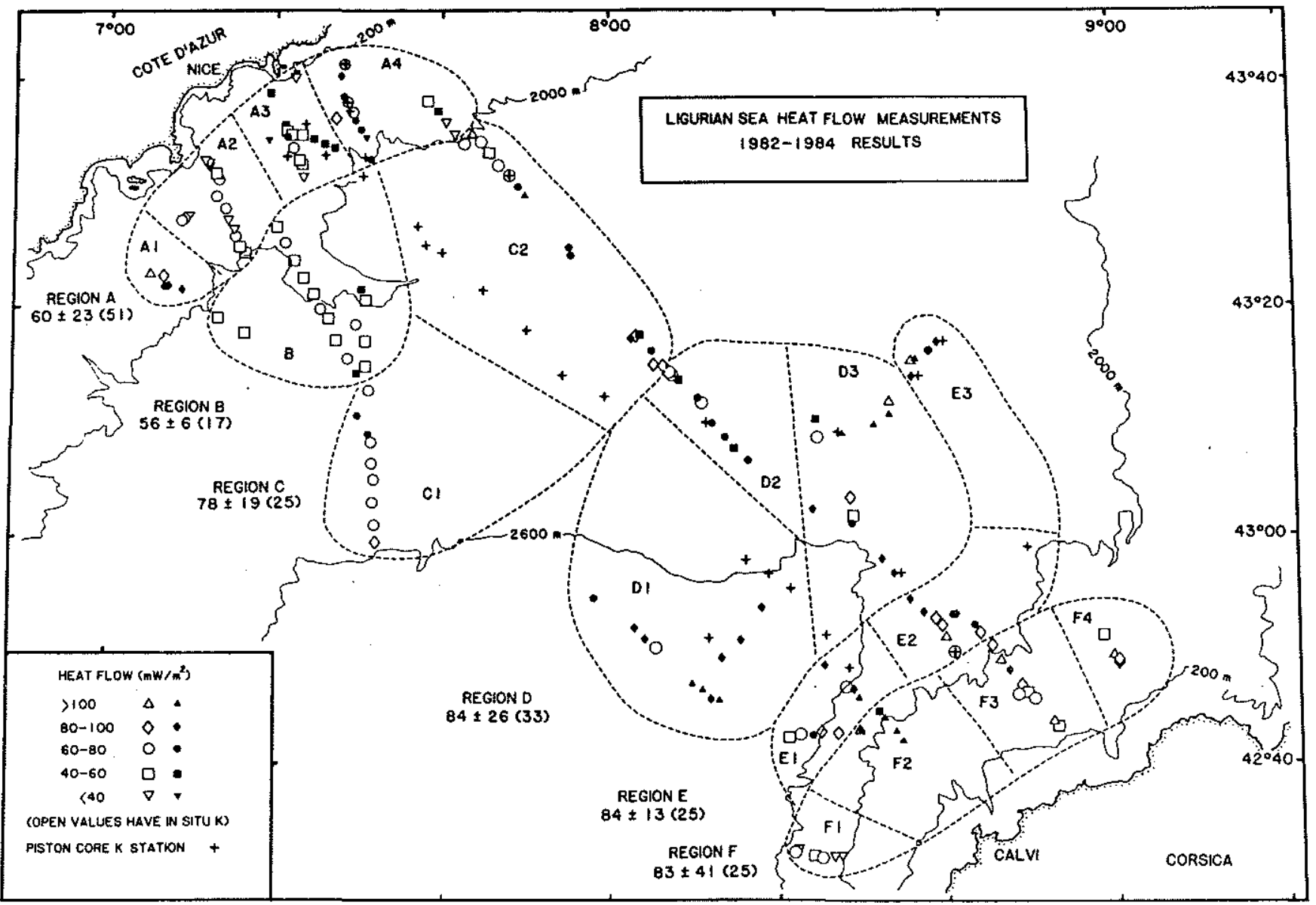

Fig. 3.1 Location map of Ligurian Sea heat flow groups. Weighted regional means with standard deviation and sample size are shown (in $\mathrm{mW} \mathrm{m}^{-2}$ ). See Figure 2.8 for further details. 
the first phase, a second heat flow phase followed in September 1984 which concentrated measurements mostly on the margins. A third and final phase of the field program consisted of single-channel reflection seismic profiles to provide control on the sediment thickness and structure. Extensive reflection seismic data collected before 1982 (cf. Rehault, 1981) enabled the heat flow survey to take place prior to the 1985 reflection seismic survey.

The Laboratoire de Geodynamique Sous-Marine in Villefranche-sur-mer, France offered excellent accommodations for oceanographic expeditions in the Ligurian Basin. The $\mathrm{R} / \mathrm{V}$ Catherine-Laurence, operated by the University of Paris VI and harbored at the Port de la Darse outside the Villefranche 1aboratory, was used exclusively in the field operations. The $21 \mathrm{~m}$ oceanographic research vessel has an A-frame style winch located at the aft of the ship which facilitated deployment of the heat flow probe and piston coring apparatus. Deck space was also sufficient for the mounting of the Villefranche $1 \mathrm{ab}$ 's air gun generator and compressor assemb1y.

Excursions were conducted out of Calvi and Ile Rousse ports of Corsica as well as from Villef ranche-sur-mer on the Cote d'Azur, France. Because of its small size, the $R / V$ Catherine-Laurence is norma11y used for day-1ong research ventures; but, once heat flow operations were proceeding well, we implemented 36 hour sessions. This facilitated multipenetration surveys in the central Ligurian Basin which required a 4-6 hour transit period to arrive on station. Unfortunately, the architecture and size of the Catherine-Laurence was not particularly we11-suited to conduct heat flow work during marine weather conditions 
of "mer agite". Perhaps $25 \%$ of the available ship time was spent idle due to adverse weather conditions experienced during the normally ca1m month of September 1984, mostly affecting operations in the southern Ligurian Basin.

Navigation. LORAN $C$ was utilized for navigation on all three campaigns, with values of latitude and longitude obtained by graphic conversion of the LORAN C coordinates. An estimate of the accuracy of the positioning is made by comparing results of two western Mediterranean surveys which included both satellite and LORAN C navigation. In Spring 1985, the site survey for the Ocean Drilling Project Leg 107 was performed in the Tyrrhenian Sea $\left(40^{\circ} \mathrm{N}, 12^{\circ} \mathrm{E}\right)$. Using the more reliable satellite fixes to correct the LORAN C-derived ship track positions, an average shift of 0.3 to $0.4 \mathrm{~km}$ is required in the Tyrrhenian Sea, with maximum shifts of $1.0 \mathrm{~km}$. Al1 the shifts are to the North quadrant. Hutchison (1983) obtained similar results between the LORAN $C$ and satellite positions derived for sites in the Balearic $\left(40^{\circ} \mathrm{N}, 5^{\circ} \mathrm{E}\right)$ and Tyrrhenian Sea $\left(40^{\circ} \mathrm{N}, 11^{\circ} \mathrm{E}\right.$ and $\left.37^{\circ} \mathrm{N}, 13^{\circ} \mathrm{E}\right)$.

A check on absolute positioning for the Ligurian Basin surveys is made by comparing the $12 \mathrm{kHz}$ bathymetric data obtained underway with that determined by the SEADOME (Pautot et al., 1984) and DELTARHO II (unpublished map) SeaBeam cruises which had satellite navigation. Roughly equivalent depths $( \pm 10 \mathrm{~m})$ for the $12 \mathrm{kHz}$ pinger records and the SeaBeam bathymetry have discrepancies which require average horizontal offsets of about $400 \mathrm{~m}$, with some station positions differing by up to $900 \mathrm{~m}$. These magnitudes are comparable to that found for the southern Balearic and Tyrrhenian Seas surveys, but the orientation of 
the shifts are not systematic to the north and instead appear to be random.

Accurate absolute positions are important in correlating heat flow data with bathymetry and with subsurface structures inferred from single-channel reflection profiles. The horizontal offset of the instrument to the ship is generally minimized by taking the following precautions before probe entry: 1) checking the trawl wire angle for non-verticality and 2) monitoring the real-time graphic recorder for change in the direct and bottom reflection arrival times of the telemetered acoustic data. If a nominal $10^{\circ}$ angle from vertical between the ship and bottom instrument occurs, a horizontal displacement of $500 \mathrm{~m}$ exists in the $2500 \mathrm{~m}$ deep central basin. The wire angle problem is of less importance on the upper margins where the water depth is smaller. Using relative pressure readings of the instrument and the underway $12 \mathrm{kHz}$ data, depth discrepancies of up to $70 \mathrm{~m}$ depth are sometimes found in regions of about $5^{\circ}$ slope, $15 \mathrm{~m}$ of which is accounted for by the effect of the slope on the depth sounding. This translates to unresolved location differences of at least $500 \mathrm{~m}$.

Instrumentation and data acquisition. The WHOI marine geothermal measurement system implemented in the Ligurian Basin consists of the digital heat flow instrument (DHF), weightstand, and probe barrel with up to 7 outrigged thermistor elements mounted individually between fin struts. The DHF instrument is contained in one pressure case and includes a digital high-density magnetic tape recorder, analog acoustic telemeter, battery package, and electronic circuitry which are documented in the WHOI DHF-6 Instruction Manual (unpublished report). 
The DHF instrument was developed in the early 1970's and featured the digital recording package composed of a voltage-to-frequency converter and a data-to-tape output. Subsequent modifications to the DHF in the late 1970 's include programmable multiplexing of the data sequence, high density ( 615 bits per inch) tape drive, dual-axis analog tilt switch, and pressure transducer.

As discussed in Appendix 2, a heater-control circuit board was installed for in situ conductivity measurements and was initially used during the R/V Shackleton 1981 (Hutchison et al., 1985) and $R / V$ Catherine-Laurence 1982 heat flow cruises. Heating was programmed to turn on for 10 minutes at a prescribed interval, i.e., every 60 minutes. A revision of the DHF for the 1984 cruise was the addition of a microprocessor-controlled circuit board for in situ conductivity determinations. The microprocessor monitors the pressure channel and applies continuous-heating only after the pressure becomes stable (i.e., in the bottom) for a preset period ( 5 minutes) during which the pertinent data for the equilibrium temperature is collected.

The DHF instrument was located in a $750 \mathrm{~kg}$ weightstand constructed by the Villefranche laboratory; the weight was increased to a total of $1000 \mathrm{~kg}$ in 1984 to increase penetration capabilities. The thermistor assemblies have a cable hookup to the DHF endcap and the cables pass through the hollow interior of the central probe barrel. The outrigger positions are located about every $60 \mathrm{~cm}$ along the probe barre1. The outrigger fins place the thermistor $70 \mathrm{~mm}$ from the central probe barrel and $50 \mathrm{~mm}$ from either fin strut (Figure A2.2). 
Different thermistor probe designs were implemented for each of the two heat flow cruises. In 1982, a biaxial probe composed of a heater element juxtaposed to a thermistor probe was employed. In 1984, the probe and cable systems were modified so that the heater and thermistor were contained in one probe housing. The implications of these two designs for in situ thermal conductivity determination are discussed in Appendix 2.

The "Villefranche" probe barrel or central strength member consists of two coupled sections of $0.95 \mathrm{~cm}$ wa11, chromium-molybdenum alloy steel, sealed at the end with a solid nose cone. The upper section has a $7.62 \mathrm{~cm} \mathrm{0.D.} \mathrm{and} \mathrm{is} 3 \mathrm{~m}$ long. The lower section extends the barre1 length by $2.5 \mathrm{~m}$. With a smaller $6.35 \mathrm{~cm} \mathrm{0.D.,} \mathrm{this} \mathrm{lower} \mathrm{section} \mathrm{gives}$ the probe barrel an overall tapered design to facilitate penetration. In practice, two probe configurations are prepared for deployment, the $5.5 \mathrm{~m}$ "long" probe with 7 thermistors and a $3 \mathrm{~m}$ "short" probe with 4 thermistors. The long probe is preferred because of the potential availability of more and deeper sediment temperature points for thermal gradient determinations. When the long probe experienced bending, the point of maximum curvature was always just below the couple. The short probe consists essentially of the upper barrel section of the long probe. Being more robust and stout, the shorter version was not susceptible to bending and was more successful in penetrating hard bottom sediment without tilt.

On the basis of records from a Precision Graphic Recorder (PGR), the probe is generally lowered to $\sim 100 \mathrm{~m}$ above seafloor. At this level in the water column, water temperatures are monitored to calibrate 
"zero-gradient" thermistor temperatures. The probe is lowered to the seafloor at a speed controlled by the winch. After penetration, the probe temperatures decay at a rate dependent on the amount of frictional heating produced on impact, as well as on the ambient subseafloor temperature. Steady-heating proceeds for a 10 minute period usually after a 5 minute period of stable pressure readings. Thus, the instrument is generally in bottom for a period of 15 minutes to obtain temperature and conductivity data. After the instrument is withdrawn from the seafloor, the thermistor temperatures are again monitored in the water column before moving to the next pogo station.

Two problems incurred during the survey were partial penetrations and post-impact instrument disturbances. To increase penetration depths in the central basin near the main channel of the Var deep-sea fan, the short probe was used with a high impact velocity. Both the piston core recovery lengths and the penetration depth of the pogo probe are of ten reduced by over $50 \%$ in these areas $(<2 \mathrm{~m})$. About fifty attempted penetrations in the centra1 basin (within sites C2, D1, D2, and D3) were unsuccessful due to the rigid seafloor sediment. At the expense of both fewer and shallower temperature points, the short probe is used where the sediment thickness is thin to the point of exposing basement outcrops, i.e., the upper continental slope of northwestern Corsica. Post-impact instrument disturbances are generally caused by the ship either drifting or pitching excessively during the measurement period. This movement subsequently affects the trawl wire tension, pulling the probe apparatus and perturbing the sensor temperatures. Rough seas are enhanced by the "Mistra1" wind from the northwest direction and surface 
currents of over 1 knot exist over the Ligurian Sea margins (Bethoux et a1., 1982). Despite attempts to compensate for current and wind conditions by maneuvering the ship and increasing the length of the instrument attachment wire, ship drift occasionally caused substantial disturbances to measurements.

\subsection{Data reduction}

Marine heat flow is determined from four basic data sets: 1) the temperature-time record for each thermistor point located at a particular depth $z$ in the sediment, 2) the reduced equilibrium temperature $T(z)$ and thermal conductivity $K(z)$ derived for each thermistor point, 3 ) the heat flow results of individual stations determined by the statistical analysis of the individual point $T(z)$ and $\mathrm{K}(\mathrm{z})$ measurements, and 4) contour mapping or regiona1 mean heat flow estimates determined from a distribution of stations. In practice, the most complicated step in the data reduction process is to determine the in situ thermal conductivities and equilibrium temperatures (see Appendices 2 and 3 ). Standard techniques have previous 1 y been applied to the WHOI outrigger-type heat flow data (e.g., Von Herzen et al., 1982). Herein, the specific analysis of the Ligurian Basin data with their various sources of error are discussed.

Equilibrium temperatures and thermal conductivities are determined by methods based on the temperature-time behavior of the thermal probes. The input variables are multiplexed in a repeating programmed data sequence with a total length of approximately 30 seconds. A different variable is sampled every 2 seconds. Among the data variables 
are thermistor resistances (up to 8 ), high and low calibration resistances, pressure, tilt reading, record label (time reference), and an external variable (usua1ly heater current status). Thus a data set comprised of temperatures as a function of time is produced, with each thermistor read every record sequence ( $\sim 30 \mathrm{~s}$; depending on the number of input variables programmed). Thermistor resistances are measured using a Wheatstone bridge-type circuit using a separate multiplexer. The out-of-balance voltage of the bridge is converted to frequency and recorded as a number of counts on magnetic tape at an equivalent temperature resolution of $0.0007 \mathrm{~K}$. For real-time monitoring purposes as we11 as recording a backup copy of the data, the voltage amplitudes are also transmitted by acoustic telemetry to the ship as a time offset in a pinger pulse pair. The thermistors are calibrated in the lab so that their resistance is a known function of temperature. A11 thermistors used for a given measurement have resistances equal to within $1 \%$ at $\sim 13{ }^{\circ} \mathrm{C}$, the approximate bottom water temperature of the Ligurian Sea. This ensures that a $\sim 1 \mathrm{~K}$ range is sufficient for medium resolution $(0.002 \mathrm{~K})$ recording of the telemetered data on the PGR. In the $1 \mathrm{ab}$, the magnetic tape is decoded. With the known resistances in the DHF bridge, the counts are converted to resistances from which the temperatures are found using the calibration curves for each thermistor. For about $10 \%$ of the stations, bad data recording or inoperative tape recording required the usage of the lower resolution PGR records are digitized and converted to temperature-time data. Temperature gradient measurement. Equilibrium temperatures are normally estimated according to the asymptotic expression of the 
cylindrical heat decay function $F(\alpha, \tau)$ (Bullard, 1954; Jaeger, 1956). We modified this approach somewhat by optimizing the origin time of the impact with the Golden Section Search (GSS) routine (cf. Appendix 3). Uncorrected reciprocal time versus temperature plots are commonly observed to be slightly convex upward, whereas theory predicts them to be linear after about 20 probe thermal time constants from impact (one probe time constant $=r^{2} / k \simeq 8 \mathrm{~s}$, where $r=$ probe radius $\simeq 1.5$ $\mathrm{mm}$ and $\kappa=$ sediment thermal diffusivity $\left.\simeq 3 \cdot 10^{-7} \mathrm{~m}^{2} \mathrm{~s}^{-1}\right)$. The intercept of the regression line is equal to the infinite-time or equilibrium temperature $\left(t^{-1}=0\right.$ as $\left.t \rightarrow \infty\right)$. A time advance of several probe time constants linearizes the curve, essentia11y causing the temperature decay to appear as if the probe had penetrated about 30 $s$ before the actual impact. Finite difference modeling of the impact heating phenomena shows that the time advance may be an expression of an initial thermal disturbance in the sediment annulus contained within several probe radii of the probe surface. By modeling various initial conditions, the optimization is justified as an improved equilibrium temperature estimate. However, the accuracy of the GSS result may decrease if excess water is introduced in the disturbed zone. Additiona11y, the GSS method requires high resolution and reasonably noise-free data. The most valuable application of the optimization routine is realized in an almost real-time automated heat flow data reduction system (e.g., Fang et a1., 1987; Villinger and Davis, 1987).

The GSS method is applied to all stations in which at least one thermistor has a nonlinear reciprocal time vs. temperature plot. The GSS method normally does not have a large effect on the measured thermal 
gradient. In a few cases, interval thermal gradients (temperature differences between adjacent thermistors) are reduced by $30 \%$. For comparison to the zero-shifted results, the mean thermal gradients change 1ittle except for site $D 1$ which has a $9 \%$ smaller mean value using the GSS optimization.

After the equilibrium temperature $T_{1}$ is obtained for each thermistor $i$, individual errors $e_{1}$ are assigned as the square root of the sum of two terms: 1) the square of the uncertainty in the intercept, determined by the t-test at $95 \%$ confidence leve1, and 2 ) the square of the error due to temperature drift (change of the thermistor temperature during the measurement period), as indicated by measurements in near-bottom waters both before and after bottom penetrations. The 1atter errors are almost always insignificant, i.e., less than $\pm 1 \mathrm{mK}$.

The relative thermistor depths $z_{1}$ are known to within $\pm 5 \mathrm{~mm}$, so that $z_{1}$ is considered the independent variable in thermal gradient calculations. The depths are corrected for the tilt of the pogo probe in bottom using the cosine of the nonvertical component given by the two-axis analog tilt meter. True tilt is obtained from the geometrical relationship of two apparent tilts measured in approximately orthogonal directions using Earle's formula (Ragan, 1973, p. 6). The majority of tilt values are less than $10^{\circ}$ and produce negligible uncertainties in the thermal gradients, although for a few scattered stations with a tilt range of $20^{\circ}$ to $30^{\circ}$, the gradient uncertainty may be as 1 arge as $5 \%$. The tilt uncertainty, generally being sma11, is not taken into account in the gradient errors. 
Temperature gradients are determined by assuming that $T(z)$ is a linear function represented by $\mathrm{n}$ data points $\left(\mathrm{T}_{\mathfrak{1}}, \mathrm{z}_{\mathrm{i}}\right)$ with associated uncertainties $e_{1}$, where $i=1, n$. However, simple least-squares fits to the Ligurian Basin data are not always adequate because of the appreciable inconsistencies in data quality between the different pogo profiles and individual measurements. For instance, some temperature-time records have high noise levels due to either bad data recording or post-impact instrument movement. To complicate matters further, $25 \%$ of the penetrations have less than 4 thermistors available for linear regression analysis.

For such conditions, formal error estimates of the unweighted and weighted least squares fit (Bevington, 1969; Press et a1., 1986) are unrealistic. The regression in the unweighted scheme assumes that all $T_{1}$ have standard deviations equal to unity $\left(e_{1}=1\right)$ so that gradient uncertainty is mainly determined by data variance (sum square of the deviations). No information concerning the independent error $e_{1}$ is included in the gradient error. Furthermore, a formal error determination for two data points is impossible because the degree of freedom is zero. The weighted scheme, on the other hand, has a slope coefficient variance which is given by a formula which includes a factor equal to the sum of $e_{i}^{-2}$ but contains no information on the lack of fit (Bevington, 1969; Press et a1., 1986).

To emphasize both the uncertainty of $T_{1}$ and the lack of $f i t$ in the gradient error estimate, we use an unweighted least squares fitting which assumes that there are two repeat measurements for each thermistor temperature, defined by the upper and lower confidence limits, $\mathrm{T}_{1}+\mathrm{e}_{1}$ 
and $T_{1}-e_{1}$, respectively. Two-point replicates give the same solution as the normal (single-point, no replicate) unweighted least squares fit, but the standard deviation of the fit is changed since the influence of $e_{1}$ is reflected in the data variance. For $\mathrm{n}$ thermistors, the gradient errors are determined at an $80 \%$ confidence level with $2 n-2$ degrees of freedom (Appendix 4). A1though a $95 \%$ confidence 1 imit is valid, it is occasionally found to be too stringent a test for stations with $\mathrm{n}=3$ since the resulting fractional error may become greater than unity.

Replications of temperatures are justified because each temperature is determined from a series of $\sim 7$ temperature-time points. Moreover, the two-point and three-point gradients are assigned realistic uncertainties, and two thermistor penetrations are incorporated into the normal data reduction scheme.

The final gradient values with uncertainties are presented in Table A4.1. Most gradient differences between the weighted and unweighted (replicated) solutions are smaller than $1 \mathrm{mK} \mathrm{m}^{-1}$, and on $1 \mathrm{y} 9$ stations have differences larger than $5 \mathrm{mK} \mathrm{m}^{-1}$. It can be subjectively argued that, in these cases, the weighted gradients are disproportionately influenced by one "good" data point if the particular temperature uncertainty is less than $1 \mathrm{mK}$. The optimized equilibrium temperatures tend to have errors which are already sma11 ( $<2 \mathrm{mK})$ so that the individual uncertainties are approximately the same. The temperature point is usually discarded if the error is >10 mK. A total of 19 individual thermistor temperatures are deleted, with errors attributed mainly to large temperature drift, unresolved recording malfunctions, or 
apparent in-bottom instrument disturbances. Thus, although gradient estimates derived from weighted least squares fitting may hypothetically be more correct, the unweighted scheme is preferred.

Plots of the gradient data and regression results are presented in Figures A4.1 - A4.21. If the sediment is not in equilibrium with the bottom water temperature (BWT), then appreciable nonlinearities in the surface sediment temperature profile may exist. Nonlinearities attributed to BWT changes are observed in the southern Aegean Sea (E. Mediterranean) where negative gradients occur in the upper meter of sediment (Jongsma, 1974). In addition to BWT changes, recent deposition or erosion of sediment by slumping or turbidity currents may affect the surface sediment temperature profile (cf. Chapter 4). For example, an October 16, 1979 turbidity current resulting from a major submarine slide of $f$ the coast of Nice, France broke two submarine cables crossing the Var channel in the Ligurian Basin bathyal plain (Gennesseaux et a1., 1980). This event and other undocumented but recent events have undoubted1y affected the uppermost sediment thermal equilibrium to some degree. Nonlinear thermal gradients may also be produced by sma11-scale topography ( $>2 \mathrm{~m}$ relief) associated with submarine gullies and channe1s, as we11 as a number of other sources (cf. Noe1, 1984).

To prevent bias in the gradient determinations from superficial phenomena, we employ an optimization routine which is based on knowledge that the lowermost thermistor temperatures are more indicative of the unperturbed heat flow. Accordingly, the upper thermistor temperature is deleted if so doing results in a lower fractional error in the linear regression. The overa11 linearity of the Ligurian Basin gradients is 
apparent in that optimization only improves the gradient fit for 12 stations. Nevertheless, the subtle curvature of the temperature profile is evaluated in a qualitative sense in Table A4.1 (i.e., convexity, concavity, or sigmoida1). Systematic curvatures related to particular water depth horizons or areas of the seafloor cannot be readily distinguished from the data on the margins, although convex upward profiles are more common in the central basin. This could be due, in part, to thermal conductivity values increasing with depth.

Thermal conductivity measurement. One-hundred and two heat flow values are determined with in situ thermal conductivity values derived by the measurement technique described in Appendix 2 (Table A4.1). Additional conductivity values are obtained by laboratory measurements made on 14 piston cores (Table A4.2) and are supplemented about a dozen other core values previously obtained by other investigators (Table A4.3). Need1e-probe measurements (Von Herzen and Maxwe11, 1959) are made in conjunction with gamma ray attenuation porosity estimator (GRAPE) logs to ensure that the needle-probe measurements are not biased due to sampling of low-density, water-laden zones where core separation or internal slumping has taken place. If the sediment grain thermal conductivity is obtained from water content and laboratory conductivity measurements, GRAPE-derived conductivity profiles give very good estimates of the bulk thermal conductivity structure (cf. Appendix 2). Conductivity profiles of the in situ data (Figures A4.1 - A4.17) and the needle-probe conductivity data (Figures A4.22 - A4.24) show a high degree of stratification for stations in the central basin influenced by the Var Fan. Since significant stratification exists, an analysis of 
the reliability of the mean conductivity determination is made using synthetic conductivity profiles (Appendix 2). Given the $0.6 \mathrm{~m}$ spacing of the outrigger probe, discrete sampling of sediments does not always produce an adequate data density. Representative profiles of the turbiditic channel and hemipelagic slope deposits show that the maximum potential error in the mean conductivity is probably less than $15 \%$ and $5 \%$, respectively (Appendix 2). An encouraging result is that the group mean of 15 in situ stations located on a levee in the Var Fan (site B) has a suprisingly small standard deviation of $\pm 4 \%$ despite the fact that individual in situ profiles show high vertical variability. Station conductivity values in Tables $\mathrm{A} 4.1$ and $\mathrm{A} 4.2$ are calculated as the harmonic mean (inverse mean resistance). As with thermal gradient determinations, the individual conductivity means are assigned errors at $80 \%$ confidence levels using the t-test. Since the needle-probe measurements are rarely quoted with individual regression errors, we use an unweighted mean calculation for the in situ data as we11. Measurements with an uncertainty greater than about $\pm 10 \%$ were rejected as being unreliable. Only 15 of the in situ measurements (over 500 total) are discarded; 7 of these are from the uppermost thermistor indicating the greater susceptibility of the upper probe barrel position to instrumental errors.

Field calibration of the the mean in situ conductivity values is made by comparing to mean values of needle-probe measurements made on nearby piston cores. Closely spaced ( $3 \mathrm{~km})$ comparisons are available for the Ligurian Basin at four localities (Table A2.3). A11 show good agreement with no apparent systematic differences. The in situ 
conductivity vs. depth profiles indicate that up to a meter of the surface sediment may be missing from the piston cores.

Heat flow stations without in situ data result from inoperative or occasionally unreliable turn-on mechanisms for the heater current. These stations are assigned mean conductivity values using the 'nearest neighbor' value. Physiography and surface sediment obtained from the $3.5 \mathrm{kHz}$, bathymetric, and piston core data are also used to assess the horizontal variablility of the sediment conductivity (cf. Chapter 2). Conductivity patterns indicate that some regions have mean conductivity differences of about $20 \%$ between pogo stations separated $\sim 1 \mathrm{~km}$ (Table A4.1). These differences may be explained by loca1 physiographic contro1 on surface sediment grain size distributions.

The Var Fan (basina1) sediments have a wide distribution of conductivity values but the slope (marginal) sediments are latera1ly fairly homogeneous (Figure 3.2). Hemipelagic sediment with a mean value of $1.15 \mathrm{~W} \mathrm{~m}^{-1} \mathrm{~K}^{-1}$ predominant $1 \mathrm{y}$ covers the continental slope on the intercanyon areas. Sandy sediments concentrated in the submarine channels of the fan have a mean of about $1.4-1.5 \mathrm{~W} \mathrm{~m}^{-1} \mathrm{~K}^{-1}$. A levee in the Var Fan composed of a mixture of hemipelagic and turbiditic sources has an intermediate value of $1.25 \mathrm{~W} \mathrm{~m}^{-1} \mathrm{~K}^{-1}$. Knolls on the basin floor may restrict sand-laden turbidite deposits to their periphery so that isolated low conductivity values may be sampled on their crests (Section 2.2).

Sharp lateral conductivity contrasts are found at the transition from the slope to the basin floor off northern Corsica. The base-of-slope transition is most pronounced for Corsica where turbidites 


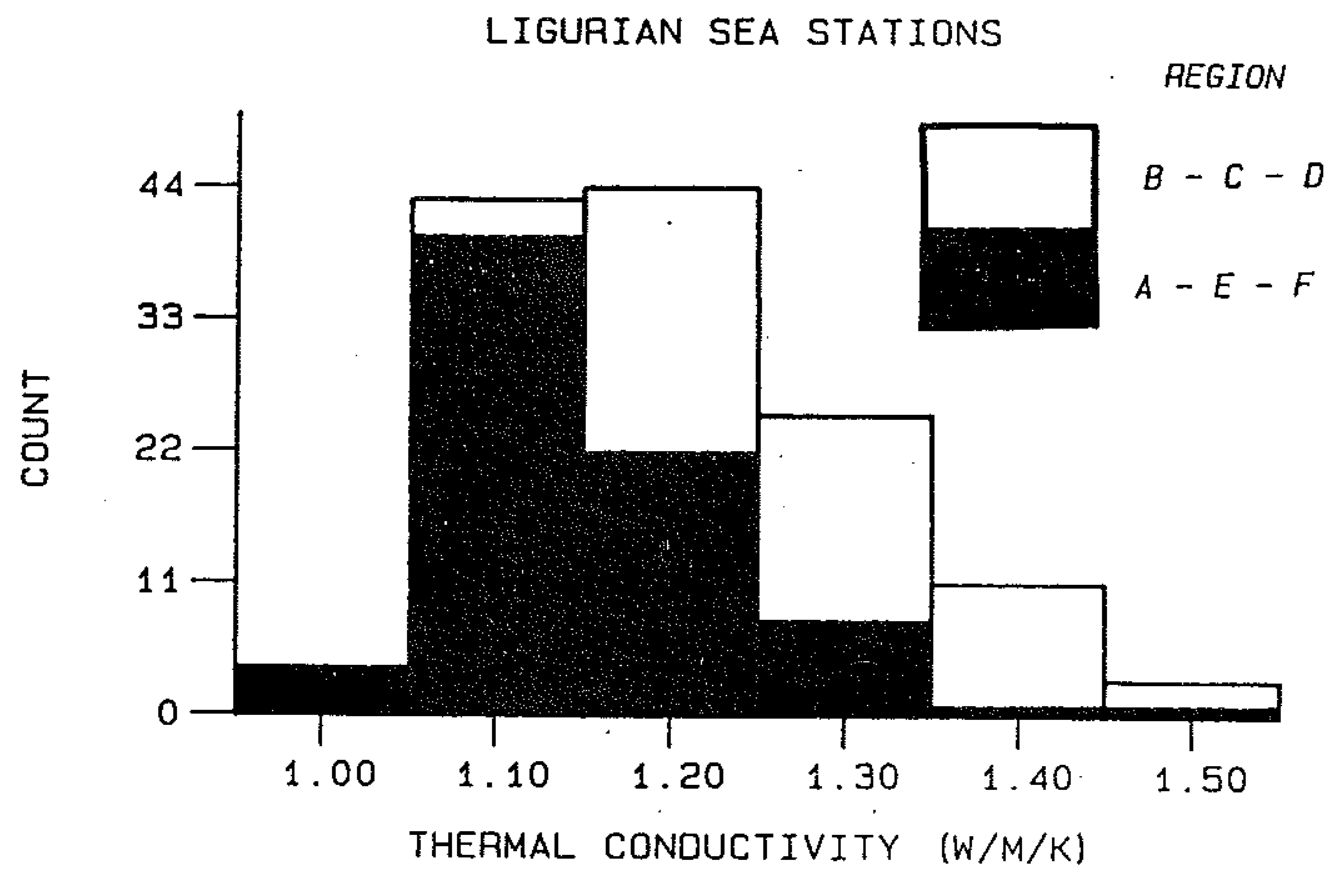

Fig. 3.2 Histogram of mean thermal conductivities for stations on the Var fan (regions $B, C$, and $D$ ) and elsewhere on the slope and rise (regions $A, E$, and $F$ ). 
terminate sharply against the slope from a seaward direction and sediment input from the canyons is insufficient to form sedimentary aprons at the base-of-slope. Thus, the continental slope bevels against the nearly horizontal basin floor with a continental rise being essentially absent. Conductivity patterns are estimated from piston cores and $3.5 \mathrm{kHz}$ echo character to define local surface sediment patterns (e.g., Figure 2.5). Revised heat flow estimates using conductivity patterns reduces the original mean heat flow of site E3 by about $10 \%$. Thus, knowledge of the surface sediment distribution in the North Corsican Basin (Figure 2.3) improves conductivity estimates, and consequent1y the heat flow determinations are presumab1y improved in accuracy .

Rather than assume regional mean values for stations without in situ conductivity, we use information from the nearest piston core or in situ station. A 'nearest neighbor' approach is taken because of the sometimes predictable lateral gradients in conductivity which may occur within the sites. If a large difference in neighboring values exists, a local mean is assumed. The assigned values are subjective but are appropriate for the Ligurian Basin where the intricacy of the surface conductivity distribution precludes simple contour mapping. Errors of the assumed conductivity $(\Delta \mathrm{K})$ are based on the following 3 grades: 1 ) $\Delta \mathrm{K}=0.1 \mathrm{~W} \mathrm{~m}^{-1} \mathrm{~K}^{-1}$ where there is direct evidence for uniform mean conductivity within $5 \mathrm{~km}$ of the station, 2) $\Delta \mathrm{K}=0.2 \mathrm{~W} \mathrm{~m}^{-1} \mathrm{~K}^{-1}$ where there is indirect evidence that uniform mean conductivity exists within $5 \mathrm{~km}, 3) \Delta \mathrm{K}=0.3 \mathrm{~W} \mathrm{~m}^{-1} \mathrm{~K}^{-1}$ in regions where significant lateral and/or vertical variability exists. Again, these choices of 
error for assumed conductivity values are subjectively determined to be compatible with the $80 \%$ confidence limits chosen for the in situ values.

\subsection{Heat flow results}

Heat flow calculation. Individual heat flow values are calculated as the product of the harmonic mean thermal conductivity and the thermal gradient and results are listed in Table A4.1. Heat flow uncertainty is determined by the root sum square of the fractional errors in the gradient and mean conductivity. Where in situ conductivity is available, the heat flow has also been calculated using the Bullard (1939) method where the linear regression of temperature versus the cumulative thermal resistance produces a slope value equal to heat flow. Excellent agreement is obtained between the two approaches: the heat flow differed by no more than $2 \mathrm{~mW} \mathrm{~m}^{-2}$ in all cases. Nonlinear temperature gradients usually resulted in nonlinear Bullard plots which suggests an environmental origin for curvatures observed in the temperature profiles. However, the highly variable conductivity-depth profiles indicate that such detailed analysis of heat flow with depth may be unwarranted since resolution of in situ depth intervals $(60 \mathrm{~cm})$ is fairly low.

Due to the availability of many measurements in a sma11 area, heat flow means yield a simple yet accurate summary of the results. A weighted mean for each of the groupings is preferred due to the variability of the data quality and the care with which the conductivity and gradient uncertainties are determined. The heat flow means presented in Table 3.1 are weighted inversely proportional to the 
fractional uncertainty in individual values (see Hutchison et a1., 1985). Alternatively, weighting with respect to the absolute uncertainties decreases the mean value giving undue importance to scattered but accurate low values. Since heat flow stations which do not have in situ conductivity values are assigned appropriately large errors, weighting emphasizes stations with in situ values over those without. In particular, the mean calculation for region $D$ downweights the data of site D1 since only one in situ conductivity station is available. Considering all data, some groups have unweighted and weighted means which differ by $\pm 15 \%$. This large discrepancy is due to the dispersion of the data created by environmental disturbances. Therefore, careful examination of the reliability of individual measurements is required.

The philosophy behind the "unweighted" uncertainty is that the error of each heat flow value is random and therefore is approximated by the standard deviation of the group heat flow (Table 3.1). Alternatively, the "weighted" uncertainty is calculated as the root of the sum of $\Delta Q_{1}^{-2}$ where $\Delta Q_{1}$ is the individual error of station $i$

(Bevington, 1969; Press et a1., 1986). Statistical formulas which compensate for the randomness of unequal individual errors as well as the randomness of data with equal uncertainties are not readily available in the literature. Thus, the error of the regional means is simply taken as the standard deviation of the data. The conductivity measurements may have $\pm 5 \%$ bias due to the instrumental errors (Von Herzen and Maxwe11, 1959; Appendix 2), but this systematic error is not 
included in the final heat flow uncertainty since it is small compared to the data variability.

Observed heat flow patterns and comparison to other data. The 176 measurements have a weighted average of $70 \pm 28 \mathrm{~mW} \mathrm{~m}^{-2}$; this number is not geophysically relevant because corrections for environmental effects have not been made. By examining the heat flow in smaller groups, significant variation in regional heat flow across the basin is evident (Table 3.1, Figure 3.1). This variability is elucidated when histograms of conjugate regions are compared (Figure $3.3 a-c$ ). The most obvious trend observed is the disparity in heat flow between the NW half of the basin (mean of $64 \mathrm{~mW} \mathrm{~m}^{-2}$ ) and the $\mathrm{SE}$ half (mean of $84 \mathrm{~mW} \mathrm{~m}^{-2}$ ). The variation parallel to the margins is fairly minor compared to the heat flow maximum centered along on the NE-SW line passing through sites D1, D3, and E3, and a heat flow minimum beneath the Var Fan (sites A3 and B). Our data may be compared to 35 regionally coincident measurements (Table A4.3) made by other investigators (Foucher et a1., 1976; Rehau1t, 1981; De1la Vedova and Pe11is, 1981; Burrus and Foucher, 1986). Excellent agreement exists for heat flow values measured in the northern part of the Ligurian Basin (region $B$ and $C$ ). The consistency substantially decreases for measurements in region D. The data obtained by other investigators are highly scattered in region $D$ and may partly resu1t from the large number ( 7 of 11 ) of partial penetrations with on1y two points available for gradient determinations (Table A4.3). Despite the fact that almost half of our measurement attempts in region $D$ consisted of failed penetrations due to hard substrate of the Var Fan main channel (Figure 2.3), our data have significantly improved the 
UPPER COTE D'AZUA MARGIN

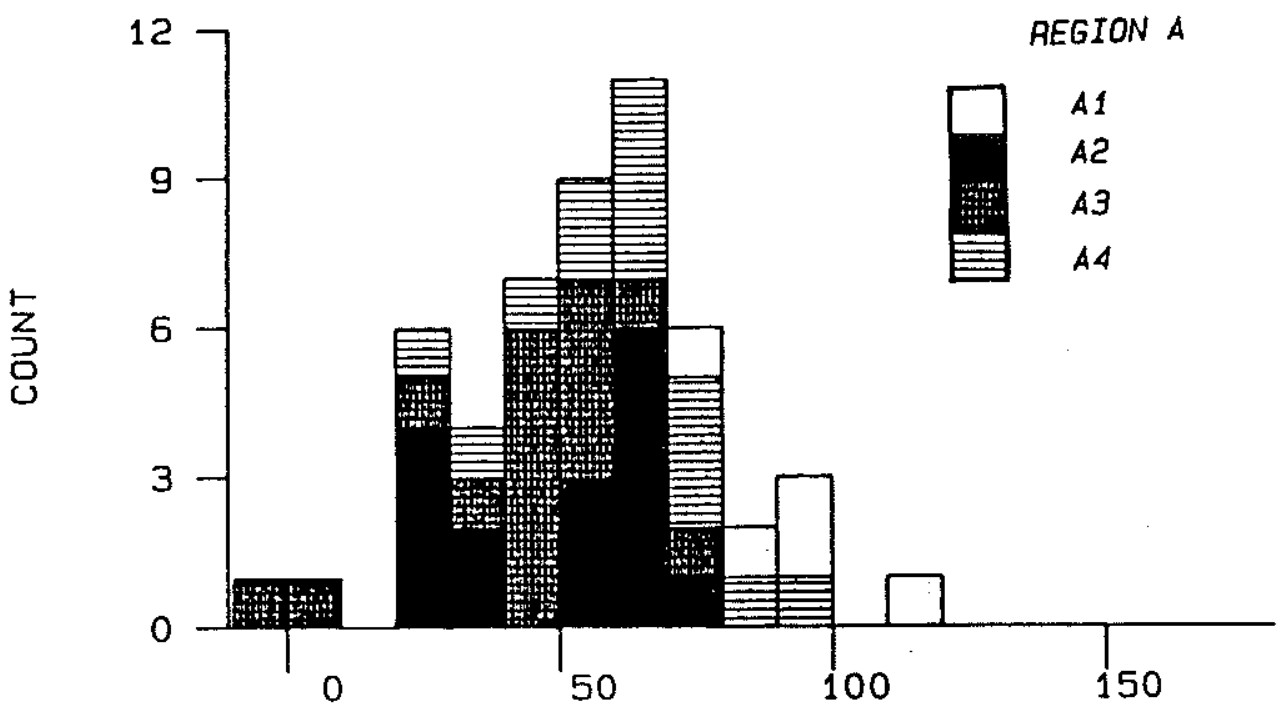

UPPER CORSICAN MARGIN

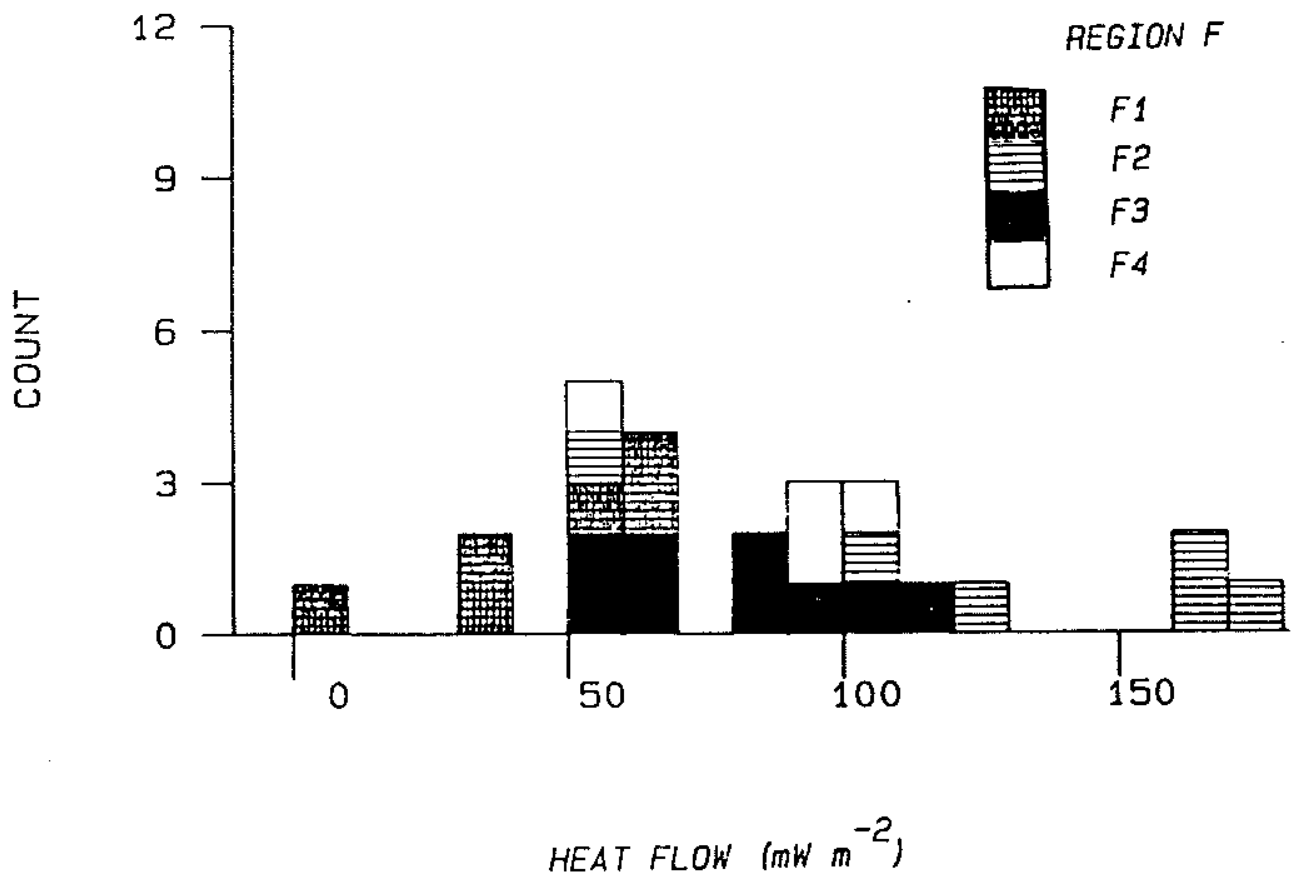

Fig. 3.3a Histograms of observed heat flow on upper margins, regions $A$ and $F$. 
LOWER COTE D.AZUR MARGIN

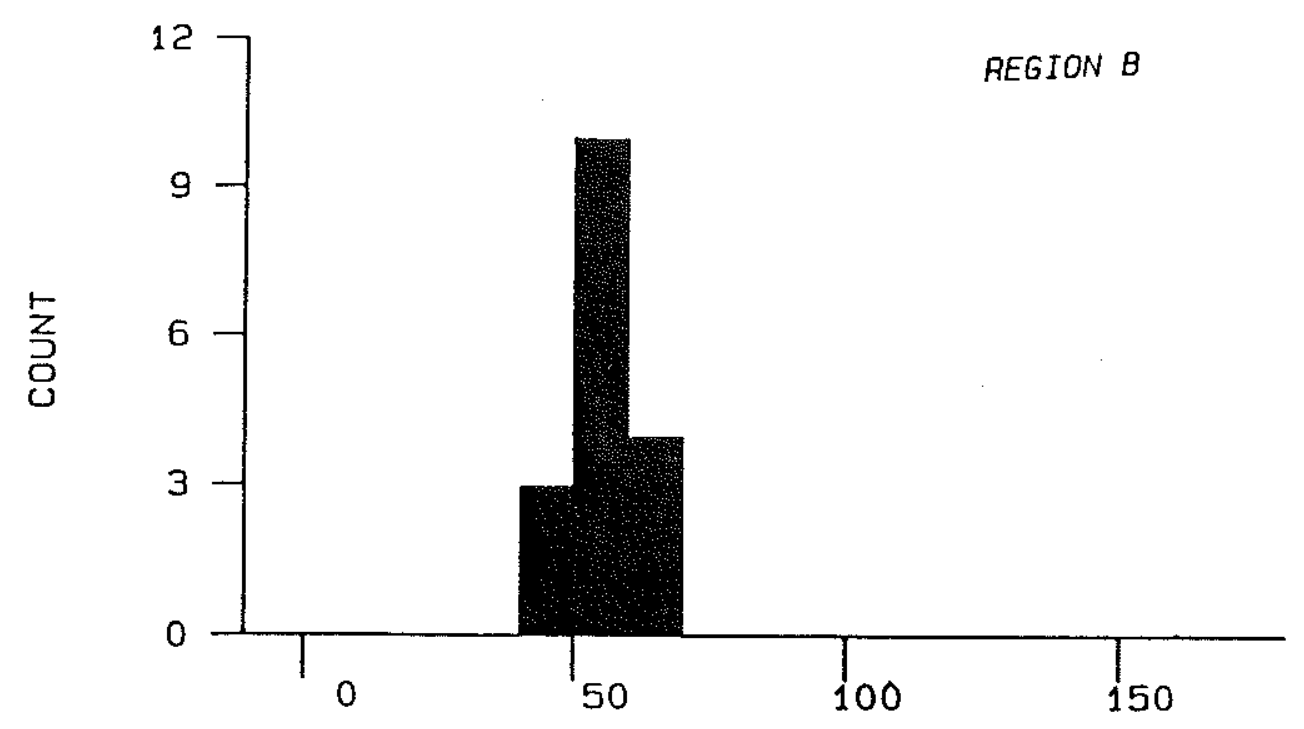

LOWEA CORSICAN MARGIN

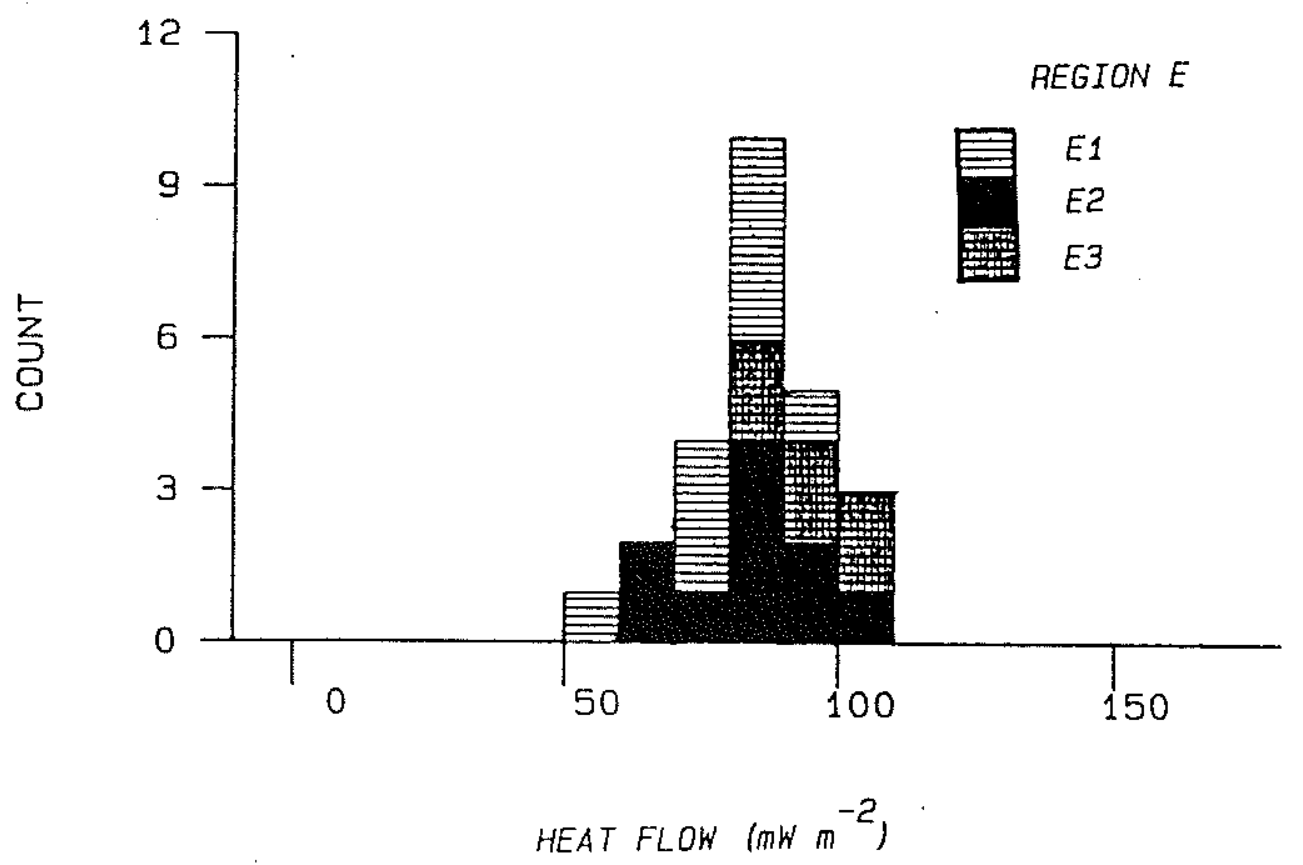

Fig. 3.3b Histograms of observed heat flow on lower margins, regions $B$ and $\mathrm{E}$. 
NOATH CENTRAL LIGURIAN BASIN

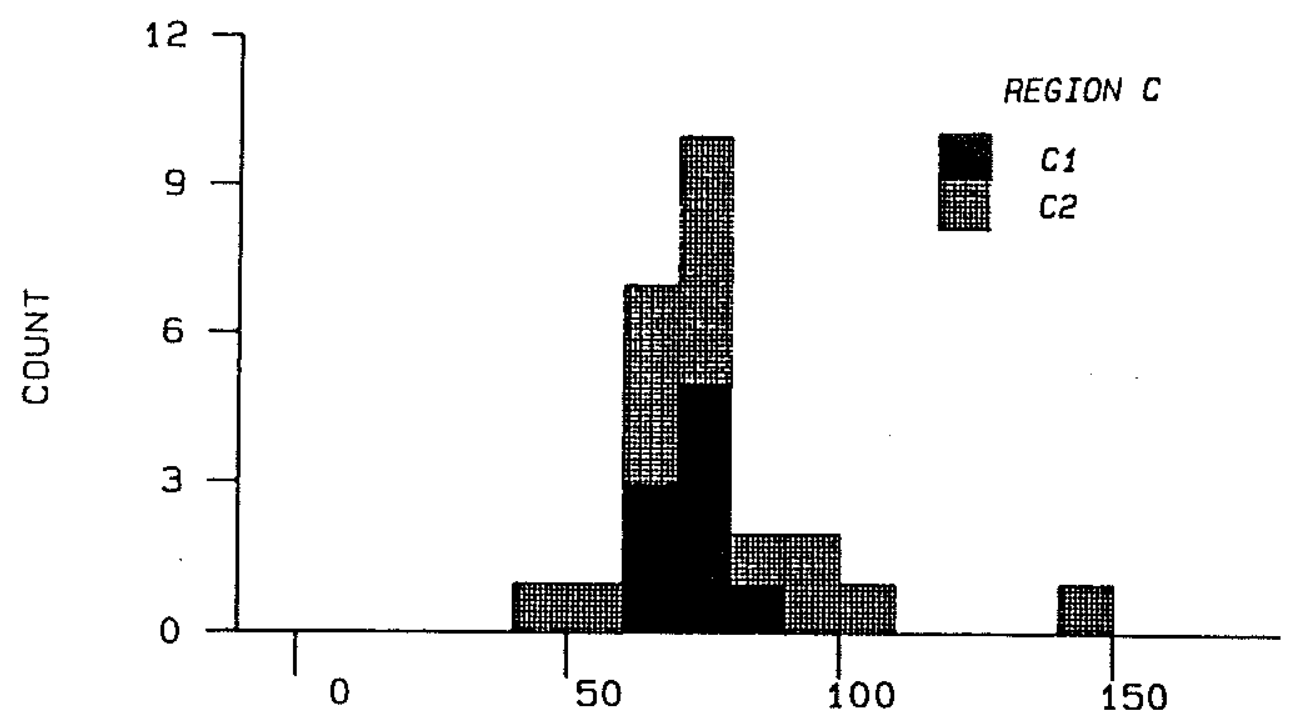

SOUTH CENTRAL LIGURIAN BASIN

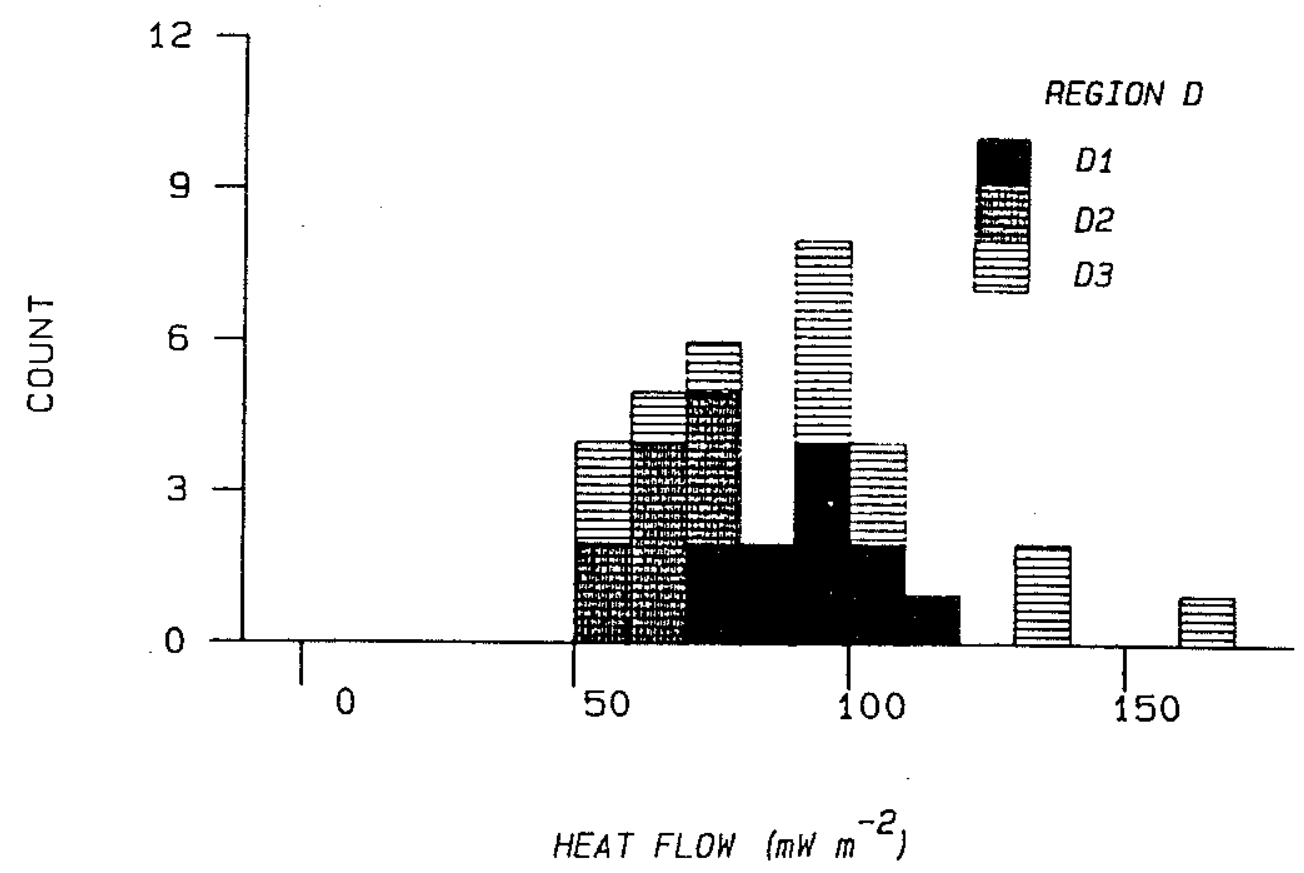
Fig. 3.3c Histograms of observed heat flow in central basin, regions $\mathrm{C}$
and D. 
regional heat flow estimate. Furthermore, seismic data show that exceptionally high values in region $D$ are probably influenced by salt structures (see Figure 2.8, Appendix 5). Few or no measurements within regions $A, E$ and $F$ have been made by other investigators. Although the various heat flow data sets complement one another, only the new data (Table 3.1, Table A4.1) are used in the analysis because of the generally adequate sample size, the known consistency of the error evaluation, and the general lack of seismic detail for the other data. To assess the tectonic significance of the Ligurian Basin data, environmental factors are carefully considered in the following chapter. 
$-115-$

Chapter 4

Environmental Disturbances and Heat Flow Corrections 
An environmental analysis is made in order to understand the variability within the heat flow groups and assess the data reliability. Local variations in heat flow are attributed to topographic disturbances, mass-wasting, thermal refraction by salt structures, and to a lesser extent, pore water migration along shallow faults above salt intrusions and bottom water temperature changes. Contrary to most young oceanic crust, the extremely thick sediment cover suppresses variability due to hydrothermal circulation: but the high depositional rates also require substantial corrections to the heat flow data for the effects of sedimentation.

In order to determine the unperturbed values for the reliable heat flow measurements, sedimentation rate histories and physical properties are obtained from seismic stratigraphy and borehole data. A multilayered sedimentation and compaction model is developed which estimates the plane-layer effects of the Messinian salt def sition in the centra1 basin, and the contemporaneous erosion on the margins. The resolution of the sedimentation parameters (porosity, compaction, thermal conductivity, radioactivity, burial rates, etc.) and the sensitivity of the heat flow results to these parameters are evaluated. Effects due to compaction (variable velocity of two-phase flow) and to thermal blanketing (advective and composite media effects) are isolated in the sensitivity analysis. Paleoclimatic corrections for bottom water temperatures which are higher today than during the late Pleistocene are also made. Systematic errors resulting from these corrections are taken into account and are combined with the data variance to produce total uncertainties in the corrected heat flow means. The final heat flow 
values indicate that, similar to the observed heat flow, an overall trend from low to high heat flow exists from $N$ to $S$ across the basin.

\subsection{Causes of local heat flow variations}

Despite the dispersion of nearby thermal conductivity values (Figure 3.2) and the occasionally large measurement errors incurred with partial penetrations, it is clear that heat flow variability is mainly due to environmental disturbances of the thermal gradient. For example, the standard deviation of the regional mean conductivity never exceeds $\pm 10 \%$, whereas a few sites have mean thermal gradients with standard deviations of greater than $\pm 30 \%$ (Table 3.1 ). Additionally, some sites on the upper margins (A1, F1, and F2) have heat flow means which vary from $-50 \%$ to over $+100 \%$ from other sites in the region. Since each group defines an area of fairly uniform sediment cover and crustal structure, most of the short-wavelength, high-amplitude variability cannot be attributed to deep thermal structure.

Histograms of the heat flow groups indicate a data distribution with four four outstanding features (Figure 3.3): 1) apparent bimodal distribution for some sites (e.g., site A2) 1ocated on the upper margins (regions $A$ and $F$ ), 2) relatively low data scatter on the lower margins (regions B and E), 3) presence of outliers (spurious values whose occurrence are highly improbable in the limited sampling of normally distributed data) found on the upper margins and central basin, and 4) asymmetry in heat flow values observed between the northern and southern central basin (regions $C$ and $D$, respectively) as well as the conjugate margins. 
The fact that the local heat flow variability decreases substantially from the continental slope onto the continental rise suggests that shallow thermal disturbances are closely related to canyons which inundate the slopes. Two likely environmental disturbances associated with canyon systems are topographic relief and mass-wasting processes. Recent bottom water temperature changes may also alter surficial gradients. High-conductivity salt structures in the central basin concentrate heat flow above their centers by 2 to 3 times the regional value. These various factors are discussed below as they pertain to particular fluctuations in the heat flow patterns.

Topographic effects. A spectrum of topographic features produce two end members in terms of their influence on sha1low geothermal gradients. One scale has relief with a wavelength less than a few heat flow probe lengths and gives rise to nonlinear gradient measurements (Lachenbruch, 1968). The other scale of topography is that which ranges from the large relief of canyons (200 to $400 \mathrm{~m}$ ) to the short-wavelength 10 to $100 \mathrm{~m}$ relief of gully systems on the canyon wa11s (Malinverno et a1., 1987) and possibly on the relatively unexplored intercanyon highs. If the $5 \mathrm{~m}$ probe is located greater than two probe lengths away from this medium-scale relief, little gradient curvature will appear. The topography however may cause an anomalous mean gradient depending on the steepness and height of the relief (Lachenbruch, 1968).

If a random sampling of a hilly area is made, the overall mean thermal gradient will be slightly lower than the equilibrium because the horizontal heat flow has not been measured. Using the Birch (1967) method of exact solutions to topographic approximations, Abbott et al. 
(1986) have shown that the heat flow on narrow intercanyon regions and in the canyon axis should have values of $50 \%$ and $125 \%$ of the regional value, respectively. A small heat flow profile within site A2 (stations L84S12.3, 4, 5; Profile 16, Appendix 5) which crosses a narrow intercanyon high produces amplitude variations in agreement with these results. Thus, pogo-probing on narrow intercanyon highs can serious1y bias the heat flow results.

Three stations in site A2 (L84S4.1, 2, 3) are within 1 to $2 \mathrm{~km}$ of the steep eastern wall of the upper Var Canyon and have a heat flow less than $50 \%$ of the regional mean; horizontal heat flow due to this proximal topographic disturbance could explain this large deviation. However, if measurements are made beyond $\sim 1 \mathrm{~km}$ ( 5 slope heights) away from the canyon walls, the heat flow should only be decreased by less than $5 \%$ of the regional mean (Lachenbruch, 1968). Most measurements on the Cote d'Azur margins are taken on broad platform areas between major canyons (see Profile 16), so that the effect of the rugged canyon topography is theoretically small. Similar values of low heat flow are occasionally measured on the Cote d'Azur slope away from the major canyons (e.g., site A2: L84S4.9\&10 and site A3: L84S5.4).

Given the available bathymetric control in the locality of the measurements, these low values cannot be conclusively linked to sma11-scale topographic highs. Sea Beam bathymetry (Pautot et al., 1984 ) indicates sma11 ridges of less than $50 \mathrm{~m}$ relief within the platforms. Negative topographic features on the intercanyon highs tend to be wide bow1-shaped gullies; therefore, no apparent topographic counterpart to these acute ridges is found which could give 
complementary high heat flow. Using the method of Lachenbruch (1968), dimensions of the submarine aretes may be estimated by assuming that linear gradients are observed at the center of plane ridges that are isosceles trapezoids in cross-section. From the observed heat flow anomaly of $50 \%$ below normal, the ridges must be at least 70 to $200 \mathrm{~m}$ wide at their base. Their height would range from 15 to $50 \mathrm{~m}$ and, more importantly, the slope of the ridge flanks must be greater than $30^{\circ}$. Such conditions cannot be discounted from the available topographic maps. Thus, the low values of the bimodal heat flow distribution found on wel1-sedimented, broad intercanyon platforms on either side of Var Canyon (site A2 and A3) may easily be explained by the occurrence of submarine aretes.

On the upper northwest Corsican margin, variations of over $3: 1$ are observed between high and low heat flow values (site F1 and site F2). To produce such scatter, topographic features such as channels or steep basement outcrops must be more common on the Corsican margin than on the Cote d'Azur margin where a thicker sediment cover serves to smooth the bathymetry. At any rate, rough sma11-scale topography cannot be adequately assessed with the survey techniques used in this study and consequent1y weakens the geothermal assessment of the steep and sediment-starved continental slopes of northwestern Corsica.

\section{Effect of sedimentary processes. For sedimentation and erosion to} account for the variability of heat flow on the margins, mass-wasting must be invoked since, within the resolution of the seismic records (Appendix 5), differences in average P1io-Quaternary sedimentation rates can explain no more than 5 to $10 \%$ of the observed heat flow deviations 
(Appendix 4). Many studies confirm that canyons of the Provencal margin are avenues of downslope sediment transport and that mass-wasting is presently active within gullies observed on canyon walls (Malinverno et a1., 1987; Gennesseaux et a1., 1980; Guillocheau et a1., 1983; Pautot et a1., 1984; Pautot, 1981; Bellaiche et a1., 1978). Moreover, regional seismicity (Rehault and Bethoux, 1984) provides an excellent triggering mechanism for destabilization of sediments resting on steep slopes (e.g., Booth et a1., 1985). Continued tilting and uplift of the margin crustal block along the boundary fault system (Chapter 2) may further enhance slope instability.

Besides creating steady-state topographic disturbances by deepening or widening canyons and gullies, mass-wasting of the slope also causes transient perturbations to the seafloor heat flow. Mass-wasting processes include erosion and scarp formation on upslope regions and mass transport deposits (gravity-driven) on downslope regions. While slide or glide blocks can remain relatively intact, mass or debris flows have high degrees of plastic deformation during their transport and emplacement (e.g., Nardin et a1., 1979). The fluidal flow regime of a turbidity current entails total mixing of the sediment grains and entrainment of bottom water. Thus, mass-wasting may have a variety of effects on the surficial heat flow, tending to increase heat flow in the source region where erosion is taking place and decrease the heat flow in regions of net accumulation.

Simple conduction theory can model the effects of mass-wasting both at the source and at the site of deposition. Rapid removal of sediments brings warm, buried sediments to the surface thus causing elevated 
temperature gradients at the seafloor. If a half-space with thermal diffusivity $k$ and temperature $T=a_{0} z$ has a thickness $d_{0}$ removed, the initial temperature structure may be given as

$$
\begin{array}{lll}
T=0 & z=0 & t \geq 0 \\
T=a_{0}\left(z+d_{0}\right) & z>0 & t=0
\end{array}
$$

The subsequent temperature with time is

$$
T(z, t)=a_{0} d o\{\operatorname{erf}(U)\}+a_{0} z
$$

and the thermal gradient at any point $z$ is

$$
\frac{\partial T}{\partial z}=a_{0}\left\{1+{\frac{d}{(\pi k} \bar{t}^{1 / 2}}_{\left(-U^{2}\right)} \exp \left(-U^{2}\right.\right.
$$

where $U=\frac{z}{(4 \kappa t)} 1 / 2$

(Carslaw and Jaeger, 1959, p. 58-62). Surface heat flow results from the sudden erosion of 10 and $100 \mathrm{~m}$ thicknesses of marine sediment are given in Figure 4.1. Convex upward nonlinearity over the length of a $5 \mathrm{~m}$ probe would only be noticeable within about 10 years after the event. Results for sudden erosion are approximately linear on a 1 og- 1 og plot of fractional change in heat flow versus time since erosion (Erickson, 1970; Abbott et a1., 1986).

The effect of sudden mass deposition can be modeled as a unit of thickness $d_{0}$ overlying a half-space with equilibrium gradient ao. The initial conditions may be written as

$\begin{array}{lcc}\mathrm{T}=0 & \mathrm{z}=0 & \mathrm{t} \geq 0 \\ \mathrm{~T}=\mathrm{b}_{\mathrm{o}} \mathrm{z} & 0<\mathrm{z} \leq \mathrm{d}_{0} & \mathrm{t}=0 \\ \mathrm{~T}=\mathrm{a}_{0}\left(\mathrm{z}-\mathrm{d}_{0}\right) & \mathrm{z}>\mathrm{d}_{0} & \mathrm{t}=0\end{array}$

where $b_{0}$ is the internal gradient of the deposit. From general solution given by Carslaw and Jaeger (1959, p. 58-62), the temperature 


\section{SUDDEN MASS REMOVAL}

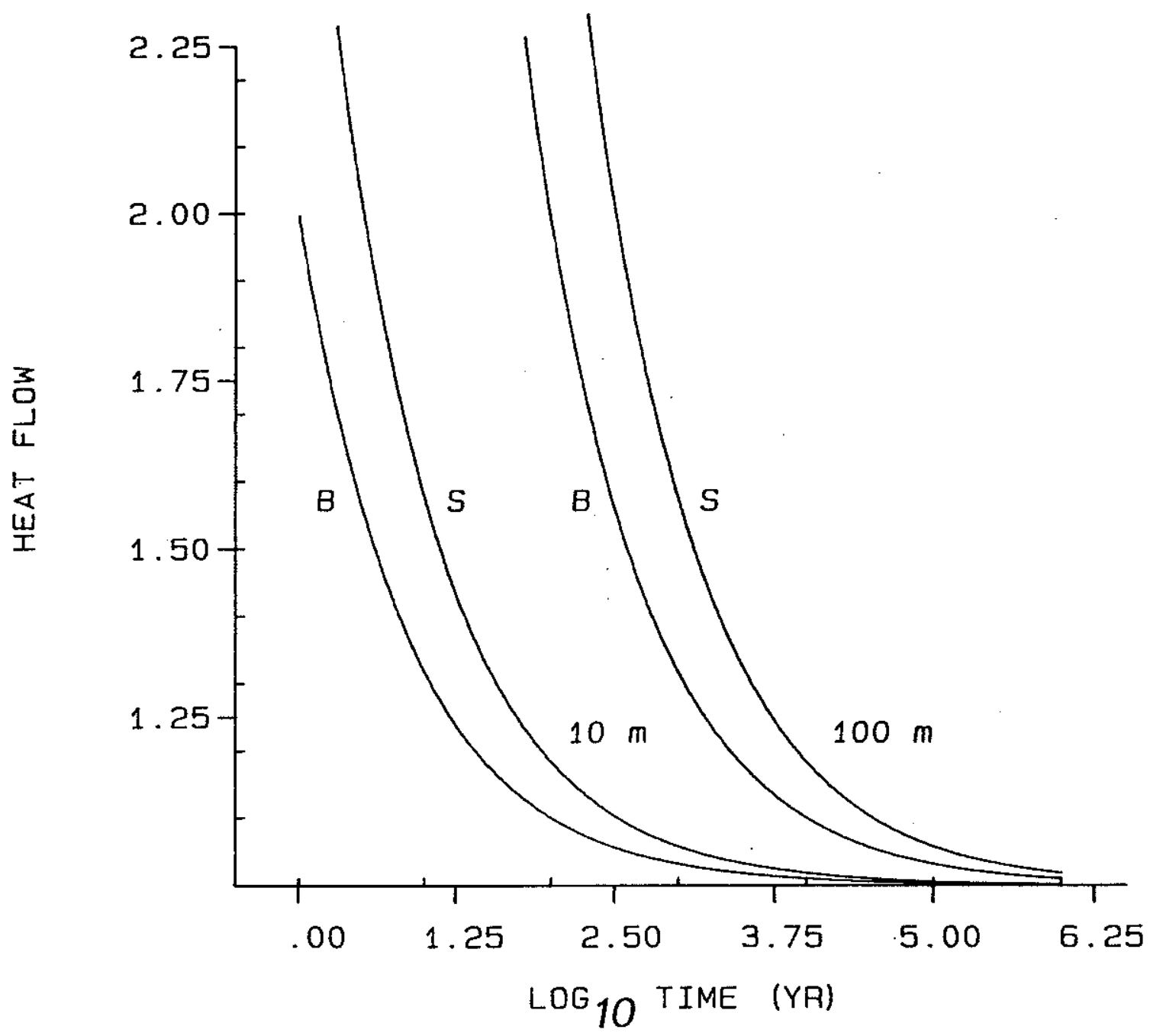

Fig. 4.1 Nondinensional heat flow with time due to sudden erosion of thicknesses of $10 \mathrm{~m}$ and $100 \mathrm{~m}$, and an equilibrium thermal gradient of $70 \mathrm{mK} \mathrm{m}^{-1}$. S indicates curves for a medium with sediment properties (thermal diffusivity $k=3 \cdot 10^{-7} \dot{\mathrm{m}}^{2} \mathrm{~s}^{-1}$ ) and $B$ for basement rock properties $\left(\kappa=1 \cdot 10^{-6} \mathrm{~m}^{2} \mathrm{~s}^{-1}\right)$. 
with time can be expressed as

$$
\begin{aligned}
T(z, t)= & b_{0} z-b_{0} \frac{z}{2}\{\operatorname{erfc}(V)+\operatorname{erfc}(W)\}+ \\
& \frac{a_{0}}{2}\left\{\left(d_{0}+z\right) \operatorname{erfc}(V)-\left(d_{0}-z\right) \operatorname{erfc}(W)\right\}+ \\
& \frac{\kappa t}{\pi}{ }^{1 / 2}\left(a_{0}-b_{0}\right)\left\{\exp \left(-W^{2}\right)-\exp \left(-V^{2}\right)\right\}
\end{aligned}
$$

and the thermal gradient as

$$
\begin{aligned}
\frac{\partial T}{\partial z}=b_{0}+ & \frac{1}{2}\left(a_{0}-b_{0}\right)\{\operatorname{erfc}(V)+\operatorname{erfc}(W)\}- \\
& \frac{b_{0} d_{0}}{(4 \pi k t)}\left\{\exp \left(-V^{2}\right)+\exp \left(-W^{2}\right)\right\}
\end{aligned}
$$

where $\mathrm{V}=\frac{\mathrm{d} 0+\mathrm{Z}}{(4 \kappa \mathrm{t})} \mathrm{1}_{1 / 2}$ and $\mathrm{W}=\frac{\mathrm{d}_{0}}{(4 \times \mathrm{z}} \mathrm{Z}_{1 / 2}$

The value of $b_{0}$ is indicative of the transport mechanism and mechanical deformation of the unit. $b_{0}=0$ implies a turbidity current deposit where the fluid support of the grains causes the sediment temperature to be equal to the water temperature (Von Herzen and Uyeda, 1963). bo=a implies a slide deposit with little or no interna1 deformation of the block (Abbott et a1., 1986). Plastic deformation of the mass block, similar to that envisioned for a debris flow (e.g., Nardin et a1., 1979), may be represented by $b_{0}>a_{0}$, i.e., the mass block is thinned in a laminar fashion subsequent1y raising the mean temperature. The results for a sudden mass deposit converge at a rate which is dependent on the thickness of the deposit, regardless of the initial thermal gradient (Figure 4.2). Also, for a given mean initial gradient, a characteristic minimum heat flow value is observed at a time dependent on the layer thickness.

Using the thermal models of sudden mass deposition or removal, the local variability within the margin can be reassessed. Emplacement of 


\section{SUDDEN MASS DEPOSIT}

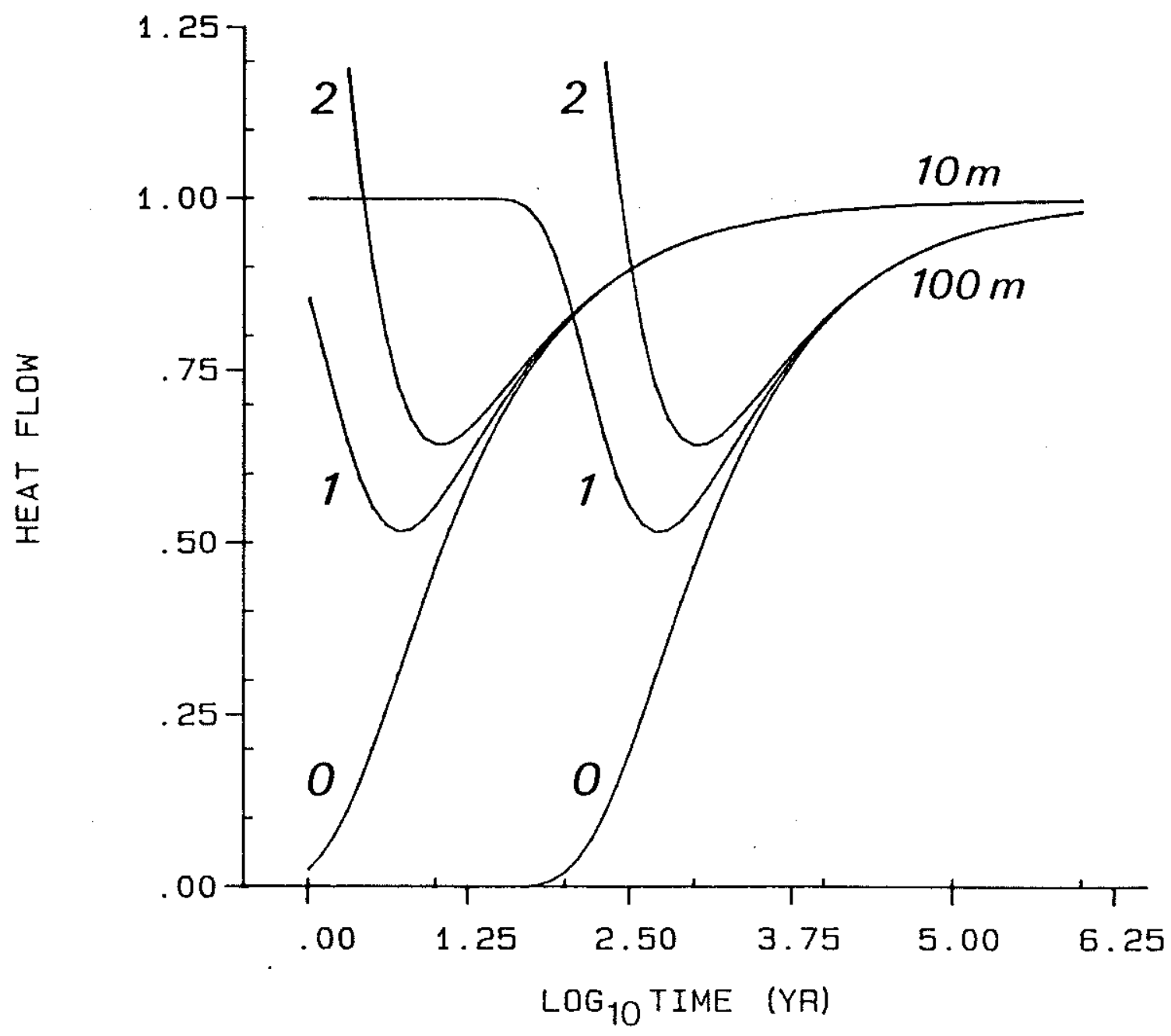

Fig. 4.2 Nondimensional heat flow with time due to sudden deposition of $10 \mathrm{~m}$ and $100 \mathrm{~m}$ layer onto a half-space with $k=3 \cdot 10^{-7}$ $\mathbf{m}^{2} \mathbf{s}^{-1}$. Numbers associated with curves represent the initial thermal gradient of the mass deposit, normalized to the equilibrium gradient of $70 \mathrm{mK} \mathrm{m}^{-1}$. 
thick mass deposits $(\sim 100 \mathrm{~m})$ are not as likely to occur on the slope as on the rise. Although slumping on the upper slope may initiate turbidity currents, the flow will generally by-pass the slope platforms and empty onto the rise and bathyal plain via submarine channel systems (Stanley et a1., 1980). A quick examination of the hemipelagic sediments sampled on the slope indicates that the sediments have little reworked material (M.P. Aubrey, personal communication, 1985) and are unstratified as far as physical properties are concerned; therefore, turbidity current deposits are probably rare on the intercanyon highs. Slumps with little or no internal deformation $\left(b_{0}=1\right)$ probably occur along submarine aretes situated at the head of the gully networks which dissect the slope platforms. It is not very likely that slumps can account for the $50 \%$ reduction in heat flow occasionally observed on the Cote d'Azur slope (Figure 4.2). Moreover, seismic data do not show any substantial slide formations. These observations are compatible with topography being the major geothermal disturbance on the intercanyon highs.

Situated below a steep upper slope escarpment on the northwest Corsican margin (Profile 7, Appendix 5), site F1 has extremely low heat flow with associated seismic evidence for a decollement surface located $100 \mathrm{~m}$ below the seafloor. In this case, a mass deposit could be argued to have occurred within the last 3000 years. A null gradient measured at one station in this site (L84S7.2) could be a result of recent deposition of a we11-mixed gravity flow associated with the slide. Environmental perturbations within site $\mathrm{F} 1$ are also indicated by the 
large variability of in situ thermal conductivity values, apparent penetration depths, gradient curvatures, and bottom water temperatures. Regions of high and variable heat flow are thought to be influenced by erosion and are generally located on upper slope regions and canyon wa11s (e.g., sites A1 and F2; Figure 3.1). Seismic profiles on the Corsican margin strongly suggest that there has been erosion by contour currents sometime during the P1io-Quaternary (Chapter 2), but in situ conductivity values indicate normal hemipelagic sediments presently cover the slope. Thus, these regions of variable and overall high heat flow are either unaffected by the winnowing action of bottom currents, or else contour currents were active prior to the late Pleistocene. As indicated by the chaotic nature of the seismic reflection data and the lack of repeatability in heat flow values between stations superimposed upon one another, sma11-scale topography also is very important in these regions. However, topography alone cannot explain the high regional heat flow.

To attain the amplitude of the anomaly in these sites $(+70 \%)$ by sudden erosion processes, unrealistic scenarios of sediment removal are necessary. For instance, $100 \mathrm{~m}$ would have to be removed within $1000 \mathrm{yr}$, or a somewhat smaller thickness would have to be eroded within the last $100 \mathrm{yr}$ (Figure 4.1). These rates of removal would strip away all sediment if continued for $10 \mathrm{kyr}$ or more in the past and therefore are not a likely mechanism. If mass-wasting is active in the form of debris flows, then these slope regions can be considered as avenues of sediment transport where erosional and depositional events alternate through time. As shown in Figure 4.2, some mass deposits may actual1y increase 
the heat flow temporarily depending on the nature of the sediment deformation.

Effect of bottom water temperature variations. Similar to other surficial perturbations, bottom water temperature variations (BTV) at the seafloor may cause overall gradient anomalies in addition to gradient nonlinearity. Long-term BTV (> $10 \mathrm{yr}$ ) will lead to mean gradient anomalies which are proportional to the amplitude of the net surface temperature change (e.g., Lachenbruch and Marsha11, 1986). Depending on the amplitude of the temperature change, short-term BTV ( $(10 \mathrm{yr}$ ) are 1ikely to be reflected in nonlinear temperature profiles measured in the upper $5 \mathrm{~m}$ of sediment. Fortuitous $1 \mathrm{y}$ linear gradients may also be created by nonuniform BTV histories or by a combination of environmental factors. Thus, to accurately assess short-term variations, BTV need to be monitored for 4 to $5 \mathrm{yr}$ at the site of the geothermal survey (Beck et a1., 1985). BTV information over such a continuous period is not readily available in the northwest Mediterranean, but knowledge of the Ligurian Sea hydrodynamics and temperature structure from physical oceanographic studies allow some insight on the potential short-term effects perturbations.

The Ligurian Sea is a semi-enclosed marine basin and hydrologically a concentration basin with evaporation exceeding precipitation (Bethoux and Prieur, 1983). The circulation pattern and the stratified temperature and salinity structure of the Ligurian Sea reflects its restricted access to adjacent basins. Atlantic 0cean surface water (0 $\rightarrow$ 100-200 m) inflows via the Straits of Gibraltar (Wust, 1961; Lacombe and Tchernia, 1972) and intermediate water (200 $\mathrm{m} \rightarrow 800 \mathrm{~m})$ inflows 
through the Corsican channel and the Straits of Sicily and Sardinia (Bethoux et a1., 1982). Intermediate water, which is actually composed of warm saline water from the Eastern Mediterranean Sea outflow, lies above a transition layer $(800 \mathrm{~m} \rightarrow 1500-2000 \mathrm{~m})$ and the colder deep water $(>1500-2000 \mathrm{~m})$.

Most deep water in the Western Mediterranean Sea is thought to form in situ within the Ligurian Sea (MEDOC, 1970; Bethoux and Prieur, 1983; Lacombe et a1., 1985). During the wintertime, strong northwesterlies lead to evaporative cooling of the northwestern Mediterranean surface waters, creating a dense, saline layer which eventually becomes unstable and convects. The general circulation pattern of the Ligurian Sea is a cyclonic gyre which creates a doming of the isopycnal surfaces; during the winter, a nearly unstratified isothermal water column void of intermediate water appears at the center of the gyre (Miller et a1., 1970; Lacombe and Tchernia, 1972; Bethoux and Prieur, 1983; Taupier-Letage and Millot, 1986). This unstratified core further enhances wintertime deep water formation, allowing the surface-cooled water to sink to various levels (Gilmour, 1972) sometimes forming a bottom layer (Lacombe et a1., 1985). During the spreading phase, the winter water mixes by diffusion and salt-fingering so that the deep water maintains its homogeneity. Thus, the deep water formation in the Ligurian Sea is a variable thermal phenomena which takes place somewhat in concert with the seasonality of the thermocline and the general circulation.

As far as bottom water variability is concerned, the temperature anomaly and residence time are the most important parameters. The 1962 
through 1964 Gostan (1967) monthly series of CTD data indicates that the seasonal temperature variability between Nice and Calvi is not periodic and is instead related to the severity of winter storms such as in early 1963 (Gostan, 1967). Exceptionally severe winter storm events may lead to large amounts of deep water formation and an overal1 warming, but not every winter has catastrophic oceanographic winter events. Thus, the near-bottom water layer may have important implications on the surficial geothermal gradients throughout the Ligurian Basin.

The bottom water layer is variable in both space and time and has anomalous temperatures of up to $0.05{ }^{\circ} \mathrm{C}$ (Lacombe et a1., 1985). Its "patchiness" has been noted in several studies (Sankey, 1973; Swa1low and Gaston, 1973). The actual residence time of the bottom water is poorly known, but could be from a few months to a couple of years depending on the volume of winter water formed and the degree of mixing during the winter phase (Taupier-Letage and Mi11ot, 1986). From Gibraltar outflow studies, the renewal of the entire deep water layer has been estimated to take 100 yr (Wust, 1961).

Near-bottom water temperatures collected during the September 1982 and 1984 heat flow measurements show an intricate vertical temperature structure with smal1-scale temperature inversions $\left( \pm 0.02{ }^{\circ} \mathrm{C}\right)$ in the bottom water $50 \mathrm{~m}$ above the seafloor. Horizontal water temperature gradients and dissimilar bottom water temperatures are a1so observed across the central basin. The temperature inversions are consistent with the fine-scale layering observed in CTD data and could be maintained by warm saline layers interfingering with the homogeneous deep water (Gilmour, 1972; Lacombe et a1., 1985). These features are 
probably transient structures due to temperature and salinity diffusion processes. The asymmetry in the deep water temperatures is related to the surface circulation patterns and the tendency for deep water formation to occur in the northern Ligurian Basin (Taupier-Letage and Millot, 1986). Although the general cyclonic circulation chiefly concerns the intermediate and surface waters (Bethoux et a1., 1982), the deep water temperature structure may also be influenced by deep contour currents (Millot and Monaco, 1984).

Using theory similar to Equations 4.1 and 4.2 , the effect of BTV step changes can be estimated. If a half-space with present surface temperature of zero, thermal diffusivity $\kappa$ and equilibrium temperature gradient ao has experienced a step change in temperature, the subsequent temperature at time $t_{1}$ is (Carslaw and Jaeger, 1959, p. $58-62)$

$$
T(z, t)=a_{0} z-T_{1}\left\{\operatorname{erfc}\left(U_{1}\right)\right\}
$$

and the thermal gradient is

$$
\frac{\partial T}{\partial z}=a_{0}+T_{1}\left\{\frac{1}{\left(\pi \kappa t_{1}\right)^{1 / 2}} \exp \left(-U_{i}^{2}\right)\right\}
$$

where $U_{1}=\frac{z}{\left(4 \kappa t_{1}\right)}{ }_{1 / 2}$ and $T_{1}$ is the relative temperature before the step change. If the temperature anomaly occurs over a number of interva1s, then a series of $n$ "box" models beginning at $t_{1+1}$ and ending at $t_{1}$ predicts the gradient to be

$$
\frac{\partial T}{\partial z}=a_{0}+\sum_{i=1}^{n} T_{1}\left\{\frac{1}{\left(\pi \kappa t_{1}\right)^{1 / 2}} \exp \left(-U_{1}^{2}\right)-\frac{1}{\left(\pi \kappa t_{1+1}\right)^{1 / 2}} \exp \left(-U_{1+1}^{2}\right)\right\}
$$

Heat flow effects due to BTV step changes simulating the dissipation of $+0.05^{\circ} \mathrm{C}$ bottom water are given in Figure 4.3. Changes of more than $10 \%$ 


\section{WINTER WATER EFFECT}

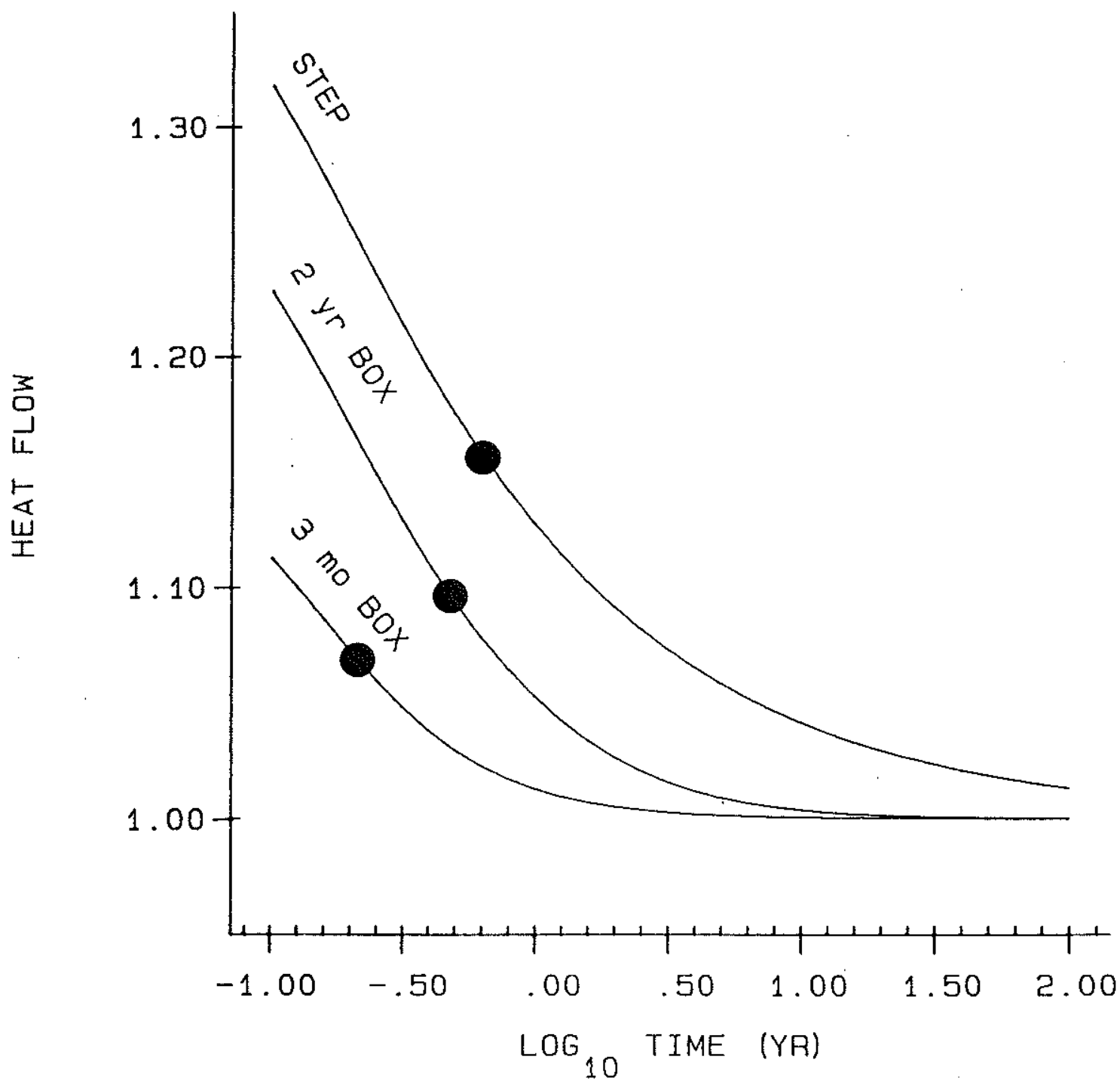

Fig. 4.3 Nondimensional heat flow versus time since instantaneous dissipation of anomalous bottom water. The temperature of the saline "winter water" is $0.05 \mathrm{~K}$ above equilibrium, and the curves represent 3 month and 2 year residence times (box model) and a step change of this amplitude. Heat flow results are calculated at $1 \mathrm{~m}$ depth in medium of $\kappa=3 \cdot 10^{-7} \mathrm{~m}^{2} \mathrm{~s}^{-1}$ with an equilibrium gradient of $70 \mathrm{mK} \mathrm{m}^{-1}$. Dots show times beyond which the heat $\mathrm{flow}$ at $1 \mathrm{~m}$ and $5 \mathrm{~m}$ depth are within $10 \%$ of one another. 
in heat flow with depth over the length of a $5 \mathrm{~m}$ probe would only occur up to 8 months after the event, depending on the residence time of the winter water. If the bottom water temperature history is essentially a step change rather than a box-type temperature-time curve, then a $10 \%$ gradient anomaly would be observed after one year. A 1 inear change instead of a step change increases the magnitude of the gradient anomaly, depending on the rate of dissipation and the time since norma1 surface temperatures have resumed.

Depending on the amplitude, spatial extent, time since dissipation, and residency of the winter water, the BTV effect could cause a $\pm 5-10 \%$ bias in the heat flow measured across the central basin. No correction for this effect on the gradients is attempted due to the incomplete BTV record. Monitoring of the bottom temperatures within a swath between Nice and Calvi would help define the role BTV may play in the local variability.

On the margins, short-term BTV are only evident in sha1low water (< $500 \mathrm{~m}$ ) stations where seasonal warming causes significant gradient nonlinearities and negative gradient anomalies. Overal1, the gradients are fairly linear and most nonlinear gradients could just as well be attributed to other environmental factors, namely small-scale topography.

Temperature changes over the last thousand years could lead to overa11 systematic errors in the gradients but would not contribute to local heat flow variability. Within the Mediterranean Sea basinal regions, but outside of areas of deep water formation, Erickson and Von Herzen (1978) have made borehole heat flow measurements more than a hundred meters below the seafloor. The general agreement of the 
borehole determinations and nearby surficial measurements suggests that BTV within the last hundred to few thousand years have not affected the heat flow results by more than a few percent. Furthermore, within the resolution of the older instruments $\left(0.5^{\circ} \mathrm{C}\right)$, the measured western Mediterranean deep water temperature has not changed within the last century (Lacombe et al., 1985).

Effect of subsurface structures. As shown in many marine geothermal studies (Von Herzen and Uyeda, 1963; Sclater et a1., 1970; Von Herzen et a1., 1972; Lewis and Hyndman, 1976; Hutchison et a1., 1985; Burrus and Foucher, 1986) thermal refraction due to buried media with dissimilar conductivity can lead to large temperature contrasts at depth and variation of heat flow values at the surface. The shape and amplitude of the variation depends on the position, configuration, and conductivity ratio of the media (Selig and Wallick, 1966; Lee and Henyey, 1974; Pinet, 1987). Low conductivity sediment ponds contrast with the igneous basement and can lead to large heat flow variations (Sc1ater et al., 1970). However, thermal refraction due to basement relief influences very few values in the Ligurian Basin and is probably a second order effect compared to other factors.

Diapiric salt structures focus heat above their centers at the expense of the peripheral heat flow, and therefore are a major source of variability in the central basin where the Messinian salt has mobilized (cf. Chapter 2). Many numerical studies of Mediterranean salt diapirs have shown the heat flow anomaly pattern above single structures and Ligurian-type diapir fields (Erickson et al., 1977; Hutchison et a1., 1985; Burrus and Foucher, 1986). Using a steady-state 2-D finite 
difference scheme to model the composite media, Hutchison et al. (1985) reproduced the maxima/minima ratio of $1.5: 1$ observed on the Balearic Rise across an undulating P1io-Quaternary/Messinian boundary. The maxima/minima ratio could range from $1.3: 1$ to $2.2: 1$, depending on a depth of burial of 500 or $0 \mathrm{~m}$, respectively (Burrus and Foucher, 1986). The overal1 amplitude of the anomaly may decrease by $8 \%$ when diapirs are spaced closely (Pinet, 1987). The vertical heat flow averaged over these salt structure fields must be conserved for a horizontal seafloor surface, so that no systematic bias results from thermal refraction. We note that the numerical experiment by Burrus and Foucher (1986) does not show heat flow conserved above the diapir field although they suggest otherwise.

Since accurate heat flow averages are reasonably assured by these theoretical studies, no numerical modeling of the thermal refraction has been attempted. Nevertheless, several problems with determining the exact relationship of heat flow to the salt need to be addressed in the Ligurian Basin. First, the upper boundary of the salt formation is not clear in most seismic profiles (see Chapter 2; Appendix 5) such that the height and width of the salt structures remains unresolved; are they penetrative domes (diapirs) or pillow formations with fractured overburden? Second, the 2-D seismic sections give only incomplete coverage of the narrow salt structures, especially since the positional uncertainty is probab1y greater than the $500 \mathrm{~m}$ half-width of most salt structures in the south central basin. The areal density of the salt structures is indicated by the perpendicular crossing of Profiles 3 and 8 (Appendix 5). Only in one case is it possible to correlate high heat 
flow with an individual salt structure. This isolated diapir is buried 200 to $300 \mathrm{~m}$ and has a $500 \mathrm{~m}$ radius (see Profile 12, Appendix 5); the thermal anomaly of $1.8: 1$ seems appropriate for this refraction geometry (Pinet, 1987).

As far as the geothermal character of central basin sites is concerned, there is a good correlation between high heat flow and moderate variability where multiple salt structures are clearly visible (maxima-minima ratio of $1.6: 1$, sites D1 and D3). Lower and more uniform heat flow are observed where local salt structures are generally absent within a few kilometers of measurements (maxima-minima ratios of $1.3: 1$, sites $\mathrm{C} 1$ and $\mathrm{D} 2)$. Although these maxima/minima ratios in surface heat flow are within the range predicted by refraction models, the higher mean value and variability seen in heat flow associated with the intense halokinetic regions may result from transient thermal effects.

Transient heat sources resulting from diapirism may be attributed to two mechanisms (Keen, 1983): advective heat transport by the hot rising diapir, and the upward migration of fluids from below and along the sides of the diapir. Halokinesis has undoubtedly been active during the late Quaternary since topographic knolls and surface faulting require rates of deformation to have exceeded the recent average sedimentation rate of 150 to $300 \mathrm{~m} \mathrm{Myr}^{-1}$ (Chapter 2). From observations of anomalously high levels of hydrocarbon maturation sampled above domes on the eastern Canada margin, Keen (1983) cites fluid circulation as a likely heating mechanism assuming that reasonably high pore water advection rates may be maintained for $\sim 3$ Myr. Alternative mechanisms fail to produce the observed maturation levels. The heat of an intruded diapir will 
dissipate in an order of magnitude less time (Keen, 1983; Pinet, 1987) and thermal refraction does not sufficiently elevate temperatures above the dome (Keen, 1983).

An attractive source for the migrating fluids in the western Mediterranean is the interstitial component of the Miocene sedimentary series below the salt (infrasalt series). This fluid is normally expelled during compaction processes. However, the rapid deposition of low porosity Messinian salt and evaporite sediment would inhibit pore water from migrating upward to a hydrostatic level. Faulting is common above and around the salt intrusion (Appendix 5), and would provide permeable pathways for the warmer pore waters beneath the salt layer to percolate upward and bathe the salt dome.

If one assumes that most of the seismic diffraction of the salt structures is due to fractures in the overburden, then the high-amplitude variability in surface heat flow would have to be explained by upward fluid migration as well. In this case, the average heat flow of random measurements over a halokinetic field may yield a value greater than the true regional heat flow. Some indication of upward pore water movement is given by the convex upward temperature profiles in sites D1 and D3, whereas nearby sites with little salt deformation do not show any systematic tendency. Unfortunately, the shallowness of penetrations, high stratification of the conductivity, fine-scale topography, recent bottom water temperature variability, and the uncertain development of the Var Fan main channe1 leave the explanation of gradient nonlinearity quite unconstrained. 
Reliability of measurements. From the analysis of the local variability, criteria are established to reject particular values which are highly unreliable indicators of the regional heat flow. Measurements are sufficiently numerous so that the removal of spurious values will not seriously decrease the statistical certainty. Such reliability assessments are routinely made for randomly-placed heat flow measurements in ocean basins with nonuniform sediment cover and rough topography (Sclater et a1., 1976a; Parsons and Sclater, 1977). Near mid-ocean ridge crests where basement outcropping is common, scattered heat flow results are enhanced by the effects of hydrothermal circulation in the permeable upper oceanic crust (e.g., Lister, 1972).

For the Ligurian Basin study, unreliable data are defined on the basis of water depth and microtopography, as we11 as the structure and acoustic character of the shallow sediment. Four classes of environmental disturbances are designated: oceanographic, sedimentary, topographic, and salt refraction. The sign of the heat flow anomaly is positive for salt diapirs, negative for oceanographic effects (warming of shallow $<500 \mathrm{~m}$ bottom waters), and is of both signs for sedimentary processes $((+)=$ erosion or $(-)=$ deposition $)$ and topography $((+)=$ canyons and gullies, or $(-)=$ ridges and spurs). Two statistical categories are used to exclude data as well. Values are considered statistically unreliable if they are outliers (ie., values greater than two standard deviations from the regional mean) or if the fractional error determined for the individual heat flow value exceeds unity.

On the basis of seismic data gathered subsequent to the heat flow surveys, four entire sites are deemed unreliable (sites A1, F1, F2, 
and $\mathrm{F} 4$ ). Basically, the procedure only reduces the number of measurements on the upper margins, where $\sim 50 \%$ of the data are qualified as unreliable. Only one value on the lower margins is identified as unreliable, emphasizing the good environmental setting provided by continental rises. Whereas both high and low values are excluded on the upper margins, generally only spurious high values are omitted from the central basin, where 9 of 58 are unreliable. A11 values obtained in halokinetic regions are retained except for outliers.

"Reliable" averages serve to give more realistic estimates of the regional heat flow, a smaller dispersion in the data, and a better working data set for heat flow corrections (Table 3.1). The resulting means are interesting in that despite the number of values rejected on the upper margins, the regional mean value has remained the same with the scatter generally reduced. In the central basin, only site $\mathrm{C} 2$ and D3 have been improved due to the removal of high values directly associated with steep scarps or diapirs. Perhaps if the density of heat flow measurements were increased by an order of magnitude, the data distribution would reflect the probability of extreme values and their relationship to the mean value. In the principal ocean basins, the preponderance of lower-than-normal heat flow values resulting in a log-norma1 distribution has been attributed to undulating topography (Birch, 1967). Likewise, the heat flow distribution in areas of faulting, diapirs, or mass-wasting may give curves characteristic of the spatial (steady-state) and temporal components of heat loss. Clearly, the analysis of heat flow distributions will require adequate control on 
the variety of environmental factors encountered in the particular physiographic setting.

\subsection{Corrections for sedimentation and erosion}

Sedimentation and compaction model. Steady sedimentation lowers near-surface sediment temperatures and insulates the basement system with a low conductivity layer. This "thermal blanketing" effect depresses surface heat flow. Hutchison (1985) developed a one-dimensional numerical model which incorporates thermal blanketing with sediment compaction processes, such as two-phase advection and increasing bulk thermal conductivity with burial. Simple analytical solutions for a moving half-space exist (Benfie1d, 1949; Von Herzen and Uyeda, 1963), but tend to over-estimate the real situation of an accreting and compacting sediment/basement system if the decompacted sedimentation rates are applied to a homogeneous semi-infinite solid (Hutchison, 1985). Herein, the Hutchison model has been modified to include systems of several lithologic units composed of variable sedimentation rate histories, with each 1 ithology defined by its thermal, compaction, and physical properties.

Assuming local thermal equilibrium between the pore water and sediment matrix in a compacting medium, the conservation of energy is satisfied by the one-dimensional advection-diffusion equation

$$
\rho_{b} C_{b} \frac{\partial T}{\partial t}=\frac{\partial}{\partial z}\left(K_{b} \frac{\partial T}{\partial z}\right)-\left(\rho_{b} C_{b} V_{g}+\rho_{w} C_{w} V_{d}\right) \frac{\partial T}{\partial z}+A
$$

where $\mathrm{T}$ is temperature, $\mathrm{t}$ is time, $\mathrm{z}$ is depth relative to the sediment/water interface, and $A$ is the internal heat generation per unit volume. $\rho, C$, and $K$ are the density, heat capacity and thermal 
conductivity, respectively, and the subscripts $b, w$, and $g$ signify the properties of the bulk wet sediment or basement rock, the pore water, and the sediment grains, respectively. $V_{g}$ is the burial rate of the sediment grains, or the velocity of the grains relative to the seafloor. At $z=0, V_{g}$ becomes the sedimentation rate; at the base of the sediment column, $V_{g}$ represents the basement advection rate. $V_{d}$ is the darcy velocity or the volume flow rate of the pore water relative to the sediment matrix (Smith, 1971)

$$
\mathrm{V}_{\mathrm{d}}=\phi\left(\mathrm{V}_{\mathrm{w}}-\mathrm{V}_{\mathrm{g}}\right)
$$

where $\phi$ is the porosity and $V_{w}$ is the average fluid velocity in the same reference frame as the sediment matrix.

Porosity and the bulk physical properties are obtained from empirical relations. Porosity is related to depth by an empirical law

$$
\phi(z)=\phi_{0} \exp (-z / \lambda)
$$

(Athy, 1930) where $\phi_{0}$ is the surface porosity and $\lambda$ is the characteristic depth, i.e., the depth at which the porosity is reduced to $37 \%$ of $\phi_{0}$. Both basin subsidence (e.g., Sclater and Christie, 1980) and hydrogeological studies (e.g., Bethke, 1986) typically use Equation 4.6 to characterize sedimentary units with hydrostatic pore pressures (norma11y-pressured), with $\phi_{0}$ and $\lambda$ reflecting the particular lithology. The bulk heat capacity per unit volume is calculated as

$$
\rho_{b} C_{b}=\rho_{w} C_{w} \phi+\rho_{g} C_{g}(1-\phi)
$$

and the bu1k thermal conductivity is determined by (Woodside and Messmer, 1961)

$$
K_{b}=K_{g}\left[K_{w} / K_{g}\right]^{(\phi)}
$$


Note that the thermal diffusivity $\kappa$ is equal to $\rho \mathrm{C} / \mathrm{K}$. Changes in the physical parameters due to temperature are not included in the model, namely, the temperature dependence of $K_{g}$ and the effect of thermal expansion of water on $V_{d}$. The sensitivity of the heat flow solution to Darcy flow and thermal conductivity are discussed later in the text.

For a constant sedimentation rate $V_{0}$ maintained over a period $t$, the height of the sediment grain column is

$$
\mathrm{Z}_{\mathrm{sg}}=\mathrm{V}_{0}\left(1-\phi_{0}\right) \mathrm{t}
$$

Sedimentation rates may be found by decompacting the sedimentary section using the method of Sclater and Christie (1980). Similarly, the basement depth $B$ is found by adding the volume of water contained in the sediment layer

$$
B=Z_{s g}+\lambda\left\{\phi_{0}-\phi(B)\right\}
$$

which can be solved by functional iteration. The mass of the sediment layer per unit cross-sectional area is

$$
M=\rho_{g} B-\left(\rho_{g}-\rho_{w}\right) \lambda\left\{\phi_{0}-\phi(B)\right\}
$$

and is essentially obtained from the average porosity of the layer. One-dimensional equations of continuity are used to determine the velocities of both phases (Smith, 1971)

$$
\begin{aligned}
& \frac{\partial}{\partial t}\left\{\rho_{g}(1-\phi)\right\}=\frac{\partial}{\partial z}\left\{(1-\phi) \rho_{g} V_{g}\right\} \\
& \frac{\partial}{\partial t}\left\{\rho_{g} \phi\right\}=\frac{\partial}{\partial z}\left\{\phi \rho_{w} V_{w}\right\}
\end{aligned}
$$

Since porosity is only a function of depth, the velocity is calculated in a straightforward manner from the mass conservation equations, assuming incompressibility of the solid and fluid phases, perfect 
permeability of the porous media, and inviscid fluid flow. The velocity equations within the accreting layer are determined by solving Equation $4.12 \mathrm{a}$ and $4.12 \mathrm{~b}$ with appropriate boundary conditions. The sediment grain velocity is determined by the prescribed sedimentation rate at $z=0$; the water velocity is constrained by the burial rate determined at the base of the sediment column. For a one-layer system, the velocities are

$$
\begin{aligned}
& \mathrm{V}_{\mathrm{g}}=\mathrm{V}_{0}\left(1-\phi_{0}\right)\{1-\phi(\mathrm{z})\}^{-1} \\
& \mathrm{~V}_{\mathrm{w}}=\mathrm{V}_{0}\left(1-\phi_{0}\right) \exp [(\mathrm{z}-\mathrm{B}) / \lambda]\{1-\phi(B)\}^{-1}
\end{aligned}
$$

(Hutchison, 1985). Both the fluid and solid phases have velocities which are depth-dependent according to the simple hydrostatic adjustment of the pore water due to pore volume reduction during compaction; the fluid velocity is indirectly time-dependent since the net water volume of the sediment column is a function of its height.

Using the mass conservation Equations 4.12, we have derived advective components for sediment systems with multiple layers which take into account for differences in compaction rates and sediment grain properties across 1ithologic boundaries. Consider a sediment system with $n$ layers; the top layer is designated as layer $i=n$ and the bottom layer $i=1$, with each layer defined by their respective compaction law, sediment grain properties, and depositional rate. For the top layer $M^{1}$ and $B^{1}$ parameters are equivalent to that given above (Equation 4.10 and 4.11 ), with $B^{1}$ referring to the depth to the lower boundary of layer $i$ and $M^{1}$ equal to the mass of the overburden above the $B^{1}$ horizon. An additional parameter $Z_{e}^{1}$ defines the depth of a uniform section which produces an overburden mass equivalent to the mass of layers $i+1$ through $n\left(M^{1+1}\right)$, but with layer $i$ parameters; this enables 
calculation of the porosity at the upper boundary of layer $i$ by rescaling of the depth in the compaction law (Equation 4.6). For the upper layer $Z_{e}^{i=n}=0$, but for layers $i<n$

$$
Z_{e}^{i}=M^{i+1} / \rho_{g}^{i}-\left(1-\rho_{w} / \rho_{g}^{i}\right) \lambda^{i}\left\{\phi^{i}\left(Z_{e}^{i}\right)-\phi_{0}^{i}\right\}
$$

which may be solved by functional iteration. Therefore, given a multi-layered sediment section, the porosity structure of the unit between $B^{i+1}<z<B^{i}$ is

$$
\phi^{i}\left(z-B^{1+1}+Z_{e}^{1}\right)=\phi_{0}^{1} \exp \left[-\left(z-B^{i+1}+Z_{e}^{i}\right) / \lambda^{i}\right]
$$

The vertical height of the solid phase of layer $i$ is

$$
\mathrm{Z}_{s g}^{1}=V_{0}^{1}\left(1-\phi_{0}^{1}\right) t^{1}
$$

where $t^{i}$ is the total duration of the layer sedimentation event. Recursive relations of $B^{i}$ and $M^{i}$ for layers $i=n-1$ to $i=1$ are found using equations $4.10,4.11,4.14$, and 4.15 to give

$$
\begin{aligned}
& B^{1}=B^{i+1}+Z_{s g}^{1}+\lambda^{1}\left[\phi^{1}\left(B^{1}-B^{1+1}+Z_{e}^{1}\right)-\phi^{1}\left(Z_{e}^{1}\right)\right] \\
& M^{i}=M^{i+1}+\rho_{g}^{1}\left(B^{1}-B^{i+1}\right)+\lambda^{i}\left(\rho_{g}^{i}-\rho_{W}\right)\left[\phi^{i}\left(B^{1}-B^{1+1}+Z_{e}^{i}\right)-\phi^{1}\left(Z_{e}^{1}\right)\right]
\end{aligned}
$$

Again, $B^{i}$ may be found by functional iteration. $V_{g}^{i}$ is determined by equating grain velocities across the stratigraphic boundaries so that for $i<n$

$$
V_{g}^{1}=V_{g}^{1+1}\left(B^{1+1}\right)\left[1-\phi^{i}\left(Z_{e}^{1}\right)\right] /\left[1-\phi^{1}\left(z-B^{1+1}+Z_{e}^{1}\right)\right]
$$

The recursive relation for $V_{w}^{1}$ is determined by the equivalence of $V_{w}$ and $V_{g}$ at the basement horizon $B^{1}$. Thus, within the bottom layer, the pore water velocity is

$$
V_{w}^{1}=V_{g}^{1}\left(B^{1}\right) \exp \left[\left(z-B^{1}\right) / \lambda^{1}\right]
$$

At all other lower boundaries $(i=2$ to $i=n)$, the condition

$$
\phi^{1}\left(B^{1}-B^{1+1}+Z_{e}^{1}\right) V_{w}^{1}\left(B^{1}\right)=\phi^{1-1}\left(Z_{e}^{1-1}\right) V_{w}^{1-1}\left(B^{1}\right)
$$

must be satisfied, which implicitly requires that a11 layers have 
nonzero porosity in order for the velocities to be bounded. Consequently, the succeeding layers $(i \geq 2)$ have water velocities

$$
V_{w}^{1}=V_{w}^{i-1}\left(B^{1}\right) \exp \left[\left(z-B^{1}\right) / \lambda^{i}\right] \phi^{i-1}\left(Z_{e}^{i-1}\right) / \phi^{i}\left(B^{i}-B^{i+1}+Z_{e}^{1}\right)
$$

Note that in the above relationships, $V_{w}^{1}$ and $V_{g}^{1}$ are functions of depth and time, and $\mathrm{B}^{1}$ and $\mathrm{Z}_{e}^{1}$ are dependent on time alone. The physical model of the basement is much simpler than the sediment medium. As in most 1ithospheric thermal mode1s, no distinction between crust and 1ithosphere thermal properties is made so that only mantle 1ithosphere constants $\left(K_{0}, \rho_{0}, C_{0}\right)$ are needed (Table 4.1).

Two options are incorporated into the mode1, geopressured zones and erosional events. Geopressured zones, sediment sections with overpressures generated by the overburden, is easily simulated by arresting the compaction process below a stratigraphic boundary and by setting the fluid and solid phases of the sediment to have velocities equal to the basement. Erosion models are assigned appropriate sediment rates prior to erosion and an upward velocity and surface removal rates during the erosional event; we assume that sediments do not decompact due to the removal of overburden.

To solve the heat transport equation (4.4), an implicit finite difference scheme is employed (Hutchison, 1985; Beaumont et al., 1982). The difference equation is derived by requiring that heat $f$ low be continuous across each node (Hutchison, 1985, Appendix). A nonuniform spatial grid spacing is made by an exponentiation transformation $\mathrm{y}=\mathrm{z}^{1 / \mathrm{N}}$ with $\mathrm{N}=2$ (Hutchison, 1985). Computations with a noninteger value of $\mathrm{N}$ lead to spurious results for unknown reasons. Boundary conditions are taken to be constant temperature at the surface $(z=0)$ and 
Table 4.1 Physical Constants for Sedimentation Corrections

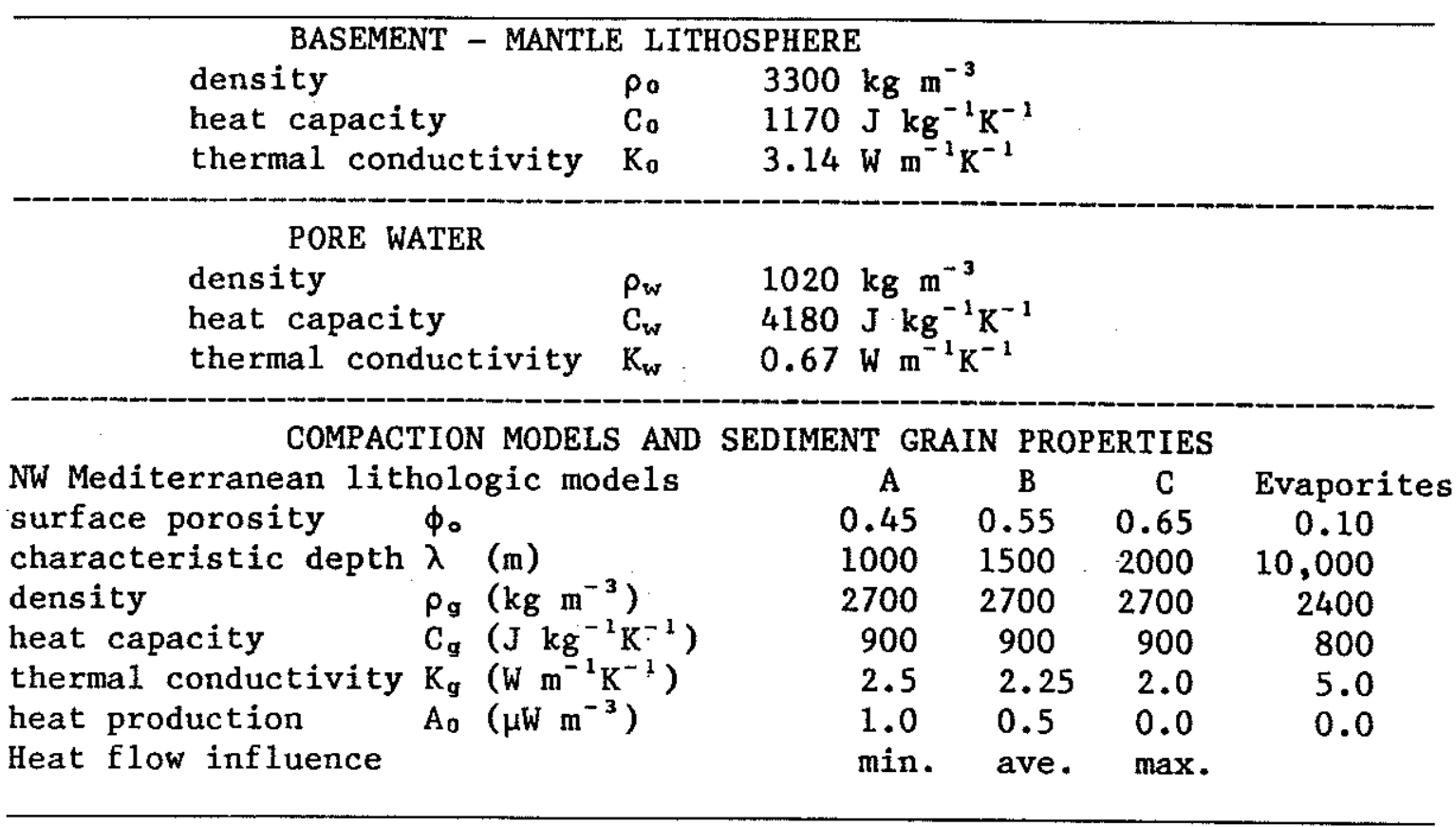


is either constant heat flow or temperature at the base of the model (usually $z=250 \mathrm{~km}$ ). For geologically reasonable sedimentation rates, the time step length for a grid spacing of $y=10$ was generally inconsequential using constant basal heat flow. However, using 1ithospheric cooling mode1s (e.g., Lister, 1977), initial conditions equivalent to a therma1 age of 1 Myr gives results within $2 \%$ of analytical solutions at 10 Myr with a 0.5 Myr time step, and $<1 \%$ for a 0.1 Myr time step. Thus, although the implicit technique is unconditionally stable (Forsythe and Wasow, 1960), model results are much more sensitive to time-stepping for perturbations consisting of high temperature gradients produced in the initial or boundary conditions (e.g., young initial thermal age or recent surface temperature changes) than to the advection rates realized in most sedimentation problems.

Since an Eulerian coordinate system is used, the nodes move with respect to the sediments making the grid parameter assignment a "bookeeping" task. At each time step, the physical parameter system is updated according the compaction model and sediment input. The thermal conductivity for grids including more than one lithologic unit or the sediment/basement interface is calculated as the harmonic mean thermal conductivity.

General sensitivity study. The general parameter dependence of the sedimentation mode1 results are reviewed in light of the large corrections required for the Ligurian Basin data. Previous1y, it has been shown that increasing thermal conductivity with burial and radiogenic heat production of the sediment grains will decrease the 
effects of a given sedimentation rate on the surface heat flow (Hutchison, 1985; Lucazeau and Le Douaran, 1985). Basic sensitivity traits for the one-layer model which are addressed include the effects of pore water movement, composite media effects, and the compaction-induced changes in sediment physical properties and burial rates. The multi-layered model is applied to the western Mediterranean situation where a substantial salt layer is sandwiched between two comparab1y thick clastic/pelagic units. We note that in this chapter, heat flow is plotted in nondimensional heat $f 10 \mathrm{Q} \mathrm{Q}_{\mathrm{Q}}$ where $Q_{0}$ is the equilibrium heat flow in the absence of sedimentation, but the

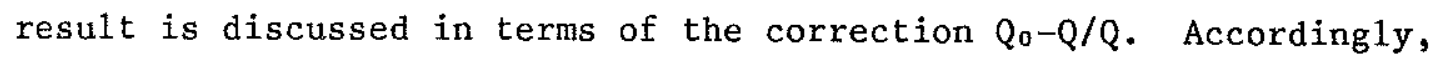
the observed heat flow $Q$ would require a $43 \%$ correction to predict $Q_{0}$ if a $30 \%$ alteration resulted from sedimentation $\left(Q / Q_{0}=0.7\right.$, $\left.Q_{0} / Q=1.43\right)$.

1) Effect of pore water flow. For a sediment system obeying Athy's Law (Equation 4.6), the maximum darcy flow rate is achieved when the sediment thickness is larger than 1-2 $\lambda$, with the highest darcy flow at the sediment boundary layer. A1though the pore water advection is accounted for in the governing equation, its contribution to the temperature structure is not wel1 understood. Most sedimentation studies have ignored the fluid phase (De Bremaecker, 1983; Lucazeau and Le Douaran, 1985). Chenet (1984) has mentioned that pore water advection is probably only important at high sedimentation rates (>1000 $\mathrm{m} \mathrm{Myr}^{-1}$ ). A1though Hutchison (1985) provided one-layer formulae for two phase flow, he did not address the significance of darcy flow on the temperature structure. 
By setting $V_{d}=0$ in the heat flow equation, advective heat due to pore water expulsion is neglected and a "conductive" medium is simulated. In analogy to the nondimensional Nusselt number for a convecting medium (the ratio of the total heat transport to the conductive heat flow), we consider the same number for two-phase flow in a compacting medium which characterizes the thermal effect of darcy flow. The Nusselt number has been calculated for relatively high sedimentation rates in Figure 4.4 . Only a 1 to $2 \%$ increase in heat flow due to pore water expulsion is experienced for very rapid sedimentation rates of $1 \mathrm{~km} \mathrm{Myr}^{-1}$, with extremely high rates (10 $\mathrm{km} \mathrm{Myr}^{-1}$ ) showing a larger darcy flow influence. It is clear that for geologically reasonable sedimentation rates sustained in monolithologic deep-sea conditions, the advective heat transport by compaction-driven fluid expulsion may be disregarded. When low-porosity sediments are rapidly deposited onto high-porosity compacting sediments, a situation similar to that in the central basins of the Mediterranean during the Messinian salinity crisis, we show that upward pore water migration is important.

Disequilibrium compaction occurs when sediment systems norma11y governed by Athy's law (Equation 4.6) deviate from their expected equilibrium porosity distribution, causing pore pressures to be elevated above hydrostatic levels. Overpressuring may easily occur for large sedimentation rates due to permeability constraints on the pore fluid expulsion. Depending on the porosity-permeability relationship, disequilibrium compaction leading to lithostatic pore pressures are only 1ike1y for sedimentation rates over $1 \mathrm{~km} \mathrm{Myr}^{-1}$ (Bethke, 1986). It is only fortuitous that both disequilibrium compaction and heat advection 


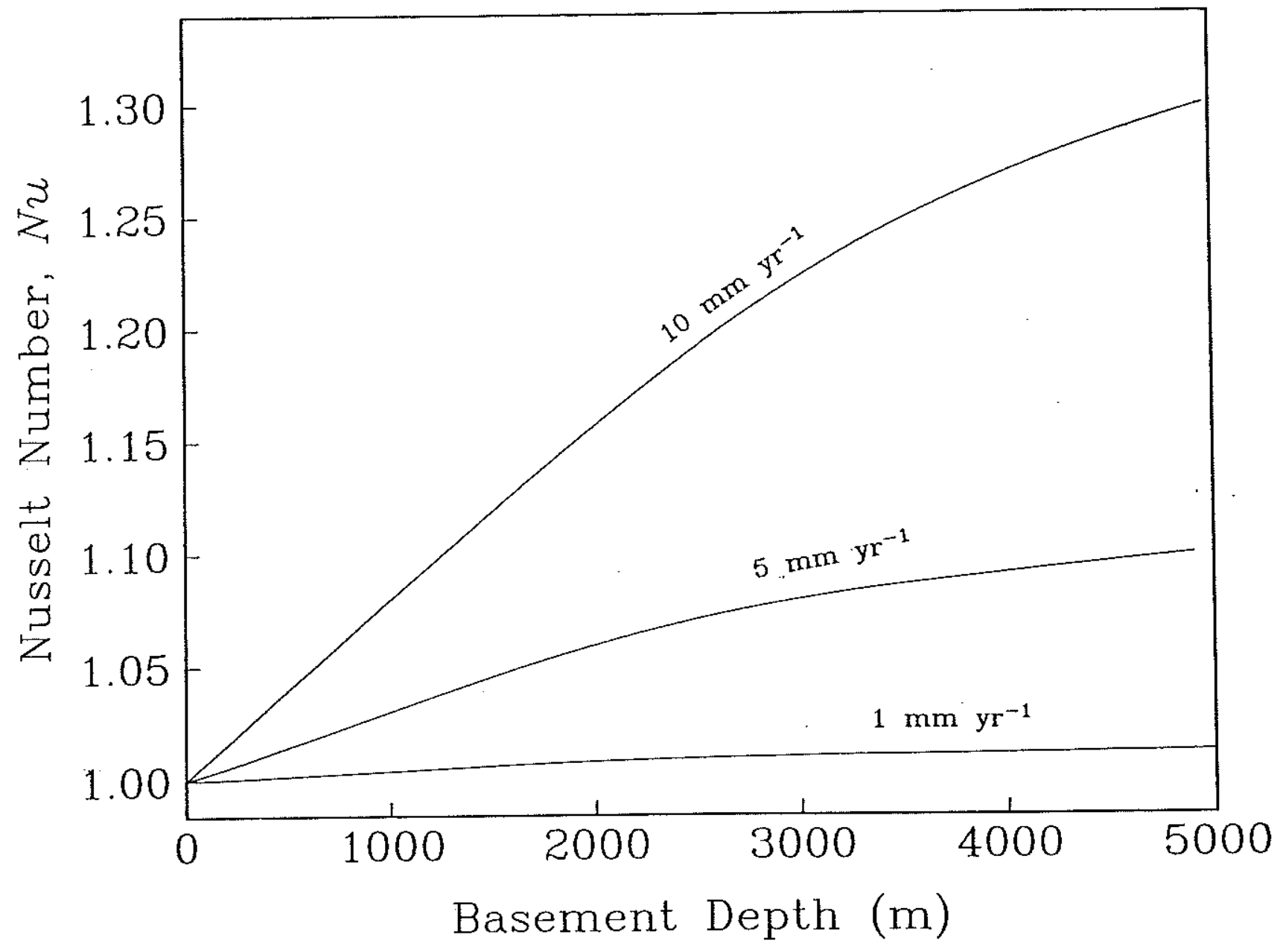

Fig. 4.4 Nusselt number of surface heat flow (see text) versus tota1 sediment thickness for high sedimentation rates $\left(\geq 1 \mathrm{mn} \mathrm{yr}^{-1}=\right.$ $\left.1 \mathrm{~km} \mathrm{Myr}^{-1}\right)$. Physical constants used are $\lambda=2000 \mathrm{~m}, \phi_{0}=0.5$, $\mathrm{K}_{\mathrm{g}}=2.5 \mathrm{~W} \mathrm{~m}^{-1} \mathrm{~K}^{-1}, \rho_{\mathrm{g}}=2700 \mathrm{~kg} \mathrm{~m}{ }^{-3}, \mathrm{C}_{\mathrm{g}}=1 \mathrm{~kJ} \mathrm{~kg}^{-1} \mathrm{~K}^{-1}$.

Pore water advection due to compaction of sediment of uniform lithology does not generally influence heat $\mathrm{flow}$. 
by pore water are consequential at similarly high sedimentation rates.

Two-dimensional considerations of the heat flow sedimentation corrections are probably minor. Excluding thermal refraction effects due to dissimilar conductivity, lateral heat flow may result from water circulation driven by forced convection (related to compaction or excess hydraulic head by continental aquifer continuing of fshore) or by free convection (large-scale hydrothermal flow within the sediment column). Gravity-driven horizontal advection can generally be neglected because of the lack of continuous sedimentary units from land to the central basin. Compaction-driven flow due to large anisotropic permeable sediment has been modeled for sedimenting intracratonic basins; little influence on the temperature structure of the basin is found, even at the edge of the basin where the hydrological barrier created by the shallow basement concentrates the lateral flow upward (Bethke, 1985). Hydrothermal circulation systems have been invoked to explain North Sea bottom-hole temperature data (Andrews-Speed et a1., 1984), but the permeability of most marine sediment is probably too low to support vigorous convection. However, fault zones may provide permeable pathways for water circulation between the surface and more permeable units at depth. Acquisition of more reliable borehole temperature data are required to accurately assess the water circulation problem in the North Sea (Barton, 1984) The Ligurian-type diapirs referred to in Chapter 3 may also have water circulation concentrated in shallow faults and fractures above and around the salt intrusions. This effect may over-estimate the equilibrium 1-D compaction result discussed later. 
2) Effect of thermal blanketing. While many basin evolution and thermal maturation studies have included the thermal effect of low conductivity sediments overlying the higher conductivity basement rock, the basic effect of composite media on the advection solution has not been adequately investigated. Figure 4.5 illustrates solutions to a moving uniform half-space for media of two extreme geological materials, pelagic sediment and mantle lithosphere. Thermal blanketing is modeled by accreting noncompacting pelagic sediments onto the mantle basement. Juxtaposition of highly contrasting media leads to corrections 2 to 3 times greater than either uniform half-space situations. Apparently, the sediment layer tends to maintain a gradient which is reduced due to the already low equilibrium gradient of the high-conductivity basement. This implies that dissimilar media produced by sedimentation enhances the heat flow alteration due to the moving uniform half-space effect originally discussed by Benfield (1949).

We define "therma1 blanketing" as the effect of lowering heat flow and sediment temperatures by deposition of low-conductivity sediments onto high-conductivity basement. De Bremaecker (1983) came to a similar conclusion concerning sediment thermal history for sedimentation rates $>100 \mathrm{~m} \mathrm{Myr}^{-1}$, but the importance of the advective and composite media components of thermal blanketing was not brought out.

Some remarks on the temperature dependence of thermal conductivity and its effect on the heat flow may be inferred from these results, with reference to the mode1 of Lucazeau and Le Douaran (1985). We know that at sediment temperatures $<200{ }^{\circ} \mathrm{C}$, thermal conductivity decreases with temperature (Clark, 1966). We estimate that the average sediment grain 
Thermal Blanketing Effect

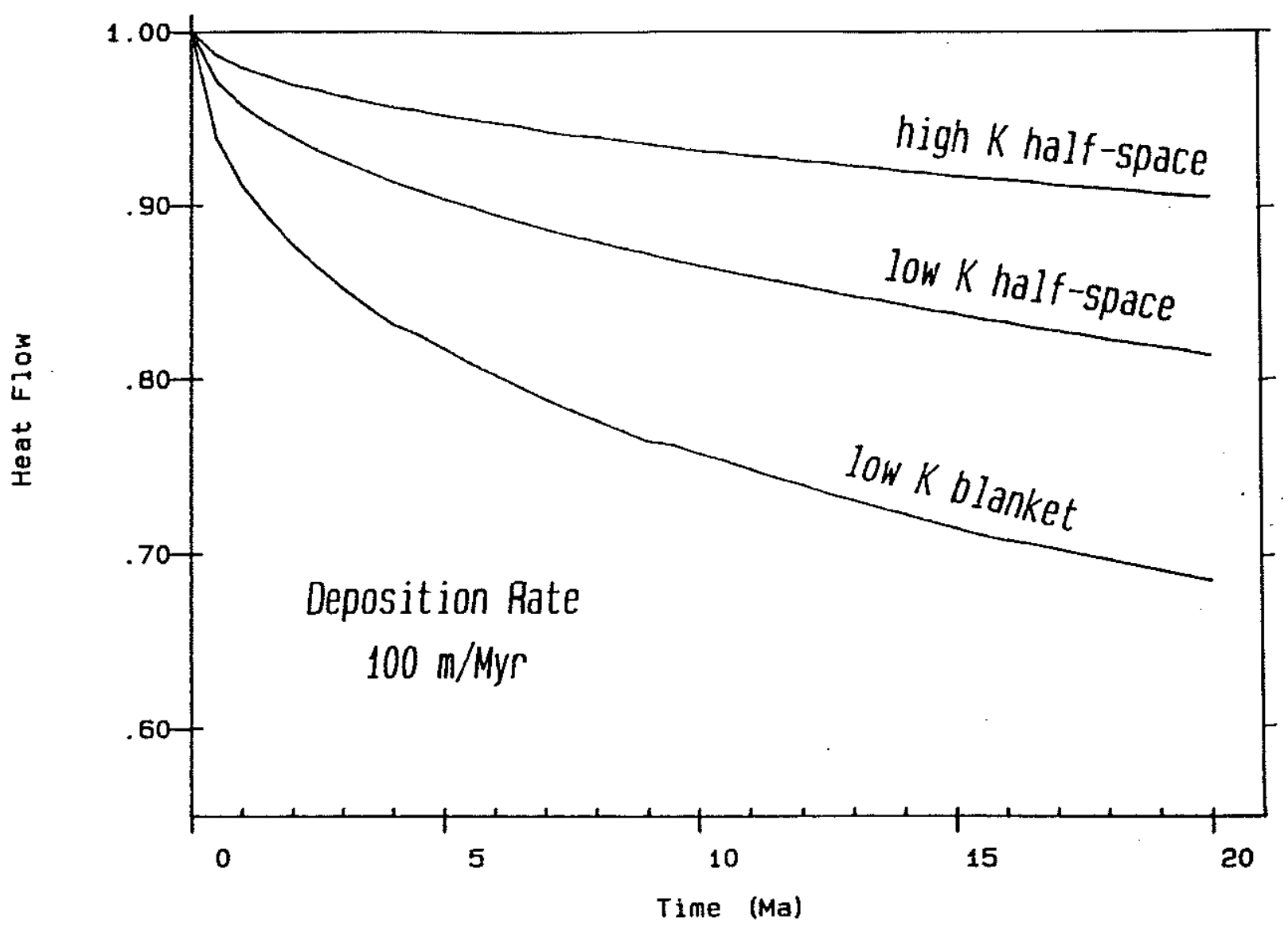

Fig. 4.5 Effect of thermal blanketing on heat conduction through a layer over a halfspace. No compaction is included in the accreting layer. Low conductivity ( $K$ ) medium has thermal constants which are $25 \%$ of the high $K$ example, the high $K$ medium has mantle 1ithosphere properties (Table 4.1) and the low $\mathrm{K}$ layer simulates pelagic sediment properties. 
conductivity decreases by $10 \%$ from 0 to $200^{\circ} \mathrm{C}$. Also, the basement thermal conductivity has a steady increase in thermal conductivity with depth due to the increasing importance of the radiative component of thermal conductivity at temperatures $>200{ }^{\circ} \mathrm{C}$ (Schatz and Simmons, 1972). The basement conductivity value in Table 4.1 is the mean lithospheric thermal conductivity so that the upper basement rock will be lower than that included in our models. We believe that the change in the sediment conductivity and upper basement thermal conductivity due to temperature probably cancels each other in terms of the therma1. blanketing effect on heat flow.

3) Effect of compaction constants. To determine sedimentation rates, the sediment thickness determined by seismic stratigraphy is usually decompacted to produce average interval sedimentation rates, i.e., the actual surface sedimentation rate through time is not usually we11-constrained. Therefore, heat flow differences resulting from equivalent sediment thicknesses of $5 \mathrm{~km}$ deposited in $20 \mathrm{Myr}$ are analyzed with extreme, but geologically reasonable, choices of compaction parameters $\phi_{0}$ and $\lambda$ (Figure 4.6). This approach indicates that the maximum uncertainty in the heat flow correction due to the given range of $\phi_{0}$ and $\lambda$ is $\pm 10 \%$. Thus, moderately large systematic errors may resu1t from assuming compaction constants: this error is enhanced for larger sedimentation rates.

Several features of the heat flow vs. time curves should be noted (Figure 4.6). The abrupt slope change at $1 \mathrm{Myr}$ in the low $\lambda /$ high $\phi_{0}$ case is understood by observing the burial rate profiles (Figure 4.7). The basement velocity of the low $\lambda /$ high $\phi_{0}$ sediment 


\section{Dependence on Compaction Constants}

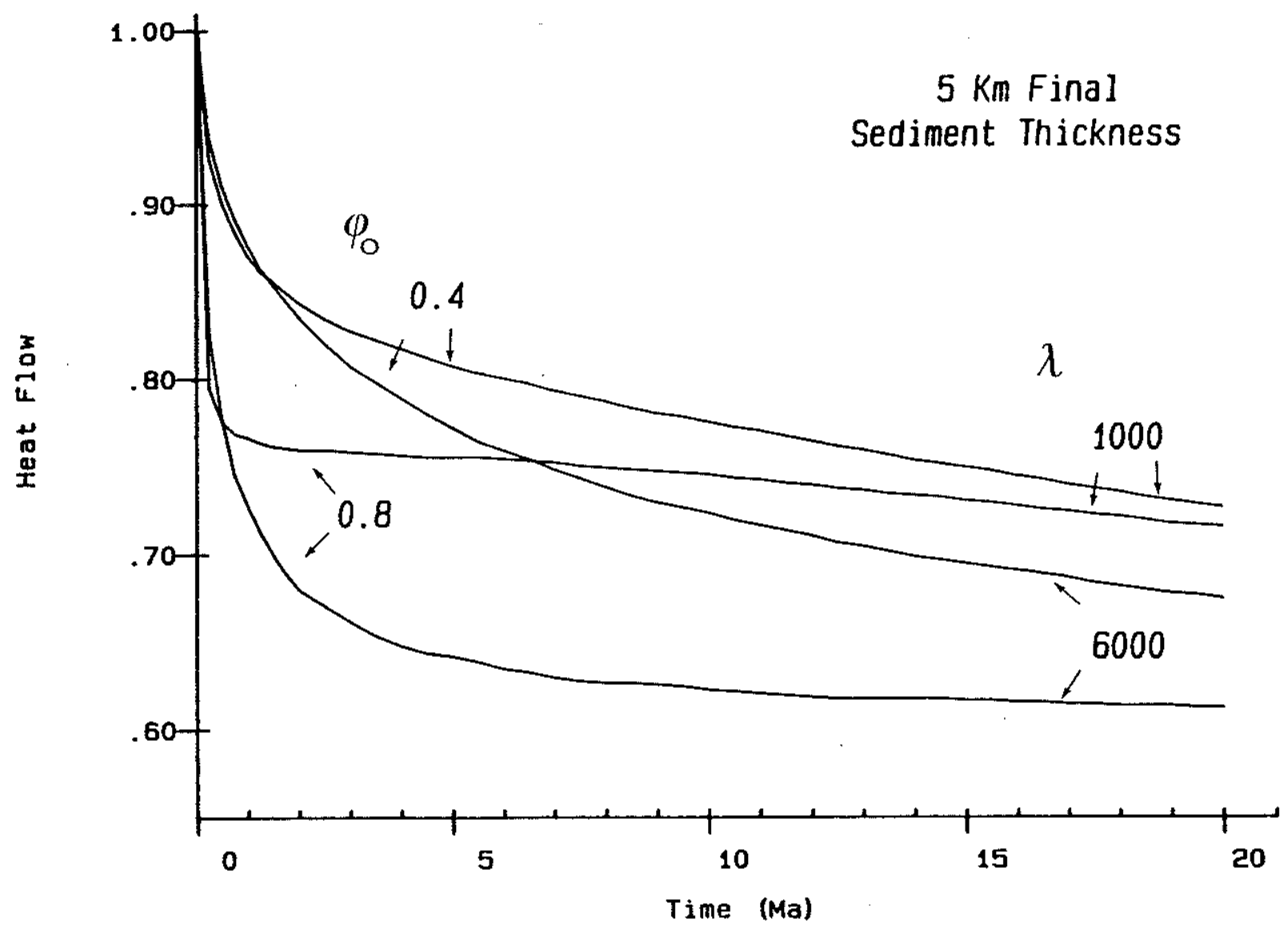

Fig. 4.6 Heat flow versus time for various compaction parameters $\phi_{0}$ and $\lambda$ (in meters). Physical properties are given in Figure 4.4. For a given sediment thickness deposited uniformly according to Athy's law. Low $\phi_{0}$ and low $\lambda$ alter the heat flow the least and high $\phi_{0}$ and high $\lambda$ the most. Constant basal heat flow assumed. 


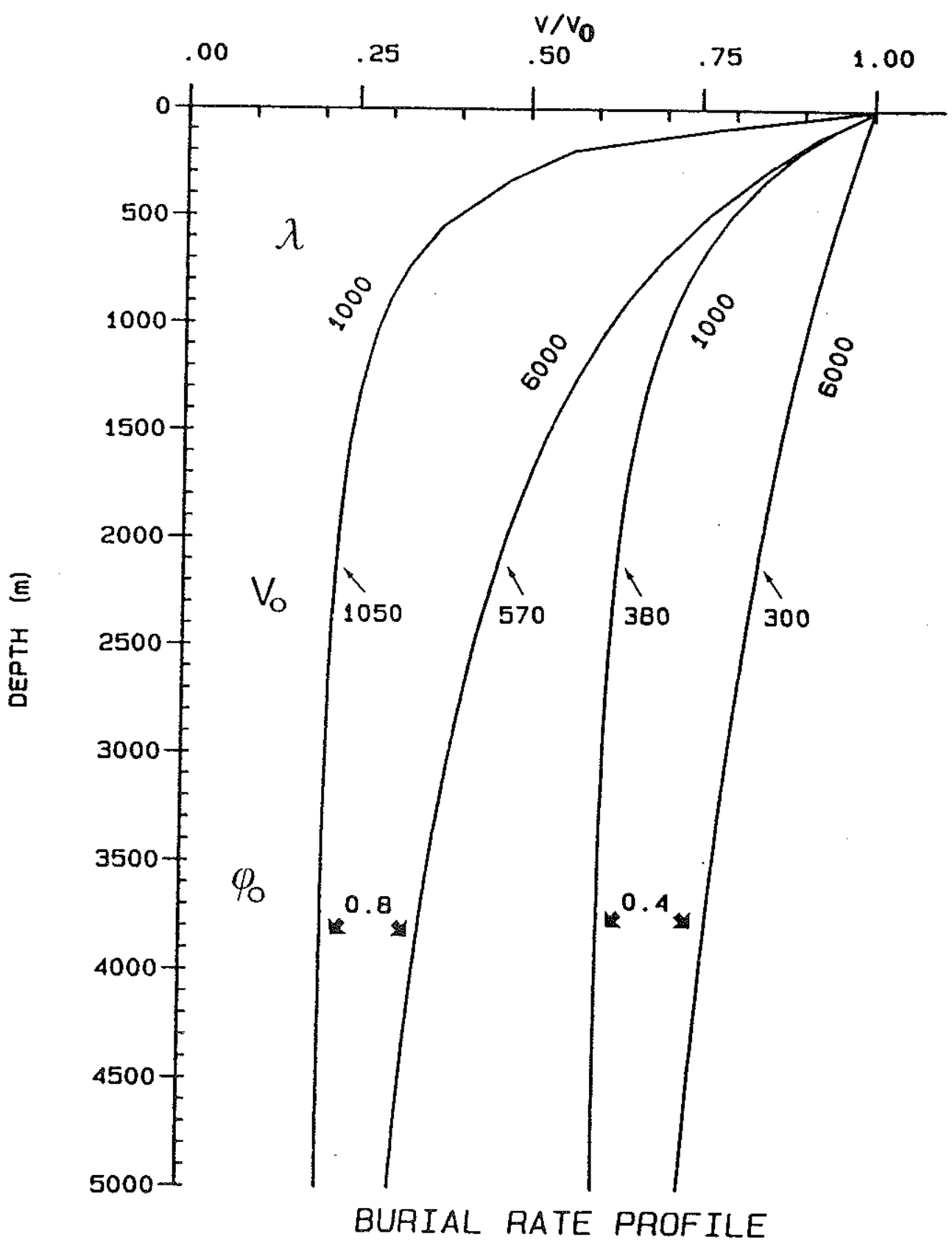

Fig. 4.7 Burial rate profiles for the range of compaction parameters. The surface sedimentation rates $V_{0}$ are given in units of m Myr ${ }^{-1}$. See Figure 4.6 for further details. 
is reduced by $75 \%$ of the initial rate after about $1 \mathrm{~km}$ of sediment is deposited ( $\sim \mathrm{Ma})$, so that a rapid change in the basement burial rate accounts for the inflection. Therefore, in terms of heat flow, the basement burial rate is a much more accurate indicator of the system advection rate than the surface sedimentation rate. Basement burial rates for all compaction curves decrease to about $250 \mathrm{~m} \mathrm{Myr}^{-1}$ after $\sim 2000 \mathrm{~m}$ of sediments have been deposited. The shallowing of a11 the heat flow vs. time curves is due in part to the slow decrease of the apparent basement velocity as we11 as changes in the layer conductivity. Changes in bulk thermal conductivity of the sediment layer with time qualitatively mimics the shape of the heat flow vs. time plot (Figure 4.8). For instance, the lowest bu1k conductivity curve given by high $\phi_{0}$ and high $\lambda$ gives a mean conductivity value $55-65 \%$ of the other three curves. The fact that the low conductivity sediment pile produces the largest surface heat flow effect is consistent with the major influence of composite media effects in thermal blanketing. Thus, sedimentation effects on heat flow may be thought of as a complex interaction between basement velocity and the layer/basement thermal conductivity contrast, and not necessarily the superficial sedimentation rate and the detailed variation of the sediment conductivity with depth as suggested by Hutchison (1985). We have not included mineralogic changes in our results. Since the high $\phi_{0} /$ high $\lambda$ is associated with sediment of lower grain density and lower grain thermal conductivity, the maximum thermal blanketing effect may be even greater. 4) Multi-1ayered sediment systems. Multi-layered compaction models allow for a more precise account of the evolution of sediment and pore 


\section{Bulk Conductivity of Sediment Layer}

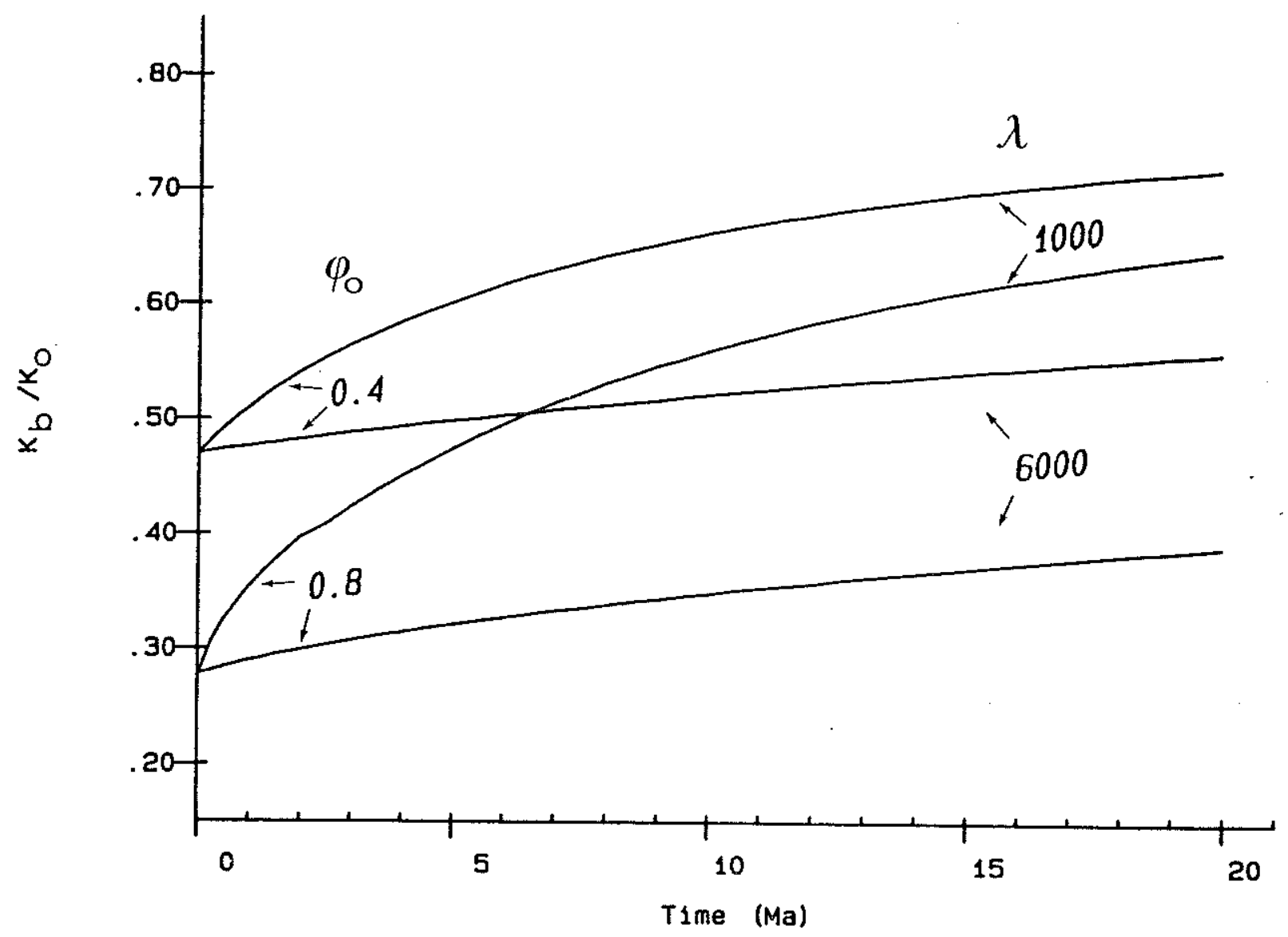

Fig. 4.8 Sediment layer bulk conductivity $\left(K_{B}\right)$, relative to the basement value $\left(\mathrm{K}_{0}=3.14 \mathrm{~W} \mathrm{~m}^{-1} \mathrm{~K}^{-1}\right)$, versus time. The relative ordering of the curves mirrors that of the heat flow vs. time plot (Figure 4.6), including the crossover point at $6 \mathrm{Ma}$. 
water velocities, as we11 as the conductivity structure of the sediment column. Due to the larger number of variables from the one-layer case, it is difficult to ascribe the relative contributions of the burial rate, thermal blanketing, and pore water movement to the surficial heat flow. However, it is clear from numerical experiments that pore water expulsion is a more important factor in a multi-1ithologic compacting media than in an uniform compacting layer, especially when there are large contrasts in the compaction parameters between adjacent units.

Boundaries between highly contrasting lithologies probably represent significant permeability changes and, in addition to rapid sediment loading, are a main cause of disequilibrium compaction (e.g., Bethke, 1986). One of the most impervious sedimentary rock types is evaporites. Sedimentation corrections to Ligurian Basin heat flow data have uncertainty attributed to the compaction of the early to middle Miocene infrasalt series which under1ies the thick late Miocene evaporite formations. In this case, the multi-layered compaction model, given by Equations 4.17-4.21, allows for some reasonable estimates of heat flow.

An example of the heat flow history for the central Ligurian Basin is presented in Figure 4.9. A three-1ayer section composed of $2 \mathrm{~km}$ of infrasalt series terrigenous sediment (early to mid-Miocene), $2 \mathrm{~km}$ of evaporites (very late Miocene), and $1 \mathrm{~km}$ of terrigenous sediment (P1io-Quaternary) is deposited assuming both a geopressured and a norma11y-pressured infrasalt unit. In order to compensate for later compaction, the norma11y-compacted infrasalt series must have higher sedimentation rate but lower basement burial rates during the Messinian 
Overpressuring of Infrasalt Series
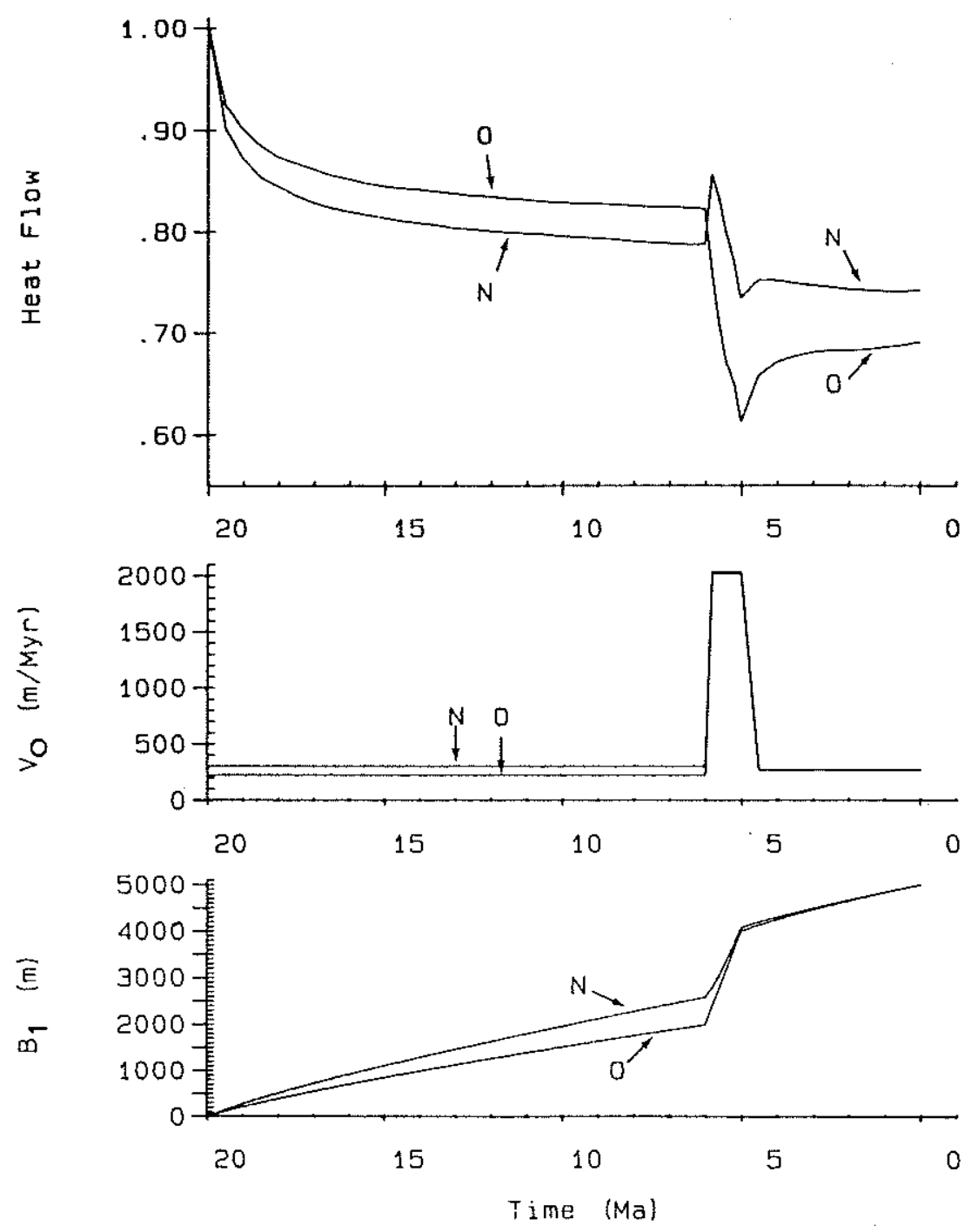

Fig. 4.9 Surface heat flow alteration, sedimentation rate $\left(V_{0}\right)$ and basement depth $\left(B_{1}\right)$ histories in the central Ligurian Basin for normal $(N)$ and overpressured $(0)$ pore waters of the infrasalt Miocene series (see text). The final stratigraphic situation for both cases is $2 \mathrm{~km}$ of sediment ( 20 to $6 \mathrm{Ma}$ ), $2 \mathrm{~km}$ of Messinian evaporites ( 6 to $5 \mathrm{Ma}$ ), and $1 \mathrm{~km}$ of sediment ( 5 to $0 \mathrm{Ma}$ ). The terrigenous units use the parameters of model B (Table 4.1). 
than the geopressured case. At the onset of the Messinian evaporite deposition, the infrasalt unit dewaters during normal compaction, causing higher heat flow due to rapid pore water advection through the low-porosity salt. Conversely, the geopressured case depresses the heat flow by a larger amount during the Messinian episode due to the lack of upward pore water movement, lack of porosity reduction of the infrasalt formation and higher basement burial rate. If the salt has $\phi_{0}=1 \%$ instead of $10 \%$, the result changes 1 ittle; but if the salt $\phi_{0}$ is equal to the underlying sediment then pore water effects would cease to be a factor, similar to the one-layer case. The difference between the two pore pressure examples amounts to $10 \%$. We take the generally high seismic velocities associated with the infrasalt series to be evidence of the compacted state of low porosity sediment. If the infrasalt series was initially overpressured, the excess pore pressures may decrease with time due to dewatering processes. Since this transient reduction of pore water pressure would be associated with smaller basement velocities and upward pore water movement, the final heat flow alteration in the geopressured case may very we11 decrease to the normally-pressured case. The role of fluid circulation due to fracturing above salt intrusions (e.g., Keen, 1983) may be related to the overpressuring problem if the source of upwelling pore waters is from the units below the P1io-Quaternary.

Sedimentation rate histories are also complicated by the occurrence of erosion on the margins during the Messinian. The Messinian unconformity is identified by seismic stratigraphy (Ryan, 1976; Montadert et al., 1978) and borehole data (Steckler and Watts, 1980; 
Hsu, Montadert et a1., 1978) and can be interpreted as an erosional vacuity or a depositional hiatus. An erosional vacuity requires a higher depositional rate for the infrasalt series to compensate for that removed by the Messinian erosion, whereas a depositional hiatus implies little or no Miocene sedimentation prior to the Messinian. Two models for the Messinian lacuna are illustrated in Figure 4.10. In either case, the late Messinian includes a short period of rapid evaporite deposition which onlaps the unconformable surface. One kilometer of Miocene sediment erosion corresponds approximately to a $4 \%$ decrease in the heat flow correction (Figure 4.10). We confirm that the effect of a large surface temperature anomaly $\left(\sim 15{ }^{\circ} \mathrm{C}\right)$ due to subaerial exposure during the Messinian is insignificant (Hutchison et a1., 1985). Parameter estimation: Northwestern Mediterranean Basin. The compaction parameters for the Ligurian Basin are determined by physical property data obtained in Northwestern Mediterranean boreholes (Figure 4.11). The porosity data illustrate the applicability of Athy's law to the nonevaporitic sediment of the Mediterranean; a slight overcompaction at $1500 \mathrm{~m}$ indicates the unconformable Messinian surface. Given a stratigraphic unit of known thickness, it is apparent that the minimum sedimentation correction is given by low values of $\phi_{0}$ and $\lambda$ and maximum corrections by high values of $\phi_{0}$ and $\lambda$ (Figure 4.6). According1y, three porosity-depth curves (A, B and C) are chosen to represent the parameters used in the minimum, average, and maximum heat flow corrections (Table 4.1). As indicated by the borehole studies (Hsu, Montadert et a1., 1978), the P1io-Quaternary and infrasa1t series are 1ithologica1ly equivalent. 


\section{Messinian Erosional Event}
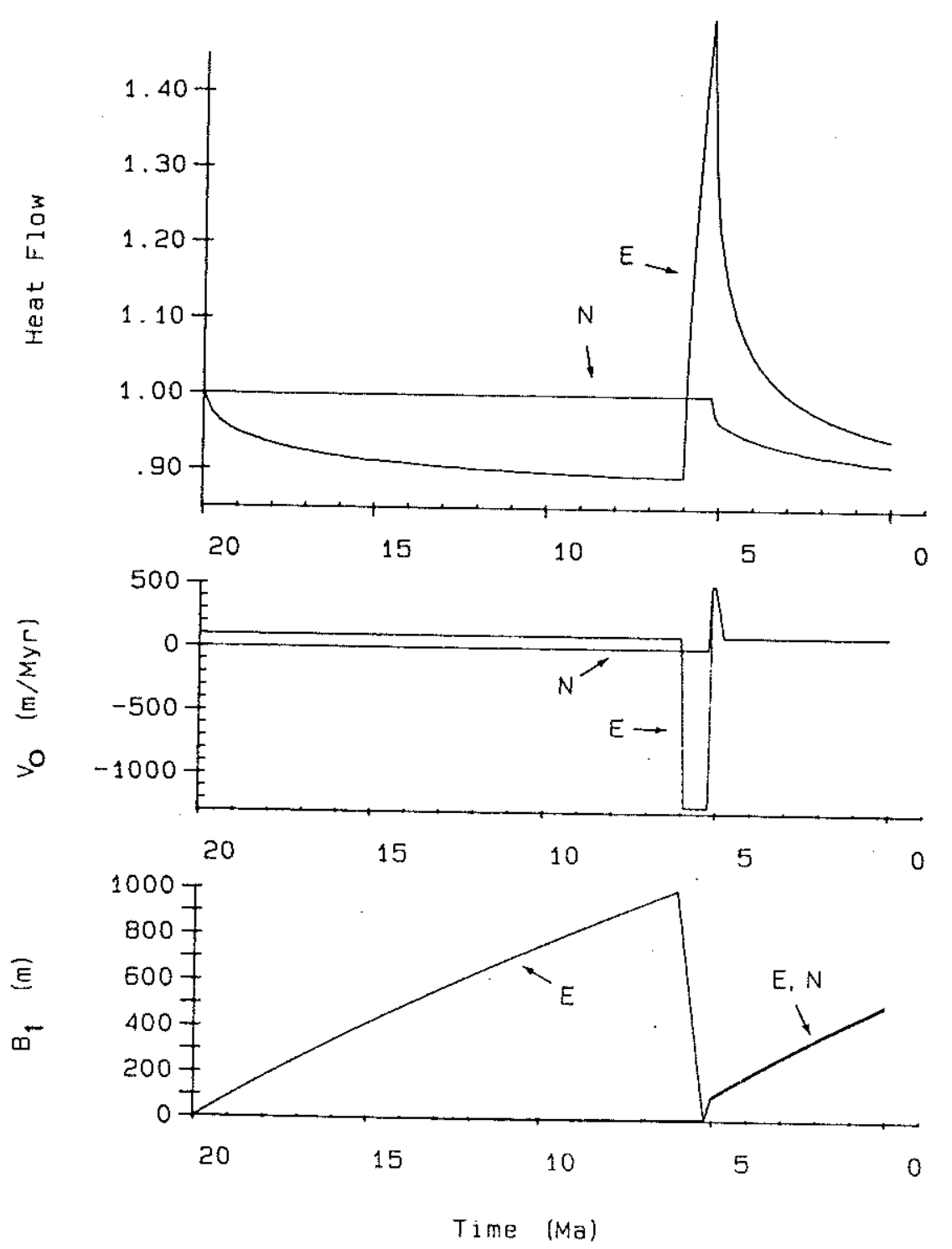

Fig. 4.10 Heat flow alteration and sedimentary evolution of a typical upper margin site located just seaward of the Messinian pinchout. A late Miocene unconformity is modeled as a depositional hiatus (N) or by an erosional vacuity (E). Sediment model B is assumed (Table 4.1) except for the thin layer of evaporite deposited above the unconformity $(5.2$ to $5.0 \mathrm{Ma})$. Constant basal heat flow is assumed. 


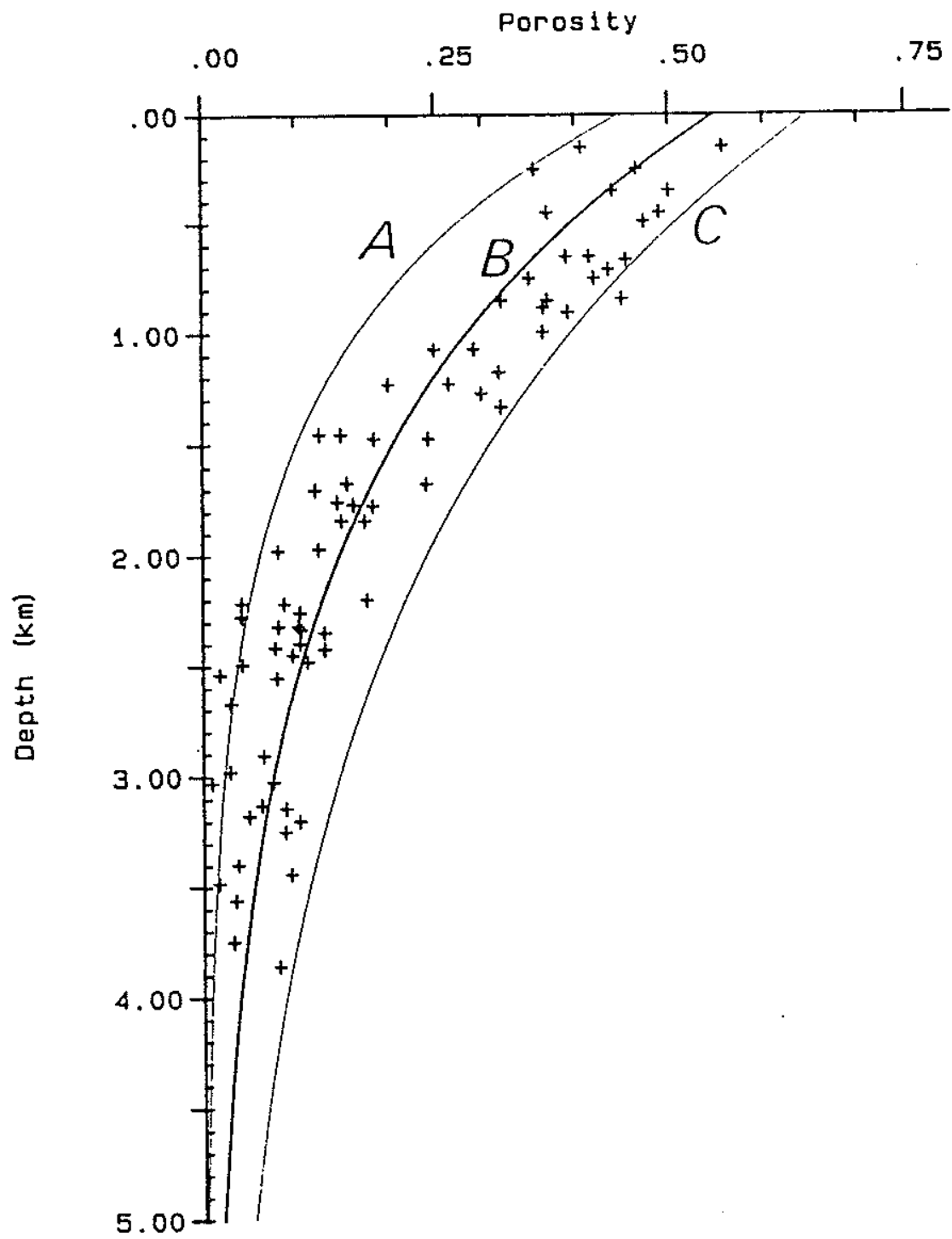

NW Mediterranean Borehole Data

Fig. 4.11 Porosity versus depth for Northwestern Mediterranean sediment from the Autan, Tramontane and Mistral wells, in the Gulf of Lion (Bessis, 1986) and Menorca Rise DSDP site 372 (Erickson, 1978). Curves $\mathrm{A}, \mathrm{B}$, and $\mathrm{C}$ are the minimum, average and maximum estimates, respectively, of the porosity using Athy's law (Equation 4.6) which correspond to the parameter constants in Table 4.1. 
The thermal properties of the compacting sediment compiled in Table 4.1 are derived from new piston core analyses, DSDP data, and the geophysical literature. Using water content, bulk density, and needle-probe conductivity measurements obtained on Ligurian Basin cores (Appendix 4), we apply the technique described in Appendix 2 to find representative grain properties. The sediment grain thermal conductivity ranges from 2.0 to $2.5 \mathrm{~W} \mathrm{~m}^{-1} \mathrm{~K}^{-1}$, the grain density is about $2700 \mathrm{~kg} \mathrm{~m}^{-3}$, and the porosity $\left(\phi_{0}\right)$ is 0.5 to 0.6 . These values are consistent with measurements of Menorca Rise DSDP Site 372 sediment samples (Erickson, 1978). Variations in heat capacity are not very we11-known for the sediment so that a constant average value is estimated (e.g., Monge11i et a1., 1982).

To determine radioactive heat production of the sediment, we consider continental measurements of granites on Corsica and Maures-Estere1 (Lucazeau and Maihle, 1986). Since the terrigenous sediment consistent1y has a carbonate content of about 50\% (Erickson, 1978; Rehau1t, 1981), the average sediment grain radioactivity is probably quite reduced from the average granite concentrations of $2 \mu \mathrm{W} \mathrm{m}^{-3}$ found on Corsica (Lesquer et a1., 1983). Moreover, the provenance of the detrital sediment of the Var bathyal fan is the Mesozoic sedimentary units within the French-Ita1ian Maritime Alps which are predominant1y calcareous. Therefore, a maximum concentration of $1.0 \mu \mathrm{W} \mathrm{m} \mathrm{m}^{-3}$ is estimated for the sediment grain heat production. The effect of this parameter range is displayed in Figure 4.12 for the approximate central Ligurian Basin situation $(\sim 5 \mathrm{~km}$ of terrigenous sediment deposited in $20 \mathrm{Myr}$, evaporitic sediments not included). The 
Deep Basin Uniform Sedimentation Models

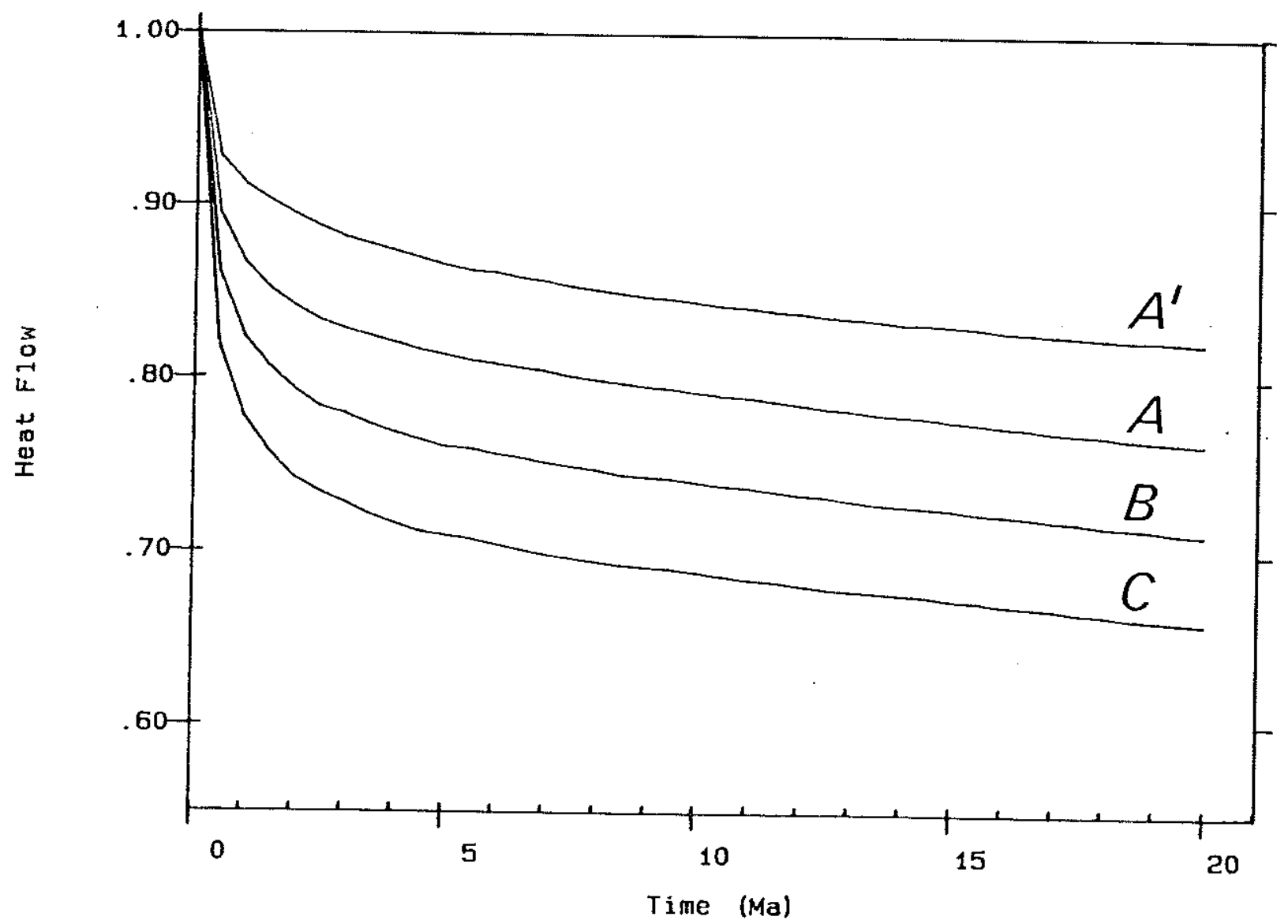

Fig. 4.12 Heat flow depression due to sedimentation using sediment models $A, B$, and $C$ for compaction (Table 4.1; Figure 4.6) with a constant basal heat flow. Curve $A^{\circ}$ is obtained with a constant $1 \mathrm{Myr} .5 \mathrm{~km}$ of sediment is depon initial lithospheric thermal age of sedimentation rates ranging from 414 in 20 Myr for each curve with Myr $^{-1}$ (mode1 C). 
uncertainty in corrected heat flow due to sediment physical and compaction properties is on the order of $\pm 7 \%$ with the average mode1 $\mathrm{B}$ taken as the best estimate. This uncertainty is reduced to $\pm 5 \%$ if the salt layer is incorporated in the model; for small sediment thicknesses typically found on the margins, it is only $\pm 2 \%$.

Evaporite compaction and physical properties are notable for their low porosity, high thermal conductivity, and lack of radiogenic heat. The salt parameters in Table 4.1 are slightly reduced from previous estimates (e.g., Beaumont et al., 1982) in order to account for the large temperature dependence of salt conductivity ( $30 \%$ decrease from 0 to $\left.100{ }^{\circ} \mathrm{C} ; \mathrm{Clark}, 1966\right)$ and the probable contamination of the evaporites with terrigenous sediment.

Sedimentation rates for each heat flow station are derived from sediment thickness data (Table A4.4) using the sediment mode1 $B$ in the decompaction calculation. Sedimentation is assumed to have commenced at 21 Ma for a11 heat flow groups in the Ligurian Basin. Mainly from the work of Ryan (1976), Steckler and Watts (1980), we estimate that between $1 \mathrm{~km}$ to $0 \mathrm{~km}$ of sediments were eroded from the continental slopes during the Messinian. Therefore, we assume an average value of $500 \mathrm{~m}$ of Miocene sediment was eroded from the marginal regions of $A, E$, and $F$. Regions $\mathrm{B}, \mathrm{C}$, and $\mathrm{D}$ assume that equilibrium compaction is maintained in the infrasalt series and that the transient thermal effects of water circulation due to 2-D compaction, diapirism and faulting are negligible.

Data for the Miocene sediment are given by multi-channel reflection profiles (Finetti and More11i, 1973; Montadert et al., 1978, Mauffret et a1., 1982) and seismic refraction experiments (Fahlquist and 
Hersey, 1969; Le Douaran et a1., 1984). In accordance with these studies (see Chapter 2), Rehault (1981) has constructed isopach maps of the infrasalt Miocene series and Messinian evaporite in the Ligurian Basin. He assumed average velocities of 4.0 and $4.4 \mathrm{~km} \mathrm{~s}^{-1}$ for the evaporite and infrasalt Miocene sediment, respectively.

Despite the large thicknesses, the uncertainties in the Miocene sedimentation rates produce relatively small changes in the resultant heat flow corrections. For instance, Miocene infrasalt thicknesses of $2000 \mathrm{~m}$ instead of $3000 \mathrm{~m}$ causes only a $3 \%$ change in the heat flow correction. If the sedimentation commenced 5 Myr earlier (e.i., 26 Myr ago), the correction would be reduced by about $2 \%$. However, if the sedimentation occurs 5 Myr later ( 16 Myr ago), the recalculated Miocene rate would the correction to $3-4 \%$ higher. The sediment physical and compaction properties chosen for the Messinian sediment (terrigenous Mode1 $B$ or the evaporite mode1) makes $<1 \%$ difference in the final correction, although the heat flow discrepancy in the early Pliocene may be $30 \%$. Apparently, the Messinian Event occurred sufficiently long ago and short enough duration that its composition does not alter the present heat flow. Also, Messinian sedimentation rates are high regardless of the compaction model assumed for the infrasalt series.

The P1io-Quaternary sediment thicknesses listed in Table A4.4 are determined by assuming an interval velocity of $2.0 \mathrm{~km} \mathrm{~s}^{-1}$, and shallow seismic data for each station are located in Appendix 5. Integration of published velocity profiles (Montadert et a1., 1978) with "M" reflector trave1 times gives a negligible difference in the sediment thickness estimates, except for the few stations where the Var levee deposits show 
$>1.0 \mathrm{~s}$ two-way travel time. In these instances, a slightly higher velocity of $2.5 \mathrm{~km} \mathrm{~s}^{-1}$ may be justified: this $25 \%$ increase in sediment thickness creates a $5 \%$ higher correction for measurements on the Var levee.

Heat flow sensitivity to the post-Miocene sedimentation rates is much higher than for the Miocene deposition, especially on the Var Fan where the Pleistocene rates are higher than elsewhere in the basin. A Pliocene unit of about $200 \mathrm{~m}$ thickness is defined throughout the Ligurian Basin (Chapter 2), and generally leads to slightly higher sedimentation rates for the Pleistocene ("Var Unit"), consistent with a 2 Myr origin for the Var Fan. A uniform P1io-Quaternary sedimentation rate produces a correction which is $5 \%$ less than the two-stage history. If the base of the Var Unit is assumed to be 1 Myr old instead of 2 Myr, a 5\% higher correction results. Away from the Var levee proximal region, the uncertainty in sedimentation rates becomes smaller due to the similar thicknesses of the upper and lower Plio-Quaternary sections.

Processes of lithospheric thinning and subsequent passive cooling are estab1ished in the Western Mediterranean by both heat flow and subsidence data (Appendix 1; Ryan, 1976; Hutchison et a1., 1985). Therefore, the bottom heat flow boundary condition in the thermal model is taken to be a constant temperature condition of $1333^{\circ} \mathrm{C}$ similar to accepted asthenospheric estimates (Parsons and Sclater, 1977). The initial conditions are set to the thermal structure of a cooling half-space of a particular thermal age using the boundary layer model of Parsons and Sclater (1977) and Lister (1977). 
A $10 \%$ smaller heat flow correction results when a 1 Myr old 1ithospheric plate as opposed to a very old plate (> 100 Myr old) or "equilibrium" plate with constant heat flow at the base is used to define the initial temperature structure. To decrease bias due to the initia1 therma1 conditions, the McKenzie (1978) uniform extension mode1 is incorporated in the initial conditions by assigning older initial thermal ages for the upper margins and younger thermal ages for the central basin. We find that the thermal age is a good approximation for the thermal conditions of 1 ithosphere stretched by an amount $\beta$ according to the empiricism

$$
t_{0}=143 B^{-2}
$$

where $t_{0}$ is the thermal plate age in Myr. Using the initial temperature structure given by the plate model at time $t_{0}$ (Equation 4.22), the heat flow of the McKenzie (1978) model is predicted to within $2 \%$ for post-rift times of 15 to 25 Myr ago and $\beta$ values of 2 to 10 .

The value of $\beta$ for each region, where $30 / \beta$ to $35 / \beta \mathrm{km}$ is the thickness of the attenuated crust, is estimated by using the following lines of evidence which are developed in greater detail in Chapter 4: 1) direct seismic observations of the Moho depth, 2) total tectonic subsidence calculations, and 3 ) by assuming the crusta1 thinning rate is approximately linear with position across the margin (Le Douaran et a1., 1984). Resulting initial thermal ages for the upper margins, lower margins, and central basin are 35, 9, and 4 Myr, respectively, and correspond to the crustal thickness estimates of Table 4.2. Using variable initial conditions to model general trends in 1 ithospheric 


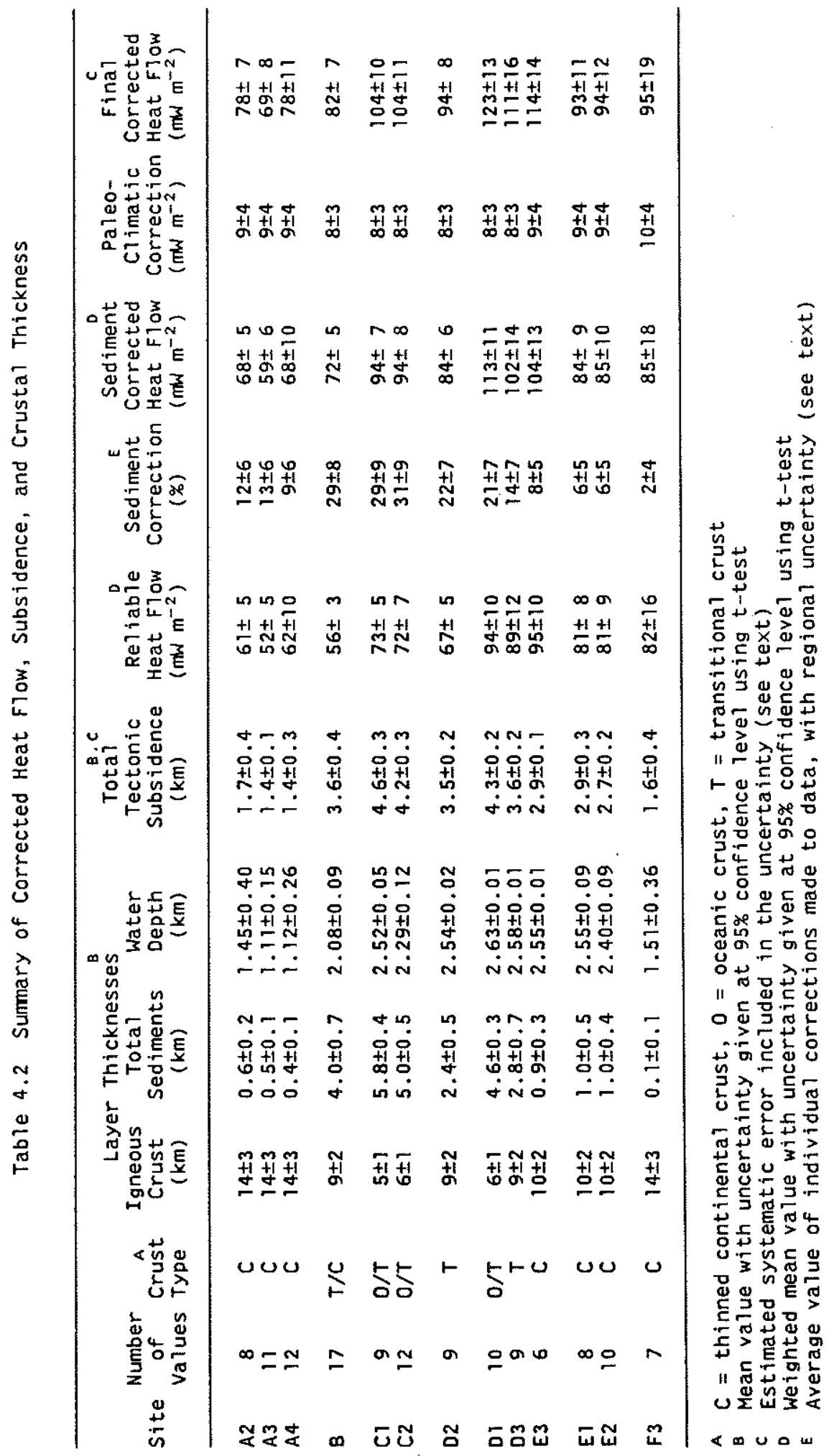


thinning reduces the fractional uncertainty in the heat flow value from $\sim 10 \%$ to $<2 \%$.

The above scheme leads to internally consistent sediment corrections for the margins and central basin of the Ligurian Basin. Heat flow results for the Western Mediterranean are checked by comparing corrections for nearby surface and borehole measurements subjected to different sedimentation rate histories. Downhole temperature measurements at DSDP site 372 (Erickson and Von Herzen, 1978) and a subsequent suite of pogo heat flow stations (site D1; Hutchison et al., 1985) are both located on the Menorca Rise. Situated on the western Balearic Sea margin, the Menorca Rise occupies a transitional geologic setting similar to that of the north Corsica Basin margin. Site 372 has a heat flow of $103 \pm 6 \mathrm{~mW} \mathrm{~m}^{-2}$, about $10 \%$ higher than the mean value of $92 \pm 10 \mathrm{~mW} \mathrm{~m}^{-2}$ at site D1 of Hutchison et al. A1though the two heat flow sites are within $10 \mathrm{~km}$, Site 372 occupies a thinner sediment section than site $\mathrm{D} 1$, so that a smaller sedimentation correction results (Figure 4.13). Also, erosion at DSDP site 372 is documented by stratigraphic studies of the core samples (Cita et al., 1978), whereas salt deposition is maintained during the Messinian at site D1. With reasonable burial rate reconstructions for infrasalt series at site D1 (Hutchison et al., 1985), a better match in the equilibrium heat flow estimate is made. The difference in sediment-corrected heat flow between the two sites is reduced by more than half of the observed difference, with 109 and $113 \mathrm{~mW} \mathrm{~m} \mathrm{~m}^{-2}$ being the mean values for sites D1 and 372 , respectively. 
Menorca Rise Comparison
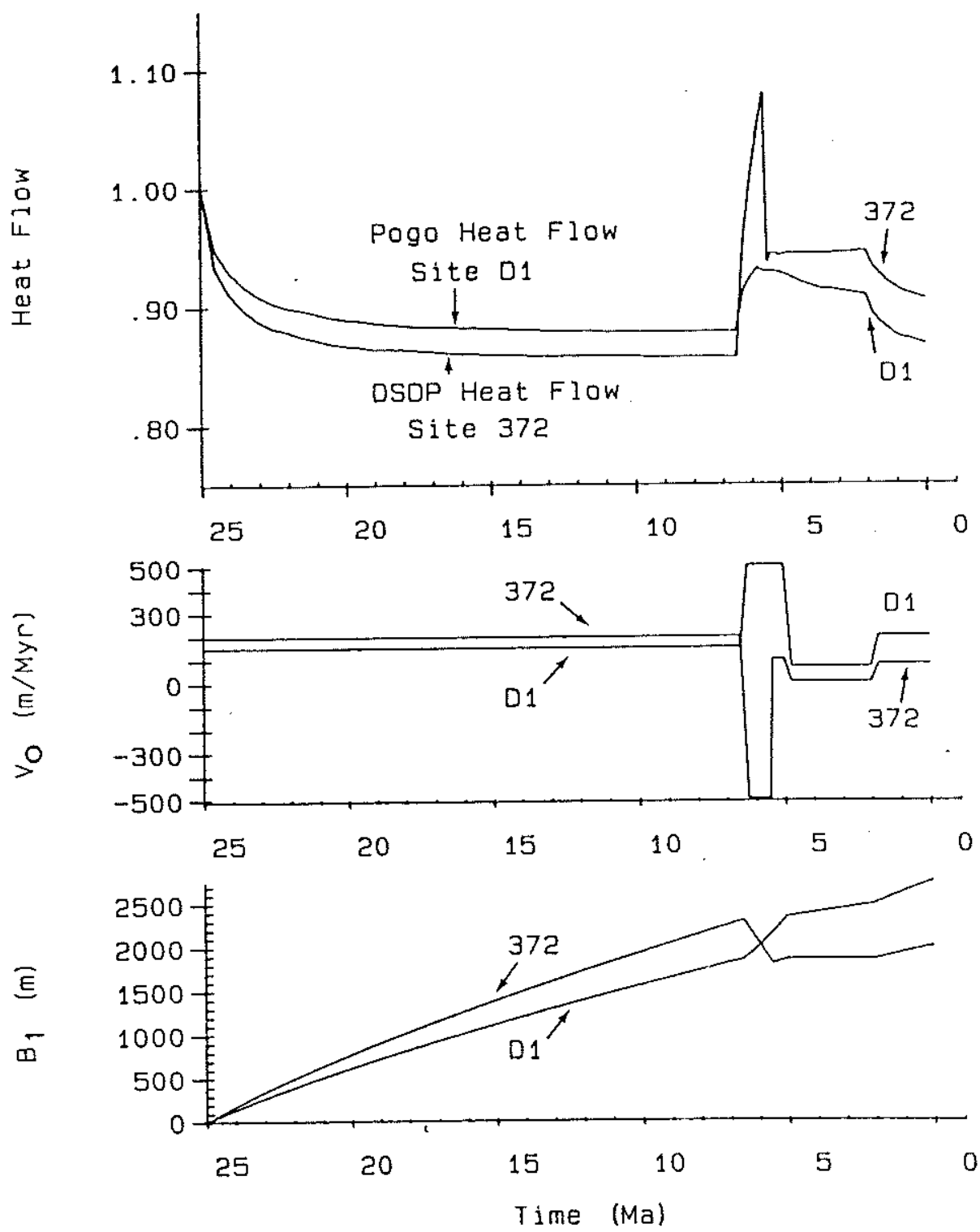

Fig. 4.13 Heat flow alteration and sedimentary evolution of two nearby sites on the Menorca Rise, western Balearic Basin. Sedimentation model $\mathrm{B}$ is assumed (Table 4.1) and an initial thermal age of 9 Myr is used with a basal temperature condition. The discrepancy in the final heat flow alteration almost compensates for the difference in the observed mean flow at each site (Erickson and Von Herzen, 1978; Hutchison et a1., 1985). 
Sedimentation correction results. The following assumptions are made in the final sediment corrections assigned in Table A4.4: 1) One-dimensional 1ithospheric cooling has been active since 21 Myr ago with an initially cooler thermal structure in the central basin than on the margins. 2) Early Miocene sedimentation began everywhere at 21 Myr ago. 3) The terrigenous sediments have compacted according to Athy's law with mode1 B properties for the nonevaporitic sediment, i.e., no overpressuring is present in the infrasalt series and diapirism has not caused hydrothermal circulation. 4) Erosion of $500 \mathrm{~m}$ of Miocene sediment occurred on the margins (regions A, E, and F). 5) The P1iocene is a period with lower average sedimentation rates $\left(\sim 100 \mathrm{~m} \mathrm{Myr}^{-1}\right)$ compared to the Pleistocene ( $300 \mathrm{~m} \mathrm{Myr}^{-1}$ ).

The group averages of the individual corrections range from about $30 \%$ for sites $\mathrm{B}, \mathrm{C} 1$, and $\mathrm{C} 2$ to $2 \%$ for region $\mathrm{F}$ on the Corsican upper margin (Table 4.2). The fact that the corrections are made individua11y (Table A4.4) does not particularly improve the data consistency, with the standard deviation for some sites slightly increasing after the corrections. This implies that only in rare instances will steady sedimentation account for local variability. Errors in the compaction and thermal properties of the sediment (i.e., application of sediment model $\mathrm{A}$ or $\mathrm{C}$ ) are estimated at $5 \%$ for region $\mathrm{C}$ and decreases to zero for region $F$. In addition to these physical property uncertainties, an uncertainty of at least $4 \%$ results from assumptions in the initial temperature structure and sedimentation rate histories. Thus, the mean sediment correction for the thickly-sedimented north central basin (region C) may range between $22 \%$ 
and $40 \%$ due to systematic uncertainties. Other sites have appropriately smaller correction uncertainties, except perhaps site D1 which is inundated by Ligurian-type salt structures (cf. Chapter 2). These salt intrusions may introduce extra heat due to the upward advection of hot salt and water circulation associated with the fracturing of the overburden.

\subsection{Corrections for paleoclimatic temperature variations}

Inference of late Pleistocene bottom water temperatures. In the Mediterranean Sea, the process of wintertime deep water formation is sensitive to climate and water budget, which in turn controls the hydrography. Thus, sea leve1 and climate changes may seriously alter the circulation and deep water temperature history (Bethoux, 1984). A1though a continuous paleotemperature record for the Mediterranean has not been established, there are several lines of evidence which indicate that late Pleistocene bottom waters were an average of 3 to $5^{\circ} \mathrm{C}$ colder than today.

First, western Mediterranean Sea deep water temperatures may be inferred from glacial winter sea surface temperature estimates for the last glacial maximum (18 $\mathrm{kyr}$ ) based on planktonic foraminifera assemb1ages (Thiede, 1978; CLIMAP, 1981; Loubere, 1982). Presently, the $\sim 13{ }^{\circ} \mathrm{C}$ deep water originates from the winter surface water of the northwest Mediterranean Sea. If the process of glacial deep water formation was similar to today's, then glacial bottom and wintertime surface water temperatures were the same. Faunal data from 18 kyr suggests that there was a maximum 6 to $7{ }^{\circ} \mathrm{C}$ decrease in the winter 
surface water temperature during the last glacial period (Thiede, 1978; Loubere, 1982). Tyrrhenian Sea planktonic assemblages from the late Pleistocene (0 to 1 Myr ago) also indicate that wintertime temperatures were 6 to $8^{\circ} \mathrm{C}$ less during glacial episodes (Thune11, 1979). However, because these assemblages lack an exact modern analog (Thiede, 1978; Thune11, 1979; Loubere, 1982), it is difficult to assign an estimate of error to the inferred bottom water temperature change.

Second, glacial maxima and minima are reflected in the oxygen isotopic composition $\delta^{18} 0$ record of the foraminiferal tests, i.e., glacials have heavier or more positive $\delta^{18} 0$ values than interglacials. The Mediterranean P1io-Quaternary $\delta^{18} 0$ record can be correlated with that of the major oceans but has a $1 \%$ enrichment in $\delta^{18} 0$ for Globigerinoides ruber in the western Mediterranean (Vergnaud-Grazzini, 1985; Thune11 and Williams, 1983). The change in $\delta^{18} 0$ values during glacial periods is a function of 1 ) seawater oxygen isotopic composition $\left(\delta^{18} 0_{\mathrm{W}}\right)$ which changes primarily due to continental ice formation, and 2) temperature at which the calcium carbonate formed (e.g., Shackleton and Opdyke, 1973). Thus, accounting for the $\delta^{18} \mathrm{O}_{W}$ variations, paleotemperatures may be derived from the $\delta{ }^{18} 0$ record. Salinity and the evaporation/precipitation conditions have a unique signature in the Mediterranean Sea, which further affects the $\delta^{18} 0_{W}$, and so the paleotemperature estimate from the $\delta^{18} 0$ value. For instance, a 1 to $2 \% 0 \delta^{18} 0$ depletion is detected in the planktonic foraminifera found in the eastern Mediterranean saprope1 formations; this isotopic signal is linked to an increase in isotopica11y-1ight fresh water run-off 
maintained in the surface waters (Vergnaud-Grazzini et a1., 1986). From the oxygen isotope values of the last glacial maximum Vergnaud-Grazzini et a1. (1986) suggest that there was a $4{ }^{\circ} \mathrm{C}$ temperature difference for the eastern Mediterranean bottom water. Additionally, Zahn et al. (1987) estimate that up to a $5{ }^{\circ} \mathrm{C}$ decrease occurred in the Mediterranean outflow at the Strait of Gibraltar. No paleotemperature estimate is formally made for the western Mediterranean deep water.

Third, paleotemperatures are inferred from amino acid racemization data (Miller et a1., 1986). This innovative technique essentia11y measures the average in situ paleotemperature of sediment core samples. Conservative estimates of the eastern Mediterranean paleobottom water temperatures relative to the $0-18 \mathrm{kyr}$ average is $-2{ }^{\circ} \mathrm{C}$ for $18-82 \mathrm{kyr}$, and $+0.5{ }^{\circ} \mathrm{C}$ for $82-135 \mathrm{kyr}$ (Miller et a1., 1986). Since the CLIMAP (1981) studies indicate a larger temperature change in the western than for the eastern Mediterranean, these values probably represent minimum values of the late Pleistocene bottom water variation in the western Mediterranean.

From these observations, a generalized temperature history is constructed for the western Mediterranean (Table 4.3). The 0-18 kyr temperatures are taken from a paleoclimatological study near the Strait of Gibraltar (Poutiers and Faugeres, 1987; Poutiers, 1987) in which the bottom water is inferred as being $5{ }^{\circ} \mathrm{C}$ lower at the last glacial maximum $(18 \mathrm{kyr})$. The paleotemperatures include a gradual warming from $18 \mathrm{kyr}$ to $12 \mathrm{kyr}$, and a sma11 cooling event (Younger Dryas event) at $10 \mathrm{kyr}$ (Vergnaud-Grazzini et al., 1986). The Holocene bottom temperatures are relatively stable as indicated by the isotopic record. However, the 
Table 4.3 Bottom Water Paleotemperature Estimates

\begin{tabular}{rr}
$\begin{array}{c}\text { Time Interval } \\
\text { (kyr B.P.) }\end{array}$ & $\begin{array}{c}\text { Deviation of Temperature } \\
\left({ }^{\circ} \mathrm{C} \text { relative to present) }\right.\end{array}$ \\
\hline $0-8$ & 0.0 \\
$8-10$ & -2.5 \\
$10-12$ & -4.0 \\
$12-15$ & -3.5 \\
$15-21$ & -4.5 \\
$21-82$ & -4.0 \\
$82-135$ & -1.5 \\
$135-700$ & -3.0 \\
$700-\infty$ & 0.0 \\
\hline
\end{tabular}


apparent Holocene isotopic stability may be an artifact of isotopic changes due to ice volume and temperature effects offsetting each other (L. Keigwin, personal communication, 1987). The average temperature in the glacial period between 21 to $82 \mathrm{kyr}$ and the last interglacial period of 82 to $135 \mathrm{kyr}$ are derived from the racemization study of Miller et a1. (1986). Late Pleistocene (0 - $900 \mathrm{kyr})$ temperatures probably reflect the similar temperature variations of the recent $100 \mathrm{kyr}$ glacial-interglacial cycle (Hays et a1., 1976). For geothermal purposes, an average paleotemperature is sufficient to model the period between $135 \mathrm{kyr}$ and $700 \mathrm{kyr}$ ago. According to a Tyrrhenian Basin $\delta^{18} 0$ record extending to the early Pleistocene, the glacial intensity has waned and the average $\delta^{18} 0$ values are similar to the present (Thune11 and Williams, 1983).

The bottom water paleotemperature mode1 (Tab1e 4.3) has a late Pleistocene (prior to $10 \mathrm{kyr}$ ) average of $-3{ }^{\circ} \mathrm{C}$ below present. This estimate is consistent with the average late Pleistocene values of $1.7^{\circ} \%$ o for $\mathrm{G}$. ruber (Thune11 and Williams, 1983), the recent value of $0.46 \%$ (Vergnaud-Grazzini et a1., 1986), and the assumption that the temperature effect contributes almost half of the isotopic shift in the western Mediterranean (e.g., Keigwin and Thune11, 1979). The $18 \mathrm{kyr}$ paleotemperature is accepted with a rather large $\pm 2{ }^{\circ} \mathrm{C}$ uncertainty in both the sea surface fauna and $\delta^{18} 0$ estimates. We are encouraged that a number of studies which use three different methods concur on the general amplitude of the temperature shifts. Paleoclimatic model results. Paleoclimatic corrections to Mediterranean basin heat flow data were first applied by Ryan et al. 
(1970). Since that time, the glacial effect in the Mediterranean has largely been ignored, or judged too dubious to use in new heat flow interpretations. The evidence summarized above for a simplistic thermal history record (Table 4.3) strongly suggests glacial corrections should be universally applied to Mediterranean Basin geotherma1 data.

The analytical theory for the gradient anomaly due to surface temperature variations is given by Equation 4.3. The Ligurian Basin requires examination of composite media in order to reduce uncertainties of $\pm 3 \mathrm{~mW} \mathrm{~m}^{-2}$ which result from assuming that the basin is a half-space composed of either homogeneous sediment or basement material. The finite difference model of Hutchison (1985) is easily configured to account for surface temperature changes, with a numerica1 time step of $100 \mathrm{yr}$ required to achieve an accuracy of $<2 \%$ for the paleotemperature model results. The calculated surface heat flow anomaly during the last $25 \mathrm{kyr}$ is shown in Figure 4.14. The sudden rise in temperature at $8 \mathrm{kyr}$, being the most recent change, accounts for the majority of the anomaly. The temperature history prior to $135 \mathrm{kyr}$ creates about $15 \%$ of the gradient anomaly assuming that temperatures similar to today were maintained prior to about $700 \mathrm{kyr}$.

The paleotemperature correction for each site is compiled in Table 4.2. The continental slope sites have a slightly higher correction because of the closer proximity of the high conductivity basement. The errors are assigned as $40 \%$ of the correction; this assumes that the shape of the trend is correct but that the peak amplitude at the last glacial maximum is in error by at most $\pm 2{ }^{\circ} \mathrm{C}$. 
$-181-$

W. Mediterranean Paleoclimatic Effect

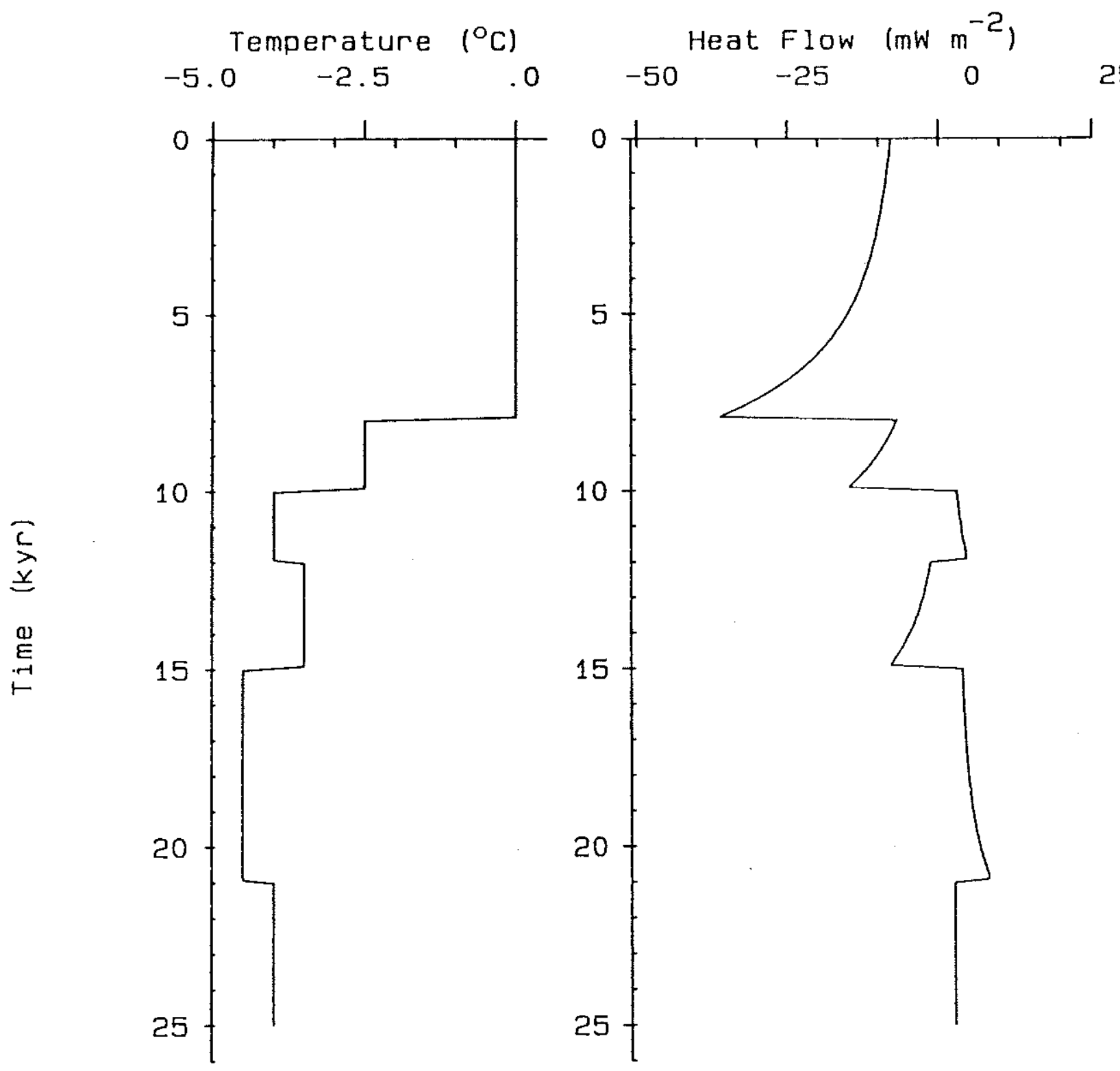

Fig. 4.14 Anomalous heat flow resulting from variations in the late Quaternary bottom water temperatures. 0 to 25 B.P. bottom water paleotemperatures are relative to present (See Table 4.3 for complete history). 


\subsection{Corrected heat flow results}

Mean values of the corrected heat flow are presented in Table 4.2; only the reliable heat flow stations are considered. The site means are calculated by averaging the individually corrected heat flows given in Table A4.4 (weighted with respect to the fractional measurement error) and adding the paleoclimatic correction according to the formula

$$
Q_{\text {cor }}=C_{\text {sed }}\left(Q_{0 b s}+Q_{c 1 i m}\right)
$$

where $Q_{c o r}$ is the mean corrected flow, $C_{s e d}$ is the sediment correction factor, $Q_{o b s}$ is the mean observed heat $f 10 w$, and $Q_{c 1 \text { im }}$ is the paleoclimatic correction. These corrected heat flow data are used to construct a heat flow contour map for the Ligurian Basin (Figure 4.15). Contour placement is determined on a fit-by-eye basis using the site mean and centroid locations and also individual values. In this manner, smooth trends are readily apparent.

The uncertainties are considered to be a combination of random errors given by the variability of the observed data and systematic errors due to the corrections. Systematic errors have not been treated with mathematical rigor, but the root sum squares of the random and systematic errors give reasonable estimates of the final uncertainties (Taylor, 1982). In this manner, the site errors $\delta_{\mathbf{s}_{1} \mathrm{te}}$ are calculated as

$$
\delta Q_{\text {site }}=\left\{\delta Q_{\text {cor }}^{2}+\left(\delta C_{\text {sed }} \bullet Q_{o b s}\right)^{2}+\delta Q_{c 11 m}^{2}\right\}^{1 / 2}
$$

where $\delta Q_{\text {cor }}$ is the $95 \%$ confidence limits for the mean of the individual corrected values, and $\delta C_{s e d}$ and $\delta Q_{c 11 m}$ are the group estimates for the systematic uncertainty in the sediment correction factor and the paleoclimatic correction, respectively. 


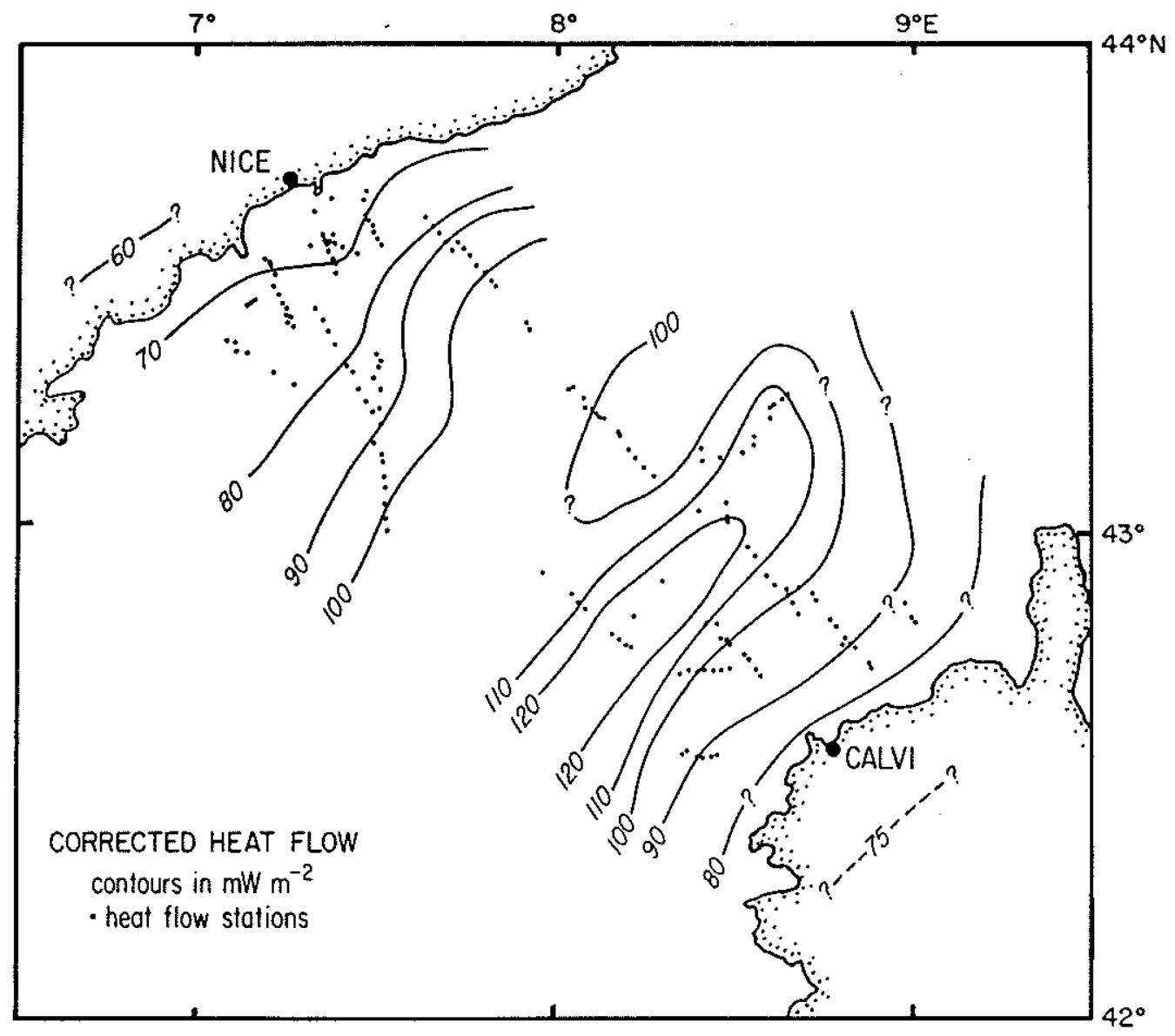

Fig. 4.15 Contour map of the final corrected heat flow in the Ligurian Basin. Continental values are from Lucazeau and Mailhe (1986). Heat flow in $\mathrm{mW}^{-2}$. 
If the total error of the site corrected means is $\sim 10 \%$, then our data presumably has important constraints on lithospheric thermal models of marginal basin evolution (e.g., McKenzie, 1978; Royden and Keen, 1980). A1though we acknowledge that the systematic errors are somewhat arbitrary, most of our sites have reasonably small final uncertainties of $\pm 9-12 \%$. Thus, our results seem significant in terms of testing basin evolution models. In comparison to detailed geothermal studies on mid-plate swells, the mean heat flow of sites on the Bermuda Rise is measured to $\sim 2-6 \%$ at the $95 \%$ confidence level (e.g., Detrick et a1., 1986). Environmental corrections may make the tota1 uncertainty a few percent higher so that, using the pogo-probe technique, the geothermal resolution of well-sedimented marginal basins is on $1 \mathrm{y} \sim 5 \%$ higher than that of "ideal" mid-plate oceanic environments. This encouraging result is achieved by our ability to measure heat flow with fairly good reproducibility, despite complications due to bathyal fan construction and salt diapirism.

The most significant difference in the heat flow data between mid-plate regions and marginal basins is the higher magnitude and variability of the thermal conductivity in smal1-basin seafloor sediments $\left(\sim 1.0-1.4 \mathrm{~W} \mathrm{~m}^{-1} \mathrm{~K}^{-1}\right)$ compared to the dominantly pelagic sediments of most mid-plate regions $\left(\sim 0.7-0.9 \mathrm{~W} \mathrm{~m}^{-1} \mathrm{~K}^{-1}\right.$; e.g., Langseth and Von Herzen, 1971). In fact, due to the lower thermal conductivity values and smal1 sedimentation effect, the measured thermal gradients are actually higher $\left(60-80 \mathrm{mK} \mathrm{m}^{-1}\right)$ on the Hawaiian Swe11 region (Von Herzen et al., 1982) than in regions $B$ and $C$ in the northern Ligurian Basin $\left(45-60 \mathrm{mK} \mathrm{m}{ }^{-1}\right.$; Table 3.1$)$. In this manner, the 
constraints given by in situ thermal conductivity values and surface sediment distribution studies, in addition to the accurate sedimentation and paleoclimatic corrective models, are invaluable to the fairly high-resolution results we have obtained.

Despite the substantially higher sedimentation corrections in the northwestern half of the basin, there remains a significant asymmetry in equilibrium heat flow estimates, with the environment-corrected values increasing by over $50 \%$ from the northern margin to the southern central basin (Figure 4.15). A heat flow minimum of $\sim 75 \mathrm{~mW} \mathrm{~m}^{-2}$ is located beneath the Cote d'Azur margin, whereas the northern Corsican margin has a heat flow of $\sim 95 \mathrm{~mW} \mathrm{~m} \mathrm{~m}^{-2}$. Within the centra1 basin, the average heat flow is $\sim 105 \mathrm{~mW} \mathrm{\textrm {m } ^ { - 2 }}$ with a linear heat flow maximum of $\sim 125 \mathrm{~mW} \mathrm{~m}^{-2}$ found in the south centra1 basin. One exception to the relatively smooth basin-wide trend is site D2 which shows relatively low corrected heat flow of $\sim 95 \mathrm{~mW} \mathrm{~m}^{-2}$ in the middle of the centra1 basin. This region may be affected by the proximal setting of the Var main channe1. However, the overa11 heat flow pattern in the centra1 basin correlates extremely well with the basement topography given by the isochron map of Rehault et a1. (1984). Two structural troughs oriented $\mathrm{N} 40 \mathrm{E}$ are clearly defined by sediment-unloaded basement depth map (cf. Chapter 5). The basement high which separates these two troughs has been interpreted as a volcanic feature or paleo-ridge (Le Douaran et a1., 1984; Burrus, 1984; Rehault et a1., 1984), yet it is associated with the lowest heat flow in the central basin.

As suggested by uniform extension mode1 (McKenzie, 1978), the heat flow and subsidence trends are related. Except for site A3, there is 
generally good repeatability in values between sites which are located on NE-SW 1ines paralle1 to the basin axis. The heat flow decreases by about $20 \%$ going from the oceanic central basin onto the continental margins, a trend consistent with less-attenuated lithosphere beneath the margins. However, the heat flow of the lower and upper margins appear to be roughly equal which suggests that uniform extension may not be applicable without some modifications to account for second-order effects of thinning in the mantle lithosphere.

Heat flow decreases by about $20 \%$ going from the margin onto the adjacent continent so that the heat flow asymmetry is maintained on the continental borderlands as well (Figure 4.15). The continental heat flow measurements by Lucazeau and Mailhe (1986) and Lesquer et a1. (1983) are not corrected for paleoclimatic, erosion and hydrogeological perturbations. It is possible that these factors may combine or act individually to alter the heat flow by as much $10 \mathrm{~mW} \mathrm{~m}^{-2}$ (e.g., England, 1977), but it is doubtful that they account for the discrepancy between two borders. Heat flow of $58 \mathrm{~mW} \mathrm{~m}^{-2}$ on the Maures-Estere1 region is taken to indicative of the reference thermal state of Hercynian-age crust; Corsican heat flow is $30 \%$ higher at $76 \mathrm{~mW} \mathrm{~m}^{-2}$ and is thought to result from Western Mediterranean tectonics. Using similar radioactive heat distribution models, the higher Corsican heat flow probably results from a thinner lithosphere beneath Corsica than the Provencal region in Southern France. Lucazeau and Mailhe (1986) state that high mantle heat flow beneath Corsica is consistent with $\sim 30 \mathrm{~km}$ normally thick crust (Hirn and Sapin, 1976) having elevations in excess of $3000 \mathrm{~m}$ in northern Corsica. Thus, any tectonic model for 
the evolution of the Ligurian Basin must account for this asymmetric trend. The relationships between heat flow, tectonic subsidence, crustal thinning, and age of rifting is investigated further in the next chapter. 


$$
-188-
$$


$-189-$

Chapter 5

Structura1 and Thermal Evolution 
A simple structural and thermal evolution is derived using observations of asymmetric distributions of corrected heat flow, subsidence, and crustal thickness. The tectonic subsidence is calculated from deep refraction and reflection profiles using local isostatic sediment-unloading schemes. Although crustal thinning is predominantly a result of an extensional mechanism, we qualify the extension estimate on the basis of possible magmatic additions to the crust. Some chronological constraints on the basin opening are given by volcanic and stratigraphic data. We develop thermal age estimates for the central basin which are consistent with the observed asymmetric structural trends and geologic ages, but which conflict with previous interpretations of the 1oca1 magnetic anomaly pattern and basement structure. Due to the thick sediment cover in the central basin, heat flow is better resolved than the tectonic subsidence, so that heat flow is actually a better relative age estimator within the central basin. We suggest that two models satisfy the observations: a temporal mode1 based on a rift jump from the northwestern to southeastern part of the basin, and a geometric model which emphasizes that rifting proceeded by asymmetric subcrustal lithospheric thinning and crustal detachment faulting. A significant trade-off between the time of rifting and the subcrusta1 1ithospheric thinning in the nonuniform extension mode1 allows for a spatiotemporal model which has the rift jump and crustal detachment schemes as end members of a series of possible rifting scenarios. 
The probable back arc setting for the Northwestern Mediterranean Basin is important to the subsidence history of the margin as we11 as the central basin. Anomalously large residual depths are inferred to result from zero-age crustal depths which $\sim 1 \mathrm{~km}$ deeper in back arc basins than on major ocean basins. A $\sim 125{ }^{\circ} \mathrm{C}$ decrease in the average upper mantle temperature beneath marginal basins explains the depth anomaly. Thin crust contributes little to the depth anomaly and changes in the $0{ }^{\circ} \mathrm{C}$ "reference" mantle density due to presumably higher degrees of mantle depletion actually causes a decrease in the total depth. From the fairly linear heat flow vs. (age $)^{-1 / 2}$ and depth vs. (age $)^{1 / 2}$ plots obtained for marginal basins, we speculate that the most significant geochemical change due to hydrous remelting in back arc basins is incurred in the thermal properties, not the reference density, of the bulk mantle rock.

\subsection{Basin structure}

Abundant geophysical surveys allow good estimation of the basement depth and crustal structure within the Ligurian Basin. We implement two sediment-unloading methods to calculate the tectonic subsidence, with discrepant results obtained for the thickly sedimented central basin. Two main troughs are indicated by the basement structure, both being parallel to the basin axis.

The deep seismic and heat flow data support the existence of an asymetric basin structure, but the gravity and magnetic data do not necessarily require a similar interpretation. One of the tenets of this study is that in the Ligurian Basin, contrary to most regions of the 
ocean floor, heat flow provides a significant and independent constraint on the basin evolution and deep structure. This opinion is maintained, despite the environmental considerations elaborated in Chapters 3 and 4, because the other geophysical observations are also degraded due to the complex geologic evolution of the Mediterranean region.

From data discussed below, we have assigned the average tectonic subsidence, crustal thickness and probable crustal type for each heat flow group in Table 4.2. The uncertainty in the mean crustal thickness includes the thickness range encompassed by each site.

Tectonic subsidence. In the subsidence analysis employed here, only the present total tectonic subsidence (TTS) is calculated (Sawyer, 1985). A subsidence history analysis (e.g., Steckler and Watts, 1978; Sclater and Christie, 1980; Royden and Keen, 1980), where basement depth through time is estimated by unloading sediment younger than a given age and decompacting the remaining sediment column, is not practical for the Ligurian Basin because the paleobathymetry is not known, except perhaps for Messinian time and for synrift 0ligocene sediments in the basal sediments of St. Tropez Canyon (Rehault et a1., 1984a, 1985; Bessis, 1986)

The main assumptions involved with using seismic stratigraphy as a too1 to study basin subsidence have been outlined by Celerier (1986). According to his analysis, the error in the TTS calculation is the culmination of uncertainties due to the following: 1) identification of the basement reflector, 2) mass calculation of the sediment column, and 3) implementation of an appropriate isostatic compensation model. 
Multichannel and deep refraction seismic data provide good basement depth information for most of the Ligurian Basin. The main profiles of the deep seismic data are shown in Figure A1.1. Good agreement exists between the basement isochron maps of Rehault (1981) and Rehault et al. (1985), and the expanding-spread refraction profiles (ESP) of Le Douaran et al. (1984). A small discrepancy exists in the interpretation of the ESP 229 velocity structure and nearby multichannel data. At this location beneath the Var Rise, Rehault (1981) suggests that the basement reflector is probably deeper than the one chosen by Le Douaran and others. An additional but minor problem with basement identification is our inability to discriminate the younger synrift sediment deposits from older allochthonous subalpine units.

Rehau1t (1981) has also mapped the thickness of the infrasalt and Messinian series in the Ligurian Basin. We have reinterpreted some of the Messinian pinchout locations in Chapter 2. In the central basin, the middle Miocene (Tortonian) to late Miocene (Messinian) transition is one of the more uncertain seismic stratigraphic boundaries due to complications by salt diapirism and uncertain velocity relationships for the Miocene section. Nevertheless, portions of the flat-1ying base of sa1t are often observed between diapiric structures in the central basin; where the salt is flat-1ying near the Rhone fan, the top of the infrasalt series can be traced to the central basin more confidently (Montadert et a1., 1978).

Given the data constraints and nonunique nature of the problem, we consider only an Airy isostatic model (1-D or loca1) in our subsidence calculations. Contrary to the sedimentation effect on surface heat 
flow, thermal coupling between the sediment layer and the basement does not affect the subsidence by more than a few tens of meters and can subsequent1y be ignored (Alvarez et a1., 1984). The Airy mode1 is simulated in a flexural (2-D) model simply by using a small elastic plate thickness, which is probably appropriate for a young basin with high heat flow (Watts et a1., 1982). Flexure will normally cause the 1-D approach to be especially biased on the margins where the crustal geometry and bathymetry change most rapidly (Watts and Ryan, 1976). However, in the deep basin where the sediment and crustal thicknesses are laterally uniform, the Airy and flexural results are nearly equivalent (Bessis, 1986).

Additional1y, the boundary fault system described in Chapter 2 serves to maintain decoupling between the continental slope and continental rise, i.e., marginal crust and basinal crust. Despite the abrupt change in the sediment load from the margin to the central basin, the decoupling may significantly decrease the overall flexural strength of the basin.

Listed in Table A4.4 are the TTS calculations for each reliable heat flow station. The sediment load was removed using two 1-D methods :

First, the linear relation of Crough (1983) is used in conjunction with the basement reflector estimate. This method simplifies the unloading since only the two-way travel time of the sediment $t_{\text {sed }}$ is required for the depth correction $d_{c o r}=600 \mathrm{~m} \mathrm{~s}^{-1} \cdot t_{s e d}$. The correction is added to the water depth to give the TTS parameter. The $600 \mathrm{~m} \mathrm{~s}^{-1}$ factor is empirically derived from borehole data in the 
Atlantic Basin and is estimated to have an accuracy of $\pm 10 \%$ (Crough, 1983). A slightly larger correction factor of $670 \mathrm{~m} \mathrm{~s}^{-1}$ is suggested by Crough (1983) for sediment thicknesses greater than $3 \mathrm{~s}$, a thickness which is approached only in the deepest regions of the Ligurian Basin. Second, average densities are calculated for each layer using the empirical relationship of Nafe and Drake (1963), using interval velocities used for the sediment thickness calculations (cf. Chapter 4), and are then backstripped similar to the method of Watts and Ryan (1976)

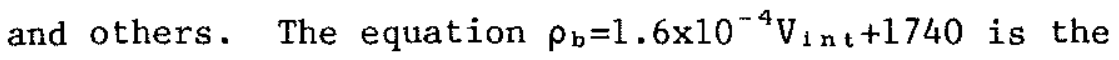
velocity-density relationship employed where $V_{I_{n}}$ is the interval velocity and $\rho_{b}$ is the average bulk density of the layer. The data are approximately linear for sediment velocities $>2000 \mathrm{~m} \mathrm{~s}^{-1}$. Density deviations from the best-fit curve average about $\pm 100 \mathrm{~kg} \mathrm{~m}^{-3}$ and are due mainly to small-scale mineralogical variability (Barton, 1986; Nafe and Drake, 1963). Western Mediterranean borehole data for the P1io-Quaternary sediment generally agree with the Nafe-Drake relationship (cf. Erickson, 1978).

The main difficulty with both sediment-unloading calculations lies with the anomalous density of the Messinian evaporites. Schreiber et a1. (1973) have measured density and velocity on DSDP evaporitic samples. Although sa1t and anhydrite have similar compressional velocities, their densities differ with the Nafe and Drake (1963) predictions. The actual density of anhydrite is about $100 \mathrm{~kg} \mathrm{~m}^{-3}$ too large and that of halite too small by $200-300 \mathrm{~kg} \mathrm{~m}^{-3}$ (Shreiber et a1., 1973). For the other terrigenous sections, an uncertainty of $\pm 100 \mathrm{~kg} \mathrm{~m}^{-3}$ in $\rho_{b}$ gives a depth correction with an accuracy of 
$\pm 10 \%$. Crough (1983) did not consider thick evaporite units in his correction scheme. Thus, depending on the ratio of anhydrite to halite, backstripping of the Messinian section may cause serious error in the depth correction. Assuming that the Messinian section is composed of low-density salt, both the Crough (1983) and Nafe and Drake (1963) depth corrections are biased to smaller values, making the TTS values minimun estimates.

TTS values for heat flow measurement locations (Table A4.4) show that for stations where $>4 \mathrm{~km}$ of sediments reside (sites $\mathrm{B}, \mathrm{C} 1, \mathrm{C} 2$, and D1), the two TTS determinations diverge by up to $400 \mathrm{~m}$, with the Crough correction giving the smaller corrected depths. This discrepancy is larger than the $\pm 10 \%$ error estimated for Crough (1983) depth correction scheme and may be attributed to the anomalous velocity-density relationship of the evaporites. Without additional seismic or deep borehole information, our best estimate of the TTS is taken as the mean of the two correction schemes.

The depth of compensation determines the density of the matter displaced by the buoyancy forces of the sediment load. A range of 3200 and $3300 \mathrm{~kg} \mathrm{~m}^{-3}$ estimates the effect of an asthenospheric and a subcrusta1 1ithosphere leve1 of compensation, respectively. Accordingly, the uncertainty due to the leve1 of compensation is $<5 \%$ of the depth correction which amounts to a $\pm 50-100 \mathrm{~m}$ uncertainty in the central basin TTS result.

In Table 4.2, the mean TTS for each heat flow group is given. Errors are determined as the root sum square of the random errors and systematic error. The random errors associated with combining the 
estimates at individual stations are obtained using the t-test at the 95\% confidence leve1. The systematic error is equal to half the difference between the high and low correction, plus an arbitrary factor equal to $10 \%$ of the actual depth correction. Steep topography on the margin sites causes the random component of error to exceed the systematic error, while for the thickly-sedimented sites in the central basin, the systematic error is larger. The absolute error in the mean TTS values is no more than $500 \mathrm{~m}$ for any of the groups.

A TTS map (Figure 5.1) of the Ligurian basin is derived from the basement isochron map of Rehau1t (1981) and the sediment-unloading method of Crough (1983). The main control for the basement reflector is given by multichannel seismic profiles (e.g., Finetti and Morelli, 1973; Mauffret et a1., 1973, 1982; Biju-Duval et a1., 1978), sha11ow refraction profiles (Recq et a1., 1979; Fahlquist and Hersey, 1969), and deep refraction surveys (Le Douaran et a1., 1984). The results for the deepest portions of the basin ( $>6.5 \mathrm{~s}$ two-way trave1 time) are considered a minimum estimate because the basement picks are conservative.

The plan view of Figure 5.1 illustrates the presence of two prominent linear troughs separated by a central basement ridge. The coincidence of the southeastern trough with the NE-SW trending heat flow maximum in Figure 4.15 is undeniable. Furthermore, the contour patterns of the TTS and corrected heat flow are fairly coherent. Correlation of 1ithospheric thinning imp1ied by heat flow (Appendix 1) with the basement subsidence suggests that, as a first approximation, a simple extensional model of basin formation is applicable to the Ligurian Basin. 


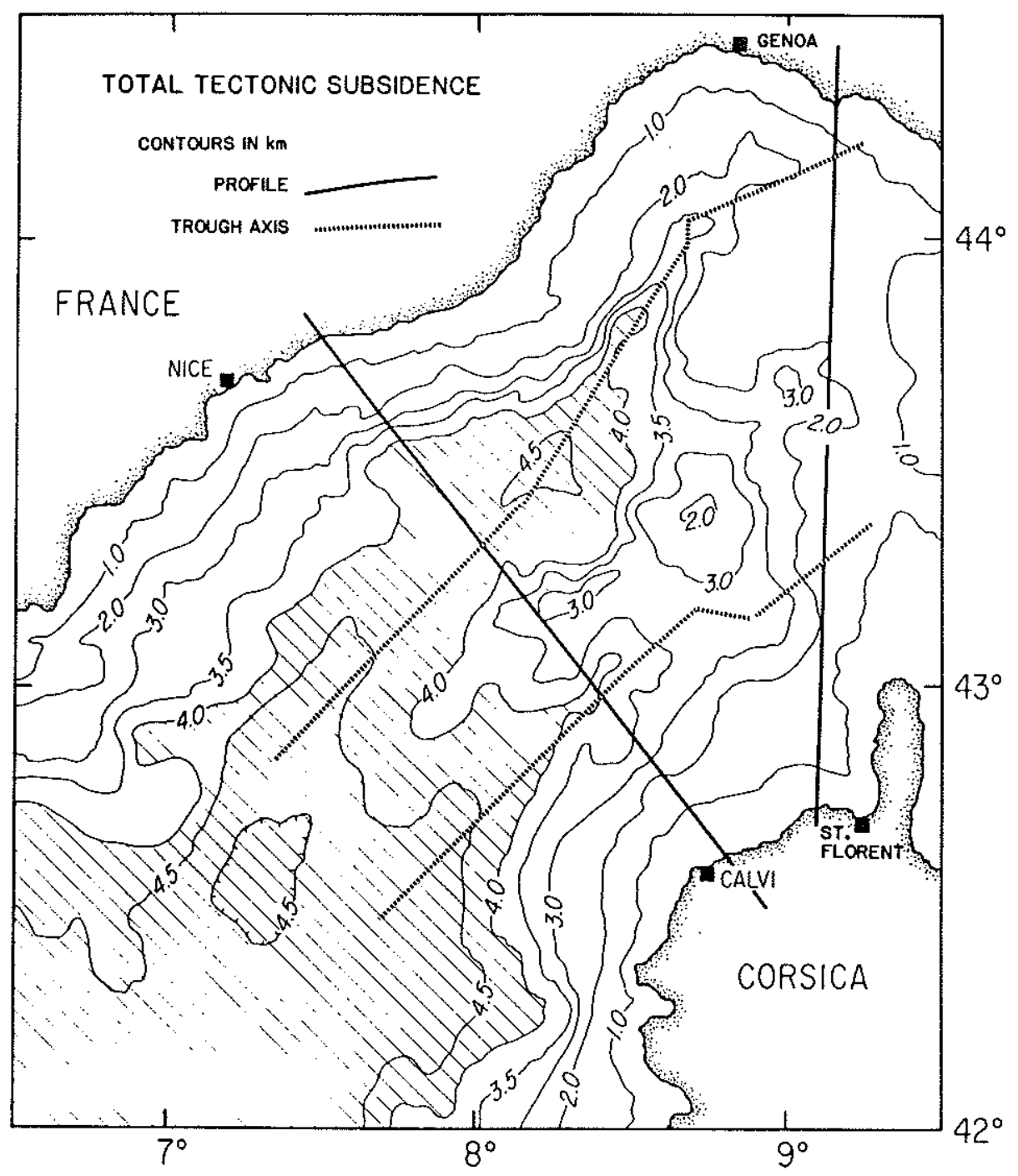

Fig. 5.1 Contour map of total tectonic subsidence calculated relative to sea level assuming local isostasy and the Crough (1983) sediment correction. The two main NE-SW trending basement troughs and cross-basin profiles are located. Using the Nafe and Drake (1963) velocity-density relationship predicts $400 \mathrm{~m}$ of additional subsidence in the the central basin (hachured region). 
Deep seismic data. The seismic velocity distribution indicates that thin crust lies beneath the central portions of the Northern Balearic (west of Corsica) and Southern Balearic (west of Sardinian) basins. From deep refraction experiments in the Northern Balearic (Fah1quist and Hersey, 1969; Nicolich, 1981; Le Douaran et a1., 1984), Moho depths of 13 to $16 \mathrm{~km}$ are found associated with 3 to $5 \mathrm{~km}$ thick crust. The crustal structure in the Nice-Calvi transect across the Ligurian Basin (Figure 5.2) is distinguished from the North Balearic Basin crust by its thicker two-1ayer arrangement (Le Douaran et a1., 1984).

Seismic data alone cannot discriminate the affinity of the central basin crust, ie., oceanic or attenuated continental crust. The quality of the ESP results of Le Douaran et a1. (1984) is degraded by the apparent loss of seismic energy due to diffraction of the deformed salt layer and the thick sediment layer above the crystalline basement. In marginal regions where sediments are thin, Whitmarsh et a1. (1986) and Duschenes et al. (1986) find evidence for attenuated crust ( $<7 \mathrm{~km}$ thick) which 1acks a lower crustal layer with a low velocity gradient (similar to oceanic seismic layer 3), so that they could define crust type on the basis of the detailed velocity structure constrained by the data. Since the Ligurian data is of poorer resolution, magnetic anomaly patterns and basement depth have also been used to delineate the oceanic domain (Le Douaran et a1., 1984; Burrus, 1984; Rehau1t et a1., 1984a).

The Genoa-St. Florent transect of Ginzburg et a1. (1986; Figure 5.2) shows a shoaling of the deeper refractors in the south central part of the profile. The central basement ridge apparent on the Nice-Calvi transect (Figure 5.2) and the TTS map (Figure 5.1) continues 


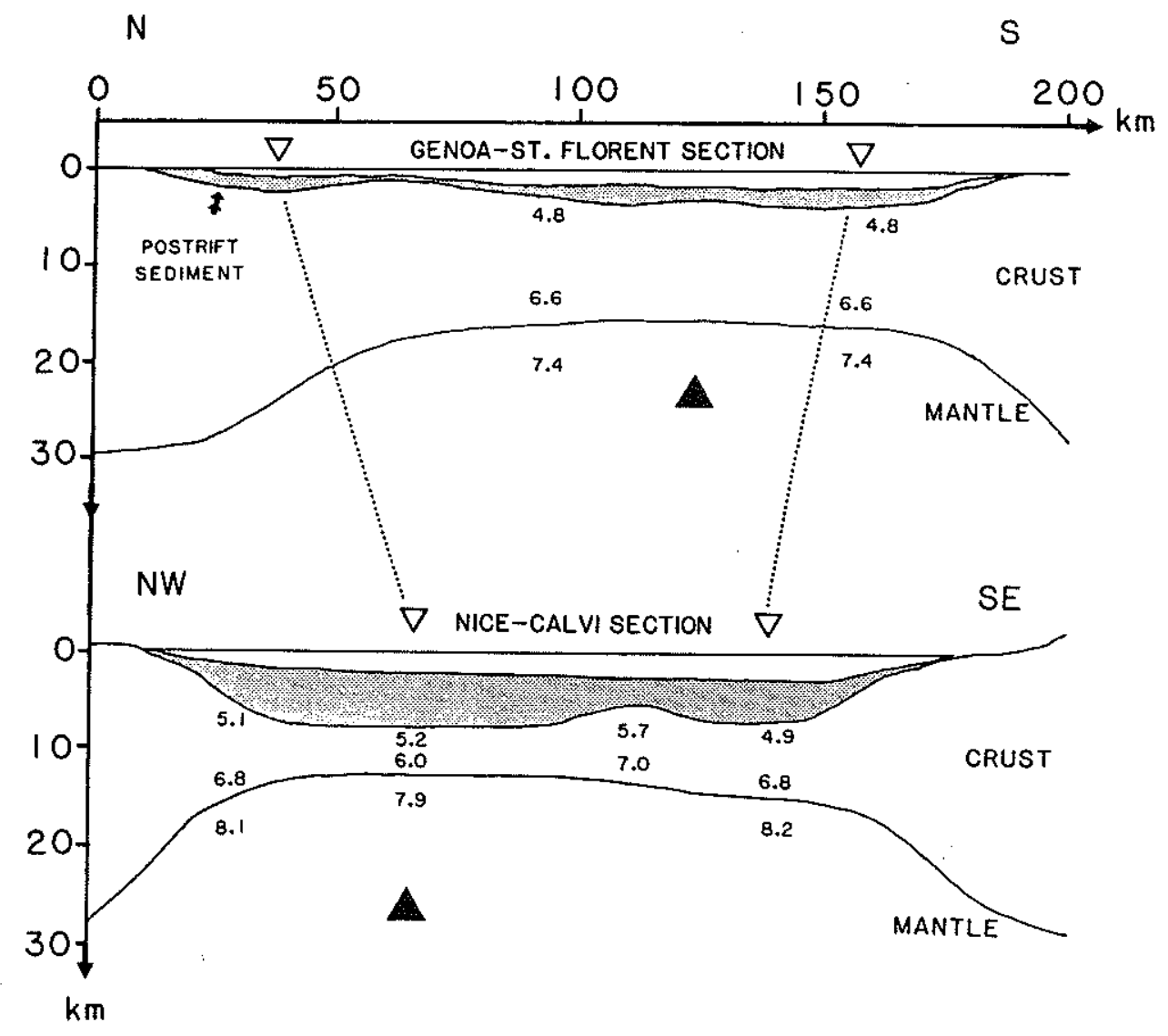

Fig. 5.2 Comparison of crustal sections extending approximately from Genoa to St. Florent and from Nice to 1986; Le Douaran et a1. 1984). Velocities (in (Ginzburg et al., for the crust and upper mantle. Velocities (in $\mathrm{km} \mathrm{s}^{-1}$ ) are shown crustal thickness and open trianglelid triangles indicate minimum indicate main basenent troughs. 
northeastward, dividing the Ligurian Basin into two $\mathrm{NE}-\mathrm{SW}$ trending sub-basins. These two basin transects also support an asymmetric Moho geometry across the basin and are consistent with the interpretation that there is an axis of maximum crustal attenuation in the south central basin, located about $40 \mathrm{~km}$ south of and parallel to an axis of extension and/or accretion confirmed in the north central basin. The southeastern trough has not been postulated before, but is substantiated by our TTS map and new data on the Moho structure.

Structure of the other Ligurian Sea margins is more difficult to quantify simply because of their narrow geometry and steeply dipping interfaces. Le Douaran et a1. (1984) estimate that an approximately linear relationship exists between crustal thickness and distance from the coast to the oceanic-continental crusta1 boundary.

Moho data from both the Corsica and the Cote d'Azur borderlands are available. A profile along the Cote d'Azur coastline shows crust composed of two $15 \mathrm{~km}$ thick layers (Thouvenot et al., 1985). The crust becomes much thicker inland toward the central Alps with large variations due to the presence of the main Alpine belt (Morelli et al., 1977; Giese et al., 1982), which implies that the borderland crust may have been attenuated during the Ligurian Basin opening. Corsica presents a much simpler case due to the generally homogeneous Hercynian massif. A $30 \mathrm{~km}$ crust beneath central Corsica thins to $25 \mathrm{~km}$ at the northeast coast (Hirn and Sapin, 1976; Egger et a1., 1985). Gravity modeling supports a bow1-shaped Moho structure beneath Corsica (Bayer et a1., 1976; More11i et a1., 1977). 
The heat flow and crustal thickness data allow for a detailed intrabasinal comparison between upper and lower 1ithospheric thinning. As with the basement subsidence, the heat flow correlates quite well with crustal geometry. Overa11 lithospheric thinning implied by the heat flow data (Appendix 1) is also supported by the results of surface wave studies. Berry and Knopoff (1967) and Panza et al. (1980) have evidence of low-velocity zones located at $40-60 \mathrm{~km}$ beneath the central western Mediterranean basin and $90-120 \mathrm{~km}$ beneath the continental borderlands.

Gravity anomalies. Free-air gravity anomalies across the centra1 Ligurian Basin are near zero, comparable to those of most ocean basins (Morelli et a1., 1975; Figure 5.3). However, -50 mgal anomalies found along the Provencal and northwestern Corsica continental slopes create a 100 mgal differential with the shelf gravity anomaly ( +50 mgal). A similar gravity inflection on the eastern U.S. continental slope has been modeled by abrupt crustal thinning beneath the continental slope (Grow et a1., 1979).

The characteristic gravity inflection is notably attenuated near the Cote d'Azur Margin (Figure 5.3). It is here where the uplift of the margin on the landward side of the boundary fault is we11-documented by raised marine terraces, stratigraphic levels, and Messinian coast-to-pinchout distances (cf. Chapter 2). We emphasize that the boundary fault is not due to sediment loading in the basin (cf. "marginal fault" of Turcotte et a1., 1977), and is opposite in sense to the reverse faulting postulated for the Cote d'Azur margin (Mauffret et a1., 1981; Rehault, 1981; Rehault and Bethoux, 1984). We speculate 


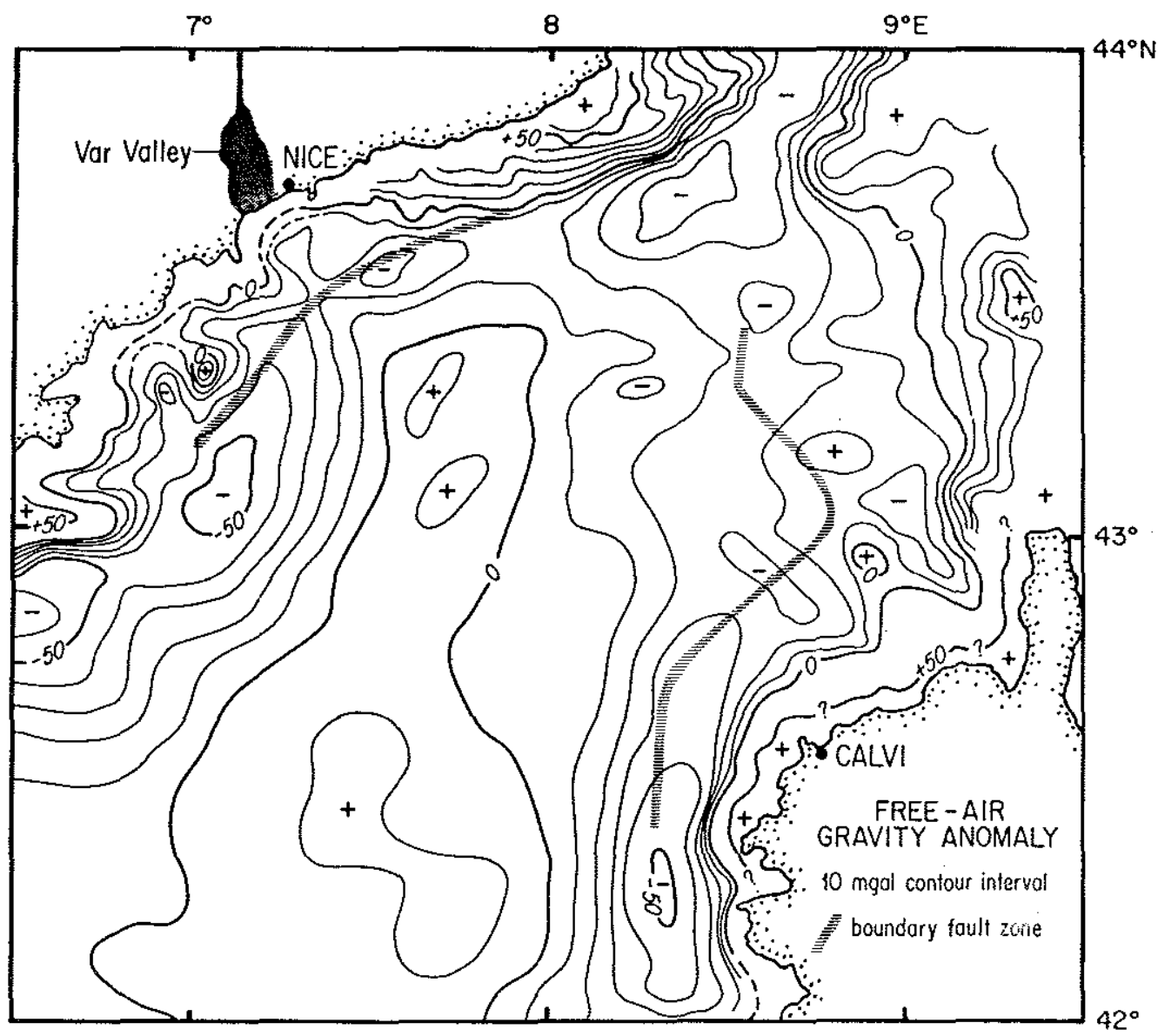

Fig. 5.3 Free air gravity contour map Erom More11i et a1. (1975). The boundary fault zone is indicated at the base-of-slope. 
that the margin gravity field is modified by the recent margin uplift. If the margin uplift is uncompensated, as implied by an erosional-rebound model for the Maritime Alps region, then the normal margin gravity signature may be reduced. Uplift may be localized to the region east of the Var Valley as indicated on Figure 5.3. This coincides with the highest elevated marine terraces on the Cote d'Azur coastline (Moullade, 1978).

Barton (1986) has noted the drawbacks in gravity modeling when a seismic velocity-bulk density relationship (e.g., Nafe and Drake, 1963) is assumed for sandstone or shale. In the sediment-unloading discussion, we have shown that evaporitic sections are especially difficult to characterize by linear velocity-density relationships. Although free-air gravity modeling of the deep structure in the Ligurian Basin is possible (Lucazeau et a1., 1986), the results are probably quite questionable due to the uncertain sediment density structure for the Miocene sediments. This lack of constraint especially applies to models derived from Bouguer anomalies.

Magnetic anomaly patterns. Magnetic anomaly data in the Western Mediterranean are quite complicated, with low amplitude anomalies in the central basin and sporadic high amplitude on the lower margins (Galdeano and Rossigno1, 1977; Figure 5.4). Areas of large positive anomalies, up to $+200 \mathrm{nT}$ amp1itude and 30 to $50 \mathrm{~km}$ in diameter, are located on the basin edges. These circular structures are most likely due to a 0.5 to $1 \mathrm{~km}$ thick basaltic layer (Vogt et al., 1971). Basalts drilled in the Valencia Trough were dated at 20 to 25 Ma which broadly corresponds with a magnetic age of anomaly 6 or earlier (Riviere et al., 1981; Ryan, Hsu 


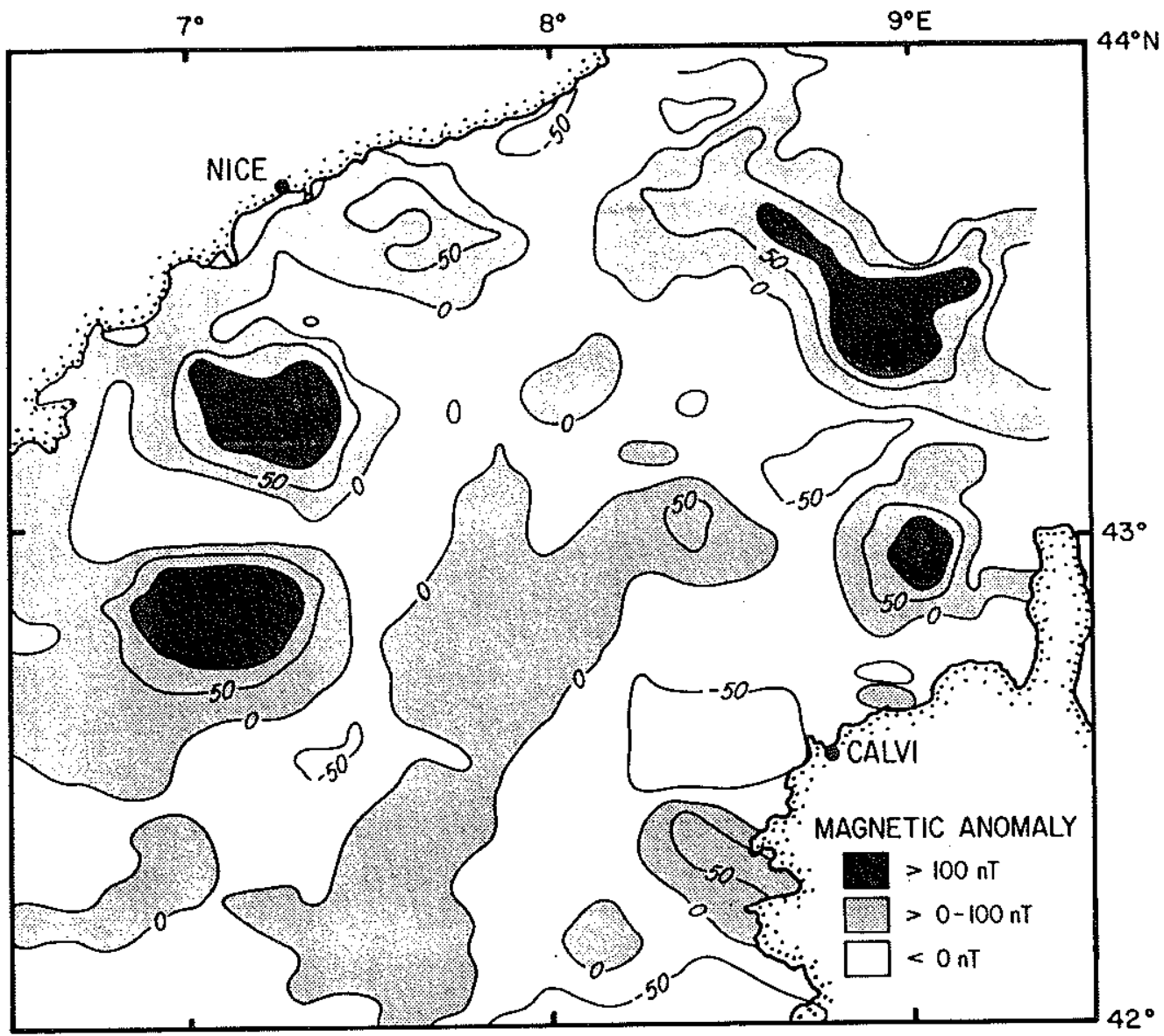

Fig. 5.4 Magnetic anomaly contour map from Galdeano and Rossignol (1977). Note the weak central anomaly and large positive anomalies near the margins. 
et a1., 1973). Burrus (1984) and Rehault (1981) propose that the oceanic crustal domain lies to the seaward direction of these large marginal anomalies where they are found in the Liguro-Provencal Basin.

A discontinuous positive anomaly which trends parallel to the basin axis may represent the paleo-spreading axis (Rehault, 1981; Rehault et a1., 1984a, 1985; Burrus, 1984). However, the central anomaly is generally less than $30 \mathrm{nT}$ and thus provides a very weak signal for interpretation which Burrus (1984) attributes to the large depth to the magnetic source $(\sim 8 \mathrm{~km})$. Arbitrary ages have been assigned to the central anomaly. Rehault correlates the central anomaly with 5D $(\sim 18$ Ma) whereas Burrus assigns the probable age as anomaly 6 ( 20 Ma). The uncertainties of these magnetic age estimates reflect those in the regional volcanic radiometric dates, as well as the timing constraints for the kinematic development of the basin, i.e., did Corsica drift before, during, or after the rotation of Sardinia? Burrus (1984) suggests that the rotation of Sardinia took place after Corsica was essentially in place. Additional signal processing and detailed three-dimensional modeling of the reduced anomaly may aid in an improved interpretation of the source structure. However, the low-amplitude signal does not guarantee a unique solution. The mode of spreading for the Western Mediterranean Basin probably is not governed by a single rift system similar to the Mid-Atlantic Ridge since lineated magnetic anomaly patterns may not necessarily occur during marginal basin development (Lawver and Hawkins, 1978; Weisse1, 1981).

Since the magnetic anomaly pattern is somewhat unclear, the basement subsidence (Figure 5.1) is of some help in identification of the oceanic 
domain. Burrus (1984) suggest that a regional change of slope in the regional basement topography is indicative of the oceanic-continental boundary; this technique is similar to the TTS approach used on the U.S. eastern margin by Sawyer (1985). Using this change-of-slope method, Burrus (1984) and Le Douaran et a1. (1984) define a 30-40 km wide portion of the northern central Ligurian Basin as underlain by oceanic crust. Alternatively, Rehault et a1. (1984b) and Bethoux et a1. (1986) believe that oceanic crust occupies a wider central zone $(60-70 \mathrm{~km})$ and extends farther to the southeast and the northeast. This viewpoint supports the notion that the central basement ridge of the Nice-Calvi transect is oceanic. The presence of thick salt and associated diapirism may tend to coincide with the oceanic crustal domain (Rehault, 1981; Pautot et a1., 1984).

Geothermal discrimination of the oceanic-continental crustal boundary is not practical. The rifted continental crust of the lower margin is generally highly thinned in the northwestern Mediterranean (Le Douaran et a1., 1984), a situation similar to other margins such as the Bay of Biscay (Avedik et a1., 1982) and the eastern Sardinian margin (Duschenes et a1., 1986). High1y-thinned continental crust which has been extended $>400 \%(B>5)$ should have 1 ithospheric geotherms nearly identical to oceanic crust of rough1y equivalent age (McKenzie, 1978; Hutchison et a1., 1985). In this case, the only major difference in the oceanic and continental margin thermal regimes is the higher radioactive heat production in the continental crust (Foucher and sibuet, 1980). The crustal contribution of the radiogenic heat component on the rifted margin is usually taken as $Q_{c} / B$, where $Q_{c}$ is the radiogenic 
component of heat flow in the unstretched crust. If $Q_{c}$ is equal to 20 to $40 \mathrm{~mW} \mathrm{~m}^{-2}$, then the heat flow change across the boundary is less than $4 \mathrm{~mW} \mathrm{~m}^{-2}$ since a small amount of radiogenic heat probably exists in the oceanic crust as we11 (e.g., Sclater et a1., 1980). Thus, the exact placement of the oceanic-continental boundary cannot be determined from heat flow data alone.

Basin asymmetry. As surmised by several authors (Rehault, 1981; Burrus, 1984; Le Douaran et a1., 1984; Burrus and Foucher, 1986), the Ligurian Basin is strongly asymmetric in the following respects: basement depth and topography, magnetic anomaly pattern, and age of continental volcanism. Moreover, within the context of the Western Mediterranean geological evolution, tectonic activity is more recent to the east and southeast where the paleo-subduction zone occurred and the northern and southern Tyrrhenian basins formed.

The shallow sediment structure is also asymmetric due to differences in the postdrift sedimentary and tectonic evolution within the basin (cf. Chapter 2). The sediment thickness and bathymetry on the Cote d'Azur margin reflect the influence of the Var and Roya fan development. The style of salt structures is also markedly different between the north central and south central basins. The P1io-Quaternary uplift is concentrated on the Provencal margin as evidenced by the Messinian pinchout leve1, coast-to-pinchout distance, depth to she1f break, and the elevated marine terraces. We speculate that many of the asymmetric developments are linked to Alpine structures antecedent to the Cote d'Azur margin formation. 
Perhaps the clearest indication of asymmetry in the Ligurian Basin is the environment-corrected heat flow distribution which show a $100 \%$ increase from the Cote d'Azur margin to the lower margin of Corsica (Figure 4.15). Other heat flow data substantiate this trend (Foucher et a1., 1976; Rehault, 1981; Burrus and Foucher, 1986). The thermal asymmetry has been attributed to older crust beneath the Var Rise and Cote d'Azur margin (Rehault, 1981) and to recent sporadic volcanism in the south centra1 basin (Burrus and Foucher, 1986).

Geothermal measurements and elevation data on the continental borderlands also support the asymmetric trend (Lucazeau and Mailhe, 1986). Heat flow in the Maures-Esterel region of southern France (southwestern Cote d'Azur) seems to be typical of most European Hercynian terrains with a mean of $\sim 58 \mathrm{~mW} \mathrm{~m}{ }^{-2}$. Heat flow in Hercynian Corsica (northwestern Corsica) is higher at $76 \mathrm{~mW} \mathrm{~m} \mathrm{~m}^{-2}$. Despite the normal crustal thickness beneath Corsica (Hirn and Sapin, 1976), the average elevation of Corsica is generally in excess of $1000 \mathrm{~m}$ and reaches heights of $3000 \mathrm{~m}$ in central Corsica. Maures-Esterel. regional elevation is subdued smaller, being only about 200 to $400 \mathrm{~m}$. We note that the Maures-Esterel region is decoupled from the mountainous centra1 Alpine region along the Var fault, west of which is probab1y undergoing an erosional-rebound phase since the Miocene with coastal

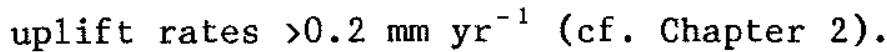

The increase in heat flow on Corsica may be attributed to a higher crustal heat contribution, higher mantle heat flow, or erosion (Lucazeau and Mailhe, 1986). Erosion elevates the heat flow above its equilibrium value, but this perturbation is complicated by the paleoclimatic 
temperature history (cf. England, 1977). Post-Eocene uplift-erosion

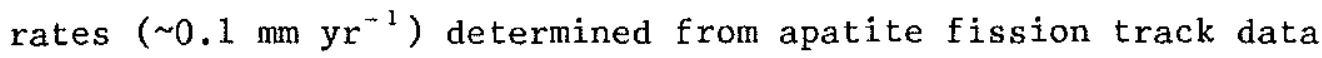
suggest that nominal uplift ( $<6 \mathrm{~km}$ including the present day elevation) has occurred (Mailhe et a1., 1986), so that the heat flow on Corsica is probab1y not influenced very much by erosion. This is consistent with the elevation change in the Messinian and P1io-Quaternary benchmarks limiting recent uplift rates to be about $0.05 \mathrm{~mm} \mathrm{yr}^{-1}$ for the northern Corsican margin (Moullade, 1978). Assuming that the radioactive heat content of the Hercynian-age crust is uniform, we concur with Lucazeau and Mailhe (1986) that the high heat flow on Corsica is probably a result of mantle heat flow which is greater than that beneath southern France.

High heat flow and elevation serve as an important constraint on the amount of mantle 1ithospheric thinning beneath Corsica. The origin of the mountainous terrain on Corsica, which contrasts with subdued elevations on the somewhat similar crust of Maures-Estere1, is most likely related to some thermal mechanism associated with the regional 01igocene-Miocene extensional tectonics. A possible explanation is that during the Ligurian Basin opening, Corsica was uplifted several kilometers due to greater mantle lithospheric thinning beneath Corsica as opposed to Maures-Estere1. Assuming that about $50 \%$ of the lithosphere was removed, the 01igocene-Miocene doming event occurred sufficiently long ago that the maximum heat flow anomaly of $\sim 20 \mathrm{~mW} \mathrm{~m}^{-2}$ has reached the surface (e.g., Von Herzen et a1., 1982). Conversely, the 1ithosphere is probably not perturbed beneath the Cote d'Azur borderland and subsequently may be taken as a reference thermal 
state for the Western Mediterranean (Lucazeau and Mailhe, 1986). This large thermal and elevation asymmetry has obvious implications for the tectonic interpretation of the Ligurian Basin geothermics.

Summary of basin structure. There are two axes of crustal thinning determined from the integrated results of refraction surveys by Le Douaran et a1. (1984) and Ginzburg et a1. (1986). The Moho seems to shallow beneath the northern central basin on the Nice-Calvi line and under the southern portion on the Genoa-St. Florent transect, with no apparent crustal root beneath the Central basement ridge (Figure 5.2). The TTS map (Figure 5.1) also defines two NE-SW 1ineated troughs (Var Basin and North Corsican Basin), separated by a prominent basement ridge. Moreover, the corrected heat flow distribution (Figure 4.15) indicates that the southeastern half of the Ligurian Basin may be underlain by an axis of minimum lithospheric thickness. We associate these parallel trends with the kinematics of the Ligurian Basin formation, and consequently present two possible explanations based on dominant1y temporal or doninantly spatial discontinuities.

Geometric asymmetry in rifting is exemplified in continental extension by large-scale detachment faulting of the lithosphere (Wernicke, 1981, 1985; Lister et a1., 1986) and the development of alternating half-graben systems along the rift axis (Bosworth, 1985). Temporal asymmetry could be manifested by a progression in the ages of maximum extension (age of initial thermal anomaly) across the basin. Asymmetric accretion of divergent plate boundaries commonly occurs in back arc basins as a result of simple ridge jumps or by asymmetric spreading at the ridge crest (Barker and Hill, 1980). Some examples of 
this temporal asymmetry are given in the western Philippine Sea basins (Scott and Kroenke, 1980), the East Scotia Sea (Barker and Hi11, 1981). More recently, heat flow, seismic stratigraphic and 0cean Drilling Project Leg 107 results indicate a detailed progressive rifting within the Tyrrhenian Basin (Hutchison et a1., 1985; Kastens, Mascle et a1., 1987; Mascle and Rehault, 1988). Mascle and Rehault (1988) suggest that at least four rifting events occurred in the Tyrrhenian, with the younger events always migrating toward the active arc-trench 1 ine. By incorporating both aspects of both the geometric and temporal asymmetry models, it is possible that a single normal detachment fault was activated during the multiple-rifting (Mascle and Rehault, 1988; Kastens, 1988). We elaborate on these spatiotemporal models for basin asymmetry in the following sections.

\subsection{Rifting processes and geophysical models}

The Ligurian rifting mechanism is an integration of four fundamental physical processes: crustal thinning, crustal extension, asthenospheric doming, and melt segregation. Crustal thinning is mainly evident from the refraction data. It seems probable that the relative importance of extension, doming and partial melting determines the mode of structural formation. With reference to the Ligurian Basin, we critique the extensiona1 mode1s for sedimentary basins (McKenzie, 1978; Royden and Keen, 1980; Royden et a1., 1980), partial me1t effects on margin subsidence (Foucher et a1., 1982), and implications of crustal detachment surfaces (Wernicke, 1985; Lister et a1., 1986). 
Crustal stretching. Tectonic extension is the dominant mechanism for crustal thinning in the Ligurian Basin as indicated by the numerous grabens. Tilted blocks are seen clearly on the Cote d'Azur margin (Profile 21, Appendix 5) and on a multichannel line in the North Corsican Basin (e.g., line MS-84; J. P. Rehault, personal communication, 1985). No mid-leve1 crustal detachment surface underlying the upper crustal layer, referred to as the "S" horizon on the we11-studied northern Bay of Biscay margin (e.g., Le Pichon and Barbier, 1987), is resolved from any of the published seismic data.

Sediment-unloaded basement depths (Figure 5.1) indicate that the conjugate margins are somewhat asymmetric in width. Le Douaran et al. (1984) define the region "oceanic" crust and find that the northwestern margin is more narrow $(\sim 30 \mathrm{~km})$ than the southeastern margin $(\sim 60 \mathrm{~km})$. However, our Figures 5.1 and 5.2 show that the interpretation of the southeastern conjugate margin is complicated by the presence of the dual trough system and central basement ridge. Aiso, we must question the margin width calculations since they are main1y based on crusta1 thickness, magnetics, and basement topography, and not on petrologic samples or detailed crustal velocity structure. Farther west on the Provencal margin (southern France) on a profile through the Gulf of Lion, rifted continental crust creates $\sim 150 \mathrm{~km}$ wide margin (Burrus, 1984; Le Douaran et al., 1984). If normal detachment faulting applies to the Liguro-Provencal margins, then the wider margin of the Gulf of Lion and northern Corsica, compared to the conjugate margins of western Sardinia and Cote d'Azur respectively, may be due to upper plate margin affinities (cf. Lister et a1., 1986). 
It is prudent to temper any structural model of margin formation with structural weaknesses provided by pre-rift tectonic fabrics and variations in pre-rift crustal thicknesses. K1itgord et a1. (1987) believes that the Mesozoic shelf platform regions on the eastern U.S. continental margin are probably controlled by Paleozoic fault structures which can be traced onshore. Many other rift studies indicate similar control by pre-rift structural weaknesses. Vink et a1. (1984) infer from 1ithospheric strength envelopes that an increase in crustal thickness form $35 \mathrm{~km}$ to $45 \mathrm{~km}$ leads a $50 \%$ decrease in the total lithosphere strength.

In the Ligurian Basin, we recognize a gross correlation of the crustal thickness and tectonic fabric of the onland units with the general width of the margin, but we do not attempt to establish any specific relationships. The narrowness of the Coted'Azur margin coincides with the juxtaposition of the borderland Alpine units, where most of the folded and thrusted Mesozoic units are oriented perpendicular to the strike of the coastline (c1auzon, 1978). Here, the pre-rift conditions of a thicker crust must dictate differences in the basin structural development. On the Gulf of Lion margin, the onland Mesozoic structures are generally parallel to the preferred rift orientation and may facilitate movement on detachment faults. Another good example of the possible influence of pre-rift tectonic fabrics is between the northern peninsula of Corsica (Cap Corse) and its western margin. If traced to central Corsica, the peninsular unit is apparently soled by a thrust fault, above which an allochthonous unit similar to the Alpine ophiolitic units has been emplaced. Due to the large 
variation in crustal structure along the margin and borderland, we suggest that the results obtained for the northern Ligurian Basin may not necessarily be extrapolated to the other western Mediterranean margins, e.g. Gulf of Lion.

The thinning of the Ligurian Sea margin crust probably occurs by a variety of stretching processes (e.g., Brun and Choukroune, 1983). Thus, to a first order, a passive rifting mode1 is appropriate, best typified by the uniform extension of the lithospheric plate (McKenzie, 1978; Le Pichon and Sibuet, 1981).

Lithospheric doming. It is generally accepted that the rifting of the Western Mediterranean Basin is preceded or accompanied by a doming phase (e.g., Rehault et a1., 1985). The actual uplift on the flanks of the northwestern Mediterranean basin is impossible to quantify and can only be inferred from erosional unconformities (Mauffret et al., 1973; Cravatte et a1., 1974; Steckler and Watts, 1980), and reversa1 in drainage patterns (Stanley and Mutti, 1968). Although there is probab1y a strong spatial dependence on the amount of doming, the fact that there is any synrift uplift at all implies that some mechanism of nonuniform or modified extension may be necessary (Royden and Keen, 1980; He11inger and Sclater, 1983), i.e., the mantle 1ithosphere has been thinned more than the crust. Similarly, observations of high therma1 subsidence rates compared to the initial subsidence may also require extra heat input to the lithosphere (e.g. Royden and Keen; Royden et a1., 1983). Disproportionate thinning of mantle lithosphere may involve either passive or active forces. Active forces are contrived mainly from hot spot theory and involve substantial vertical stress at the base of the 
1ithosphere due to thermal or dynamic sources. For example, asthenospheric convective mechanisms that produce thinning and delamination can easily produce doming and appropriately higher heat flow (Spohn and Schubert, 1983). Upwelling of an asthenospheric diapir by thermal1y-driven or compositionally-driven buoyancy forces could also cause uplift.

Thinning of the mantle lithosphere beyond the uniform extension estimates may also take place by passive thermal processes. Lateral heat conduction is such a process, but theoretically can produce no more than a few hundred meters of uplift on the rift flanks (Steckler, 1981). Uplift in excess of $1000 \mathrm{~m}$ inferred on the Gulf of Suez rift flanks has been attributed to secondary smal1-scale asthenospheric convection induced by large lateral temperature gradients (Steckler, 1985). Buck (1986) has performed numerical experiments which illustrate that this "passive" small-scale convection is a viable thinning mechanism.

Additionally, crustal faulting geometries and 1ithospheric shearing scenarios may produce passive uplift. Tilting occurs on the main border faults of many graben systems (Hellinger and Sclater, 1983). This produces regional upwarping of the 1 ithosphere as a flexural response to the resulting local mass deficit between the graben and rift flank. Wernicke (1985) considers a simple shear model for the lithosphere along a single low-angle detachment. As mantle 1ithosphere below the detachment surface is displaced toward the lower plate margin, the upper plate margin will be uplifted (e.g., Bosworth et a1., 1987; Lister et a1., 1986). 
Me1t segregation and emplacement. Magmatic processes modify rifted crust by underplating and dike intrusion. Partial melting beneath extended lithosphere is also likely to have profound implications on the transition between rifted margin crust and oceanic crust, since the processes of me1t segregation, me1t migration and oceanic crusta1 accretion must dominate at the onset of sea-floor spreading (Le Pichon and Sibuet, 1981; Foucher et a1., 1982). The magma source for underplating or intrusion is segregation of partial me1t produced by upwelling asthenosphere (e.g., Ahern and Turcotte, 1979). Because liquid basalt is buoyant compared to residual mantle, upward migration occurs to form typically a $5-8 \mathrm{~km}$ thick oceanic crust in mature mid-ocean ridge regions.

As a result of melt segregation, a discrete petrologic zoning of the oceanic 1ithosphere occurs consisting of the following layers: crust (basalt/gabbro), depleted mantle (harzburgite or 1herzolite), and undepleted mantle (1herzolite) (e.g., Ringwood, 1969; 0xburgh and Parmentier, 1977; Dick et a1., 1984). This layering is compatible with the vertical stratification of the crust and uppermost mantle observed in ophiolites (e.g., E1thon et a1., 1982) and is supported by gravity models of active and fossil mid-ocean ridges (Hall et al., 1986).

Partial me1t production has been incorporated in the uniform extensional mode1 by Foucher et a1. (1982) and in principle can be included in the nonuniform model as we11. Melting is assumed to occur when undepleted lherzolite is elevated above the solidus temperature along an adiabatic trajectory during isentropic ascent of the asthenosphere. Foucher et a1. (1982) and White et a1. (1987b) have 
emphasized the role that asthenospheric temperature plays in the amount of magma generated by partial melting. Depending on the mantle chemistry, each $100^{\circ} \mathrm{C}$ warming of the initial upwelling asthenosphere leads to an additional 8 to $10 \mathrm{~km}$ of crust (White et al., 1987b), with a maximum of $6 \mathrm{~km}$ of "oceanic" crust generated for asthenosphere at $1300{ }^{\circ} \mathrm{C}$ (Ahern and Turcotte, 1979). Lachenbruch et a1. (1985) consider the thermal consequences of underplating and intrusion, but they only consider a steady-state mode1 representing an active pull-apart basin (Salton Trough). We investigate the evidence for magmatic processes and consider the thermal and isostatic consequences.

1) Underplating. Underplating of continental crust results from the ponding of basaltic magma beneath the thick, high-viscosity crustal section. Underplating has been identified with 7.0 to $7.5 \mathrm{~km} \mathrm{~s}^{-1}$ velocities found beneath active rifts (Fuis et al., 1984; Bonatti and Seyler, 1987) and near the oceanic-continental boundary of several rifted margins (LASE, 1986; White et a1., 1987a). Theoretical seismic velocities of underplated material and calculated thicknesses of crustal additions are consistent with the underplated structures (Furlong and Fountain, 1986; Foucher et a1., 1982; White et a1., 1987b).

In some respects, the central basin of the Nice-Calvi transect can be considered to be totally underlain by crust intermediate in character to continental and oceanic crust. The transitional nature is especially distinguished in ESP 224 in the northern central Ligurian Basin by a 1ow-velocity two-layer crust (Le Douaran et a1., 1984). The present resolution of the Ligurian seismic and magnetic data leaves open the question of the precise nature of the thin crust in other regions of 
the central basin. Underplating on the lower margins is unclear as well.

In the Genoa-St. Florent transect of Ginzburg et a1. (1986), intriguing evidence for underplating may be argued. Using ray tracing techniques, Ginzburg et a1. (1986) define a $14 \mathrm{~km}$ crust underlain by a thick $7.4 \mathrm{~km} \mathrm{~s}^{-1}$ layer (Figure 5.2). They attribute the low velocity of this lower layer to temperature effects on upper mantle material or very recent intrusion processes indicated by the presently high heat flow in the region. However, laboratory measurements of peridotite at $600 \mathrm{MPa}$ indicate that there is only a small change in seismic velocity, from $8.0 \mathrm{~km} \mathrm{~s}^{-1}$ at $350{ }^{\circ} \mathrm{C}$ to $7.7 \mathrm{~km} \mathrm{~s}^{-1}$ at $700{ }^{\circ} \mathrm{C}$ (Kern and Richter, 1981). Thus, it is doubtful that anomalously high heat flow can account for a $0.6 \mathrm{~km} \mathrm{~s}^{-1}$ decrease in mantle velocity implied by Ginzburg et a1. (1986). Neglecting a serpentined a1lochthonous Alpine unit as a likely cause, a compositional origin for the $7.4 \mathrm{~km} \mathrm{~s}^{-1}$ medium is consistent with underplating processes near the base of the crust, with the source of the magma being partial melt incurred from 1ithospheric thinning during the 01igocene Miocene basin formation, or perhaps the middle to late Neogene rifting of the Northern Tyrrhenian Basin and Gulf of Genoa she1f. In this case, the $7.4 \mathrm{~km} \mathrm{~s}^{-1}$ layer is not necessarily mantle sensu stricto.

2) Dikes. Mafic intrusions crop out on the southwestern Corsican margin near the Gulf of Bonifacio (e.g. Bellon et al., 1985) as well as other locations on the margins (Rehau1t, 1981). The associated circular magnetic anomalies also support that significant igneous bodies have been emplaced by extrusion or shallow intrusion processes. 
The possible profusion of dike swarms accompanying rifted margin development provided the impetus for Royden et a1. (1980) to construe the dike-intrusion extensional model. This model assumes that the dike composition within the attenuated crust is peridotitic in composition, not basaltic. Peridotite is about $300 \mathrm{~kg} \mathrm{~m}^{-3}$ denser than basalt and is not a constituent of dikes or sills at crustal levels. Thus, in the dike-intrusion model, the intruded and attenuated crust is modeled as being less buoyant than if basaltic dikes are assumed. Consequently, the initial subsidence is over-estimated if the intrusion factor is combined with the stretching factor. Moreover, observations of crustal thinning and tilted blocks within the Western Mediterranean Basin negate the possibility of extension by dike intrusion alone.

Heat flow implications of the mode of emplacement are probably negligible for an inactive basin. A gross estimate of the potential difference may be made from comparing the dike-intrusion and the uniform extensional models. Royden et a1. (1980) show that the differences between the two models decay rapidly with time. For a 20 Myr old extensional basin, heat flow is approximate1y equal, with the dike-intrusion model providing a slightly higher surface heat flow. Therefore, shallow basaltic intrusives pose no serious problem for this interpretation of heat flow in the Ligurian Basin. Additiona11y, the effects of the latent heat of fusion in the depleted mantle is small and can be ignored in the heat flow calculations (Ahern and Turcotte, 1979). 3) Mantle me1ting and isostasy. Whether the mode of emplacement is by underplating, pervasive dike intrusions, or extrusives, the basement subsidence will essentially be the same for a given volume of magmatic 
additions. This elevation change is incorporated as part of the initial subsidence assuming an Airy model of isostatic compensation for the crust (Foucher et a1., 1982; Beaumont et a1., 1982; McKenzie, 1984). Additiona11y, the basement subsidence is altered by mantle density changes incurred by partial melting. Many authors (0'Hara, 1975; Oxburgh and Parmentier, 1977; Jordan, 1979; K1ein and Langmuir, 1987) suggest that the density difference between depleted and undepleted mantle in oceanic 1ithosphere is $1.5-3.0 \%$ (a decrease of $40-60 \mathrm{~kg} \mathrm{~m}^{-3}$ in the depleted phase), depending on the compositional model and peridotite samples used for the upper mantle. In their comparison, they assume that the fertile mantle composition is a garnet 1herzolite phase.

On the contrary, the most extensively depleted mantle probably resides in the plagioclase $(<30 \mathrm{~km})$ or spine1 $(30-70 \mathrm{~km})$ 1herzolite stability field (E1thon et al, 1982). In thinned continental lithosphere, me1t production is also limited to the shallow mantle (<40-70 km; Foucher et a1., 1982) which is within the spinel, not garnet, peridotite stability fields. Thus, the density contrast due to depletion may not necessarily concern the high-density garnet phase. Accordingly, the effect of mantle depletion on the subsidence of major and marginal basins may be much smaller surmised by Jordan (1979). To estimate the subsidence behavior of melting-induced density changes in the mantle, we have used modal compositional analyses by Dick et a1. (1984) and Michael and Bonatti (1985) of "fertile" and "residual" upper mantle peridotites. These abyssal peridotite samples represent a range of approximately $0-15 \%$ partial melting, so that the most diopside-rich samples may give an estimate of undepleted mantle and 
relatively diopside-poor samples provide estimates of more depleted residual lherzolites and harzburgites (Table 5.1). The major element contents of the abyssal peridotites which have the lowest $\mathrm{Mg} / \mathrm{Mg}+\mathrm{Fe}$ ratios are similar in modal mineralogy composition and major element chemistry to the most fertile xenolith lherzolites inferred to be representative of undepleted upper mantle (Hart and Zindler, 1986; J. Casey, unpublished data, 1988). Moreover, a value of $15 \%$ is thought to represent the average degree of partial melting beneath axial mid-ocean ridge systems (e.g. Klein and Langmuir, 1987). Because garnet is not present in the shallow mantle (Ringwood, 1969), its density contribution can be neglected, the most-depleted residual mantle is therefore less dense than its fertile counterpart by $0.3 \%$ (Tab1e 5.1 ) than the $3 \%$ difference estimated by Oxburgh and Parmentier (1977) and others.

This simple density scheme is applied to water-loaded subsidence of young oceanic lithosphere in Table 5.1. A $40 \mathrm{~km}$ thick depleted upper mantle will decrease the water depth by less than $0.2 \mathrm{~km}$, while a $6 \mathrm{~km}$ thick basaltic crust increases the 1 ithosphere elevation by $1 \mathrm{~km}$. Thus, the isostatic effect of chemical zonation in the upper mantle due to partial me1ting processes is on $1 y$ about $10 \%$ of the total elevation change, the remaining $90 \%$ due to the low-density crust. In comparison, the petrologic model estimated by others would have the mantle depletion effect account for levels of subsidence about $50 \%$ of the crustal loading (Klein and Langmuir, 1987). We suggest that the isostatic term for the depleted mantle may be neglected in the formulations of Foucher et a1. (1982) and Beaumont et a1. (1982) without serious error. Thus, an important point is that the mantle isostasy in extended lithosphere is 
Table 5.1 Mineralogy, Density, and Isostasy of the Uppermost Mantle

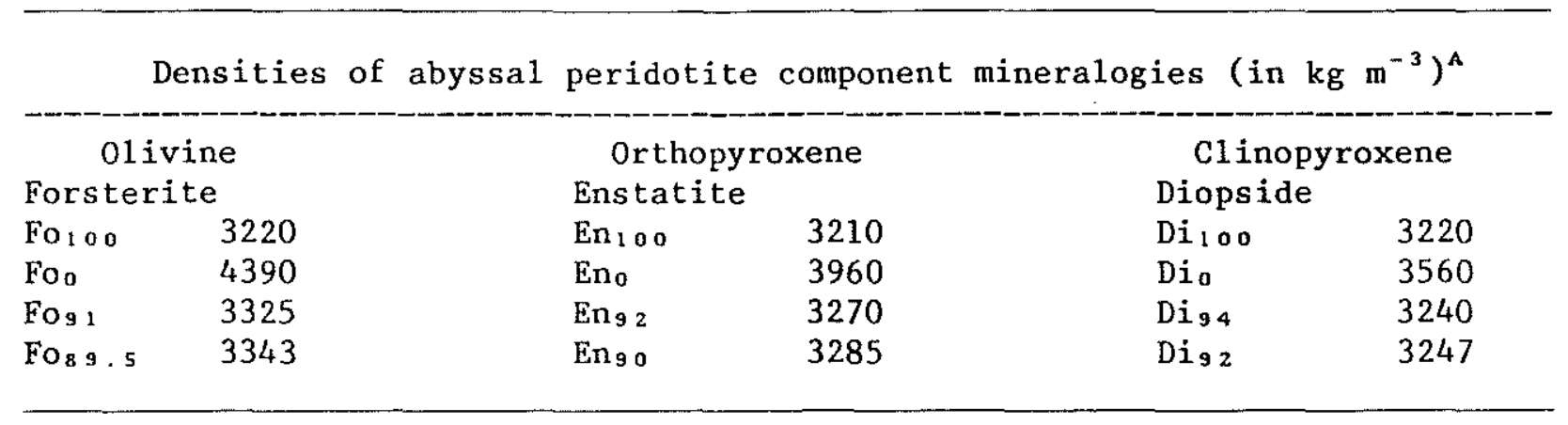

Representative depleted and undepleted samples of uppermost mantle ${ }^{B}$

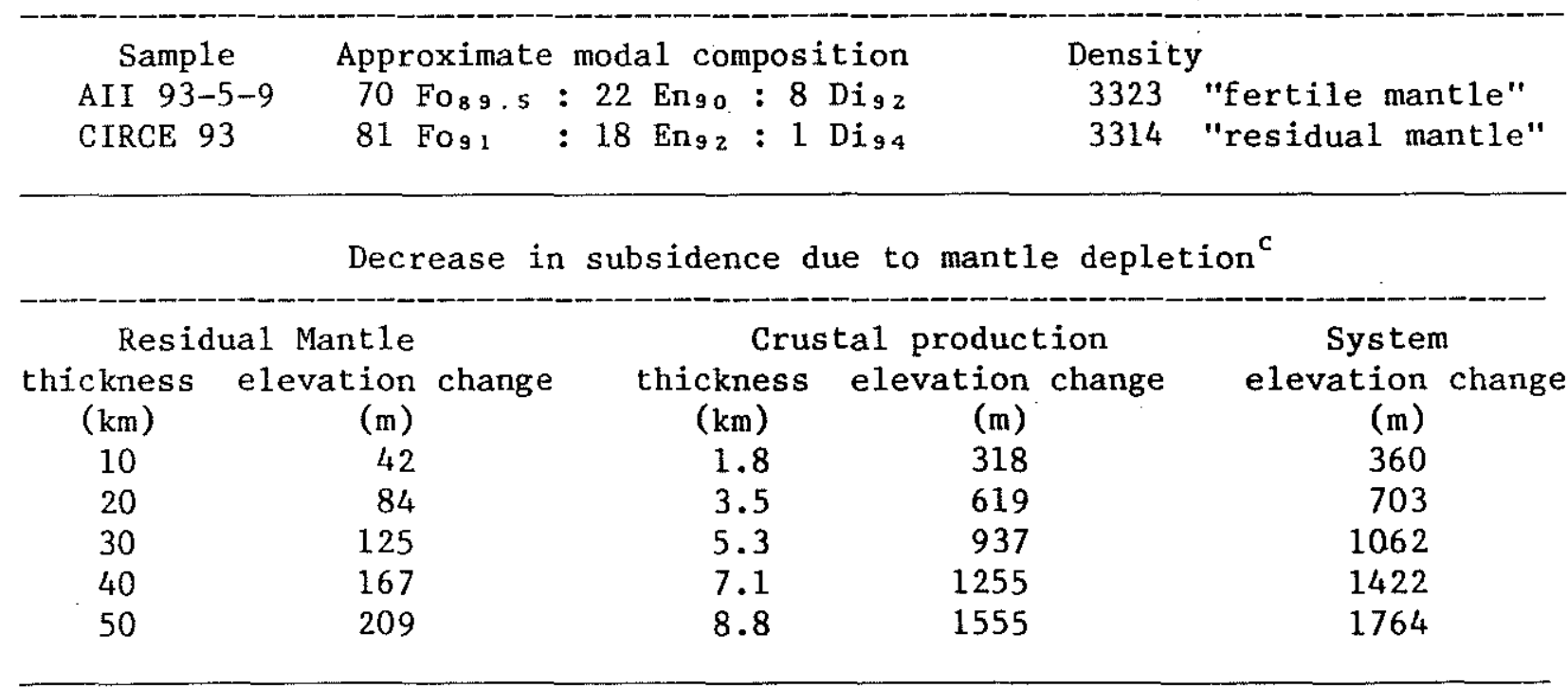

A End members of solid solution series from Deer et al. (1966)

Bodal and chemical data from Dick et a1. (1984)

c Assuming 15\% partial melting, an asthenospheric level of compensation, asthenospheric density $=3180 \mathrm{~kg} \mathrm{~m}^{-3}$, and crustal density $2800 \mathrm{~kg} \mathrm{~m}^{-3}$ 
insensitive to the partial melting process.

Since isostatic effects of mantle depletion are sma11, the nonuniform extension model may accurately mimic the subsidence caused by uniform extension of the 1 ithosphere with magmatic additions to the stretched crust. McKenzie (1984) suggested the same, but he did not address the isostatic contribution of the residual mantle. Our estimate of crustal extension is made by seismic measurements of crustal thickness, so that magmatic additions will lead to an underestimation of the extension. We feel that this fundamental process has been overlooked in most continental margin evolution studies. In theory, crustal addition is a1so a passive mechanism to produce uplift during the rifting phase (McKenzie, 1984; Lachenbruch et a1., 1985). We have no geophysical evidence which disproves underplating or intrusion in the Ligurian Basin crust. Therefore, the ramifications of a discrepancy between crustal thinning and crustal extension is included in our analysis.

\subsection{Central basin evolution}

Central basin heat flow values (sites $\mathrm{C} 1, \mathrm{C} 2$ and D1) are in accordance with geologic estimates for basin formation, assuming one-dimensional cooling of an initially isothermal half-space (boundary-1ayer mode1). The asymmetric heat flow distribution suggests that a rift jump occurred between the rifting and drifting stages of basin opening. An intrabasinal rift jump to the $S E$ is consistent with the two NE-SW trough formations, volcanic ages in the region, and an arc-trench system migration scheme typical of back arc basins. Lateral 
heat loss predicted for small marginal basins is not apparent, suggesting that mantle thermal properties and initial conditions assumed in two-dimensional models may be inappropriate.

We evaluate the residual depth anomaly using recent studies on mid-ocean ridges as well as back arc basins; back arc trends indicate that the anomaly is created at the ridge axis (zero-age). We revise the interpretation that little variation exists in the thermal structure of back arc basins compared to the major oceans (Anderson, 1980; Louden, 1980). Instead, we recommend that a cooler mantle structure is accompanied by an overall higher mean mantle thermal conductivity; this mode1 satisfies the heat flow and subsidence data for most back arc basins.

Cooling of oceanic lithosphere: an overview. The simplest expression for the thermal evolution of oceanic lithosphere is given by the cooling half-space or boundary-layer model. Using reasonable physical parameters, the boundary-layer model fits observed subsidence and reliable heat flow data for crust at least 60 Myr old (Davis and Lister, 1974; Lister, 1977; Parsons and Sclater, 1977; Cochran, 1986). Gravity, geoid, flexural, surface wave and teleseismic data also support a 1ithospheric cooling model for the major ocean basins. The subsidence and heat flow history of oceanic crust is derived from the temperature solution of a cooling half-space for an initially isothermal, homogeneous material with a zero degree boundary condition at the surface. Both the surface heat flow and the thermal subsidence are given by (age $)^{1 / 2}$ laws (e.g., Turcotte and Schubert, 1982); we term the inverse relation age estimators. 
With the parameter defined in Table 5.2, the age estimators are expressed as

$$
\begin{aligned}
& Q(t)=Q_{1}(t)^{-1 / 2} \\
& S(t)=S_{0}+S_{1}(t)^{1 / 2}
\end{aligned}
$$

where the rate coefficients are defined as

$$
\begin{aligned}
& Q_{1}=K T_{1}(\pi \kappa)^{-1 / 2} \\
& S_{1}=2 \alpha_{I} T_{1}(\kappa / \pi)^{1 / 2}
\end{aligned}
$$

and the isostatically modified thermal expansion coefficient is

$$
\alpha_{I}=\rho_{0} \alpha\left(\rho_{0}-\rho_{W}\right)^{-1}
$$

where $\mathrm{K}=\mathrm{K} \rho \mathrm{C}$. The constant $\mathrm{S}_{1}$ is identical to the subsidence parameter $C_{1}$ in the notation of Parsons and Sclater (1977).

As opposed to the boundary-1ayer mode1, the plate mode1 appears to better characterize the thermal state of 1ithosphere older than about 60-80 Ma (see Parsons and Sclater, 1977, and references therein). Beyond these ages, the oceanic depth-age curve tends to shallow suggesting that the 1 ithosphere thickness is maintained at a nearly constant level by steady heat input from the asthenosphere. The extra source of heat could be due to organized small-scale convection in the asthenosphere (Parsons and Sclater, 1977) or the relatively disorganized interaction of moving plates and hot spots (Heestand and Crough, 1981; Schroeder, 1984). Asthenospheric heat input is genera11y not important in marginal basins because they are typically $<80$ Myr old.

In terms of the plate model, the ridge depth $S_{0}$ represents the difference in the final depth of the plate $\left(S_{\infty}\right)$ and the theoretical ridge crest

$$
\mathrm{S}_{0}=\mathrm{S}_{\infty}-\mathrm{a} \alpha_{\mathrm{I}} \mathrm{T}_{1} / 2
$$


Table 5.2 Lithospheric Constants

\begin{tabular}{ll}
\hline & \\
$Q_{1}$ & heat decay rate \\
$\mathrm{S}_{0}$ & initial ridge depth \\
$\mathrm{S}_{1}$ & thermal subsidence rate \\
$\mathrm{S}_{\infty}$ & final depth of plate \\
$\mathrm{D}_{c}$ & depth of compensation \\
$\mathrm{T}_{1}$ & asthenospheric temperature \\
$\mathrm{K}$ & average thermal conductivity \\
$\kappa$ & average thermal diffusivity \\
$\rho_{0}$ & density of mantle $\left(0^{\circ} \mathrm{C}\right)$ \\
$\rho_{a}$ & asthenospheric density \\
$\rho_{c}$ & crustal density \\
$\rho_{W}$ & density of water \\
$\alpha$ & coefficient of thermal expansion \\
$\mathrm{a}$ & final plate thickness \\
$\mathrm{t}_{c}$ & crustal thickness \\
\hline
\end{tabular}


The quantity $S_{0}-S_{\infty}$ is the total thermal subsidence of the oceanic plate and is equivalent to the subsidence parameter $\mathrm{C}_{3}$ of Parsons and Sclater (1977); $\mathrm{S}_{\infty}$ is observed to be about $6400 \mathrm{~m}$. An analytical expression for $S_{0}$ in the boundary-layer model is not readily available because a reference level is lacking. In principle, the ridge crest depth is related to the crustal thickness $\left(t_{c}\right)$, depth of compensation $\left(D_{c}\right)$ and density structure of the upper mantle. Variations in the ridge depth may be obtained by using the simple mass column approximation

$$
M=\rho_{a}\left(D_{c}-S_{0}-t_{c}\right)+\rho_{c} t_{c}+\rho_{w} S_{0}
$$

where the asthenospheric density is

$$
\rho_{\mathrm{a}}=\left(1-\alpha \mathrm{T}_{1}\right) \rho_{0}
$$

with other parameters defined in Table 5.2. Klein and Langmuir (1987) give a more complex treatment of the ridge depth approximation assuming an isostatically distinct residual mantle layer, partial melting relationships, and adiabatic temperature gradients.

Published values for the boundary-layer coefficients show a moderate degree of regional variability (see Table 5.3); basement depths are generally much better resolved than heat flow due to the higher variability in superficial heat flow measurements (e.g. Sclater et al., 1980). However, important smal1-scale residual depth anomalies occur along-axis and off-axis of the mid-ocean ridges. Intermediate and fast-spreading ridges have ridge crest axia1 depths which are generally deeper than predicted by about $200 \mathrm{~m}$ (Davis and Lister, 1974; Cochran, 1986). The ridge crest topography at slow-spreading ridges is additiona1ly complicated by the formation of a deep axial valley. on 
Table 5.3 Heat Flow and Depth-Age Relations $<80$ Myr Lithosphere

\begin{tabular}{|c|c|c|c|}
\hline Depth- & e Relation: & $S=S_{0}+S_{1} t^{1 / 2}$ & \\
\hline Location & $S_{0}(m)$ & $\mathrm{S}_{1}\left(\mathrm{~m} / \mathrm{Myr}^{1 / 2}\right)$ & Reference \\
\hline \multicolumn{4}{|l|}{ North Pacific: } \\
\hline & ---- & 390 & Davis and Lister (1974) \\
\hline & $2500 \pm 200$ & $354 \pm 30$ & Parsons and Sclater (1977) \\
\hline & 2967 & 305 & Schroeder (1984) \\
\hline $11^{\circ} \mathrm{S}$ to $22^{\circ} \mathrm{S}$ & 2700 & $\begin{array}{l}375(E) \\
215(W)\end{array}$ & $\underset{" \text { Cochran }}{(1986)}$ \\
\hline \multicolumn{4}{|l|}{ South Pacific: } \\
\hline & 2681 & 337 & Schroeder (1984) \\
\hline \multirow{3}{*}{$\begin{array}{l}33^{\circ} \mathrm{S} \text { to } 55^{\circ} \mathrm{S} \\
\text { North Atlantic: }\end{array}$} & 2400 & 385 & Cochran (1986) \\
\hline & $2500 \pm 350$ & $342 \pm 65$ & Parsons and Sclater (1977) \\
\hline & 2700 & 295 & Heestand and Crough (1981) \\
\hline \multicolumn{4}{|l|}{ South Atlantic: } \\
\hline \multirow{2}{*}{$\begin{array}{c}15^{\circ} \mathrm{S} \text { to } 20^{\circ} \mathrm{S} \\
\text { " }\end{array}$} & 2150 & $370(E)$ & Hayes $(1988)$ \\
\hline & 3000 & $270(W)$ & " \\
\hline \multirow[t]{2}{*}{$21^{\circ} \mathrm{S}$ to $29^{\circ} \mathrm{S}$} & 2875 & $300(\mathrm{E})$ & $"$ \\
\hline & 2825 & $330(W)$ & $"$ \\
\hline \multirow{2}{*}{$35^{\circ} \mathrm{S}$ to $45^{\circ} \mathrm{S}$} & 2200 & $290(E)$ & $"$ \\
\hline & 2300 & $380(W)$ & $"$ \\
\hline \multicolumn{4}{|l|}{ Southeast Indian: } \\
\hline \multirow{2}{*}{$\begin{array}{c}130^{\circ} \mathrm{E} \text { to } 137^{\circ} \mathrm{E} \\
\text { " }\end{array}$} & 2650 & $473(N)$ & Hayes (1988) \\
\hline & 2600 & $380(\mathrm{~S})$ & " \\
\hline \multirow{2}{*}{$120^{\circ} \mathrm{E}$ to $127^{\circ} \mathrm{E}$} & $3200 *$ & $338(\mathrm{~N})$ & $"$ \\
\hline & $3450 *$ & $287(\mathrm{~S})$ & $"$ \\
\hline \multirow{2}{*}{$111^{\circ} \mathrm{E}$ to $119^{\circ} \mathrm{E}$} & 3000 & $300(\mathrm{~N})$ & $"$ \\
\hline & 3050 & $290(S)$ & $"$ \\
\hline \multicolumn{4}{|c|}{ major ocean basins: } \\
\hline & 2500 & 350 & Parsons and Sclater (1977) \\
\hline & 2700 & 300 & Hayes $(1988)$ \\
\hline back arc basins: & 3500 & 290 & this study \\
\hline
\end{tabular}

Heat Flow-Age Relation: $Q=Q_{1} t^{-1 / 2}$

Method

derived from depth-age data and 1 ithospheric constants back arc basin heat flow data for ages $>10 \mathrm{Ma}$
$Q_{1}\left(\mathrm{mWMyr}^{1 / 2} / \mathrm{m}^{2}\right) \quad$ Reference

473 Parsons and Sclater (1977)

$500 \quad$ Lister (1977)

$512 \quad$ this study 
the ridge crest, the extrapolated value of $S_{0}$ determined by the subsidence rate generally best fits the rift mountain elevation, not the rift valley floor depth. The average rift valley wall height is about $1500 \pm 1000 \mathrm{~m}$ in the North Atlantic (Le Douaran and Francheteau, 1981), illustrating that a large discrepancy exists for zero-age depth interpretations on slow versus fast spreading ridges.

Regiona1 variations of over $3000 \mathrm{~m}$ in ridge crest depth $\left(\mathrm{S}_{0}\right)$ are mainly attributed to differences in local mantle temperature, composition, or crustal thickness (Watts and Daly, 1981, Le Douaran and Francheteau, 1981; Bowin et al., 1984; Klein and Langmuir, 1987). For example, the average ridge crest depth for the Australian-Antarctic Discordance "cold spot" is greater than $3700 \mathrm{~m}$ (Hayes, 1988) whereas the Azores and Iceland "hot spots" have elevations above sea-leve1. In comparison, the zero-age depth of normal seafloor is usually taken to be about 2500 to $2700 \mathrm{~m}$. The average ridge axis depth also may be influenced by the proximity of hot spots or triple junctions where deep mantle flow may dynamically support the topography. The relationship between anomalous ridge depth $\left(S_{0}\right)$ and final depth $\left(S_{\infty}\right)$ is unclear; advocates of the plate model address variation in $S_{\infty}$ in a planform sense but do not consider the consequences of anomalous ridge crest elevation. As may be inferred from Table 5.1, the crustal thickness is an important variable in regional topographic anomalies, with $1 \mathrm{~km}$ of crust causing $200 \mathrm{~m}$ difference in water depth. Crustal thickness is taken into account in the initial subsidence of the continental extensional models, but not in the standard oceanic models. 
Individual bathymetric profiles for crust ranging from 2-5 Myr to at least 60 Myr old approximate the square root of age law quite we11, but variations in the subsidence rate $\left(S_{1}\right)$ are evident between different mid-ocean ridge segments (Table 5.3). Rough average values of $\mathrm{S}_{1}$ are estimated to be about $350 \mathrm{~m} \mathrm{Myr}^{-1 / 2}$ by Parsons and Sclater (1977) and $300 \mathrm{~m} \mathrm{Myr}^{-1 / 2}$ by Hayes (1988). However, variations in $\mathrm{S}_{1}$ of 200 to over $400 \mathrm{~m} \mathrm{Myr}^{-1 / 2}$ occur independent of the variations in ridge depth and spreading rate. For example, subsidence rate is fairly constant in the North Atlantic Basin whereas ridge depth varies by over $1500 \mathrm{~m}$ (Sclater et a1., 1975; Le Douaran and Francheteau, 1981).

The discrepancy between variations in subsidence rate $\mathrm{S}_{1}$ and ridge depth So suggests a nonthermal component to the total subsidence. Besides the asthenospheric temperature, the crust and residual mantle thickness and composition are the most important effect on the depth (e.g., Klein and Langmuir, 1987). However, within some "tectonic corridors" of the ocean floor, Hayes (1988) and Cochran (1986) observes significant asymmetry in the subsidence rate of conjugate flanks, while adjacent corridors have symmetric spreading. They suggest that the most likely cause for this asymmetric subsidence are sma11 lateral asthenospheric temperature gradients which produce temperature differences of $\sim 100{ }^{\circ} \mathrm{C}$. Although boundary-cooling processes explains the first-order variations of the seafloor evolution, hot spot phenomena or other heterogeneous mantle phenomena (sma11-scale convection?) may be required to explain the detailed subsidence history for some sections of ocean floor. 
The lack of unperturbed heat flow measurements for young crust $(<20-40 \mathrm{Ma})$ of the major ocean basins does not allow us to assess the heat $f$ low decay rate $\left(Q_{1}\right)$ accurately. Regiona1 heat flow measurements for mid-ocean ridges are almost always minimum values due to the convective heat loss by hydrothermal circulation. In practice, the value of $Q_{1}$ is derived from constraints on the rate of subsidence and by guessing an appropriate mantle thermal conductivity. For instance, Lister (1977) declares that values of $Q_{1}$ from 350 to $800 \mathrm{~mW} \mathrm{Myr}{ }^{1 / 2} \mathrm{~m}^{-2}$ are amenable with possible mantle rock properties although a value near 500 is generally accepted (Table 5.3). A small crustal contribution $\left(\sim 4 \mathrm{~mW} \mathrm{~m}^{-2}\right)$ to the heat flow may be necessary due to radiogenic sources (Sclater et al., 1980).

Heat flow data on old lithosphere ( $>110 \mathrm{Ma}$ ) have reliable averages which are about 47 to $52 \mathrm{~mW} \mathrm{~m}^{-2}$ and maintain values which are 10 to $15 \mathrm{~mW} \mathrm{~m}^{-2}$ above the plate and half-space cooling models (Davis et al., 1984; Detrick et a1., 1986; Louden et a1., 1987; Von Herzen et a1., 1987; Cordery, 1988). No satisfactory resolution to the heat flow and depth-age disparity for old 1ithosphere has been found (cf. Davis, 1988). These perplexing results do not necessarily have immediate bearing on young oceanic lithosphere, where a half-space cooling law is readily apparent for both heat flow and subsidence.

Therma1 age estimates. The therma1 evolution of marginal basins may be represented by the boundary layer model if the initial geotherm is similar to that of mid-ocean ridges. We feel that the thin crust of the central Liguro-Provencal Basin represents such a situation. With good age constraints, the boundary-layer mode1 may predict heat flow through 
time. Conversely, when precise dates are not available, we can estimate the 1ithospheric age from heat flow and depth. We show that, for several reasons, heat flow is a better age estimator than depth. The Ligurian and other appropriate marginal basins provide a heat flow-age test of the boundary-1ayer mode1.

1) Sensitivity of age estimators. The sensitivity of the heat flow and depth-age relationships (Equations 5.1 and 5.2) are obtained by differentiating the age estimators with respect to time:

$$
\begin{aligned}
& \frac{\partial Q}{\partial t}=\left(-Q_{1} / 2\right) t^{-3 / 2} \\
& \frac{\partial S}{\partial t}=\left(-S_{1} / 2\right) t^{-1 / 2}
\end{aligned}
$$

The age estimators have resolutions which decay with time, with heat flow decaying more rapidly than depth. The sensitivities (Equation 5.9 and 5.10) are a minimum for the actual age resolution of the data given a regional lack-of-fit for the age estimators and some parameter dependence on the rate coefficients. The ratio

$$
\frac{\partial Q}{\partial S}=\left(Q_{1} / S_{1}\right) t^{-1}
$$

defines a function for which the age resolution of the corrected values of the heat flow and depth are equivalent. This sensitivity ratio $\partial Q / \partial S$ is plotted against heat flow in Figure 5.5. Taking $\partial Q$ and $\partial S$ as the uncertainties in the site mean values for the corrected heat flow and depth, respectively, we can compare the potential resolution of the age predicted by heat flow and depth (Equation 5.1 and 5.2). Sites in which the heat $\mathrm{flow}$ is a better age estimator than the calculated TTS plot below the sensitivity curve. 


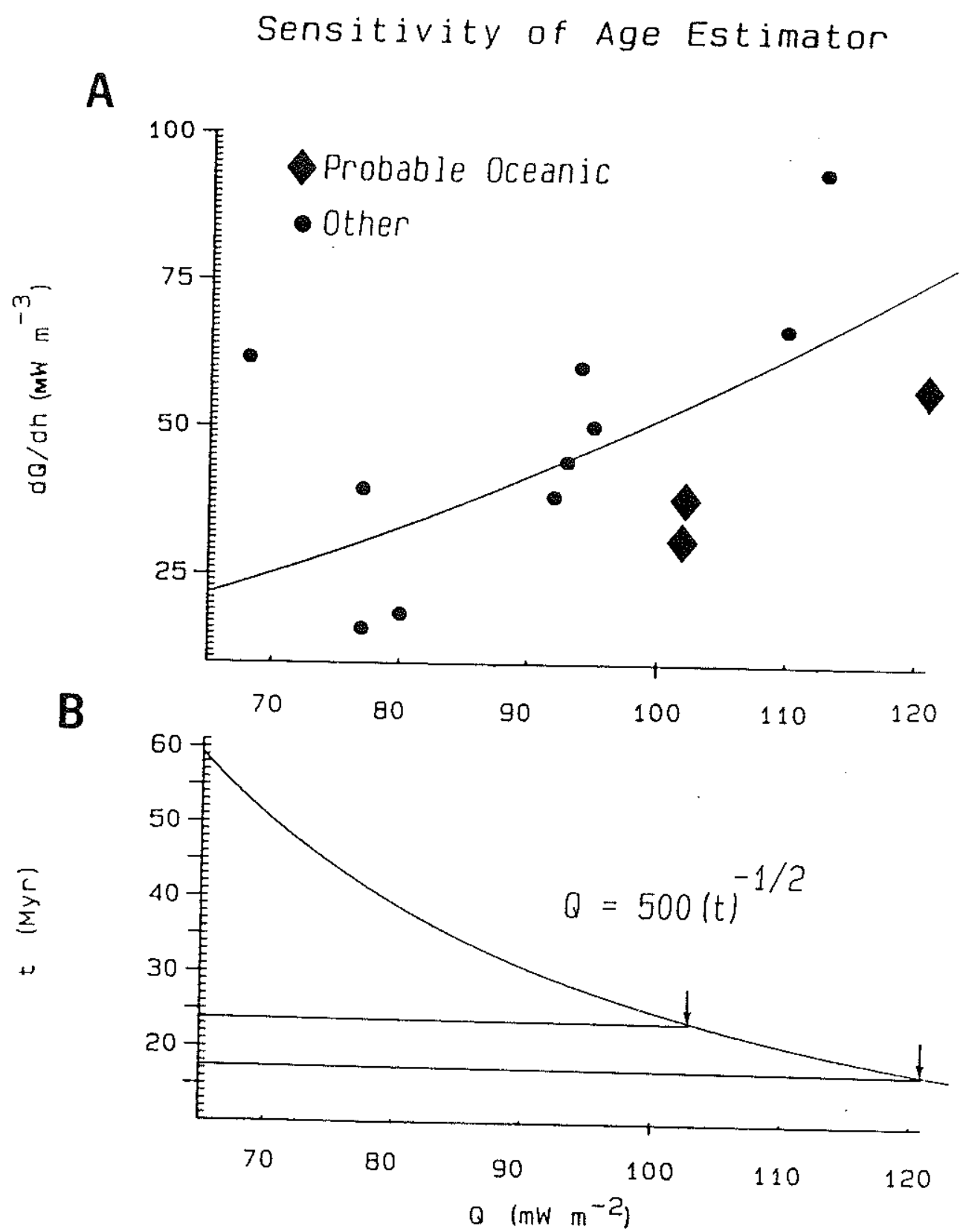

Fig. 5.5 a) Ratio of uncertainty of the heat flow to the depth values for the Ligurian Basin sites versus heat flow. The sensitivity ratio from the boundary layer model is shown as the solid curve, with heat flow being a better age estinator for points below the curve. Sites are as given in Table 4.2. b) Boundary 1ayer model heat flow vs. age curve. Age estimation is made by assuming an oceanic geotherm, which is appropriate for the probable oceanic
sites. 
We are able to determine the central basin age more accurately by using heat flow data than subsidence data. For sites $\mathrm{C} 1$ and $\mathrm{C} 2$ of the northwestern basement trough and site D1 of the south central basin, the age estimate using heat flow is roughly twice as well-resolved as the prediction of the central basin subsidence. The large depth corrections from sediment-1oading (70\%) compared to the sedimentation correction to the heat flow data (30\%) accounts for this significant result. Since the Ligurian Basin is most likely a back arc basin with an associated depth anomaly (see below), a serious bias in the depth-age relationship exists and degrades the utility of the depth-age estimator for the margina1 basins compared to the major ocean basins.

2) Heat flow vs. age. To test the boundary-layer model for back arc basins, we compare heat flow means of marginal basins of various ages (Table 5.4). Previously, Lister (1977), Anderson (1980) and Sclater et a1. (1980) have shown that Equation 5.1 is an extremely effective predictor of the heat flow-age relationship. From their work, in addition to the western Mediterranean study presented here and by Hutchison et a1. (1985), we are able to improve the age range for which reliable heat flow means are available (Figure 5.6). Some marginal basins for which heat flow data are available are not included because of tectonic or environmental disturbances. The Bering Sea or Aleutian Basin ( $>100 \mathrm{Ma}$ ) has good heat flow measurements but there is evidence that the basin has been thermally rejuvenated during the Tertiary (Langseth et al., 1980). Similar to mid-ocean ridge environments, the very young ( $<5 \mathrm{Ma}$ ) Mariana Trough has overal1 low and scattered heat flow values due to hydrothermal processes (Anderson, 1975; 1980). Heat 
Table 5.4 Reliable Mean Heat Flow Estimates of Marginal Basins

\begin{tabular}{|c|c|c|c|}
\hline Location & $\begin{array}{c}\text { Age Range } \\
\text { (Ma) }\end{array}$ & 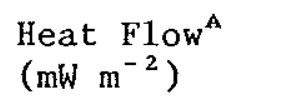 & Reference \\
\hline S. C. Tyrrhenian & $3-6$ & $171 \pm 14(26)$ & Hutchison et al. $(1985)^{\mathrm{B}}$ \\
\hline S. W. Tyrrhenian & $7-12$ & $155 \pm 13(18)$ & Hutchison et a1. $(1985)^{\mathrm{B}}$ \\
\hline Ligurian & $18-24$ & $112 \pm 16(19)$ & sites $\mathrm{C} 1 \& \mathrm{D} 1$ (this study) \\
\hline Parece Vela & $18-32$ & $95 \pm 7(6)$ & Sclater et al. $(1976 \mathrm{~b})^{\mathrm{c}}$ \\
\hline Caroline & $28-34$ & $7(6)$ & Anderson $(1980)^{\mathrm{c}}$ \\
\hline West Philippine & $38-50$ & $76 \pm 7(6)$ & Sclater et al. $(1976 \mathrm{~b})^{\mathrm{c}}$ \\
\hline Coral Sea & $56-64$ & $74 \pm 6(7)$ & Anderson $(1980)^{c}$ \\
\hline
\end{tabular}

A Corrected mean, standard deviation, and number

B $10 \mathrm{~mW} \mathrm{~m} \mathrm{~m}^{-2}$ added to correct for the effect of glacial temperatures

c Nominal $+5 \%$ correction made for effect of sedimentation rates of $\sim 20 \mathrm{~m} \mathrm{Myr}^{-1}$ in these basins 


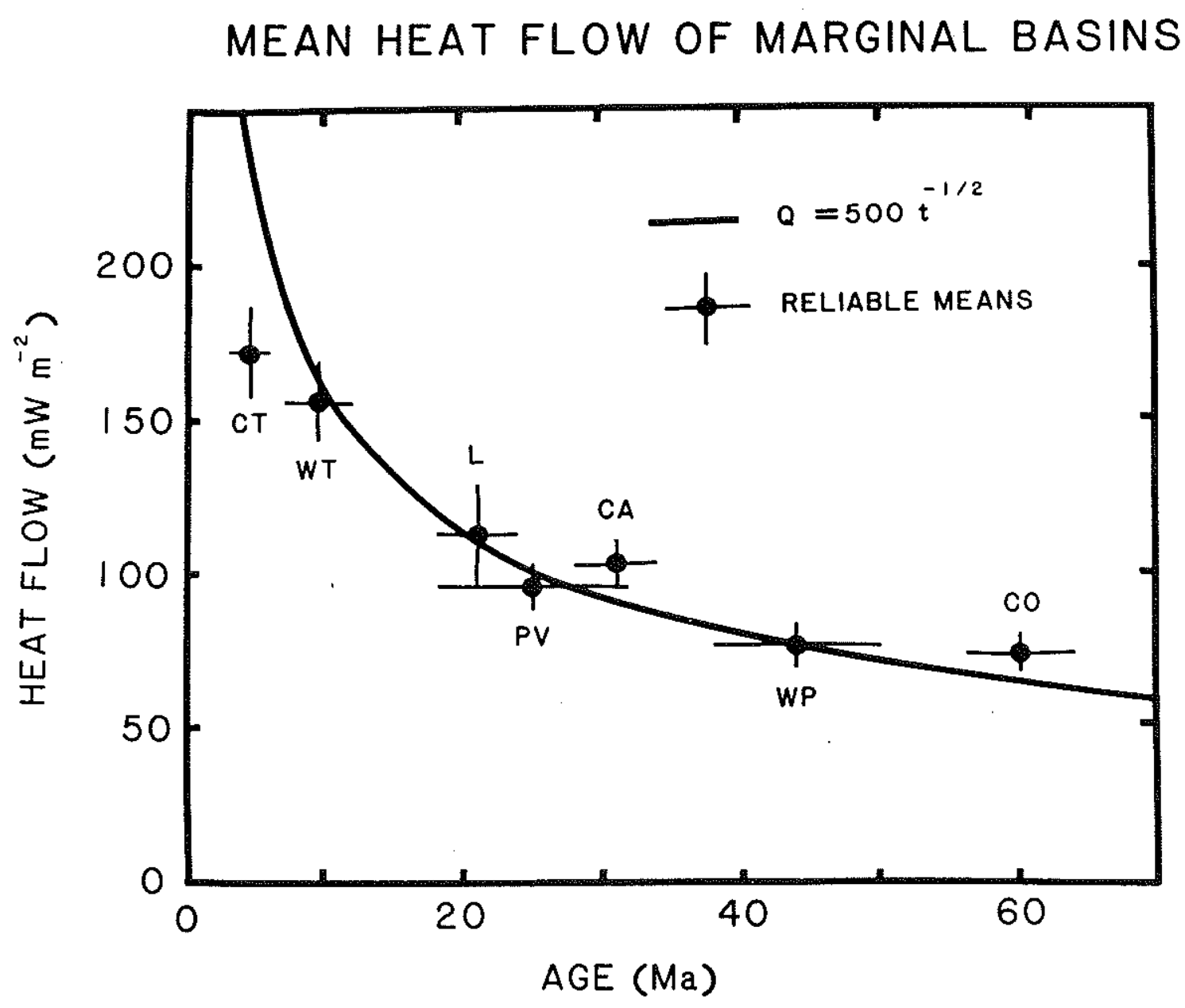

Fig. 5.6 Corrected mean heat flow vs. age for marginal basins in the western Pacific and western Mediterranean with the theoretical (age) relation. Data are given in Table 5.4 including the south central Tyrrhenian (CT), west central Tyrrhenian (WT), Ligurian (L), Parece Vela (PV), Carolina (CA), western Philippine (WP), and Coral Sea (CO) marginal basins. 
flow of the youngest site in the Tyrrhenian Sea is also probably affected by hydrothermal effects (De11a Vedova et a1., 1984; Hutchison et a1., 1985).

The assumption of purely conductive heat transfer is crucial to accurate thermal age determinations. Convective heat loss due to hydrothermal circulation should be arrested when the sediment thickness covers the seafloor topography (Anderson et al., 1977). The earliest these conditions are met on mid-ocean ridges is about 6 Myr on the Galapagos Ridge (Green et a1., 1981). In the Ligurian Basin, hydrothermal circulation is minimized by the ubiquitous early Miocene sediment cover. The average sedimentation rate in the central basin for the early Miocene is $>300 \mathrm{~m} \mathrm{Myr}^{-1}$ (Chapter 4), thus the potential for entirely conductive heat transfer occurs extremely early.

Overa11, marginal basin heat flow data indicate that the square root of age law is a good estimator of relative (if not absolute) age. Considering sites greater than about $5 \mathrm{Myr}$ in age, the best value for $Q_{1}$ is $512 \mathrm{~mW} \mathrm{Myr}^{1 / 2} \mathrm{~m}^{-2}$, with the values of 400 to 600 serving as a we11-constrained envelope for the theoretical heat flow. In contrast to the findings of Burrus and Foucher (1986), our results confirm that the corrected heat flow in the Liguro-Provencal Basin is in excellent agreement with boundary-layer cooling predictions for two main rifting events within the central basin.

Rift jump mode1. Our best estimate of the average thermal age is about $21 \mathrm{Ma}$. This is consistent with the the absolute age estimates determined from volcanic and sedimentary data on land and on the margins (see Chapter 2). However, environment-corrected heat flow pattern and 
other geophysical evidence strongly suggests an asymmetric spatiotemporal development for the basin. We use the heat flow-age estimator to out1ine basin evolution resulting from a temporal variation in rifting across the central basin. Not only does the consistency of the thermal and chronologic data suggest a half-space cooling mechanism, but the heat flow trends reflect the distribution of 1 ithospheric thinning across the basin. Therefore, we also consider an alternative model based on an asymetric 1ithospheric thinning mechanism (see Section 5.4$)$

Using Equations 5.1 and 5.9 and a heat flow decay rate $Q_{1}$ of $512 \mathrm{~mW} \mathrm{Myr}^{1 / 2} \mathrm{~m}^{-2}$, the north central basin (site $\mathrm{C1}$ ) has an age of $25 \pm 5$ Myr and the south central basin (site D1) is younger at $18 \pm 4$ Myr (Figure 5.5). For a lower $Q_{1}$ of $473 \mathrm{mw} \mathrm{Myr}{ }^{1 / 2} \mathrm{~m}^{-2}$, the north and south central basins have ages of $21.5 \pm 5$ and $15 \pm 4 \mathrm{Myr}$, respectively. Assuming that each sub-basin maintained an initial geotherm similar to the mid-ocean ridges, we assert that an age difference of approximately $7 \pm 5$ Myr exists between the north central trough and south central trough. Because of the uncertainty in $Q_{1}$, we place a higher degree of confidence in the relative age rather than the absolute age determinations.

One shortcoming of using heat flow to define a minimum age for the southeastern trough (site D1) is that the sedimentation rates become much higher than that used in our corrections, since we must increase the age of oldest Miocene sediment assumed to be 21 Myr everywhere in the original results (Appendix 4). If we forward mode1 the heat flow and incorporate an appropriately younger initial 1ithosphere, the higher 
sedimentation rates depress the heat flow by a larger amount so that a younger initial age is required. This results in a 2 Myr decrease in the age estimate from 18 to $16 \mathrm{Myr}$ ago. Although this shift in age is within the \pm 4 Myr resolution calculated for site D1 heat flow, the calculated sedimentation rates appear to be excessively large. If the mean corrected heat flow is $5 \mathrm{~mW} \mathrm{~m}^{-2}$ too high due to perhaps disequilibrium compaction or bottom water changes, etc., the forward modeling converges to the minimum age of $18 \mathrm{Myr}$.

Corroborating evidence for later rifting on the Corsican margin than on the Cote d'Azur margin is given by comparing volcanic ages in the two regions. Volcanics off southwestern Corsica are dated at $17 \pm 2$ Myr (Bellon et al., 1985) and graben formation in the Gulf of Bonifacio occurred on the northwestern Sardinian margin roughly 17 to $19 \mathrm{Myr}$ ago (Thomas and Genneseaux, 1986). In contrast, a calc-a1kaline volcanic unit drilled in the basement of the Valencia Trough dated at 23.8 \pm 1.2 Myr (Riviere et al., 1.981) is associated with the Gulf of Lion margin formation. The Valencia Trough opening may correspond to the latter stages of rifting on the northern margin of the Liguro-Provencal Basin. Thus, volcanics on the Corsican margin probably postdate the main spreading episode and are definitely later than evidence for rifting on the southern French margin.

The preferred temporal model is that a punctuated rift jump rather than a gradual rift migration occurred within the central basin. The south central basin formation probably coincides with the final stages of drifting of Corsica and Sardinia ( $18 \mathrm{Ma})$. The north central basin is a deep trough that formed concurrently with the Valencia Trough 
( $24 \mathrm{Ma})$. This late 01 igocene to early Miocene event represents the transition between continental rifting on the European margin and the main spreading phase in the Balearic Basin. Stratigraphic evidence for this transition is demonstrated by an Aquitanian and lower Burdigalian (24-21 Ma) marine transgressive series recorded in the Sardinia continental rift (Cherchi and Montadert, 1982) and on the western Balearic and Gulf of Lion margins (Hsu, Montadert et a1., 1978; Cravatte et a1., 1974).

The hypothesis of progressive rifting within the Liguro-Provencal Basin is impossible to disprove on the basis of the magnetic anomaly lineations (Figure 5.4). We suggest that the interpretation of magnetic data by Burrus (1984) and others is in need of revision. We do not support the idea that the central positive magnetic anomaly in the Nice-Calvi transect is associated with the main spreading center, especially since the fine structure of the magnetic signal is probably highly attenuated by the thick sediment cover and consequent large basement depths. In fact, the asymmetric trends in therma1, Moho, and basement structures are more easily explained by two distinct trough formations within the central basin.

The mechanism by which rift jumps occur is poorly understood. Rift jump mechanisms may be similar to those invoked for asymmetric spreading (Barker and Hil1, 1980). Wood (1983) suggests that the magnitude of rift jumps are determined by 1 ithosphere thickness; short jumps of 6-26 $\mathrm{km}$ occur on the Galapagos Ridge which has a thickness $\sim 10 \mathrm{~km}$ (Hey et a1., 1980). The proposed rift jump in the Ligurian Basin is on the order of $30 \mathrm{~km}$, which is proabably in good agreement with the 
lithosphere thickness at that time.

In the context of a back arc basinal setting, rift jumps may be a consequence of the episodic migration of the arc-trench system due to "local" (active) or "globa1" (passive) forces (Taylor and Karner, 1983). A "rollback" mode1 is one such "passive" mechanism in that back arc extension occurs as a result of the subducted plate retreating from the overriding plate (e.g., Dewey, 1980). After a short period of back arc spreading, the regional axis of minimum lithosphere strength may be transposed from the quasi-extinct back arc spreading center to the active island arc. When extension due to trench migration occurs again, the new rift relocates near the island arc volcanic line. This type of basin to arc jump accurately describes the relationships of the Parece Vela Basin and Mariana Trough in the Philippine Sea (Karig, 1971), and probably between the Balearic and Tyrrhenian Basins. The fact that the new rift axis always relocates toward the island arc is consistent with a component of "active" mantle diapirism perhaps induced by the subducting plate (cf. Karig, 1971), with the locus of main asthenospheric upwelling controlled by the subducted slab geometry.

An intrabasinal rift jump, instead of a rift jump from the centra1 basin to a mature island arc, is required to explain the heat flow distribution within the Ligurian Basin. By "intrabasinal" rift jump, we cannot include the possibility that the new rift was superimposed on an immature island arc which may have been forming at the base of the back arc basin margin closest to the trench. Although Sardinia is considered the representative volcanic arc throughout the Liguro-Provencal Basin opening (Montigny et al., 1981), it is possible 
that an immature island arc may have existed at the base of the north and western margin of Corsica where the rift relocated. Intrabasinal rift jumps are inferred for the Mariana Trough (Bibee et a1., 1980) and Tyrrhenian Basin (see below). The transient stress regime and short spreading histories experienced by many back arc basins (Weisse1, 1981) may promote intrabasinal jumps, which in turn may cause apparently diffuse spreading centers observed in some marginal basins (Lawver and Hawkins, 1978). A good indication of a distinct regional stress change in the Western Mediterranean is given by the transition from translational to rotationa1 movement of the Corsican-Sardinian continenta1 block (Rehault et a1., 1984; Burrus, 1984). Thus, asymmetric heat flow in a young back arc basin may be symptomatic of marginal basins involved in a migrating arc-trench system.

Recent findings from Ocean Drilling Project Leg 107 in the Tyrrhenian Basin (Kastens, Mascle et a1., 1987) provides insights into possible mode1s for the Ligurian Basin development. The Tyrrhenian and the Ligurian Basins are similar since both have asymmetric margin widths, a back arc setting (probable), rift duration on the order of $\sim 10$ Myr, and two major oceanic-type sub-basins with the younger basin near the island arc and the older near the remnant arc block. Moreover, the asymmetric heat flow distribution in both basins is consistent with NW to SE intrabasinal rift jumping (see also Hutchison et a1., 1985). The main difference is the basin geometry and width; the linear, $\sim 150 \mathrm{~km}$ wide Liguro-Provencal Basin contrasts with the triangular, $600 \mathrm{~km}$ wide Tyrrhenian Basin. Also, the disposition of prerift crusta1 lineaments may facilitate detachment faulting in the Tyrrhenian as 
opposed to the Ligurian region (Mascle and Rehau1t, 1988).

To explain the Tyrrhenian Basin evolution, the preferred model of Mascle and Rehault (1988) and Kastens (1988) evoke both crustal detachment faulting and rift jumping. The main evidence for detachment faulting is given by the Sardinian margin $(200 \mathrm{~km})$ being wider than the Calabrian margin $(100 \mathrm{~km})$, with the Sardinian margin possessing numerous tilted blocks. In the asymmetric margin development mode1 of Lister et a1. (1986), the Sardinia margin is the lower plate margin above which the breakaway zone occurs. Drilling results indicate that the Sardinia lower margin was actually higher-standing than the upper margin during the Messinian, since relatively thick evaporite deposits are found on the upper margin and an erosional unconformity is found on the lower margin. Perhaps due to a new phase of rifting, movement on the detachment surface proceeded faults was abandoned and tilted blocks were left behind up-dip on the lower plate margin and the locus of main extension is transferred to a position farther down-dip. Eventually the crust thinned to a point where magmatic processes became important and the first oceanic sub-basin, the Vavilov Basin, formed in P1iocene time. Upper mantle rock is exposed in the Vavilov Basin and its emplacement is thought to result from the latter stages of simple shearing of the 1ithosphere. A formal rift jump accounts for the formation of the Marsili Basin, the Pleistocene oceanic sub-basin.

Since we are unable to resolve such a detailed structural progression in the Ligurian Basin, the role of detachment faulting and simple shearing of the lithosphere in the formation of asymmetric heat flow pattern remains ambiguous. Using heat flow results and crustal 
thickness estimates for the continental margin sites (Table 4.2) and preliminary calculations of the ratio of subcrustal to crustal thinning using the nonuniform extension mode1 (Royden and Keen, 1980; He11inger and Sclater, 1983), we infer that some asymmetric structural thinning of the 1ithosphere has taken place. Since the duration of rifting is $<10 \mathrm{Myr}$, the rifting/drifting event is essentially instantaneous and the simple extensional models may be employed without producing large errors in the heat flow calculations (Jarvis and McKenzie, 1980). Comparisons of the heat flow and crustal data in the central basin are complicated by certain magmatic additions to the thin crust so that the extension estimates derived from the crustal thickness alone are poor. Since the two structural sub-basins have oceanic-type crust and some constancy in heat flow, we assume that the boundary layer model is appropriate. The rift jump model characterizes their relationship quite we11.

In terms of age variations which are consistent with the two sub-basins, the heat flow suggests that the Cote d'Azur margin is . younger than the Corsican margin. We speculate that the following sequence of thermotectonic events may have occurred in the Ligurian region:

a) $\sim 35$ to 30 Myr: graben formation took place on the present upper margins,

b) 30 to $22 \mathrm{Ma}$ : rifting of the lower margins and development of the deep northwestern trough off southern France,

c) 22 to $20 \mathrm{Ma}$ : transition from translationa1 to rotationa1 movement of the Corsican block, rift jump made to Corsican lower margin, 
d) 19 to $17 \mathrm{Ma}$ : development of North Corsican Basin (southeastern trough) and rotation of Corsica to its present position. Assuming a rift age of $\sim 20 \mathrm{Myr}$, the mantle 1 ithosphere beneath the Cote d'Azur margin (e.g., region B) had thinning factor about half that of the crust implying signigicant nonuniform extension. For an older formation age of 32 Myr, uniform lithospheric extension is appropriate (cf. McKenzie, 1978). Converse1y, 20 Myr old uniform extension is compatible with the lower Corsican margin data and an older formation ( 25 Myr ago) requires excessive mantle thinning. Perhaps the best evidence for asymmetric margin development is given by the Corsican continental borderland where the heat flow suggests that about $50 \%$ of the mantle lithosphere has been removed during the Ligurian Basin opening. Although we have little structural evidence for a low-angle normal detachment fault and are somewhat uncertain in the age of margin formation, the heat flow-crustal thickness relationships of the Ligurian margins are consistent with some degree of asymmetric subcrustal thinning, similar to that predicted by the simple shear model (cf. Wernicke, 1985; Lister et a1., 1986). The Cote d'Azur margin is the lower plate margin above which the "breakaway" takes place, and the Corsican block served as the upper plate.

Lateral heat loss. The good fit of the marginal basin heat flow with the simple half-space cooling model (Figure 5.5) strongly contrasts with the theoretical results predicted by two-dimensional 1ithospheric heat conduction models. Alvarez et al. (1984) and Cochran (1983) have modeled small basins ( $100 \mathrm{~km}$ wide), and conclude that the heat flow may be reduced by up to $50 \%$ of the one-dimensional case; the lateral 
effect is dependent on the basin width, extension factor ( $($ ), and duration of rifting. Alvarez et a1. (1984) also suggest that lateral heat conduction prevents normal oceanization due to quenching of the partial me1ting process.

It is difficult to reconcile the overall high heat flow with the narrow geometry of the Ligurian basin. A1so, lateral heat flow gradients indicated by the surface measurements are high at $1 \mathrm{~mW} \mathrm{~m} \mathrm{~m}^{-2}$ per kilometer. The asymmetric distribution with lower heat flow on the European side of the basin (NW) is consistent with the structure of the borderlands. The thicker and cooler European continental block should theoretically extract more heat from the NW trough than Corsican block conducts from the $\mathrm{SE}$ trough. Horizontal heat flow is also ascribed as an important effect on the subsidence of the Gulf of Lion shelf (Steckler and Watts, 1980). However, the NW basin heat flow should be reduced by more than $50 \%$ of the one-dimensional solution due to the abrupt crustal thinning across the Cote d'Azur margin: this large thermal depression is not observed. We present three possible explanations for the apparent lack of lateral heat loss in the Ligurian Basin: regionally thin 1 ithosphere, anisotropic thermal conductivity in the upper mantle, and an improper one-dimensional solution.

Alvarez et al. (1984) show that an important factor in the amount of lateral heat conduction is the ratio of lithospheric thinning to the basin width. If the marginal lithosphere is anomalously thin before or during rifting, the mean horizontal temperature gradient at the depth of the newly-formed oceanic lithosphere is minimized. Therefore, a thin equilibrium 1ithosphere prior to rifting or a regional lithospheric 
thinning during rifting are plausible mechanisms by which low horizontal heat flow is maintained in the central basin.

Evidence for regional thinning of the mantle lithosphere is consistent with observations of doming and uplift on the Ligurian borderlands (Chapter 2). Alternatively, a thin equilibrium 1ithosphere (100 km or less) would aid in restricting lateral heat loss from the oceans to the continents. A thin 1ithosphere for the Maures-Esterel region would suggest that the radioactive contribution of the crust is much sma1ler than that estimated by Lucazeau and Mailhe (1986). They guess that the heat flow due to radioactivity is $40 \mathrm{~mW} \mathrm{~m} \mathrm{~m}^{-2}$ which implies a $165 \mathrm{~km}$ 1ithosphere. A much sma1ler radiogenic component of 15-20 $\mathrm{mW} \mathrm{m}^{-2}$ would be consistent with $100 \mathrm{~km}$ thick lithosphere below southern France. This value is also compatible with surface wave studies in western Europe (Panza et al., 1980).

The apparent lack of lateral heat loss may also be explained by an anisotropic thermal conductivity structure in which the preferred direction is the vertical. No directional conductivity data for the upper mantle material is available in the literature, but anisotropy of the appropriate sign may be inferred from related studies. Velocity $( \pm 5 \%)$, grain, and crystallographic anisotropies are indicated by structural petrologic studies of ophiolites and by seismic refraction and surface wave studies of the upper mantle (e.g., Salisbury and Christensen, 1985; Forsyth, 1975). Anisotropic conductivity of olivine crystals is inferred by large discrepancies ( $100 \%)$ in values for single crystal measurements versus ceramic samples (see Lister, 1977, and references therein). The olivine a (100) crystallographic axis, 
which may be taken as the low conductivity direction, is preferentially oriented in the direction of spreading at the mid-ocean ridge. The $\underline{c}$ (001) axis, the high conductivity direction, is probably subvertical in the upper mantle. Thus, the higher gradients and conductivity would minimize lateral heat conduction in the upper mantle, making the one-dimensional solution an adequate model of the central basin.

A third possibility is that lateral heat flow does exist, and that the observed heat flow-age relationship agreement with the one-dimensional solution (Figure 5.5 ) is coincidental. If the actual heat flow decay rate $\left(Q_{1}\right)$ is about twice as high (1000 vs. $500 \mathrm{~mW}$ Myr ${ }^{1 / 2} \mathrm{~m}^{-2}$ ), then the observed heat flow in the Ligurian Basin would agree with two-dimensional predictions. As suggested by Lister (1977), values of up to $800 \mathrm{~mW} \mathrm{Myr}^{1 / 2} \mathrm{~m}^{-2}$ may be compatible with mantle properties. However, this high heat flow decay rate requires a large systematic decrease of heat flow for each marginal basin, implying that processes such as convective heat loss due to hydrothermal circulation and lateral heat loss are more pervasive than previously thought. However, it is doubtful that the heat $f$ low-(age $)^{-1 / 2}$ data for marginal basins are arbitrarily linear due to these effects.

Thus, our preference is that an anisotropic upper mantle conductivity together with an anomalously thin lithosphere genera11y suppresses the effects of lateral heat flow in small oceanic basins. The most 1ikely sites for significant lateral heat conduction are pull-apart basins such as the Los Angeles Basin (Sawyer et al., 1987) which are not largely influenced by regiona1ly upwelling asthenosphere. 
Residual depth anomaly of back arc basins. On the basis of the observed calc-alkaline volcanism and reconstructed kinematic development, the Liguro-Provencal Basin is considered a result of back arc extension. Assuming one-dimensional cooling applies as suggested by the heat flow data, the depth-age relationships for back arc basins are fundamentally different from that of the major ocean basins. Typically, the subsidence of the western Pacific marginal basins is on the order of 1 $\mathrm{km}$ deeper for similarly-aged normal crust, while the heat flow remains nearly norma1 (Sclater et a1., 1976b; Watanabe et a1., 1977; Anderson, 1980; Louden, 1980). Since oceanic crust is a quasi-end member in continental lithospheric stretching models (infinitely-thinned continental crust with melt segregation), back arc margins may also have abnormal subsidence behavior compared to passive margins of the major oceanic basins.

The residual depth anomaly is the difference between sedimentunloaded basement depth and the predictions of thermal models. In Appendix 1, we establish that the central basin subsidence was over several hundreds meters deeper than predicted from an ocean basin mode1. We suggested that the depth anomaly could be accounted for by the back arc setting and by the thin crust $(<6 \mathrm{~km})$. Negative depth anomalies are also observed throughout the central Balearic Basin (Rehault et al., 1984) and on the Gulf of Lion margin (Burrus and Bessis, 1986). Explanations for the depth anomaly in the Liguro-Provencal Basin include the following: dynamic forcing of the topography, thin crustal loads, anomalous composition of the upper mantle, or a low average upper mantle temperature. 
Since the observed heat flow is apparently normal, the general consensus among geophysicists is that the depth anomaly is generated by mantle composition differences in back arc versus major ocean basins. Like1y causes are a dense slab at depth (e.g., Louden, 1980) or subduction-related chemical changes in the upper mantle (Yoshii, 1973). Anderson (1980) points out that the good match of the marginal basin heat flow to the half-space model (Figure 5.6) precludes the thermal structure being substantially different from normal oceanic 1ithosphere. On the other hand, geochemists have suggested that a relatively cool mantle is consistent with the petrology of back arc basin basalts (BABB). Dick $(1980 ; 1982)$ proposed that hydrous melting of the subducted and overriding plates is consistent with the high $\mathrm{H}_{2} \mathrm{O}$ content of BABB. Dick $(1980 ; 1982)$ also inferred that the residual depth anomaly is a consequence of relatively cool mantle associated with convection induced above subduction zones as opposed to mantle derived from the passive upwelling of asthenosphere at mid-ocean ridges. The major element geochemistry of $\mathrm{BABB}$ (e.g., high $\mathrm{Al}_{2} \mathrm{O}_{3}$, low $\mathrm{FeO}$, high $\mathrm{SiO}_{2}$ ) are further evidence for substantial melting (8-20\%) of a cool convecting mantle (e.g., Sinton and Fryer, 1987). Moda1 studies of peridotite (Dick and Fisher, 1984) indicate that the extent of me1ting in ophiolites with probable back arc affinity are similar to those of major ocean mantle, so that one may speculate that back arc regions are slightly more depleted in iron-bearing phases (olivine = low forsterite content; pyroxene = diopside-poor). We use the back arc subsidence and heat flow data to establish a back arc thermal evolution model which is consistent with geochemical and mineralogical data. 
Many interacting forces are involved in subduction. Suction due to downwelling of the subducted slab or flexure due to in-plane stress generated at the trench are two possible elements which may maintain a bathymetric low. We exclude dynamic support as being important because the depth anomaly generally persists for inactive basins far removed from the subduction zone, as is the case for the Ligurian region. Moreover, negative gravity, negative geoid, and residual depth anomalies in the Philippine Sea back arc basins are adequately explained by an isostatically compensated mass excess located $25-100 \mathrm{~km}$ in the upper mantle (Bowin, 1981). External forcing or deep slab sources for the depth anomaly cannot account for both the total subsidence and the gravity/geoid data. We pursue anomalous crustal loading or high upper mantle density as possible mechanisms in the Ligurian Basin.

We use the deep refraction data of Le Douaran et al. (1984), Nicolich (1981), and Fahlquist and Hersey (1967) to investigate the sediment and crustal-1oading effect on the subsidence. According to their results, a total of 23 stations detect Moho in the central Liguro-Provencal Basin and are accompanied by negligible free air gravity anomalies ( \pm 20 mgal). The two methods applied to the seismic stratigraphy data in Section 5.1 are used to calculate the sediment-unloaded depths: the Crough (1983) method for sediment trave1-times, and the backstripping method using the Nafe and Drake (1963) velocity-density relationship. As in the calculations using seismic stratigraphy, we find that these two methods give results which are mutual1y exclusive assuming a $\pm 10 \%$ uncertainty in the depth correction. Depending on the unloading scheme, the corrected basement 
depths are about 500 to $1000 \mathrm{~m}$ greater than normal oceanic crust, with an average crustal thickness of $\sim 4 \mathrm{~km}$ in the Northwestern Mediterranean (Figure 5.7).

The possibility that the back arc depth anomaly is a result of thin crust has been hypothesized by a number of investigators (Karig, 1971; Sclater et a1., 1976b; Watanabe et al., 1977). However, it has not been demonstrated conclusively that back arc basin crust is in fact thinner (cf. Louden, 1980). As shown in Table 5.1, a crust which is 1 to $2 \mathrm{~km}$ thinner than normal can account for at most several hundred meters of additional subsidence. To remove the effect of crustal variations, a "free mantle" depth-age curve for back arc basins is constructed (Figure 5.8). For consistency with other back arc data (see Louden, 1980 and references therein), the Nafe and Drake (1963) relationship is used to derive crust-unloaded mantle depths.

After accounting for crustal loading, an anomaly of about 500 to $750 \mathrm{~m}$ sti11 remains for the Liguro-Provencal Basin. The south centra1 Tyrrhenian Basin crustal section of Duschennes et a1. (1986), with age constraints provided by recent borehole studies in the Vavilov Basin (Kastens, Mascle et a1, 1987), has a depth anomaly of similar magnitude. Thus, the subsidence trends are consistent with a back arc origin for the western Mediterranean basins, as are the increasing heat flow (Hutchison et a1., 1985) and the general decrease in volcanic ages from west to east (Bellon, 1981).

The depth-age curve (Figure 5.8) indicates that back arc basins maintain a subsidence rate $\left(S_{1}=290 \mathrm{~m} \mathrm{Myr}^{-1 / 2}\right)$ that is not significantly different than normal ocean floor (Table 5.3). Moreover, the depth and 


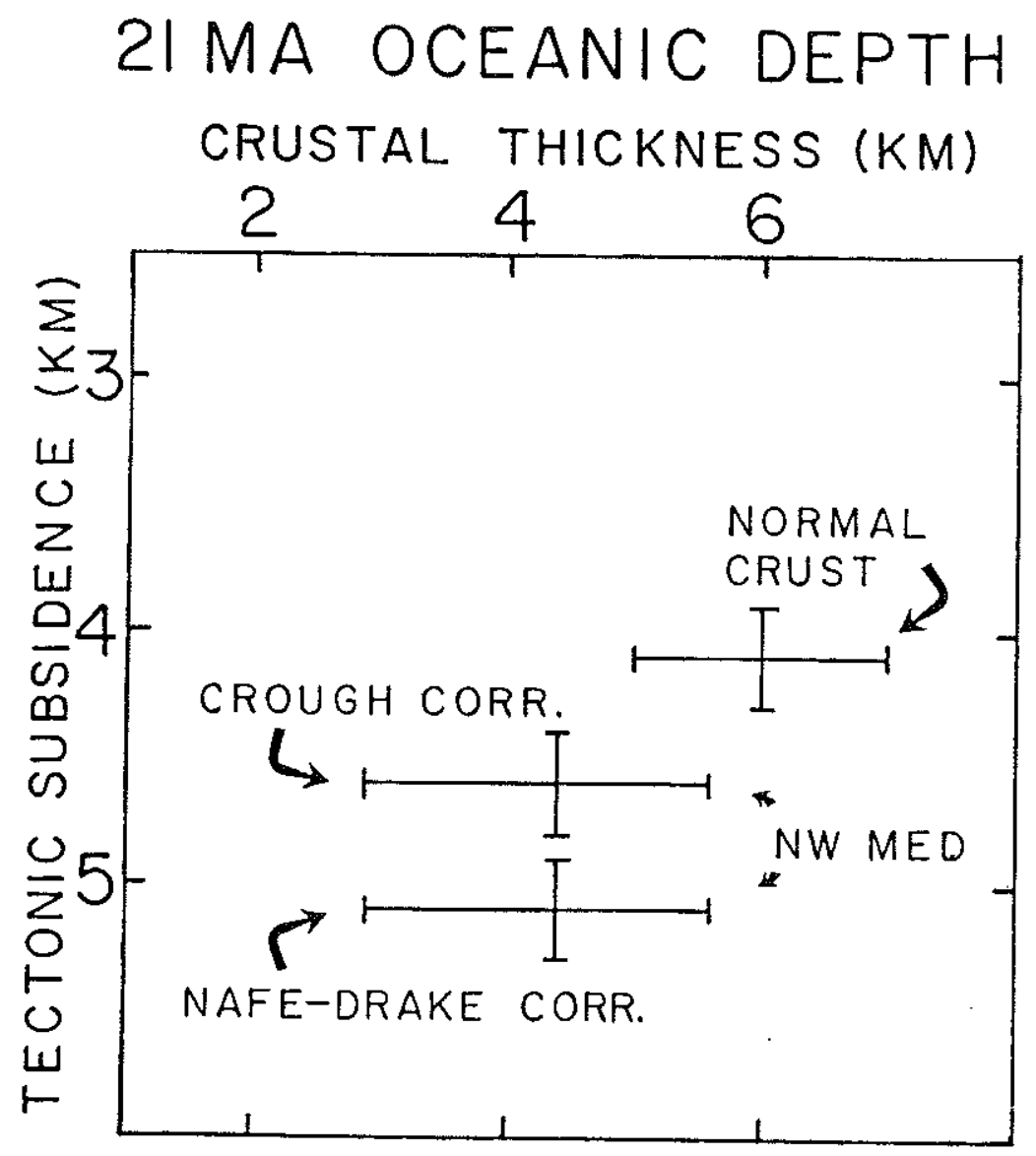

Fig. 5.7 Sediment-unloaded basement depths vs. oceanic crustal thickness of Northwest Mediterranean seismic refraction profiles (see text). Both the Nafe and Drake (1963) and Crough (1983) corrections for sediment loading are given. Error bars are standard deviation of the data. Theoretical value for the plate model is a1so shown. 


\section{FREE MANTLE DEPTH}

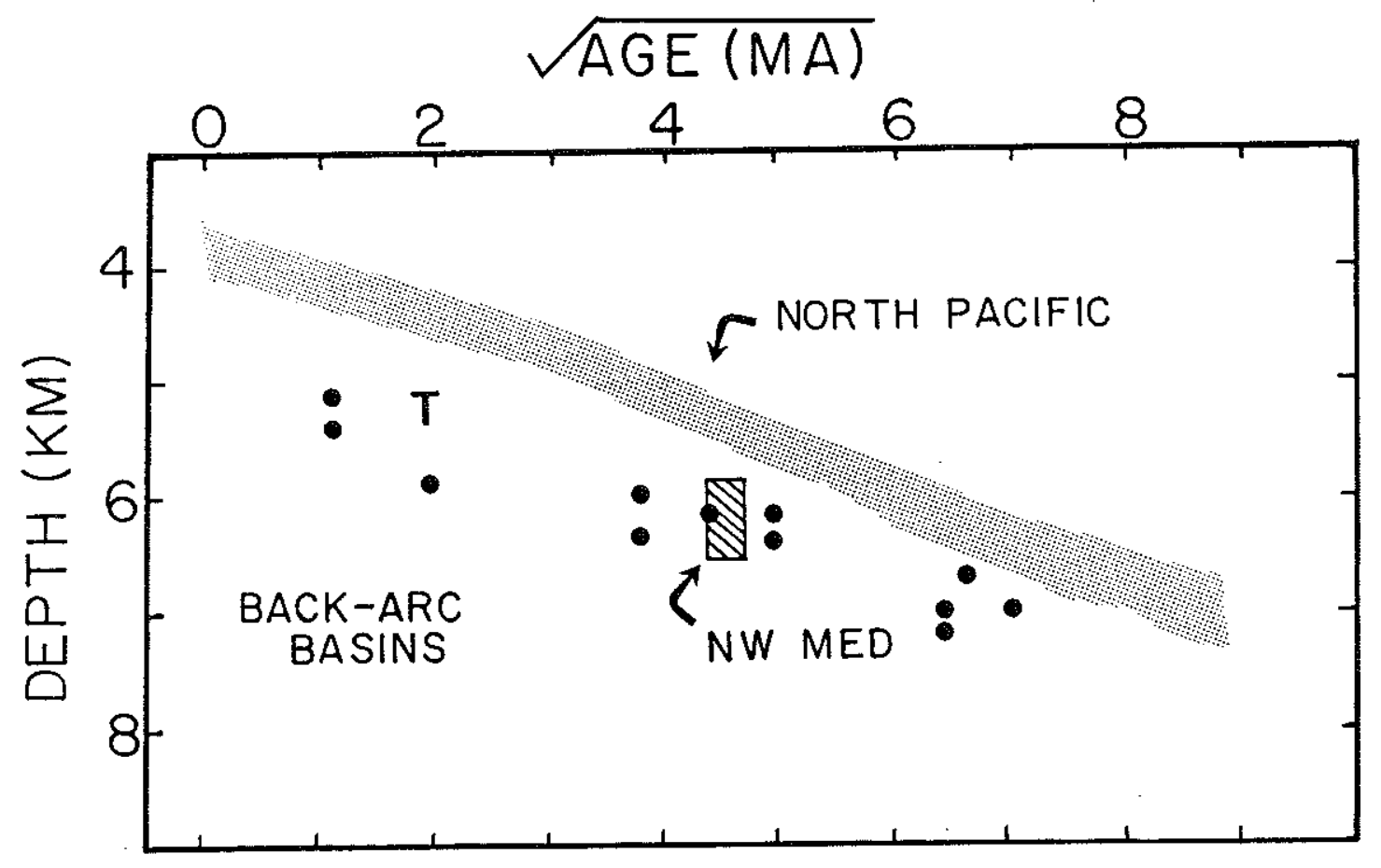

Fig. 5.8 Unloaded mantle depths vs. (age $)^{1 / 2}$ for the northern Pacific Ocean Basin (stippled region) and the marginal basins of the Philippine Sea (dots), the Liguro-Provencal Sea (hachured) and south central Tyrrhenian Sea (shown as T). The North Pacific and Philippine basin data are taken from Louden (1980). 
heat flow-age trends do not require abnormal cooling histories, i.e., a two-stage thermal evolution (Watanabe et a1., 1977) or steady-state boundary condition at the 1 ithosphere-asthenosphere boundary (Louden, 1980). Assuming a $6 \mathrm{~km}$ crustal thickness for back arc basins, the extrapolated ridge depth $\left(S_{0}=3500 \mathrm{~m}\right)$ is about a kilometer greater than that calculated for normal mid-ocean ridges (Parsons and Sclater, 1977). Thus, as suggested by Watanabe et al. (1977) and Anderson (1980), the depth anomaly is attributed to a ridge crest offset, not to abnormal subsidence rates.

We can document the zero-age depth for only a few back arc basins. The active spreading center of the Mariana Trough maintains a ridge depth of about $3400 \mathrm{~m}$ despite a normal crustal thickness (Karig et al., 1978; Bibee et a1, 1980). The Tyrrhenian Basin has no actual linear spreading center, but the Marsili Basin is probably no older than 2 Myr and also has a similar residual depth anomaly. Exceptions to the marginal basin depth anomaly are the okinawa Trough and Lau Basin (Kobayashi, 1984). The Okinawa Trough is a very young back arc rift and cannot be considered as a well-developed back arc basin similar to the Mariana spreading center. The Lau Basin is a site of disorganized spreading with triple junction complications (Weisse1, 1981); triple junctions are normally sites of anomalously shallow ridge depths (Le Douaran and Francheteau, 1981).

In the spectrum of axial depths ranging from "hot spots" on the Mid-Atlantic Ridge (Azores and Iceland) and a "cold spot" on the southeast Indian Ridge (Australian-Antarctic Discordance; Hayes, 1988), back arc basins would lie near the colder extreme. Thus, we hold that 
the back arc residual depth anomaly is explained by the same mechanisms by which the deeper segments of mid-ocean ridges are formed.

Ridge crest depth, geochemistry, and mantle temperature have been correlated in the major ocean basins (Bowin et a1., 1984; Klein and Langmuir, 1987). Using Equation 5.6, we relate the ridge variation to the reference mantle density $\left(\rho_{0}\right)$, the asthenospheric temperature $\left(T_{1}\right)$, and the depth of compensation $\left(D_{c}\right)$. For the reference mantle density to account for the depth increase, an increase of $100-200 \mathrm{~kg} \mathrm{~m}^{-3}$ acting over a depth range 100 to $200 \mathrm{~km}$ is required. If we assume that back arc mantle tends to be more depleted than average, as suggested by chemical data for some ophiolites in island arc settings (Dick and Fisher, 1984), we would expect the ridge depth to be more shallow due to the slight decrease in the residual mantle density upon partial melting (Table 5.1). Thus, geochemical changes within the back arc mantle are not a likely mechanism to cause denser upper mantle.

We propose that the mean mantle temperature beneath the back arc basin is lower than similarly-aged normal lithosphere. With reasonable estimates of depth of compensation, temperature anomalies of the order of $-125 \pm 50{ }^{\circ} \mathrm{C}$ in the asthenosphere give an appropriately denser mantle (Figure 5.9). This difference in temperature is consistent with the compositional and mineralogical character of back arc mantle (klein and Langmuir, 1987; Sinton and Fryer, 1987; Dick 1980, 1982), and is not unreasonable given estimates of global asthenospheric temperature variations (Klein and Langmuir, 1987; Hayes, 1988). A cooler upper mantle in back arcs is created by the restricted exchange with the deep mantle due to the proximity of the subducted slab and associated 
RELATIVE RIDGE DEPTH

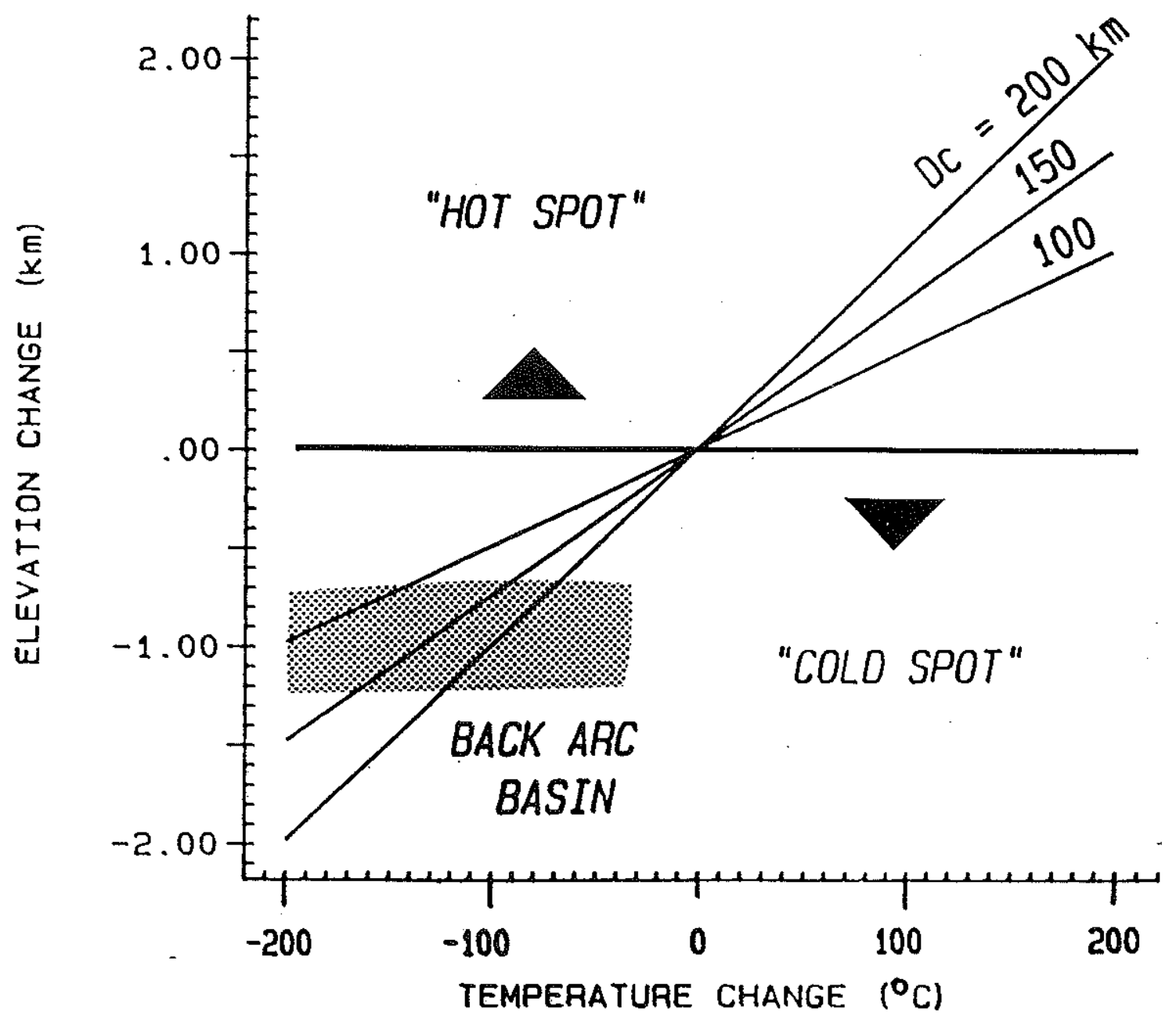

Fig. 5.9 Relative change in ridge crest elevation due to mean upper mantle temperature changes. Curves for various depths of compensation $\left(D_{c}\right)$ are calculated using $\alpha=3.28 \times 10^{-5}$ and $\rho_{0}=3330 \mathrm{~kg} \mathrm{~m}^{-3}$. $\mathrm{T}_{1}=1333^{\circ} \mathrm{C}$ and $\mathrm{S}_{0}$ are taken as "normal" ridge crest parameters. 
counterflow processes. The slab itself may serve as a heat sink to the overlying back arc mantle.

With this $10 \%$ temperature anomaly, the theoretical heat flow in back arc basins would be expected to be about $10 \%$ lower than that of the major ocean basins (Equation 5.3). We acknowledge that the heat flow is not. Instead, we propose that the apparent lack of low heat flow is reconciled by a higher effective thermal conductivity (10-20\%) compared to the major ocean upper mantle. This resolves the paradox of cooler, more dense lithosphere with near normal levels of heat flow.

Higher mantle thermal conductivity is predicted for back arc basins as depleted (i.e., Mg-rich) mantle has higher conductivity than relatively undepleted mantle. Partial melting increases the forsterite content of the residual olivine and the Mg非 of orthopyroxene while decreasing the percentage of diopside in the mantle. From the work of Schatz and Simmons (1972), we infer that each of these compositiona1 changes will increase the conductivity. In addition to the properties of depleted mantle, the overa11 lower temperatures will also increase the back arc mantle thermal conductivity. As a semiquantitative estimate, we can interpolate a change of about $0.5-1.0 \mathrm{~W} \mathrm{~m}^{-1} \mathrm{~K}^{-1}$ between the olivine phase of the "fertile" versus the "residual" mantle of Table 5.1. Thus, to increase the conductivity by $10 \%$, an increase of $1 \%$ in the forsterite content of olivine may be sufficient. A1though the conductivity estimates for the upper mantle are not very good, the agreement between geochemical and geophysical observations suggest that our model is internally consistent and not unrealistic. 
In terms of compositional variations in the upper mantle, thermal properties are largely overlooked; instead, geophysicists generally consider mantle density (e.g., Jordan, 1979). This bias is a result of the tools which are largely used to look at upper mantle structure, seismic velocity and gravity/geoid anomalies. The problem of estimating upper mantle thermal conductivity has been recognized for some time (Lister, 1977; Parsons and Sclater, 1977). Parsons and Sclater (1977) state in their final conclusions, ". . . it should be noted that knowledge of thermal conductivities is critical in many ways to the arguments and calculations of this paper. Repeated measurements to verify the presently accepted values . . and to check the degree of variation possible in the upper mantle would reduce further any uncertainties". Suprisingly, little laboratory work on upper mantle thermal properties have been performed in the last decade. It is the correlation of heat flow, depth, crustal thickness and age which points to regional variations in thermal conductivity and thermal diffusivity, with anisotropic upper mantle fabrics possibly affecting thermal structure in sma11 basins. With the continued collection of reliable heat flow data in regions of anomalous mid-ocean ridge crest elevations, the geophysical interpretations of 1ithospheric thermal structure are sure to change. 
$-261-$

Chapter 6

Conclusion 
Geophysical data has been collected and analyzed in order to constrain simple models of marginal basin formation. For young basins ( $<30-50 \mathrm{Ma})$, heat flow measurements provide a direct test of lithospheric cooling models. In addition to new sediment-unloaded basement depth map and extant crustal structure determinations, heat flow patterns indicate that the Ligurian Basin evolved by an asymmetric 1ithospheric thinning mechanism. Detailed environmental studies have elucidated the precise nature of geothermal variations, and hold promise for heat flow applications in other well-sedimented marginal basins.

If thermal gradient data are combined with in situ thermal conductivity measurements, piston core physical property data, $3.5 \mathrm{kHz}$ echo reflections and detailed bathymetry, reliable heat flow trends may be estimated. Reliability is subjectively defined by the local data scatter as well as the sedimentary environment and shallow subsurface structure given by seismic reflection profiles. The most favorable seafloor setting for consistent heat flow measurements in the Ligurian Basin is the upper continental rise between the lower canyon channels. Heat flow values on the continental slope are complicated by microtopography, with the regions of thicker sediment (>100 m) giving more consistent heat flow. Despite the large variability on the upper margin, the mean heat flow does not appear to be biased. In the thickly-sedimented $(\sim 5 \mathrm{~km})$ central basin, erosive channels, sha1low faulting, and diapiric structures cause isolated high values of heat flow. This contrasts with heat flow in relatively sediment-starved marginal basins (e.g., Tyrrhenian Basin and Mariana Trough) in that basement outcrops tend to create high scatter due to sediment/basement 
conductivity contrasts and hydrothermal circulation, but generally bias the mean to low values (Hutchison et al., 1985; Anderson, 1975).

Systematic lowering of the surface heat flow in the Ligurian Basin is incurred due to the sediment thermal blanketing and paleoclimatic temperature changes. Sedimentation varies laterally leading to corrections of 15 to $30 \%$ in the central basin and 0 to $15 \%$ on the margins. Modeling of the thermal history is complicated by the pore pressure evolution during deposition of the Messinian evaporite sequence. In the unlikely event that the infrasalt Miocene shaly unit is overpressured since the beginning of the Messinian, the central basin heat flow correction would be $\sim 10 \%$ higher due to the overall higher basement burial rate and lack of upward pore water advection. Messinian phenomena such as erosion on the margins and surface temperature variations have a negligible effect on the present heat flow. However, a $\sim 4{ }^{\circ} \mathrm{C}$ late Glacial bottom water temperature change is inferred from amino acid racemization, faunal assemblages, and oxygen isotopic data in the Mediterranean Sea. This requires paleoclimatic corrections of 8-10 $\mathrm{mW} \mathrm{m} \mathrm{m}^{-2}$ for a11 Mediterranean Basin heat flow data. Uncertainties in the environmental corrections are generally $<10 \%$, which is about equal to the data variability in most cases. Combining random and systematic uncertainties in a root-sum-square fashion results in a $9-14 \%$ accuracy for regional equilibrium heat flow estimates which is adequate1y sma11 to test thermal models of asymmetric 1ithospheric thinning.

A we11-defined heat flow versus age relationship exists for the Mediterranean and western Pacific marginal basins which, in turn, 
potentially allows heat flow to be a good age estimator. Based on the heat flow of two "oceanic" structural sub-basins within the Ligurian trough, a rift jump from the northwestern to the southeastern margin is suggested to occur just before the rotation of Sardinia $\sim 21$ Myr ago (Montigny et a1., 1984). The rifting age for the two margins differ by $>5$ Myr as a result of the southeastward migration of the extensional center. This transposition of rifting is consistent with the back arc evolution for the western and central Mediterranean (Rehault et al., 1984b) and has a direct analogy with the intrabasinal rift jump between the Vavilov and Marsili sub-basins in the Tyrrhenian Sea (Mascle and Rehault, 1988).

Although rift jumping is in agreement with heat flow and subsidence patterns, the previous kinematics cited for the western Mediterranean assumed a symmetric opening (Rehault et a1, 1984a; Burrus, 1984). These reconstructions are constrained by the low-amplitude magnetic anomalies which are attenuated by the large $(>8 \mathrm{~km})$ basement depths. Due to the unresolved nature of the magnetic anomalies, more confidence may be placed on tectonic models derived from heat flow. Furthermore, the corrected heat flow in the central Ligurian Basin is too high according to theoretical two-dimensional studies of basin formation (Cochran, 1983; A1varez et a1, 1984), so that the effect of lateral heat 1oss in narrow basins may be over-estimated. Possible factors which may enhance one-dimensional cooling are a regionally thin prerift 1ithosphere and significant anisotropy for the upper mantle thermal conductivity.

Total tectonic subsidence within the Ligurian Basin generally supports the uniform extension model (McKenzie, 1978). However, two 
anomalous features are apparent: P1io-Quaternary uplift of the margins (postrift) and a negative residual depth anomaly in the central basin (synrift). High-resolution seismic reflection records show a circum-base-of-slope basement fault which has been reactivated in a normal sense, opposite to that predicted by the regional compression (e.g., Rehault et a1., 1984a). This "boundary fault" is the main dislocation surface in the flexural system composed of the basin and borderlands. On the basis of Messinian and Glacial paleostrand line positions and elevations, and the sediment-unloaded fault displacement, the Cote d'Azur margin has been uplifted by almost one kilometer. The uplift is consistent with a passive erosion-isostatic rebound phase within the Alps. Alternative mechanisms may be invoked to explain the smaller uplift $(<200 \mathrm{~m})$ observed on other Mediterranean margins. Seaward of the boundary basement fault, the subsidence is affected little by the borderland uplift with the upper Messinian sediment-unloaded depths relatively undisturbed by basement faulting. The total tectonic subsidence versus age data for back arc basins are anomalously deep by 500 to $1000 \mathrm{~m}$ compared to the depth-age relationship for the major ocean basins (Louden, 1980; Anderson, 1980). The Ligurian central basin subsidence is consistent with this back arc subsidence trend, and cannot be accounted for by the thinner-than-normal crust $(\sim 4 \mathrm{~km})$. The depth anomaly is attributed to anomalous zero-age depths incurred in the back arc setting as a result of higher density upper mantle. Geochemical changes in the probably highly depleted mantle will only create lower densities. A high density upper mantle is probably a result of an anomalously cool thermal structure maintained by 
the limited influence of deep asthenospheric upwelling behind subduction zones. Since the "cold-spot" regime maintained in back arc settings has "normal" heat flow and subsidence decay trends, the processes of plate recycling and hydrous melting incurred in marginal basins (Dick, 1982; Dick and Fisher, 1984) may promote the formation of upper mantle rock with a higher thermal conductivity, i.e., less diopside and more olivine with an enriched forsterite component.

The amplitude of the thermal asymmetry on the conjugate margins and borderlands in the Northwestern Mediterranean Basin (Lucazeau and Mai1he, 1986; Burrus and Foucher, 1986) requires some rift mechanism other than a simple rift jump in the central basin. The relationship of crustal thinning to the heat flow suggest that the margins have undergone discrepant nonuniform 1ithospheric extension, with the northeastern margin having substantial1y thicker ( $50 \%)$ mantle 1ithosphere than the southeastern margin. The margin up1ift and the central basin depth anomaly degrade the utility of subsidence in constraining 1 ithospheric extension processes. Lithospheric extensional models for margin formation which are consistent with the heat flow distribution are the simple shear (Wernicke, 1985; Lister et a1., 1986) and asymmetric pure shear models (Martinez, Buck et a1., 1988).

In summary, heat flow and subsidence of the Ligurian Basin show that that the uniform extension model is a good first order approximation to the margin evolution. However, due to proposed spatiotempora1 variations in the basin formation, significant geothermal asymmetry in the deep thermal structure is found which requires a revision in previous kinematic schemes for the basin opening based on the magnetic 
anomaly pattern. In reality, the subsidence and shallow geomagnetic source of the central basin basement are more perturbed by the thick sediment cover than the heat flow, making geothermal measurements a very good geophysical prospecting tool. The most significant discrepancies between the observations and simple stretching model are the following:

1) Recent margin uplift due to passive isostatic rebound mechanisms within the borderland.

2) Excessive sediment-unloaded basement depths in the central basin due to the back arc basin affinity and regional "cold spot" affinity.

3) For a given crustal thickness, the mantle lithosphere has been thinned more for the Corsican margin than the Cote d'Azur margin.

4) Asymmetric heat flow in the central Ligurian Basin is consistent with a rift jump which created to "oceanic" sub-basins.

Future work concerning the tectonics of the Northwestern Mediterranean include basement drilling to substantiate the progression of rifting ages to the southeast. Subsequent geothermal mapping in other wel1-sedimented marginal basins (e.g, North Algerian Basin) may suggest similar asymmetric evolutionary models. On a global theme, the heat flow and subsidence data for back arc basins suggest that there is a regional dependence of upper mantle thermal parameters associated with geochemical heterogeneities. More physical property data for upper mantle rock are required to establish the importance of mantle depletion on the depth variations of zero-age crust. 
$-268-$ 


\section{References}

Abbott, D. H., M. A. Hobart, and R. W. Embley, Heat flow and mass-wasting in the Wilmington Canyon region: U. S. Continental Margin, Geo-Mar. Lett., 6, 131-138, 1986.

Abramowitz, M. and I. A. Stegun, Eds., Handbook of Mathematical Functions, Dover, New York, 1965.

Ahern, J. L. and D. L. Turcotte, Magma migration beneath an ocean ridge, Earth Planet. Sci. Lett., 45, 115-122, 1979.

Alinat, J., G. Bellaiche, G. Gierman, 0. Leenhardt, and G. Pautot, Morphologie et sedimentolgic d'un dome de la plaine abyssale 1igure, Bu11. Inst. Oceangr., 69 (1400), 22 pp., 1970.

Alvarez, F., J. Virieux and X. Le Pichon, Thermal consequences of 1ithosphere extension over continental margins: the initial stretching phase, Geophys. J. R. Astron. Soc., 78, 389-411, 1984.

Anderson, R. N., Heat flow in the Mariana Marginal Basin, J. Geophys. Res., $\underline{80}, 4043-4048,1975$.

Anderson, R. N., 1980 Update of heat flow in the East and Southeast Asian Seas, in D. E. Hayes (ed.), The Tectonic and Geologic Evolution of Southeast Asian Seas and Islands, Geophys. Mon., 23, Am. Geophys. Un., Washington, D.C., 319-326, 1980.

Anderson, R. N., M. G. Langseth and J. G. Sclater, The mechanisms of heat transfer through the floor of the Indian Ocean, J. Geophys. Res., 82, 3391-3409, 1977 .

Anderson, R. N., M. A. Hobart, and C. Keen, Geothermal structure of the southern continental margin of China and its relation to rifting history and hydrocarbon maturation, Am. Assoc. Pet. Geo1. Bu11., submitted, 1988 .

Andrews-Speed, C. P., E. R. Oxburgh, and B. A. Cooper, Temperatures and depth-dependent heat $\mathrm{flow}$ in Western North Sea, Am. Assoc. Pet. Geo1. Bu11., 68, 1764-1781, 1984.

Arpaci, V. S., Conduction Heat Transfer, Addison-Wesley, Reading Mass., 550 pp., 1966.

Arthaud, F. and P. Matte, Determination de la position initiale de la Corse et de la Sardaigne a la $\mathrm{f}$ in de l'orogenese hercynienne grace aux marqueurs geologiques ante-mesozoiques, Bull. Soc. Geo1. Fr., $19,833-840,1977$. 
Athy, L. F., Density, porosity, and compaction of sedimentary rocks, Am. Assoc. Pet Geo1. Bul1., 14, 1-24, 1930.

Avedik, F., A. L. Camus, A. Ginzburg, L. Montadert, D. G. Roberts, and R. B. Whitmarsh, A seismic refraction and reflection study of the continent-ocean transition beneath the North Biscay margin, Phil. Trans. Roy. Soc. Lond., A305, 5-26, 1982.

Bally, A. W., Musings over sedimentary basin evolution, Phil. Trans. Roy. Soc. Lond., A305, 325-338, 1982.

Barker, P. F, and I. A. Hill, Asymmetric spreading in back-arc basins, Nature, 285, 652-654, 1980 .

Barker, P. F. and I. A. Hil1, Back-arc extension in the Scotia Sea, Phi1. Trans. Roy. Soc. Lond., A300, 249-262, 1981.

Barton, P. J., Crustal stretching in the North Sea, implications for thermal history, in B. Durand (ed.), Thermal Phenomena in Sedimentary Basins, Editions Technip, Paris, 227-223, 1984.

Barton, P. J., The relationship between seismic velocity and density in the continental crust--a useful constraint?, Geophys. J. R. Astron. Soc., 87, 195-208, 1986.

Bayer, M., R. Bayer, and A. Lesquer, Quelques remarques sur 1a structure geologique de la Corse d'apres la gravimetrie et le magnetisme, Bu11. Soc. Geol. Fr., 18, 1189-1194, 1976.

Beaumont, C., C. E. Keen, and R. Boutilier, on the evolution of rifted continental margins: comparison of models and observations for the Nova Scotian margin, Geophys. J. R. Astron. Soc., 70, 667-715, 1982.

Beck, A. E., K. Wang, and P. Y. Shen, Sub-bottom temperature perturbations due to temperature variations at the boundary of inhomogeneous lake or oceanic sediment, in: A. E. Beck (ed.), Terrestrial Heat Flow and Therma1 Regimes, Tectonophysics, 121, $11-24,1985$.

Bellaiche, G. and G. Pautot, Sur la presence de niveaux a pyrite au sommet d'un dome de la plaine abyssale ligure, C. R. Acad. Sc. Paris, 267, Serie D, 991-993, 1968.

Be1laiche, G., M. Genesseaux, A. Mauffret, and J. P. Rehault, Prevelements systematiques et caracterisation des reflecteurs acoustiques, nouvelle etape dans la comprehension de 1a geologie de 1a Mediterranee occidentale, Mar. Geo1., 16, 47-56, 1974. 
Bellaiche, G., F. Coumes, F. Irr, F. Roure, and J. R. Vanney, Structure des canyons sous-marine provencaux. Sedimentation, diagenese et erosion pendant 1e Quaternaire, C. R. Acad. Sc. Paris, 286, Serie D, $1779-1782,1978$.

Bellaiche, G., et al. (Groupe Cyaligure), Plongees en submersible dans les canyons Mediterraneen : principaux resultats de la campagne Cyaligure, Bul1. Soc. Geol. Fr., 21, 533-543, 1979.

Bellon, H., Chronologie radiometrique (K-Ar) des manifestations magmatiques autour de la Mediterranee occidentale entre 33 et $1 \mathrm{Ma}$, in F. C. Weze1 (ed.), Sedimentary Basins of Mediterranean Margins, Urbino Col1. C. N. R. Ita1. Proj. of Oceanogr., Tecnoprint, Bologna, $341-360,1981$.

Bellon, H. and R. Brousse, L'age oligo-miocene du volcanism 1igure, C.R. Acad. Sc. Paris, 272, 3109-3111, 1971.

Bellon, H., R. Maury, G. Bellaiche, J. P. Rehault, J. F. Mermet, and J. M. Auzende, Age et nature des formations volcaniques prismees observees et prelevees dans le Canyon des Moines (Sud-0uest Corse) pendant 1a campagne Cyaligure, Mar. Geo1., 67, 163-176, 1985.

Benfie1d, A. E., The effect of uplift and denudation on underground temperatures, J. App1. Phys., 20, 66-70, 1949.

Berry, M. J, and L. Knopoff, Structure of the upper mantle under the western Mediterranean Basin, J. Geophys. Res., 72, 3613-3626, 1967.

Bessis, F., Some remarks on the study of subsidence of sedimentary basins: Application to the Gulf of Lion margin (Western Mediterranean), Mar. Pet. Geol., 3, 37-63, 1986.

Bethke, C. M., A numerical mode1 of compaction-driven groundwater flow and heat transfer and its application to the paleohydrology of intracratonic basins, J. Geophys. Res., 90, 6817-6828, 1985.

Bethke, C. M., Inverse hydrologic analysis of the distribution and origin of Gulf Coast-type geopressured zones, J. Geophys. Res., 91, $6535-6545,1986$.

Bethoux, J. P., Paleo-hydrologie de la Mediterranee au cours des derniers 20,000 ans, 0ceanol. Acta, $7,43-48,1984$.

Bethoux, J. P. and L. Prieur, Hydrologie et circulation en Mediterranee Nord-Occidentale, Petrole et Techniques, 299, 25-34, 1983.

Bethoux, J. P., L. Prieur, and F. Nyffeler, The water circulation in the North-Western Mediterranean Sea, its relations with wind and atmospheric pressure, in: J. C. J. Nihoul (ed.), Hydrodynamics of Semi-Enclosed Seas, E1sevier Oceanog. Ser., 34, 129-142, 1982. 
Bethoux, N., F. Petit, J. P. Rehault, B. Massinon, and J. P. Montagner, Several location methods for underwater shots in the Gulf of Genoa (Western Mediterranean): Structural implications, Tectonophysics, $\underline{128}, 357-379,1986$.

Bevington, P. R., Data Reduction and Error Analysis for the Physical Sciences, McGraw-Hill, New York, 336 pp., 1969.

Bibee, L. D., G. G. Shore, Jr., and R. S. Lu, Inter-Arc spreading in the Mariana Trough, Mar. Geo1., 35, 183-197, 1980.

Biju-Duva1, B., Les marges continentales francaises de la Mediterranee, in G. Boillot (ed.), Les mages continentales et fossiles autour de 1a France, Masson ed. Paris, 249-334, 1984.

Biju-Duval, B., J. Letouzey, and L. Montadert, Structure and evolution of the Mediterranean basins, in Hsu, K., L. Montadert et al., Initial Rep. Deep Sea Dri11. Proj., 42(1), 509-514, 1978.

Birch, F., Low values of oceanic heat flow, J. Geophys. Res., 72 , 2261-2262, 1967.

Bizon, G., J. J. Bizon, and B. Biju-Duva1, Comparison between formations drilled at DSDP Site 372 in the western Mediterranean and exposed series of land, K. Hsu and L. Montadart et a1. (eds.), Initial Rept. Deep Sea Dri11. Proj., 42, 897-901, 1978.

Blackwel1, J. H., Radial-axial heat flow in regions bounded internally by circular cylinders, Gan. J. Physics, 31, 472-479, 1953.

Blackwe11, J.H., A transient-flow method for determination of thermal constants of insulating materials in bulk, J. Appl. Phys., 25, $137-144,1954$.

Boccaletti, M. and G. Guazzone, Remnant arcs and marginal basins in the Cenozoic development of the Mediterranean, Nature, 252, 18-21, 1974.

Bonatti, E. and M. Seyler, Crustal underplating and evolution in the Red Sea rift: uplifted gabbro/gneiss crustal complexes on Zabargad and Brothers Islands, J. Geophys. Res. 92, 12,803-12,821, 1987.

Booth, J. S., D. A. Sangrey, and J. K. Fugate, A nomogram for interpreting slope stability of fine-grained deposits in modern and ancient marine environments, J. Sed. Petr., 55, 29-36, 1985.

Bosworth, W., Geometry of propagating continental rifts, Nature, 316 , $625-627,1985$.

Bosworth, W., Off-axis volcanism in the Gregory rift, east Africa: implications for models of continental rifting, Geology, 15, $397-400,1987$. 
Bowin, C. 0., Gravity and geoid anomalies of the Philippine Sea: evidence of the depth of compensation for the negative residual water depth anomaly, Mem. Geol. Soc. China, 4, 103-119, 1981.

Bowin, C., G. Thompson, and J. G. Schilling, Residual geoid anomalies in Atlantic Ocean basin: Relationship to mantle plumes, J. Geophys. Res., 89, 9905-9918, 1984.

Boyce, R. E., Physical properties - methods, in N. T. Edgar, J. B. Saunders, et a1. (eds.), Initial Rep. Deep Sea Drill. Proj., $15,1115-1127,1973$.

Brun, J.-P., and P. Choukroune, Normal faulting, block tilting, and decollement in a stretched crust, Tectonics, 2, 345-356, 1983.

Buck, W. R., Sma11-scale convection induced by passive rifting: the cause for uplift of rift shoulders, Earth Planet. Sci. Lett., 77, 1986.

Bullard, E. C., Heat flow in South Africa, Proc. Roy. Soc. Lond. Series, A, 173, 474-502, 1939 .

Bullard, E. C., The flow of heat through the floor of the Atlantic Ocean Proc. Roy. Soc. London, A222, 408-429, 1954.

Bullard, E. C. and A. Day, The flow of heat through the floor of the Atlantic Ocean, Geophys. J. R. Astron. Soc., 4, 284-292, 1961.

Burrus, J., Contribution to a geodynamical synthesis of the Provencal Basin (North Western Mediterranean), Mar. Geo1., 55, 247-269, 1984.

Burrus, J. and J. P. Foucher, Contribution to the thermal regime of the Provencal Basin based on FLUMED heat flow surveys and previous investigations, in D. A. Ga1son and St. Mue1ler (eds.), The European Geotraverse, Part 2, Tectonophysics, 128, 303-334, 1986.

Carter, N. L. and F. D. Hansen, Creep of rocksa1t, Tectonophysics, 92, $275-333,1983$.

Carslaw, H. S., and J. C. Jaeger, Conduction of Heat in Solids, Oxford University Press, London, 510 pp., 1959.

Celerier, B., Models for the evolution of the Carolina Trough and their limitations, Ph.D. thesis, Massachusetts Institute of Technology, Cambridge, Mass., 1986.

Chenet, P. Y., Therma1 transfer in sedimentary basins, paleotemperature reconstruction and maturation studies in the Gulf of Lion margin, in B. Durand (ed.), Therma1 Phenomena in Sedimentary Basins, Editions Technip, Paris, 257-269, 1984. 
Cherchi, A. and L. Montadert, The 0ligo-Miocene rift of Sardinia and the ear1y history of the Western Mediterranean Basin, Nature, 298, $736-739,1982$.

Cita, M. B., The Messinian salinity crisis in the Mediterranean: A review, in $H$. Berckhemer and K. Hsu (eds.), Alpine-Mediterranean Geodynamics, Geodyn. Ser., 7, Am. Geophys. Un., Washington, 113-140, 1982 .

Cita, M. B., W. B. F. Ryan, and R. B. Kidd, Sedimentation rates in Neogene deep-sea sediments from the Mediterranean and geodynamic implications of their changes, in Hsu, K. J., L. Montadert et al., Initial Rep. Deep Sea Dril1. Proj., 42(1), 991-1002, 1978.

Clauzon, G., The Messinian Var canyon (Provence, Southern France)-paleogeographic implications, Mar. Geo1., 27, 231-246, 1978.

Clauzon, G., Le canyon Messinien de 1a Durance (Provence, France): une preuve paleogeographique du bassin profound de dessication, Palaeogr. Palaeoclimat. Palaeoeco1., 29, 15-40, 1979.

CLIMAP Project Members, Seasonal reconstructions of the Earth's surface at the last glacial maximum, Geol. Soc. Am. Map and Chart Ser., MC-36, 6 sheets, 1981 .

Cloetingh, S., H. McQueen, K. Lambeck, On a tectonic mechanism for regional sealeve1 variations, Earth P1anet. Sci. Lett., 75, 157-166, 1985.

Cochran, J. R., The magnetic quiet zone in the eastern Gulf of Aden: implications for the early development of the continental margin, Geophys. J. R. Astron. Soc., 68, 171-201, 1982.

Cochran, J. R., Effects of finite rifting times on the development of sedimentary basins, Earth Planet. Sci. Lett., 66, 289-302, 1983.

Cochran, J. R., Variations in subsidence rates along intermediate and fast spreading mid-ocean ridges, Geophys. J. R. Astron. Soc., 87, 421-454, 1986 .

Cordery, M. J., Thermal Origin of the Hawaiian Swe11 II: New heat flow evidence, Genera1 Examination paper, Massachusetts Institute of Technology/Woods Hole Oceanographic Institution Joint Program in Oceanography, 1988.

Coutellier, V., G. Bellaiche, L. Droz, and Y. Mear, La pente continentale du golfe du Lion et 1 'enventail sous-marin profound du Rhone: cartographie des facies acoustiques obtenus par sondage 3.5 $\mathrm{kHz}$, C. R. Acad. Sc. Paris, 299, Serie II, 717-720, 1984. 
Cravatte, J., P. Dufaure, M. Prim, and S. Rouaix, Les sondages du Golfe du Lion; stratigraphie et sedimentologie, Notes Mem. C.F.P., 2, 209-274, 1974.

Cronin, T. M., Rates and possible causes of neotectonic vertical crustal movements of the emerged southeastern United States Atlantic Coastal P1ain, Geo1. Soc. Amer. Bu11., 92, 812-833, 1981.

Crough, S. T., The correction for sediment loading on the seafloor, $\mathrm{J}$. Geophys. Res., 88, 6449-6454, 1983.

Damuth, J. E., Echo character of the western equatorial Atlantic floor and its relationship to the dispersal and distribution of terrigenous sediments, Mar. Geol., 18, 17-45, 1975.

Damuth, J. E., Use of high-frequency $(3.5-12 \mathrm{kHz})$ echograms in the study of near-bottom sedimentation processes in the deep-sea: a review, Mar. Geo1., 38, 51-75, 1980.

Davis, E. E., Thermal aging of oceanic 1ithosphere, in. J. Wright and K. Louden (eds.), Handbook of Seafloor Heat Flow, CRC Series in Marine Science, CRC Press, Inc., in press, 1988.

Davis, E. E. and C. R. B. Lister, Fundamentals of ridge crest topography Earth Planet. Sci. Letts., 21, 405-413, 1974.

Davis, E. E., C. R. B. Lister, and J. G. Sclater, Toward determining the thermal state of old ocean lithosphere, Geophys. J. R. Astron. Soc., 78, 507-545, 1984 .

De Bremaecker, J. C1., Temperature, subsidence, and hydrocarbon maturation in extensional basins: A finite element mode1, Am. Assoc. Pet. Geo1. Bu11., 67, 1410-1414, 1983.

Deer, W. A., R. A. Howie, and J. Zussman, An introduction to the rock-forming minerals, Wiley, London, pp. 528, 1966.

De1la Vedova, B. and G. Pellis, Misure di flusso di calore nel Mar Ligure e nel Tirreno settentrionale: risultati preliminari, unpublished report, Istituto di Miniere e Geofisica Applicata de11'Universita di Trieste, 42 pp., 1981.

De11a Vedova, B., G. Pellis, J. P. Foucher, and J.-P. Rehau1t, Geotherma1 structure of the Tyrrhenian Sea, Mar. Geo1., 55, 271-289, 1984.

Detrick, R. S., R. P. Von Herzen, B. Parsons, D. Sandwe11, and $M$. Dougherty, Heat flow observations on the Bermuda Rise and thermal mode1s of mid-plate swel1s, J. Geophys. Res., 91, 3701-3723, 1986. 
Dewey, J. F., Episodicity, sequence, and style at convergent plate boundaries, in D. W. Strangway (ed.), The Continental Crust and Its Mineral Deposits, Geo1. Assoc. Can. Spec. Paper, 20, 533-574, 1980.

Dick, H. J. B., Vesicularity of Shikoku Basin basalt: a possible correlation with the anomalous depth of back-arc basins, Initial Rep. Deep Sea Dri11. Proj., 58, 895-904, 1980.

Dick, H. J. B., The petrology of two back-arc basins of the northern Philippine Sea, Am. J. of Sci., 282, 644-700, 1982.

Dick, H. J. B., and R. L. Fisher, Mineralogic studies of the residues of mantle melting: abyssal and alpine-type peridotites, in $\mathrm{J}$. Kornprobst (ed.), Kimberlites II: The Mantle and Crust-Mantle Relationships, E1sevier, Ams terdam, 295-308, 1984.

Dick, H. J. B., R. L. Fisher, and W. B. Bryan, Mineralogic variability of the uppermost mantle along mid-ocean ridges, Earth Planet. Sci. Lett., 69, 88-106, 1984.

Duschenes, J., M. C. Sinha, and K. E. Louden, A seismic refraction experiment in the Tyrrhenian Sea, Geophys. J. R. Astron. Soc., 85, $139-160,1986$.

Egger, A., J. Ansorge, and St. Mueller, Crustal structure of Corsica and the lower lithosphere under Corsica-Sardinia block, in D.A. Galson and St. Mueller (eds.), Second EGT Workshop: the Southern Segment, European Science Foundation, Strasbourg, 207-213, 1985.

E1thon, D., J. F. Casey, and S. Komor, Mineral chemistry of ultramafic cumulates from the north arm mountain massif of the Bay of Island ophiolite: evidence for high-presssure crystal fractionation of oceanic basalts, J. Geophys. Res., 87, 8717-8734, 1982.

England, P. C., The effect of erosion on palaeoclimatic and topographic corrections to heat flow, Earth Planet. Sci. Lett., 39, 427-434, 1978.

Erickson, A. J., The measurement and interpretation of heat $f 10$ in the Mediterranean and Black Seas, Ph.D. thesis, Massachusetts Institute of Technology and Woods Hole Oceanographic Institution, Cambridge, Mass., 1970.

Erickson, A. J., Leg 42A physical properties data, in Hsu, K. J., L. Montadert et a1., Initial Rep. Deep Sea Dri11. Proj., 42(1), $1199-1206,1978$.

Erickson, A. J. and R. P. Von Herzen, Downhole temperature measurements, DSDP Leg 42A, in Hsu, K., L. Montadert et al., Initial Rep. Deep Sea Dril1. Proj., 42(1), 857-871, 1978 . 
Erickson, A. J., G. Simmons, and W. B. F. Ryan, Review of heatflow data from the Mediterranean and Aegean Seas, in: B. Biju-Duval and L. Montadert (eds.), Structural History of the Mediterranean Basins, Editions Technip, Paris, 263-275, 1977.

Estocade (Groupe), Messinian subaerial erosion of the Stoechades and Saint-Tropez canyons: a submersible study, Mar. Geol., 27, 247-269, 1978.

Fahlquist, D. A. and J. B. Hersey, Seismic refraction measurements in the Western Mediterranean Sea, Bull. Inst. Oceanogr., 67(1386), 52 pp., 1.969.

Falvey, D. A., The development of continental margins in plate tectonic theory, Aust. J. Petrol. Explor., 14, 95-106, 1974.

Fang, C., Marine heat flow measurement, Ph.D. thesis, Memorial University of Newfoundland, St. John's Newfoundland, 1985.

Fang, C., J. P. Jemsek, R. P. Von Herzen, and M. J. Cordery, 1987, Heat flow data reduction: Optimization and automation, Trans. Am. Geophys. Union (EOS), 68, 424, 1987.

Fanucci, F. and M. Firpo, Application de la sismique reflexion a 1 'etude de la marge continentale de la mer Ligure: quelques examples, Bul1. Geof. Teor. App1., 23, 145-157, 1981.

Fierro, G., M. Gennesseaux, and J.-P. Rehau1t, Caracteres structuraux et sedimentaires du plateau continental de Nice a Genes (Mediterranee nord-occidentale), Bu11. B. R. G. M., 2, 193-208, 1973.

Finetti, I. and C. More11i, Geophysical exploration of the Mediterranean Sea, Bo11. Geof. Teor. App1., 15, 263-341, 1973.

Forsyth, D. W., The early structural evolution and anisotropy of the oceanic upper mantle, Geophys. J. R. Astron. Soc., 43, 103-162, 1975.

Forsythe, G. E. and W. R. Wasow, Finite-Difference Methods for Partial Differential Equations, John Wiley, New York, 444 pp., 1960.

Foucault, A., F. Baltzer, G. Glacon, and D. Lellouche, Turbidites et hemipelagites sur la pente sud de la ride du Var (mer Ligure, Mediterranee occidentale), Bu11. Soc. Geo1. France, 8 , II, 675-679, 1986.

Foucher, J. P. and J. C. Sibuet, Thermal regime of the northern Bay of Biscay continental margin in the vicinity of the D.S.D.P. Sites 400-402, Phi1. Trans. Roy. Soc. Lond., A294, 97-103, 1980. 
Foucher, J. P., X. Le Pichon, and J. C. Sibuet, The ocean-continent transition in the uniform 1ithospheric stretching model: role of partial melting, Phil. Trans. Roy. Soc. Lond., A305, 27-40, 1982.

Foucher, J. P., J. M. Auzende, J. P. Rehault, and J. L. 01ivet, Nouvelles donnees de flux geothermique en Mediterranee occidentale, 4 eme RAST., Paris, 174, 1976.

Fuis, G. S., W. D. Mooney, J. H. Healy, G. A. McMechan, and W. J. Lutter, A seismic refraction survey of the imperial valley region, California, J. Geophys. Res., 89, 1165-1189, 1984.

Furlong, K. P. and D. M. Fountain, Continental crustal underplating: thermal considerations and seismic-petrologic consequences, $\mathrm{J}$. Geophys. Res., 91, 8285-8294, 1986.

Galdeano, A. and J. C. Rossigno1, Assemblage a altitude constante des cartes d'anomalies magnetiques couvrant 1 'ensemble du bassin occidental de 1a Mediterranee, Bul1. Soc. Geol. Fr., 19, 461-468, 1977.

Galdeano, A. and M. Ciminale, Aeromagnetic evidence for the rotation of Sardinia (Mediterranean Sea): comparison with the paleomagnetic measurements, Earth Planet. Sci. Lett., 82, 193-205, 1987.

Gennesseaux, M. and Y. Thommeret, Datation par le radiocarbone de quelques sediments sous-marins de la region nicoise, Rev. Geogr. Phys. Geo1. Dynam., 10, 375-382, 1968.

Gennesseaux, M., A. Mauffret, and G. Pautot, Les glissements sous-marine de la pente continentale Nicoise et la rupture de cable en mer Ligure (Mediterranee occidentale), C. R. Acad. Sc. Paris, 290, Serie D, 959-962, 1980 .

Giese, P., K. J. Reutter, V. Jacobshagen, and R. Nicolich, Explosion. seismic studies in the Alpine Mediterranean region and their implications to tectonic processes, in $\mathrm{H}$. Berckhemer and $\mathrm{K}$. Hsu (eds.), Alpine- Mediterranean Geodynamics, Geodynamic Series, 7, Am. Geophys. Un., Washington, 39-73, 1982.

Gilmour, A. E., Temperature stratification in the western Mediterranean Sea, Deep-Sea Res., 19, 341-353, 1972.

Girod, M. and N. Girod, Contribution de 1a petrologie a la connaissance de 1'evolution de la Mediterranee occidentale depuis 1 'oligocene, Bu11. Soc. Geo1. Fr., 19, 481-488, 1977.

Ginzburg, A., J. Makris, and R. Nicolich, European geotraverse: A seismic refraction profile across the Ligurian Sea, Tectonophysics, 126, 85-97, 1986 . 
Gostan, J., Resultats des observations hydrologiques effectuees entre les cotes de Provence et de Corse ( 6 aout 1962 - 30 juillet 1964), Cah. Oceanog., 19, 1-69 pp., 1967.

Green, K. E., R. P. Von Herzen, and D. L. Williams, The Galapagos spreading center at $86^{\circ} \mathrm{W}$ : A detailed geothermal field study, J. Geophys. Res., $\underline{86}, 979-986,1981$.

Grow, J. A., C. O. Bowin, and D. R. Hutchison, The gravity field of the U.S. Atlantic continental margin, Tectonophysics, 59, 27-52, 1979.

Guillocheau, F., G. Pautot, and J. M. Auzende, Les canyons du Var et du Paillon (marge des Alpes meridionales-Mediterranee occidentale): une origine quaternaire par glissement, C. R. Acad. Sc. Paris, 296, Serie II, 91-96, 1983.

Ha11, S. A., J. F. Casey, and D. L. E1thon, A possible explanation of gravity anomalies over mid-ocean ridges, J. Geophys. Res., $\underline{91}$, $3724-3738,1986$.

Hart, S. R. and A. Zindler, In search of a bulk-earth composition, Chem. Geol., 57, 247-267, 1986.

Hayes, D. E., Age-depth relationships and depth anomalies in the Southeast Indian Ocean and South Atlantic Ocean, J. Geophys. Res., 93, 2937-2954, 1988.

Hays, J. D., J. Imbrie, and N. J. Shackleton, Variations in the Earth's orbit: pacemaker of the Ice Ages, Science, 194, 1121-1132, 1976.

Heestand, R. L. and S. T. Crough, The effect of hot spots on the oceanic age-depth relation, J. Geophys. Res., $\underline{86}, 6107-6114,1981$.

Hellinger, S. and J. G. Sclater, Some comments on two-layer extensional models for the evolution of sedimentary basins, J. Geophys. Res., $\underline{88}, 8251-8269,1983$.

Hey, R., F. K. Duennebier, and W. J. Morgan, Propagating rifts on mid-ocean ridges, J. Geophys. Res., 85, 3647-3658, 1980.

Hi11, I. D., Algorithm 109, Golden Section Search, The Computer Journal, 22, 383-385, 1979 .

Hirn, A. and M. Sapin, La croute terrestre sous 1a Corse: donnees sismiques, Bul1. Soc. Geo1. Fr., 18, 1195-1199, 1976.

Hsu, K. J., M. B. Cita, and W. B. F. Ryan, Origin of the Mediterranean evaporites, in Ryan, W. B. F., K. J. Hsu, et a1., Initial Rep. Deep Sea Dri11. Proj., 13(2), 1203-1231, 1973. 
Hsu, K. J., L. Montadert et a1., Site 372: Menorca Rise, Initial Rep. Deep Sea Dril1. Proj., 42(1), 59-150, 1978.

Huppert, H. E. and J. G. Sclater, On the in situ measurement of the therma1 conductivity of deep sea sediments, Marine Phys. Lab. Tech. Memo., 191, Scripps Inst. Ocean., University of Calif., San Diego, 1968 .

Hutchison, I., Heat flow studies in the Gulf of Oman and western Mediterranean, Ph.D. thesis, Univ. of Cambridge, Cambridge, 1984.

Hutchison, I., The effects of sedimentation and compaction on oceanic heat flow, Geophys. J. R. Astron. Soc., 82, 439-459, 1985.

Hutchison, I, K. E. Louden, R. S. White, and R. P. Von Herzen, Heat flow and age of the Gulf of Oman, Earth Planet. Sci. Lett., 56, 252-262, 1981 .

Hutchison, I., R. P. Von Herzen, K. E. Louden, J. G. Sclater, and $\mathrm{J}$. Jemsek, Heat flow in the Balearic and Tyrrhenian Basins, western Mediterranean, J. Geophys. Res., 90, 685-701, 1985.

Hyndman, R. D., E. E. Davis, and J. A. Wright, The measurement of marine geothermal heat flow by a multipenetration probe with digital acoustic telemetry and in situ thermal conductivity, Mar. Geophys. Res., 4, 181-205, 1979.

Imbrie, J. and N. Kipp, A new micropaleontological method for quantitative paleoclimatology: application to a late Pleistocene Caribbean core, in: K. Turekian (ed.), The Late Cenozoic Glacial Ages, Yale University Press, 71-181, 1971.

Irr, F., Paleoenvironments et evolution geodynamique neogenes et quaternaires de la bordure nord de Bassin Mediterraneen 0ccidental, These doctorat es Sciences, Univ. of Nice, 1984.

Jackson, M. P. A. and C. J. Talbot, External shapes, strain rates, and dynamics of salt structures, Geol. Soc. Am. Bu11., 97, 305-323, 1986.

Jaeger, J. C., Conduction of heat in an infinite region bounded internally by a circular cylinder of a perfect conductor, Australian J. Physics, 9, 167-179, 1956.

Jaeger, J. C., The measurement of thermal conductivity and diffusivity with cylindrical probes, Trans. Amer. Geophys. Union, 36, 708-710, 1958.

Jarvis, G. T. and D. P. McKenzie, Sedimentary basin formation with finite extension rates, Earth Planet. Sci. Lett., 48, 42-52, 1980. 
Jaupart, C., J. Francheteau, and X. J. Shen, On the thermal structure of the southern Tibetan crust, Geophys. J. R. Astron. Soc., 81, $131-155,1985$.

Jemsek, J. P., R. P. Von Herzen, J. P. Rehault, D. L. Williams, and J. G. Sclater, Heat flow and lithospheric thinning in the Ligurian Basin (N. W. Mediterranean), Geophys. Res. Lett., 12, 693-696, 1985a.

Jemsek, J. P., R. P. Von Herzen, and P. Andrews, In-situ measurement of thermal conductivity using the continuous-heating line source method and WHOI outrigged probe, Tech. Report WHOI-85-28, Woods Hole Oceanographic Institution, 73 pp., 1985b.

Jongsma, D., Heat flow in the Aegean Sea, Geophys. J. R. Astron. Soc., 37, $337-346,1974$.

Jordan, T. H., Mineralogies, densities and seismic velocities of garnet 1herzolites and their geophysical implications, in F. R. Boyd and $\mathrm{H}$. 0 . A. Meyer (eds.), The mantle sample: inclusions in kimberlites and other volcanics, Proc. 2nd Int. Kimberlite Conf., 2, 1-14, 1979.

Karig, D. E., Origin and development of marginal basins in the western Pacific, J. Geophys. Res., 76, 2542-2561, 1971.

Karig, D. E., R. N. Anderson, and L. D. Bibee, Characteristics of back arc spreading in the Mariana Trough, J. Geophys. Res., 83, $1213-1226,1978$.

Karner, G. D., Effects of lithospheric in-plane stress on sedimentary basin stratigraphy, Tectonics, 5, 573-588, 1986.

Kastens, K., The case for asymmetrical rifting above a detachment fault in the opening of the Tyrrhenian Sea, Central Mediterranean, EOS, $\underline{69}, 465,1988$.

Kastens, K. A., J. Mascle, et al., ODP Leg 107 in the Tyrrhenian Sea: Insights into passive margin and back-arc basin evolution, Geol. Soc. Am. Bul1., submitted, 1987.

Keen, C. E., Salt diapirs and therma1 maturity: Scotian basin, Bu11. Can. Petr. Geo1., 31, 101-108, 1983.

Keen, C. E., The dynamics of rifting: deformation of the lithosphere by active and passive driving forces, Geophys. J. R. Astron. Soc., 80 95-120, 1984 .

Keigwin, L. D. and R. C. Thune11, Middle Pliocene climatic change in the western Mediterranean from faunal and oxygen isotopic trends, Nature, 282, 294-296, 1979. 
Kern, H. and A. Richter, Temperature derivatives of compressional and shear wave velocities in crustal and mantle rocks at $6 \mathrm{kbar}$ confining pressure, J. Geophys., 49, 42-56, 1981.

Klein, E. M. and C. H. Langmuir, Global correlations of ocean ridge basalt chemistry with axial depth and crustal thickness, J. Geophys. Res., 92, 8089-8115, 1987.

Klitgord, K. D., D. R. Hutchinson, and H. Schouten, U. S. Atlantic Continental Margin: Structural and tectonic framework, in R. E. Sheridan and J. A. Grow (eds.), The Atlantic Continental Margin: U. S., Geological Society of America, in Press, 1987.

Kobayashi, K., Subsidence of the Shikoku Back-arc Basin, in R. L. Carlson and K. Kobayashi (eds.), Geodynamics of Back-arc Regions, Tectonophysics, 102, 105-117, 1984.

Lachenbruch, A. H., Rapid estimation of the topographic disturbance to superficial therma1 gradients, Rev. Geophys., 6. 365-400, 1968.

Lachenbruch, A. H., and B. V. Marsha11, Heat flow through the Arctic Ocean floor: The Canada Basin-Alpha Rise Boundary, J. Geophys. Res., 71, 1223-1248, 1966.

Lachenbruch, A. H., and B. V. Marsha11, Changing climate: Geothermal evidence from permafrost in the Alaskan Arctic, Science, 234, $689-696,1986$.

Lachenbruch, A. H., J. H. Sass, and S. P. Galanis, Jr., Heat flow in southernmost California and the origin of the Salton Trough, J. Geophys. Res., 90, 6709-6736, 1985.

Lacombe, H. and P. Tchernia, Caracteres hydrologiques et circulation des eaux en Mediterranee, in: D. J. Stanley (ed.), The Mediterranean Sea: A Natural Sedimentation Laboratory, Dowden, Hutchison and Ross Inc., Strousburg, Pennsylvania, 25-36, 1972.

Lacombe, H., P. Tchernia, and L. Gamberoni, Variable bottom water in the Western Mediterranean Basin, Prog. Oceanog., 14, 331-338, 1985.

Langseth, M. G. and R. P. Von Herzen, Heat flow through the world oceans, in The Sea, $4(1)$, A. E. Maxwe11, Ed., Interscience, New York, p. 299-352, $19 \overline{7} 1$.

Langseth, M. G., X. Le Pichon, and M. Ewing, Crustal structure of the mid-ocean ridges, 5., Heat flow through the Atlantic 0cean floor and convection currents, J. Geophys. Res., 71, 5321-5355, 1966.

Langseth, M. G., M. A. Hobart, and K. Horai, Heat flow in the Bering Sea, J. Geophys. Res., 85, 3740-3750, 1980 . 
LASE Study Group, Deep structure of the U. S. east coast passive margin from large aperture seismic experiments (LASE), Marine and Petr. Geol., 3, 234-44, 1986.

Lawver, L. A. and J. W. Hawkins, Diffuse magnetic anomalies in marginal basins: Their possible tectonic and petrologic significance, Tectonophysics, $\underline{45}, 323-339,1978$.

Le Douaran, S., J. Burrus, and F. Avedik, Deep structure of the Northwestern Mediterranean Basin: Results of a two-ships seismic survey, Mar. Geo1., 55, 325-345, 1984.

Le Douaran, S. and J. Francheteau, Axial depth anomalies from 10 to $50^{\circ}$ north along the Mid-Atlantic Ridge: correlation with other mantle properties, Earth P1anet. Sci. Lett., 54, 29-47, 1981.

Le Pichon, X. and J. C. Sibuet, Passive margins: A mode1 of formation, J. Geophys. Res., $\underline{86}, 3708-3720,1981$.

Le Pichon, $X$. and F. Barbier, Passive margin formation by low-angle faulting within the upper crust: the northern Bay of Biscay margin, Tectonics, 6, 133-150, 1987.

Lee, T. C. and T. L. Henyey, Heat flow refraction across dissimilar media, Geophys. J.R. Astron. Soc., 39, 319-333, 1974.

Lefebvre, D., Evolution morphologique et structurale du Golfe du Lion: Essai de traitement statistique des donnees, These 3eme cycle, Paris VI, 1980 .

Lesquer, A., M. Page1, J. B. Orsini, and B. Bonin, Premieres determinations du flux de chaleur et de la production de chaleur en Corse, C. R. Acad. Sc. Paris, 297, Serie II, 491-494, 1983.

Lewis, J. F. and R. D. Hyndman, Oceanic heat flow measurements over the continental margins of eastern Canada, Can. J. Earth Sci., 13, $1031-1038,1976$.

Lister, C. R. B., Geothermal gradient measurement using a deep sea corer, Geophys. J. R. Astron. Soc., 7, 521-533, 1963.

Lister, C. R. B., Measurement of in situ conductivity by means of a Bullard-type probe, Geophys. J. R. Astron. Soc., 19, 521-533. 1970.

Lister, C. R. B., On the thermal balance of a mid-ocean ridge, Geophys. J. R. Astron. Soc., 26, 515-535, 1972.

Lister, C. R. B., Estimators for heat flow and deep rock properties based on boundary layer theory, in A. M. Jessop (ed.), Heat Flow and Geodynamics, Tectonophysics, 41, 157-171, 1977. 
Lister, C. R. B., The pulse-probe method of conductivity measurement, Geophys. J. R. Astron. Soc., 57, 451-461, 1979.

Lister, G. S., M. A. Etheridge, and P. A. Symonds, Detachment faulting and the evolution of passive continental margins, Geology, 14, $246-250,1986$.

Loubere, P., The western Mediterranean during the Last Glacial: attacking a no-analog problem, Mar. Micropaleo., 7, 311-325, 1982.

Louden, K. E., The crustal and lithospheric thicknesses of the Philippine Sea as compared to the Pacific, Earth Planet. Sci. Lett., 50, 275-288, 1980 .

Louden, K. E., D. 0. Wallace, and R. C. Courtney, Heat flow and depth versus age for the Mesozoic northwest Atlantic Ocean: results from the Sohm abyssal plain and implications for the Bermuda Rise, Earth Planet. Sci. Lett., 83, 109-122, 1987.

Lucazeau, F. and S. Le Douaran, The blanketing effect of sediments in basins formed by extension: a numerical model. Application to the Gulf of Lion and Viking graben, Earth Planet. Sci. Lett., 74, 92-102, 1985.

Lucazeau, F. and A. Mailhe, Heat flow, heat production and fission track data from the Hercynian basement around the Provencal Basin (Western Mediterranean), in D. A. Galson and St. Mueller (eds.), The European Geotraverse, Part 2, Tectonophysics, 128, 335-356, 1986.

Mailhe, D., F. Lucazeau, and G. Vasseur, Uplift history of thrust belts: an approach based on fission track data and thermal modelization, Tectonophysics, $124,177-191,1986$.

Malinverno, A. and W. B. F. Ryan, Extension in the Tyrrhenian Sea and shortening in the Apennines as result of arc migration driven by sinking of the 1ithosphere, Tectonics, $\underline{5}, 227-245,1986$.

Malinverno, A., W. B. F. Ryan, G. Auffret, and G. Pautot, Sonar images of the path of failure events on the continental margin off Nice, France, Geo1. Soc. Am. Specia1 Paper, in press, 1987.

Martinez, F., R. Buck, M. S. Steckler, J. R. Cochran, Thermal consequences of 1ithospheric extension: Assymetric pure shear vs. simple shear, EOS, $69,465,1988$.

Mascle, J. and J. P. Rehault, A revised seismic stratigraphy of the Tyrrhenian Sea: Implications for the basin evolution, in Kastens, K., J. Mascle et al. (eds.), Init. Rep. Ocean Dri11. Proj., Leg 107 (Pt. B), submitted 1988 . 
Mauffret, A., M. Labarbarie, and L. Montadert, Les affleurements de series sedimentaires pre-P1iocenes dans le bassin Mediterranee Nord-Occidenta1, Mar. Geol., 45, 159-175, 1982.

Mauffret, A., L. Montadert, M. Lavergne, and C. Willm, Geological and geophysical setting of DSDP site 372, in Hsu, K. J., L. Montadert, et al., Initial Rep. Deep Sea Drill. Proj., 42(1), 889-897, 1978.

Mauffret, A., J. P. Fai1, L. Montadert, J. Sancho, and E. Winnock, Northwestern Mediterranean sedimentary basin from seismic reflection profile, Am. Assoc. Pet. Geol. Bu11., 57, 2245-2262, 1973.

Mauffret, A., J. P. Rehault, M. Gennesseaux, G. Bellaiche, M. Labarbarie, and D. Lefebvre, Western Mediterranean basin evolution: from a distensive to a compressive regime, in F. C. Wezel (ed.), Sedimentary Basins of Mediterranean Margins, Urbino Co11. C. N. R. Ital. Proj. Oceanogr., Tecnoprint, Bologna, 67-81, 1981 .

McCoy, F. W. and R. P. Von Herzen, Deep-sea corehead camera photography and piston coring, Deep-Sea Res., 18, 361-373, 1971.

McCoy, F. W., Photographic analysis of coring, Mar. Geo1., 38, 263-282, 1980 .

McKenzie, D., Some remarks on the development of sedimentary basins, Earth Planet. Sci. Lett., 40, 25-32, 1978.

McKenzie, D., A possible mechanism for epeirogenic uplift, Nature, 307, $616-618,1984$.

MEDOC Group, Observations of formation of deep water in the Mediterranean Sea, 1969, Nature, 227, 1037-1040, 1970.

Michael, P. J. and E. Bonatti, Peridotite composition from the North Atlantic: regional and tectonic variations and implications for partial melting, Earth Planet. Sci. Lett., 73, 91-104, 1985.

Miller, A. R., P. Tchernia, H. Charnock, and D. A. McGill, Mediterranean Sea Atlas, Woods Hole Oceanographic Institution, Atlas Series, 3 , $190 \mathrm{pp} ., 1970$.

Miller, G. H., S. J. Lehman, N. J. Shackleton, and J. P. Kennett, Pleistocene bottom-water temperature changes deduced from amino acid racemization in foraminifera, abstract, 2nd Int. Conf. Paleoceanog., Woods Hole Oceanographic Institution, 1986.

Millot, C. and A. Monaco, Deep strong currents and sediment transport in the Northwestern Mediterranean Sea, Geo-Mar. Lett., 4, 13-17, 1984. 
Miyashiro, A., Volcanic rock series and tectonic setting, Ann Rev. Earth. Planet. Sci., 3, 251-269, 1975.

Monge11i, F., M. Loddo, and A. Tramacere, Thermal conductivity, diffusivity, and specific heat variation of some Travale field (Tuscany) rocks versus temperature, in M. L. Gupta (ed.), Terrestrial Heat Flow, Tectonophysics, $\underline{83}, 33-43,1982$.

Montadert, L., J. Letouzey, and A. Mauffret, Messinian event: Seismic evidence, in $\mathrm{Hsu}, \mathrm{K}$. J., L. Montadert et a1., Initial Rep. Deep Sea Dri11. Proj., 42(1), 1037-1050, 1978.

Montadert, L., 0. de Charpa1, D. Roberts, P. Guennoc, and J. C. Sibuet, Northeast Atlantic passive continental margins: Rifting and subsidence processes, in M. Talwani, W. Hay, and W. B. F. Ryan (eds.), Deep Drilling Results in the Atlantic Ocean - Continental Margins and Paleoenvironments, Maurice Ewing Ser., 3, 154-186, 1979.

Montigny, R., J. B. Ede1, and R. Thuizat, O1igo Miocene rotation of Sardinia: K/Ar ages and paleomagnetic data of Tertiary volcanics, Earth Planet. Sci. Lett., 54, 261-271, 1981.

More11i, C., M. Pisani, and C. Gantar, Geophysical anomalies and tectonics in the Western Mediterranean, Bu11. Geof. Teor. App1., 67, $211-249,1975$.

More11i, C., et al., Crustal and upper mantle structure of the Northern Apennines, the Ligurian Sea, and Corsica, derived from seismic and gravimetric data, Bu11. Geof. Teor. App1., 75-76, 199-260, 1977.

Moullade, M., The Ligurian Sea and the adjacent areas, in A. E. M. Nairn and W. H. Kanes (eds.), The Western Mediterranean, The Ocean Basins and Margins, 4B, Plenum Press, New York, 67-148, 1978.

Nafe, J. E. and C. L. Drake, Variation with depth in shallow and deep water marine sediments of porosity, density and the velocities of compressional and shear waves, Geophysics, 22, 523-552, 1957.

Nafe, J. E. and C. L. Drake, Physical properties of marine sediments, in M. Hi11 (ed.), The Earth beneath the Sea, The Sea, 3, 794-815, 1963.

Nairn, A. E. M. and M. Westphal, Possible implications of the paleomagnetic study of late Paleozoic igneous rocks of Northwestern Corsica, Palaeogeogr. Palaeoclimato1. Palaeoeco1., 5, 179-204, 1968.

Nardin, T. R., F. J. Hein, D. S. Gorsline, and B. D. Edwards, A review of mass movement processes, sediment and acoustic characteristics, and contrasts in slope and base-of-slope systems versus canyon-fan-basin floor systems, in L. J. Doyle and 0. H. Pilkey (eds.), Geology of Continental Slopes, Soc. Econ. Paleontologists and Mineralogists Spec. Pub., 27, 61-73, 1979. 
Nicolich, R., Crustal structures in the Italian Peninsula and surrounding seas: a review of DSS data, in F. C. Weze1 (ed.), Sedimentary Basins of Mediterranean Margins, Urbino Col1. C. N. R. Ita1. Proj. Oceanogr., Tecnoprint, Bologna, 3-17, 1981.

Noel, M., Origins and significance of nonlinear temperature profiles in deep-sea sediments, Geophys. J. R. Astron. Soc., 76, 673-690, 1984.

O'Hara, M. J., Is there an Icelandic mantle plume?, Nature, 253, $708-710,1975$.

Oxburgh, E. R. and E. M. Parmentier, Compositional and density stratification in oceanic lithosphere--causes and consequences, $\mathrm{J}$. Geo1. Soc. Lond., 133, 343-355, 1977.

Panza, G. F., S. Mueller, and G. Calcagnile, The gross features of the 1ithosphere-asthenosphere system in Europe from seismic surface waves and body waves, Pageoph., 118, 1209-1213, 1979.

Parsons, B. and J. G. Sclater, An analysis of the variation of ocean floor heat flow and bathymetry with age, J. Geophys. Res., $\underline{82}$, 803-827, 1977.

Pautot, G., Cadre morphologique de la Baie des Anges (Nice - Cote d'Azur): Modele d'instabilite de pente continentale, Oceanol. Acta, 4, 203-211, 1981 .

Pautot, G., C. Le Cann, A. Coute1le, and Y. Mart, Morphology and extension of the evaporitic structures of the Liguro-Provencal Basin: new Sea-Beam data, Mar. Geo1., 55, 387-409, 1984.

Pautot, G. and J. P. Rehault, Carte bathymetrique du Bassin Liguro-Provencal, IFREMER, 1986.

Pierrot, S., Carte bathymetrique de la mer Ligure, Mus. Oceanogr. Monoco, 1972.

Pinet, c., The thermal anomaly in and around a salt diapir: Parametric study and transitory effects, unpublished report, University of Paris VI, 24 pp., 1987.

Poutiers, J., Was there any deep water formation in the Mediterranean Sea before 8000 years B. P., Deep-Sea Res., 34, 309-312, 1987.

Poutiers, J. and J. C. Faugeres, L'evolution de 1 'hydrologie de la Mer d'Alboran et des courants de contour de la marge sud-iberique du Quaternaire recent: apports de certain modeles physiques, Bul1. Soc. Geo1. Fr., 8, 899-911, 1987. 
Press, W. H., B. P. Flannery, S. A. Teukolsky, and W. T. Vetterling, Numerical Recipes: The Art of Scientific Computing, Cambridge University Press, New York, 818 pp., 1986.

Purdy, G. M. and R. S. Detrick, Crustal structure of the mid-Atlantic ridge at $23^{\circ} \mathrm{N}$ from seismic refraction studies, J. Geophys. Res., 91, 3739-3762, 1986 .

Puxeddu, M., Structure and Late Cenozoic evolution of the upper lithosphere in southwest Tuscany (Italy), Tectonophysics, 101, $357-382,1984$.

Ragan, D. M., Structura1 Geology: An Introduction to Geometrical Techniques, John Wiley, New York, 209 Pp., 1973.

Ratcliffe, E. H., The thermal conductivities of ocean sediments, J. Geophys. Res., 65, 1535-1541, 1960.

Recq, M., Contribution a 1'etude de 1'evolution des marges continentales du Golfe de Genes, Tectonophysics, 22, 363-375, 1974.

Recq, M., G. Bellaiche, and J. P. Rehault, Interpretation de quelques profiles de sismique refraction en mer Ligure, Mar. Geo1., 32, $39-52,1979$.

Rehau1t, J. P., Evolution tectonique et sedimentaire du Bassin Ligure, These doctorat es Sciences, Paris VI, 1981.

Rehau1t, J. P. and N. Bethoux, Earthquake relocation in the Ligurian Sea (Western Mediterranean): Geological interpretation, Mar. Geo1., 55, 429-445, 1984.

Rehault, J. P., G. Boillot, and A. Mauffret, The Western Mediterranean Basin geological evolution, Mar. Geol., 55, 447-477, $1984 a$.

Rehault, J. P., J. Mascle, and G. Boillot, Evolution geodynamique de1 la Mediterranee depuis 1'01igocene, Mem. Soc. Geol. It., 27, 85-96, $1984 \mathrm{~b}$.

Rehault, J. P., G. Boillot, and A. Mauffret, The Western Mediterranean Basin, in D. J. Stanley and F. C. Weze1 (eds.), Geologic Evolution of the Mediterranean Basin, Springer-Verlag Inc., New York, 101-129, 1985 .

Rehault, J. P., E. Moussat, and A. Fabbri, Structural evolution of the Tyrrhenian back-arc basin, Mar. Geo1., 74, 123-150, 1987.

Rehault, J. P., J. M. Cantagrel and C. Robin, Laves alcalines Miocenes de type rift en mer 1igure: Precisions sur 1 'ouverture du Bassin de Mediterranee Occidentale, preprint, 1988. 
Ringwood, A. E., Composition and evolution of the upper mantle, Geophys. Mon., 13, 1-17, 1969 .

Riviere, M., H. Bellon et C. Bonnot-Courtois, Aspects geochimiques et geochronologiques du volcanisme pyroclastique fore dans le Golfe de Valence: site 123 DSDP, Leg 13 (Espagne)-consequences geodynamiques, Mar. Geo1., 41, 295-307, 1981.

Ross, D. A. and W. R. Riede1, Comparison of upper parts of some piston cores with simultaneously collected open-barrel cores, Deep-Sea Res., 14, 285-294, 1967.

Rotschy, F., C. Vergnaud-Grazzini, G. Bellaiche, and H. Chamley, Etude paleoclimatologique d'une carotte prevelee sur un dome de la plaine abyssale ligure ("Structure Alinat"), Palaeogr. Palaeoclimat. Palaeoeco1., 11, 125-145, 1972.

Royden, L. and C. E. Keen, Rifting process and thermal evolution of the continental margin of eastern Canada determined from subsidence curves, Earth P1anet. Sci. Lett., 51, 343-361, 1980.

Royden, L., J. G. Sclater, and R. P. Von Herzen, Continental margin subsidence and heat flow: Important parameters in formation of petroleum hydrocarbons, Am. Assoc. Pet. Geol. Bu11., 64, 173-187, 1980 .

Royden, L., F. Horvath, A. Nagymarosy, and L. Stegena, Evolution of the Pannonian Basin system, 2, Subsidence and therma1 history, Tectonics, 2, 91-137, 1983.

Ryan, W. B. F., Quantitative evaluation of the depth of the western Mediterranean before, during and after the Late Miocene salinity crisis, Sedimentology, 23, 791-813, 1976.

Ryan, W. B. F. and M. B. Cita, The nature and distribution of Messinian erosional surfaces - Indicators of several-kilometer-deep Mediterranean in the Miocene, Mar. Geo1., 27, 193-230, 1978.

Ryan, W. B. F., D. J. Stanley, J. B. Hersey, D. A. Fahlquist, and T. D. Allan, The tectonics and geology of the Mediterranean Sea, in A. Maxwe11 (ed.), The Sea, 4(1), 387-492, 1970.

Ryan, W. B. F., K. J. Hsu, et a1., Initial Rep. Deep Sea Dril1. Proj., $\underline{13}, 1447 \mathrm{pp} ., 1973$.

Salisbury, M. H. and N. I. Christensen, Olivine fabrics in the Bay of Islands Ophiolite: implications for oceanic mantle structure and anisotropy, Can. J. Earth Sci., 22, 1757-1766, 1985. 
Sankey, T., The formation of deep water in the Northwestern Mediterranean, in: B. A. Warren (ed.), Prog. Oceanog., 6, 159-179, 1973.

Sass, J. H., Theoretical temperature-time curves for the cylindrical therma1 conductivity probe, in W. H. K. Lee (ed.), Terrestrial Heat Flow, Geophys. Mono. 8, Amer. Geophys. Union, Washington, D.C., Appendix chap. 3, 1965.

Sawyer, D. S., Thermal evolution of the northern U.S. Atlantic continental margin, Ph.D. thesis, Massachusetts Institute of Technology, Cambridge Mass., 1982.

Sawyer, D. S., Total tectonic subsidence: a parameter for distinguishing crust type at the U.S. Atlantic continental margin, J. Geophys. Res., 90, 7751-7769, 1985.

Sawyer, D. S., A. Hsui and M. N. Toksozöz, Extension, subsidence and thermal evolution of the Los Angeles basin: a two-dimensional model, Tectonophysics, 133, 15-32, 1987.

Schatz, J. F. and G. Simmons, Thermal conductivity of Earth materials at high temperatures, J. Geophys. Res., 77, 6966-6983, 1972.

Schouten, H., S. P. Srivastava, and K. D. Klitgord, Iberian plate kinematics: the African connection, (submitted to Nature).

Schreiber, E., P. J. Fox, and J. J. Peterson, Compressional wave velocities in selected samples of gabbro, schist, limestone, anhydrite, gypsum and halite, in Ryan, W. B. F., K. J. Hsu, et al., Initial Rep. Deep Sea Dri11. Proj., 13(2), 595-597, 1973.

Schroeder, W., The empirical age-depth relation and depth anomalies in the Pacific Ocean basin, J. Geophys. Res., 89, 9873-9883, 1984.

Sclater, J. G. and P. A. F. Christie, Continental stretching: An explanation of the post-mid-Cretaceous subsidence of the Central North Sea Basin, J. Geophys. Res., ㅍ5, 3711-3739, 1980.

Sclater, J. G., C. E. Correy, and V. Vacquier, In-situ measurement of the thermal conductivity of ocean-floor sediments, J. Geophys. Res., 74, 1070-1081, 1969.

Sclater, J. G., E. J. Jones, and S. P. Miller, The relationship of heat flow, bottom topography and basement relief in Peake and Freen Deeps, northeast Atlantic, Tectonophysics, 1ㅁ, 283-300, 1970.

Sclater, J. G., L. A. Lawver, and B. Parsons, Comparison of long-wavelength residual elevation and free air gravity anomalies in the north Atlantic and possible implications for the thickness of the lithospheric plate, J. Geophys. Res., 80, 1031-1052, 1975. 
Sclater, J. G., J. Crowe, and R. N. Anderson, on the reliability of oceanic heat flow averages, J. Geophys. Res., 81, 2997-3006, 1976a.

Sclater, J. G., D. Karig, L. A. Lawver, and K. Louden, Heat flow, depth, and crustal thickness of the marginal basins of the south Philippine Sea, J. Geophys. Res., 81, 309-319, 1976b.

Sclater, J. G., C. Jaupart, and D. Galson, The heat flow through oceanic and continental crust and the heat loss of the Earth, Rev. Geophys. Space Phys., 18, 269-311, 1980.

Scott, R. and L. Kroenke, Evolution of back arc spreading and arc volcanism in the Philippine Sea: interpretation of Leg 59 DSDP results, in Hayes, D. E. (ed.), The Tectonic and Geologic evolution of southeast Asian Seas and the Islands, Geophysical Monograph, 23, 283-291, 1980 .

Selig, F. and G. C. Wallick, Temperature distribution in salt domes and surrounding sediments, Geophysics, 31, 346-361, 1966.

Sengor, A. M. C. and K. Burke, Relative timing of rifting and volcanism on earth and its tectonic implications, Geophys. Res. Lett., $\underline{5}$, 419-421, 1978.

Shackleton, N. J. and N. D. Opdyke, Oxygen isotope and palaeomagnetic stratigraphy of equatorial Pacific core V28-238: oxygen isotope temperatures and ice volumes on a $10^{5}$ year and $10^{6}$ year scale, Quat. Res., 3, 39-55, 1973.

Sheridan, R. E., J. A. Grow, J. C. Behrendt, and K. C. Bayer, Seismic refraction study of the continental edge of the eastern United States, Tectonophysics, 59, 1-26, 1979.

Sinton, J. M. and P. Fryer, Mariana Trough Lavas from $18^{\circ} \mathrm{N}$ : Implications for the origin of back arc basin basalts, J. Geophys. Res., 92, 12,782-12,802, 1987.

Sleep, N. H., Thermal effects of the formation of Atlantic continenta1 margins by continental breakup, Geophys. J.R. Astron. Soc., 24, $325-350,1971$.

Smith, J. E., The dynamics of shale compaction and evolution of pore-f1uid pressures, Math. Geo1., 3, 239-263, 1971.

Spohn, T. and G. Schubert, Convective thinning of the lithosphere: a mechanism for rifting and mid-plate volcanism on Earth, Venus, and Mars, Tectonophysics, 94, 67-90, 1983.

Stanley, D. J., Post-Miocene depositional patterns and structura1 displacement in the Mediterranean, in A. E. M. Nairn, W. H. Kanes, and F. G. Stehli (eds.), The Ocean Basins and Margins, 4A, P1enum Press, New York, 77-150, 1977. 
Stanley, D. J., Mud redepostion and problems of assessing microfossil, isotopic and radiocarbon data in the Mediterranean, Mar. Geo1., 62, $381-389,1985$.

Stanley, D. J. and E. Mutti, Sedimentological evidence for an emerged land mass in the Ligurian Sea during the Paleogene, Nature, 218, $32-36,1968$.

Stanley, D. J., F. W. McCoy, and L. Diester-Haass, Balearic Abyssal Plain: an example of modern basin plain deformation by salt tectonism, Mar. Geo1., 17, 183-200, 1974a.

Stanley, D. J., H. Got, O. Leenhardt, and Y. Weiler, Subsidence of the western Mediterranean Basin in Pliocene-Quaternary time: Further evidence, Geology, 2, 345-350, $1974 \mathrm{~b}$.

Stanley, D. J., J. P. Rehault, and R. Stuckenrath, Turbid-layer bypassing model: The Corsican Trough, Northwestern Mediterranean, Mar. Geo1., 37, 19-40, 1980.

Steckler, M. S., The thermal and mechanical evolution of Atlantic-type continental margins, Ph.D. thesis, Columbia Univ., New York, 1981.

Steckler, M. S. and A. B. Watts, Subsidence of the Atlantic type continental margin off New York, Earth Planet. Sci. Lett., 41, 1-13, 1978.

Steckler, M. S. and A. B. Watts, The Gulf of Lion: subsidence of a young margin, Nature, 287, 5781, 425-430, 1980.

Steckler, M. S., Uplift and extension at the Gulf of Suez: indications of induced mantle convection, Nature, 317, 135-139, 1985.

Stein, S., N. H. Sleep, R. J. Geher, S. C. Wang, and G. C. Kroeger, Earthquakes along the passive region of Eastern Canada, Geophys. Res. Lett., 6, 537-540, 1979.

Stephenson, R. and K. Lambeck, Erosion-isotatic rebound models for uplift: an application to southeastern Australia, Geophys. J. R. Astron. Soc., 82, 31-55, 1985.

Stow, D. A. V. and A. E. Aksu, Disturbances in soft sediment due to piston coring, Mar. Geol., 28, 135-144, 1978.

Swallow, J. C. and G. F. Caston, The preconditioning phase of MEDOC 1969-I. Observations, Deep-Sea Res., 20, 429-448.

Swift, S. A., Late Pleistocene sedimentation on the continental slope and rise off western Nova Scotia, Geol. Soc. Am. Bu11., 96, 832-841, 1985 . 
Talbot, C. J. and M. P. A. Jackson, Internal kinematics of salt diapirs, Am. Assoc. Petr. Geo1. Bul1., 71, 1068-1093, 1987.

Tapponnier, P., Evolution tectonique du systeme alpine en Mediterranee: poinconnement et ecrasement rigide-plastique, Bull. Soc. Geol. Fr., $19,437-460,1977$.

Taupier-Letage, I. and C. Millot, General hydrodynamical features in the Ligurian Sea inferred from the DYOME experiment, Oceano1. Acta, 9 , $119-131,1986$.

Taylor, B. and G. D. Karner, On the evolution of marginal basins, Rev. Geophys. Space Phys., 21, 1727-1741, 1983.

Taylor, J. R., An Introduction to Error Analysis, University Science Books, Mill Valley, California, 270 pp., 1982.

Thiede, J., A Glacia1 Mediterranean, Nature, 276, 680-683, 1978.

Thomas, B. and M. Gennesseaux, A two-stage rifting in the basins of the Corsica-Sardinian Straits, Marine Geology, 72, 225-239, 1986.

Thouvenot, F., J. Asorge, and C. Evs, Deep structure of the Alps: new constraints from EGT-S Seismic Experiment, in D. A. Galson and St. Mueller (eds.), Second EGT Workshop: The Southern Segment, European Science Foundation, Strasbourg, 109-114, 1985.

Thune11, R. C., Pliocene-Pleistocene paleotemperature and paleosalinity history of the Mediterranean Sea: results from DSDP Sites 125 and 132, Mar. Micropaleo., 4, 173-187, 1979.

Thune11, R. C. and D. F. Williams, The stepwise development of Pliocene-Pleistocene paleoclimatic and paleoceanographic conditions in the Mediterranean: oxygen isotopic studies of DSDP Sites 125 and 132 , in: J. E. Meulenkamp (ed.), Reconstruction of Marine Paleoenvironments, Utrecht Micropaleo. Bu11., 30, 111-127, 1983.

Trusheim, F., Mechanism of salt migration in northern Germany, Am. Assoc. Pet. Geo1. Bul1., 44, 151.9-1540, 1960.

Tucholke, B. E., Acoustic environment of the Hatteras and Nares Abyssa1 Plains, western North Atlantic Ocean, determined from velocities and physical properties of the sediment cores, J. Acoust. Soc. Am., 68 , $1376-1390,1980$.

Turcotte, D. L., J. L. Ahern and J. M. Bird, The state of stress at continental margins, in D. Denham (ed.), Stress Environment and Displacements at Continental Margins, Tectonophysics, 42, 1-28, 1977.

Turcotte, D. L. and G. Schubert, Geodynamics, John Wiley, New York, 450 pp., 1982. 
Urai, J. L., C. J. Spiers, H. J. Zwart, and G. S. Lister, Weakening of rock salt by water during long-term creep, Nature, 324, 554-557, 1986.

Vasseur, G., Synthese des resultats de flux geothermique en France, Ann. Geophys., 38, 189-201, 1982.

Vasseur, G., and Y. Nouri, Trend of heat flow in France: relation with deep structures, Tectonophysics, 65, 209-223, 1980.

Vergnaud-Grazzini, C., Mediterranean late Cenozoic stable isotopic record: Stratigraphic and Paleoclimatic implications, in: D. J. Stanley and F. C. Wezel (eds.), Geological Evolution of the Mediterranean Basin, Springer-Verlag, New York, 413-451, 1985.

Vergnaud-Grazzini, C., M. Devaux, and J. Znaidi, Stable isotopic "anomalies" in Mediterranean Pleistocene records, Mar. Micropaleo., 10, 35-69, 1986 .

Vergnaud-Grazzini, C., M. B. Cita, and W. B. F. Ryan, Stable isotopic fractionation, climate change, and episodic stagnation in the eastern Mediterranean during the late Quaternary, Mar. Micropaleo., 2, 353-370, 1977.

Villinger, H. and E. E. Davis, 1987, A new reduction algorithm for marine heat-flow measurements, J. Geophys. Res., 92, 12,846-12,856, 1987.

Vine, F. J. and D. H. Matthews, Magnetic anomalies over oceanic ridges, Nature, 199, 947-949, 1963.

Vink, G. E., W. J. Morgan and W. L. Zhao, Preferential rifting of continents: A source of displaced terrains, J. Geophys. Res., 89 , $10,072-10,076,1984$.

Vogt, P. R., R. H. Higgs, and G. L. Johnson, Hypotheses on the origin of the Mediterranean Basin: Magnetic data, J. Geophys. Res., 76, $3207-3228,1971$.

Von Herzen, R. P. and A. E. Maxwe11, The measurement of therma1 conductivity of deep-sea sediments by a needle-probe method, J. Geophys. Res., 64, 1557-1563, 1959.

Von Herzen, R. P. and S. Uyeda, Heat flow through the eastern Pacific ocean floor, J. Geophys. Res., 68, 4219-4250, 1963.

Von Herzen, R. P. and R. N. Anderson, Implications of heat flow and bottom water temperature in the Eastern Equatorial Pacific, Geophys. J. R. Astron. Soc., 26, 427-458, 1972.

Von Herzen, R. P. and C. Fang, 1987, Improved marine heat flow instrumentation Trans. Am. Geophys. Union (EOS), 68, 424, 1987. 
Von Herzen, R. P., H. Hoskins, and T. H. Van Ande1, Geophysical studies in the Angola diapir field, Geol. Soc. Am. Bul1., 83, 1901-1910, 1972 .

Von Herzen, R. P., D. Finckh, and K. J. Hsu, Heat-flow measurements in Swiss 1akes, Geophys. J. R. Astron. Soc., 40, 141-172, 1974.

Von Herzen, R. P., R. S. Detrick, S. T. Crough, D. Epp, and U. Fehn, Thermal origin of the Hawaiian swe11: Heat-flow evidence and therma1 mode1s, J. Geophys. Res., 87, 6711-6723, 1982.

Von Herzen, R. P., M. J. Cordery, C. Fang, R. S. Detrick, and B. Parsons, Thermal origin of the Hawaiian Swe11: new heat flow evidence, Trans. Am. Geophys. Union, (EOS), 68, 1462, 1987.

Watanabe, T., M. G. Langseth, and R. N. Anderson, Heat flow in back-arc basins of the western Pacific, in M. Talwani and W. C. Pitman III (eds.), Island Arcs, Deep Sea Trenches and Back-Arc Basins, Maurice Ewing Ser., 1, 137-161, 1977.

Watts, A. B. and W. B. F. Ryan, Flexure of the 1ithosphere and continental margin basins, Tectonophysics, 36, 25-44, 1976.

Watts, A. B. and S. F. Daly, Long wavelength gravity and topography anomalies, Ann. Rev. Earth Planet. Sci., 9, 415-448, 1981.

Watts, A. B. and M. S. Steckler, Subsidence and eustasy at the continental margin of eastern North America, in M. Talwani, W. Hay, and W. B. F. Ryan (eds.), Deep Drilling Results in the Atlantic Ocean - Continental Margins and Paleoenvironments, Maurice Ewing Ser., 3, 218-234, 1979.

Watts, A. B., G. D. Karner, and M. S. Steckler, Lithospheric flexure and the evolution of sedimentary basins, Phil. Trans. Roy. Soc. Lond., A305, 249-281, 1982 .

Weisse1, J. K., Magnetic lineations in marginal basins of the western Pacific, Phil. Trans. Roy. Soc. Lond., A300, 223-247, 1981.

Weisse1, J. K. and D. E. Hayes, The Australian-Antarctic discordance: New results and implications, J. Geophys. Res., 79, 2579-2587, 1974.

Wernicke, B., Low-angle normal faults in the Basin and Range Province: Nappe tectonics in an extending Orogen, Nature, 291, 645-648, 1981.

Wernicke, B., Uniform-sense normal simple shear of the continental 1ithosphere, Can. J. Earth Sci., 22, 108-125, 1985. 
White, R. S., G. K. Westbrook, S. R. Fowler, G. D. Spence, P. J. Barton M. Joppen, J. Morgan, A. N. Bowin, C. Prestcott, and M. H. P. Bott, Hatton Bank (northwest U. K.) continental margin structure, Geophys. J. R. Astron. Soc., 89, 265-272, 1987a.

White, R. S., G. D. Spence, S. R. Fowler, D. P. McKenzie, G. K. Westbrook, and A. N. Bowin, Magmatism at rifted continental margins, Nature, $330,439-444,1987 \mathrm{~b}$.

Whitmarsh, R. B., F. Avedik, and M. R. Saunders, The seismic stucture of thinned continental crust in the northern Bay of Biscay, Geophys. J. R. Astron. Soc., 86, 589-602, 1986.

Wood, C. A., Continental rift jumps, in P. Morgan and B. H. Baker (eds.), Processes of Continental Rifting, Tectonophysics, 94 , $529-540,1983$.

Woodside W. and J. H. Messmer, Thermal conductivity of porous media, J. App1. Physics, 32, 1688-1706, 1961.

Wust, G., On the vertical circulation of the Mediterranean Sea, J. Geophys. Res., 66, 3261-3271, 1961.

Yoshii, T., Upper mantle structure beneath the north Pacific and the margina1 seas, J. Phys. Earth, 21, 313-328, 1973.

Zahn, R., M. Sarnthein, and H. Erlenkeuser, Benthos isotope evidence for changes of the Mediterranean outflow during the late Quaternary, Paleoceanog., submitted, 1987. 
Biographical sketch

Between the rows of corn and soybeans of central Illinois, I was born the fifth and last child of Dr. John and Marijane Jemsek. I resided at 3009 Western Avenue from infancy, attending St. Mary's and St. Joseph's elementary schools with the "Green Hornets" and then to Central Junior High for one year, home of the "Yellowjackets". It was in $9^{\text {th }}$ grade when my hopes of playing varsity basketba11 were forever crushed, for I was too small to make the team. Upon attending Mattoon Senior High School, I spent the next year and half suffering from stomach cramps, shin splints, and sore feet from doing LSD (Long Slow Distance) with the "Fightin' Green Wave" cross country and track team. After that, I was content to pump gas at Texaco and D-Co during the energy crisis. For college, I followed the footsteps of two of my sisters to South Bend, Indiana, where I entered the Department of Earth Sciences at the U. of Notre Dame. My interest in geology began during my H.S. senior english class when I was writing a paper on alternative energy sources. Numerous road trips doing field geology with the N.D. geologists reinforced my interests in the subject. Along the way to my B.S. in 1981, I perused subjects such as migrating ore fluids and the stick-slip behaviour of sawcut rock. I entered M.I.T. the fall following my graduation, with the intention of doing research in geophysics and plate tectonics. Before my first semester of graduate schoo1 was complete, I participated in the first of several

oceanographic expeditions to the Mediterranean and southern France. The success of the initial cruise resulted in my transfer to the Woods Hole/M.I.T. Joint Program, and in essence, this thesis. I spent my post-general examination years in Woods Hole enjoying some of the best windsurfing and golfing in the country, and doing lots of research. With an eagerness to work on applied problems, endeavours in environmental sciences and liquid waste management are on the horizon. 


\section{Curriculum Vitae}

John P. Jemsek

March, 1988

Geophysicist

Visiting Investigator

Woods Hole Oceanographic Institution

Woods Hole, MA 02543

Tel. (617) 548-1400 ext. 2463

Birth: May 28, 1959; Mattoon, Illinois.

\section{Education:}

B.S.: Earth Sciences, University of Notre Dame, Notre Dame, Indiana, 1981.

Ph.D.: Oceanography (geology and geophysics), Massachusetts Institute of Technology / Woods Hole Oceanographic Institution, Woods Hole, Massachusetts, 1988. Thesis entitled: "Heat flow and tectonics of the Ligurian Sea basin and margins".

\section{Professional Experience:}

Graduate Research Assistant, Massachusetts Institute of Technology, 1981 to 1982.

Graduate Research Assistant, Massachusetts Institute of Technology / Woods Hole Oceanographic Institution, 1982 to 1987.

Teaching Assistant, Marine Geophysics (course), Woods Hole Oceanographic Institution, 1985 \& 1986 fall semesters.

Visiting Investigator, Woods Hole Oceanographic Institution, February 1988 to present.

Field Experience:

Geologist: Indiana University Field Course, field mapping in Wyoming and Montana, June and July, 1980.

Geophysicist: RRS SHACKLETON, Leg 3B, heat flow and seismic refraction survey of W. Tyrrhenian Basin, December, 1981.

Geophysicist: CATHERINE LAURENCE N/O, heat flow survey of the Ligurian Basin, September, 1982.

Co-Chief Scientist: CATHERINE LAURENCE N/O, heat flow survey of the Ligurian Sea margins, September, 1984.

Co-Chief Scientist: CATHERINE LAURENCE N/O, high resolution single-channel seismic survey of the Ligurian Basin, September, 1985.

\section{Professional Affiliation:}

American Geophysical Union

\section{Research Interests:}

1) Heat flow, potential field and seismic studies of oceanic basins and margins to infer upper mantle evolution, rifting and seafloor spreading processes.

2) Numerical modeling of heat and mass transfer in porous media.

3) Optimization and environmental analysis of marine heat flow measurements.

4) Seismic stratigraphy and physical properties of sediments and sedimentary rocks using piston core and borehole geophysical methods.

5) Earthquake seismology and faulting in extensional regimes. 


\section{Publications:}

Hutchison, I., R. P. Von Herzen, K. E. Louden, J. G. Sclater, and J. Jemsek, Heat flow in the Balearic and Tyrrhenian Basins, Western Mediterranean, J. Geophys. Res., 90, 685-701, 1985.

Jemsek, J., R. Von Herzen, and P. Andrew, In situ measurement of thermal conductivity using the continuous-heating line source method and W.H.O.I. outrigged probe, Tech. Report WHOI-85-28, Woods Hole Oceanographic Institution, 73 pp., 1985.

Jemsek, J., R. Von Herzen, J. P. Rehault, D. L. Williams, and J. Sclater, Heat flow and lithospheric thinning in the Ligurian Basin (N.W. Mediterranean), Geophys. Res. Lett., 12, 693-696, 1985.

Jemsek, J. P., E. A. Bergman, J. L. Nabelek, and S. C. Solomon, Focal depths and mechanisms of large earthquakes on the Arctic mid-ocean ridge system, J. Geophys. Res., 91, 13,993-14,005, 1986.

Jemsek, J. and R. Von Herzen, Measurement of in situ sediment thermal conductivity: continuous-heating method with outrigged probes, in: J. Wright and K. Louden (eds.), Handbook of Seafloor Heatflow, CRC Series in Marine Science, CRC Press Inc. (in press).

\section{Abstracts and Presentations:}

Von Herzen, R., I. Hutchison, J. Jemsek, and J. Sclater, Geothermal flux in Western Mediterranean Basins, EOS, 63, 1121, 1982.

Jemsek, J. P., E. A. Bergman, J. L. Nabelek, and S. C. Solomon, Focal depths and mechanisms of large earthquakes on the Mid-Arctic Ridge system, EOS, 65, 273, 1984.

Jemsek, J. and R. Von Herzen, Heat flow of the Ligurian Basin (W. Mediterranean), EOS, $65,1115,1984$.

Jemsek, J. and R. Von Herzen, Heat flow and lithospheric thinning in the Ligurian Basin (Northwest Mediterranean), Geosciences Section, Ocean Industry Program, Woods Hole Oceanographic Institution, 1985.

Jemsek, J., R. Von Herzen, and J. P. Rehault, Heat flow-age and depth-age relationships of the central Ligurian Basin, Northwestern Mediterranean Sea, EOS, 66, 1985.

Fang, C. L., J. P. Jemsek, R. P. Von Herzen, and M. J. Cordery, Heat flow data reduction: Optimization and automation, EOS, 68, 424, 1987.

Jemsek, J. P., J. P. Rehault, and R. P. Von Herzen, Asymmetric thermal and structural development of the Ligurian Basin (NW Med.): Back arc rift jumping and detachment faulting, EOS (submitted). 
Manuscripts in preparation:

Jemsek, J. P., R. P. Von Herzen, and J. P. Rehault, Heat flow analysis of marginal basins: An environmental interpretation of measurements in the Ligurian Basin and margins, (from Ch. 3 \& 4 of Ph.D. dissertation), to be submitted to J. Geophys. Res.

Jemsek, J. P., J. P. Rehault, and R. P. Von Herzen, Asymetric thermal and structural development of the Ligurian Basin: Back arc rift jumping and detachment faulting, (from Ch. 5 of Ph.D dissertation), to be submitted to J. Geophys. Res.

Jemsek, J. P. and J. P. Rehault, Plio-Quaternary evolution of the Ligurian Basin, Northwestern Mediterranean: Margin uplift and Var Fan development, (from Ch. 2 of Ph.D. dissertation), to be submitted to Marine Geology.

Jemsek, J. P. and B. Tucholke, Thermal effects of salt diapirs on gas hydrate formations, to be submitted to Am. Assoc. Petr. Geol. Bull.

Fang, C. L., J. P. Jemsek, and R. P. Von Herzen, Improved heat flow instrumentation and data analysis, to be submitted to Mar. Geophys. Res. 
Appendix 1

Heat Flow and Lithospheric Thinning in the Ligurian Basin (N. W. Mediterranean) 
Heat Flow and Lithospheric Thinning in the Ligurian Basin (N. W. Mediterranean)

J. Jemsek

MIT/WHOI Joint Program in Oceanography Woods Hole Oceanographic Institution Woods Hole, MA 02543

R. Von Herzen Department of Geology and Geophysics Woods Hole Oceanographic Institution Woods Hole, MA 02543

J. P. Rehau1t

Laboratoire de Geodynamique Sous-marine B. P. 48

06230 Vil1ef ranche-sur-mer, France

D. L. Williams

U.S. Geological Survey

Box 25046 Denver Federa1 Center

Lakewood, CO 80225

J. G. Sclater

Institute for Geophysics University of Texas at Austin Austin, TX 78751

Geophysical Research Letters, v. 12, p. 693-696, 1985. 


\section{A1.1 Abstract}

We present preliminary results of 78 new heat flow measurements collected on a transect across the central Ligurian Basin (South France to Corsica margins). The basin-wide flux has an average of $79 \pm$ $21 \mathrm{mWm}^{-2}$ with significant 1 ocal and regional variability. Correction for the deposition of up to $5 \mathrm{~km}$ of postrift sediment gives a mean value of $102 \mathrm{mWm}^{-2}$ which is similar to values for normal oceanic crust of the same age (21 Ma). The total tectonic subsidence (TTS) calculated for the region with probable oceanic crustal structure is comparable to or somewhat greater than 21 Ma crust of the major ocean basins. The heat flow data overall are compatible with the observed TTS in showing substantial 1ithospheric thinning, but do not tightly constrain thermal models of continental extension and rifting.

\section{A1.2 Introduction}

The concept that continental margins and marginal basins result from simple tectonic processes was quantified by McKenzie (1978) in the uniform extension mode1. According to the model, the tectonic subsidence includes two components, (a) an initial elevation change due to extension of the crust during rifting, and (b) a postrift thermal subsidence due to lithospheric cooling. When the crust has been stretched, or thinned, by a factor ( $(B)$ greater than 5 , accretion of oceanic 1ithosphere is probable. Subsequently, the subsidence and heat flow will behave as predicted by the oceanic plate model (e.g., Parsons and Sclater, 1977). More elaborate models have since been developed mainly to fit subsidence history derived from well data (e.g., Royden 
and Keen, 1980). For young ( $<30 \mathrm{Ma}$ ) margins and basins, additional important constraints may be derived from measurements of heat flux. In this paper, we present surface heat flow measurements from the $21 \mathrm{Ma}$ Ligurian Basin (NW Mediterranean). Existing seismic data allow calculations of sediment-corrected heat flow, sediment-unloaded basement depth, and crustal thinning beneath the central basin and adjacent lower margins (Figure A1.1). We compare these observations to values predicted by the uniform extension and oceanic plate models.

\section{A1.3 Geologic setting}

The Ligurian Basin is best explained as a marginal basin generated by a north to northwest subduction of the Africa-Apulia plate beneath the European plate (e.g., Biju-Duval et a1., 1978). The separation of Corsica-Sardinia from Southern Europe is part of the 01igocene and early Miocene rifting of the Western Mediterranean following the Eocene collision of the French Maritime portion of the Alpine chain. The crusta1 structure of the Ligurian Basin is interpreted as follows: (a) a relatively narrow $(30-70 \mathrm{~km})$ band of oceanic crust in the deep central basin, where the Moho discontinuity is 12 to $14 \mathrm{~km}$ below sea leve1, and (b) rifted continental crust in the $60-110 \mathrm{~km}$ wide zone between the deep basin and the present shoreline, with crustal thickness increasing landward (Fah1quist and Hersey, 1969; Le Douaran et a1., 1984). This interpretation is consistent with a 200 mgal positive Bouguer gravity anomaly in the central basin (Morelli et al., 1975) and distribution of magnetic anomalies (Burrus, 1984). The best estimate for the timing of the main phase of basin opening is between 21 and $18 \mathrm{Ma}$, constrained by 


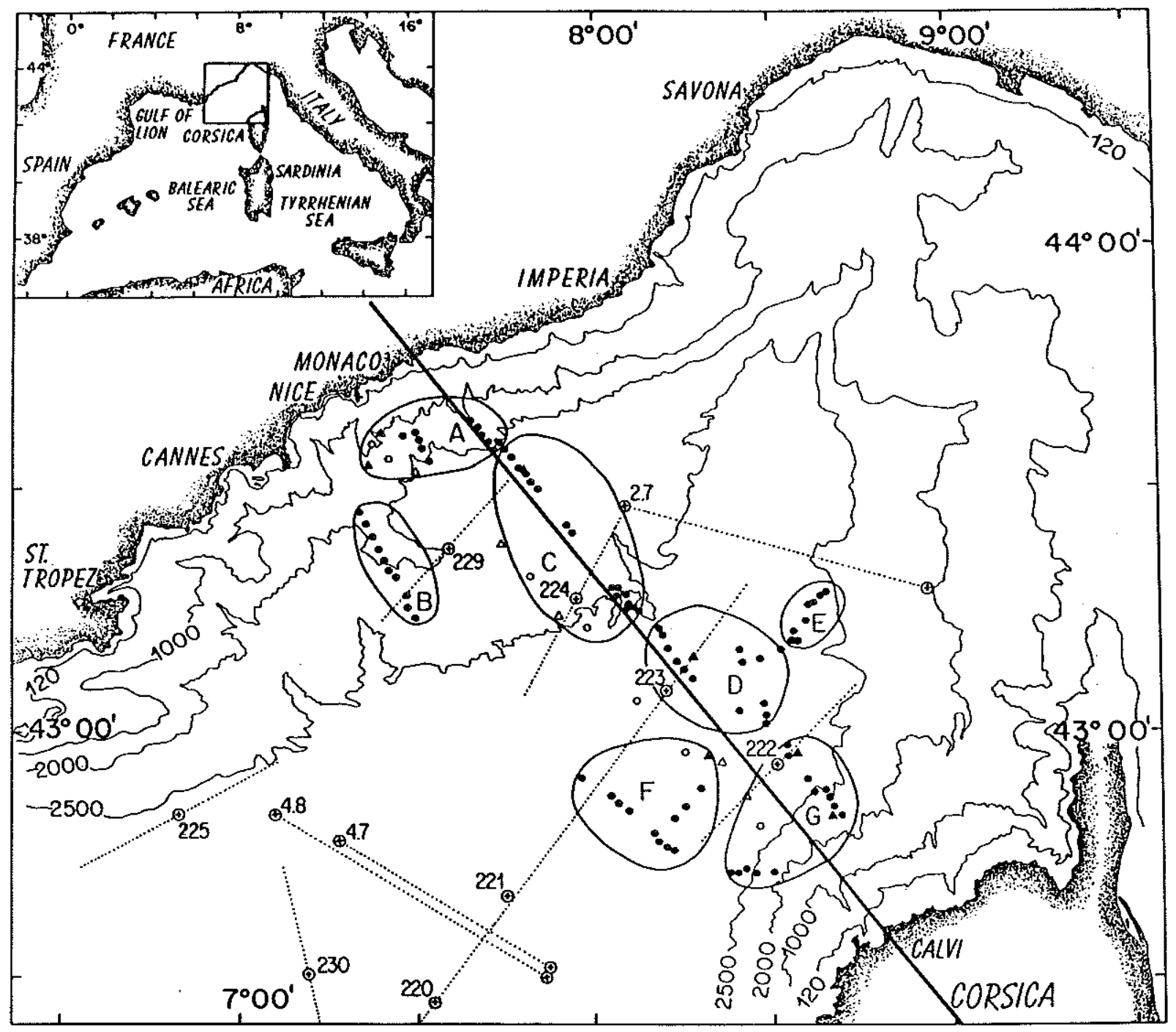

Fig. A1.1. Map (Mercator projection) of Ligurian Sea with heat flow measurement locations. Inset gives location of study area in northwest Mediterranean. Depth contours are 120,1000 , $2000,2500 \mathrm{~m}$ isobaths. Filled circles are new heat flow sites, filled triangles are locations of cores recovered for thermal conductivity measurements. Open circles and open triangles are previous heat flow and piston core stations (Rehault, 1981). Outlined lettered regions are those given in Table Al.1. Heavy straight line oriented NW-SE is section of Figure A1.2. Dotted lines centered on circled + symbols are expanding spread profiles of Le Douaran et al. (1984). Conventional reversed refraction profiles of Fahlquist and Hersey (1969) are located between circled + symbols. 
paleomagnetic data from Tertiary volcanics on Sardinia (Montigny et al., 1981).

The sedimentary facies inferred from various seismic profiles reflect the tectonic subsidence since the main rifting phase (Rehault et a1., 1984). A sedimentary sequence 5 to $6 \mathrm{~km}$ thick has been deposited in the central part of the deep basin (Figure A1.2) and is subdivided into three main units: the $3 \mathrm{~km}$ thick Miocene section (Burdigalian to Tortonian, 22 to $6.1 \mathrm{Ma}$ ); a 1 to $2 \mathrm{~km}$ thick Messinian evaporite sequence including a salt layer ( 6.1 to $5.0 \mathrm{Ma})$; and the Pliocene/Quaternary turbiditic sediments up to $1 \mathrm{~km}$ thick ( $5.0 \mathrm{Ma}$ to present).

\section{A1.4 Heat flow and subsidence results}

The new heat flow measurements were obtained between the Nice-Monaco margin and Corsica (Figure A1.1). Values were calculated from measurements of vertical thermal gradients, and from measurements of therma1 conductivity either on cores or in situ. Thermal gradients were obtained with up to 7 outrigged thermistor sensors mounted on a bottom-penetrating probe ranging in length from about 3.5 to $5.5 \mathrm{~m}$. Therma1 conductivity was determined by the needle-probe method on 7 sediment cores retrieved during our field work. A scaled-up version of this technique was also developed to measure conductivity in situ with the same thermistor probes utilized for thermal gradient measurements. In-situ values were obtained on 39 of the penetrations and compared we11 with nearby sediment core values. Some locations showed considerable vertical variability in conductivity with standard deviations up to $20 \%$ of the station mean. A11 measurements were made in water depths greater 


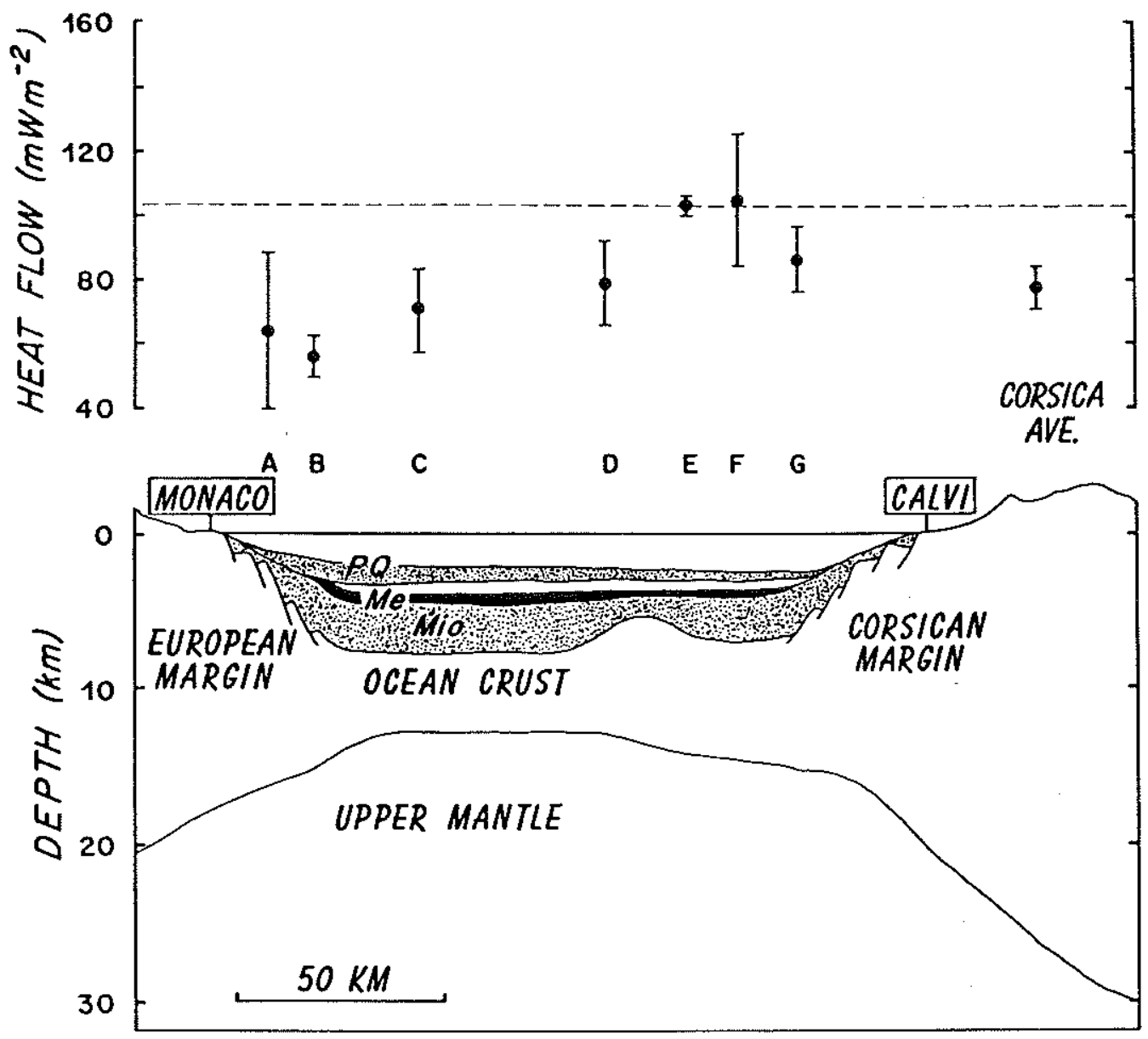

Fig. Al.2. Schematic section of Ligurian Basin between margins of southern France and Corsica located in Figure Al.1. Sedimentary sequences depicted are Plio-Quaternary ( $P Q$, stippled), Messinian evaporites (Me, white with salt layer in black), and Miocene section (Mio, stippled); layer depths controlled by seismic data, Moho depths interpolated from nearby refraction data. Centroids of heat flow regions (Figure A1.1) with mean values and ranges (Table A1.1) are projected normal to section line; value for Corsica from Lesquer et al. (1983). Dashed line is theoretical heat flow for sea floor formed $21 \mathrm{Ma}$ (Parsons and Sclater, 1977). 
than $1 \mathrm{~km}$, and were located as closely as possible to existing seismic reflection profiles in an attempt to avoid areas with salt diapirs and other structural or tectonic complications which could perturb the mean heat flux. Coarse sediments in the deepest parts of the Ligurian basin associated with turbidite deposition occasionally limited bottom penetration to 2 meters or less. From heat flow measurements in Western Mediterranean drill holes (Erickson and Von Herzen, 1978) and the general linearity of our measured thermal gradients, there is 1ittle or no evidence of recent water temperature fluctuations affecting the surficial heat flow values. The 78 measurements have been subdivided into seven different regions (Figure A1.1, Table A1.1) based on the distribution of the values obtained, as we11 as depth and basin structure.

The basin-wide heat flow average is $79 \pm 21 \mathrm{mWm}^{-2}$. The regional heat flow means (Table A1.1) show significant variability across the basin (Figure A1.2), ranging from $56 \mathrm{mWm}^{-2}$ on the lower French continental slope to $105 \mathrm{mWm}^{-2}$ near the lower Corsican margin. For comparison, previous scattered values for the Ligurian Basin range between 32 and $180 \mathrm{mWm}^{-2}$ (Foucher et al., 1976; Rehau1t, 1981); on the Hercynian-age (280 Ma) Corsica terrain, the mean of 8 values is $76 \pm 6$ $\mathrm{mWm}^{-2}$ (Lesquer et a1., 1983).

The sedimentation rates in the Ligurian Basin are sufficiently high to cause the measured surface heat flow to be up to 30 percent lower than that expected without sedimentation. For each region, we have corrected the measured flux using a formulation developed by Hutchison (1985), assuming that the sediment has been deposited at a uniform rate 
Table A1.1 Ligurian Heat Flow and Subsidence Data

\begin{tabular}{llcccc}
\hline Region & $\begin{array}{c}\mathrm{K} \\
\left(\mathrm{Wm}^{-1} \mathrm{~K}^{-1}\right)\end{array}$ & $\begin{array}{c}\mathrm{QM} \\
\left(\mathrm{mW} \mathrm{m} \mathrm{m}^{-2}\right)\end{array}$ & $\begin{array}{c}\mathrm{QE} \\
\left(\mathrm{mW} \mathrm{m}^{-2}\right)\end{array}$ & $\begin{array}{l}\mathrm{TTS} \\
(\mathrm{km})\end{array}$ & $\begin{array}{c}\mathrm{QT} \\
\left(\mathrm{mWm}^{-2}\right)\end{array}$ \\
\hline $\mathrm{A}$ & $1.20 \pm .13(11)$ & $65 \pm 24(11)$ & 77 & 2.4 & $74-91$ \\
B & $1.26 \pm .04(9)$ & $56 \pm 7(10)$ & 73 & 3.4 & $91-101$ \\
$\mathrm{C}$ & $1.30 \pm .10(14)$ & $71 \pm 13(15)$ & 103 & 4.0 & $98-105$ \\
D & $1.29 \pm .15(7)$ & $78 \pm 13(14)$ & 95 & 3.4 & $90-100$ \\
E & $1.15 \pm .10(4)$ & $103 \pm 3(5)$ & 121 & 3.0 & $84-97$ \\
F & $1.28 \pm .09(5)$ & $105 \pm 21(11)$ & 147 & 4.1 & $99-105$ \\
G & $1.09 \pm .02(11)$ & $86 \pm 11(12)$ & 104 & 2.8 & $80-95$ \\
\hline
\end{tabular}

Region 1ocations in Figure A1.1

$\mathrm{K}=$ mean therma1 conductivity $\pm \mathrm{S}$. D. of all in situ and core values, (total number)

$\mathrm{QM}=$ mean measured heat flow $\pm \mathrm{S}$. D., (total number)

$\mathrm{QE}=$ mean heat $\mathrm{flow}$ corrected for sedimentation effects

TTS $=$ mean sediment-unloaded basement depth

$\mathrm{QT}=$ range of theoretical heat flow (see text). 
and has thermal and compaction properties appropriate for a shale 1ithology. Corrected regional mean values range between 73 and $147 \mathrm{mWm}^{-2}$, and the estimated basin-wide equilibrium heat flow is $102 \mathrm{mWm}^{-2}$, similar to values expected for normal 21 Ma sea floor (e.g., Parsons and Sclater, 1977).

In our subsidence analysis, we define total tectonic subsidence (TTS) as the present basement depth corrected for sediment loading (Sawyer, 1985). For refraction profiles where Moho depth is determined (1ocations in Figure A1.1), the TTS parameter is obtained using Crough's (1983) correction for sediment loading. On1y profiles associated with free-air gravity anomalies of 20 mgal (More11i et a1., 1975) are considered as local isostatic compensation is assumed. Although the occurrence of salt was not studied by Crough (1983), its relatively low density would tend to make the depth correction a minimum. The stretching factor for each profile is determined by dividing the observed crustal thickness by an estimated prerift crustal thickness of $30 \mathrm{~km}$, which is the depth to Moho beneath Corsica (Hirn and Sapin, 1976).

We compare these observed data with the theoretical TTS for a $21 \mathrm{Ma}$ basin as predicted by the models (Figure A1.3). The uniform extension mode1 parameters are as follows:

$\begin{array}{ll}\text { initial lithospheric thickness } & 125 \mathrm{~km} \\ \text { initial crustal thickness } & 30 \mathrm{~km} \\ \text { thermal expansion coefficient } & 3.28 \times 10^{-5}{ }^{\circ} \mathrm{C}^{-1} \\ \text { asthenospheric temperature } & 1333^{\circ} \mathrm{C} \\ \text { asthenospheric density } & 3.22 \mathrm{gcm}^{-3} \\ \text { crusta1 density }\left(0^{\circ} \mathrm{C}\right) & 2.80 \mathrm{gcm}^{-3} \\ \text { thermal time constant } & 62.8 \mathrm{My}\end{array}$

The above parameters are chosen so that the initial continental crust is 


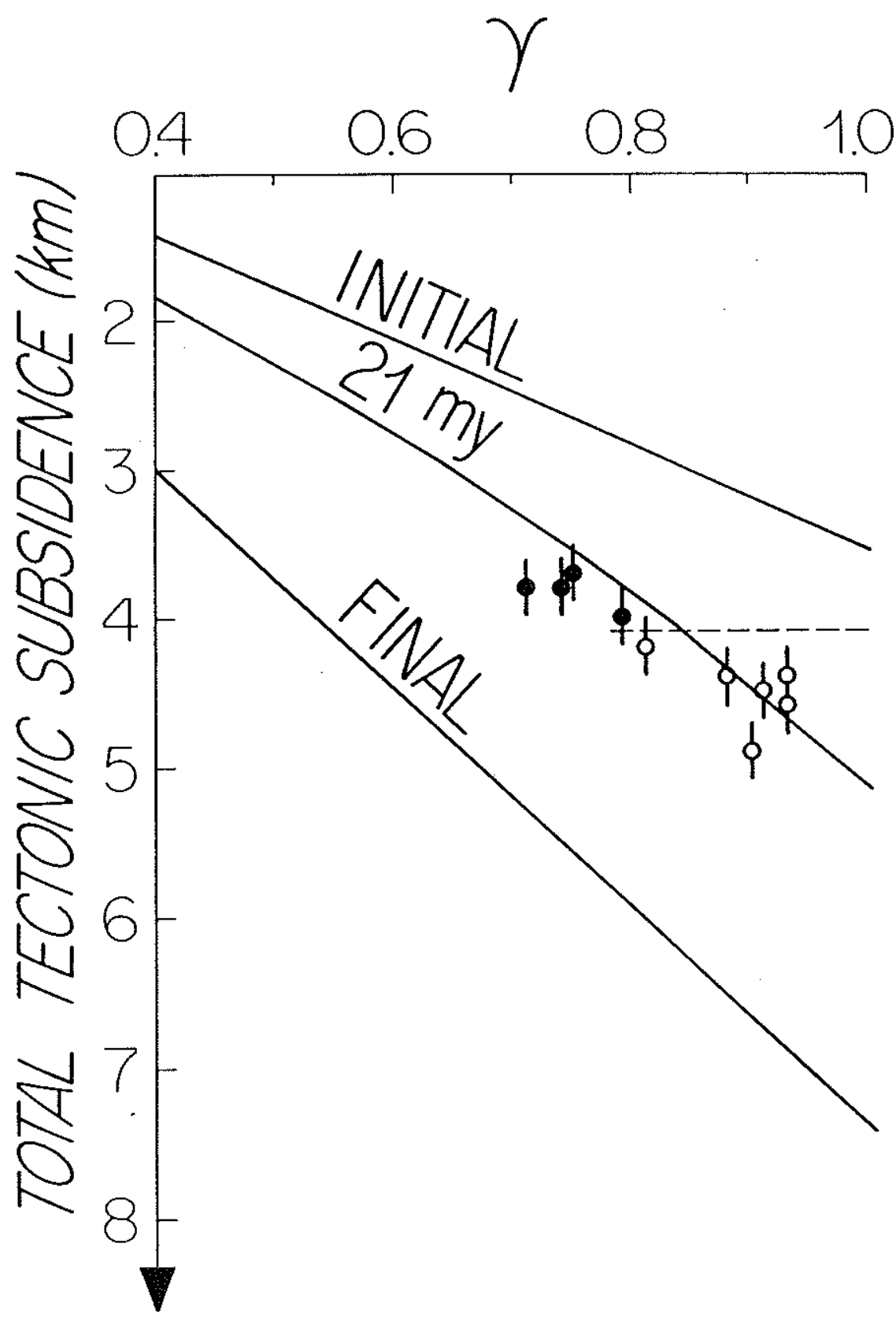

Fig. A1.3. Tectonic subsidence vs. crustal thinning, $Y=1-1 / \beta$. Data from refraction profiles located on Figure A1.1. Open circles are probable oceanic crust values of the central basin; solid circles are sub-oceanic or highly stretched continental crust of the margins. Error bars are $\pm 10 \%$ of sediment unloading correction. Solid lines are theoretical values of the uniform extension model (see text). Dashed line is $21 \mathrm{Ma}$ theoretical oceanic subsidence (Parsons and Sclater, 1977). 
in isostatic balance with the estimated crustal structure of the deep basin $\left(2.9 \mathrm{~km}\right.$ zero-age depth, $3.4 \mathrm{~km}$ crustal thickness, and $2.8 \mathrm{gcm}^{-3}$ crustal density) and are taken mostly from Parsons and Sclater (1977). The smaller effects of flexure, lateral heat conduction, finite rifting and thermal blanketing by the sediment are not considered since the heat flow and subsidence observations are only approximately corrected.

The TTS parameter for each region (Table A1.1) is obtained from the basement two-way travel times given by Rehault et a1. (1984), using the procedure of Crough (1983). The regional crustal thinning is then estimated from the TTS parameter using the uniform extension model at 21 Myr (see Figure A1.3). According to the extension model, the heat flow is the sum of three components; the equilibrium heat flow from the mantle (33.5 $\mathrm{mWm}^{-2}$ from Parsons and Sclater (1977)), the transient heat flow depending on the amount of extension $(B)$, and the heat flow due to the radiogenic elements in the stretched crust $\left(Q_{c} / B\right)$. By simply adding the radiogenic heat contribution from the crust, we have ignored the smaller effect of the vertical distribution of the radiogenic elements on the temperature structure of the lithosphere, and the radiogenic heat production in the sediments. The $Q_{c}$ is estimated to be 17 to $55 \mathrm{mWm}^{-2}$ from the measured range of radiogenic heat production in the Hercynian-age granites, $1.76-5.3 \mu^{-3}$ (Lesquer et a1., 1983). Therefore, the heat flow predicted by the extension mode1 (Table A1.1) is dependent on the crustal thinning of each region. 


\section{A1.5. Discussion}

Geothermal heat flux in the Ligurian Basin is similar to that of the Balearic portion of the Western Mediterranean (Hutchison et al., 1985) and reinforces other geophysical evidence for a young opening of the Western Mediterranean. Crustal radioactivity probably accounts for some of the regional variability. Local variability within each region is attributed to thermal conductivity uncertainties, sedimentary processes, topography, and perhaps thermal refraction due to basement and sediment structure. Region F (Figure A1.1) encompasses an area strongly affected by salt diapirism (Rehault, 1981) with the probability of some high values caused by nearby undetected salt domes. Regions B and E, with lower and higher than expected heat flow, respectively, will be further analyzed with additional seismic, sedimentologic, and geothermal data collected since this study was completed.

The TTS data of Figure A1.3 have good agreement with that predicted by the uniform extension model. However, the TTS calculated for the oceanic crust of the central basin appears to be several hundred meters greater than predicted by the depth-age relationship of the major ocean basins. Although the thin crust may account for some of the depth anomaly, the depth and heat flow signatures of the Ligurian Basin are not unlike that reported for the Western Pacific marginal basins (Louden, 1980) and Tyrrhenian Sea (Hutchison et a1., 1985).

In summary, the heat flow in conjunction with the observed subsidence genera11y supports 1 ithospheric stretching as the mode of basin formation for the Ligurian Basin. Further study is underway to 
determine what extent the regional variability in heat flow reflects actual variations in the sub-basement thermal structure.

A1.6 Acknowledgements.

We are grateful to the captain and crew of the $R / V$. Catherine

Laurence for their assistance, and to G. Pelletier for maintenance of instrumentation, during the field operations (September 1982). We thank B. Celerier, G. Jones, J. Karson, and L. Royden for their comments on this ms. This investigation was supported by grants OCE-8024287 and 8025181 from the National Science Foundation. This is Contribution No. 5761 of the Woods Hole Oceanographic Institution. and No. 282 of the Groupe d'Etude de 1a Marge Continentale. 
$-315-$

Appendix 2

Measurement of In Situ Sediment Thermal Conductivity:

Continuous-Heating Method with Outrigged Probes 
Measurement of In Situ Sediment Thermal Conductivity: Continuous-Heating Method with Outrigged Probes

\author{
J. Jemsek \\ MIT/WHOI Joint Program in Oceanography \\ Woods Hole Oceanographic Institution \\ Woods Hole, MA 02543 \\ R. Von Herzen \\ Department of Geology and Geophysics \\ Woods Hole Oceanographic Institution \\ Woods Hole, MA 02543
}

In: Wright, J. and K. Louden (eds.), Handbook of Seafloor Heat Flow, CRC Press, Inc., in press. 


\section{A2.1 Abstract}

A multipenetration heat flow instrument featuring outrigged thermal probes has been modified to include in situ thermal conductivity measurement capabilities using a transient heating technique similar to the needle-probe method used on sediment cores. Due to the small radial dimension of the outrigged probes, simple analytical approximations can be used for predicting probe temperatures at relatively short times (2 minutes), which allows accurate equilibrium in situ temperature and thermal conductivity measurements to be made in less than 15 minutes of recording time. The largest instrumental error is incurred in estimating the sediment thermal diffusivity from empirical relationships between conductivity and diffusivity. Although the diffusivity is less certain for sediment of high conductivity, the fractional uncertainty in conductivity is only $2 \%$ for nearly al1 marine sediment. The total instrumental uncertainty for the single probe design is estimated to be 3\%. A biaxial probe design, which has the heater and temperature sensor housed in separate steel tubes, has an additional $3 \%$ uncertainty due to the imprecise nature of the effective probe radius used in the calculation of the probe time constant. Field calibration of the in situ conductivity measurements was made by comparing the mean conductivity of in situ stations to needle-probe measurements of nearby piston cores. For ten selected sites, in situ and laboratory means show agreement to within $6 \%$ with no systematic differences. Significant differences in such field comparisons can be attributed to the discrete sampling of the sediment section. Realistic synthetic conductivity profiles are obtained from gamma ray attenuation (GRAPE) logs of 
sediment cores in conjunction with water content and needle-probe conductivity measurements. Such profiles illustrate that the potential error in mean conductivity determinations may exceed $10 \%$ if large amplitude vertical variations in conductivity exist at a characteristic wavelength which is smal1 compared to the probe separation.

\section{A2.2 Introduction}

By increasing the areal density of thermal gradient measurements via pogo-probing (multipenetration stations) and by use of digital recording, the quality of marine geothermal surveys has been greatly improved. Regional heat flow trends are better defined since the random comporent of sma11-scale environmental effects may be averaged out. If the marine heat flow system includes capabilities of thermal conductivity measurement in situ, fewer core samples may be necessary and the efficiency of the pogo-probing technique is preserved. A more accurate evaluation of the local heat flow may also be made when in situ conductivity is measured in the same interval as the thermal gradient measurement.

A pogo-probing heat flow system composed of a cylindrical strength member to facilitate penetration, outrigged thermal probes designed for rapid response to sediment temperatures, and acoustic telemetry to monitor instrument operation aboard ship has been employed by the Woods Hole Oceanographic Institution (WHOI) since 1969 (Von Herzen and Anderson, 1972). The design of the WHOI outrigger heat flow probe (Figure A2.1) has recently been modified to include the continuous-heating method of measuring in situ thermal conductivity at 


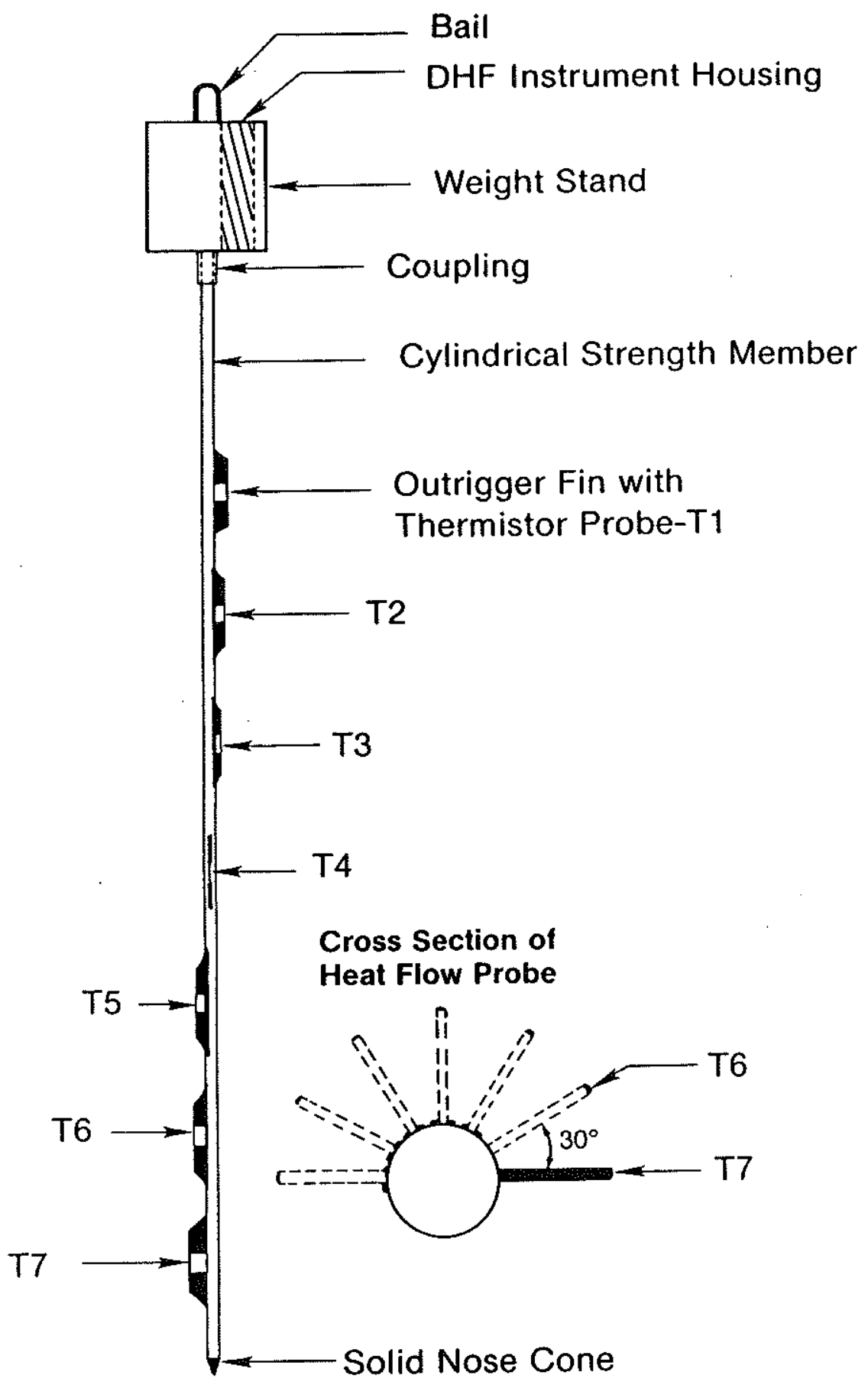

Fig. A2.1. The WHOI heat flow system, pogo probe with outrigged therma1 probes. 
points in the sediment where temperatures are determined for thermal gradient calculations. Previously, thermal conductivity values were only obtained on sediment core samples using the needle-probe technique (Von Herzen and Maxwe11, 1959).

In situ techniques have the following advantages over the widely-used needle-probe method: 1) The needle-probe conductivity values from the cores are accurate within $5 \%$, but require a correction for the ambient temperature and pressure conditions of the ocean bottom (Ratcliffe, 1960). 2) Measurements on the core may not correspond with the sediment intervals sampled in the temperature gradient stations due to lateral and vertical sediment variability. 3) To varying degrees, the piston coring process can disturb mass physical properties such as water content or porosity of the sediment sample (Ross and Riedel, 1967). 4) Additional ship time is required to retrieve piston cores. 5) Shipboard monitoring of temperature data a11ows the determination of in situ conductivity and heat flow values in real time.

A drawback of the in situ technique is that the horizontal conduction rather than the vertical conduction is measured. Although anisotropy in sediment conductivity is not generally observed, conductivities 2 to $3 \%$ higher in the horizontal direction have been found (B. De1la Vedova, pers. comm., 1984). Additiona1ly, when significant detailed conductivity stratification exists, the density of measurements on the core sample can readily be increased whereas the number of measurements in situ is limited by the thermistor arrangement.

An a1ternative pogo-probing heat flow instrument which has had much success in measuring conductivities in situ is the violin-bow probe 
(Hyndman et a1., 1979; Hutchison, 1983). In situ conductivity is obtained using a heat pulse technique (Lister, 1979) which has generally been used in conjunction with the relatively large diameter $(0.78 \mathrm{~cm})$ violin-bow temperature sensor and heater tube. Although the pulse-heating technique clearly has improved battery energy efficiency, we show that the accuracy of the conductivity values is generally comparable to that of the steady-heating techniques. The violin-bow probe can easily be configured to house a multipoint averaging thermistor chain along the probe length. An averaging sensor, instead of point sensors, is particularly useful in determining the mean resistivity of vertically heterogeneous sediment (Lister, 1970). Adaption of the WHOI outrigger pogo probe and digital heat flow (DHF) electronic instrumentation to include the continuous-heating method of in situ conductivity determination was rather straightforward because both the durable design of the outrigger fins (Figure A2.2) and the relatively low voltage output of the DHF battery pack (nominally 18 volts regulated to 5 volts) were retained. The pertinent hardware designs and the basic theory of heat conduction in cylindrical regions for the in situ transient-heating technique are presented. Instrumenta1 uncertainties, including those associated with the use of a biaxial probe design, are determined analytically and are found to be similar to the needle-probe method (Von Herzen and Maxwe11, 1959) and the violin-bow with pulse-heating (Hyndman et al., 1979).

Laboratory conditions simulating ambient conditions of marine sediment in situ are difficult to reproduce. Thus, the results of field experimentation are important in calibrating the in situ technique. 


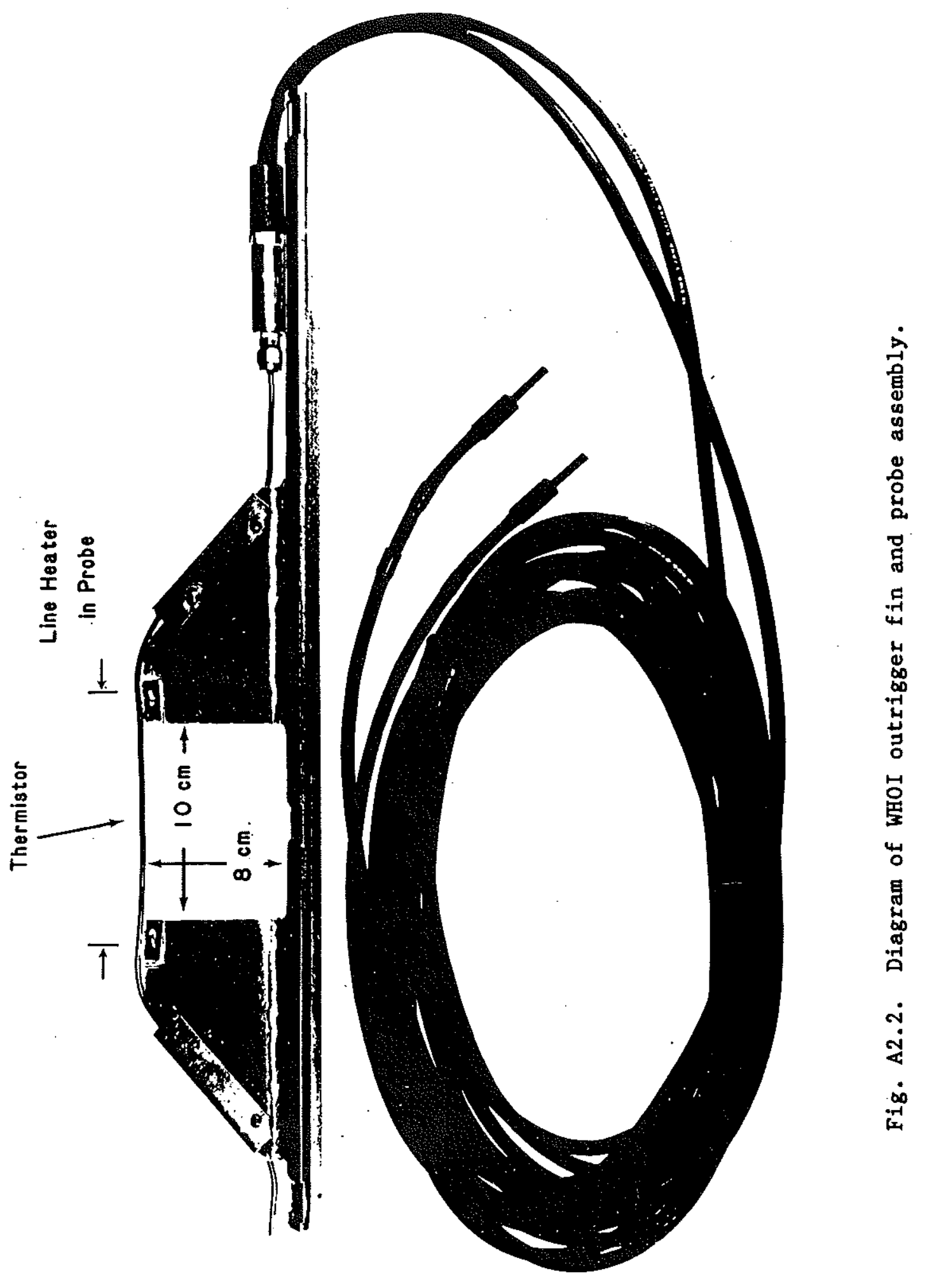


Numerous in situ conductivity data from the Ligurian Basin in the Western Mediterranean Sea (Jemsek et a1., 1985a) and Bermuda Rise (Detrick et al., 1986) are compared to needle-probe measurements obtained on nearby sediment core samples. Considering the probable vertical and lateral variability in sediment properties, very good agreement between the measurements is found. Additionally, the reliability of the mean in situ conductivity is evaluated in light of the discrete sampling problem of the outrigged point thermistors. Core data such as needle-probe conductivity, water content and gamma ray attenuation logs (GRAPE) are used to assist in calibration of in situ measurements .

\section{A2.3 Measuring Therma1 Conductivity In Situ With Continuous-Heating}

The continuous-heating method for applications in situ can be considered as a scaled-up version of the needle-probe method (Von Herzen and Maxwe11, 1959) which has proved successful in the accurate determination of thermal conductivity of marine sediment retrieved with piston and gravity corers. The needle-probe method involves the insertion of a thin cylindrical thermal probe into a sediment core sample. The probe is then heated continuously along its length at a constant rate. The rise in temperature against time approaches a logarithmic asymptote whose slope is equal to $(Q / 4 \pi K)$ where $Q$ is the heat input per unit length per unit time and $K$ is the thermal conductivity. The rate at which the asymptote is approached depends on the radius of the probe. For a needle probe of $0.1 \mathrm{~cm}$ diameter the asymptote is reached rather quickly ( $<20 \mathrm{~s}$ ) which allows for an 
Table A2.1

Characteristic Time Constants for Thermal Probes

\begin{tabular}{llc} 
probe type & \multicolumn{1}{c}{$\begin{array}{c}\text { radius, } \\
(\mathrm{cm})\end{array}$} & $\begin{array}{c}\mathrm{r}^{2} \mathrm{~K}^{-1} * \\
(\mathrm{~s})\end{array}$ \\
\hline & & \\
needle probe & & 0.5 \\
WHOI outrigger probe $^{2}$ & 0.04 & 8.5 \\
violin-bow probe & 0.46 & 53 \\
Bullard probe & 0.40 & 330 \\
& 1.0 & \\
\hline
\end{tabular}

*Assuming a sediment diffusivity $\kappa$ of $0.3 \times 10^{-6} \mathrm{~m}^{2} \mathrm{~s}^{-1}$

References: 'Von Herzen and Maxwe11 (1959)

${ }^{2}$ Hyndman et al. (1979)

${ }^{3}$ Bu1lard (1954) 
accurate conductivity measurement in only a few minutes.

Until recently, the continuous-heating method has only been applied to in situ measurements for a single sliding outrigger attached to a Bullard probe (Sclater et a1., 1969) and to the active length of the Bullard probe (Lister, 1970). The latter probe has a large radius (see Table A2.1) and can require up to 30 minutes of measuring time for a single heat flow station. As the probe radius increases, longer times are required to approximate the theory formulated in detail by Jaeger (1956) in which the probe is treated as a perfect conductor. If the conductivity measurement is made in a shorter time period it is also less 1 ikely that the measurement will be affected by a mechanical disturbance due to drift of ship position and a subsequent increase in tension of the traw1 wire. The Bullard probe is not a multipenetration probe so that the above designs have been superceded with the increased usage of pogo-probing.

Outrigger probe instrumentation and data acquisition. The WHOI heat flow system consists of up to 7 outrigged thermistor sensors mounted to a $8 \mathrm{~cm}$ diameter probe barrel whose end is sealed with a solid nose cone (Figure A2.1). Several different configurations have been used. A robust version has a $3.5 \mathrm{~m}$ long probe barrel with 4 thermal probes attached at $.65 \mathrm{~m}$ spacing. A probe barre1 of $7 \mathrm{~m}$ length with as many as 7 outrigged thermistors has also been used. However, this configuration tends to be susceptible to bending when partial or no penetration in hard bottom occurs, or during pullouts which apply high bending moments to the barre1. 


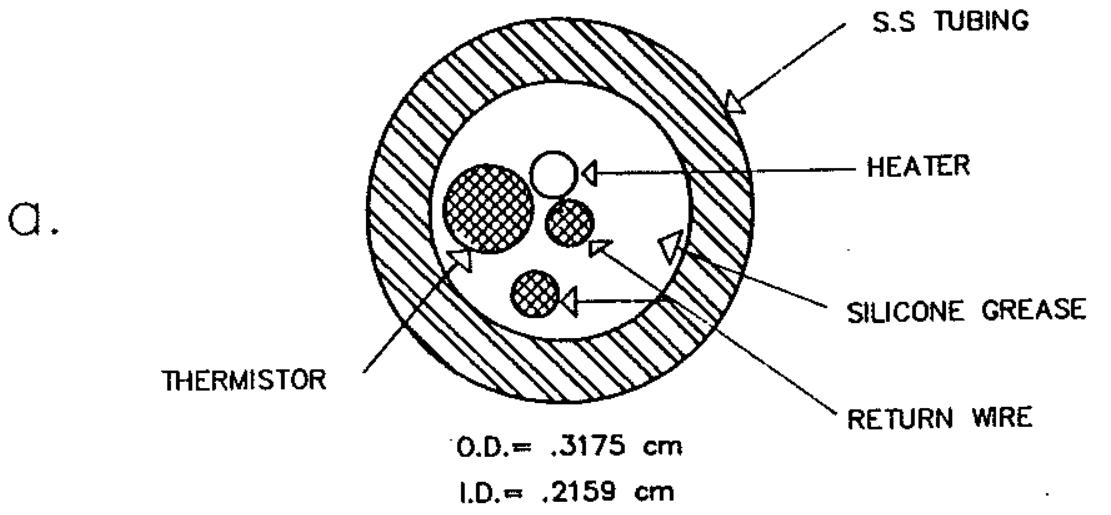

D.

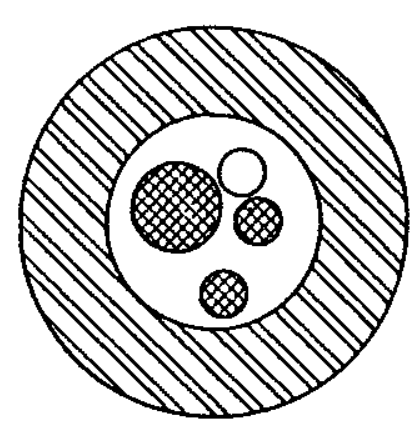

$$
\begin{aligned}
& \text { O.D. }=.3175 \mathrm{~cm} \\
& \text { I.D. }=.1753 \mathrm{~cm}
\end{aligned}
$$

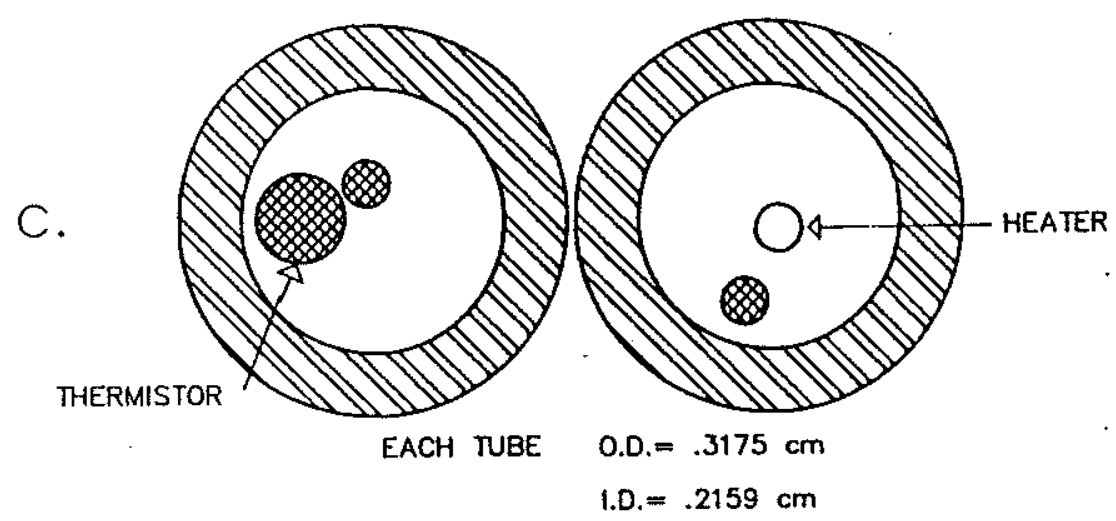

Fig. A2.3. Cross section of thermal probes. a) single-probe design (thin wall). b) single-probe design (thick wall)., c) double-probe design. 
The thermal probe is mounted at a radial distance of $8 \mathrm{~cm}$ from its mounting base (Figure A2.2) to insure that there is no measurable thermal effect of the probe barrel sensed by the thermal probes. Each thermistor probe is secured by two fins separated by an axial distance of $10 \mathrm{~cm}$, with the actual thermistor being centered between the two fins in the middle of the tube. Several outrigged thermal probe designs have been used, each with slightly different thermal properties (see Figure A2.3). For the thin-walled probe, the heat capacity per unit length $\mathrm{m}$ is found as $22 \mathrm{~J} \mathrm{~m}^{-1} \mathrm{~K}^{-1}$ from: stee $154 \%, \rho C=3.88 \mathrm{MJ}$ $\mathrm{m}^{-3} \mathrm{~K}^{-1}$; probe internal contents $46 \%, \rho \mathrm{C}=1.54 \mathrm{MJ} \mathrm{m}^{-3} \mathrm{~K}^{-1}$. The thick-walled version has $\mathrm{m}=25 \mathrm{~J} \mathrm{~m}^{-1} \mathrm{~K}^{-1}$ with the probe being $70 \%$ stee1. A procedure for the construction of the thermal probe is presented by Jemsek et a1. (1985b). An ear1ier version of the in situ probe was of a biaxial or double probe design (Figure A2.3c) which consisted of a steel tube housing the thermistor adjacent to the same size tubing containing a heater wire.

The heating power per unit length, Q, determines the relative temperature rise of the heating curve. $Q$ is calculated as $I^{2}(R / L)$ where $I$ is current and $(R / L)$ is resistance of the wire per unit length. The heater current is normally maintained at a value near $250 \mathrm{~mA}$ D.C. (depending on the instrument used) by a constant current regulator of maximum $15 \mathrm{~V}$ output powered by a battery pack. The resistance of the heating wire is about $35 \Omega \mathrm{m}^{-1}$ giving the value of $Q$ as about $2 \mathrm{~W}$ $\mathrm{m}^{-1}$. After 10 minutes the temperature rise for the in situ probe in sediment is generally less than $1 \mathrm{~K}$. 
The electronic circuitry for the heat flow instrument together with the digital tape recorder, acoustic transponder and battery pack are housed in a single pressure casing located within the weightstand at the top of the probe barrel. Inputs are sequentially sampled at $2 \mathrm{~s}$ intervals and include a pressure transducer, continuous tilt meter, heater current, time counter, and two reference resistors in addition to as many as eight thermistors. Thus, each variable is typically measured each $28 \mathrm{~s}$. The thermistors and heater system are connected to the heat flow instrument by a cable, plug, and socket assembly, with the heaters being in a series circuit to assure uniform heating of each probe.

The digital data is recorded on a magnetic tape cassette as we11 as being telemetered to the sea surface for real-time monitoring of the recorded data. The digital data is normally analyzed as it has the highest resolution $(0.5 \mathrm{mK})$. The graphical record is used for real-time monitoring of instrumentation, but can also be used for detailed analysis if the digital tape record is absent or faulty. If the telemetered data is preset for approximately $1 \mathrm{~K} \mathrm{full} \mathrm{scale,} \mathrm{the}$ potential resolution is 2 to $3 \mathrm{mK}$. Thus, at a much lower resolution, the graphical data can be digitized with reasonable accuracy and processed in the same way as the cassette tape record.

Pogo-probing usually maintains a 1 to $2 \mathrm{~km}$ spacing between penetrations, with the DHF instrument battery power allowing up to 25 penetrations for a single heat flow profile. A typical temperature record for each heat flow penetration can be divided into four sections (Figure A2.4): 1) the 2-minute period before initial penetration when the probe is held steady a sma11 distance (50 to $100 \mathrm{~m}$ ) above the 


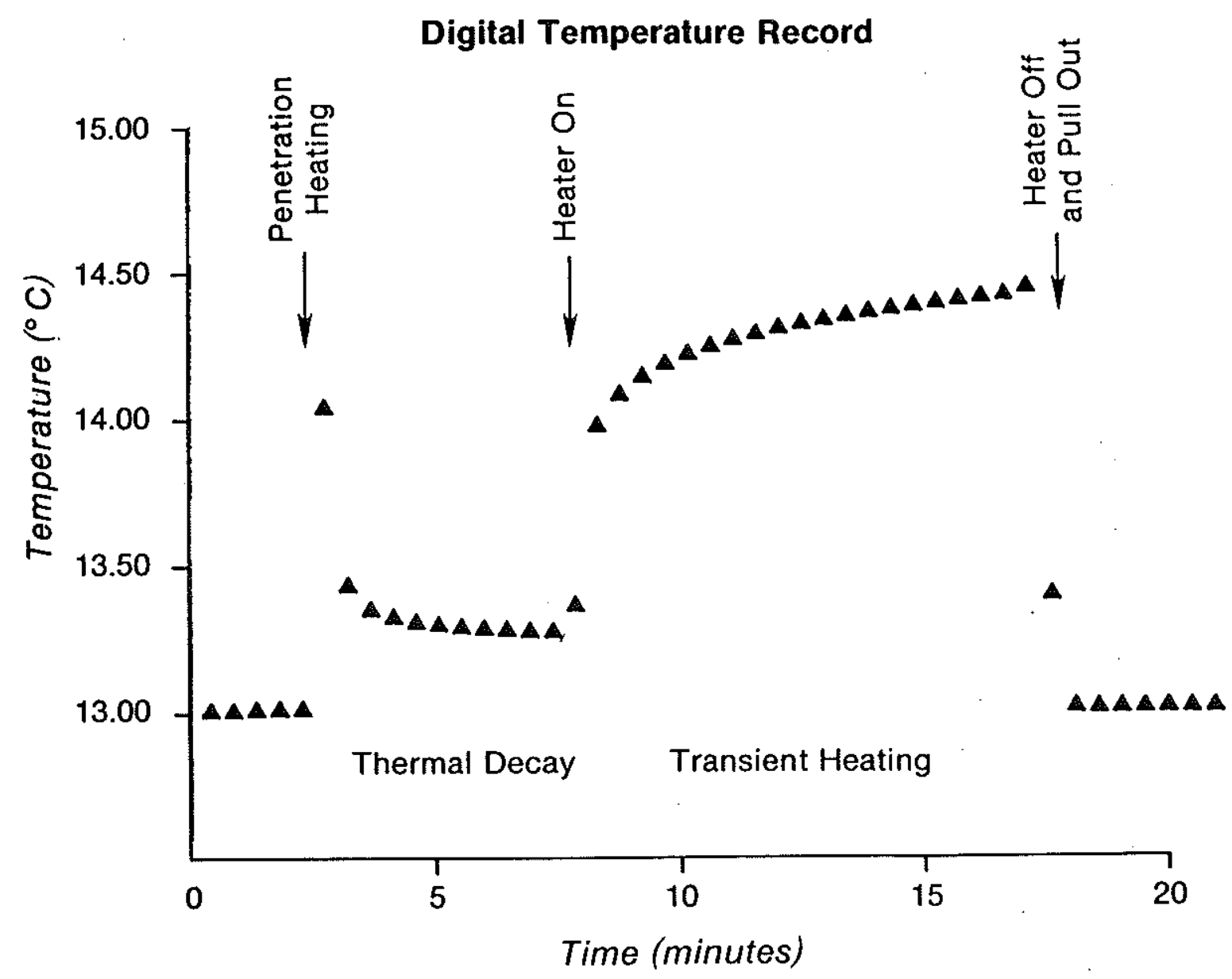

Fig. A2.4. Plot of digital temperature record of a single thermistor (see text). 
bottom, 2) 5-minute period for the temperature decay after the initial penetration, 3) the 10-minute period of continuous heating and 4) the 2-minute period holding above bottom after pullout of the instrument. The temperatures before penetration and after pullout are used to calculate any temperature drift during the penetration and also determine the relatively uniform near-bottom water temperature recorded by each thermistor as a reference temperature. Thermistor calibrations may not fully account for the lead resistance of the cables and contact resistance at the plug/socket connections. Thus, the equilibrium temperatures are determined relative to the water temperatures and are not necessarily accurate absolute values. The thermistors usually reproduce each other within $\pm 0.1 \mathrm{~K}$; offsets of this magnitude are inconsequential for either temperature gradients or in situ conductivity.

The equilibrium temperature is estimated from the smooth decay of the frictional heating event, and the temperature versus time record after the heater current is activated constitutes the in situ conductivity data set (Figure A2.4). The heater current is norma11y programmed (by a microprocessor) to turn on after 5 minutes of stable pressure readings and is applied for 10 minutes. The pressure transducer has a range of 0 to $8 \mathrm{~km}$ and is converted to a digital value with a resolution of about $\pm 0.3 \mathrm{~m}$. A stable pressure reading is usually specified to be $\pm 3 \mathrm{~m}$. After penetration of the instrument into the sea bottom, the pressure normally does not change until data acquisition is complete and the instrument is pulled out. With rough seas or in a region of large current drift, when the instrument is susceptible to being disturbed prematurely by an increase in the traw1 
wire tension, a preset time delay heater turn-on program can be used as an alternative.

Analytical development of the in situ technique. The analytical derivation and data analysis of the in situ continuous-heating line source method has been described by Sclater et al. (1969). As they note, the reduction of the in situ time-temperature record is slightly altered from that of the needle-probe data. An asymptotic solution cannot be readily used because of the longer time constant of the in situ probe. Also, the frictional heating effect of the heat flow probe penetrating the sediment must be removed from the in situ heating curve.

1) Temperature history of a probe subjected to frictional heating. As discussed by Bullard (1954) and Jaeger (1956), the probe is idealized as an infinitely long, perfectly conducting cylinder of radius $r$ and heat capacity per unit length $\mathrm{m}$ embedded in homogeneous sediment that has an equilibrium temperature $\theta_{1}$, therma1 conductivity $\mathrm{K}$, therma1 diffusivity $\kappa$, specific heat $\mathrm{C}$ and density $\rho$. Due to the frictional heating along the probe surface during penetration into the sediment, the probe is at an elevated temperature $\theta_{0}$ at time $t=0$. The subsequent temperature of the probe, $\theta$, is given by

$$
\theta=\theta_{1}+\theta_{0} F(\alpha, \tau)
$$

where $F(\alpha, \tau)$ is the decay function derived by Bullard (1954) as

$$
F(\alpha, \tau)=\frac{4 \alpha}{\pi^{2}} \int_{0}^{\infty} \frac{\exp \left(-\tau x^{2}\right) d x}{x \Delta(x)}
$$

where

$$
\left.\Delta(\mathrm{x})=[\mathrm{xJ} / \mathrm{x})-\alpha \mathrm{J}_{1}(\mathrm{x})\right]^{2}+\left[\mathrm{xY},(\mathrm{x})-\alpha \mathrm{Y}_{1}(\mathrm{x})\right]^{2}
$$


and $J_{N}(X)$ and $Y_{N}(X)$ are the Besse1 functions of order $n$ of the first and second kinds, respectively. The nondimensional quantity $\tau$ is the probe thermal time constant, given by

$$
\tau=\kappa t / r^{2}
$$

The nondimensional probe parameter, $\alpha$, is given by

$$
\alpha=2 \pi r^{2} \rho C / m
$$

and is equal to twice the ratio of the thermal capacity of the sediment to that of the probe. The value of $\alpha$ for most steel probes is near 2.0 but varies slightly depending on the sediment thermal properties. The exact solution to the $F(\alpha, \tau)$ decay curve has been tabulated by severa1 investigators (Bu11ard, 1954; Jaeger, 1956; Huppert and Sclater, 1968). For $\tau>4$, the approximation (Blackwe11, 1954)

$$
F(\alpha, \tau) \simeq 1 / 2 \alpha \tau-1 / 4 \alpha \tau^{2}-\frac{(\alpha-2)}{4 \alpha^{2} \tau^{2}}(\ln 2.246 \tau-1)+0 \frac{\ln \tau}{\tau^{3}}
$$

is within $1 \%$ of the exact value. The asymptote is given by

$$
F(\alpha, \tau) \simeq \frac{1}{2 \alpha \tau}=\frac{m}{4 \pi K t}
$$

and is a simple function of reciprocal time.

In practice, equilibrium temperatures are determined using Equation A2.1 and the asymptotic expression for $F(\alpha, \tau)$, fitting the observed temperatures versus time since penetration to

$$
\theta=\theta_{1}+b t^{-1}
$$

in a least-squares sense. Since $F(\alpha, \tau)$ tends to zero as $t$ approaches infinity, $\theta_{1}$ is simply the intercept of the regression line with the coefficient $b$ as the slope (Figure A2.5). Equation A2.5 is not valid for small $t$ so that the temperatures recorded immediately after the initial penetration must be disregarded in the computation of 


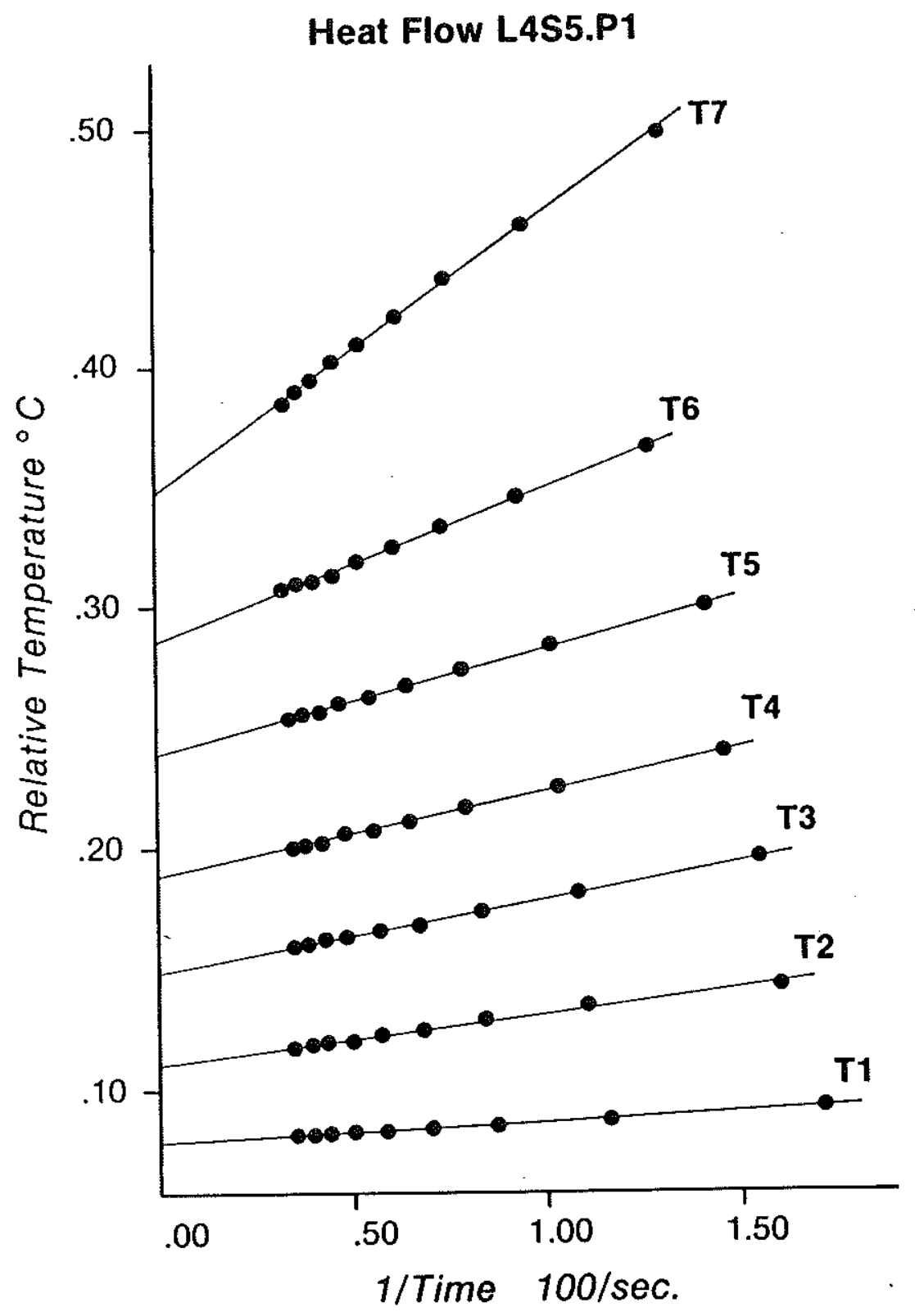

Fig. A2.5. P1ot of temperature, $\theta$ vs. the reciprocal of time for seven thermal probes during a single penetration. All data are relative to the bottom water temperature. 
Table A2.2 Values for $G(\alpha, \tau)$ with $\alpha=2.0$

\begin{tabular}{rccc}
\hline$\tau$ & $\begin{array}{c}\text { Exact } \\
\text { Solution* }\end{array}$ & $\begin{array}{c}\text { Blackwe11 } \\
\text { Approximation }\end{array}$ & Asymptote \\
\hline 1 & 0.09768 & 0.10416 & 0.06437 \\
2 & 0.13804 & 0.13942 & 0.11953 \\
3 & 0.16459 & 0.16505 & 0.15179 \\
4 & 0.18445 & 0.18462 & 0.17468 \\
5 & 0.20033 & 0.20039 & 0.19243 \\
6 & 0.21357 & 0.21357 & 0.20694 \\
7 & 0.22491 & 0.22489 & 0.21921 \\
8 & 0.23484 & 0.23480 & 0.22983 \\
9 & 0.24367 & 0.24362 & 0.23920 \\
10 & 0.25161 & 0.25156 & 0.24759 \\
11 & 0.25884 & 0.25879 & 0.25517 \\
12 & 0.26546 & 0.26541 & 0.26209 \\
13 & 0.27158 & 0.27152 & 0.26846 \\
14 & 0.27725 & 0.27720 & 0.27436 \\
15 & 0.28255 & 0.28250 & 0.27985 \\
16 & 0.28752 & 0.28747 & 0.28498 \\
17 & 0.29220 & 0.29215 & 0.28981 \\
18 & 0.29662 & 0.29656 & 0.29435 \\
19 & 0.30080 & 0.30075 & 0.29866 \\
20 & 0.30478 & 0.30473 & 0.30274 \\
24 & 0.31897 & 0.31895 & 0.31729 \\
32 & 0.34144 & 0.34143 & 0.34018 \\
40 & 0.35895 & 0.35894 & 0.35794 \\
\hline
\end{tabular}

* data from Huppert and Sclater (1968) and Sass (1965) 
$\theta_{1}$. To check the validity of Equation A2.5 for early times, synthetic temperature data have been generated using the exact solution of the $F(\alpha, \tau)$ decay curve (Equation A2.1) assuming $\theta_{0}=1 \mathrm{~K}$ and thermal properties appropriate for $\mathrm{b}=1.7 \mathrm{~K} \mathrm{~s}$. Applying the above linear regression and neglecting temperatures generated for $\tau<10$ (within 80 to $90 \mathrm{~s}$ of penetration for the WHOI probe), an equilibrium temperature is obtained that is within $0.5 \mathrm{mK}$ of the true value. Thus, accurate equilibrium temperatures can be determined with only a few minutes of in-bottom recording time.

2) Applying the transient line heat source. The thermal conductivity is determined by applying a heat input $Q$ at a constant rate along the length of the cylinder. Assuming the cylinder to be at zero initial temperature, Jaeger (1956) gives the solution

$$
\theta=Q / K G(\alpha, \tau)
$$

where $\mathrm{K}$ is the thermal conductivity. The function $\mathrm{G}(\alpha, \tau)$ is given by

$$
G(\alpha, \tau)=\frac{2 \alpha^{2}}{\pi^{3}} \int_{0}^{\infty} \frac{1-\exp \left(-\tau x^{2}\right)}{x^{3} \Delta(x)}
$$

where $\Delta(x)$ is as given in Equation $A 2.2$ and $\tau$ and $\alpha$ from Equations A2.3 and A2.4. Equation A2.7 has been evaluated by Jaeger (1956) and Huppert and Sclater (1968), and tabulated for almost all useful values of $\alpha$ by Sass (1965) (see Table A2.2). The B1ackwe11 (1954) approximation

$$
G(\alpha, \tau) \simeq \frac{1}{4 \pi}\left\{\ln 2.246 \tau+\frac{1}{2 \tau}+\frac{(\alpha-2)}{2 \alpha \tau} \ln 2.246 \tau\right\}
$$

is within $1 \%$ of the exact solution for $\tau>3$ and the asymptote

$$
G(\alpha, \tau) \simeq \frac{1}{4 \pi} \ln 2.246 \tau
$$


is within $1 \%$ of the solution for $\tau>14$ (Table A2.2). As previous1y mentioned, the asymptotic result is used in the needle-probe method.

In the application of the continuous-heating method with the in situ probe, the thermal transient due to the frictional heating event must be removed since the probe is not at an equilibrium temperature of zero as assumed in Equation A2.6. Both Equations A2.1 and A2.6 are solutions of linear differential equations and therefore can be combined as

$$
\theta=\theta_{1}+\theta_{0} F\left(\alpha, \tau_{1}\right)+Q / K G(\alpha, \tau)
$$

where $\tau$ refers to the time since the instant the heater turns on and $\tau_{1}$ is given by

$$
\tau_{1}=\kappa\left(t+t_{1}\right) / r^{2}
$$

where the heater is known to turn on a time $t_{1}$ after penetration. Since solutions for both $\theta_{1}$ and $\theta_{0}$ have been previously obtained, $\mathrm{K}$ can be determined by fitting the modified temperatures in Equation A2.9 (Figure A2.6). However, to estab1ish $\tau$ and $\alpha$ the sediment diffusivity $\kappa$ must be known and an iterative routine using an empirical relation of $k$ to $K$ must be used. The effect of the uncertainty of $\kappa$ on the computed $\mathrm{K}$ is discussed later in the chapter.

The B1ackwe11 approximation for $G(\alpha, \tau)$ (Equation $A 2.8$ ) is applied because, compared to the asymptotic solution, much earlier times of the heating curve can be used with nearly the accuracy of the exact solution. For the WHOI probe, temperatures are typically retrieved from $\tau=7$ to $\tau=50$ (about 60 to $450 \mathrm{~s}$ ). For this range in $\tau$ and for $\alpha=2$, the Blackwe11 approximation gives a differential of $G(\alpha, \tau)$ that is within $0.1 \%$ of that given by the exact solution and so generates negligible error in the $\mathrm{K}$ determination. If the asymptote is used in a 


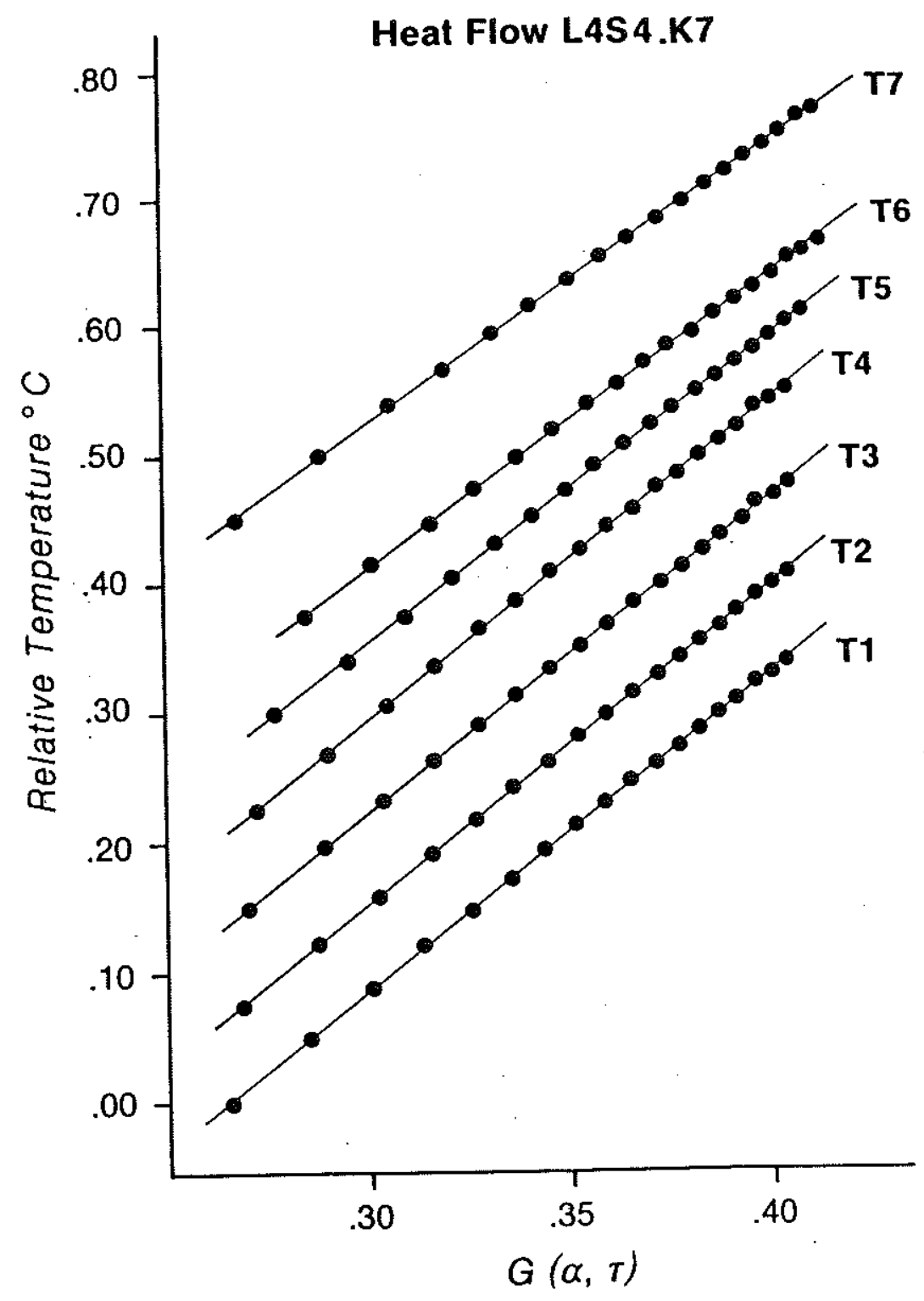

Fig. A2.6. P1ot of modified temperature, $\theta-\theta_{1}-b t_{-1}$ vs. $G(\alpha, \tau)$ for seven thermistors. For clarity, the temperatures for each thernistor are of $f$ set. The regression lines of slope $Q / K$ are also shown. 
similar $\tau$ range, $G(\alpha, \tau)$ will be underestimated by $1.0 \%$ at $\tau=14$ and $0.4 \%$ at $\tau=40$. This discrepancy will cause a bias of $2.3 \%$ higher conductivity estimate and is readily verified by analysing the same data set with both the Blackwe11 and asymptotic solutions.

The formal error in $\mathrm{K}$ calculated from the regression analys is is quoted at the $95 \%$ confidence level using the student's t-test. This curve fit error is generally less than 1 to $2 \%$; a conductivity with a statistical error $>5 \%$ suggests that the value is unreliable. Large curve fit errors are attributed to the following: 1) premature pul1 of the attachment cable, 2) settling of the instrument subsequent to the initial penetration, 3) poor extrapolation of the frictional heating decay, or 4) instrument malfunction or noise.

A factor in the level of confidence that can be assigned to the $\mathrm{K}$ value is the number and frequency of the digitally recorded temperatures used in the regression. For example, the seven data sets plotted in Figure A2.6 do not show any apparent nonlinear trends in the recorded temperatures and have a low average curve $\mathrm{fit}$ error of $\pm 0.6 \%$ using the 18 total data points measured in the time range of 90 to $600 \mathrm{~s}$ after the heater is activated. If only the 9 temperatures at earliest times are used, the average fit error increases to $3.4 \%$ whereas if every other temperature is used ( 9 total) the average error is only $1.0 \%$. Thus, in order to minimize the statistical error for a given sample size, a greater range of time sampled is probably more important than the sample f requency.

For the outrigger probe configuration (Figure A2.2), the useful measuring time is 1 imited by the proximity of the fins to the 
thermistor. Lister (1963) uses an experimental approach to show that conduction from a heated fin to the probe may cause error in the calculation of equilibrium temperature. Conversely, Blackwe11 (1953) has analyzed the diffusion problem of a heated probe which is bounded by isothermal surfaces perpendicular to the axis of the probe. According to the results of Blackwe11 (1953), there is less than a $1 \%$ difference to the radial heat flow solution for a probe with a length (fin to thermistor) to radius ratio of 32 for times up to $\tau=75$, which is equivalent to 10 minutes of heating for the WHOI probe. This result is consistent with our field measurements. No discernable departure from theory has been noted in the later part of the heating curve which could be attributed to thermal perturbation by the fins (see Figure A2.6).

\section{A2.4 Analysis of Instrumental Error}

The in situ continuous-heating method is evaluated in light of the analytical approximations and possible instrument uncertainties. The errors incurred in the $G(\alpha, \tau)$ estimate are mainly due to the uncertainty of the sediment thermal diffusivity value in the $\alpha$ and $\tau$ parameters. Minor random errors are also attributed to the uncertainty of the heater turn-on time as well as the calibration of the heater current itself. The overall mean uncertainty caused by these factors is about 3\% for the WHOI probe. A double-probe design (Figure A2.3c) has a greater uncertainty because the heater and thermistor are separated by several millimeters, each being housed in its own probe.

Effect of heater output. A small uncertainty in $\mathrm{K}$ is attributed to the heater output $Q$. The current is calibrated in the lab to known 
standards with an accuracy of $\pm 0.1 \mathrm{ma}$. The relative value of the current is also known to better than 0.1 ma of a total 250 ma during in situ measurements, and is monitored every record. If the heater current falls below its regulated value due to low battery voltage, the temperature versus $G(\alpha, \tau)$ curve shows significant lack of fit and the measurement may be disregarded. The heating wire is a copper-nicke1 alloy with a uniform resistance per unit length $(39.17 \pm 0.10 \Omega$ $\mathrm{m}^{-1}$ ) and temperature coefficient on the order of $10^{-5} \mathrm{~K}^{-1}$. Thus, the uncertainty in conductivity due to $Q$ is $\pm 0.5 \%$.

Effect of heater origin time. The initiation of the heating period is critical in the determination of conductivity. For the continuous-heating method, a shift of one $\tau$ in the heater origin time can lead to a $3 \%$ error in $\mathrm{K}$. Therefore, the small-diameter needle probe (Table A2.1) is more sensitive than the larger diameter outrigger probe to equivalent errors in the heater timing. The heater for the DHF instrument is programmed to turn on at the beginning of the $2-\mathrm{s}$ cycle whereas temperatures assigned for each cycle are approximately recorded during the middle of the cycle. Considering the timing of the data written on the tape and finite conductivity of the internal probe components, there is probably less than a $1 \mathrm{~s}$ uncertainty in heater origin time. Figure A2.7 illustrates that for shifts in the assigned time of up to one $\tau(8 \mathrm{~s})$ there is a fairly linear change in $\mathrm{K}$. According1y, the fractional uncertainty in $\mathrm{K}$ due to the heater timing is $\pm 0.5 \%$. We note that a time shift of a few seconds can affect the $K$ value, but it does not produce an appreciable lack of fit (nonlinearity) in the temperature versus $G(\alpha, \tau)$ plot. 


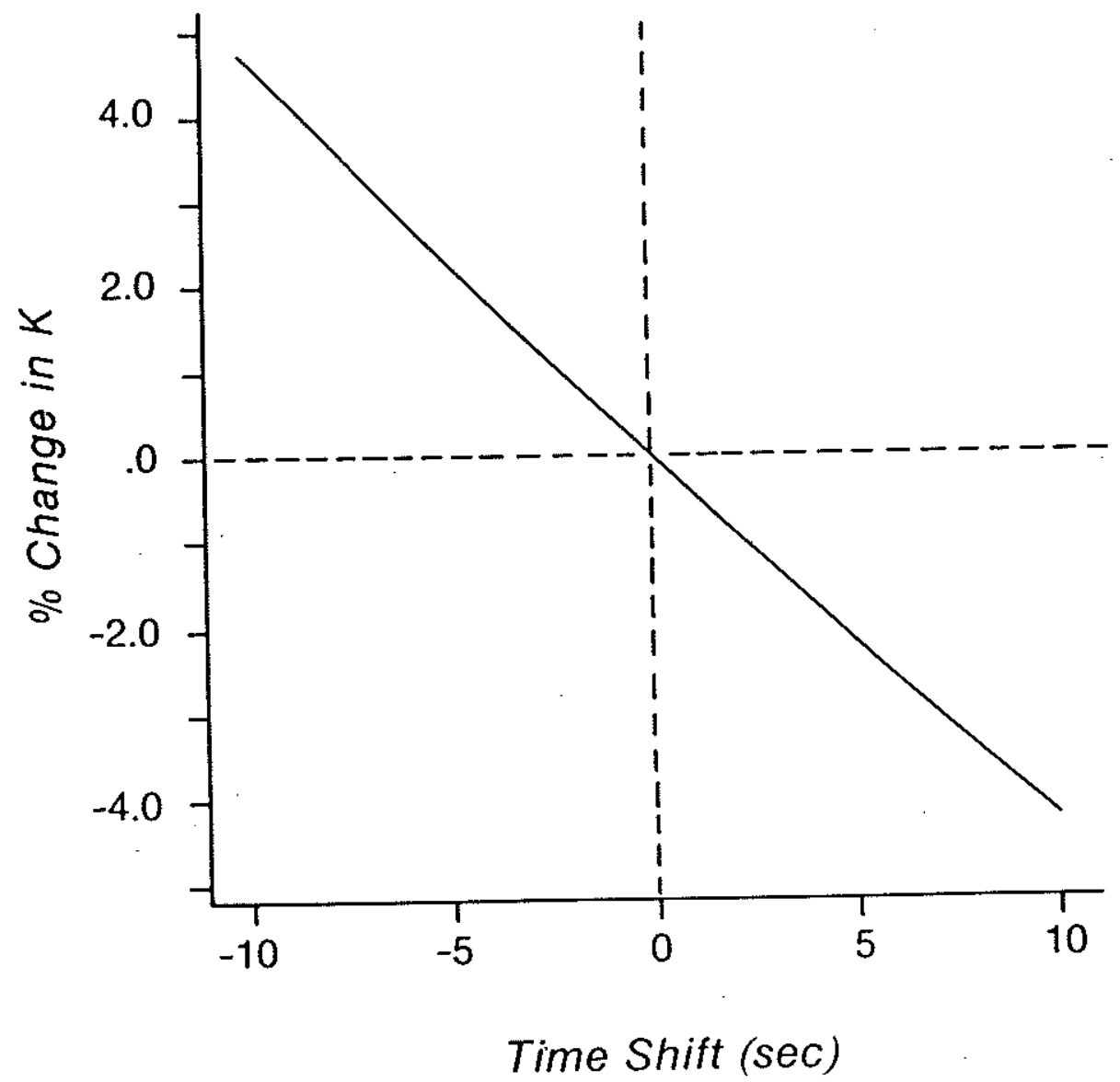

Fig. A2.7. Variation in conductivity due to uncertainty in time since the heater is active for the WHOI probe. 
Effect of thermal contact resistance. Somewhat analagous to the effect of a start time delay is the existence of a thermal contact resistance in the form of disturbed sediment or even water between the steel probe and sediment. Such a boundary zone of different conductivity, if not accounted for, could produce nonlinearity in the predicted heating curve as discussed by Jaeger (1956). The possibility of a deviation from the predicted curve emphasizes the value of utilizing the entire temperature vs. time record rather than determining its slope only from the end points. It has been assumed that the thermal decay in the pulse-heating is less sensitive to contact resistance than the continuous-heating method (Hyndman et a1., 1979; Lister, 1979). However, this is probably true only in that, in presence of a contact resistance, the net change in the probe temperature would be greater throughout a continuous-heating experiment than a pulse-heating one. The shape of the temperature/time curves would be about equally distorted in both cases (see Jaeger, 1956; Figures 2 and 5).

No systematic evidence for the inclusion of a contact resistance parameter in the data reduction scheme is suggested by the in situ data obtained with the WHOI outrigger probe. Apparently, the small probe diameter and the outrigger fins angularly separated around the axis of the probe barre1 (see Figure A2.1) ensure intimate thermal contact at the sediment/probe interface.

This is not necessarily the case with the violin-bow design. For example, Hutchison (1983) found that since the uppermost section of the thermal probe pulls through the same sediment disturbance created by the 
lowermost section, a water-filled gap between the uppermost violin string and sediment can sometimes occur (see Hutchison and Owen, this volume). Having sections of the violin bow outrigged at different azimuthal positions down the length of the probe would ensure a smaller "pul1-through" disturbance on the sediment surrounding the probe. The internal probe configuration and contents of the in situ probe may also be closely related to the problem of contact resistance since the heat conduction theory for cylindrical probes assumes the probe to be an infinitely good conductor. As indicated by numerical experiments (Hyndman et a1., 1979), a probe in which the thermistor is in good thermal contact with the metal housing can improve the response time of the probe to the sediment temperature.

Effect of estimating thermal diffusivity. The largest uncertainty in determining $\mathrm{K}$ lies in the estimation of the thermal diffusivity $\kappa$. Since $\kappa$ is incorporated into the $\alpha$ and $\tau$ parameters, its value can significantly alter the $G(\alpha, \tau)$ variable determined for the specified times during the continuous-heating period. In practice, $\kappa$ for marine sediments is found using an empirical relation with $\mathrm{K}$ such as

$$
\kappa=(3.66 \mathrm{~K}-.70) \times 10^{-7}
$$

given by Von Herzen and Maxwe11 (1959) where units are in $\mathrm{W} \mathrm{m}^{-1} \mathrm{~K}^{-1}$

for $K$, and $\mathrm{m}^{2} \mathrm{~s}^{-1}$ for $\kappa$. A similar relation

$$
\kappa=\frac{K}{10^{6}\left(5.79-3.67 \mathrm{~K}+1.016 \mathrm{~K}^{2}\right)}
$$

has been established by Hyndman et a1. (1979). Both relations (Equations $\mathrm{A} 2.10$ and $\mathrm{A2} .11$ ) are derived by using measurements of $\mathrm{K}$ and water content $W$, and by assuming thermal capacities and densities for 
the liquid and solid components of the sediment. The theoretical relationship used to determine $\kappa$ is

$$
\kappa=\frac{K}{\rho_{\mathrm{W}} \mathrm{C}_{\mathrm{W}}} \frac{1+\frac{1-W}{W}}{1+\frac{\rho_{\mathrm{W}}}{\rho_{\mathrm{s}}}}
$$

where $W$ is the water fraction by weight, $\rho_{w}$ and $\rho_{s}$ are the density of the water and solid components, and $\mathrm{C}_{\mathrm{w}}$ and $\mathrm{C}_{\mathrm{s}}$ are the heat capacities of the water and solid, respectively.

Water content can be either measured directly, as was done above, or estimated using the empirical relation of Bullard and Day (1961)

$$
K=(a W+b)^{-1}
$$

where $a$ and $b$ are constants. $K$ vs. $W$ plots for marine sediments generally have considerable scatter. As noted by Davis et al. (1984), the thermal conductivity of the constituent mineral grains accounts for some variability. Sediment grain shape, intergrain contacts and anisotropic properties also play a role in the conductivity values and in their subsequent relationship to water content. The variability of $W$ with respect to $K$ implies a similar uncertainty in the thermal diffusivity estimate.

Two published $K$ - W relations (Equation A2.13) for marine sediment are that of Bullard and Day (1961) and that of Lachenbruch and Marsha11 (1966). These relations have proved to be useful extremes for the ocean floor; the Lachenbruch-Marshall relation was derived for Arctic Ocean sediment and typifies sediment with a moderate terrigenous input, and the Bullard-Day relation is sampled from Pacific and Atlantic pelagic regions. The field studies considered in this chapter, the Bermuda Rise 
and Ligurian Basin, are located near an island and continental margin, respectively. Consequently, the overall sediment grain thermal conductivity and density can be expected to be higher than typical deep-sea sediment (Langseth and Von Herzen, 1971). The water content data in the study regions substantiate that high grain conductivities do exist for these two regions. Figure A2.8 illustrates that the Ligurian Sea sediments have overa11 low water content values $(<45 \%)$ and follow a moderately high conductivity relation similar to Arctic sediments. The water content data are from four different piston cores for which bulk density data also exist. Data points for which calculated grain densities were two standard deviations from the mean had physically unrealistic values and so were excluded from the data set (16 deleted out of 92 tota1). Physical property data southwest of Bermuda (Davis et a1., 1984) also support a $\mathrm{K}-\mathrm{W}$ relationship similar to the Ligurian and Arctic sediment.

To investigate the maximum and minimum bounds for the $k$ vs. $K$ curves, we have used the Bullard-Day relation (with $\rho_{s}=2500 \mathrm{~kg}$ $\mathrm{m}^{-3}$ ) and the Lachenbruch-Marsha11 relation (with $\rho_{\mathrm{s}}=2600 \mathrm{~kg}$ $\mathrm{m}^{-3}$ ) of Figure A2.8 in conjunction with Equation A2.12 (see curves a and $\mathrm{c}$, respective1y, Figure $\mathrm{A} 2.9$ ). The $\mathrm{K}-\mathrm{W}$ relations are appropriate for in situ temperature and pressure which required a $4.5 \%$ decrease in the 1aboratory $K$ values. We have assumed a value of $\rho_{\mathrm{w}}=1030 \mathrm{~kg}$ $\mathrm{m}^{-3}$, with $\mathrm{C}_{\mathrm{w}}=3930 \mathrm{~J} \mathrm{~kg}^{-1} \mathrm{~K}^{-1}$ and $\mathrm{C}_{\mathrm{s}}=770 \mathrm{~J} \mathrm{~kg}^{-1} \mathrm{~K}^{-1}$ (from Bullard ${ }^{13}$ ). A decrease in the assumed density of the solid component from $2600 \mathrm{~kg} \mathrm{~m}^{-3}$ to $2500 \mathrm{~kg} \mathrm{~m}^{-3}$ will increase the $\mathrm{k}$ values by $3 \%$. Also shown in Figure A2.9 are the empirical relations of 


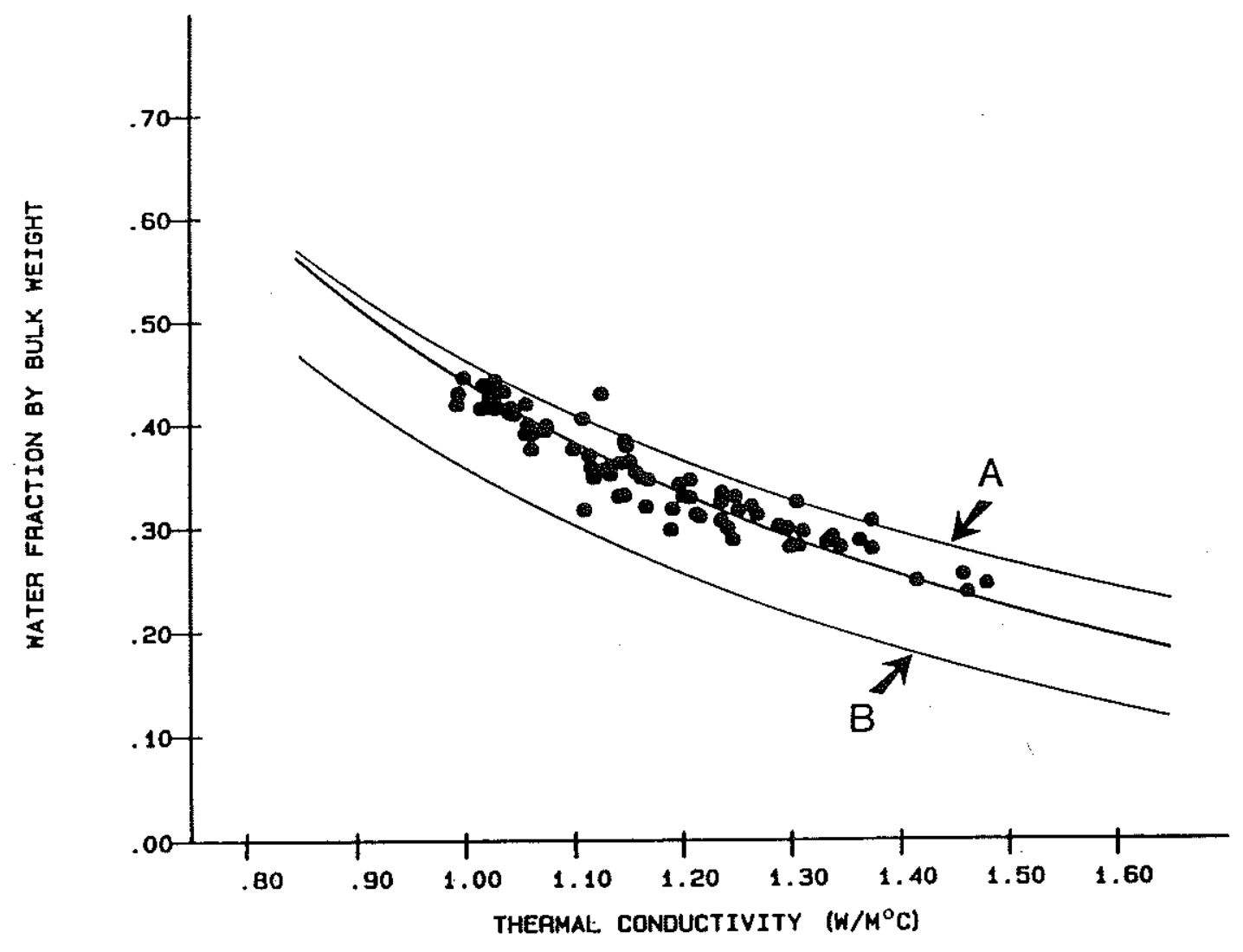

Fig. A2.8. Water content $W$ determined by fraction of bulk weight plotted against needle-probe conductivity values for selected Ligurian Sea piston cores. Curve A is the Lachenbruch and Marshal1 (1966) relation, $K=(91+709$ W $)^{-1}$, and curve $B$ is a minimum estimate given by Bullard and Day $(1961), K=(175+682 W)^{-1}$. Both relations have been adjusted to lab temperature and pressure conditions using the correction given by Ratcliffe (1960). The heavy solid line is the best fit to the data. 


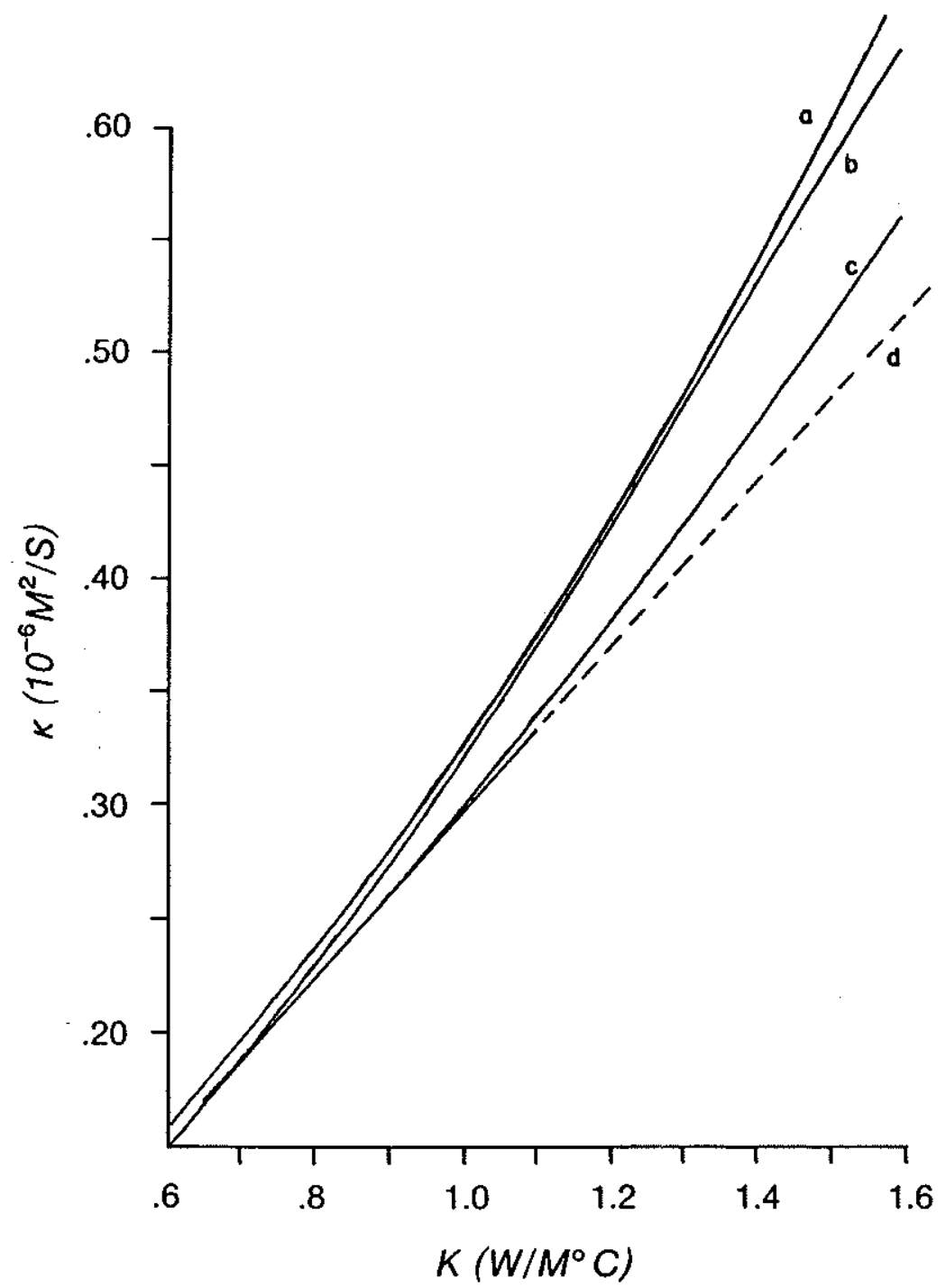

Fig. A2.9. P1ot of thermal diffusivity $\kappa$ versus conductivity $K$ curves derived from empirical relations. Curves a and $c$ use Equations $\mathrm{A} 2.12$ and $\mathrm{A} 2.13$ (see text), curve $\mathrm{b}$ is from Equation A2.11, and curve d from Equation A2.10. Curve $d$ is extrapolated for $\mathrm{K}$ values $\geq 1.1 \mathrm{~W} \mathrm{~m}^{-1} \mathrm{~K}^{-1}$. 

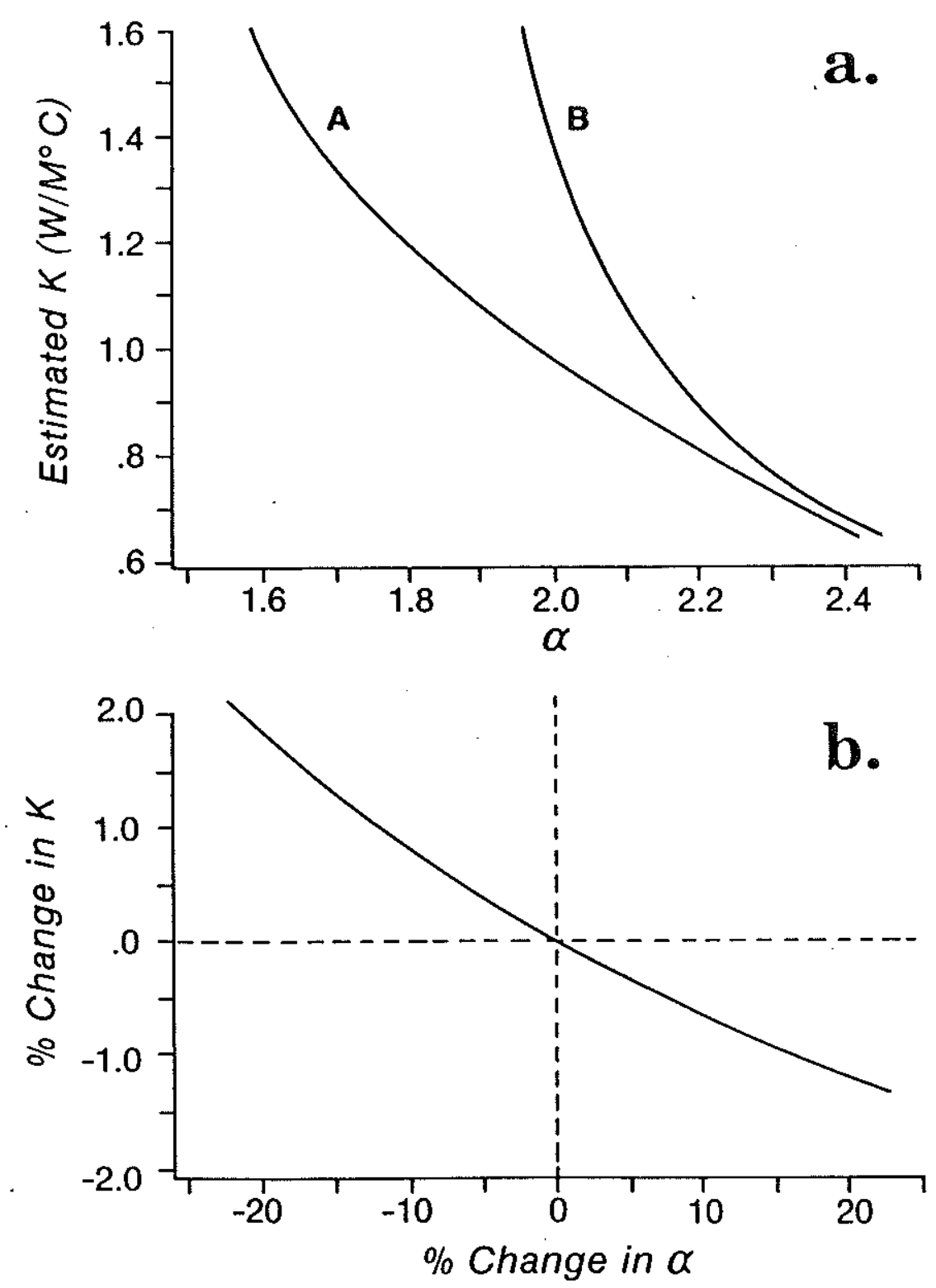

Fig. A2.10. a) $\alpha$ vs. $K$ curves for probe with heat capacity of $m=25$ $\mathrm{J} \mathrm{m}^{-1} \mathrm{~K}^{-1}$ for two $\kappa-\mathrm{K}$ relationships. Curve A uses Equation A2.11 and curve B uses Equation A2.10. b) Error in $\alpha$ vs. percent change in $K$. The change in $K$ is determined by evaluating $G(\alpha, \tau)$ at $\tau=10$ and 40 for different cases of $\alpha . \alpha=2.0$ is assumed as the true value. 
Equations A2.10 (curve d) and A2.11 (curve b). In practice, Equation A2.10 has been implemented for the WHOI data reduction scheme which is closely related to the $K-W$ derived curve $c$ of Figure A2.9.

Considering the envelope produced by the uppermost and lowermost curves, the uncertainty in $\kappa$ scales with increasing $K$, such that the uncertainty in values of $\mathrm{K}$ are about $1 \%$ for $\mathrm{K}=0.7,8 \%$ for $\mathrm{K}=1.0$, and $20 \%$ for $\mathrm{K}=1.4 \mathrm{~W} \mathrm{~m}^{-1} \mathrm{~K}^{-1}$.

Values of $\alpha$ (Equation A2.4) for a range of conductivities are shown in Figure A2.10a. The uncertainty of $\alpha$ is on the order of $10 \%$ depending on the $\kappa-K$ relation chosen. Figure A2.10b indicates that assuming an arbitrary value of $\alpha=2.0$ would give rise to a small \pm $0.5 \%$ error in the computed value of $\mathrm{K}$. The fractional uncertainty of $\mathrm{K}$ due to $\tau$ is isolated by choosing a constant value of $\alpha$ and examining $G$ between $t=100$ and $t=400 \mathrm{~s}$. From Figure A2.11, it is apparent that $\kappa$ uncertainty increases from about $10 \%$ for smal1 $\kappa\left(\mathrm{K}=0.7 \mathrm{~W} \mathrm{~m}^{-1}\right.$ $\left.\mathrm{K}^{-1}\right)$ to $20 \%$ for larger $\mathrm{K}\left(\mathrm{K}=1.4 \mathrm{~W} \mathrm{~m}^{-1} \mathrm{~K}^{-1}\right)$. Therefore, we have constructed two curves suitable for a low $\left(0.7 \mathrm{~W} \mathrm{~m}^{-1} \mathrm{~K}^{-1}\right)$ and high $\left(1.4 \mathrm{~W} \mathrm{~m}^{-1} \mathrm{~K}^{-1}\right)$ conductivity to investigate the error in $\mathrm{K}$ due to $\tau$ (Figure $\mathrm{A} 2.11$ ). The $\mathrm{K}$ determination is more sensitive to uncertainties in $\tau$ at low conductivities, but our knowledge of $\kappa$ is also more accurate for smal1 $\mathrm{K}$. If the total error in $\alpha$ and $\tau$ that arises from the probable inaccuracy in $\kappa$ is considered (Figure A2.12), then the fractional uncertainty in $K$ is less than $2 \%$ which is comparable with that found by Hyndman et al. (1979) for the pulse-heating method. Thus, the fractional uncertainty in $\mathrm{K}$ due to $\kappa$ is sma11 but could be reduced by calibrating the $\kappa-K$ relation with water content and 


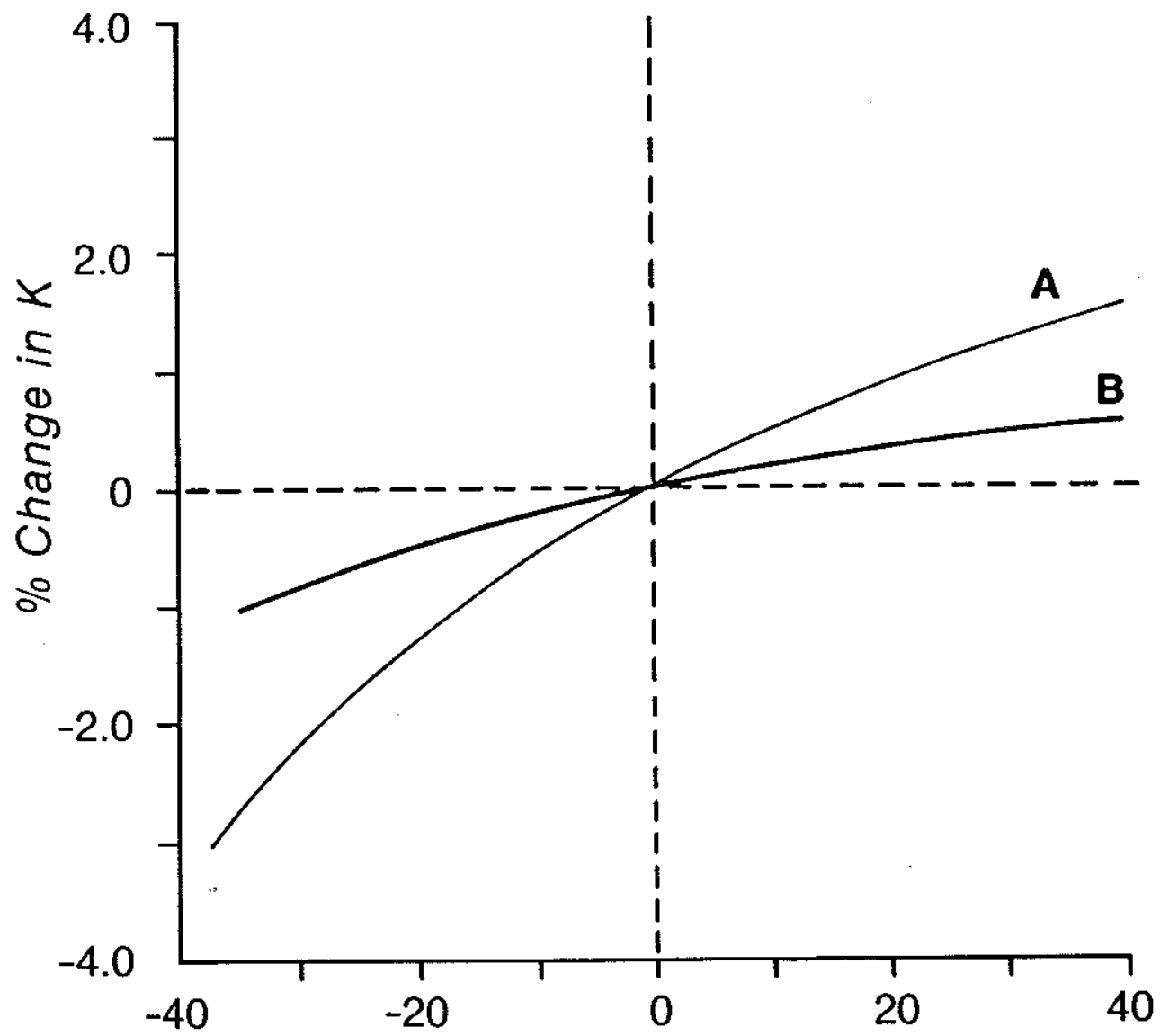

$\%$ Change in $\tau$

Fig. A2.11. Error in $\tau$ vs. percent change in K. Equation A2.10 is used for the $K-K$ relation. Curve $A$ assumes $K=0.7 \mathrm{~W}$ $\mathrm{m}^{-1} \mathrm{~K}^{-1}$ and $\alpha=2.7$. Curve $B$ assumes $\mathrm{K}=1.4 \mathrm{~W}$ $\mathrm{m}^{-1} \mathrm{~K}^{-1}$ and $\alpha=2.3$. 


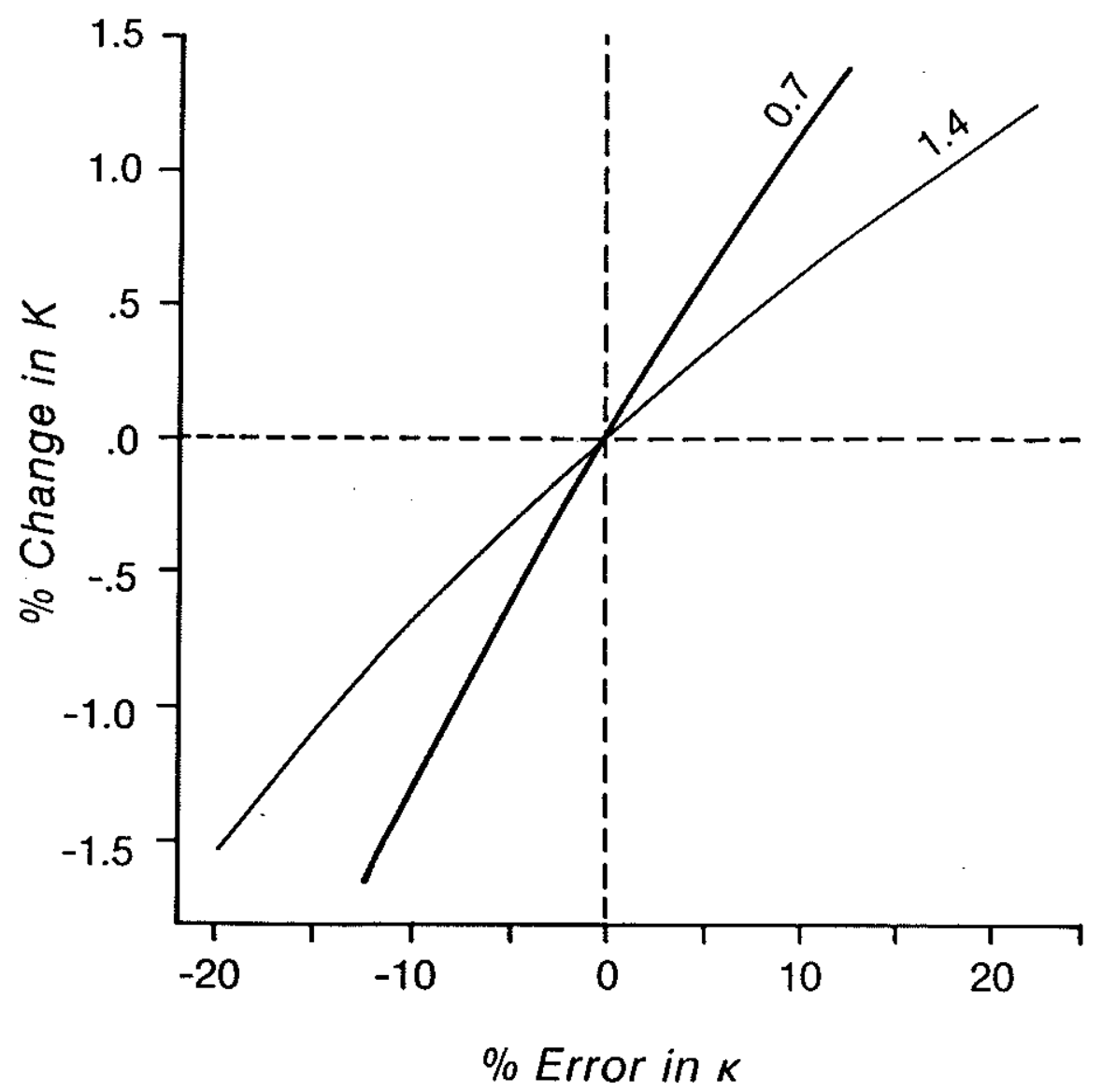

Fig. A2.12. Error in $\kappa$ vs. percent change in $K . G(\alpha, \tau)$ is determined at $t=100 \mathrm{~s}$ and $400 \mathrm{~s}$ after heater is active. Equation $A 2.10$ is used as the $\kappa-K$ relation. Curves assume $\mathrm{K}=0.7$ and $1.4 \mathrm{~W} \mathrm{~m}^{-1} \mathrm{~K}^{-1}$ and are extended to realistic uncertainty in $\kappa$ according to Figure A2.9. 
piston core $K$ data in the specific survey area.

Use of a biaxial probe design. The double-probe design (Figure A2.3c) was a consequence of a simple conversion of the already existing temperature probe into assemblies capable of measuring conductivity in situ. The single-probe design (Figure A2.3a) closely approximates analytical theory because the heater wire and temperature sensor are located near the center of a probe that has a good conducting wall of cylindrical geometry. The more complicated geometry of the biaxial probe results from the placement of an externally mounted heater wire probe adjacent to the thermistor probe. The two probes will sometimes separate slightly during field use and consequently have variable thermal contact along their lengths. However, at sufficiently long times, the biaxial probe must approach the behavior of an equivalent single probe since temperatures will only be a function of the asymptote (logarithm time) as a result of the radius of the heating front in the sediment becoming large compared to the probe dimensions.

Since we are interested in using as early times as possible to recover the conductivity data, the finite heat capacity of the double probe is taken into account (see Equation A2.8). The therma1 capacity of the biaxial probe has approximately doubled, as has the volume of sediment displaced by the probe. Thus, $\alpha$ is similar to that of the uniaxial probe.

In the case of the double probe, the radius $r$ is uncertain so that the relationship of $r$ to $G(\alpha, \tau)$ must be analyzed. The biaxial probe is approximated by assuming an effective radius which lies between the radius of the uniaxial probe $(r=0.16 \mathrm{~cm})$ and the distance between the 
axes of the heater and thermistor probes $(r=0.32 \mathrm{~cm})$. Thus, with a larger uncertainty than the single probe, the actual conductivity can be bracketed between high and low estimates. An analytical test of the double probe is made to determine the range of times for which Equation A2.8 is an adequate approximation.

The Blackwe11 approximation (Equation A2.8) for the probe model is compared to an off-axis model described by Jaeger (1958) in which temperature $\theta$ is recorded a distance $d$ from an infinite line heat source in an infinite medium of thermal diffusivity $\kappa$ and conductivity $\mathrm{K}$. The medium is initially at $\theta=0$ and at time $t>0$ heat is supplied at a rate $Q$ per unit length per unit time. For $t>0, \theta$ is given by

$$
\theta=-\frac{Q}{4 \pi K} E_{i}\left(\frac{-d^{2}}{4 \kappa t}\right)
$$

where $-\mathrm{E}_{1}(-\mathrm{x})$ is the exponential integral whose series expansion is (Abramowitz and Stegun, 1965)

$$
-E_{1}(-x)=-\gamma-\ln x-\sum_{n=1}^{\infty} \frac{(-x)^{n}}{n n !}
$$

$\gamma=0.57721$ is Euler's constant. For the double probe, $d$ is analogous to the distance between the heater wire and thermistor located in the adjacent cylindrica1 probes. The main inaccuracy in the off-axis model is that the high conductivity and possibly different heat capacity of the steel probes are not taken into account; instead, the model assumes that the sediment is the material between the heater and thermistor sensor and is a relatively poor conductor, which is the extreme case for two probes in contact. Equating the probe radius $r$ with $d, k \theta / Q$ of the B1ackwe11 approximation (Equation A2.8) is compared to the of $\mathrm{f}$-axis 


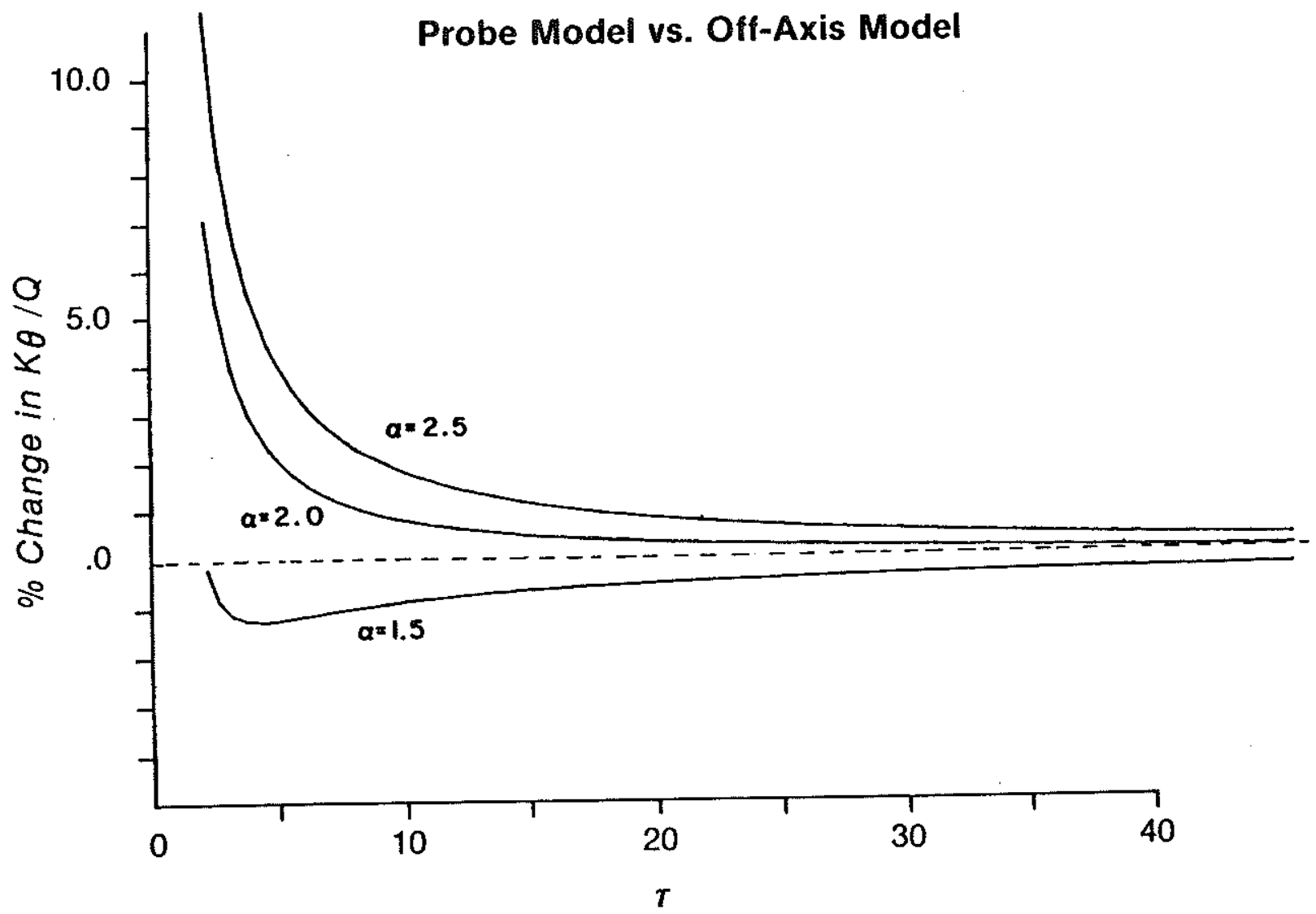

Fig. A2.13. Percent difference in $K \theta / Q$ value for probe model to the off-axis model for $\mathrm{kt} / \mathrm{r}^{2}$ (see Equations $\mathrm{A} 2.6$ and A2.14). Curves drawn for cases of $\alpha=2.5,2.0$, and 1.5. Distance between heater and thermistor in off-axis model is equated to radius of probe model. 
mode1 (Equation A2.14) in Figure A2.13. At $\tau=7$ and $\alpha=2.0, \mathrm{~K}$ calculated for the uniaxial probe is about $1 \%$ higher than the off-axis model with the solutions converging for large $\tau$. Accepting $\tau=7$ as the minimum $\tau$ for Equation A2.8 to become valid for the double probe, the minimum time is 60 to $235 \mathrm{~s}$ for sediment of $\kappa=0.3 \times 10^{-6} \mathrm{~m}^{2} \mathrm{~s}^{-1}$ depending on the value of the effective radius being 0.16 or $0.32 \mathrm{~cm}$, respectively. Accordingly, if temperature data recorded later than 200 $\mathrm{s}$ are successively omitted, 1ittle change in the computed $\mathrm{K}$ is found, regardless of the radius used. However, if temperatures recorded $<100$ $s$ after the heater turns on are utilized, the computed $\mathrm{K}$ will be underestimated by a few percent and will have a larger curve fit error.

When using high and low estimates of the probe radius in the $\mathrm{K}$ determination, the small radius case produces a higher $\mathrm{k}$ value. In Figure A2.14, the increase in $\mathrm{K}$ computed with $\mathrm{r}=0.16 \mathrm{~cm}$ rather than $\mathrm{r}$ $=0.32 \mathrm{~cm}$ is plotted against the $\mathrm{K}$ value using $\mathrm{r}=0.32 \mathrm{~cm}$. The theoretical curves are dependent on the minimum time value utilized. When short times are considered, there is a larger discrepancy between the computed $\mathrm{K}$ for the two radii. For a delay time of $150 \mathrm{~s}$, a change of about $0.04-0.05 \mathrm{~W} \mathrm{~m}^{-1} \mathrm{~K}^{-1}$ in $\mathrm{K}$ can be expected.

Due to the variable thermal contact of the double-probe construction, a "proper" value of radius cannot easily be found using minimization techniques in the curve fit error or using a numerical modeling approach. In practice, the final $\mathrm{K}$ value is obtained either by averaging solutions to the low estimate $(r=0.16 \mathrm{~cm})$ and high estimate $(r=0.32 \mathrm{~cm})$ or by using an intermediate value for the radius $(r=0.23$ $\mathrm{cm}) . A \pm 0.03 \mathrm{~W} \mathrm{~m}^{-1} \mathrm{~K}^{-1}$ uncertainty is generally attributed to 


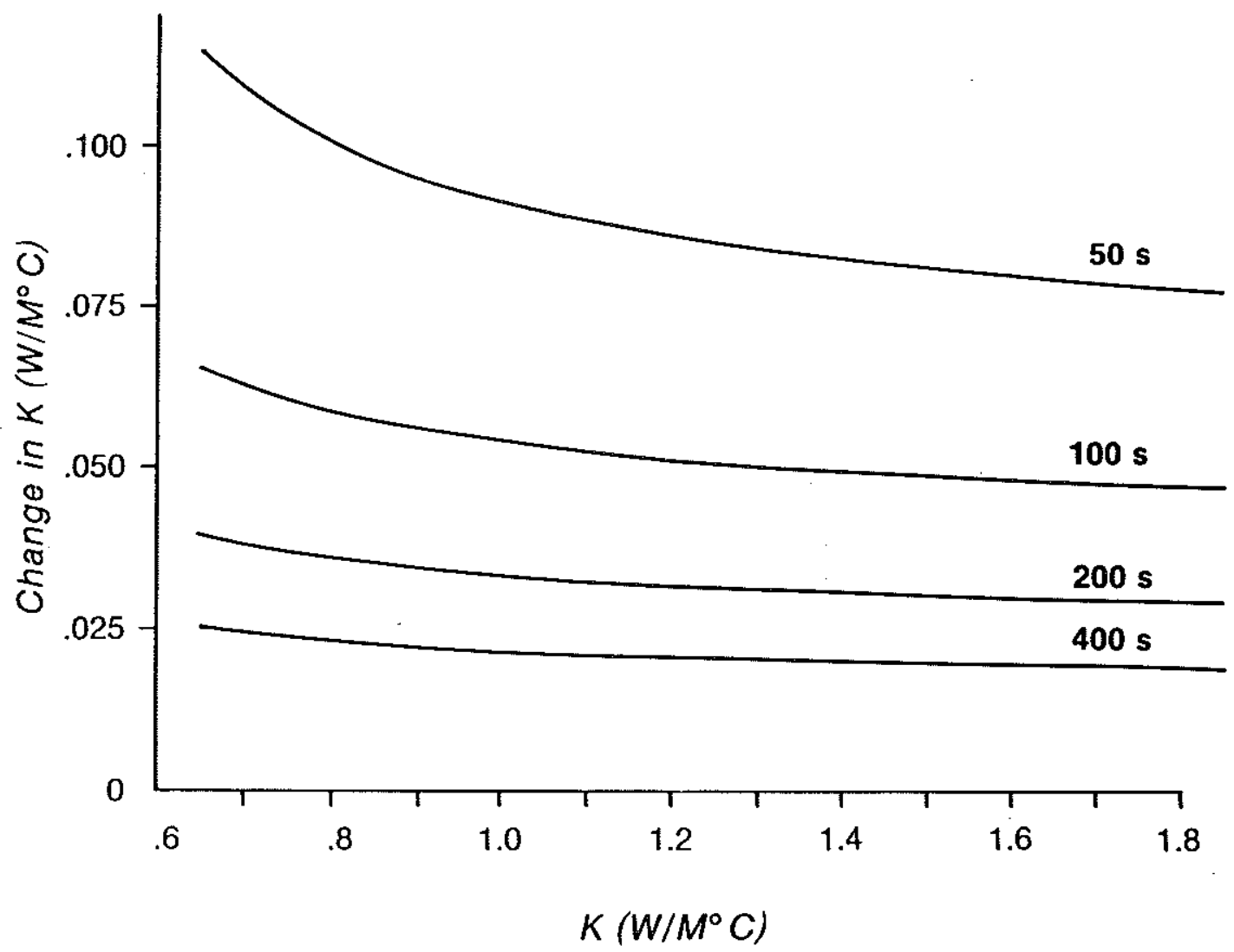

Fig. A2.14. Conductivity $K$ obtained using $r=0.32 \mathrm{~cm}$ is plotted with the increase in $\mathrm{K}$ found using $\mathrm{r}=0.16 \mathrm{~cm}$. Curves show the relation that the initial time considered in the temperature record $(50,100,200,400 \mathrm{~s})$ has on the difference in the computed $K$ for the two radii. 
uncertainty in the effective radius, making the total instrumental error for the double probe about $\pm 6 \%$. The single-probe design is a physical system more easily quantified by analytical theory for heat conduction in cylindrical probes, and therefore has a greater precision compared to the biaxial probe design.

\section{A2.5 Field Testing}

An independent check on the accuracy of the in situ thermal conductivity values is made by comparing the in situ data with available physical property data of sediment core samples. Since the in situ measurement determines $\mathrm{K}$ only in the horizontal direction, bias in the in situ $\mathrm{K}$ values may occur if significant anisotropy exists.

Conversely, some mass physical properties of the sediment core may be prone to a sampling disturbance caused by the piston coring process (Ross and Riede1, 1967; McCoy and Von Herzen, 1971; Stow and Aksu, 1978; McCoy, 1980). It is reasonable to suspect some bias in the needle-probe values will result from core disturbance phenomena. Therefore, irreversible changes in the sediment due to core recovery techniques places a special emphasis on the applicability of in situ measurements over shipboard measurements. Furthermore, corrections of the core data for the ambient pressure and temperature on the seafloor (Ratcliffe, 1960) may also be in error, but probably to a lesser extent than the coring effects.

Comparison of in situ measurements to core sample values. Field calibration of the in situ $\mathrm{K}$ measurements is performed by comparing them to needle-probe values obtained from nearby piston cores. Sites are 
located in the Ligurian Basin and Bermuda Rise (Table A2.3). Each site includes 1 to 3 pogo-probing stations located within $3 \mathrm{~km}$ of a single piston core station. For each station, the average $\mathrm{K}$ is determined as the harmonic mean (reciprocal of the arithmetic mean of the $1 / \mathrm{K}$ values). A data set with a standard deviation (SD) of $20 \%$ produces an arithmetic mean with a systematic error of $3 \%$ above the harmonic mean. The in situ and core values are restricted to roughly the same depth interval such that needle-probe values below the upper $7 \mathrm{~m}$ of the piston core are not genera11y considered.

In Figure A2.15, the harmonic mean for each site as determined by the in situ values is plotted against that determined by the core values. The deviation between the core and in situ values is < $6 \%$ which is within the instrumental techniques; no systematic difference between the in situ and needle-probe values is apparent. The biaxial probe performance seems to be similar to the uniaxial design. In a geothermal survey of the Tyrrhenian Basin site, the biaxial probe instrumentation has been compared to the pulse-heating method on a violin-bow instrument (Hutchison et al., 1985). Both in situ methods gave $\mathrm{K}$ values within $2 \%$ of each other in a region with a homogeneous sediment distribution.

Good agreement exists for individual conductivity-depth profiles of the core stations (corrected to in situ conditions) compared to in situ pogo-probe values (Figure A2.16). These comparisons are made in sediments of different mean conductivity. Where sediment conductivity is uniform with depth, the agreement is most clear (Figure A2.16a). If significant conductivity stratification occurs, missing upper core sections are evident (Figure A2.16b-d). A better fit of the 


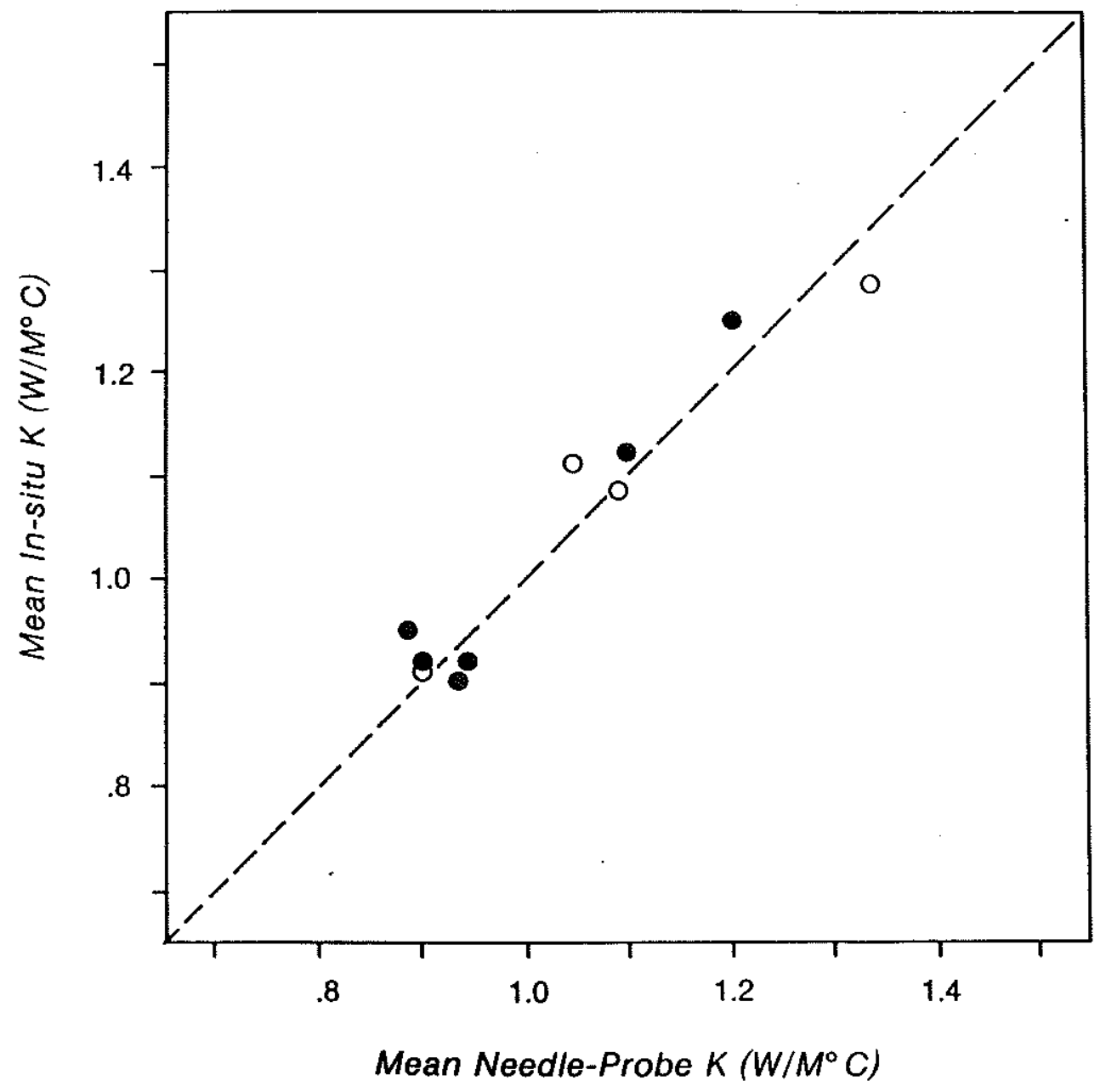

Fig. A2.15. P1ot of the harmonic mean conductivity from a11 needle-probe and in situ data at selected sites S1 - S6 (single-probe design, closed circle) and D1 - D4 (double-probe design, open circle) (see Table A2.3). 
Table A2.3 Selected Piston Core and In Situ Pogo Stations

\begin{tabular}{|c|c|c|c|c|c|c|}
\hline Site' & Station ${ }^{2}$ & Latitude & Long itude & $\mathrm{N}^{3}$ & $\begin{array}{l}\text { Mean } K \\
\left(W m^{-1} K^{-1}\right)\end{array}$ & $\begin{array}{l}\Delta K^{4} \\
\left(W m^{-1} K^{-1}\right)\end{array}$ \\
\hline S1 & $\begin{array}{l}\mathrm{B} 83 \mathrm{PCO} 4 \\
\mathrm{~B} 83 \mathrm{~S} 6 \mathrm{~B} .4 \\
\mathrm{~B} 83 \mathrm{~S} 6 \mathrm{~B} .5\end{array}$ & $\begin{array}{l}30^{\circ} 12.5 \mathrm{~N} \\
30^{\circ} 12.3 \mathrm{~N} \\
30^{\circ} 12.2 \mathrm{~N}\end{array}$ & $\begin{array}{l}69^{\circ} 47.8 W \\
69^{\circ} 48.3 W \\
69^{\circ} 47.4 W\end{array}$ & $\begin{array}{r}15 \\
5 \\
5\end{array}$ & $\begin{array}{l}0.898 \\
0.918 \\
0.918\end{array}$ & $\begin{array}{l}0.008 \\
0.036 \\
0.036\end{array}$ \\
\hline $\mathrm{S} 2$ & $\begin{array}{l}\text { B83PC05 } \\
\text { B83S10.8 } \\
\text { B83S10.11 }\end{array}$ & $\begin{array}{l}31^{\circ} 08.0 \mathrm{~N} \\
31^{\circ} 08.3 \mathrm{~N} \\
31^{\circ} 09.8 \mathrm{~N}\end{array}$ & $\begin{array}{l}68^{\circ} 08.1 \mathrm{~W} \\
68^{\circ} 06.5 \mathrm{~W} \\
68^{\circ} 07.3 \mathrm{~W}\end{array}$ & $\begin{array}{r}19 \\
7 \\
7\end{array}$ & $\begin{array}{l}0.946 \\
0.909 \\
0.935\end{array}$ & $\begin{array}{l}0.022 \\
0.031 \\
0.028\end{array}$ \\
\hline s3 & $\begin{array}{l}\text { B83PC06 } \\
\text { B83S9.5 } \\
\text { B83S9.6 } \\
\text { B83S9.7 }\end{array}$ & $\begin{array}{l}31^{\circ} 12.1 \mathrm{~N} \\
31^{\circ} 12.6 \mathrm{~N} \\
31^{\circ} 12.5 \mathrm{~N} \\
31^{\circ} 12.2 \mathrm{~N}\end{array}$ & $\begin{array}{l}68^{\circ} 03.8 \mathrm{~W} \\
68^{\circ} 04.8 \mathrm{~W} \\
68^{\circ} 03.3 \mathrm{~W} \\
68^{\circ} 01.8 \mathrm{~W}\end{array}$ & $\begin{array}{r}19 \\
5 \\
5 \\
5\end{array}$ & $\begin{array}{l}0.937 \\
0.923 \\
0.905 \\
0.893\end{array}$ & $\begin{array}{l}0.028 \\
0.087 \\
0.053 \\
0.022\end{array}$ \\
\hline S4 & $\begin{array}{l}\mathrm{B} 83 \mathrm{PCO} \\
\mathrm{B} 83 \mathrm{~S} 11.4 \\
\mathrm{~B} 83 \mathrm{~S} 12.1\end{array}$ & $\begin{array}{l}31^{\circ} 01 \cdot 5 \mathrm{~N} \\
31^{\circ} 02.1 \mathrm{~N} \\
31^{\circ} 02.3 \mathrm{~N}\end{array}$ & $\begin{array}{l}66^{\circ} 29.7 \mathrm{~W} \\
66^{\circ} 27.8 \mathrm{~W} \\
66^{\circ} 31.6 \mathrm{~W}\end{array}$ & $\begin{array}{r}18 \\
7 \\
6\end{array}$ & $\begin{array}{l}0.890 \\
0.961 \\
0.959\end{array}$ & $\begin{array}{l}0.009 \\
0.072 \\
0.033\end{array}$ \\
\hline s5 & $\begin{array}{l}\text { L84PC03 } \\
L 84 S 5.6\end{array}$ & $\begin{array}{l}43^{\circ} 38.3 \mathrm{~N} \\
43^{\circ} 38.2 \mathrm{~N}\end{array}$ & $\begin{array}{l}7^{\circ} 28.4 \mathrm{E} \\
7^{\circ} 28.6 \mathrm{E}\end{array}$ & $\begin{array}{r}27 \\
7\end{array}$ & $\begin{array}{l}1.098 \\
1.120\end{array}$ & $\begin{array}{l}0.035 \\
0.088\end{array}$ \\
\hline S6 & $\begin{array}{l}\mathrm{L} 84 \mathrm{PCO} 4 \\
\mathrm{~L} 84 \mathrm{~S} 5.9\end{array}$ & $\begin{array}{l}43^{\circ} 41.6 \mathrm{~N} \\
43^{\circ} 41.6 \mathrm{~N}\end{array}$ & $\begin{array}{l}7^{\circ} 28.4 \mathrm{E} \\
7^{\circ} 28.2 \mathrm{E}\end{array}$ & $\begin{array}{r}27 \\
7\end{array}$ & $\begin{array}{l}1.200 \\
1.251\end{array}$ & $\begin{array}{l}0.031 \\
0.108\end{array}$ \\
\hline D1 & $\begin{array}{l}\mathrm{L} 82 \mathrm{PC} 01 \\
\mathrm{~L} 82 \mathrm{~S} 9.1\end{array}$ & $\begin{array}{l}42^{\circ} 49.9 \mathrm{~N} \\
42^{\circ} 49.9 \mathrm{~N}\end{array}$ & $\begin{array}{l}8^{\circ} 40.8 \mathrm{E} \\
8^{\circ} 40.8 \mathrm{E}\end{array}$ & $\begin{array}{r}18 \\
4\end{array}$ & $\begin{array}{l}1.090 \\
1.085\end{array}$ & $\begin{array}{l}0.038 \\
0.039\end{array}$ \\
\hline $\mathrm{D} 2$ & $\begin{array}{l}\text { L82PC05 } \\
\text { L82S16.9 } \\
\text { L82S16.10 }\end{array}$ & $\begin{array}{l}43^{\circ} 31.8 \mathrm{~N} \\
43^{\circ} 32.7 \mathrm{~N} \\
43^{\circ} 31.8 \mathrm{~N}\end{array}$ & $\begin{array}{l}7^{\circ} 48.2 \mathrm{E} \\
7^{\circ} 46.8 \mathrm{E} \\
7^{\circ} 48.2 \mathrm{E}\end{array}$ & $\begin{array}{r}12 \\
4 \\
4\end{array}$ & $\begin{array}{l}1.331 \\
1.413 \\
1.178\end{array}$ & $\begin{array}{l}0.124 \\
0.300 \\
0.144\end{array}$ \\
\hline D3 & $\begin{array}{l}\mathrm{B} 83 \mathrm{PC} 09 \\
\mathrm{~B} 83 \mathrm{~S} 14.2 \\
\mathrm{~B} 83 \mathrm{~S} 14.4\end{array}$ & $\begin{array}{l}31^{\circ} 32.8 \mathrm{~N} \\
31^{\circ} 32.6 \mathrm{~N} \\
31^{\circ} 33.3 \mathrm{~N}\end{array}$ & $\begin{array}{l}65^{\circ} 42.1 \mathrm{~W} \\
65^{\circ} 41.9 \mathrm{~W} \\
65^{\circ} 41.7 \mathrm{~W}\end{array}$ & $\begin{array}{r}18 \\
6 \\
6\end{array}$ & $\begin{array}{l}1.045 \\
1.069 \\
1.150\end{array}$ & $\begin{array}{l}0.036 \\
0.104 \\
0.052\end{array}$ \\
\hline D4 & $\begin{array}{l}\text { B83PC13 } \\
\text { B83S21. } 1 \\
\text { B83S21.2 } \\
\text { B83S21.3 }\end{array}$ & $\begin{array}{l}33^{\circ} 44.0 \mathrm{~N} \\
33^{\circ} 43.0 \mathrm{~N} \\
33^{\circ} 43.1 \mathrm{~N} \\
33^{\circ} 42.7 \mathrm{~N}\end{array}$ & $\begin{array}{l}67^{\circ} 27.7 \mathrm{~W} \\
67^{\circ} 29.6 \mathrm{~W} \\
67^{\circ} 29.0 \mathrm{~W} \\
67^{\circ} 28.0 \mathrm{~W}\end{array}$ & $\begin{array}{r}21 \\
7 \\
7 \\
7\end{array}$ & $\begin{array}{l}0.900 \\
0.864 \\
0.911 \\
0.955\end{array}$ & $\begin{array}{l}0.019 \\
0.023 \\
0.034 \\
0.031\end{array}$ \\
\hline
\end{tabular}

1 site Sn has in situ data using single probe, Dn using double probe

2 piston core stations (nnnPCnn), pogo stations (nnnsnn.nn)

3 number of measurements

4 uncertainty derived from $95 \%$ confidence level using student $t$-test based on $\mathrm{N}$ measurements 

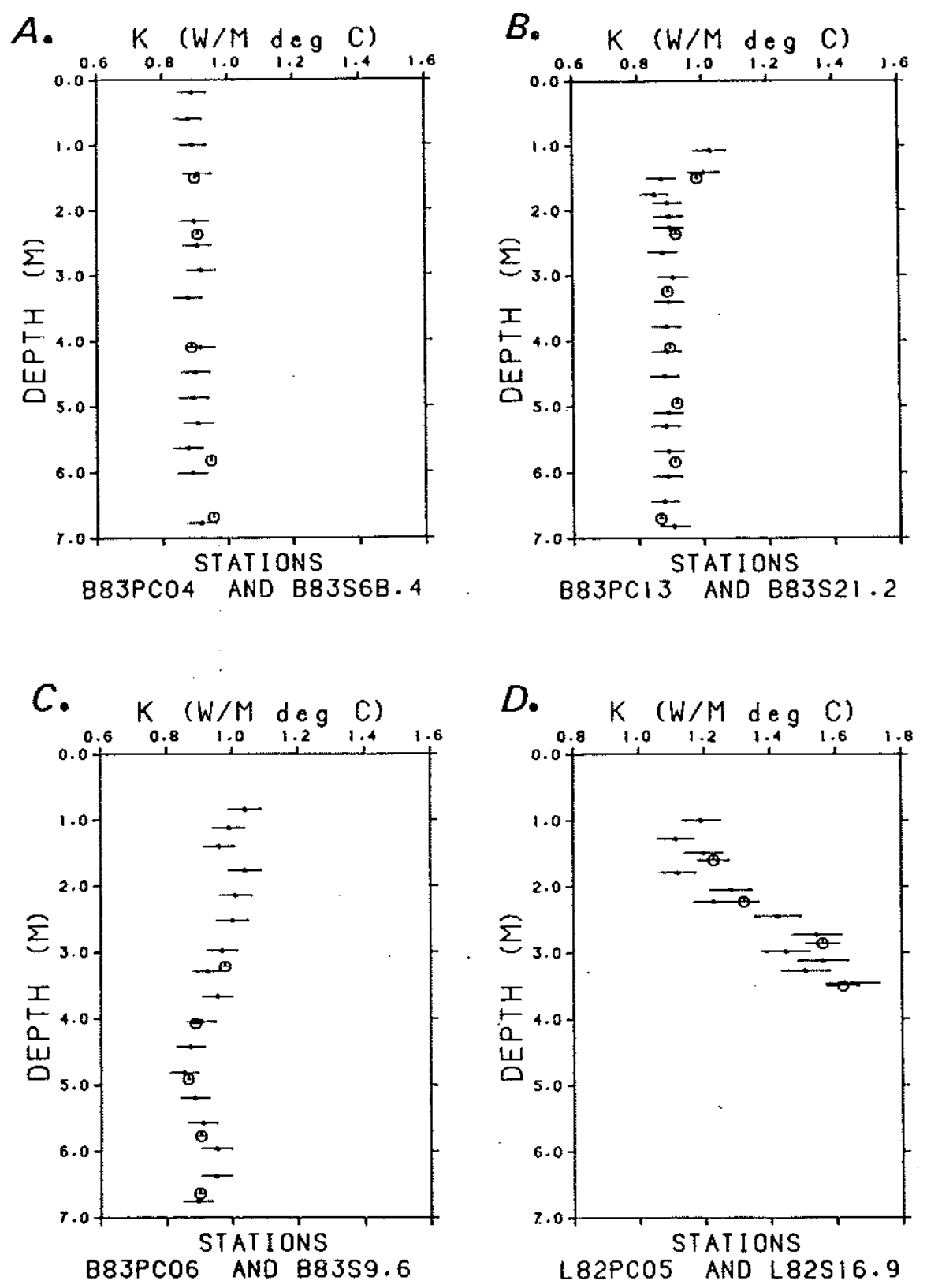

Fig. A2.16. Comparison of conductivity-depth profiles of piston core and pogo probe stations. Needle-probe values of core are shown as diamonds with error bars of $\pm 5 \%$ uncertainty. In situ data is given by circles. Error bar at center of the circle is the curve fit error. Positions of stations are given in Table A2.3. a) B83PC04 and B83S6B.4 profiles. b) B83PC13 and B83S21.2 profiles. To improve the fit-by-eye of the core profile to the in situ prnfile, the piston core depth has been increased by $\Delta=1.0 \mathrm{~m}$. c) B83PC05 and B83S10.11 profiles, $\Delta=0.7 \mathrm{~m}$. d) L82PC05 and L82S16.9 profiles, $\Delta=0.8 \mathrm{~m}$. 
needle-probe and in situ profiles is clearly obtained if the piston core depths (as determined as distance from top of core) are increased by up to 1 meter. The upper portion of the piston core may be lost frequently because of the uncertainty of the piston coring process (McCoy and Von Herzen, 1971). Heat flow measurements allow for an estimation of actual in situ depths by extrapolation of the geothermal gradient to the sediment surface. Consequent1y, the core conductivity profiles have been shifted to greater depths to best align with the conductivity stratigraphy indicated by the in situ conductivities and depths.

Reliability of mean conductivity estimates. The reliability of the field comparison depends on the variability of the sediment conductivity. Langseth and Von Herzen (1971) discuss the conductivity patterns in the deep-sea and tendency of variability to increase with the average conductivity. Regions of more uniform conductivity are genera1ly associated with pelagic clays of high water content where normal $\left(0.75\right.$ to $\left.0.95 \mathrm{~W} \mathrm{~m}^{-1} \mathrm{~K}^{-1}\right)$ and below normal $\left(<0.75 \mathrm{~W} \mathrm{~m}^{-1}\right.$ $\mathrm{K}^{-1}$ ) conductivity is found. Overa11 higher than normal conductivity (> $0.95 \mathrm{~W} \mathrm{~m}^{-1} \mathrm{~K}^{-1}$ ) exists near continental margins due to the proximity of terrigenous sources. Data presented in Table A2.3 is consistent with higher mean conductivities associated with larger variability. High conductivity layers with low water content can be associated with quartz-rich abyssal turbidites or with carbonate-rich deposits; the occurrence of both type of deposits can be greatly influenced by global climate changes.

To a large degree, discrepancies in mean $\mathrm{K}$ values between the in situ and core data probably reflect actual heterogeneities in the 
sediment composing each site. Horizontal variability seems to be significant in the $30 \mathrm{~km}^{2}$ area delimited by site D4 (Table A2.3). Each of the four stations has < $3 \%$ uncertainty in the mean so that site D4 may have lateral variation in mean sediment conductivity of up to $5 \%$. For site $\mathrm{D} 2$, which has the highest mean $\mathrm{K}$ of all sites, the discrepancy between the core and in situ values is significant with the mean $\mathrm{K}$ of one in situ station being $11 \%$ less than the core value and another being $6 \%$ higher. In this case, vertical heterogeneity in conductivity is implied by the magnitude of the variance or error assigned to the mean.

If there is no net linear change in $\mathrm{K}$ with depth, the mean conductivity is usually taken at face value and the error is of little concern in the calculation of the heat flow. Since the in situ mean $\mathrm{K}$ is calculated from discrete measurements (up to $1 \mathrm{~m}$ spacing) in sediment of nonuniform conductivity, more accurate mean conductivity can only result from increasing the density of measurements with depth or analyzing the effect of extant sma11-scale conductivity layering. Below, the discrete samp1ing problem is investigated using synthetic conductivity stratigraphy.

1) GRAPE-derived conductivity data. Gamma Ray Attenuation Porosity Evaluator (GRAPE) logs (Boyce, 1973) obtained in the Ligurian Sea are analyzed to estimate continuous conductivity profiles. The basic procedure is as follows: a) From the GRAPE records, $4 \mathrm{~cm}$ intervals on the core section are identified that are relatively uniform in bulk density $( \pm 3 \%)$ and so are suitable for accurate needle-probe measurements. b) The GRAPE $\log$ is digitized at $1 \mathrm{~cm}$ intervals and 
converted to bulk densities in a manner similar to that described by Boyce (1973) for the Deep Sea Drilling Project. c) Water content is measured at positions coincident with the needle-probe measurements for direct comparison of grain density and porosity to conductivity.

The bulk density $\rho$ and water fraction of bulk weight $W$ are used to determine the grain density $\rho_{g}$

$$
\rho_{g}=\frac{\rho(1-W)}{1-\left(\rho W / \rho_{w}\right)}
$$

where $\rho_{\mathrm{w}}$ is the density of the pore water $\left(1030 \mathrm{~kg} \mathrm{~m}^{-3}\right)$. The porosity $\phi$ is estimated as

$$
\phi=\frac{\rho_{g}-\rho}{\rho_{g}-\rho_{W}}
$$

and is basically a function of the bulk density. The Woodside and Messmer (1961) relation is used to model the conductivity of the water-saturated sediment. It is given by the geometric mean equation

$$
K=K_{w}^{\phi} K_{g}^{(1-\phi)}
$$

where $K_{w}$ and $K_{g}$ are the thermal conductivity of water $\left(0.61 \mathrm{~W} \mathrm{~m}^{-1}\right.$ $\mathrm{K}^{-1}$ ) and of the sediment grains, respective1y. From Equations A2.15, A2.16 and A2.17, the grain conductivity can be represented as

$$
K_{g}=\frac{\exp \left[\left(\rho-\rho_{W}\right) \ln K-\left(\rho_{g}-\rho\right) \ln K_{W}\right]}{\rho-\rho_{W}}
$$

Substituting densities for porosity in the Woodside-Messmer relation, the bulk thermal conductivity is related to the bulk density according to

$$
\mathrm{K}=\exp (\mathrm{a} \rho+\mathrm{b})
$$

where the coefficients a and $b$ are mainly determined by the average values for $\rho_{\mathrm{g}}$ and $\mathrm{K}_{\mathrm{g}}$. 
Using the same sediment samples plotted in Figure A2.8, conductivity as a function of bulk density is shown in Figure A2.17. The empirica1. curve is of the form of Equation A2.18 with coefficients $a=1.02$ and $b$ $=-1.54$, and is based on the average values of $\rho_{g}=2430 \mathrm{~kg} \mathrm{~m}^{-3}$ and $\mathrm{K}_{\mathrm{g}}=2.55 \mathrm{~W} \mathrm{~m}^{-1} \mathrm{~K}^{-1}$. There is a $\pm 10 \%$ variation in $\mathrm{K}$ about the formulated curve, and it can be quantitatively demonstrated that the scatter is attributable to the variability in both $\rho_{g}(S D= \pm 120$ $\left.\mathrm{kg} \mathrm{m}^{-3}\right)$ and $\mathrm{K}_{\mathrm{g}}\left(\mathrm{SD}= \pm 0.27 \mathrm{~W} \mathrm{~m}^{-1} \mathrm{~K}^{-1}\right)$.

For appropriate cores, synthetic conductivity profiles can be generated from the GRAPE-derived bulk density log using the $\rho-K$ relation found above. Figure A2.18 illustrates the predictive nature of the synthetic profile for a piston core composed of an abyssal turbidite sequence deposited near a channel of the Var deep sea fan in the Ligurian Sea. The core is particularly useful in showing high interval conductivity contrasts which are substantiated by the needle-probe data. The conductivity maxima are characterized by a $30 \%$ greater grain conductivity and $20 \%$ smaller water content than the minima. The synthetic data appears to be a good predictor of the observed data and can be used as a reliable indicator of detailed variability along the core length.

2) Effect of thermistor spacing. One of the concerns of the outrigger pogo probe with a 0.6 to $1.0 \mathrm{~m}$ distance between thermistor sensors is that the in situ data may not be of sufficient density to adequately sample the conductivity profile. Obviously, by decreasing the thermistor separation and increasing the density of sensors, more confidence can be placed on the calculated mean. The overall 


\section{LIGURIAN SEA PISTON CORE DATA}

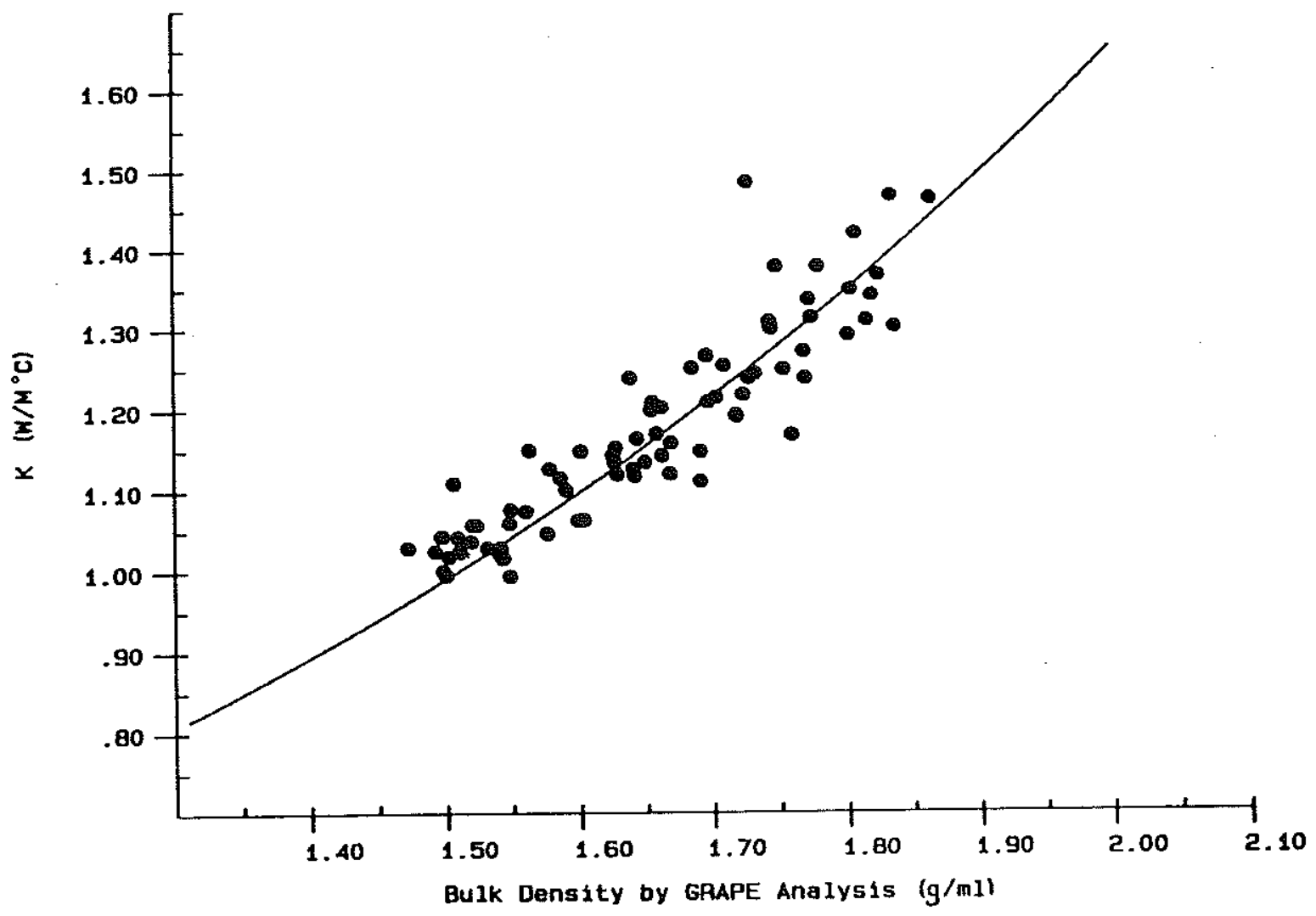

Fig. A2.17. Plot of needle-probe conductivity values versus bulk density. The conductivity and density measurements are from identical postions on the core and the bulk density is derived from GRAPE data. 


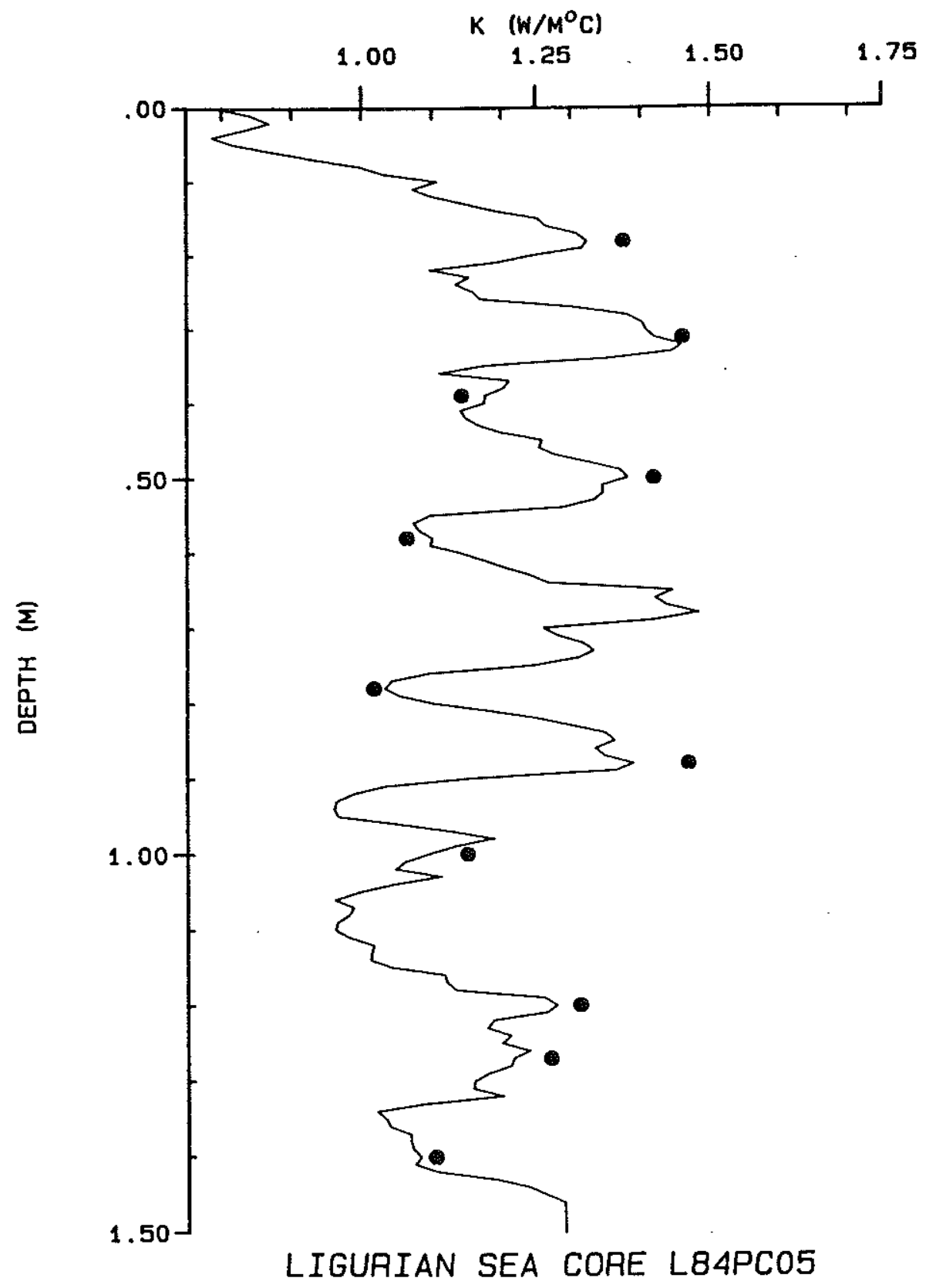

Fig. A2.18. Downcore plot of GRAPE-derived conductivity profile (1ine) and needle-probe conductivity values (circles). Core location is $43^{\circ} 10.1^{\prime} \mathrm{N}$ and $8^{\circ} 11.9^{\prime} \mathrm{E}$. 
conductivity variability given by the sediment structure will also be an important factor in determining the accuracy of a particular outrigger spacing, such that a turbiditic deposit requires a higher density of sensors than a homogeneous pelagic deposit.

Synthetic data have been generated by sampling the GRAPE-derived conductivity profile of Figure A2.18 at discrete intervals analogous to probe spacings. An autocorrelation with respect to the harmonic mean is made by the following procedure: a) From the GRAPE 1 og, a continuous conductivity profile (equally spaced at $1 \mathrm{~cm}$ ) is obtained using the $\rho$ - K empirical relation. b) The true mean is calculated using a11 points of the conductivity profile. c) A hypothetical thermistor array is defined as extending the length of the core with a particular spacing between sensors. d) With the uppermost sensor of the array positioned at the top of core, the mean conductivity is calculated and compared to the true mean. e) In a sequential manner, the array is offset by $1 \mathrm{~cm}$ and the new mean is again compared to the true mean; the total number of lag positions is determined by the thermistor separation.

Correlograms are shown for core L84PC05 in Figure A2.19 for two different cases of thermistor separation. A $64 \mathrm{~cm}$ spacing is analogous to the distance between thermistors for the outrigger pogo probe from which the in situ measurements of this study were made. For this spacing, $45 \%$ of the runs had conductivity means which deviated more than $\pm 5 \%$ from the true mean with some values differing by over $\pm 10 \%$. Thus, the relative mean differs by over $20 \%$ between some lags. Where a smaller thermistor spacing of $16 \mathrm{~cm}$ is employed, the accuracy of the 


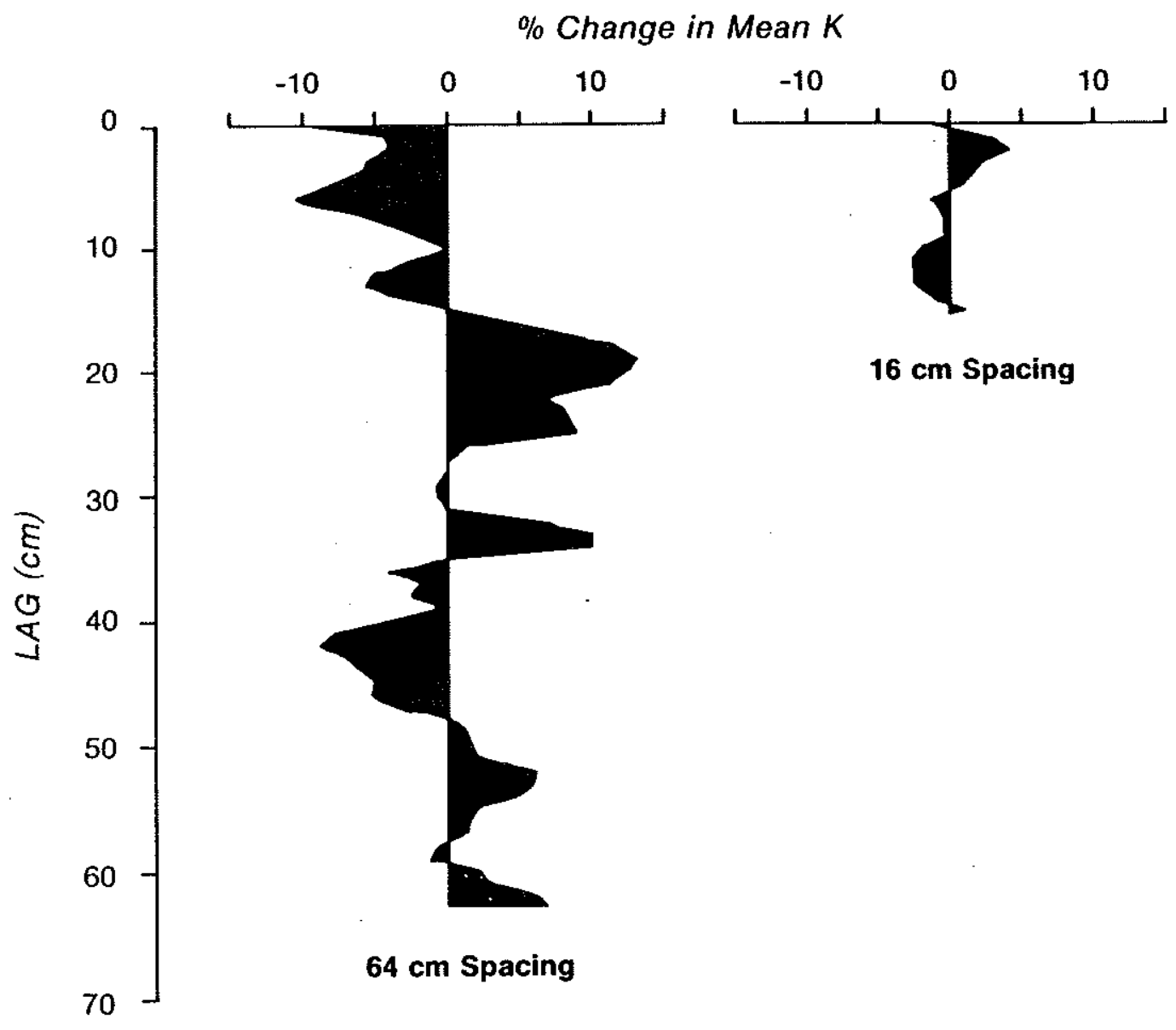

Ligurian Sea Core L84PC05

Fig. A2.19. Correlograms show the percent change in mean conductivity from the true mean (mean obtained from data at $1 \mathrm{~cm}$ spacing). For the calculation of the mean, the $64 \mathrm{~cm}$ spacing has 2 to 3 sample points and the $16 \mathrm{~cm}$ spacing has 9 to 10 sample points. The conductivity profile of L84PC05 is illustrated in Figure A2.18. 
Table A2.4 Maximum Difference to the True Mean Conductivity

\begin{tabular}{ccc}
\hline \multirow{2}{*}{$\begin{array}{c}\text { Sample spacing } \\
(\mathrm{cm})\end{array}$} & \begin{tabular}{c} 
Maximum deviation (in percent) \\
\cline { 2 - 3 } Nonlayered sediment \\
core L84PC03
\end{tabular} & $\begin{array}{c}\text { Layered sediment } \\
\text { core L84PC05 }\end{array}$ \\
\hline 1 & 0.0 & 0.0 \\
4 & 0.1 & 0.4 \\
8 & 0.3 & 1.5 \\
16 & 1.1 & 4.3 \\
32 & 2.5 & 9.8 \\
64 & 3.7 & 13.2 \\
\hline
\end{tabular}


mean conductivity improves and only a $4 \%$ maximum deviation from the true mean occurs.

One should note that core L84PC05 which is also illustrated in Figure A2.18 has unusua1ly large amplitude fluctuations in the synthetic conductivity profile. The dominant wavelength of the conductivity layers is on the order of 10 to $20 \mathrm{~cm}$ which suggests that optimal sampling of this particular core should be performed with a thermistor spacing of $10 \mathrm{~cm}$ or less. A comparison of the maximum deviation in mean $\mathrm{K}$ to the true mean for the layered core of L84PC05 and the relative1y unlayered L84PC03 core (see site S5, Tab1e A2.3) is given in Table A2.4. The unlayered core has a relatively structureless conductivity profile and is more typical of hemipelagic and pelagic sediment deposits. For such cores, the $64 \mathrm{~cm}$ spacing poses no serious discrete sampling problem in the determination of the mean $\mathrm{K}$.

Improving heat flow estimates with in situ conductivity. The acquisition of accurate thermal conductivity measurements made at exact points where equilibrium temperatures are measured in situ can reduce the uncertainties in heat flow for individual stations (penetrations). Additiona11y, the pogo-probing technique can increase the accuracy of the regional heat flow estimate, especially if conductivity is determined in situ. For example, the suite of measurements plotted in Figure A2.20 indicates that there is slightly less scatter in heat flow values than in the thermal gradient. The individual heat flow values, calculated as the product of the gradient $G$ and mean in situ conductivity $\mathrm{k}$, have a $3-4 \%$ variability within the $400 \mathrm{~km}^{2}$ site. The 


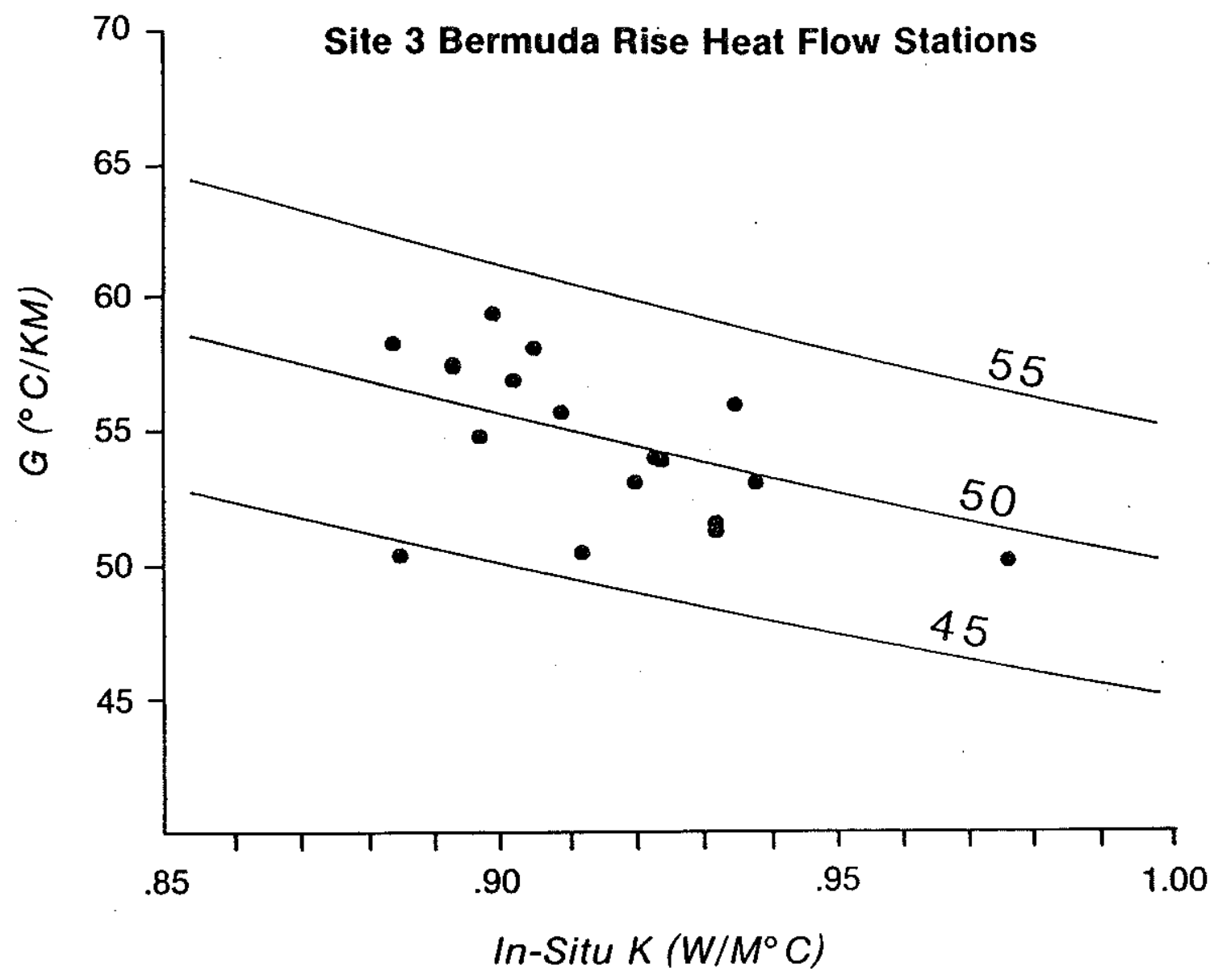

Fig. A2.20. Measured heat flow values as a function of thermal gradient $G$ and in situ thermal conductivity $K$. Contours of constant heat flow for values of 45,50 and $55 \mathrm{~mW} \mathrm{~m}^{-2}$ are also shown. After Detrick et al. (1986). 
uncertainty range of each heat flow value is generally calculated as $\Delta \mathrm{Q}=\mathrm{K} \Delta \mathrm{G}+\mathrm{G} \Delta \mathrm{K}$

where $\Delta \mathrm{G}$ and $\Delta \mathrm{K}$ are the uncertainties in the gradient and conductivity, respectively. These uncertainties are determined at the $95 \%$ confidence leve1 using the t-test parameter. For the data in Figure A2.20, the two terms on the right-hand side of Equation A2.19 are equal which suggests that the fractional uncertainty of the mean in situ conductivity is comparable to that of the gradient determination. The average $\Delta Q$ of the measurements is $\pm 5 \mathrm{~mW} \mathrm{~m}^{-2}$ and is slightly larger than the heat flow variations of the site.

To reduce the statistical uncertainty in the mean conductivity as we11 as the thermal gradient determination, the number of thermistors for the given measurement interval can be increased. With increased resolution of temperatures and sediment thermal properties with depth, the important problem of vertical porewater movement as indicated by nonlinear temperature profiles (Noe1, 1984) may be better understood. To identify the effects of temperature nonlinearity when conductivity $K(z)$ varies with depth $z$, an appropriate heat flow equation to determine the temperature-depth profile $T(z)$ is (Bullard, 1939)

$$
T(z)=T_{0}+Q \int_{z=0}^{D} \frac{d z}{K(z)}
$$

where $T_{0}$ is the surface temperature and $Q$ is heat flow. An outrigger probe design which includes either more point thermistors or an averaging thermistor array would increase the number of conductivity values per penetration and consequently allow for more accurate heat flow measurements. 


\section{A2.6 Summary}

The outrigged thermal probes of the WHOI multipenetration marine geothermal instrument have been adapted to measure thermal conductivity in situ by the continuous-heating line source technique. The transient heating applied to the outrigged probe is essentially a scaled-up version of the needle probe used for core measurements. The main attribute of the outrigger design is the thermal probes of sma11 radial dimension mounted on fins offset azimuthally about the centra1 strength member. Because of the small diameter, simple analytical approximations are attained for predicting probe temperatures at relatively short times ( $<2$ minutes), and accurate equilibrium in situ temperature and thermal conductivity measurements are made in less than 15 minutes of recording time. This short measurement time reduces the risk of temperature perturbations due to probe disturbances.

Instrumental uncertainties due to the heater output and effective heater origin time are small compared to the possible errors in estimating the thermal diffusivity. Although the diffusivity can be estimated with less certainty for sediment of high conductivity, the fractional uncertainty in conductivity due to diffusivity is no greater than $2 \%$ for practically all marine sediments. A biaxial probe design, which has the heater and temperature sensor housed in separate stee1 tubes, is bounded by a minimum and maximum estimate of the effective radius which produces an additional $3 \%$ uncertainty in the conductivity. The tota1 instrumental uncertainty in applying the analytical theory to the single probe and double probe configurations is found to be $3 \%$ and $6 \%$, respective1y. 
Thermal conductivity measured in situ at several hundred marine heat flow stations in the Ligurian Basin and Bermuda Rise has assisted in the field calibration of the continuous-heating method. For ten selected sites, the mean conductivity of in situ and needle-probe measurements show agreement to within $6 \%$ with no systematic differences. The conductivity profiles of associated in situ and core data indicate that the piston coring process frequently does not retrieve the upper meter of surficial sediment.

Lateral variations in conductivity between stations can account for some of the differences found in the field comparison. However, vertical variability can give rise to large errors in the mean conductivity determination by causing a relative undersampling of the sediment section by the discretely spaced thermistors. Using GRAPE data combined with water content and needle-probe conductivity measurements, realistic synthetic conductivity profiles are obtained which indicate the degree of conductivity stratification in the survey region. Using such profiles, possible differences of up to $25 \%$ in mean conductivity for nearby in situ stations or about $10 \%$ from the true mean for individual stations have been found for sediment with large amplitude vertical variations in conductivity.

In sediment of homogeneous conductivity, significant improvements in local heat flow determinations are possible if the in situ thermal conductivity measurement is employed with the pogo-probing technique. Heat flow surveys may be improved by using sediment core studies to calibrate the diffusivity-conductivity relationship and estimate the effect of vertical variability on the mean conductivity determination. 
For regions with small-scale conductivity layering, an outrigger probe design with a high linear density of thermistors may be desired.

\section{A2.7 Acknowledgements}

We thank P. Andrew, M. Dougherty, M. Van Goo1, G. Pelletier, P. Schweitzer, S. Tavares and A. Tricca for providing assistance in various phases of this study. J.P. Rehault gracious1y contributed GRAPE logs and water content measurements for the Ligurian Sea sediment cores. C. Bowin, G. Jones and J. Mienert provided helpful criticisms of the manuscript. This project was stimulated particularly by geotherma1 measurements made in the Western Mediterranean and on the Bermuda Rise with the support of grants from the U. S. Nationa1 Science Foundation (OCE-8025181, -8117886, and -8409170). This is Contribution No. 6300 of the Woods Hole Oceanographic Institution. 
Appendix 3

Equilibrium Temperature Estimation Using the Golden Section Search: Numerical Simulations of Probe Thermal Response 


\section{A3.1 Abstract}

Marine geothermal data reduction using the Golden Section Search optimization routine (cf. Press et a1., 1986) is evaluated in order to ascertain the accuracy of equilibrium temperature estimates. The adjustable variable is the origin time of the probe impact and the criterion is the linearity of the postimpact temperature-reciprocal time $\left(\mathrm{T}-\mathrm{t}^{-1}\right)$ data. $\mathrm{T}-\mathrm{t}^{-1}$ plots, which should ideally reproduce the 1inear asymptotic results of the $F(\alpha, \tau)$ cylindrical decay function, are observed to be systematically nonlinear in a convex-upward sense in both outrigger and violin-bow probe data. In the outrigger probe data, the convexity produces an optimal origin time which precedes the actual impact origin time by up to $60 \mathrm{~s}$. Simple changes in the probe therma1 parameters ( $\alpha$ or $\tau$ ) do not satisfy the magnitude of the convexity. Also, contrary to previous notions, thermal contact resistance at the probe surface will only cause concavity in the $\mathrm{T}-\mathrm{t}^{-1}$ plot.

To address the nonlinearity problem and the time-advance results, one-dimensional numerical experiments are performed which vary the sediment temperature structure adjacent to an outrigger probe. Probe temperature decay is generally only sensitive to thermal properties within a 6 probe radii annulus. An initial thermally "disturbed zone" in an annulus of 2 to 3 probe radii produces results similar to the observed time-advances. Typical optimized results have an accuracy $\sim 1 \mathrm{mK}$, or $\sim 10 \%$ of the net temperature change from the zero-shifted case (usually $10 \mathrm{mK}$ ). In the unlikely event that the thermally disturbed zone is water rather than sediment, the accuracy is reduced to $50 \%$ of the net temperature change. In genera1, The Golden Section 
Search gives improved equilibrium temperature estimates and may be a viable component of automated heat flow data reduction schemes.

\section{A3.2 Introduction}

Formulas derived from the analysis of a cylindrical heat source in an infinite medium are extensively used in heat flow data reduction schemes. The essential problem in the determination of marine geothermal gradients is the infinite-time extrapolation of the temperature decay of a probe penetrated into seafloor sediment. The theoretical function $F(\alpha, \tau)$ (Bullard, 1954; Jaeger, 1956; see formulae below) characterizes this observed decay to high accuracy, predicting probe temperatures $T$ to decrease rapidly at early times after penetration, and at large times $(\tau>10)$, to decrease linearly with the reciprocal of time $t$. For the WHOI outrigger probe (see Appendix 2), the $t^{-1}$ asymptote is an adequate expression for $F(\alpha, \tau)$.

With heat flow instrumentation capable of obtaining time-temperature records of high resolution $(0.5 \mathrm{mK})$, the main obstacle to automating the reduction of noise-free data is the selection of the origin time of the probe penetration or impact. Optimization of the effective origin time, using the Golden Section Search method, is achieved by maximization of the linear correlation coefficient of the $T$ vs. $t^{-1}$ relation. The results show that significant and consistent shifting of the origin times are necessary to obtain the most linear $t^{-1}$ decays. The sense of time-shifting is a time-advance i.e., the origin time of the impact heating event appears to occur prior to the actual penetration using the $F(\alpha, \tau)$ mode1. Herein, the feasibility of using the GSS method on 
the impact-heating temperature decay is discussed in the light of the Ligurian Sea heat $f$ low results and numerical simulations of radial heat conduction.

\section{A3.3 Cylindrical decay function theory}

Thermal decay of the probe frictional heating is simulated by heat conduction theory for a medium with a possible contact resistance to an infinitely long, perfectly conducting cylinder of radius $r_{0}$, at an initial temperature $T_{0}$ above that of the initially uniform medium temperature $T_{1}$. The solution for the probe temperature is

$$
\mathrm{T}=\mathrm{T}_{1}+\mathrm{T}_{0} F(\mathrm{~h}, \alpha, \tau)
$$

\section{(A3.1)}

where $F(h, \alpha, \tau)$ is the decay function given by Jaeger $(1956$, eq. 6,7$)$

as

$$
F(h, \alpha, \tau)=\frac{4 \alpha}{\pi^{2}} \int_{0}^{\infty} \frac{\exp \left(-\tau x^{2}\right) d x}{x \Delta(x)}
$$

where

$$
\Delta(\mathrm{x})=\left[\mathrm{xJ},(\mathrm{x})-\left(\alpha-h \mathrm{x}^{2}\right) \mathrm{J}_{1}(\mathrm{x})\right]^{2}+\left[\mathrm{xY}_{0}(\mathrm{x})-\left(\alpha-h \mathrm{x}^{2}\right) \mathrm{Y}_{1}(\mathrm{x})\right]^{2}
$$

and $J_{N}(X)$ and $Y_{N}(X)$ are the Bessel functions of order $n$ of the first and second kinds, respectively. Time is nondimensionalized with the parameter

$$
\tau=\kappa \mathrm{t} / \mathrm{r}_{0}^{2}
$$

and $\alpha$ is twice the heat capacity of the sediment divided by that of the probe

$$
\alpha=2 \pi \rho C r_{0}^{2} / S
$$

where $\kappa, \rho, C$, and $k$ are the medium thermal diffusivity, density, 
heat capacity, and thermal conductivity, respectively, and $S$ is the probe heat capacity per unit length of the cylinder. The nondimensional thermal contact resistance is

$$
\mathrm{h}=\mathrm{K} / \mathrm{r}_{0} \mathrm{H}
$$

where $H$ is the surface conductance or coefficient of surface heat transfer which is defined as the skin conductivity divided by the skin 1ayer thickness (Carslaw and Jaeger, 1959, p. 19).

The above result (Equation $\mathrm{A} 3.2$ ) is obtained by the Laplace transformation method as in Carslaw and Jaeger (1959, Ch. 13). For the case of perfect thermal contact $h=0$, the solution simply reduces to the $F(\alpha, \tau)$ equation of Bullard (1954). Equation (A3.2) is solved numerically, but for large times, convenient approximations can be made which simplify the calculation of $T_{1}$. For large $\tau$, the Blackwe11 (1954) approximation given by Jaeger (1956) is

$$
\begin{aligned}
F(h, \alpha, \tau)= & (2 \alpha \tau)^{-1} \\
& +\left(4 \alpha^{2} \tau^{2}\right)^{-1}[(4 h-\alpha)-(\alpha-2)\{\ln (4 \tau / C)-1\}]
\end{aligned}
$$

and is accurate to within $1 \%$ of the exact value for $\tau>4$. The asymptotic expression is

$$
F(h, \alpha, \tau)=(2 \alpha \tau)^{-1}=S(4 \pi K t)^{-1}
$$

To find the equilibrium temperature $T_{1}$, the data may be fit to the equation

$$
\mathrm{T}=\mathrm{a}+\mathrm{bt}-1
$$

using standard least-squares techniques of linear regression. The $y$-intercept ' $a$ ' represents $T_{1}$ and the slope ' $b$ ' equals $\mathrm{T}_{\mathrm{o}} \mathrm{S}(4 \pi \mathrm{K})^{-1}$. Data plotted as $\mathrm{T}-\mathrm{t}^{-1}$ pairs should theoretically lie close to a straight line after about $10 \tau$. Using an ideal data 
set derived with no contact resistance, the bias in implementing the asymptotic expression (Equation A3.8) to determine $T_{1}$ is $5 \cdot 10^{-4} \mathrm{~T}_{0}$ too large or on the order of $<1 \mathrm{mK}$ for most outrigger data.

The sediment thermal conductivity may be found using the same $F(\alpha$, $\tau)$ theory. This type of conductivity measurement has received widespread application with the advent of the pulse-heating method introduced by Lister (1979). Heat is emitted along the probe length at a known rate for a pulse duration of $0.2-1 \tau$, so that a quantity of heat per unit length $Q$ is produced in the probe. According to the model, the initial temperature rise $\mathrm{T}_{0}$ is equal to $\mathrm{Q} / \mathrm{S}$. Thus, substituting $Q / S$ into Equation $\mathrm{A} 3.1$ and assuming the asymptotic expression of $F(\alpha, \tau)$ (Equation A3.7), the estimate for the conductivity is

$$
\mathrm{K}=\mathrm{Q} / 4 \pi \mathrm{Tt}
$$

where $\mathrm{T}$ is the residual temperature of the pulse-heating event corrected for the frictional-heating effects of the penetration and $t$ is the time since the center of the heat pulse. Therefore, the pulse-heating method essentially consists of noting at least one temperature at a known time after the pulse, performing a correction to achieve an asymptotic-equivalent temperature (see Lister, 1979; Hyndman et a1., 1979; Villinger and Davis, 1987), and calculating $\mathrm{K}$ with Equation $\mathrm{A3.9.}$ Equilibrium temperature measurements are simple for the sma11 radius WHOI outrigger probe. The probe has a $1.6 \mathrm{~mm}$ radius and consequently has a characteristic thermal time constant, given by $r_{0}^{2} / \kappa$, which is about $6-10 \mathrm{~s}$ for most oceanic sediment. Due to the sma11 time 
constant, asymptotic times are achieved in a little over a minute after the probe entry. One must only know the origin time of the penetration heating which is generally assumed to be the point at which the probe thermistor senses its highest temperature.

In practice, there are several problems with the origin time assumption. First, the penetration is not instantaneous because the probe enters the sediment at a finite speed. The mean entry speed is usually about $2 \mathrm{~m} / \mathrm{s}$, but this rate is undoubtedly affected by oscillation generated by cable elasticity and surface waves/ship interaction. Second, there is uncertainty in the origin time due a data acquisition rate limited to $2 \mathrm{~s}$ per variable. Thus, the accuracy of the assigned impact time defined as the maximum probe temperature is at best 2-6 $s$ due to the presence of household variables in the data sequence (record labe1, calibration resistors, etc.). Additional information on the penetration may be obtained from acoustic telemetered data. Third, contrary to the mode1, the probe is not isothermal at all times. The actual probe has finite conductivity, such that nonideal probe structure exists which is reflected in the time delay at which the thermistor at the center of the probe senses perturbations at the probe surface. The time delay of the pulse-heating method is the inverse situation in which the heat must spread from the center of the probe to the outer surface (see Hyndman et a1., 1979). This time delay for the WHOI outrigger probe is $1 \mathrm{ike} 1 \mathrm{y}$ to be no greater than $1 \tau$.

Additiona1 complications may arise by assuming that the sediment is of uniform temperature. Since the frictional heating occurs at the probe surface, a boundary layer in the sediment maybe formed where drag 
due to shear stress was experienced during penetration. This

hypothetical 'disturbed zone' would occur only in sediment that has been in the vicinity of the rigid outrigged probe and fin assemblies and would be expected to be asymmetric due to the fin position. The boundary layer might be expected to be greater in thickness for the uppermost probe section where the stress leading to sediment deformation has operated for a longer period of time. Depending on the kinematics of probe entry, significant sediment deformation may occur during penetration behind the leading edge of the central barrel and fins.

Effects indicated above may manifest themselves by simple nonlinearity (convexity or concavity) in the $T-t^{-1}$ plots. Careful observations of the Ligurian Sea impact decay data indicate that nonlinear $\mathrm{T}-\mathrm{t}^{-1}$ plots are quite common and that in almost a11 instances the curvature is convex upward. Both the single and double outrigger probe (see Appendix 2) are equa1ly affected. A review of the marine heat flow literature shows that the convex upward impact-heating decay plots are not limited to the outrigger probe but occur frequently with the the larger radius violin-bow (Bullard probe) instrument (Hutchison, 1983; Davis et a1., 1984). In such instances, the best estimate of the equilibrium temperature has been made by using a least-squares polynomial fit or by extrapolating the best-fitting line determined by the latest points of the $T-\mathrm{t}^{-1}$ data.

Although a theoretical proof has not been formulated, it has been demonstrated that simple shifts in the effective origin time can remove the convexity or concavity of the pulse-heating method temperature decay (Hyndman et a1., 1979). Recently, Villinger and Davis (1987) and Fang 
et a1. (1987) have implemented minimization routines for finding optimal origin times, thus setting the stage for automated heat flow data reduction.

\section{A3.4 Golden Section Search method}

An optimization technique (Golden Section Search) is used to determine an effective origin time which produces the maximum linear correlation coefficient to the impact-heating decay data. This time-shifting of temperature data may provide some physical insight into the possible causes of the nonlinear decays as well as more accurate equilibrium temperature estimates. The use of the Golden Section Search (GSS) in heat flow data reduction has previously been suggested by Fang (1985).

We wish to maximize a function of one variable, ie., $R\left(\Delta t_{s}\right)$, where $R$ is the linear correlation coefficient of the $\mathrm{N}$ data points $\left(x_{1}, y_{1}\right)$ defined by $x_{i}=\left(t_{1}+\Delta t_{s}\right)^{-1}$ and $y_{1}=T_{1}$ (Equation A3.8). The GSS presents itself as an excellent algorithm for optimization problems in which the maximum can be bracketed in the first place. The GSS for one-dimensional maximization is essentially the analog of the bisection method for root-finding in that the process of iterative 'bracketing' without calculation of a derivative is used to find the desired result (Press et a1., 1986). The requirements of the GSS method are that the maximum of the function $R\left(\Delta t_{s}\right)$ must lie within the range $\Delta t_{s m i n}<\Delta t_{s}<\Delta t_{s m a x}$ and that $R\left(\Delta t_{s}\right)$ must be monotonically increasing from $\Delta t_{s}=\Delta t_{s m i n}$ to the maximum position and then monotonically decreasing to $\Delta \mathrm{t}_{\mathrm{s}}=$ 
$\Delta t_{\text {smax }}(H i 11,1979)$. Otherwise, the user may obtain only a local maximum. If the search converges at one of the original endpoints, the search must be revived with a new bracketing interval.

After the initial bracketing interval for the time shifts is selected, the function $R\left(\Delta t_{s}\right)$ is evaluated at both endpoints according to standard statistica1 formulae (e.g., Bevington, 1969). The endpoint with a larger $R\left(\Delta t_{s}\right)$ is retained and the revised endpoint is determined by decreasing the bracketing interval to 0.618 times the preceding interval ( 0.618 is the Golden Section of the ancient Phythagoreans, coined "golden" because of the aesthetic qualities of the ratio). In other words, if $R\left(\Delta t_{\operatorname{smin}}\right)<R\left(\Delta t_{s \max }\right)$ then $\Delta t_{s m 1 n}$ must be changed to

$$
\Delta t_{\sin }{ }^{\prime}=\Delta t_{\sin }+0.382\left(\Delta t_{s m a x}-\Delta t_{\sin }\right)
$$

Conversely, if $R\left(\Delta t_{\sin }\right)>R\left(\Delta t_{\operatorname{smax}}\right)$ then a new value for

$\Delta t_{\mathrm{smax}}$ is required

$$
\Delta t_{\text {max }}{ }^{\prime}=\Delta t_{\text {smin }}+0.618\left(\Delta t_{\operatorname{smax}}-\Delta_{s t m i n}\right)
$$

The primes are dropped and the procedure is repeated until the distance between $\Delta t_{s m i n}$ and $\Delta t_{s m a x}$ is sufficiently sma11 according to predetermined criterion. Starting with an $80 \mathrm{~s}$ window, the optimum time shift is known to within $1 \mathrm{~s}$ after 10 iterations.

\section{A3.5 Heat flow applications}

Examples of $\mathrm{T}-\mathrm{t}^{-1}$ plots for two heat flow stations are given in Figure A3.1, illustrating the improvement in the linear $\mathrm{fit}$ achieved with time-shifting. For a11 8 decay plots shown, the sense of the nonlinearity is convex upward and the net shifting results in a 

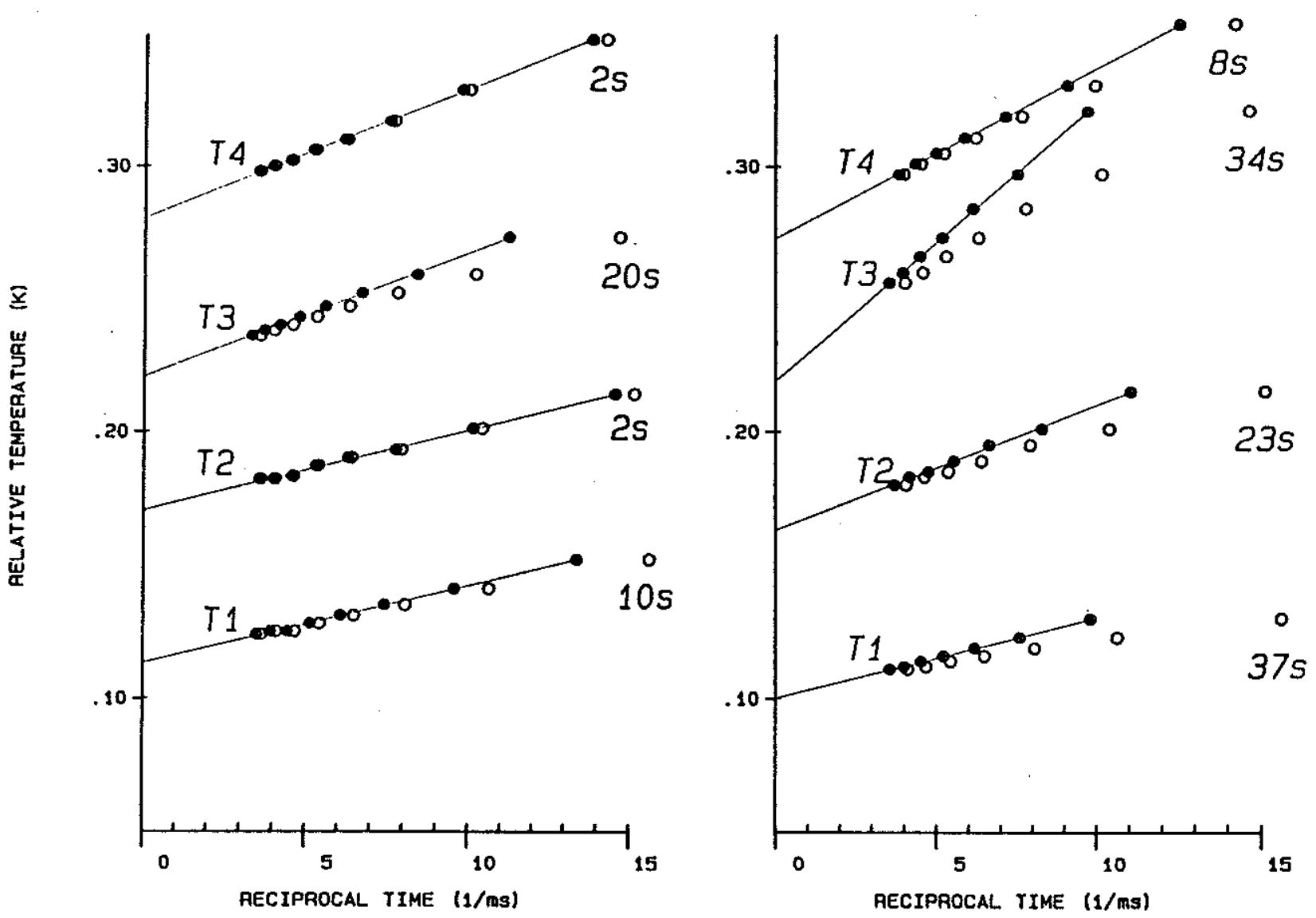

Fig. A3.1. P1ot of temperature vs. inverse time for two penetrations of the same pogo profile (See Table A4.3). Open circles represent the zero shifted data, solid circles and regression line are the optimized results. The value of the time advance is shown to the right. 
time-advance, ie., the initial conditions assumed for the $F(\alpha, \tau)$ solution seem to have occurred at a time prior to the actual impact. Station L82S8.1 has 1inear decays and small time shifts. On the other hand, a station in the same pogo profile, L82S8.6, has obvious nonlinear decays which consequently require larger time-advances. Depending on the particular thermal decay, the changes in the intercept values without time-shifting are less than $1 \mathrm{mK}$ for L82S8.1 but range from 1 to $8 \mathrm{mK}$ for L82S8.6. Note that the $\mathrm{T}_{1}$ estimate (given by the intercept value) is decreased for al1 GSS results in which there is a time-advance. For a given time shift, thermal decay data with a large slope will have a correspondingly large change in the $\mathrm{T}_{1}$ estimate. In Figure A3.2, we have examined whether there might be, in turn, a correlation between the time shift and slope. The data from the 24 stations indicate the following: 1) Nearly all thermistors have time-advances (negative time delays, $\Delta t_{s}>0$ ) with a range of 0 to $60 \mathrm{~s}$ bracketed by the standard deviation of the data. 2) There is a general tendency for the time-advance to increase with the amount of frictional heating (given by the slope value, b). In fact, 13 of 14 of the decays with b > 10 have a time-advance over $30 \mathrm{s.} \mathrm{3)} \mathrm{No} \mathrm{clear} \mathrm{relationship} \mathrm{exists}$ between the time-advance and normal instrument tilts in the range of $0^{\circ}$ to $20^{\circ}$.

To investigate the possible causes of the time-advance, independent variables such as probe position, subseafloor depth of penetration, sediment type, and probe entry speed have been investigated. The GSS results of a suite of five stations are given Table A3.1. The data set was chosen because they compose a sequence of pogo stations made in a 
POGO PROFILES L82SB. L82S9. \& L82S13

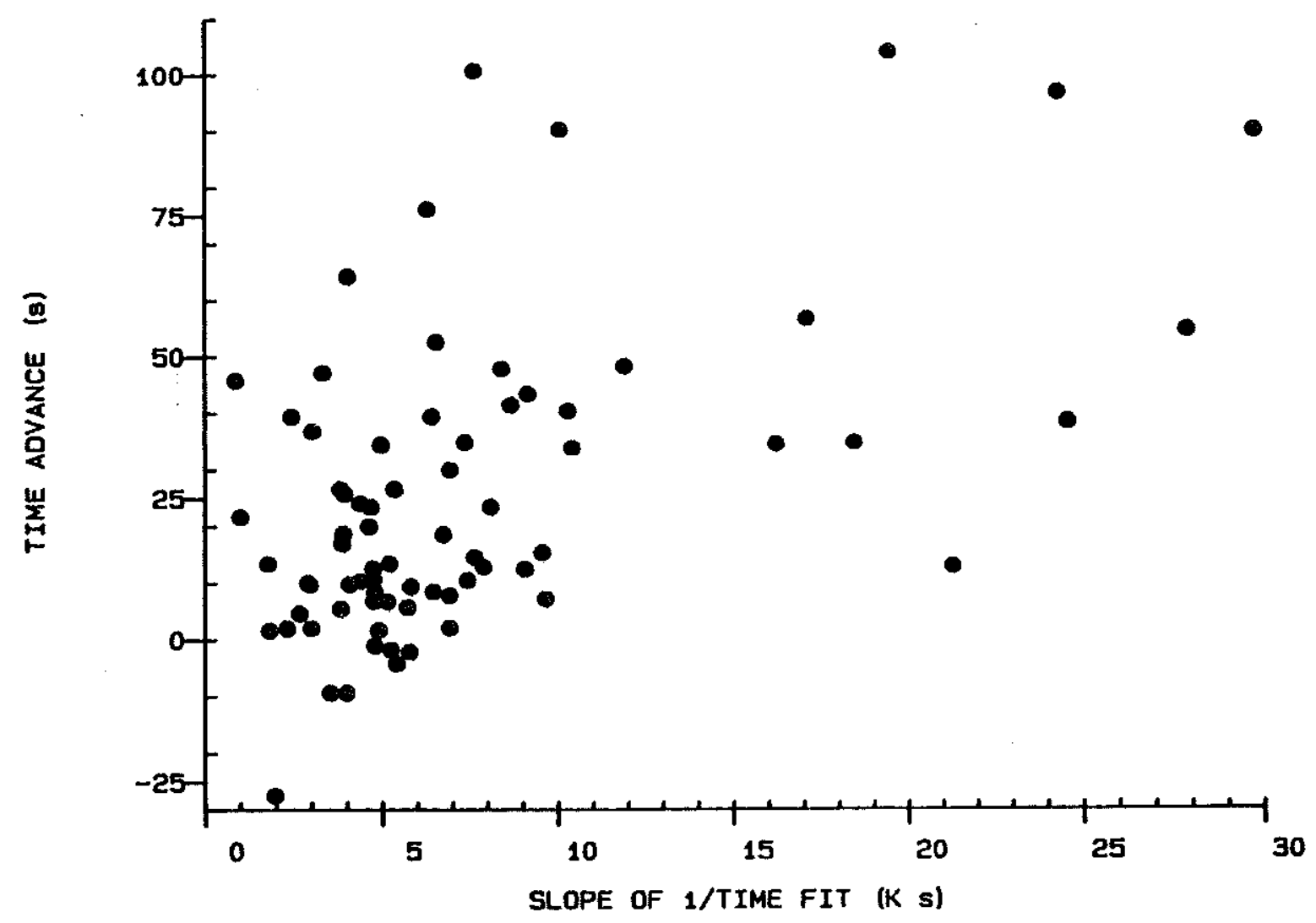

Fig. A3.2. Time advance and resultant slope of $T-t^{-1}$ fit using the GSS method for all temperature data of three pogo profiles. Three thermistors which had a slope greater than $40 \mathrm{~K}$ s are not shown. 
region of uniform sediment as suggested by $3.5 \mathrm{kHz}$ and piston core data. All had full penetration, small tilts $\left(<10^{\circ}\right)$, and mean entry speeds of about $2 \mathrm{~m} / \mathrm{s}$. It is apparent that the lowermost outrigger (T4) has the smallest time shift, which is consistent with the upper probes coming to rest in sediment that is only slightly disturbed by the passage of the lower section of the probe.

An example of the influence of the impact velocity on the frictional. heating is clearly given by station L82S8.15. With an entry speed of $7-9 \mathrm{~m} / \mathrm{s}$, the lowermost probe had a $\mathrm{T}-\mathrm{t}^{-1}$ slope $\mathrm{b}$ of $55 \mathrm{~K} \mathrm{~s}$, a $40 \mathrm{~s}$ time-advance, and a consequent infinite time temperature that was over $50 \mathrm{mK}$ lower using the GSS. For comparison, other stations in the profile are those of Table A3.1. The impact speed of L82S8.15 was made high (near1y free fal1) because the hard bottom prevented successful penetrations in the three previous attempts in the pogo profile. Generally, rigid sediments of the turbiditic abyssal plain have larger time-advances than hemipelagic sediment, but measurements in the rigid sediment are also associated with higher-than-normal entry velocities and partial penetrations.

Two other factors that could explain the variability in the time-shifting are 1) the relative directions between the outrigger fin azimuths and the tilt bearing (this could account for the randomness), and 2) the horizontal drift of the instrument. Horizontal movement, caused by the drift of the ship or by swinging of the instrument wire to a vertical alignment, is suspected because of the nature of the first station of each of the three pogo profiles presented in Figure A3.2. The $\Delta t_{s}$ for these stations only range from -2 to $20 \mathrm{~s}$ with an 
Table A3.1

GSS Results for Individua1 Outrigger Probes*

\begin{tabular}{lccccc}
$\begin{array}{c}\text { Probe } \\
\text { Depth }\end{array}$ & $\begin{array}{c}\text { Time Advance** } \\
(\mathrm{m})\end{array}$ & $\begin{array}{c}\text { Slope** } \\
(\mathrm{K} \mathrm{s})\end{array}$ & $\begin{array}{c}\text { Temperature** } \\
\text { Shift }(\mathrm{mK})\end{array}$ & $\begin{array}{c}\text { Temperature Error } \\
(\mathrm{mK})\end{array}$ \\
\hline $\mathrm{T} 1$ & 1.22 & $28 \pm 16$ & $3.7 \pm 2.1$ & $-3.2 \pm 2.3$ & $1.6 \pm 1.2$ \\
$\mathrm{~T} 2$ & 1.85 & $24 \pm 15$ & $5.0 \pm 2.4$ & $-3.4 \pm 2.5$ & $1.9 \pm 0.7$ \\
$\mathrm{~T} 3$ & 2.50 & $34 \pm 26$ & $6.6 \pm 2.3$ & $-5.2 \pm 4.1$ & $1.4 \pm 0.6$ \\
$\mathrm{~T} 4$ & 3.13 & $7 \pm 4$ & $6.0 \pm 1.3$ & $-1.4 \pm 1.3$ & $1.2 \pm 0.2$ \\
\hline
\end{tabular}

* Data from pogo station L82S8, penetrations 1, 3, 4, 5, and 6 . ** Standard deviation shown 
average of $7 \mathrm{~s}$, whereas the average of the subsequent stations is $34 \mathrm{~s}$. Exceptionally smal1 wire angles are possible on the first station because the instrument is simply lowered from the ship to the bottom so that any appreciable horizontal displacement would be unlikely.

Application of the GSS method is only valid if the $R\left(\Delta t_{s}\right)$ function is unimodal. As illustrated in Figure A3.3, this is precisely the case, with the shape of the observed curves being similar to the theoretical result. The asymmetry produced by the more gentle curvature for the positive limb is an outcome of the time-shifting operating on an inverse function. In other words, larger time-advances can cause the maximum $t^{-1}$ value to increase rapidly and essentially affect the regression as an 'outlier' point would. Noisy data can create problems for the GSS method by creating local minima in $R\left(\Delta t_{s}\right)$ or by flattening the peak of the global minimum. Therefore, appropriate precautions should be taken in application of the algorithm.

Reasonable variations in the dimensionless parameters of $\alpha$ and $\tau$ can only account for $\pm 0.5 \tau$ in the time shift. This falls extremely short of the observed amplitude of time-shifting illustrated in Figure A3.2 $(0<\Delta<5 \tau)$. Moreover, one would expect that nonideal probe structure would have a time delay effect $\left(\Delta t_{s}<0\right)$ on the temperature decay by causing the probe to retain heat longer than according to the physical model.

Another factor is the inclusion of a thermal contact resistance (Equation A3.5). We find that a contact resistance will only produce concavity and a time delay instead of the observed convexity and a time-advance. This result directly conflicts with that surmised by 

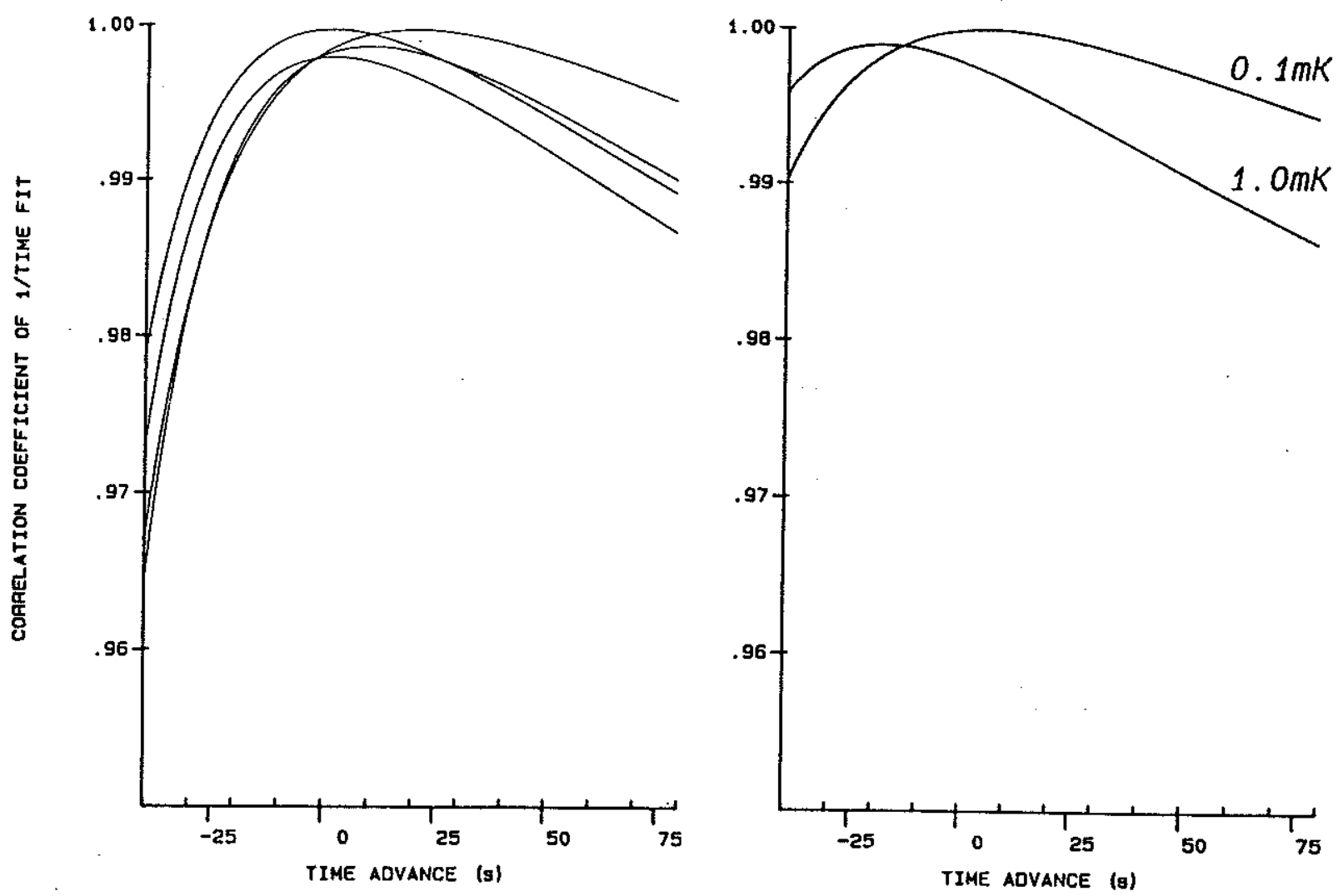

Fig. A3.3. Plot of linear correlation coefficient $R\left(\Delta t_{*}\right)$ against this time shift $\Delta t_{s}$. Time shifting is performed at $1 \mathrm{~s}$ intervals and no smoothing is performed. Observed data of one four-thermistor penetration (on left) have single maxima similar to the theoretical data (on right). The low resolution curve is obtained by truncating the least significant digit of the high resolution curve data set. 
Hutchison (1983) and Villinger and Davis (1987). They observed convexity in the impact heat decays in almost a11 of the violin-bow heat flow measurements (Hyndman et a1., 1979) and attribute it to contact resistance phenomena. In Hutchison's case, the frictiona1-heating curvature was only fit by eye and the convexity was incorrectly associated with the time delay required by the pulse-heating technique with the violin-bow instrument (Lister, 1979; Hyndman et a1., 1979). In an effort to automate the data reduction, Villinger and Davis (1987) present impact decay data with time-advances. They have minimized the regression errors but do not attempt to explain plausible physical mechanisms for the time-shifting or the apparent discrepancy between the impact-heating data (net time-advances) and pulse-heating fits (net time delays).

Since systematic convexity does not appear to be limited to the outrigger probe, one would not expect it to be instrumental in nature. Nevertheless, if the fins were to influence the probes as an 'end effect' (B1ackwe11, 1954), they would have to act as a heat sink to cause the convexity. The general rule of thumb to limit the effect of axia1 heat conduction is that the probe design should have a $20: 1$ length to diameter ratio; the outrigger probe has a $16: 1$ ratio and so generally satisfies this criterion. A1so, the fins should experience frictional heating on the same order of magnitude as the probe sensor, which would help maintain a nu11 axial temperature gradient. However, since the fins have a smaller surface/mass ration $(1 / 2)$ than the probes, a small axial gradient undoubtedly exists. 
Evidence that the convexity is produced by excess heat outside the probe comes from data at station L82S8.2. This station had the continuous-heating operating when the instrument penetrated. The heater remained on for about one minute thus elevating the temperatures outside the probe. That the time-advance mechanism is due to initial heat outside the probe is indicated by the GSS results for this station. Assuming the penetration origin time was the heat turn-off time, all four thermistors had $\Delta t_{s}$ of 70 to $80 \mathrm{~s}$. Although the excessive heating may bias the individual equilibrium temperatures determined by the GSS, the relative temperatures and thermal gradient compare we 11 with nearby stations.

\section{A3.6 Numerical mode1}

The purpose in modeling the probe impact-heating decay is 1) to elucidate the physical mechanisms responsible for the convexity of the $\mathrm{T}-\mathrm{t}^{-1}$ plots, and 2) to validate the GSS method results as being an improved estimate of the equilibrium temperature. The discussion is limited to the parameter range delineated by Figure A3.2.

The above observations indicate that the time-advance depends heavily on the dynamics of the probe entry. The inability to explain the convexity using the analytical formulation suggests that the initial conditions and/or the medium properties are inadequately represented. Using finite differences, we have modeled the initial temperature anoma1y to extend to a broader region in the sediments around the probe. In addition to perturbation of the temperature structure beyond the probe, the presence of a water layer is also examined. Analytical 
solutions to these problems can probably be contrived using formulae given by Carslaw and Jaeger (1959), but the flexibility desired in the initial conditions inhibit their utility.

Explicit finite difference formulation. The governing equation for transient, one-dimensional heat conduction in cylindrical coordinates is represented in its conservative form as

$$
\rho C \frac{\partial T}{\partial t}=\frac{1}{r} \frac{\partial}{\partial r}(r K) \frac{\partial T}{\partial r}
$$

where $\rho$ is density, $C$ is specific heat capacity, and $K$ is thermal conductivity of the medium and $\mathrm{T}, \mathrm{r}$, and $\mathrm{t}$ are the temperature, space, and time variables, respectively. In the case of thermal decay in regions of uniform thermal properties, Equation (A3.12) may be written as

$$
\rho C \frac{\partial T}{\partial t}=\frac{K}{r} \frac{\partial T}{\partial r}+K \frac{\partial^{2} T}{\partial r^{2}}
$$

For the purposes of the cylindrical heat decay problem, it is useful to cast the variables as the following dimensionless quantities:

$$
\begin{array}{lc}
\rho=\rho_{0} \rho^{\prime} & C=\mathrm{C}_{0} \mathrm{C}^{\prime} \\
\mathrm{K}=\mathrm{K}_{0} \mathrm{~K}^{\prime} & \mathrm{r}=\mathrm{r}_{0} \mathrm{~K}^{\prime} \\
\mathrm{T}=\mathrm{T}_{0} \mathrm{~T}^{\prime} & \mathrm{t}=\mathrm{r}_{0}^{2} \mathrm{~K}_{0}^{-1} \mathrm{t}^{\prime} \quad\left(\mathrm{t}^{\prime}=\tau\right) \\
\mathrm{K}_{0}=\mathrm{K}_{0} \rho_{0}^{-1} \mathrm{C}_{0}^{-1} \quad \text { (therma1 diffusivity) }
\end{array}
$$

where $\rho_{0}, C_{0}$, and $K_{0}$ are reference values for the medium which is internally bounded by the cylinder of radius $r_{0}$ and initial temperature $\mathrm{T}_{0}$ above that of the medium. Substituting the nondimensional expressions (Equations A3.14) into Equation A3.12 and dropping the primes gives a nondimensional form of the heat equation which is identical to the original formula. Unless otherwise noted, the 
Table A3.2

Reference states of physical parameters used in numerical solutions

$$
\text { probe radius, } r_{0}=1.5 \cdot 10^{-3} \mathrm{~m}
$$

initial temperature of probe above medium, $\mathrm{T}_{0}=1 \mathrm{~K}$ density heat capacity of medium, $p_{0} \mathrm{C}_{0}=3 \cdot 10^{6} \mathrm{Jm}^{-3} \mathrm{~K}^{-1}$

thermal conductivity of medium, $\mathrm{K}_{0}=1.0 \mathrm{Wm}^{-1} \mathrm{~K}^{-1}$ 
values of $T, \rho, C$, and $K$ will be given in dimensionless quantities using the reference values of Table A3.2.

An explicit finite difference approximation to Equation A3.12 is made to examine the cylindrical decay problem. It was found that preserving the conservative form of the heat equation is essential to the analysis of heterogeneous media. The temperature and space variables are $T_{i, n}$ and $r_{1}$, respectively, where $i$ is the spatial node and $\mathrm{n}$ is the time level. The difference approximation of the space derivative is centered on the $i$ node of a grid of dimension $M$ and spacing $\Delta r$ (Figure 3.4). Forward differences requires that the time derivative expression is relative to time level $\mathrm{n}$ using a time step $\Delta$ t. Upon making the appropriate substitutions, the finite difference equation employed is

$\mathrm{T}_{1, \mathrm{n}+1}=$ $\beta\left[\gamma_{1} T_{i+1, n}-\left(\gamma_{1}+\gamma_{2}\right) T_{1, n}+\gamma_{2} T_{1-1, n}\right]+T_{1, n}$ where $\quad \beta=\Delta t\left(4 \rho_{1} C_{1} r_{i} \Delta r^{2}\right)^{-1}$

$$
\begin{aligned}
& \gamma_{1}=\left(r_{i}+r_{i+1}\right)\left(K_{1}+K_{i+1}\right) \\
& \gamma_{2}=\left(r_{i-1}+r_{i}\right)\left(K_{i-1}+K_{i}\right)
\end{aligned}
$$

$\rho_{1}, C_{1}$ and $K_{i}$ are density, heat capacity and conductivity, respectively, and are assigned as the average values about node $i$ for the interval $\left[r_{1}-\Delta r / 2, r_{1}+\Delta r / 2\right]$.

At the axis, the expression for uniform media (Equation A3.13) can be applied with a no heat flow boundary condition, $\partial \mathrm{T} / \partial \mathrm{r}=0$. This is satisfied by forcing symmetry about the axis, $T_{i+1, n}=T_{1-1, n}$ at node $i=1(r=0)$. However, at $r=0$ the first term of the RHS of 

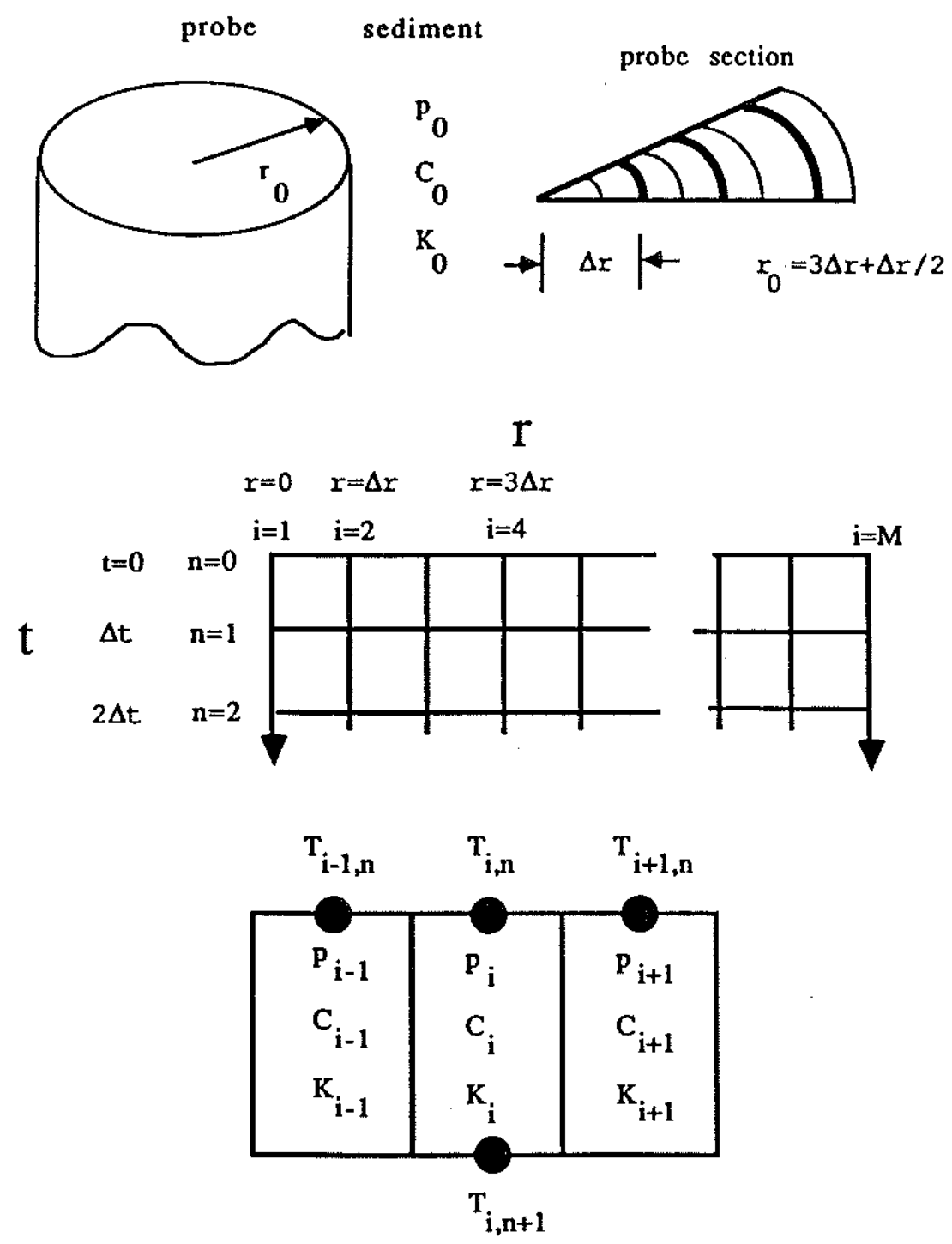

Fig. A3.4. Outline of the numerical setup of the probe model: In upper left, diagram of probe with reference values of physical properties. Upper right, spatial segmentation of $1-D$ section of probe used in the finite difference model, the effective radius is given as $r_{0}$. Center, characterization of solution in $r-t$ space where intersections are nodal points. On bottom, assignment of physical properties and temperatures in the difference equations. 
Equation A3.2 is singular. Applying L'Hopital's rule at $r=0$, the substitution

$$
\lim _{r \rightarrow 0}\left(K r^{-1} \partial T / \partial r\right)=K \underline{\partial}^{2} \frac{T}{\partial r^{2}}
$$

(Arpaci, 1966) is made so that the finite difference equation at the boundary $i=1$ becomes

$$
T_{1, n+1}=4 \Delta t K_{i}\left(T_{i+1, n}-T_{i, n}\right)\left(p_{i} C_{i} \Delta r^{2}\right)^{-1}+T_{i, n}
$$

The outer boundary is prescribed to be constant temperature so that for the case of $M$ nodes, $T_{M, n}=0$.

Although the finite difference calculations should converge to the exact solution as $\Delta r$ and $\Delta t$ approach zero, the solutions given above are sensitive to the nodal spacing and time step choices. For the one-dimensional transient situation, the choices of $\Delta t$ and $\Delta r$ are dependent on the modulus of stability

$$
\mathrm{K}_{1} \Delta \mathrm{t}\left(\rho_{1} \mathrm{C}_{1} \Delta \mathrm{r}^{2}\right)^{-1}<0.5
$$

(Carslaw and Jaeger, 1959, p. 471). Accordingly, since $\Delta t$ and $\Delta r$ are constant, the modulus is calculated using the maximum value of $\mathrm{K}_{1} / \mathrm{p}_{1} \mathrm{C}_{1}$ in the grid matrix. If the modulus is not sufficiently smal1, as defined above, then the errors due to the approximation will become larger as the solution progresses with each time step.

Simulation of analytical solutions. The numerical model (FATDIF) is compared to known analytical solutions. Three cases are considered (A1, A2, and A3 mode1s), a11 of which concern a medium of zero initia1 temperature bounded internally by a cylinder of elevated temperature $\mathrm{T}=$ 1. The $A 1$ model is the uniform medium case $(\rho C=1$ and $K=1$ for $r=0, \infty)$ and has the solution at $\mathrm{r}=0$ given by Carslaw and Jaeger (1959, p. 260)

$$
T=1-\exp (-1 /(4 \tau)
$$


Because the model does not have a high conductivity probe, the temperature solution of Equation A3.18 is significantly higher than $F(\alpha=2, \tau)$ at $\tau=1(>30 \%)$, but at $\tau=16$ the two analytical models are within $2 \%$ of each other. This shows the insensitivity of the large time temperatures of the cylindrical decay models to the details of the probe structure.

With the mode1 Al, FATDIF was run with different grid spacings to test the convergence of the solution. Excellent agreement $(<1 \%$ at $\tau=4$ ) was found for $\Delta r=r_{0} / 3$ and $\Delta t=0.005 \tau$ (modulus of 0.25). However, the probe radius is effectively a half grid spacing beyond the outermost node of initial temperature anomaly, ie., the mode1 radius must be redefined as $r_{0}=3 \Delta r+\Delta r / 2$ (Figure A3.4). A denser grid spacing of $\Delta r=r_{0} / 12$ gave results within $0.01 \%$ at $\tau=$ 4.

The $F(\alpha, \tau)$ function was then modeled using a high conductivity cylinder designated as mode1s A2 $(K=4)$ and $A 3(K=16)$. Modeling nonuniform media has its pitfalls since heat flow may not necessarily be conserved across boundaries if poorly conceived finite difference schemes are used. We find that implementing the conservative form of the heat equation A3.1 minimizes the problem.

While these models fall short of the assumption of a perfectly conducting probe as in the analytical derivation, they are sufficient in representing the $F(\alpha, \tau)$ solutions. Mode1 A2 is appropriate for a composite probe of stee1 and oil. With the effective radius determined as $\Delta \mathrm{r} / 2$ beyond the outermost node of the probe, the solution at $\tau=$ 4 for $\Delta r=r_{0} / 3$ is only $1 \%$ above the exact solution. Using the same 
numerical setup, the higher conductivity mode1 A3 has a solution $2 \%$ lower. On the other hand, halving the grid spacing increases the numerical accuracy of the solution. Accordingly, the numerical solution is guaranteed to converge to the $F(\alpha, \tau)$ results, at the expense of of additional computer time, as $\Delta \mathrm{r}$ goes to zero and the $\mathrm{K}$ of the probe becomes larger. For $\tau>10$, where the pertinent data of the outrigger probe lies, the differences between the analytical and numerical solutions are insignificant.

The A2 probe mode1 successfully reproduces the GSS time-advance results of the analytical solution. As illustrated in Figure A3.3 the solutions are unimodal, but the maximum correlation is shown to be dependent on the resolution of the temperatures. Best results are obtained when data has a resolution of $10^{-4} \mathrm{~T}_{0}$, or $0.5 \mathrm{mK}$ for most outrigger data. Thus, for low levels of impact heating or with noisy data, the GSS method may give spurious results. Note that the theoretical data of high resolution has a $0.5 \tau(\sim 4 \mathrm{~s})$ time-advance due to the convexity of the exact solution in $\mathrm{T}_{-} \mathrm{t}^{-1}$ space.

Physical models of the time advance. For the temperature decays to behave as if the penetration occurred tens of seconds before actual (Figure A3.2), the initial temperature perturbation may extend we11 beyond the probe surface. The temperature structure of mode1 A2 at selected times, shown in Figure A3.5, suggests specific forms of the initial temperature structure that could account for the prescribed time-advance.

We have developed this argument by modeling the region near the probe as a "disturbed zone" with arbitrary temperature structure and 


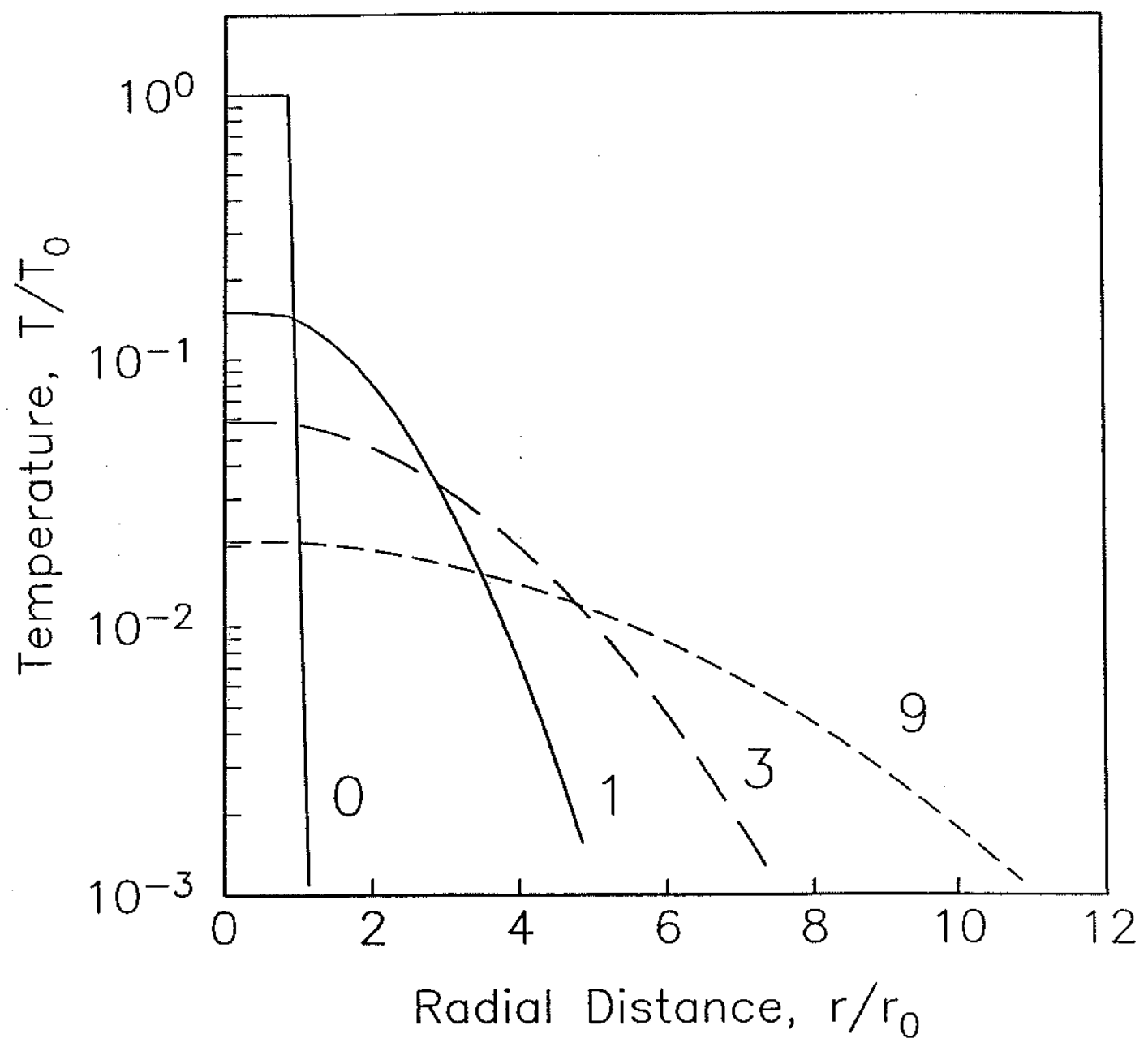

Fig. A3.5. Nondimensional plot of radial temperatures for selected times of probe thermal decay using the mode1 A2 (Table A3.2). Curves are labeled with the value of $\tau$. 


\section{Initial Conditions for 'Disturbed Zone' Models}
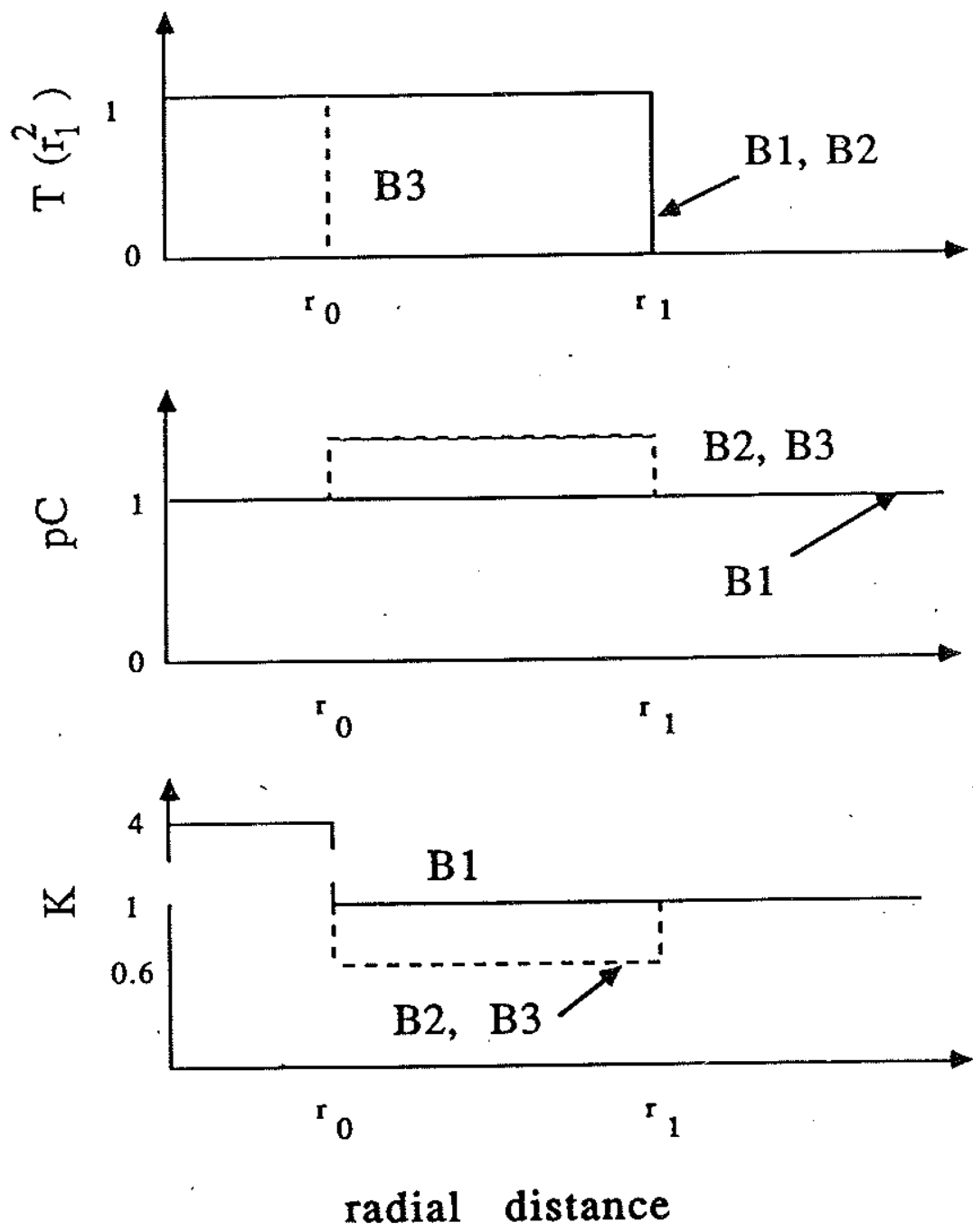

Fig. A3.6. Initial temperature distribution, heat capacity $\bullet$ density and conductivity in dimensionless values for three models $B 1, B 2$, and $B 3$. $r_{0}$ is the probe radius and $r_{1}$ is the outer radius of the initial disturbance. Mode1 B1 includes temperature effects in the "disturbed" sediment zone, model B3 contains water-equivalent properties simulating sediment deformation within this zone, and model B2 has both effects. 
therma1 properties (Figure A3.6). The outer radius of the disturbed annulus is varied to simulate a temperature perturbation (B1 mode1), a water layer (B3 mode1), or a combination of the two (mode1 B2). For simp1icity, a radial step function in the initial temperature condition is chosen (Figure A3.6). In scaling the initial temperature anomaly with $r_{1}^{-2}$, the total heat input is kept constant $\left(Q=T_{0} S\right.$ when $\left.r_{1}=r_{0}\right)$. This has been done in order to check the slope results of the GSS method for studies of the significance of time shifts used in conductivity determinations. The heat capacity per unit volume $\rho C$ is appropriate for a probe with $\alpha=2 ; \rho C$ of the water layer is $33 \%$ larger than the rest of the medium. The conductivity of the probe is $400 \%$ higher than the sediment and the water $40 \% 1$ lower.

The GSS time-advance results of the sediment disturbance models are shown in Figure A3.7. As expected, larger radii of disturbance are consistent with larger time-advances. For mode1s B1 and B2, the GSS solution diverges, changing rapidly when the initial temperature anomaly has a radius of $r_{1}>4-6 r_{0}$. An associated water-1aden zone coinciding with the initial temperature disturbance (mode1 B2) enhances the magnitude of the time shift. However, a subtle feature of very thin water layers $\left(r_{1}<3 r_{0}\right)$ is that they decrease the time-advance in comparison to the temperature anomaly in absence of water (mode1 B1). This feature is related to the contact resistance effect caused by a thin skin of water (see mode1 B3). The effect of the water-equivalent value of $\rho C$ in mode1 $B 2$, as opposed to the homogeneous case where $\rho C$ $=1$, is to slightly increase the time-advance. 

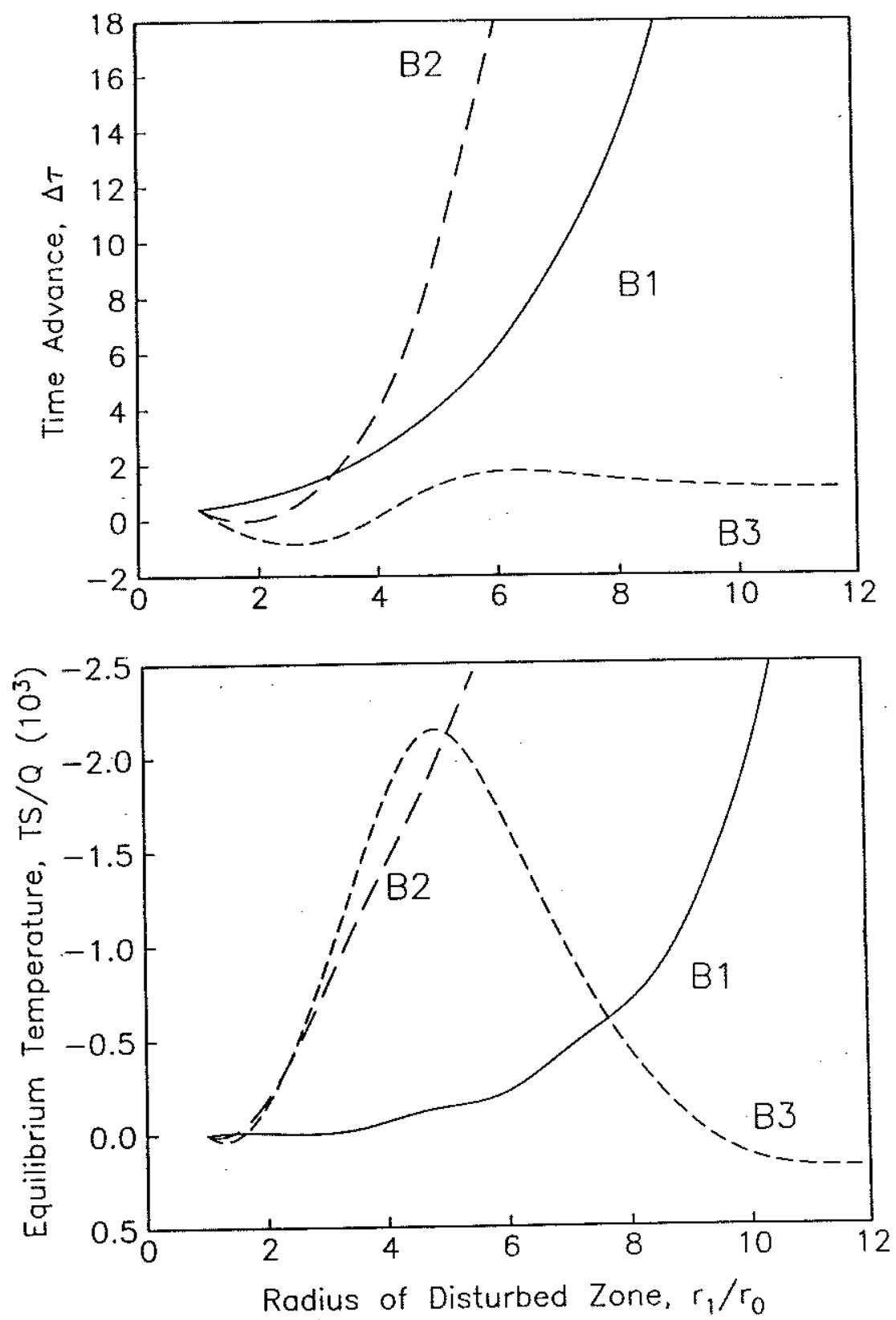

Fig. A3.7. Nondimensional plots showing effect of an increasing disturbed zone radius on the axial temperature data set using the Golden Section Search. a) Time advance for three distrubed zone models of Figure A3.6 with curves representing models B1, B2, and B3. b) Accuracy of the equilibrium temperature solution assuming a medium of zero temperature. The absolute values of temperature are scaled to $Q / S$ where $Q$ is the initial heat per unit volume in the disturbed zone and $S$ is the probe thermal parameter (see text). To apply the curves to the data of Figure $A 3.2$ with mean $b=6$, simply multiply the temperature quantity by 3 and read as $\mathrm{mK}$. 
A water layer without the temperature anomaly (mode1 B3) has a relatively sma11 effect on the magnitude of the time shift. Mode1 B3 is appropriate for the thermal contact resistance boundary condition of the probe surface heat flow and, as discussed later, generally does not agree with the predictions of analytical model formulated by Jaeger (1956). Contrary to assertions by Hutchison (1983) and Villinger and Davis (1987), the numerical results show that contact resistance causes $t^{-1}$ plots which are convex downward instead of convex upward.

\section{A3.7 Discussion}

Time shifting has no dependence on the quantity of heat input. Instead, it is the radial geometry of the initial temperature and/or physical property anomaly that controls the time-advance. The trend of higher time-advances with larger slopes (Figure A3.2) is probab1y a result of a broader physical disturbance correlated with greater frictional heating. We have only modeled a single annulus of temperature perturbation. A more appropriate model may have multiple annuli with the inner cylinder at a higher temperature than the outer annuli, similar to the distribution of Figure A3.5. Other more physically plausible models may be derived from studies on deformation and frictional heating effects of solid cylinder (probe) or slab ( $\mathrm{fin}$ ) penetration into a viscous medium.

Equilibrium temperature estimation. As mentioned previously, the temperature estimate is more sensitive to changes in origin time for larger $\mathrm{T}-\mathrm{t}^{-1}$ slopes or greater values of initial heat input. Referring to Figure A3.7, if the time-advance is due to temperature 
effects alone, then the GSS-derived infinite-time temperature is quite accurate. With the time-advance range for the outrigger probe is $0-5 \tau$ corresponding to a disturbed radius of $r_{0}$ to $6 r_{0}$, the GSS result may be an order magnitude closer to the actual equilibrium value compared to the zero-shifted value.

Problems with the GSS method occur mainly with the introduction of water into the disturbed zone. Both models B2 and B3 illustrate that water complicates the GSS results and in some instances gives poorer estimates of the equilibrium temperature than the zero-shifted intercept. Thus, the danger in using the GSS method is that it may 'overshoot' the time shift that would generate the true equilibrium temperature. With water alone (mode1 B3), the GSS result is actually a time delay. According to the data of Figure A3.2, this suggests that model $\mathrm{B} 3$ is atypical of the situation encountered in most penetration-heating examples of marine heat flow surveys.

The only evidence available that gives an independent check on the presence of water at the probe surface is to compare the time shifts of the impact-heating decay to the pulse-heating decay. To do so, 1986 Hawaiian swe11 data obtained with the new WHOI microprocessor-controlled heat flow instrument with continuous- or pulse-heating options (Von Herzen and Fang, 1987) is utilized. Using basically the same data reduction procedure as above (Fang et a1., 1987), it is found that the time shifts are almost an order of magnitude less for the pulse-heating event. This suggests that the large time-advances which are experienced in the impact-heating decays are due mainly to an entry-induced temperature perturbation around the probe and fins. Being a transient 
effect, the temperature disturbance deteriorates enough in the five minute postimpact period so that it is a negligible effect when the pulse-heating cycle commences.

Thermal contact resistance. As illustrated by mode1 B3 in Figure A3.7, a water layer produces a distinct maximum in the temperature resolution curve at $r_{1}=5 r_{0}(h=6)$, which for the WHOI outrigger probe is equivalent to a water layer $6 \mathrm{~mm}$ thick. Beyond that point, the GSS slope reaches a somewhat constant value, appropriate for a medium conductivity equal to that of water, so that the probe essentially senses the water layer as the medium. The water layer loses its contact resistance qualities, as characterized by an increasing time delay at $r_{1}=2 r_{0}(h=2)$, which is about $2 \mathrm{~mm}$ from the probe surface for the outrigger probe.

For marine geothermal applications, there should be a practical upper bound associated with the nondimensional contact resistance parameter h (Equation A3.5). Above this upper 1 imit, $F(h, \alpha, \tau)$ ceases to be an adequate representation to the cooling of a thermal probe with a surface layer of water. The tacit assumption of the surface resistance $1 / \mathrm{H}$ as defined by Jaeger (1956) is that there is a linear thermal gradient across the contact. This becomes impossible as the contact thickness becomes large compared to the probe diameter. Limiting values of $H$ have never been considered in marine geothermal studies simply because the heat transfer at the probe surface has always been treated in a qualitative sense.

Further investigations of the thermal contact resistance theory should be made, with special emphasis on the accuracy of the Blackwell 
(1954) approximation (Jaeger, 1956). We note that the differences in the GSS results for the finite difference model and the analytical model with a contact resistance is quite large. In fact, the Blackwe11 (1954) approximation, as derived by Jaeger (1956), is probably applicable only for values of $h<2$. For values of $h>20$, the value of $F(h, \alpha, \tau)$ is apparently over an order of magnitude too small using this approximation (see Jaeger, 1956, Figure 2).

Probe thermal response: evidence from continuous-heating. An optimization routine for the continuous-heating method for thermal conductivity determination (Appendix 2), as suggested by Fang et al. (1987) and Villinger and Davis (1987), has not been tested. However, in examining the applicability of the GSS technique, a prominent discrepancy was found for the $G(\alpha, \tau)$ vs. Tred regression line intercept, where $T_{r e d}$ is the reduced temperature corrected for the effect of the frictional heating of penetration and $G(\alpha, \tau)$ is the theoretical probe testing function. According to theory (Jaeger, 1956), the intercept should be equal to the equilibrium temperature. This is not the case for the outrigger probe in that the biaxial probe design (Appendix 2) has an intercept value about $200 \mathrm{mK}$ less than equilibrium value, whereas the uniaxial probe, with the heater directly in contact with the thermistor, has an intercept that is 100 to $700 \mathrm{mK}$ above equilibrium.

Disagreement among uniaxial and biaxial data intercept values and the theoretica1 results may be explained by effects of finite probe conductivity and nonideal probe structure. The intercept seems to be consistent from station to station for a particular thermistor probe 
which suggests that it is a systematic effect resulting from the particular probe. The uniaxial probe is warmer than predicted because the finite conductivity of the composite probe maintains high internal thermal gradients instead of transferring the heat instantaneously as a 'perfect conductor' would. The temperature offset seen in the uniaxial probe undoubtedly occurs to some extent in the needle-probe measurements as we11. The biaxial probe has relatively poor thermal contact between the heat source and temperature sensor so that the temperature rise at early times is less than in theory and, consequently, the intercept attains negative values. Thus, depending on the relative position of the thermistor to the heater (uniaxial versus biaxial design), the thermistor temperature will be higher or lower than the average probe temperature.

Steady-heating using the needle-probe method has been calibrated to within $1 \%$ of standard values for fused silica glass (Goldberg et al., 1980). Since the outrigger probe is essentially a scaled-up version of the needle probe, the in situ $\mathrm{K}$ determinations are probably unaffected as wel1. Therefore, the intercept temperature shift associated with the continuous-heating technique is probably due to short-time phenomena of the heated cylindrical probe. Valuable constraint on the probe thermal properties and response characteristics may be provided by further investigations of the intercept offset generated during steady-heating.

\section{A3.8 Sumnary}

The temperature decay of marine geothermal probes has been accurately quantified by cylindrical heat conduction theory put forth by 
Bullard (1954) and Jaeger (1956) in the $F(\alpha, \tau)$ function. When displayed as temperature vs. the reciprocal of time since impact (asymptotic expression for the $F(\alpha, \tau)$ function), the data should theoretically plot on a straight line. In reality, most thermal probe $\mathrm{T}-\mathrm{t}^{-1}$ data plots are slightly nonlinear in a convex upward sense. Time-shifting of the effective origin time can correct the nonlinearity. We have employed the Golden Section Search routine to optimize the time shift according to a linear correlation criterion. A11 time shifts are time-advances, ie., the temperature data suggest that the penetration occurred 0 to $5 \tau$ before the actual impact. Depending on the net amount of frictional heating experienced by the probe, the time-advance decreases the equilibrium temperature estimate by 0 to over $15 \mathrm{mK}$. If noise-free data is available, the Golden Section Search is found to be an accurate and efficient algorithm to automatically find the effective origin time.

Simple variation of the parameters used in the $F(\alpha, \tau)$ analytica1 model cannot explain the convexity of the temperature decays. A1so, the effect cannot be directly attributed to the outrigger probe design or nonideal probe structure. An analysis of the experimental conditions indicates that the magnitude of the time shifts may instead depend on the kinematics of probe entry. Penetrations with high impact velocity and probably large concurrent lateral movement promote large time shifts, and the lowermost probe generally is the least affected by the nonideal conditions of probe entry.

Numerical modeling was used to investigate the validity of the equilibrium temperature results using the Golden Section Search 
time-shifting routine. This proof is deemed a critical step in the application of automated heat flow data reduction schemes. The convex upward temperature decays are reproduced if initial heat is present in a thermally disturbed zone of sediment located adjacent to the probe. The magnitude of the time shift is dependent on the outer radius of the disturbance and is independent on the net amount of heat in the system. Outrigger temperature data suggest that the disturbed zone is on the order of several probe radii beyond the probe surface. According to the model, the Golden Section Search equilibrium temperature estimate is accurate to within $1 \mathrm{mK}$ if the radius of disturbance is less than 7 to 10 times the probe radius.

If excess water is introduced into the disturbed zone, the Golden Section Search result may be seriously degraded and the accuracy may be comparable to a normal zero-shifted data reduction procedure. However, independent observations of the probe thermal response to a calibrated heat pulse suggest that an appreciable increase in water content of the sediment surrounding the probe does not occur and that the sediment disturbance is mainly thermal in origin.

Thermal contact resistance is simulated if a water layer about the probe is included without an associated temperature perturbation. The numerical model results suggest that the analytical formulation for skin resistance of marine geothermal probes is only adequate for thin water layers, perhaps with a thickness of less than $50 \%$ of the probe radius. Numerical models demonstrate that contact resistance alone cannot account for the observed time shifts. The decay of heat from the probe is generally only sensitive to the thermal properties of the region 
which is located within 5 probe radii of the probe, so that a water layer of a given thickness will have more serious consequences for small radius probes. Additional modeling of pulse-heating phenomena will establish the sensitivity of thermal conductivity determinations to various configurations and states of sediment disturbance. 
$-415-$

Appendix 4

Heat F1ow Data Tables and Plots. 
Ligurian Sea $1982-1984$ heat flow data

The heat flow data for each station is given in Table A4.1. As described in Chapter 3, a11 errors are determined at the $80 \%$ confidence level (two-sided $t$-test). Plots of the data are divided into two formats, dependent on whether in situ thermal conductivity data is available. Figures A4.1 - A4.17 show the 102 heat flow stations which have in situ conductivity and Figures A4.18 - A4.21 illustrate the 74 thermal gradient stations without conductivity information. In situ conductivity is obtained using the steady-heating method (Appendix 2). Most equilibrium temperature data were improved using the Golden Section Search optimization routine (Appendix 3 ).

Piston core thermal conductivity data

Table A4.2 presents the results of the piston core data. A summary of conductivity measurements made using the needle-probe method and the semi-automated procedure implemented is described in Von Herzen et al. (1982, Appendix B). Correcting to the in situ temperature and pressure (Ratcliffe, 1960), the values have been slightly reduced to about $97 \%$ of the actual laboratory measurement. The harmonic means have uncertainties assigned at the $80 \%$ leve1 of confidence (two-sided t-test). Plots of thermal conductivity versus depth for piston cores are given in Figures $\mathrm{A} 4.21-\mathrm{A} 4.24$.

other Ligurian Sea heat flow and piston core data

A11 data collected by other investigators which coincide in the general region of the Nice-Calvi transect is compiled in Table A4.3, and 
grouped according to regions described in the text. Positions are plotted in Figure 2.8.

Sedimentation, subsidence and sediment-corrected heat flow The simplified stratigraphy for each reliable heat flow station is given in Table A4.4. Sediment thicknesses are used to determine the sediment-unloaded basement depths and sedimentation rates used to correct the heat flow values. $500 \mathrm{~m}$ of erosion is assumed to have occur in Regions $A, E$, and $F$ and is not reflected in the sediment thickness tabulation. Paleoclimatic corrections are not included in Table A4.4 but range from 8 to $10 \mathrm{~mW} \mathrm{~m} \mathrm{~m}^{-2}$ for each station (See Table 4.2). See Chapter 4 and 5 for further discussions of methods and uncertainties. 
$\stackrel{+}{n}$

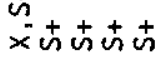

$\stackrel{\bullet}{\bullet} \vdash$ $\stackrel{1}{\leftarrow}$ oxx $x \propto \alpha \propto x+x \alpha \alpha \propto \alpha+x+1$

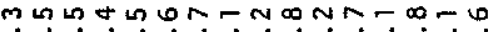

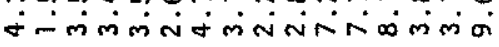

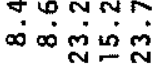
$0 \infty \pi$ on

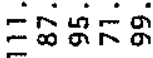

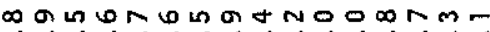
MNํํำ

䓵。录

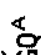

总

- $=1$ andor

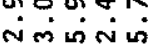

$m m-0$ un مَّم

点。

$\stackrel{>}{+}$

$\div \frac{1}{2}$

苛

S文

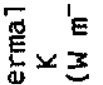

$\stackrel{\stackrel{5}{F}}{ }$

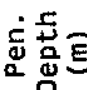

产部。

离紊家

تَّة

ס ه

م 0 苞苍苍

농옹유유

००ं0ல

$\underline{0}$

$\therefore \therefore \therefore$

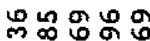

نंசंச்

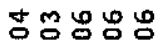

minmm

o OMNRNRMGRn

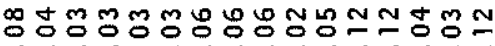
- ó00000000000

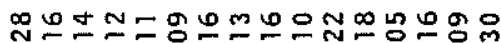

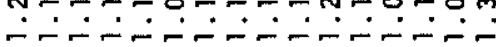

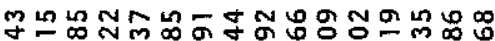
ف

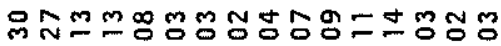

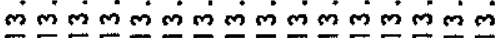

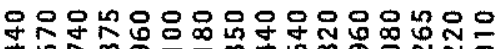

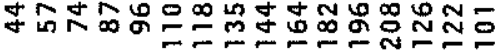

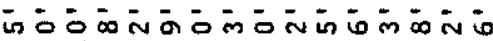

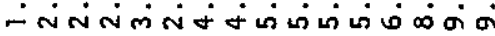

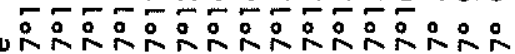
응

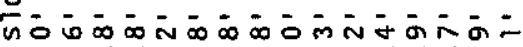

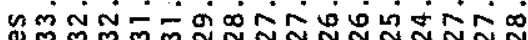
Do: 0

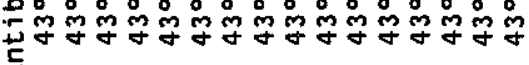

ชับำแ

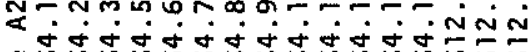

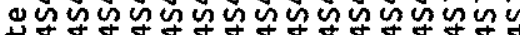
in
0
$\stackrel{1}{n}$
$\dot{x} 0 \sin \alpha \alpha x \alpha \alpha \alpha \alpha \alpha \alpha$

nat

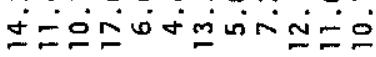

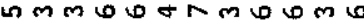

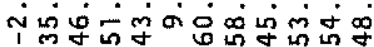

nด」

MNG

mo un un on om mo

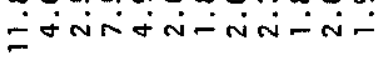

onna-nad

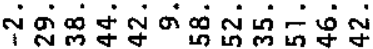

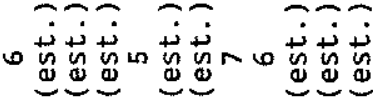

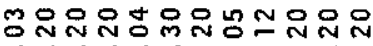
¿0ं00ं0ं00ं

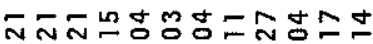

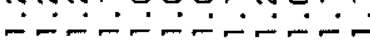

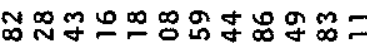

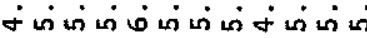

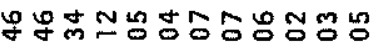
mற்ற㇒்

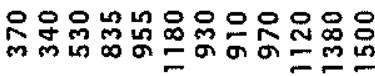

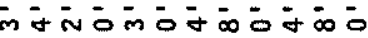

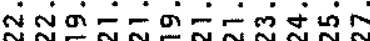

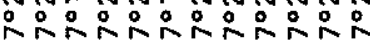

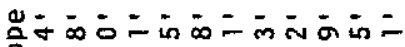

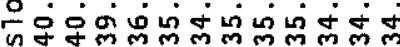

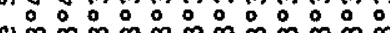

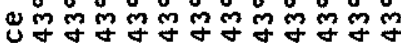
z

$\ddot{m}-N m N m+-N m+L 6$ ष्்-

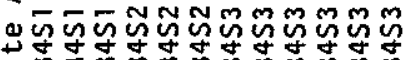

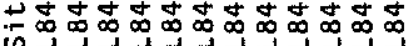


$\alpha \alpha \alpha+\quad \sin \alpha+\frac{1}{1} \alpha \alpha \alpha \alpha \alpha \alpha \alpha \alpha \alpha \alpha$

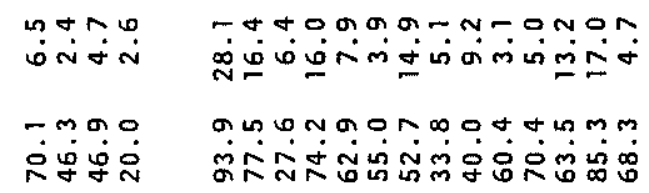

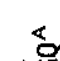$$
\text { 窇 }
$$$$
\text { 要 }
$$$$
\stackrel{i}{i}
$$$$
\text { 总 }
$$

㝘营咅

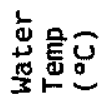

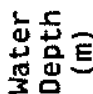

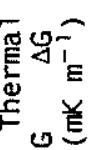

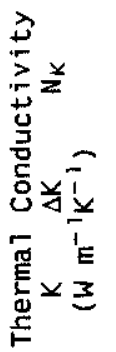

F

$0+\Delta$

$\wedge 606$

mo.

-0:-1

gìm

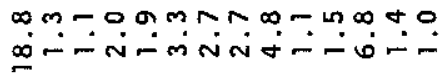

כ

mow

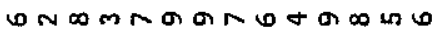

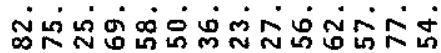

号ㅇํㅇ

:0ं0

푸옹

ก่

ㅇํㅇำ

$\dot{m} \dot{\sim} \dot{m} \dot{m}$

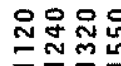

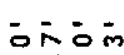

กิing

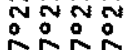

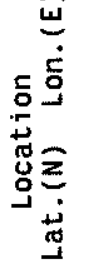

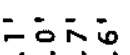

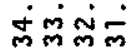

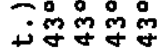

范

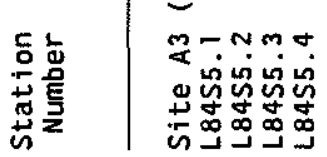

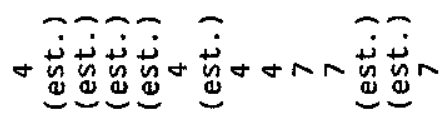

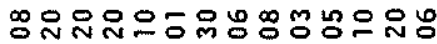

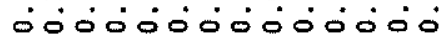

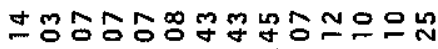

$\therefore \therefore \therefore$

ธ

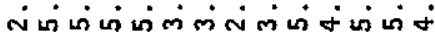

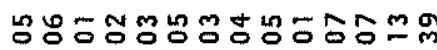

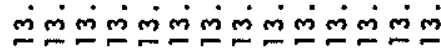

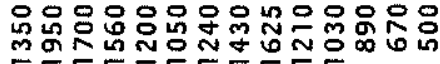

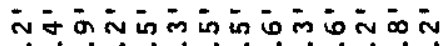
సं心

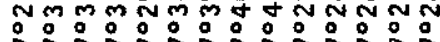

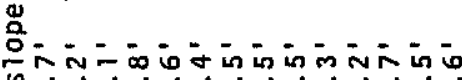

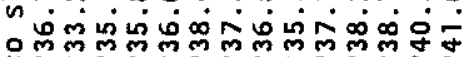

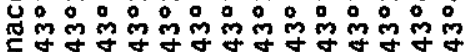
$\frac{10}{2}$

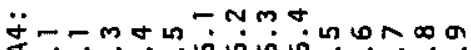

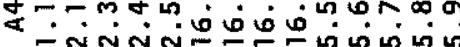

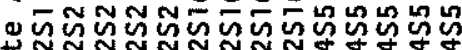
政 N⿴囗⿰丿㇄心 $\alpha \alpha \alpha \alpha \alpha \alpha \alpha \alpha \alpha \alpha \alpha \alpha \alpha \alpha \alpha \alpha \alpha$

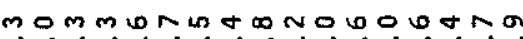

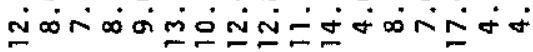

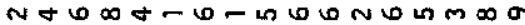

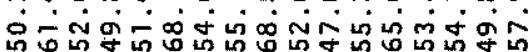

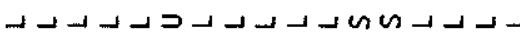

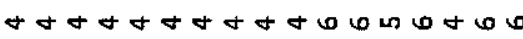

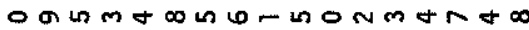
من

$m-\infty m-n \infty \infty n-m+\infty-N m$

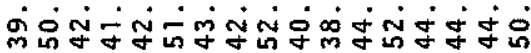

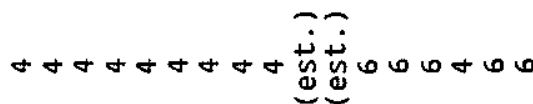

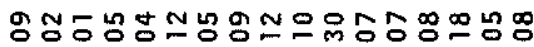
000000000000000

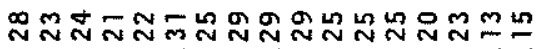
$\because-\ddot{-}-\dot{-}-\dot{-}-\dot{-}-\dot{-}-\dot{-}$

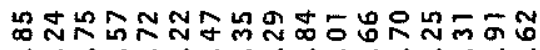

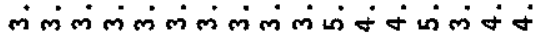

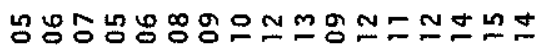

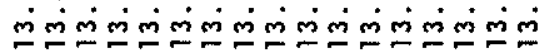

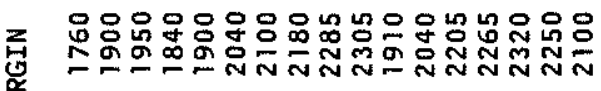

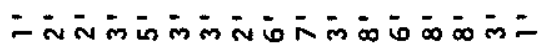
ลิ่สก 50रำ

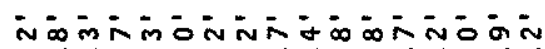

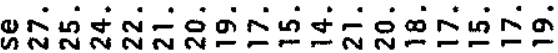
药

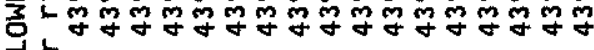
$>$

i -NmoLon zörinisinisina

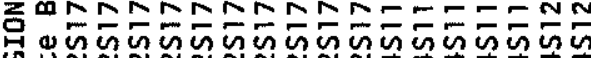

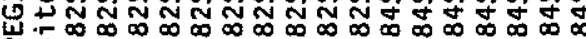




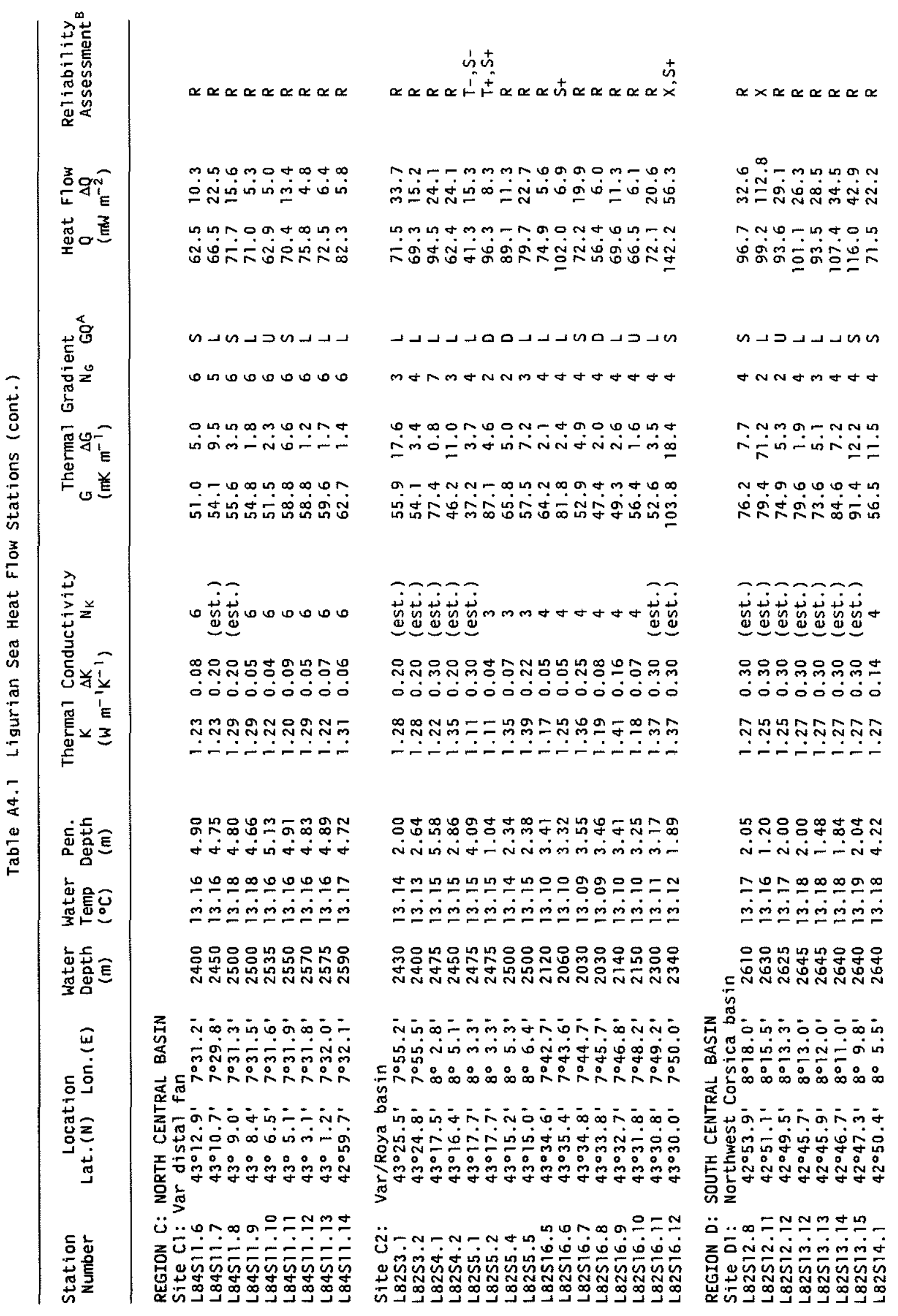


$\alpha \propto \alpha \quad \alpha \alpha \alpha \alpha \alpha \alpha \alpha \propto \alpha \quad \alpha x \propto \alpha \alpha \times \alpha x$

$\alpha x \alpha \alpha \alpha x^{n} x^{n} x^{n} \propto \alpha \alpha \alpha \alpha$

ด

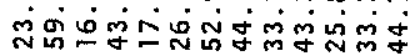

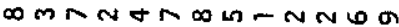

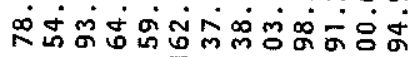

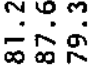

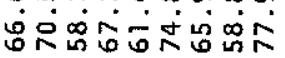

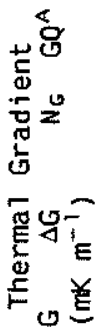

\lrcorner כes

Nmo

กo-

$\ddot{0} \underset{\sim}{\infty}$

$\stackrel{4 \infty}{\circ \infty}$

نं

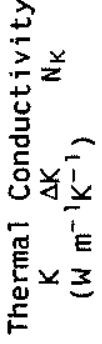

这咅总

离鮟。

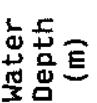

تُ

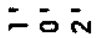

$\dot{\theta} \dot{0} \dot{0}$

$\infty \stackrel{\infty}{\infty}$

ن

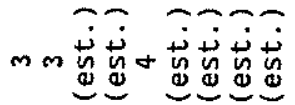

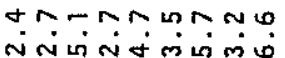

- L

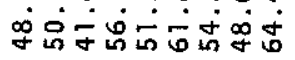

을융요

¿ं0

능유은융ㅇㅅㅇ

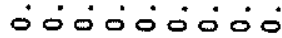

กิก

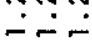

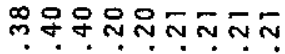

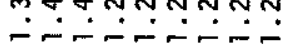

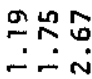

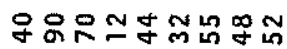

N-ñ்-ñNi

$\stackrel{\infty}{\infty}$

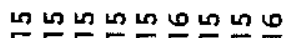

$\dot{m} \dot{m} \dot{m} \dot{m} \dot{m} \dot{m} \dot{m}$

윰

응웅ㅇ으느응

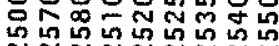
d

융

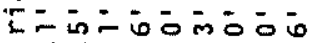

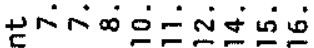

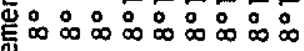
$\sim \sim \infty$

-

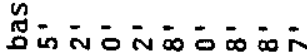

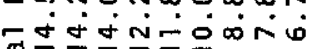

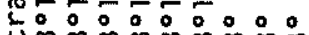

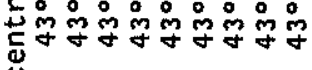
芒尔等 过

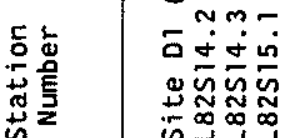

กั山na-Nm+no نे

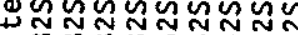
is

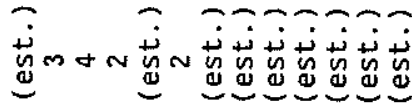

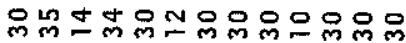
ió $\dot{0} 0 \dot{0} 0 \dot{0} 0 \dot{0}$

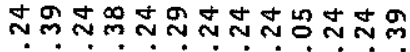

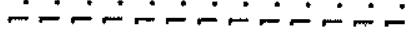

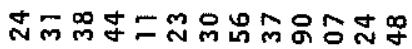

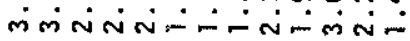

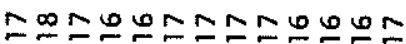

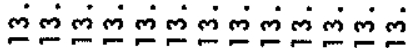

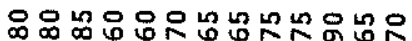

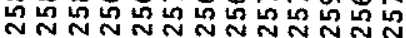

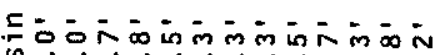

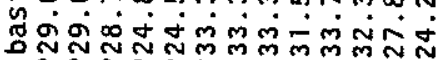

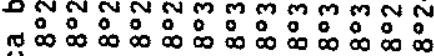

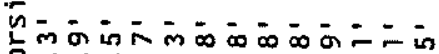
Uே$\ddot{m}-N m$ 음ำ

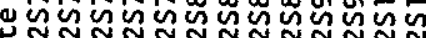
in

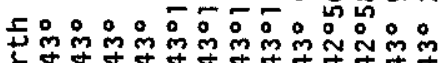

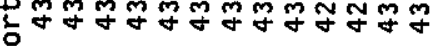

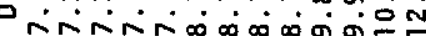

in $\alpha \alpha \alpha \propto x \alpha \alpha$

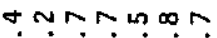
$\therefore \dot{0} \dot{\infty} \underset{\mathrm{m}}{\mathrm{m}}$

N L NNA แ 0

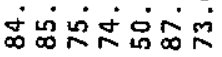

$\supset\lrcorner-\lrcorner-\neg 0$

mmmmNo

todann$\dot{0} \dot{m} \dot{m} \dot{0} \dot{0}$

Nammom 당ํำ

$m$ 迎m

형으으잉잉 نं

도응유는 $\therefore \because \because \because \div$

ํํㅇ용ำ मंलिंलिंत्रिं $\pm 0 \Omega \infty ⿻ \infty N$ $\dot{m} \dot{m} \dot{m} \dot{m} \dot{m} \dot{n}$ 总

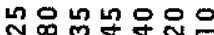

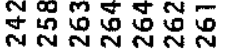

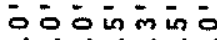

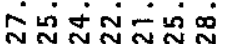

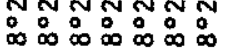

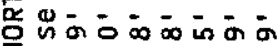
In்⿻弋𠃋⿻ 岁: 戛

ن̈...m约

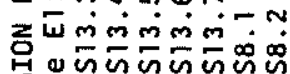

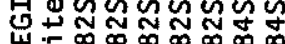




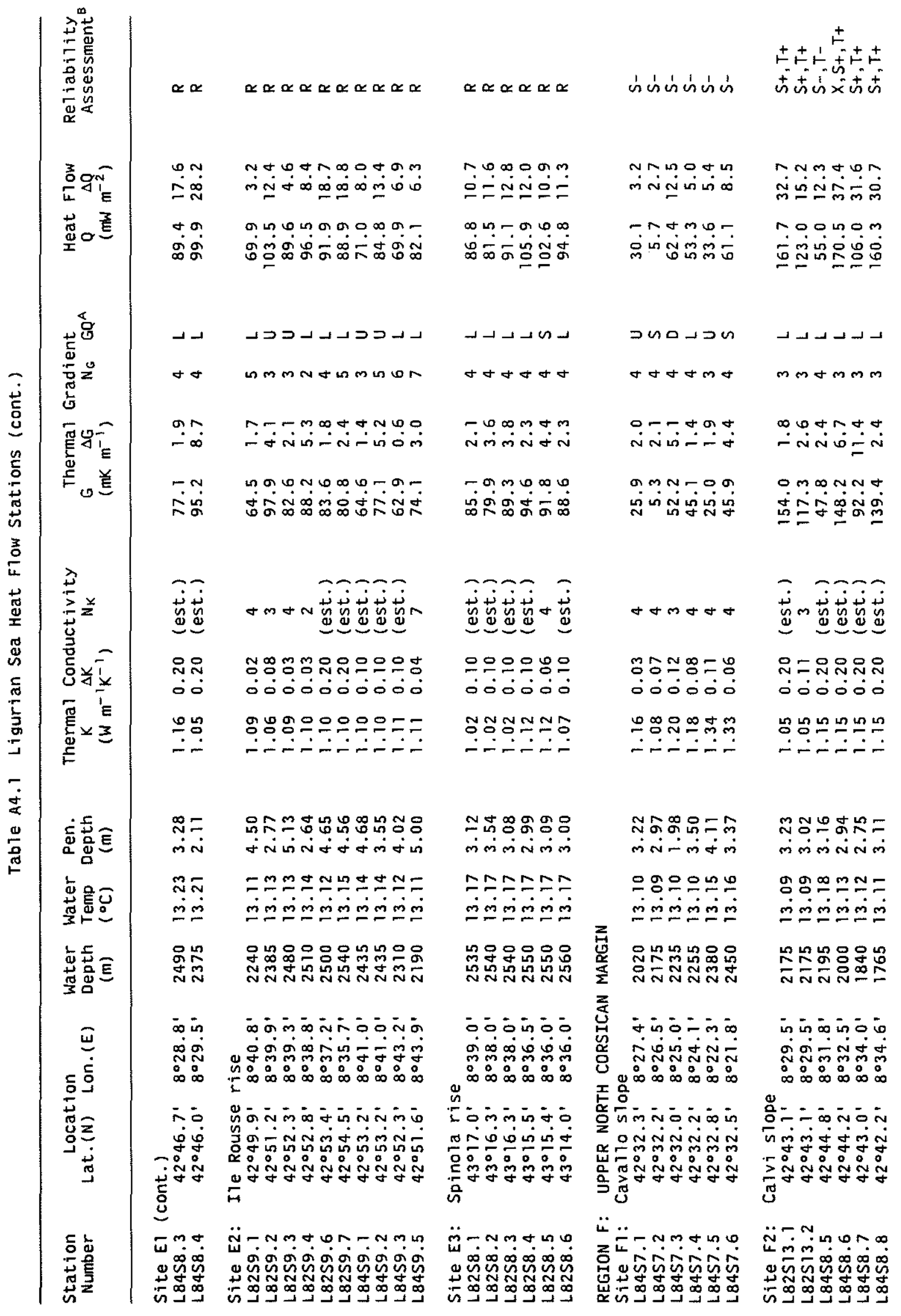




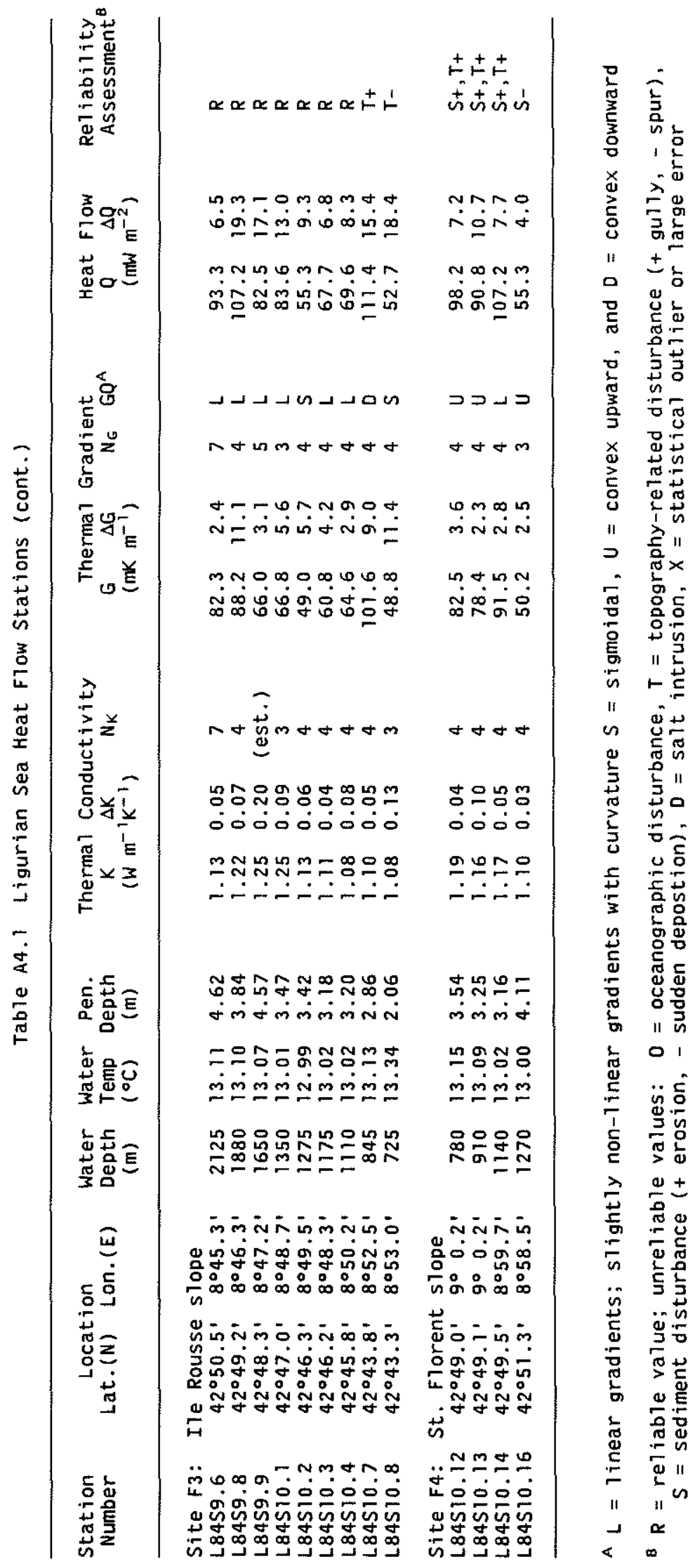


Fig. A4.1 - A4.17. In situ temperature and thermal conductivity versus depth for pogo stations of the 1982 and 1984 Ligurian Sea geothermal surveys. The best-fitting linear thermal gradient is also shown. Temperature is relative to the measured (or inferred) bottom water temperature (BWT). The depths below seafloor are found by adjusting the depths so that the BWT extrapolated from the thermal gradient equals that actually measured by the water thermistor located within the weightstand. Due to large discrepancies between measured and extrapolated BWT, stations L84S1.1, L84S1.2, and L84S2.4 have depths appropriate for full (norma1) penetration to the bottom of the weightstand. The temperature error bars represent the confidence limits using the two-sided $95 \%$ leve1 t-test. To optimize the linear gradient value, the uppermost thermistor of 13 stations, marked "d" on the plot, were not included in the least-squares fitting calculation. The conductivity points are plotted using a variable offset scale for each penetration, and are shown with $95 \%$ level confidence limits. The uncertainty associated with the off-axis heater element of the double-probe design (Appendix 2) is included in the 1982 in situ conductivity data. 

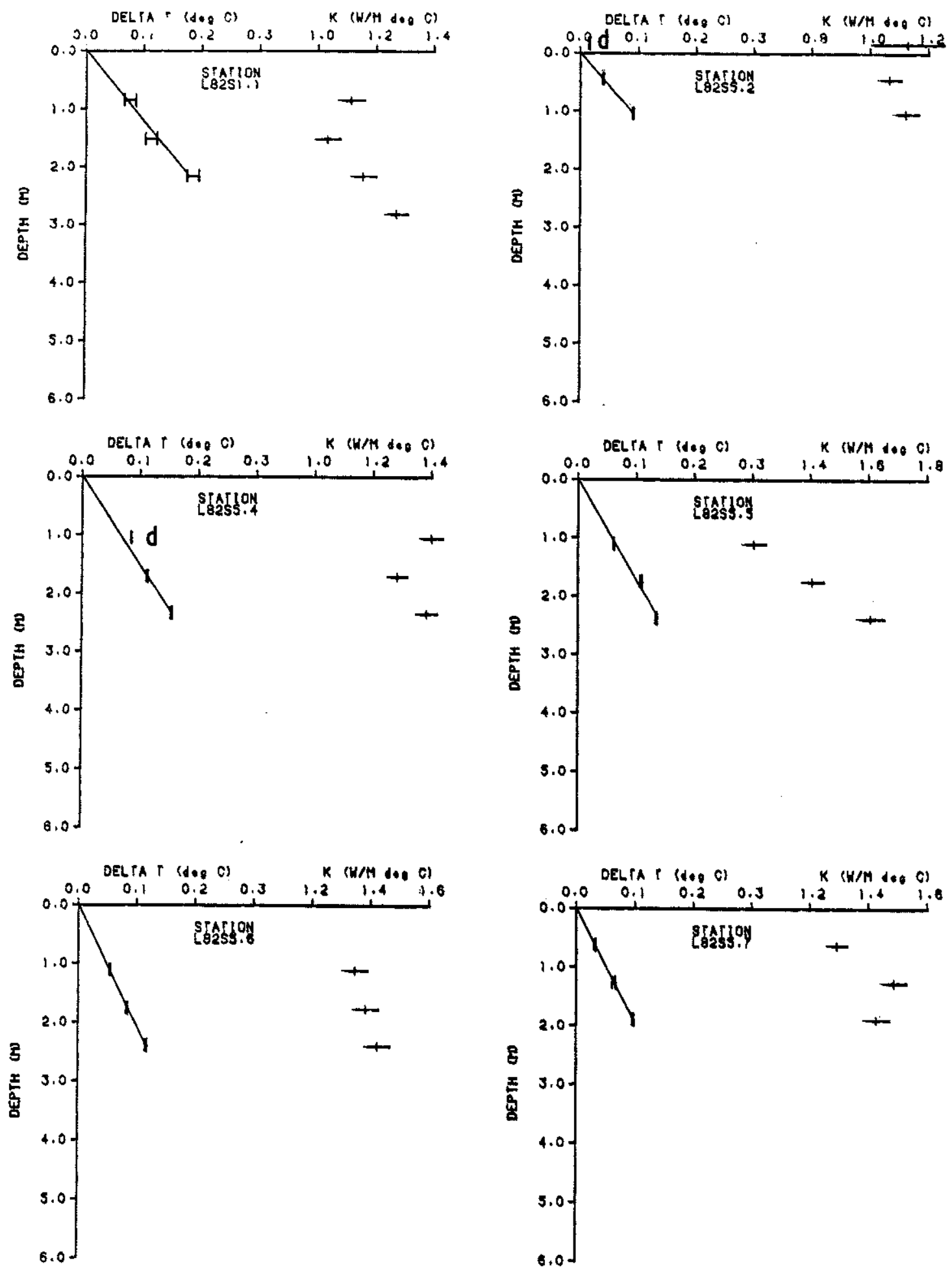

Fig. A4.1 

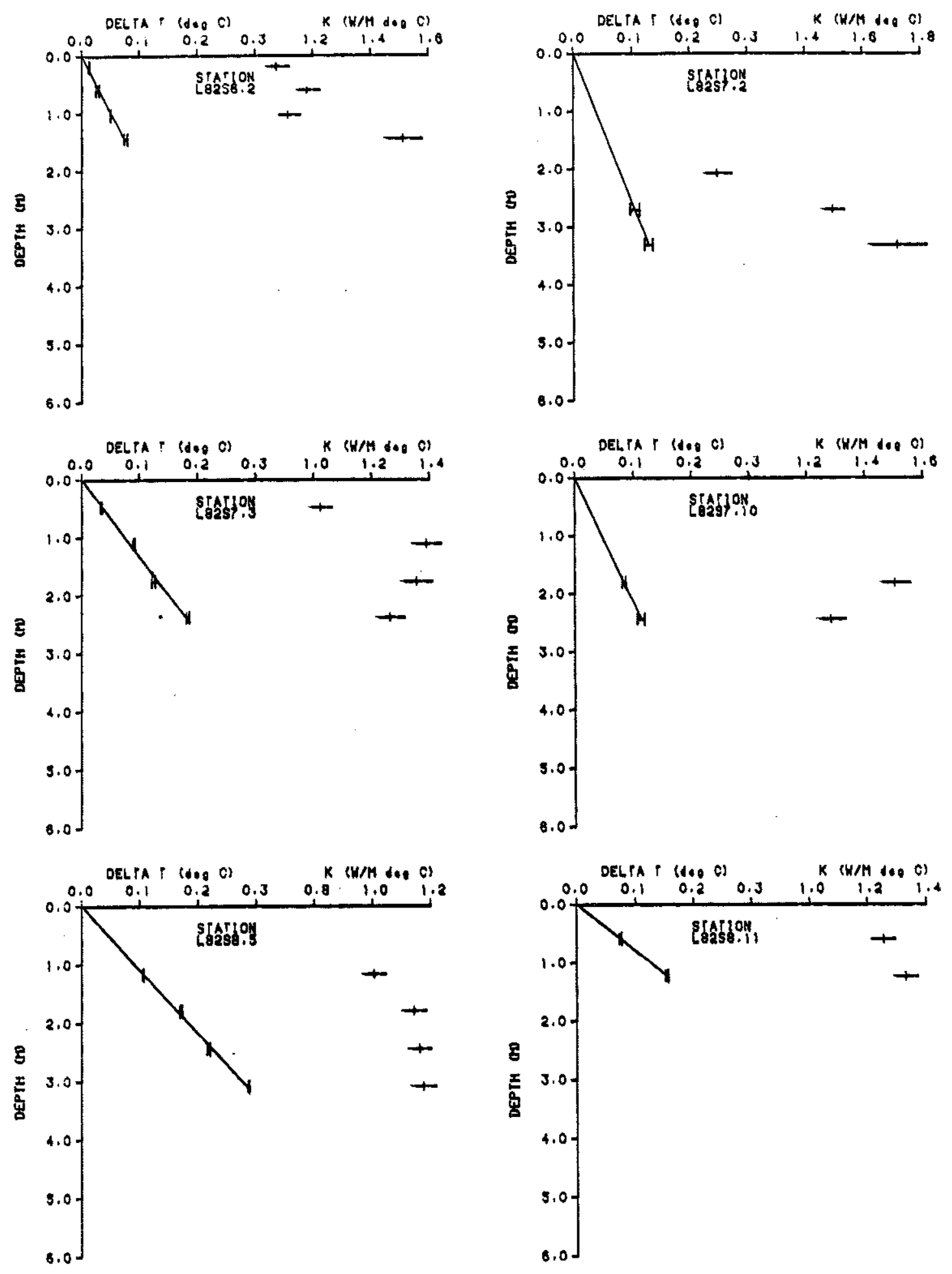

Fig. A4. 2 

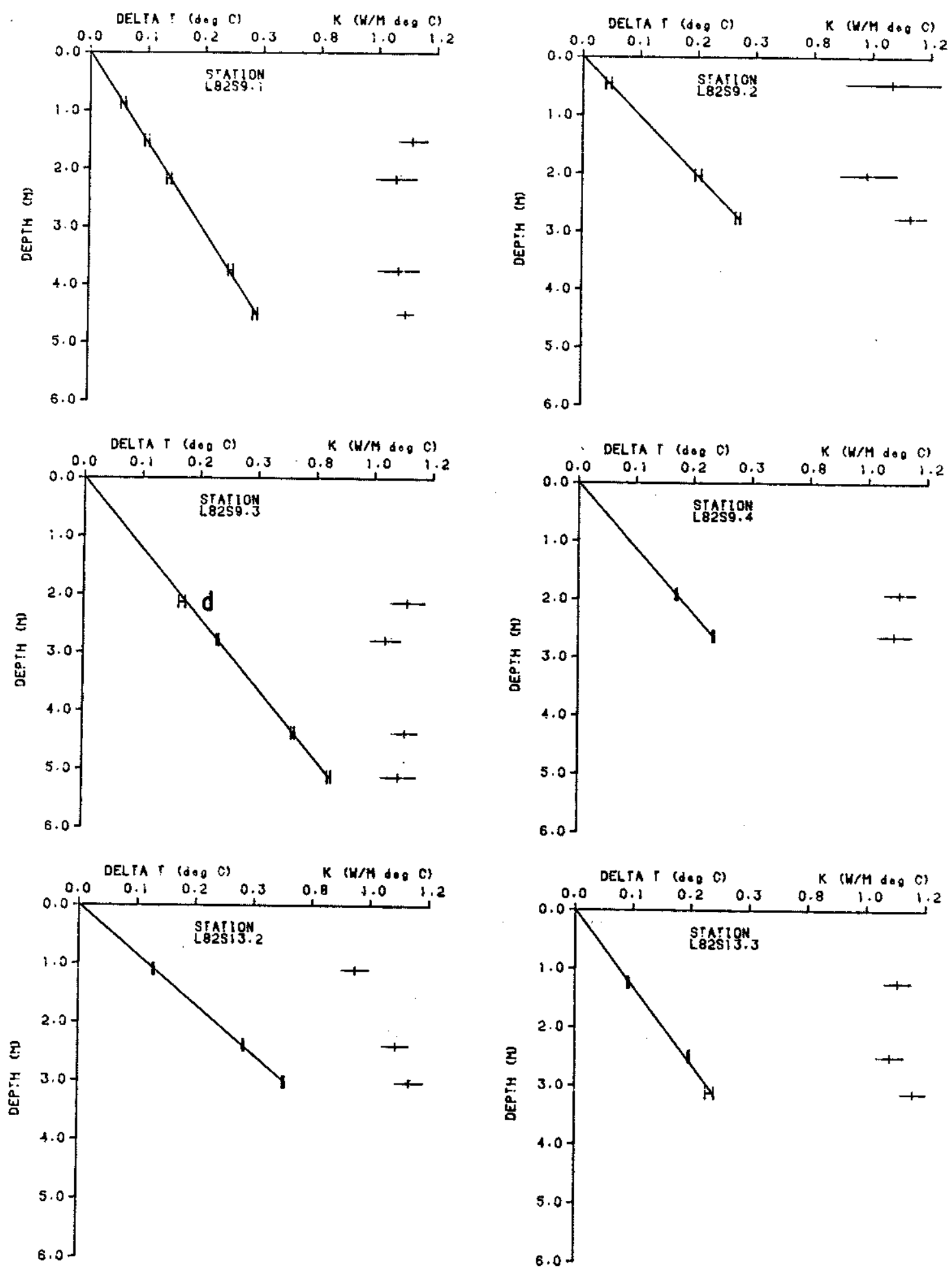

Fig. A4. 3 

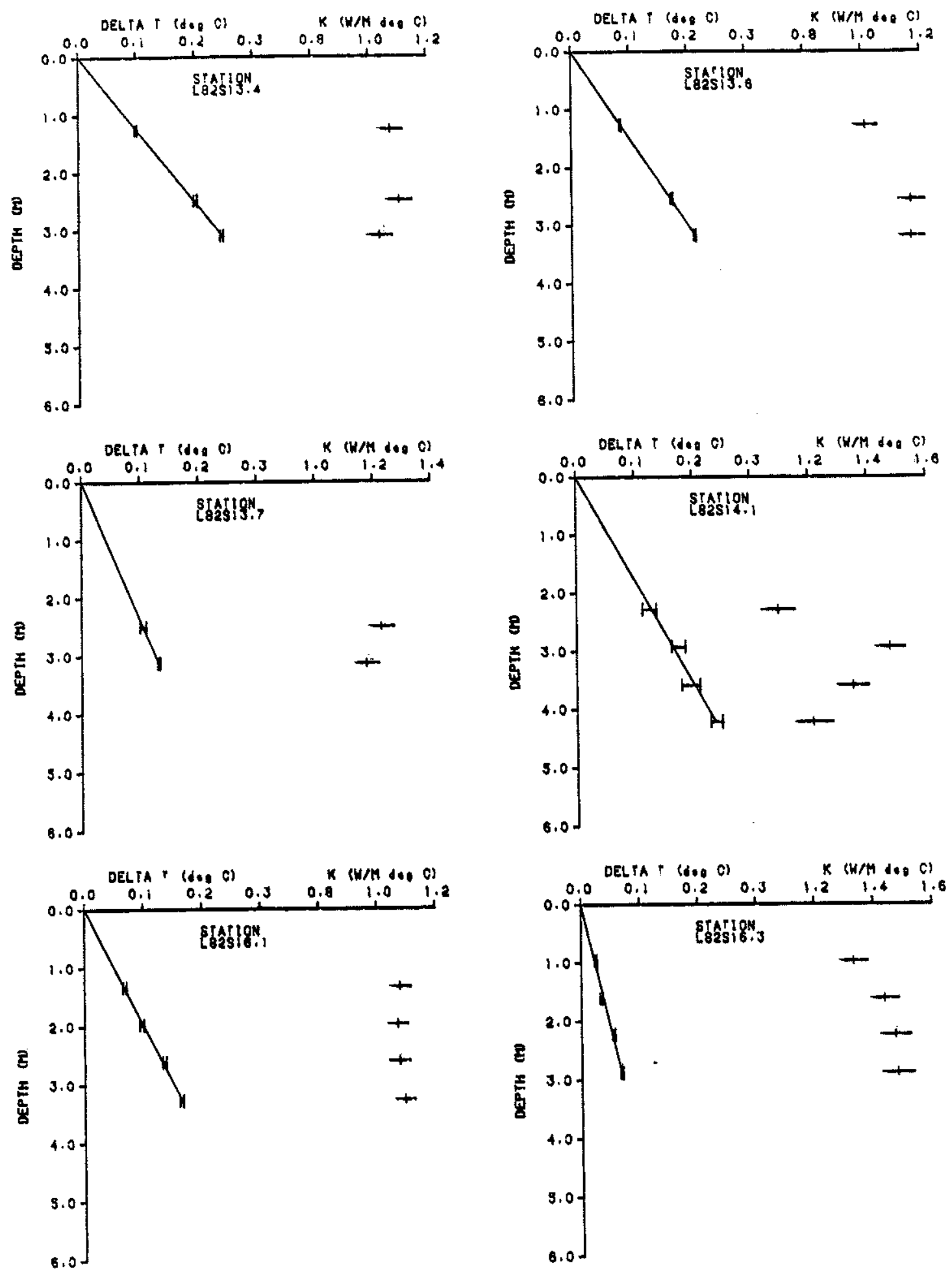

Fig. A4. 4 

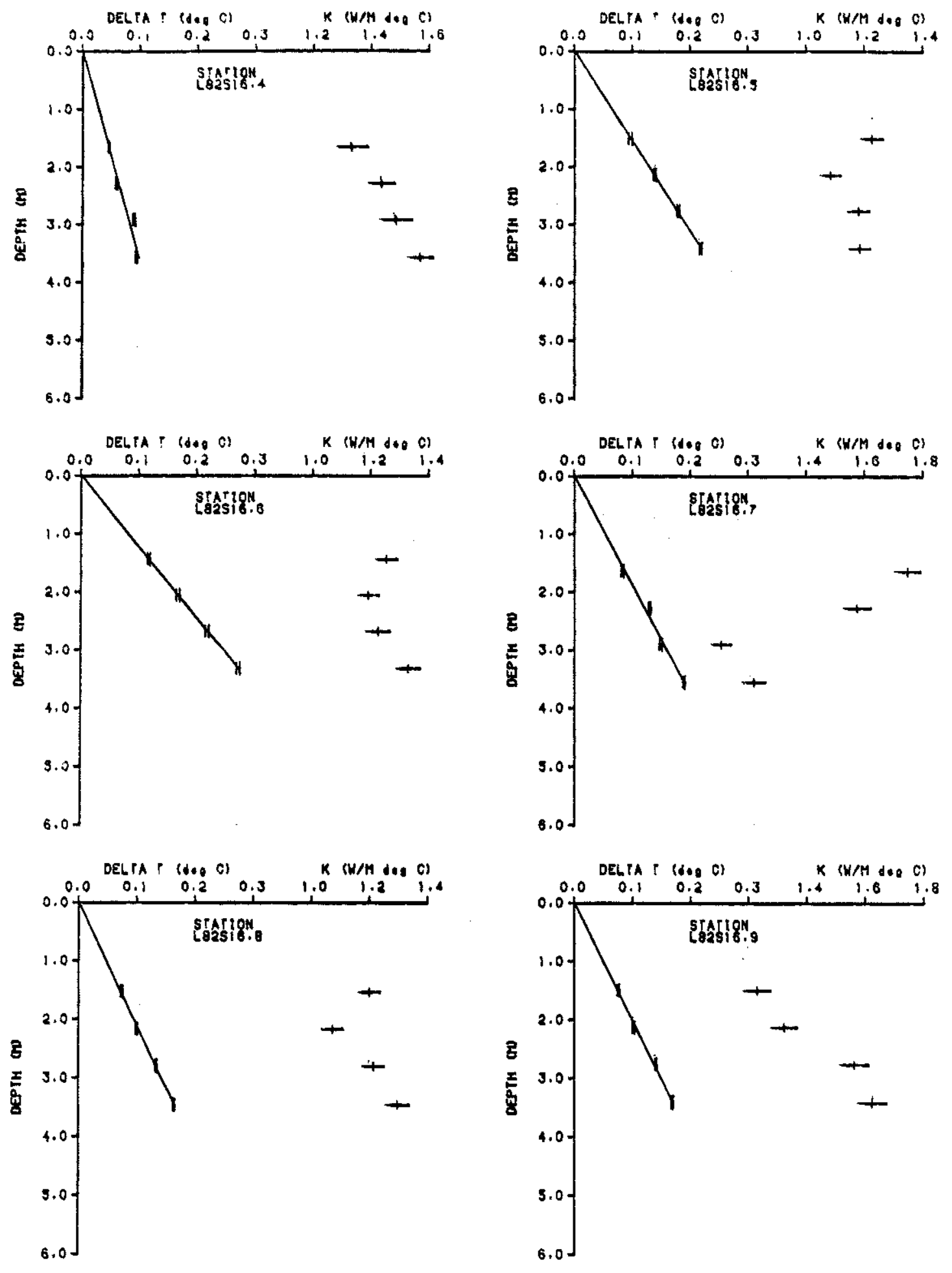

Fig. A4. 5 

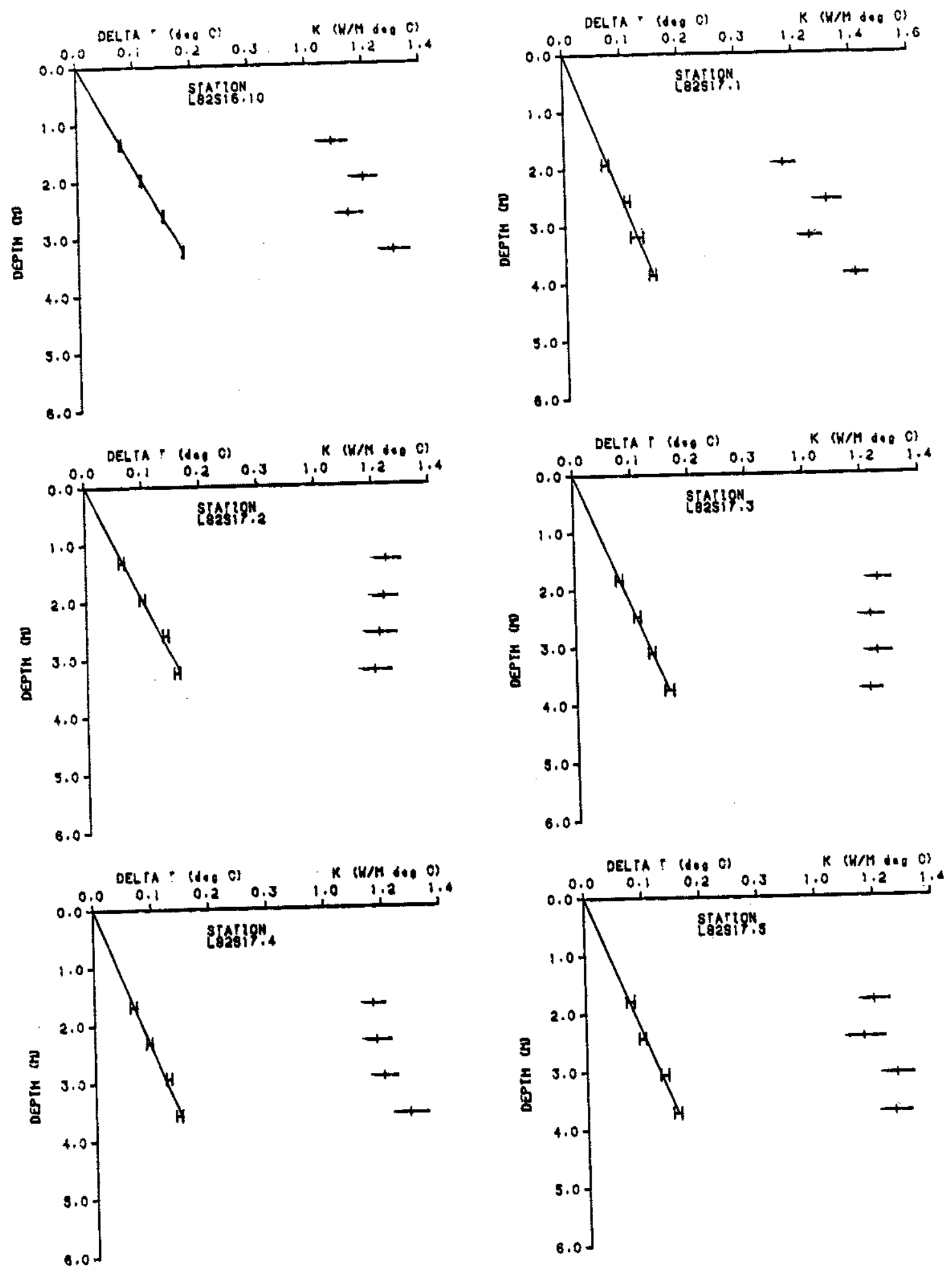

Fig. A4.6 

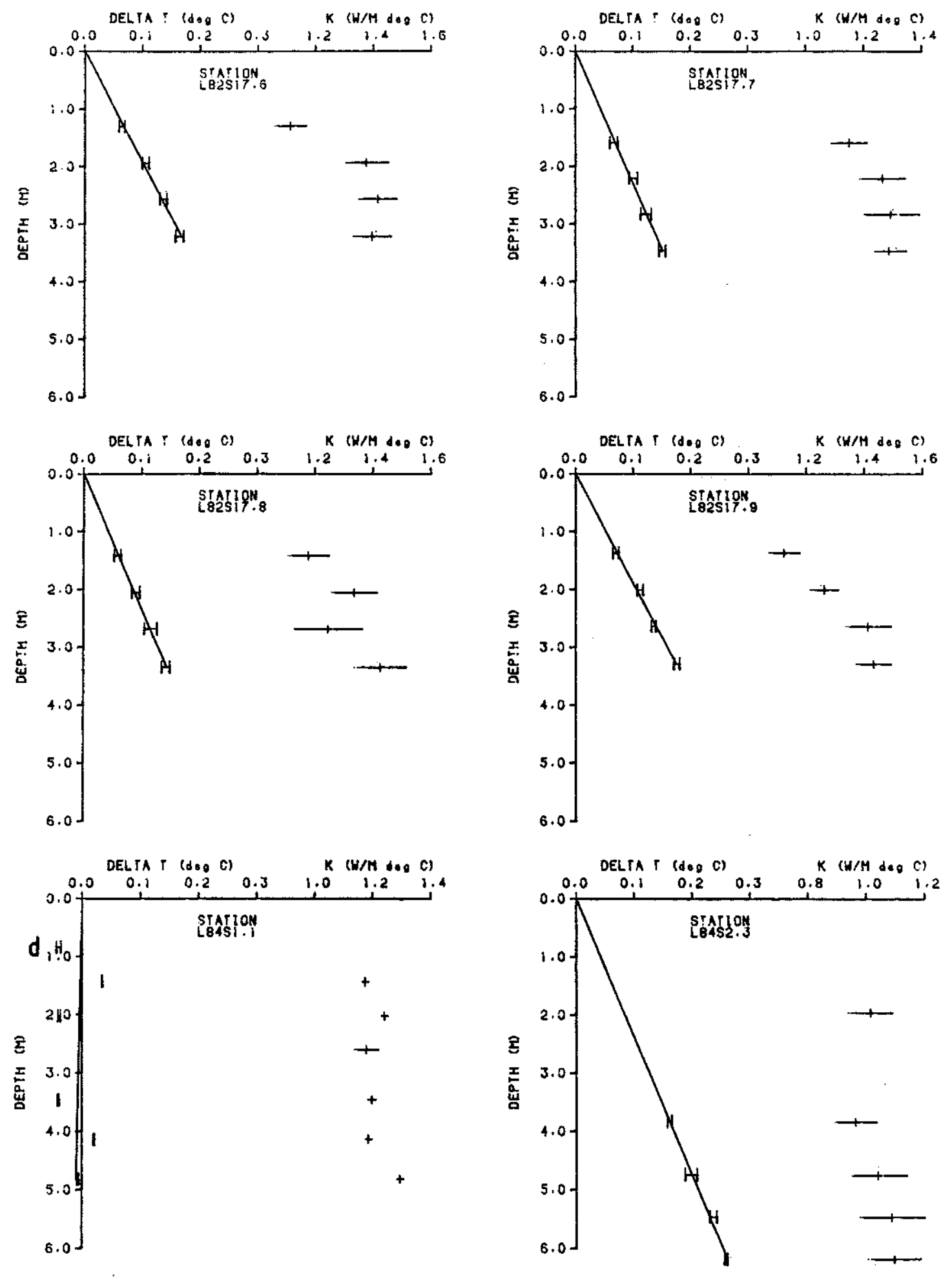

Fig. A4. 7 

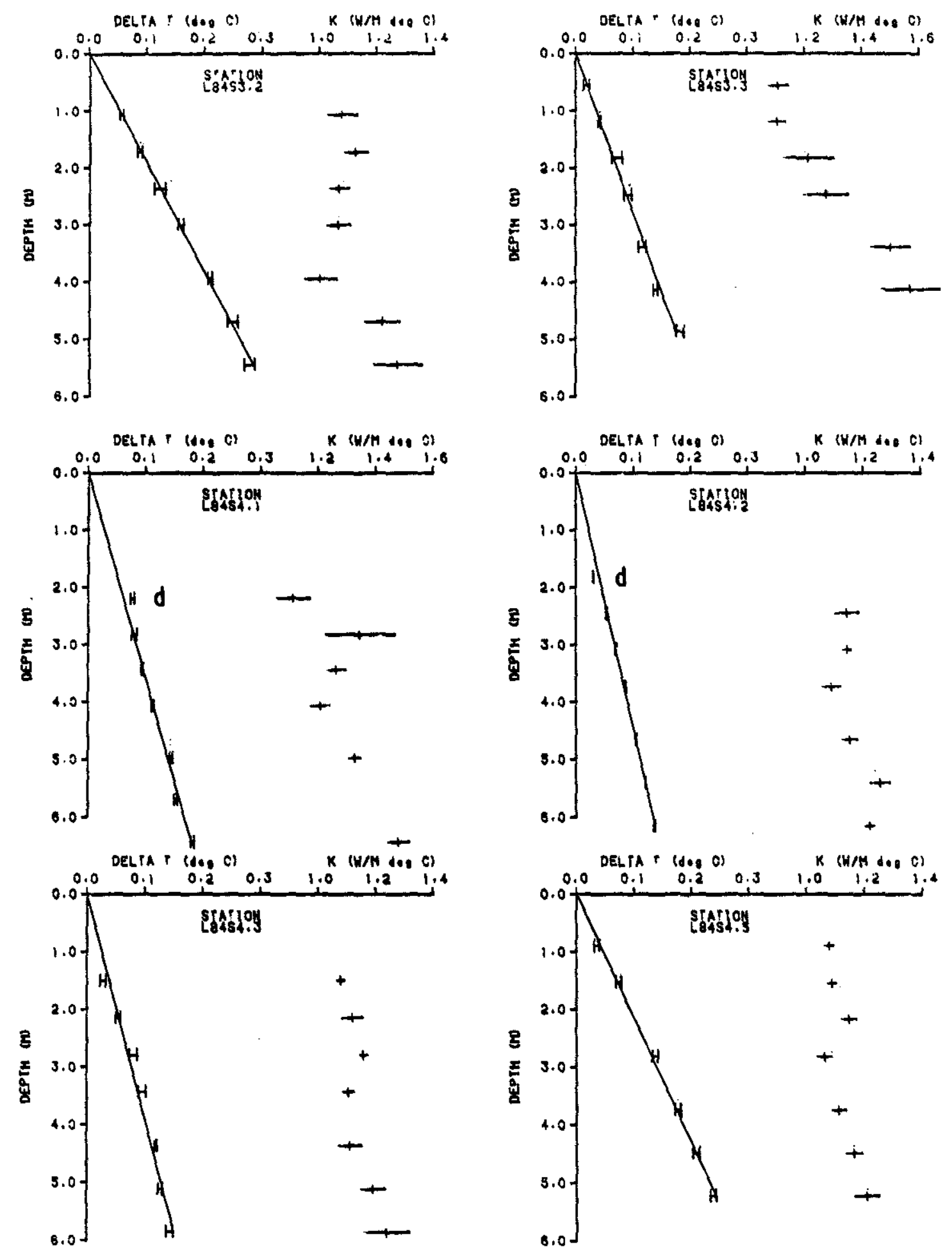

Fig. A4.8 

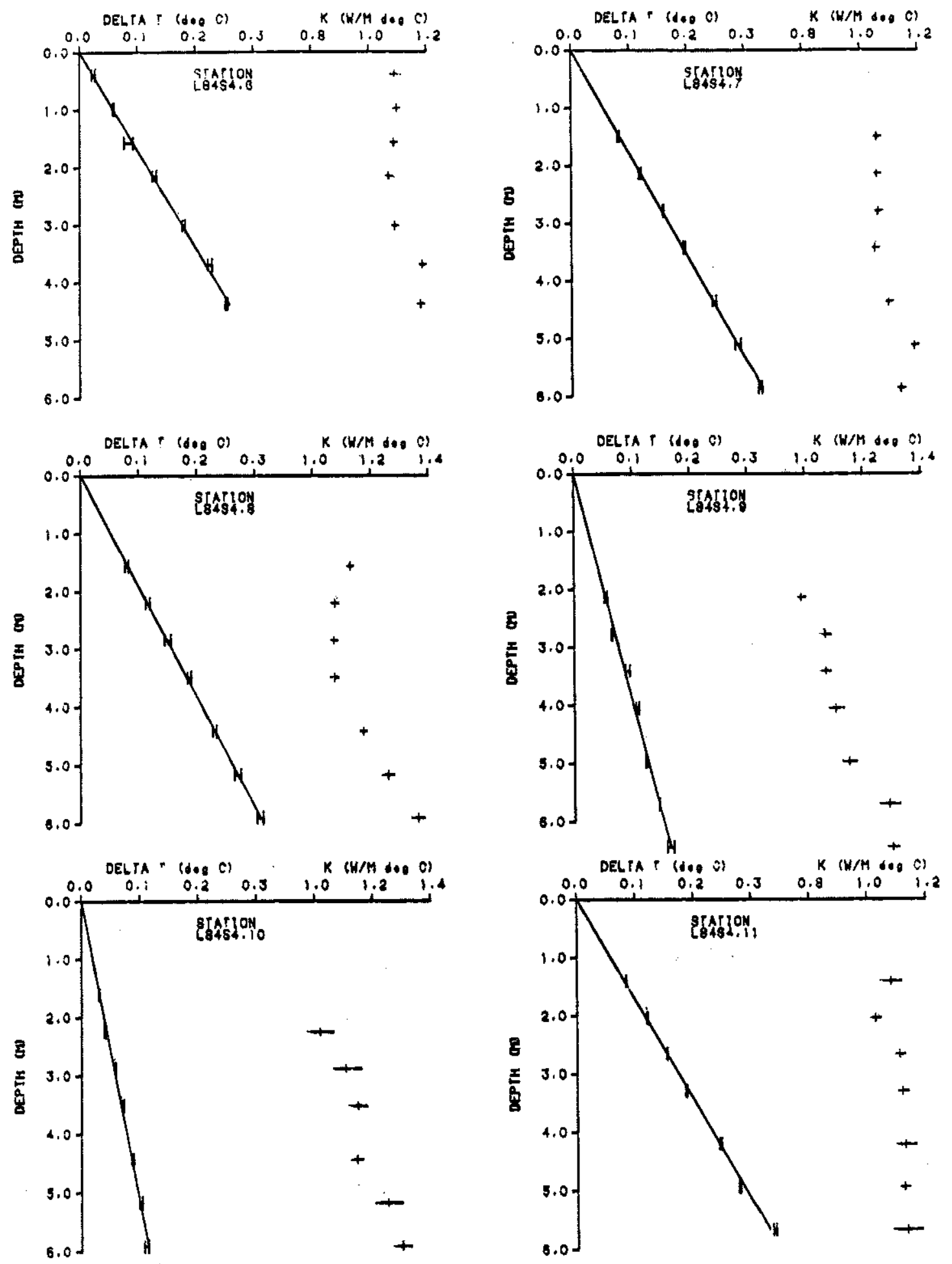

Fig. A4.9 

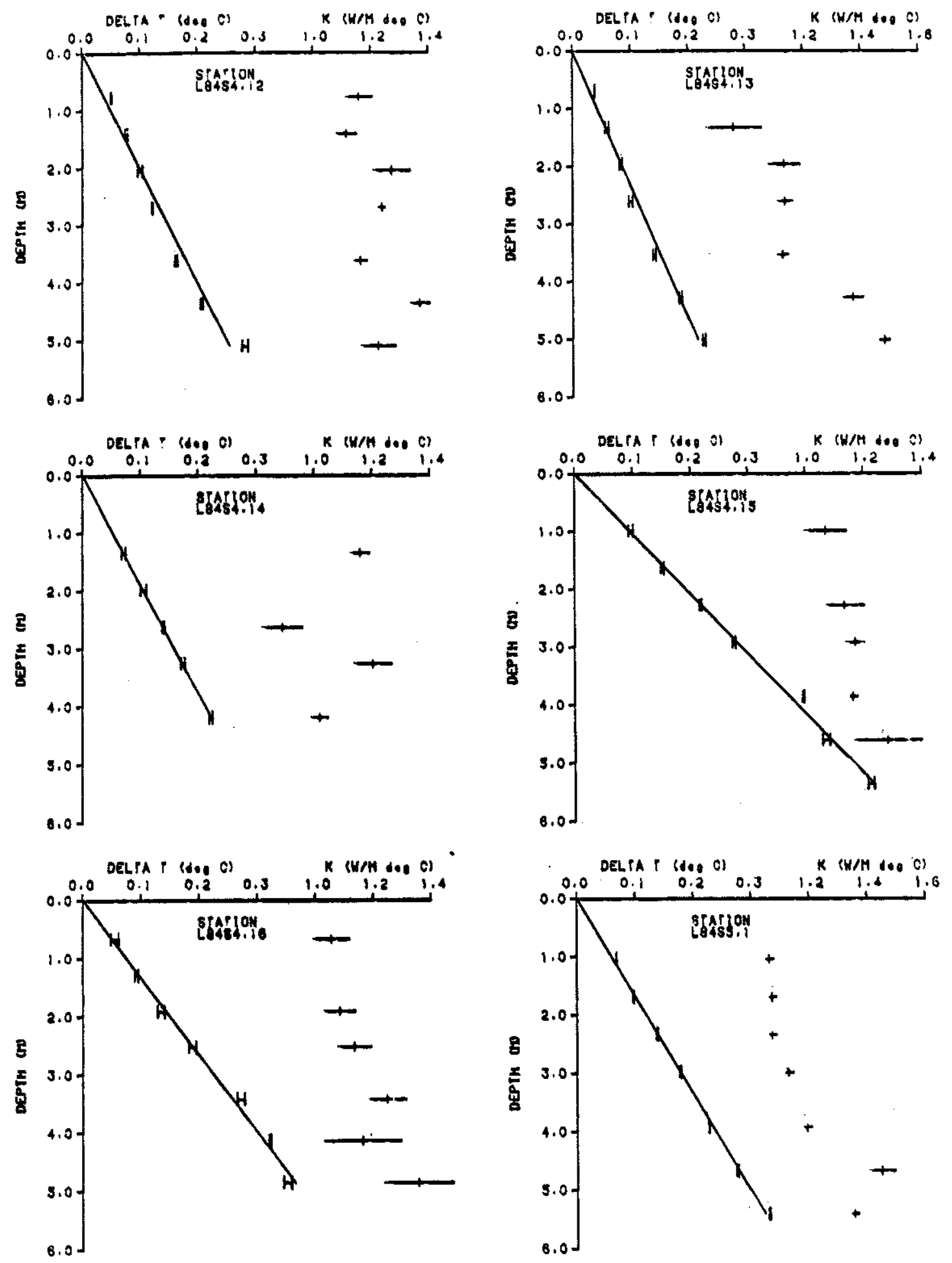

Fig. A4. 10 

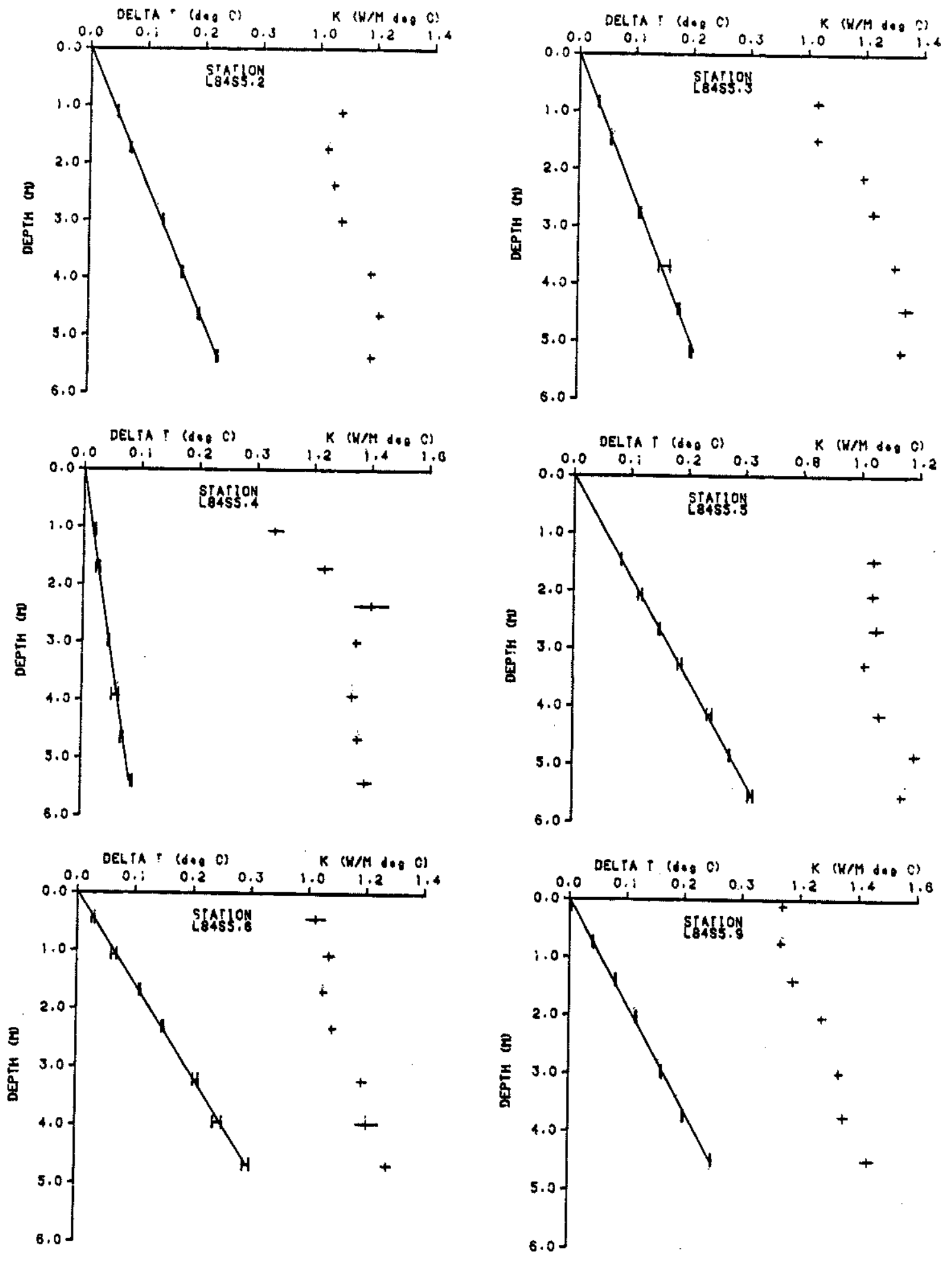

Fig. A4.11 

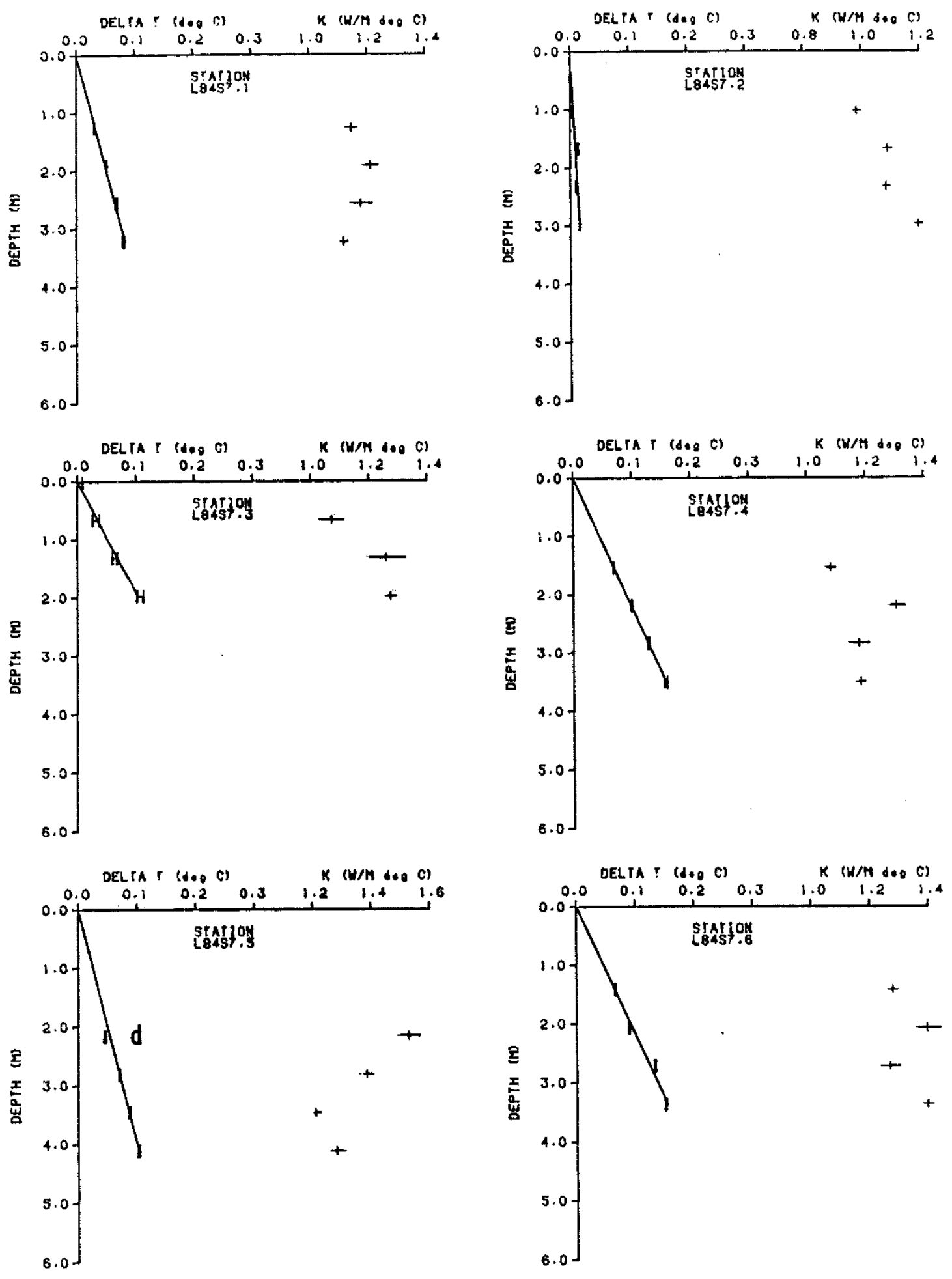

Fig. A4.12 

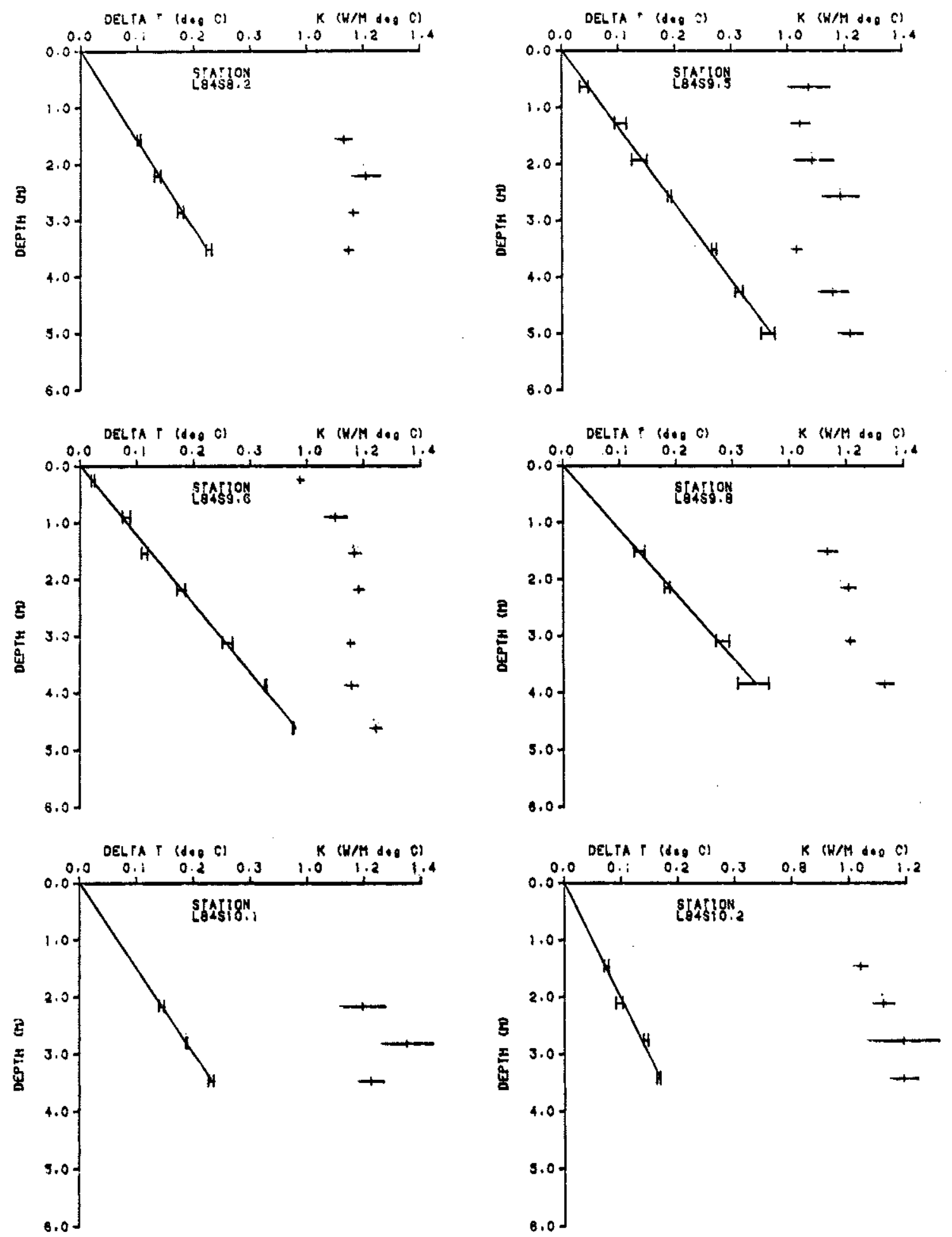

Fig. A4.13 

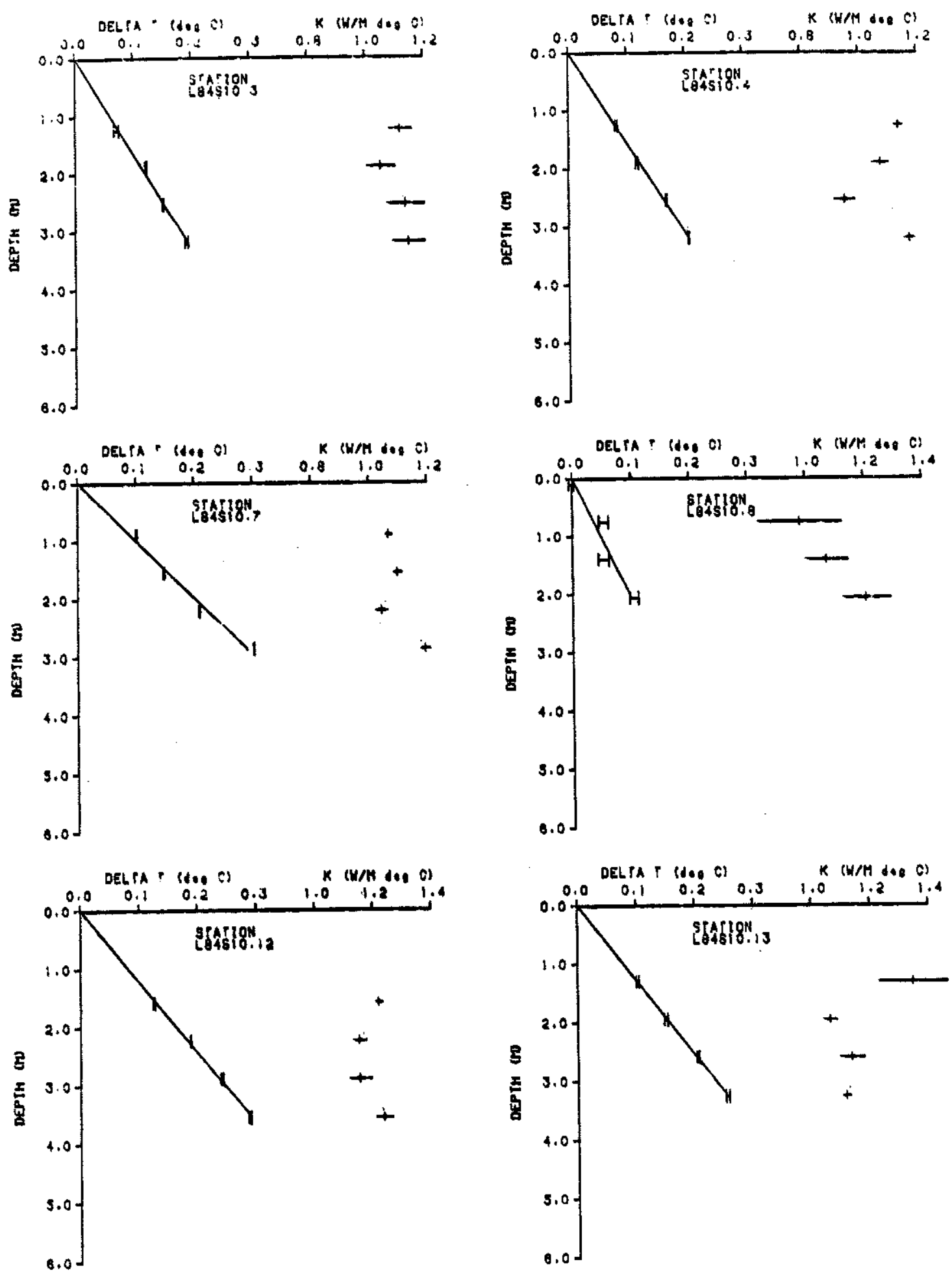

Fig. A4.14 

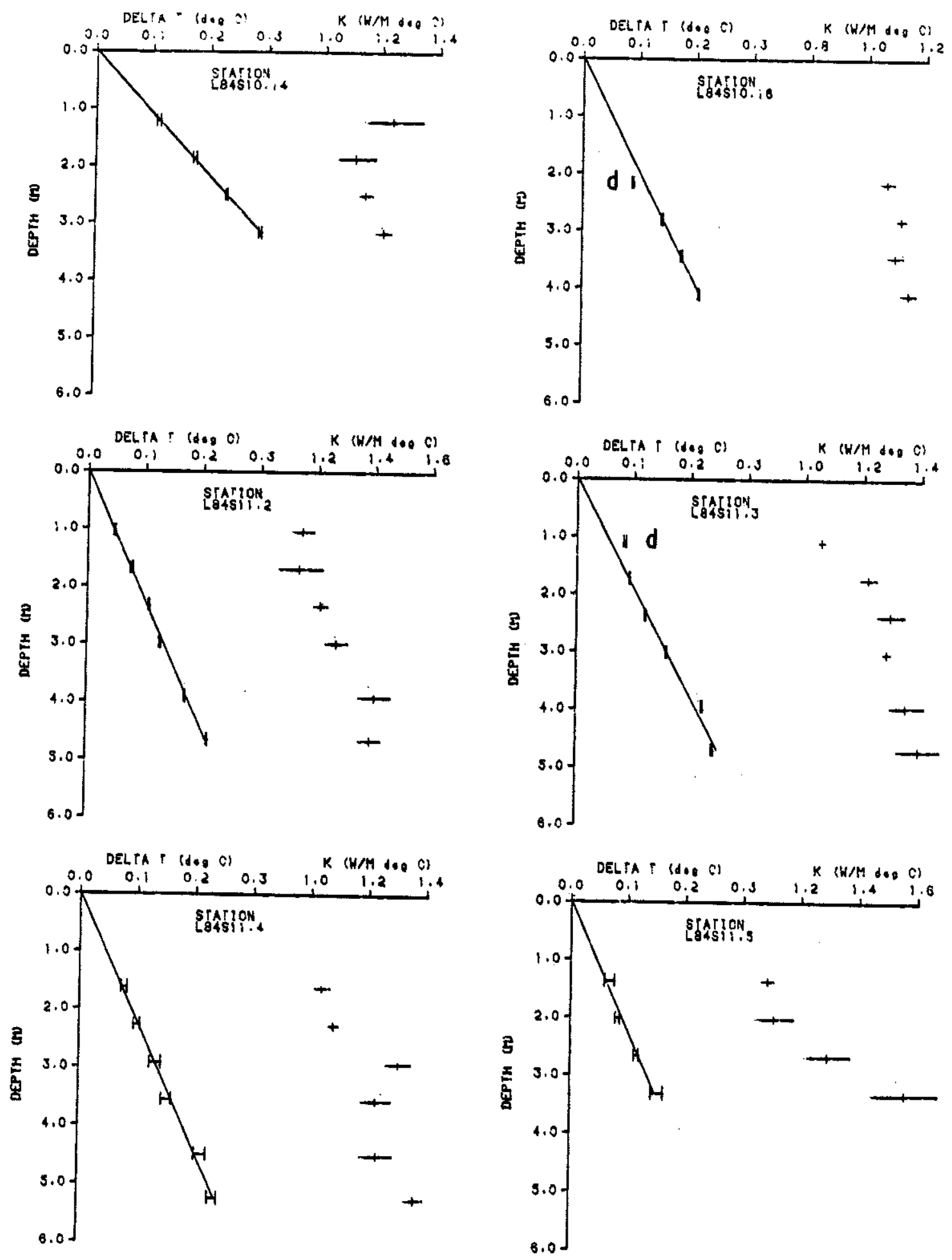

Fig. A4.15 

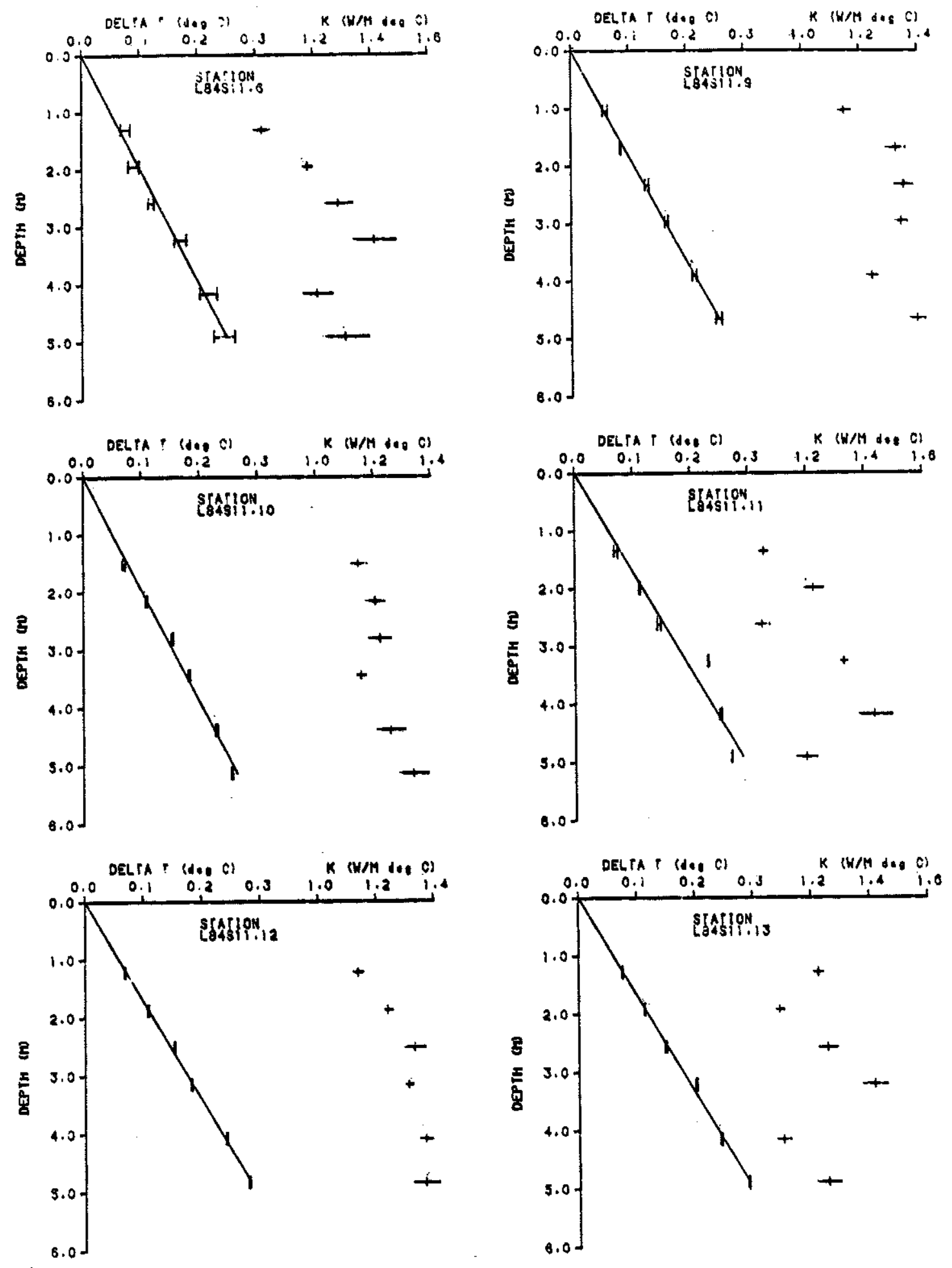

Fig. A4.16 

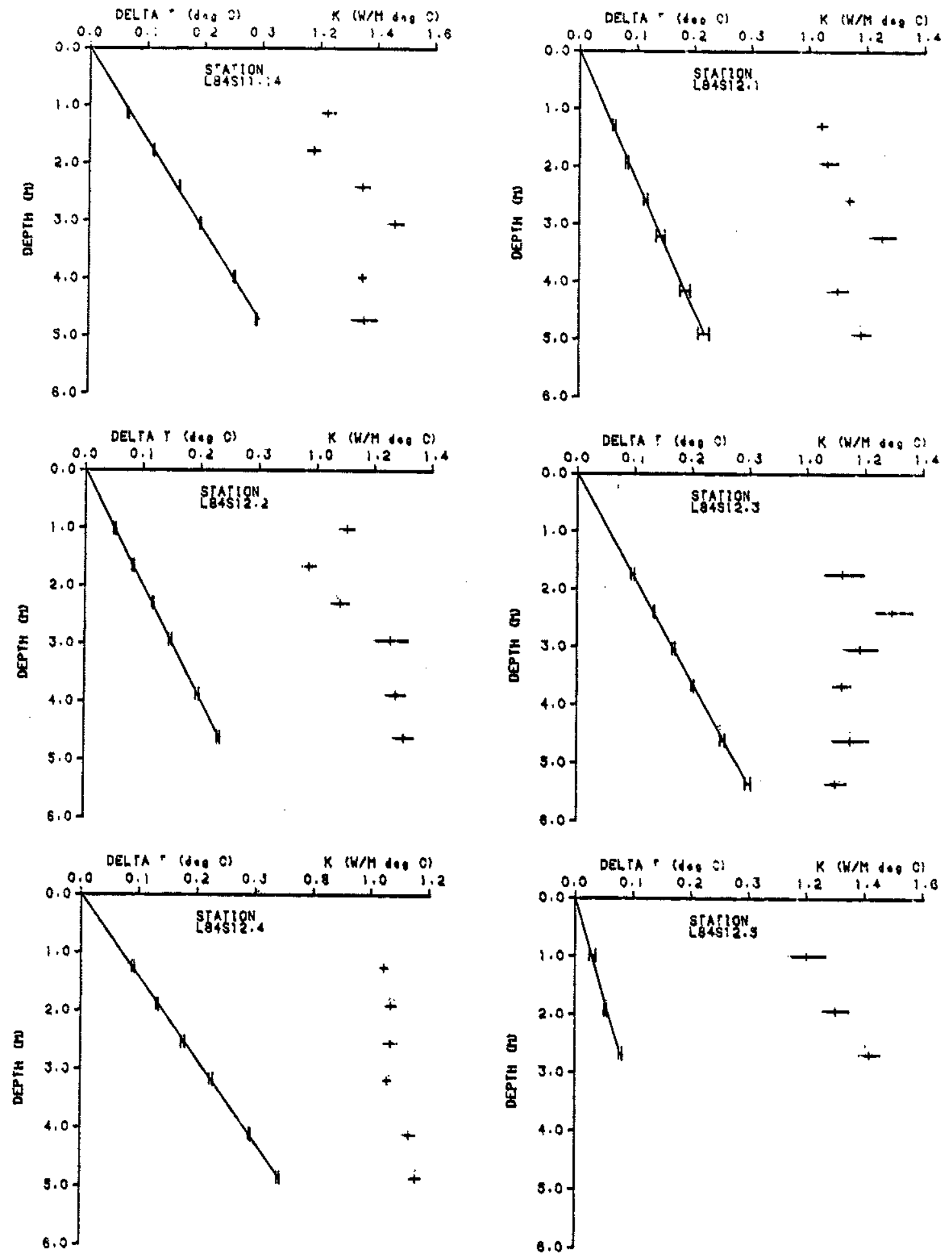

Fig. A4.17 
Figs. A4.18 - A4.21. Temperature versus depth plots and linear regression results for pogo stations without in situ conductivity. Adjacent station plots have temperatures offset by a multiple of $0.05 \mathrm{~K}$. See Figure A4.1 for further explanation. 

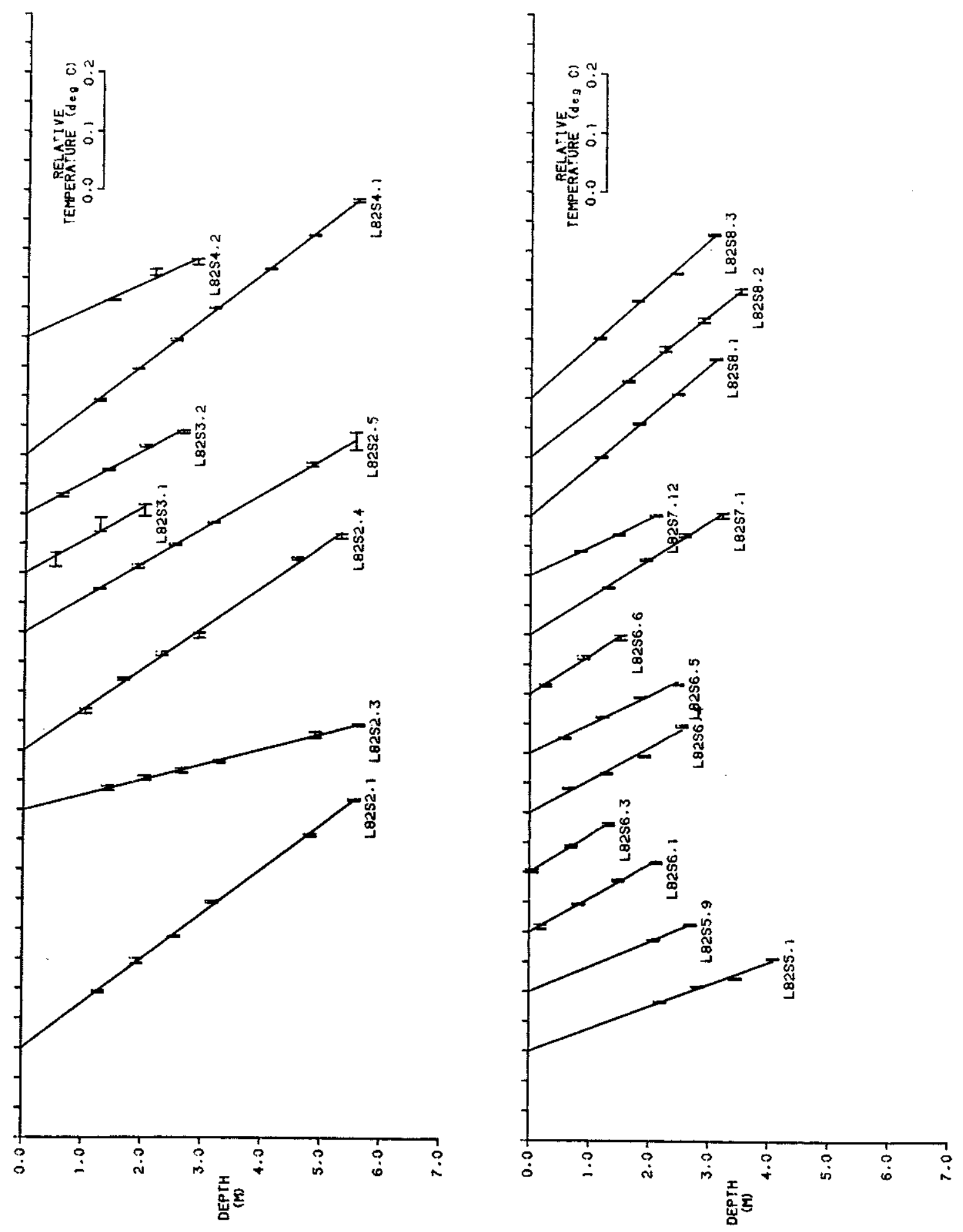

Fig. A4. 18 

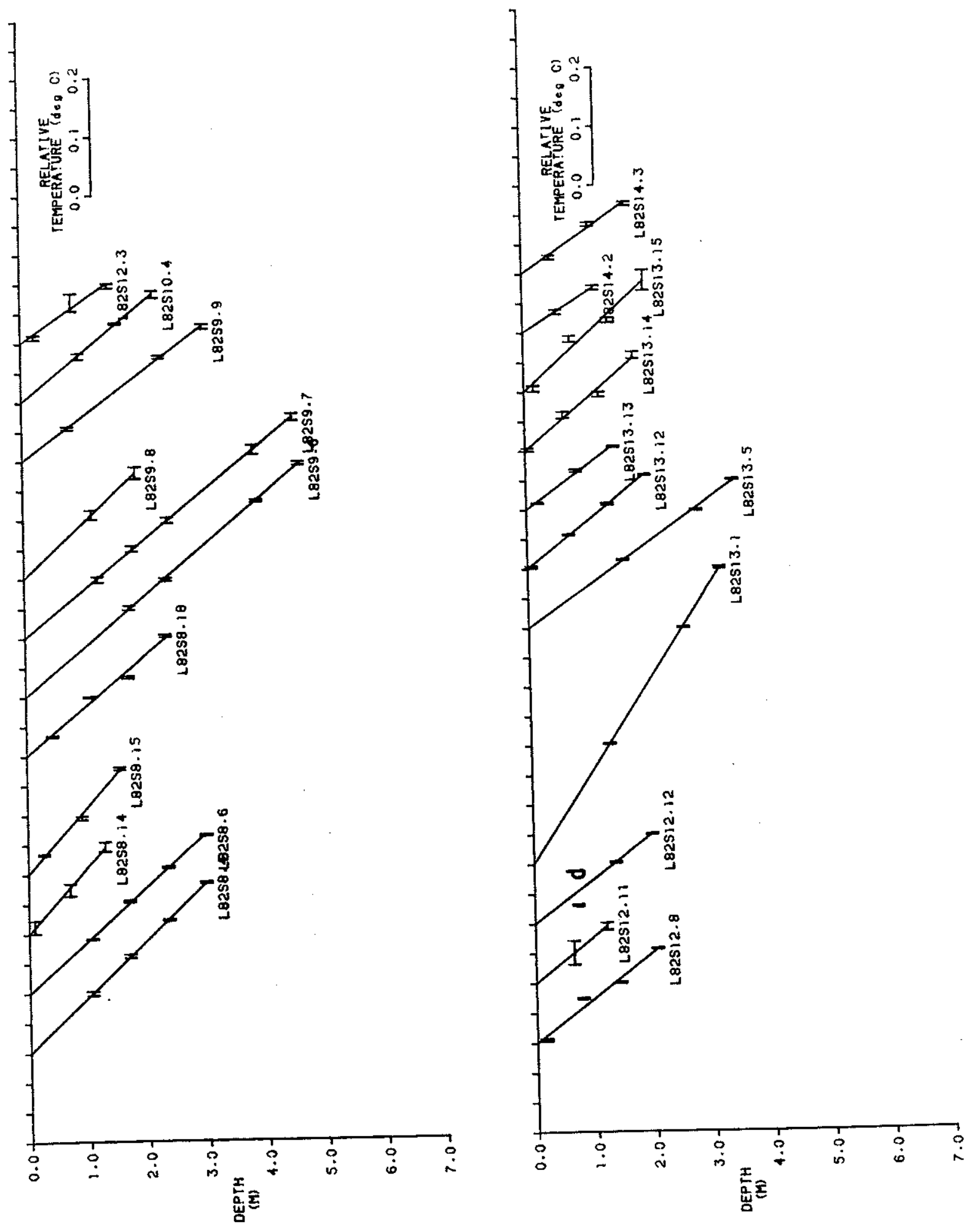

Fig. A4.19 

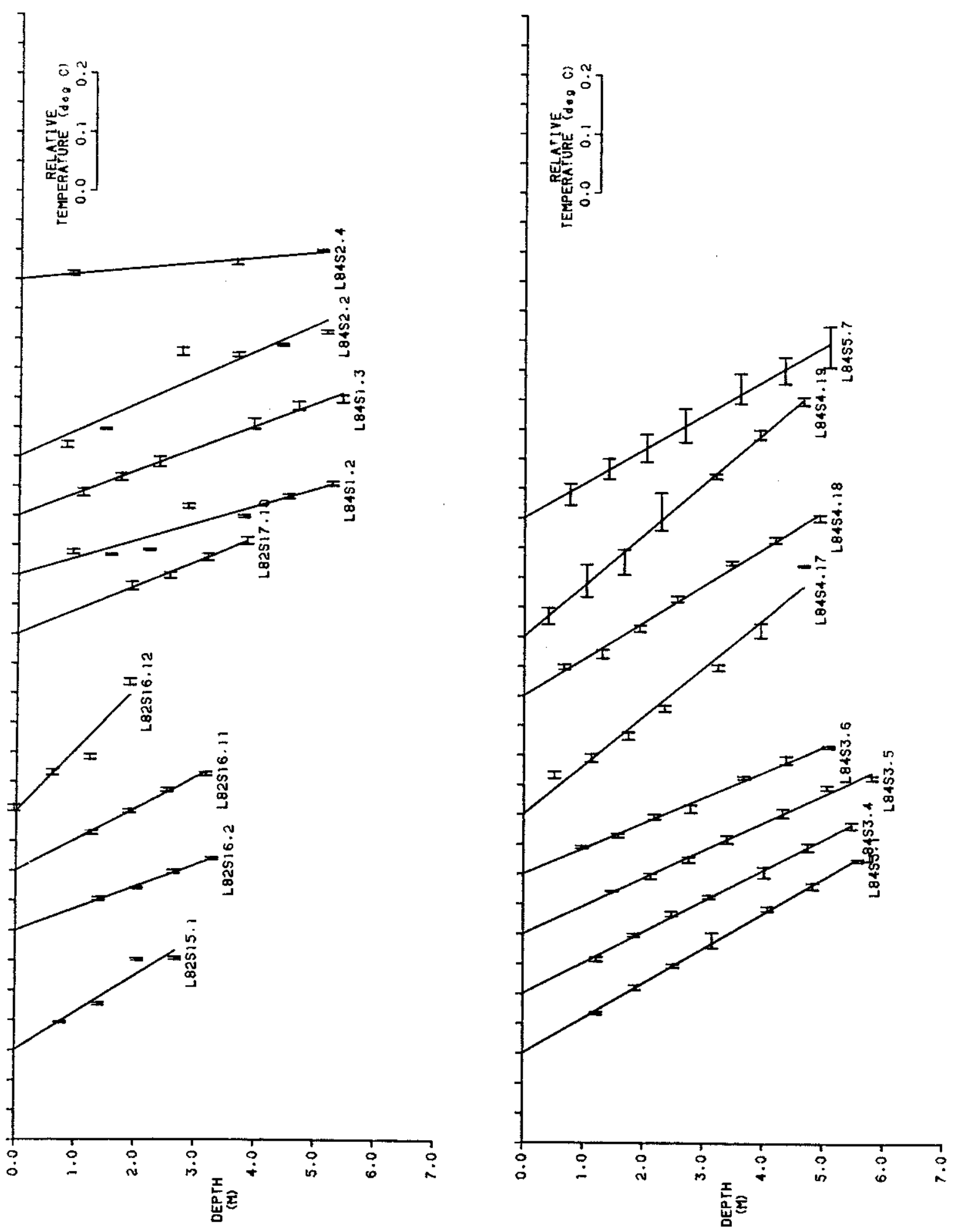

Fig. A4. 20 
$-446-$
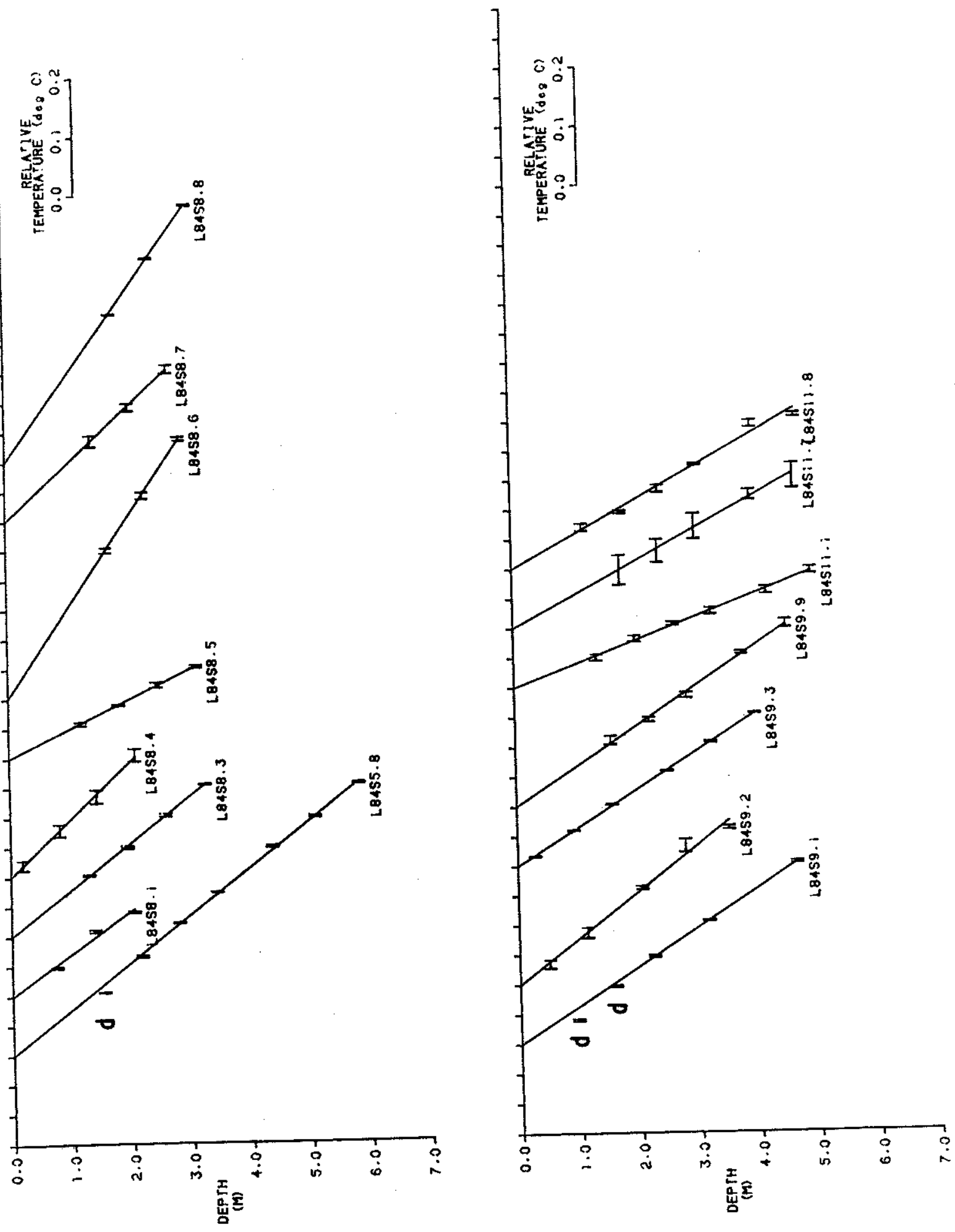

Fig. A4.21 
Table A4.2 Ligurian Sea Piston Core Stations

\begin{tabular}{|c|c|c|c|c|c|c|c|c|}
\hline \multirow{2}{*}{$\begin{array}{l}\text { Station } \\
\text { Number }\end{array}$} & \multirow[t]{2}{*}{ Site } & \multicolumn{2}{|c|}{ Location } & \multirow{2}{*}{$\begin{array}{l}\text { Water } \\
\text { Depth } \\
(m)\end{array}$} & \multirow{2}{*}{$\begin{array}{c}\text { Core } \\
\text { Length } \\
(\mathrm{m})\end{array}$} & \multirow{2}{*}{$\begin{array}{c}\text { Thermal } \\
\text { K } \\
\text { (W n }\end{array}$} & \multirow{2}{*}{$\begin{array}{c}\text { Conduct } \\
\Delta \mathrm{K} \\
\left.\mathrm{n}^{-1} \mathrm{~K}^{-1}\right)\end{array}$} & \multirow{2}{*}{$\begin{array}{l}\text { ivity } \\
\mathrm{N}_{\mathrm{K}}\end{array}$} \\
\hline & & Lat. $(\mathrm{N})$ & Lon. (E) & & & & & \\
\hline \multicolumn{9}{|l|}{ REGION A } \\
\hline L82PC06 & A3 & $43^{\circ} 33.3^{\prime}$ & $7^{\circ} 21.2^{\prime}$ & 1890 & 2.66 & 1.09 & 0.03 & 9 \\
\hline $\mathrm{L} 82 \mathrm{PC} 07$ & A4 & $43^{\circ} 37.4^{\prime}$ & $7^{\circ} 28.8^{\prime}$ & 980 & 3.06 & 1.14 & 0.05 & 9 \\
\hline L84PC01 & $\mathrm{A} 4$ & $43^{\circ} 33.2^{\prime}$ & $7^{\circ} 31.1$ & 2130 & 3.78 & 1.03 & 0.01 & 25 \\
\hline L84PC02 & $\mathrm{A} 4$ & $43^{\circ} 36.6^{\prime}$ & $7^{\circ} 29.1^{\prime}$ & 1450 & 3.25 & 1.07 & 0.02 & 21 \\
\hline $\mathrm{L} 84 \mathrm{PC} 03$ & $\mathrm{~A} 4$ & $43^{\circ} 38.3^{\prime}$ & $7^{\circ} 28.4^{\prime}$ & 1080 & 4.37 & 1.10 & 0.02 & 27 \\
\hline $\mathrm{L} 84 \mathrm{PCO} 4$ & A4 & $43^{\circ} 41.6^{\prime}$ & $7^{\circ} 28.2^{\prime}$ & 505 & 4.37 & 1.20 & 0.02 & 27 \\
\hline \multicolumn{9}{|c|}{$\begin{array}{l}\text { REGION B } \\
\text { (none taken) }\end{array}$} \\
\hline \multicolumn{9}{|l|}{ REGION C } \\
\hline L82PC05 & $\mathrm{C} 2$ & $43^{\circ} 31.8^{\prime}$ & $7^{\circ} 48.2^{\prime}$ & 2150 & 2.66 & 1.33 & 0.07 & 12 \\
\hline \multicolumn{9}{|l|}{ REGION D } \\
\hline $\mathrm{L} 82 \mathrm{PCO} 2$ & D3 & $42^{\circ} 56.9^{\prime}$ & $8^{\circ} 33.7^{\prime}$ & 2560 & 1.67 & 1.05 & 0.04 & 9 \\
\hline L82PC03 & D1 & $42^{\circ} 57.0^{\circ}$ & $8^{\circ} 19.0^{\prime}$ & 2600 & 1.46 & 1.21 & 0.13 & 9 \\
\hline L82PC04 & D3 & $43^{\circ} 9.3^{\circ}$ & $8^{\circ} 27.3^{\prime}$ & 2565 & 1.87 & 1.21 & 0.11 & 8 \\
\hline L84PC05 & $\mathrm{D} 2$ & $43^{\circ} 10.1^{\prime}$ & $8^{\circ} 11.9^{\prime}$ & 2525 & 1.40 & 1.21 & 0.08 & 15 \\
\hline \multicolumn{9}{|l|}{ REGION E } \\
\hline L82PC01 & E2 & $42^{\circ} 49.9^{\prime}$ & $8^{\circ} 40.8^{\prime}$ & 2360 & 2.75 & 1.09 & 0.02 & 18 \\
\hline L84PC06 & E3 & $43^{\circ} 14.0^{\circ}$ & $8^{\circ} 36.0^{\prime}$ & 2555 & 2.96 & 1.07 & 0.02 & 29 \\
\hline $\mathrm{L} 84 \mathrm{PC} 07$ & E3 & $43^{\circ} 17.0^{\prime}$ & $8^{\circ} 39.0^{\prime}$ & 2535 & 2.47 & 1.02 & 0.03 & 22 \\
\hline
\end{tabular}


Figs. A4.22 - A4.24. Plots of thermal conductivity versus depth for piston cores obtained in the Ligurian Sea during the 1982 and 1984 heat flow surveys. Depths are from the top of the core, although these depths may have to be increased by 0.5 to $1 \mathrm{~m}$ to represent in situ depth below the bottom (see Appendix 2). Locations and the harmonic means are given in Table A4.2. 

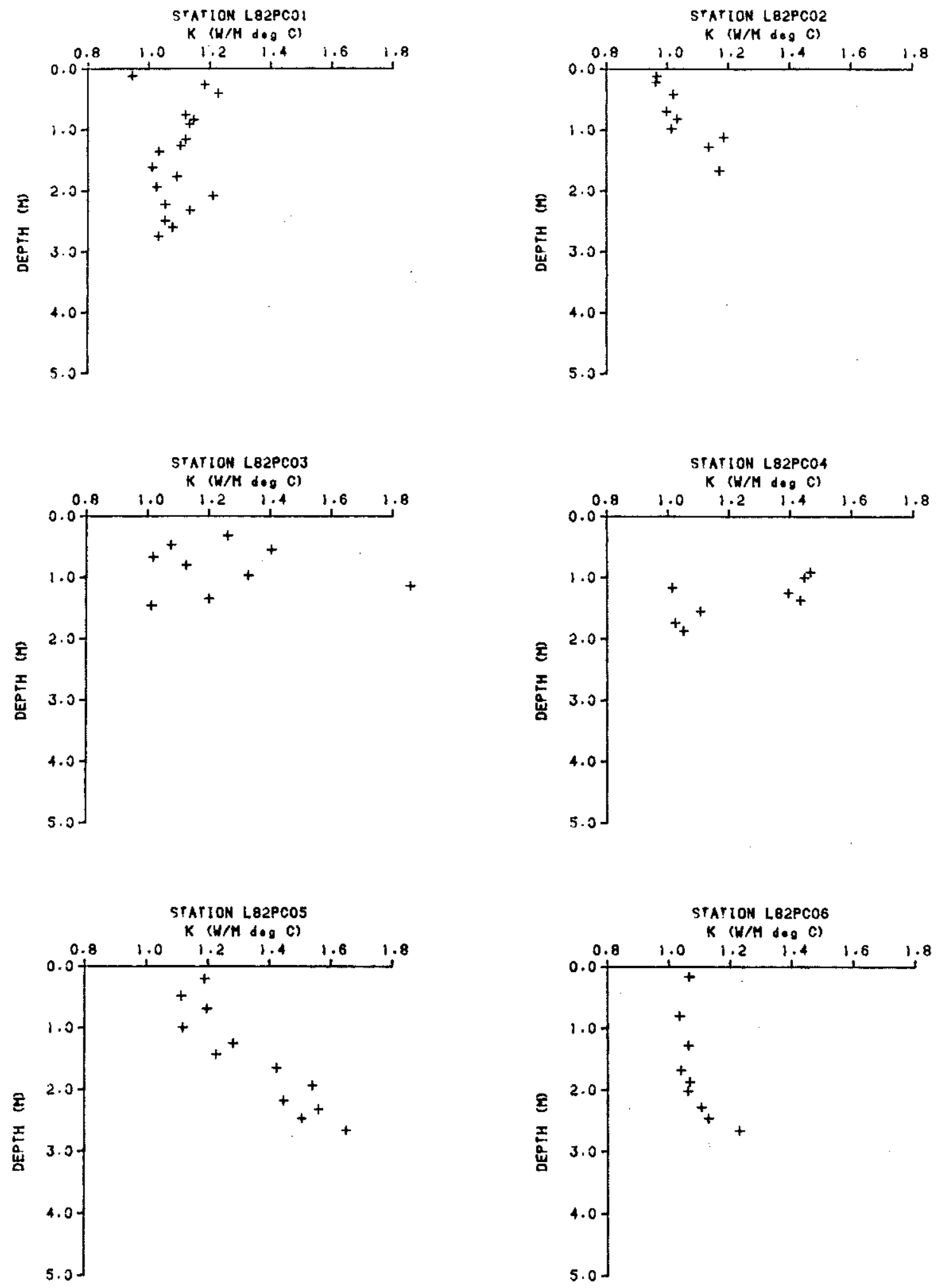

Fig. A4.22 

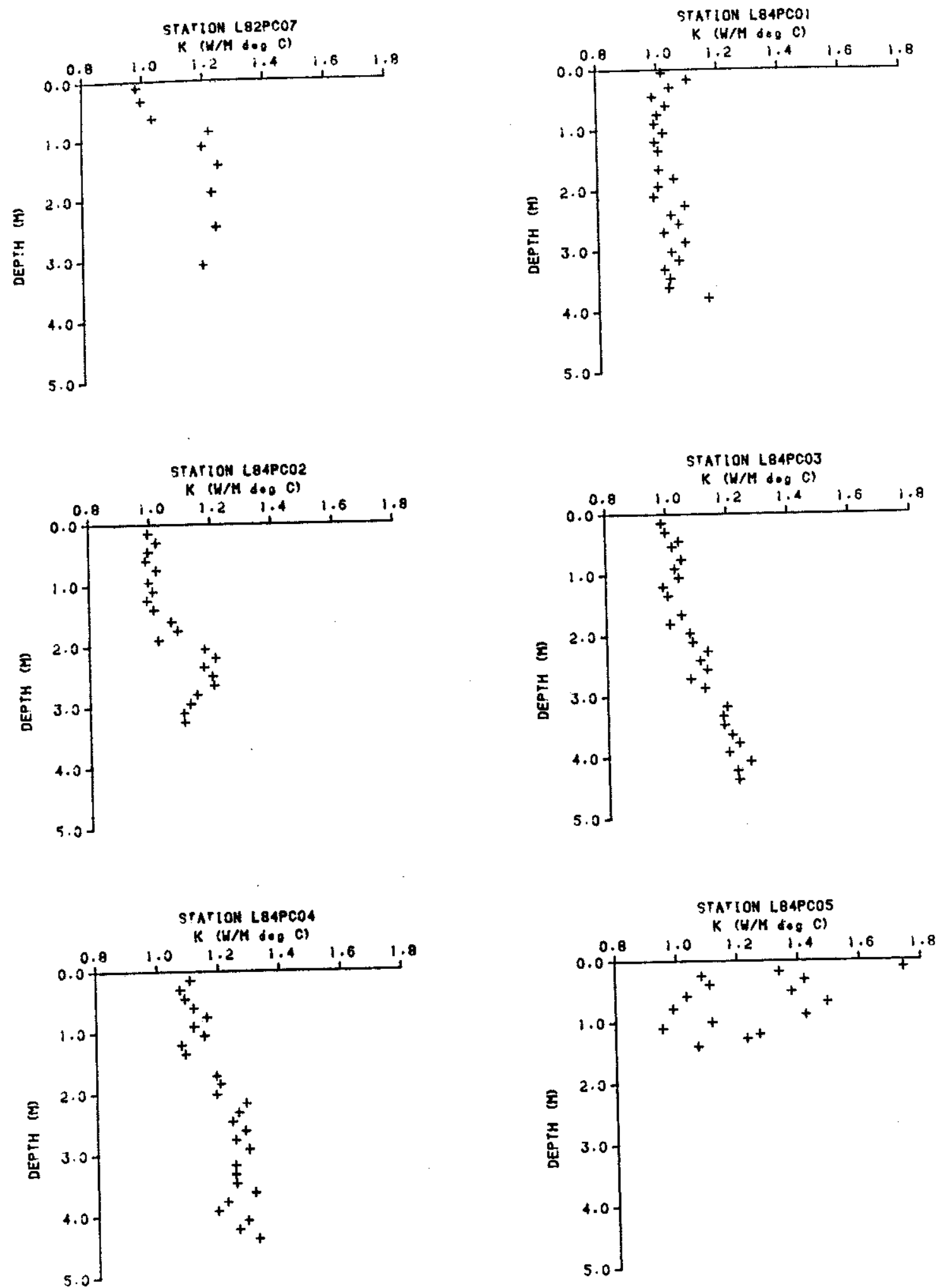

Fig. A4.23 

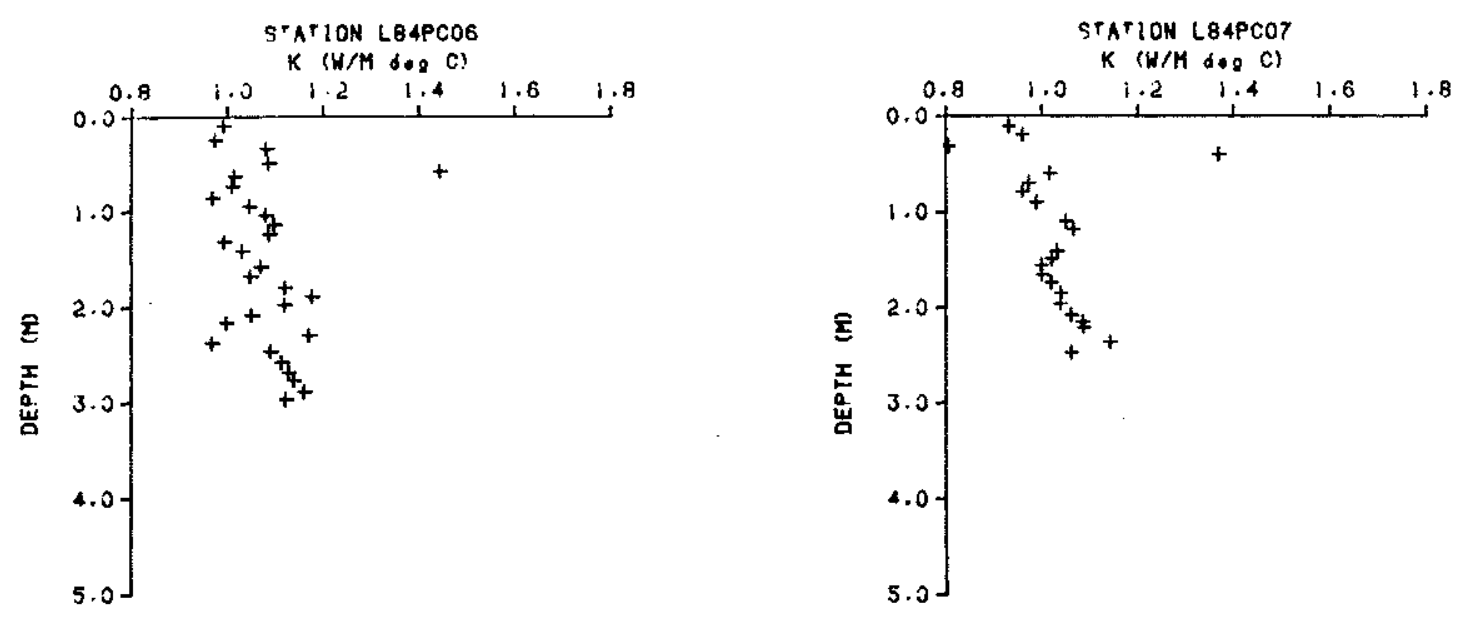

Fig. A4.24 


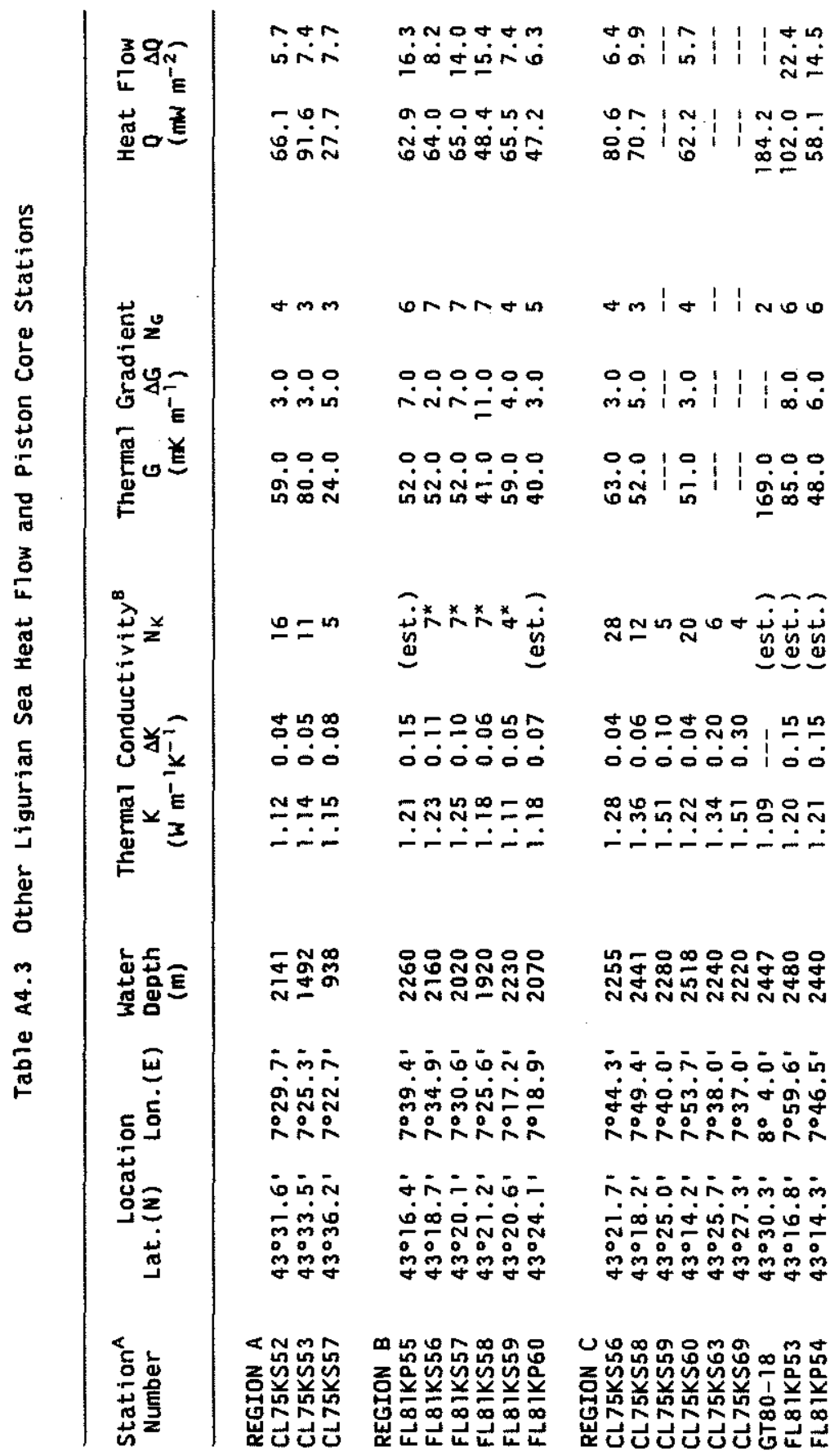




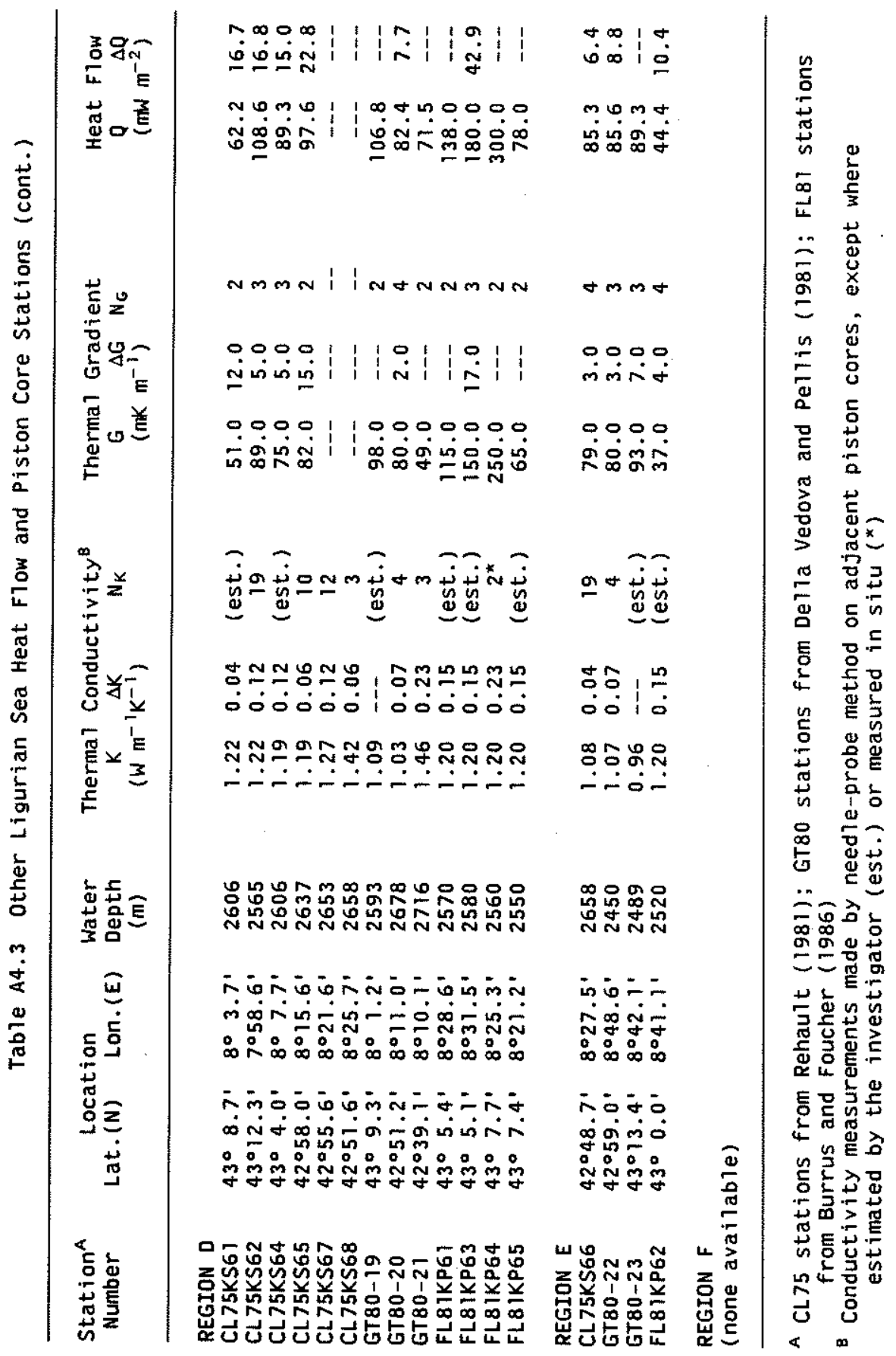




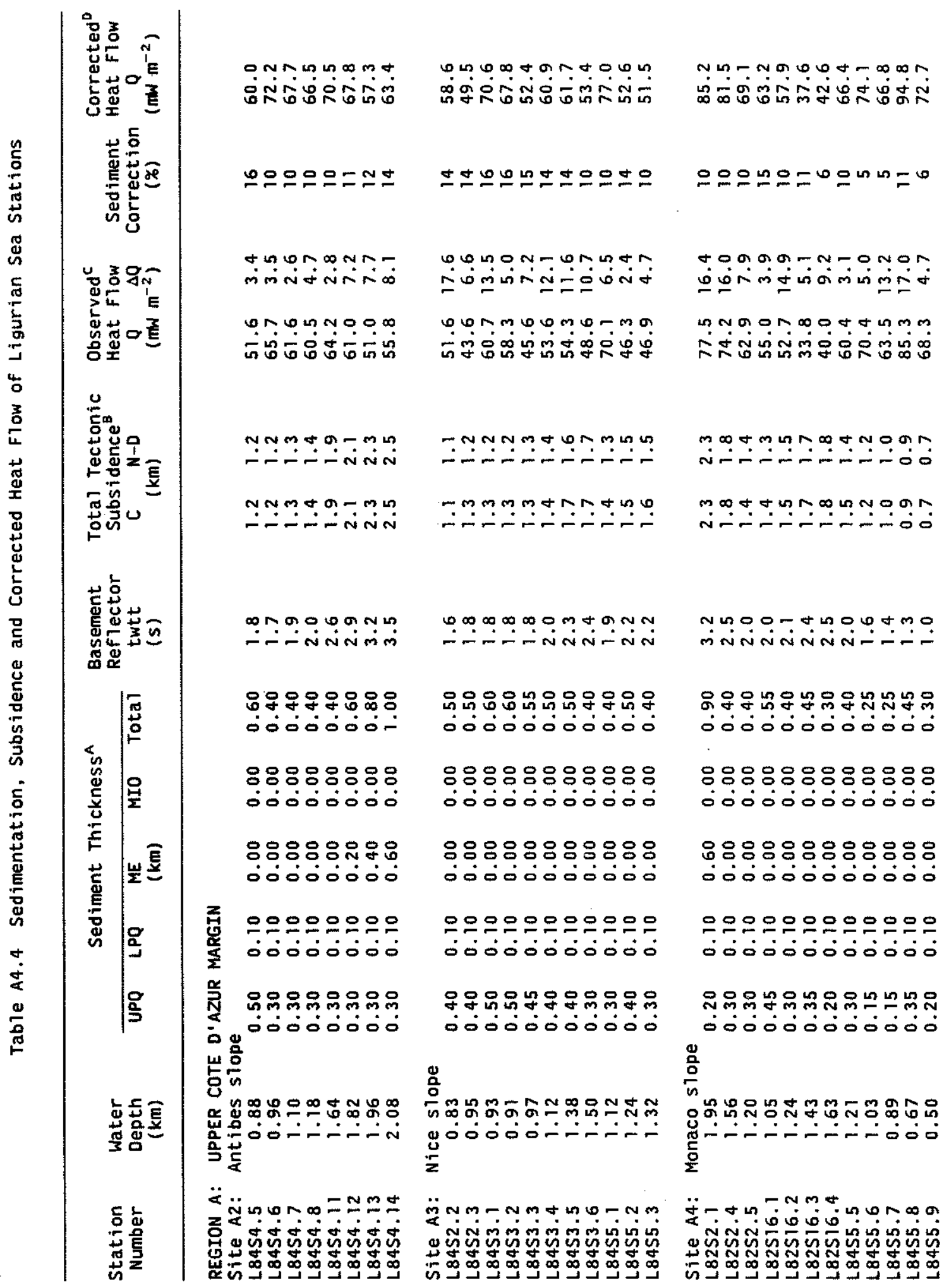




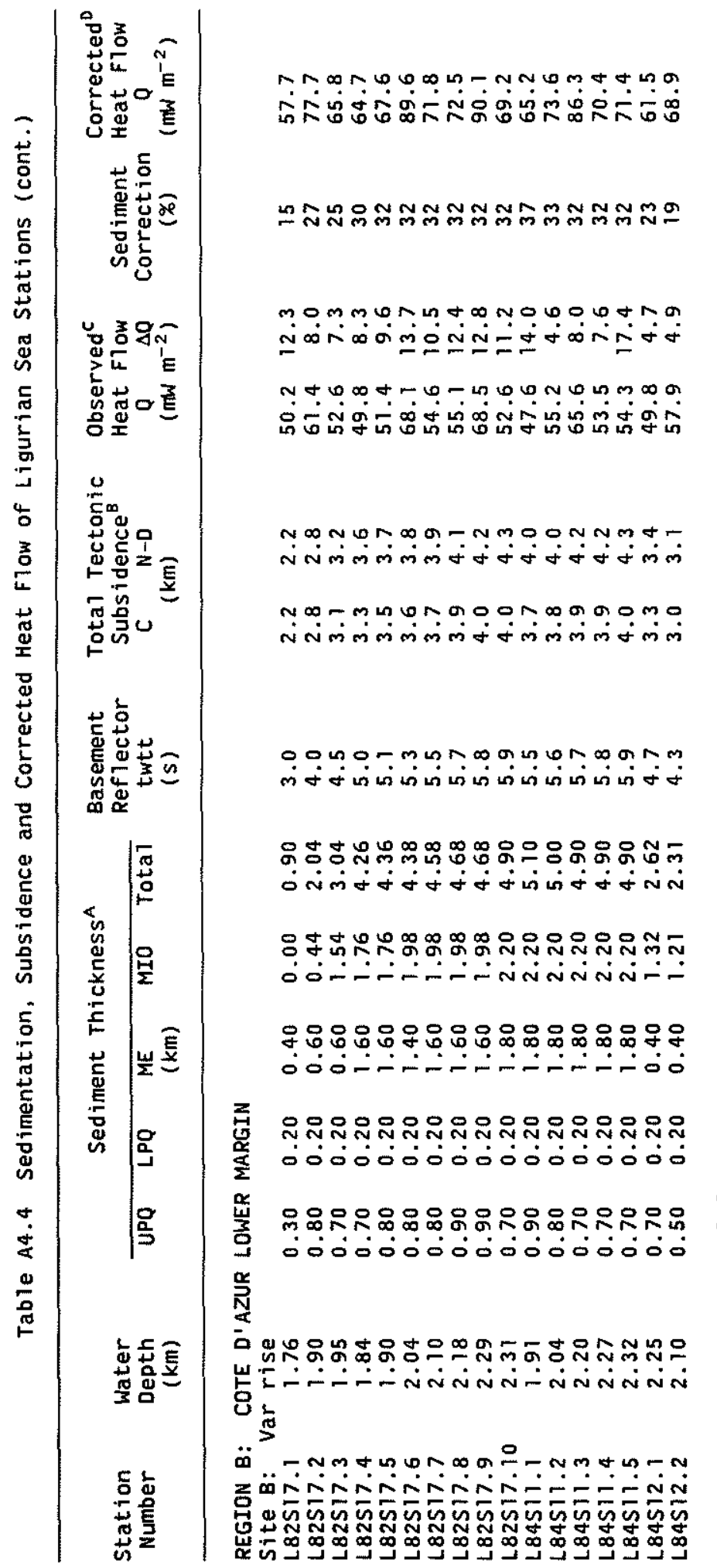

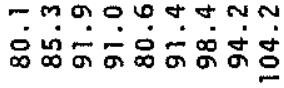

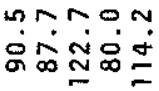

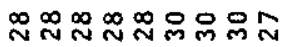

กิกำ:

mน0mot $0+\infty$ ำกำ

แ นก

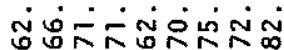

กำ: M늄ㄷㄴ

กตนก -

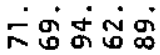

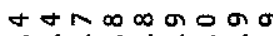

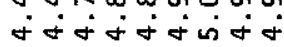

- -

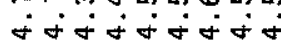

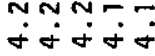

$00+40 \wedge \infty 00$

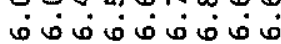

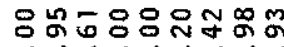
ن

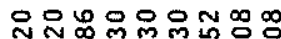

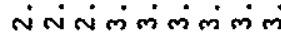

ํํำำำำ

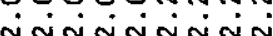

ํํํํํํํํํํำ

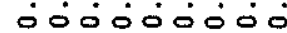

壳

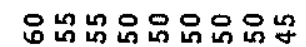
प 窟

.

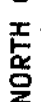

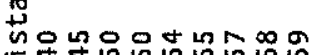

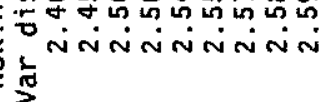

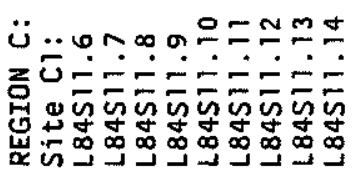

- nmo

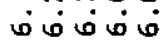

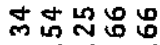
जिंजिक

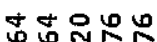
inNi-

ำํํำ nNNNN

ํํํํํํำ ठवं०ठ

은은유요 ᄃ00000 咅

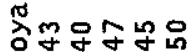
Inininin $\stackrel{5}{5}$

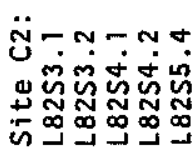




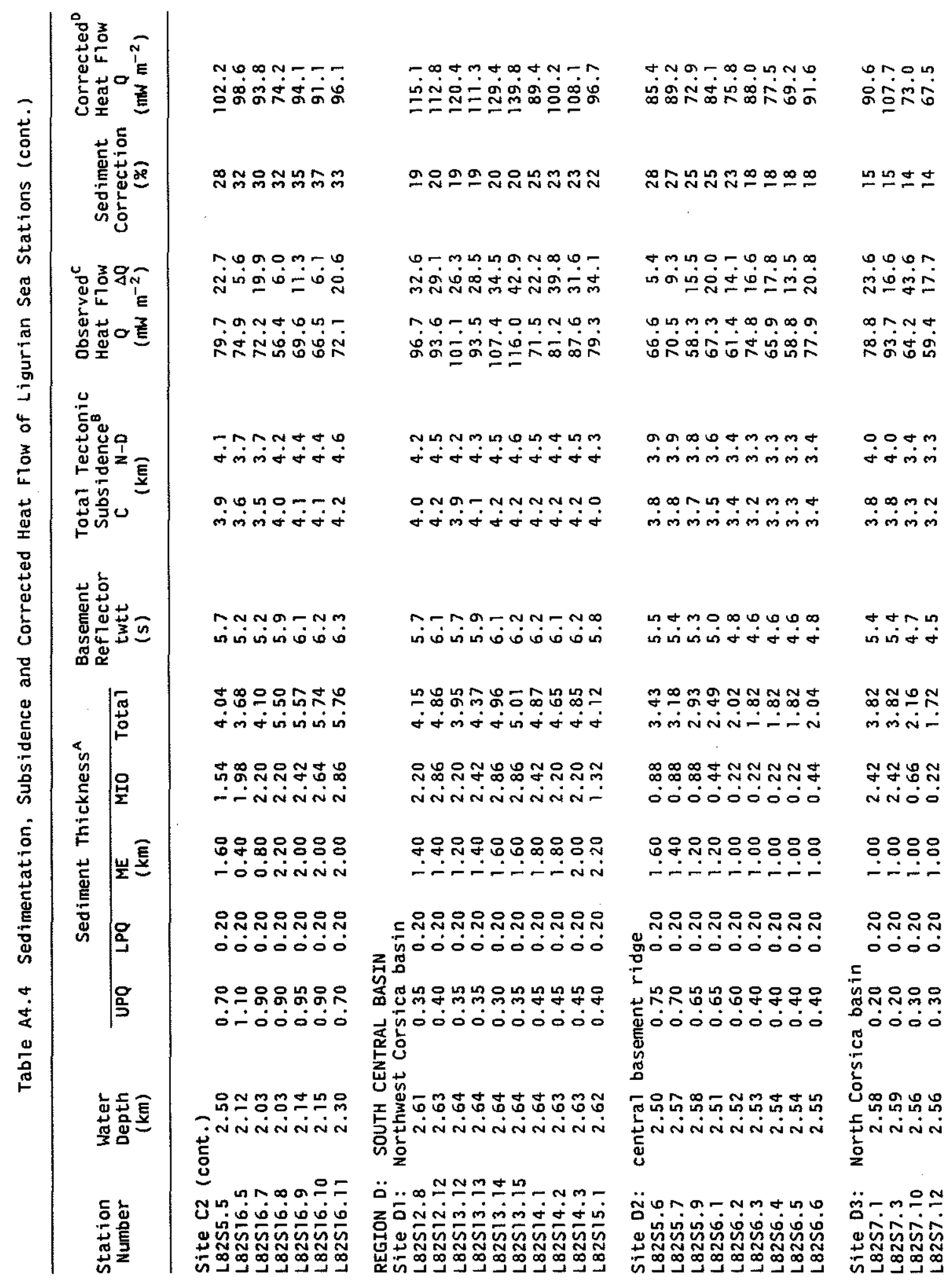




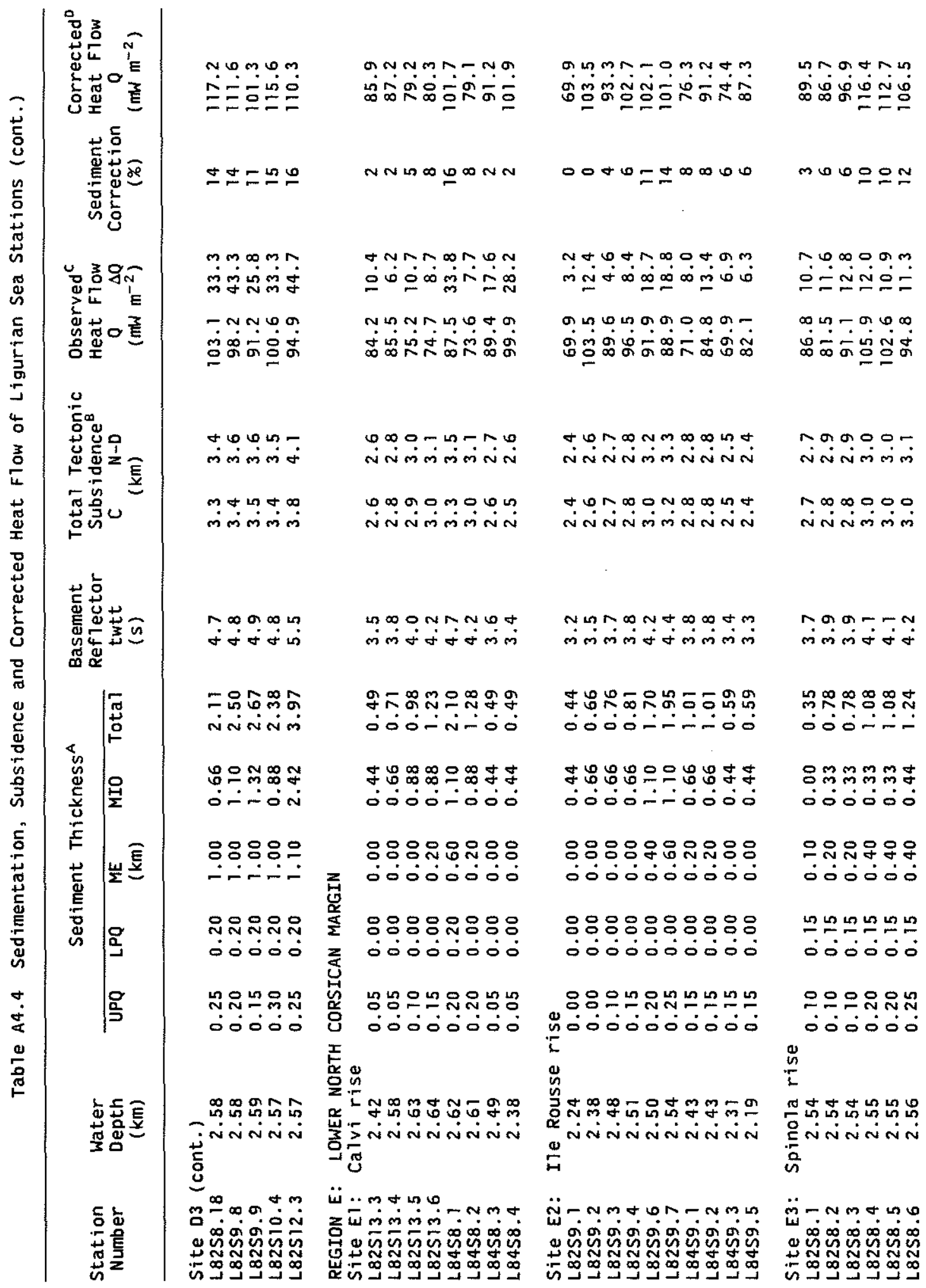




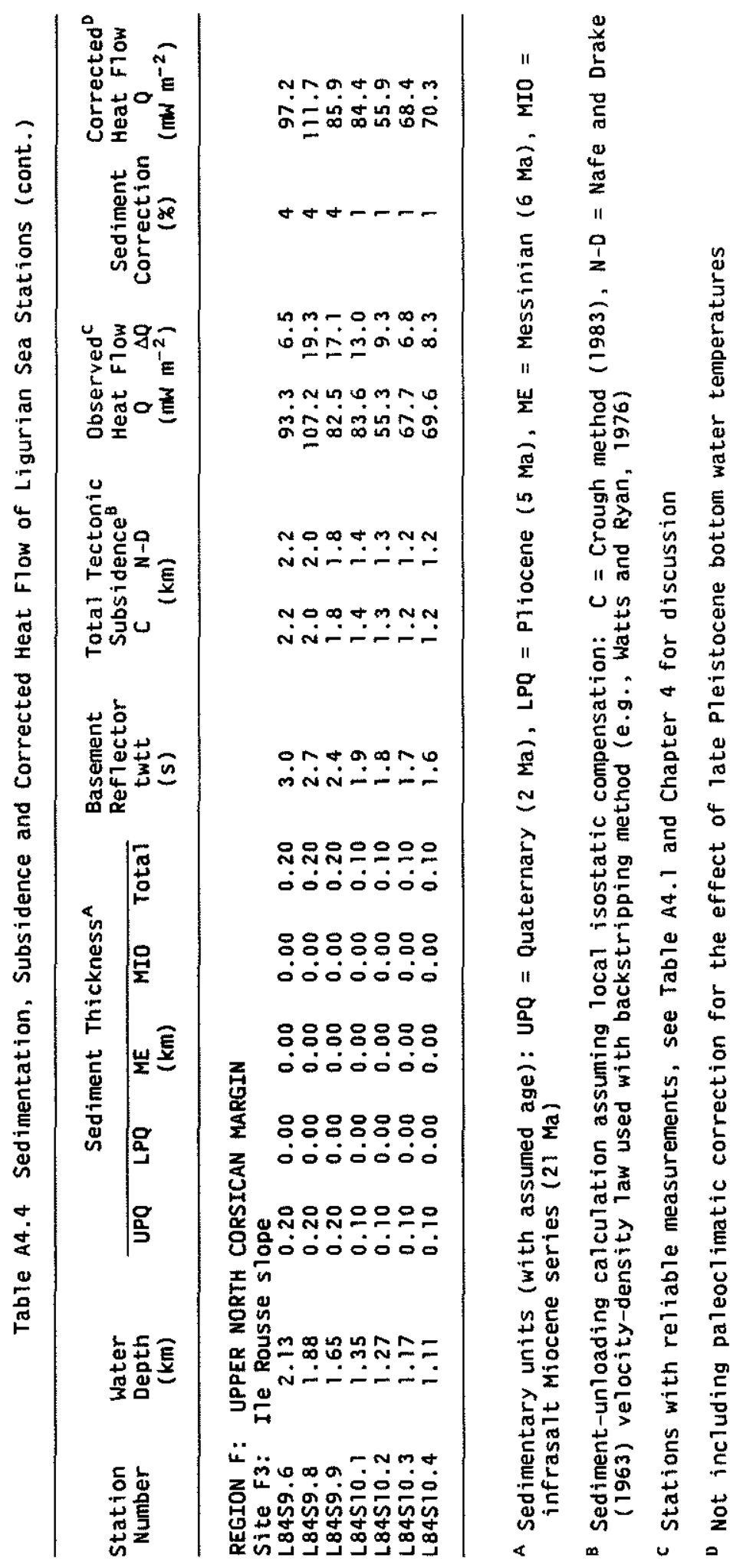


$-459-$

Appendix 5

Seismic Profiles and Heat Flow Results 
During an 8-day expedition in 1985,18 high-quality single-channe1 seismic profiles were obtained on the $\mathrm{R} / \mathrm{V}$ Catherine-Laurence in order to resolve the shallow structure and stratigraphy near the heat flow stations. Although nearby seismic data were originally available for the heat flow surveys, the heat flow variability made it imperative that complementary seismic profiling be made. The source employed was a Bolt $10 \mathrm{in}^{3}, 2000 \mathrm{psi}(140 \mathrm{bar})$ airgun. Firing occurred every $5 \mathrm{~s}$ while the ship maintained a speed near 5 knots. The receiver was a $200 \mathrm{~m}$ streamer with a $50 \mathrm{~m}$ active length composed of 48 pairs of hydrophones and was designed to reduce noise caused by longitudinal strain. Data were recorded on an analog system and stored on magnetic tape. Two hardcopies were produced in real-time: a 1 s recording window filtered at 100 to $300 \mathrm{~Hz}$, and for deeper penetration a $2.5 \mathrm{~s}$ record with a 50 to $200 \mathrm{~Hz}$ filter. Using this system, excellent resolution was obtained with the $1 \mathrm{~s}$ record giving especially fine definition. Little useful information was obtained beyond $1.5 \mathrm{~s}$ of penetration using the $2.5 \mathrm{~s}$ window length. The LORAN-C coordinates were noted every 15 minutes and were graphically transformed to values of latitude and longitude and plotted on the ship track map illustrated in Figure A5.1. Supplementary profiler data (Profiles 19 - 29) are also shown in Figure A5.1, and the DELTARHO II survey tracks are displayed in Figure A5.2. The profiles pertinent to the heat flow data are illustrated in Figures A5.3-26 and plotted in Figure 2.8. The heat flow sites, stations and their positions on the profiles have been cross-referenced in Table A5.1. 


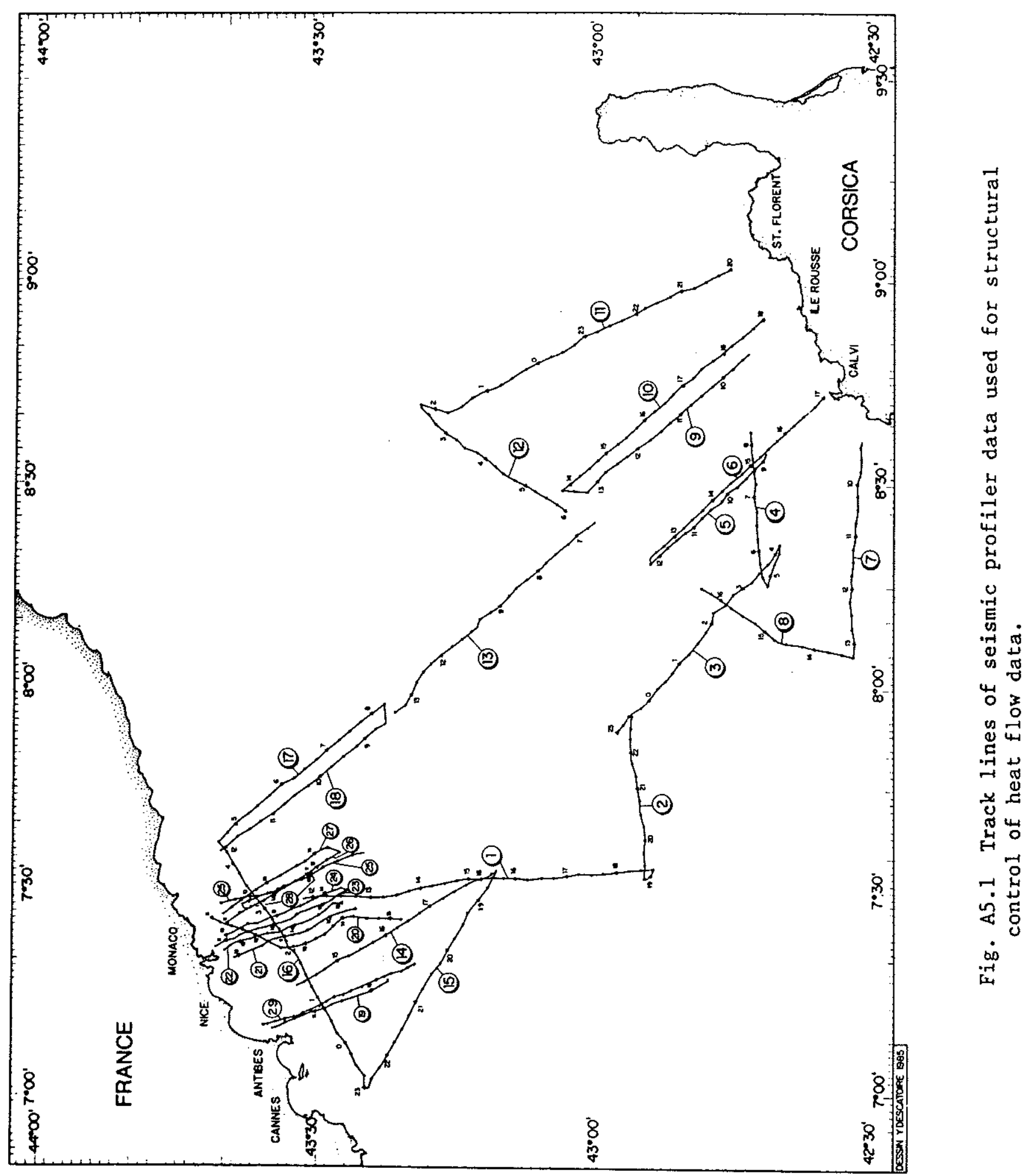




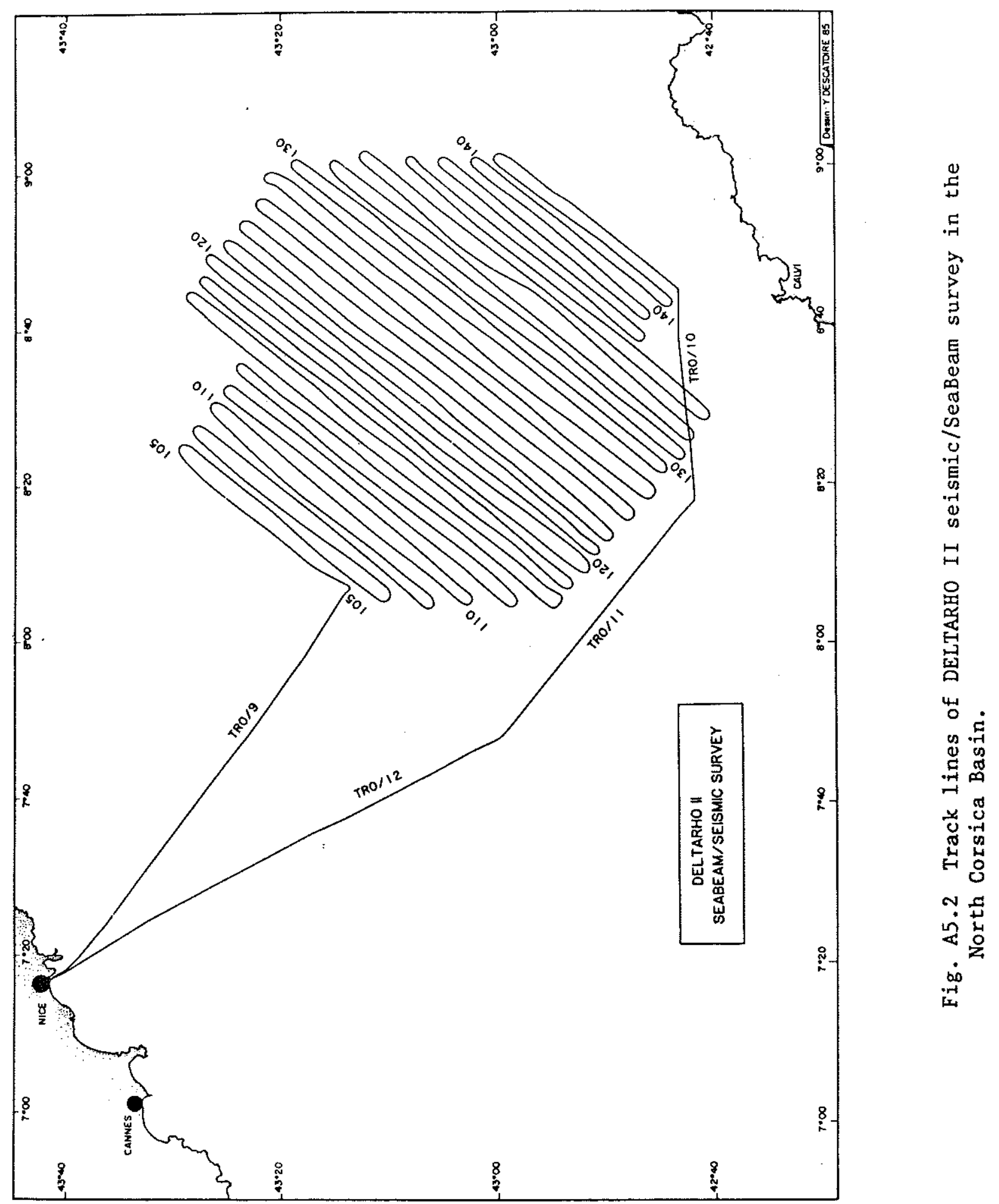


Table A5.1 Heat Flow Stations and Sites Presented in Sefsmic Profiles.

\begin{tabular}{|c|c|c|c|c|}
\hline $\begin{array}{l}\text { Physiographic } \\
\text { Region }\end{array}$ & Profile & Figure & & $\begin{array}{l}\text { Heat Flow Measurements" } \\
\text { (Site: Stations) }\end{array}$ \\
\hline \multirow{8}{*}{$\begin{array}{l}\text { Cote d'Azur } \\
\text { Upper Margin }\end{array}$} & 16 & A5. 3 & $\begin{array}{l}\text { A2: } \\
\text { A3: } \\
\text { A4: }\end{array}$ & $\begin{array}{l}\text { L84S12.3, } 4,5 ; L 84 S 4.7 \\
\text { L84S5.2;L84S3.4, } \\
\text { L84S2.5;L84S5.5 }\end{array}$ \\
\hline & 15 & A5. 4 & Al: & $\begin{array}{l}284 S 4,15,16,17,18,19 \\
284 S 12,1,2\end{array}$ \\
\hline & 29 & A5. 5 & A2: & $28454,14,5,2,3,1$ \\
\hline & 21 & A5. 6 & A3: & $L 84 S 2.2,3 ; L 84 S 3.1,2,3 ; L 84 S 5.1,2,3,4$ \\
\hline & 24 & A5.7 & A3: & $\mathrm{L} 84 \mathrm{~S} 3.4,5,6$ \\
\hline & 25 & A5. 8 & A4: & L84S5.8, 7, 6; L82S2.1 \\
\hline & 27 & A5. 9 & A4: & $L 84 S 5.5 ; L 82 S 2.5,4,3$ \\
\hline & 18 & A5. 10 & $\begin{array}{l}\text { A4: } \\
\text { C2: }\end{array}$ & $\begin{array}{l}\text { L82S16.1, 2, 3, } 4 \\
\text { L82S16.5 }\end{array}$ \\
\hline \multirow{2}{*}{$\begin{array}{l}\text { Cote d'Azur } \\
\text { Lower Margin }\end{array}$} & 14 & A5.11 & B: & $\begin{array}{l}\text { L82S17.1, } 2,3,4,5,6,7,8,9,10 \\
\text { L84S11.6 }\end{array}$ \\
\hline & in & A5 .12 & B: & 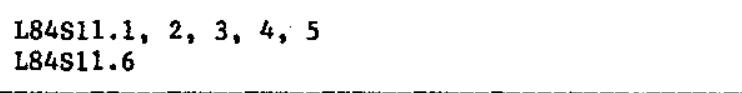 \\
\hline \multirow{3}{*}{$\begin{array}{l}\text { North Central } \\
\text { Basin }\end{array}$} & is & A5.13 & $\mathrm{Cl}:$ & $284 \mathrm{~S} 11.8,9,10,11,12,13,14$ \\
\hline & 17 & A5.14 & $\mathrm{C2}:$ & $L 82 S 16.6,7,8,9,10,11,12 ; L 82 S 3.1,2$ \\
\hline & $13 N$ & A5.15 & $\begin{array}{l}\text { C2: } \\
\text { D2: }\end{array}$ & $\begin{array}{l}\text { L82S4.1; L82S5.1, 2; L82S4.2; L82S5.4, } \\
\text { L82S5.6, } 7,9\end{array}$ \\
\hline \multirow{4}{*}{$\begin{array}{l}\text { South Central } \\
\text { Basin }\end{array}$} & 3 & A5. 16 & D1: & L82S15.1; L82S14.3, 2; 1; L82S13.15, 14, 13, 12 \\
\hline & 8 & A5.17 & D1: & L82S13.13 \\
\hline & 123 & A5. 18 & DI: & $\mathrm{L} 82 \mathrm{~S} 12.8,11,12$ \\
\hline & 135 & A5.19 & D2: & $L 8256.1,2,3,4,5,6$ \\
\hline \multirow{7}{*}{ Corsican Margin } & 7 & A5. 20 & F1: & $L 8457.6,5,4,3,2,1$ \\
\hline & 4 & A5. 21 & $\begin{array}{l}\text { E1: } \\
\text { F2: }\end{array}$ & $\begin{array}{l}\operatorname{L8} 2 S 13.7,6,5,4,3 \\
\operatorname{L8} 2 S 13.2,1\end{array}$ \\
\hline & 6 & A5. 22 & $\begin{array}{l}\text { E1: } \\
\text { F2: }\end{array}$ & $\begin{array}{l}L 84 \mathrm{~S} 8.1,2,3,4 \\
\mathrm{~L} 84 \mathrm{~S} 8.5,6,7,8\end{array}$ \\
\hline & 9 & A5. 23 & $\begin{array}{l}\text { D3: } \\
\text { E2: }\end{array}$ & 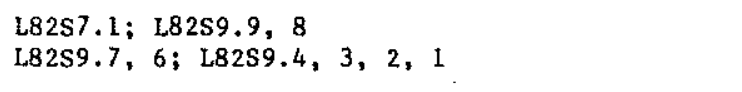 \\
\hline & 10 & A5. 24 & $\begin{array}{l}\text { E2: } \\
\text { F3: }\end{array}$ & $\begin{array}{l}L 84 S 9.1,2,3 ; L 84 S 9.5 \\
L 84 S 9.6,8,9 ; L 84 S 10.1,3,2,4,7,8\end{array}$ \\
\hline & 11 & A5. 25 & F4: & $L 84 S 10,16,14,13,12$ \\
\hline & 12 & A5. 26 & $\begin{array}{l}\text { D3: } \\
\text { E3: }\end{array}$ & $\begin{array}{l}\text { L82S8.18, 15, 14, 11 } \\
\text { L82S8.6, } 5,4,3,2,1\end{array}$ \\
\hline
\end{tabular}

${ }^{1}$ Heat flow stations are listed sequentially as read from left to right on the respective figure 
Figs. A5.3 - A5.26 Seismic sections of the profiles used in heat flow analysis. Vertical scale is in two-way travel time. Locations of profiles are given in Figures A5.1 and A5.2. Table A5.1 1ists the heat flow station labels used for each profile. The following labels have been used:

$M=$ Messinian reflector of upper evaporites or erosional surface SS = salt structures ranging from pillow formations to small

intrusive domes

MePO = Messinian evaporite pinchout locations

$\mathrm{BF}=$ boundary fault or fault zone found at the base-of-slope on the margins

$\mathrm{SF}=$ sha1low faults affecting the P1io-Quaternary layer

$\mathrm{BR}=$ pre- or synrift basement reflectors sometimes referring to tilted blocks on the Cote d'Azur margin. 


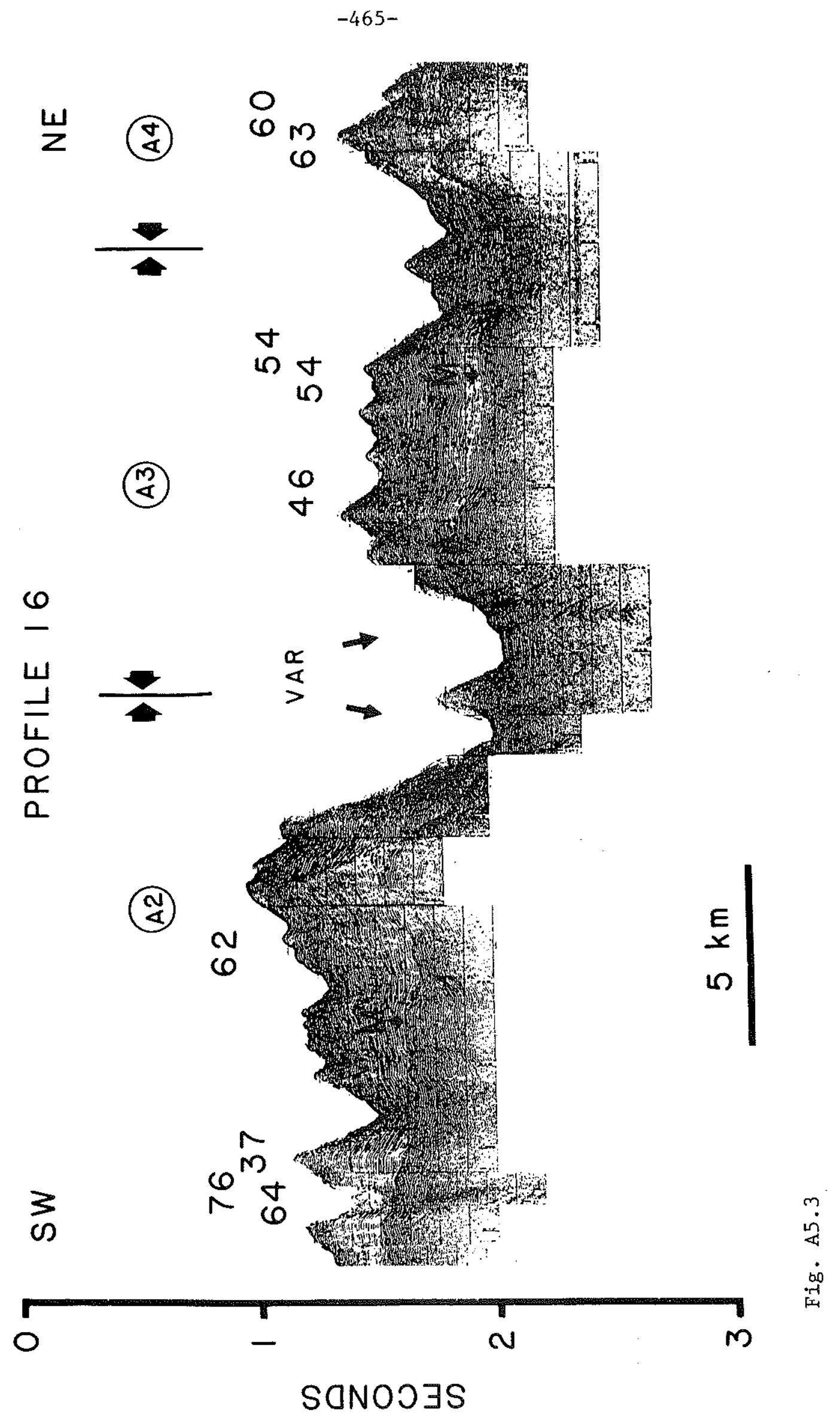




$$
\text { W }
$$

0
-
$\frac{1}{4}$
0
0
0

(0)
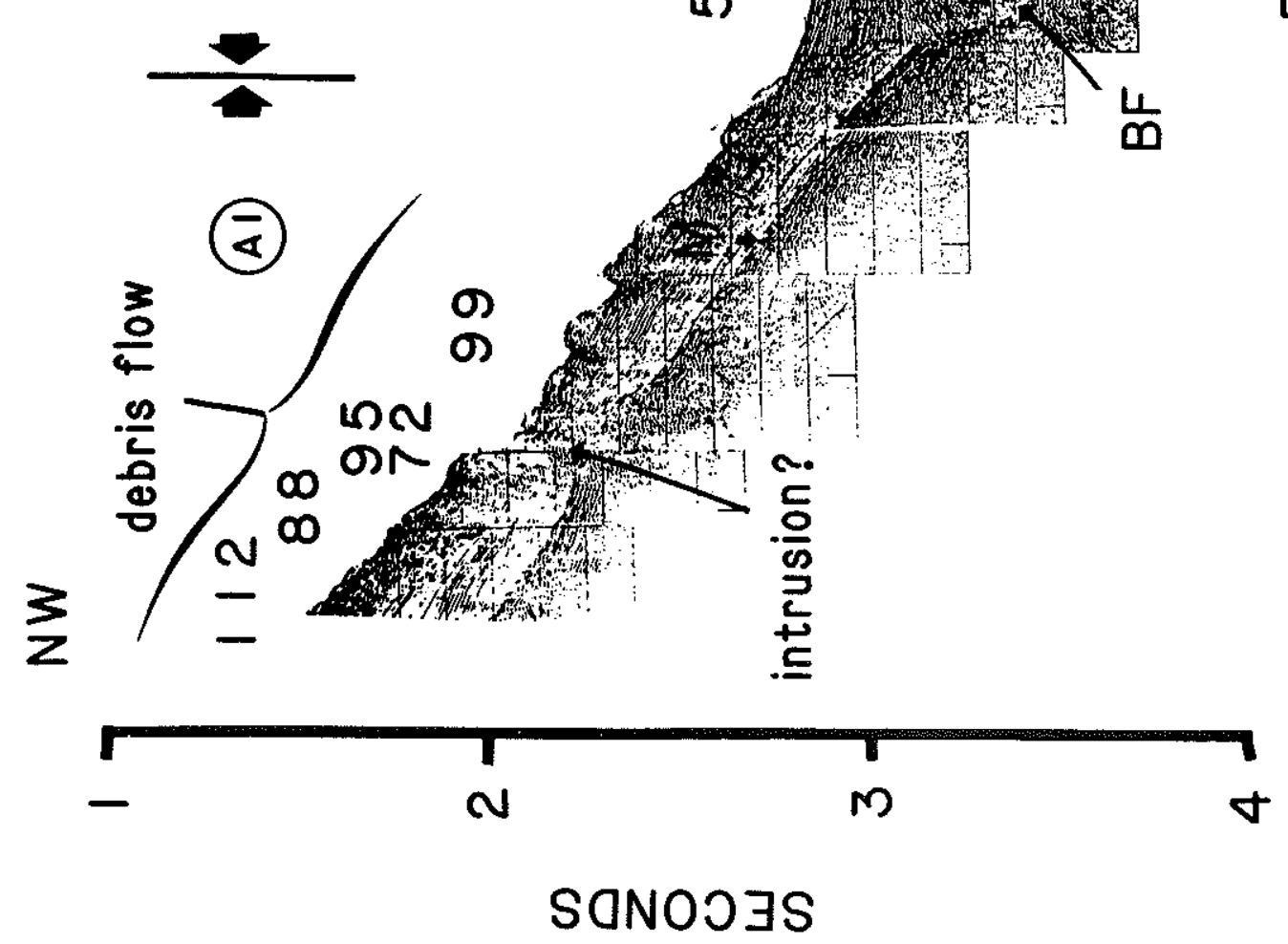

妾

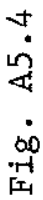




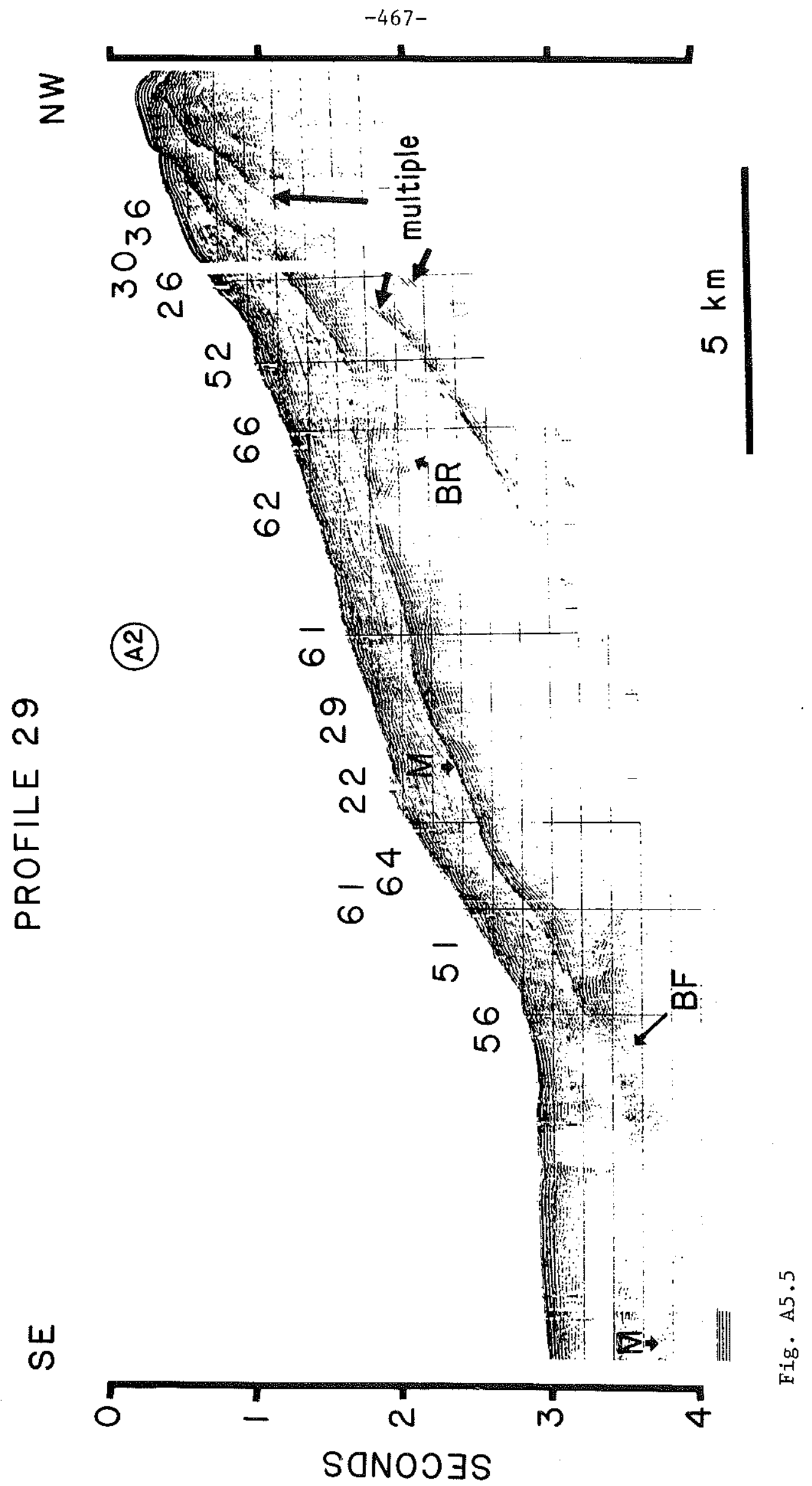




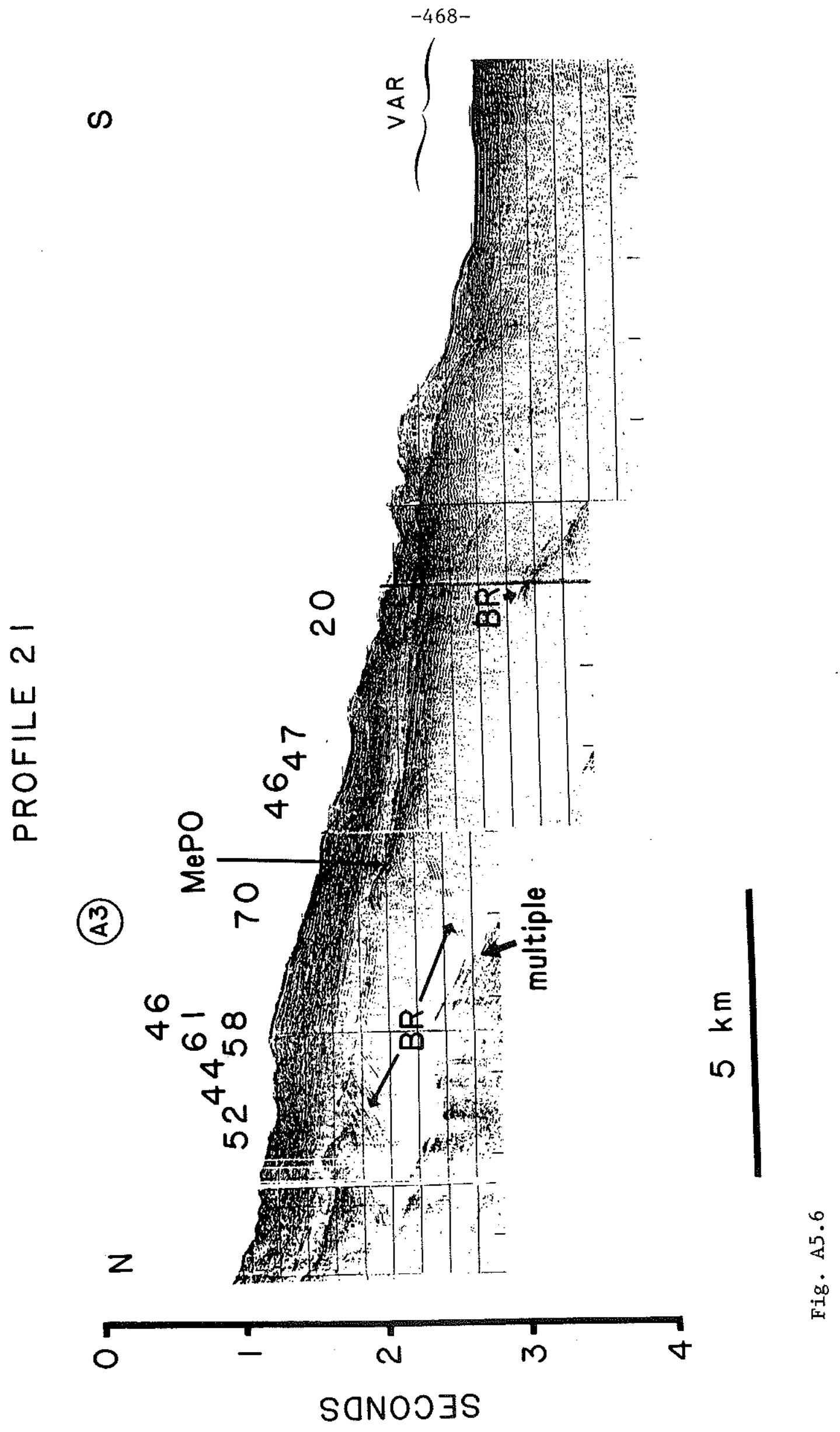




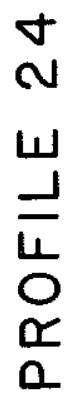

$\infty$

(4)
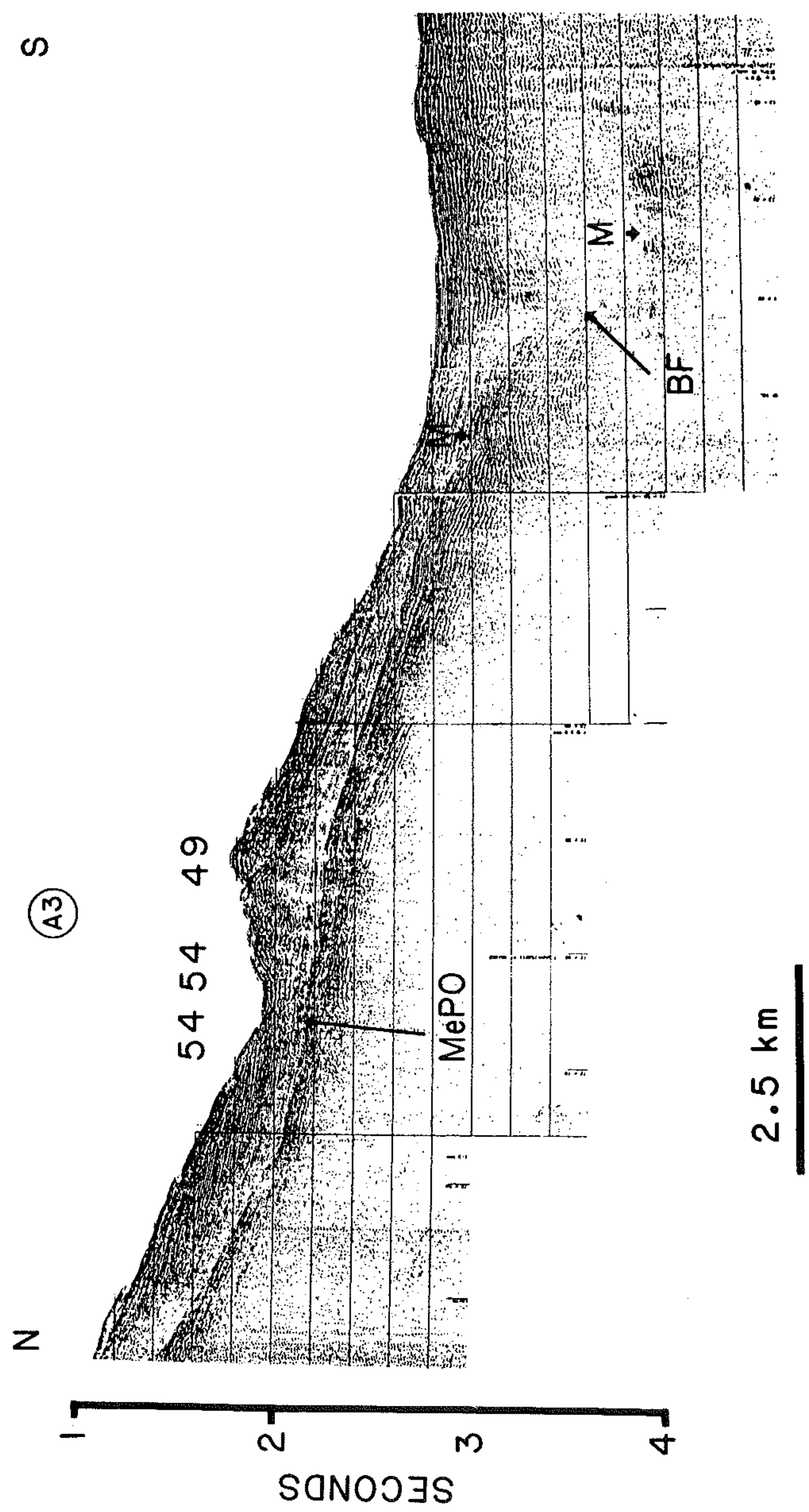

$\sim$
$\dot{4}$
$\dot{0}$
$\dot{10}$ 
U

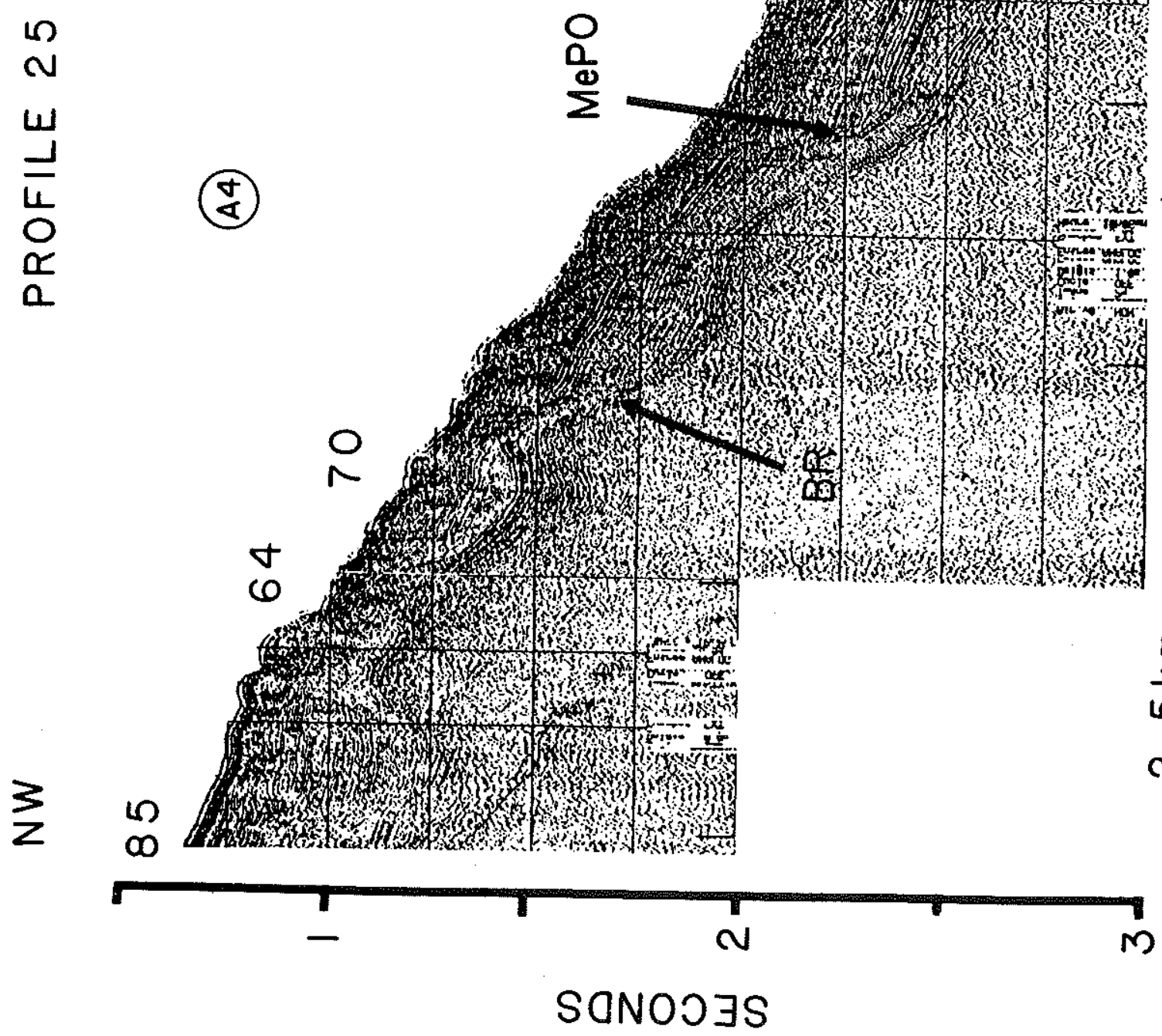

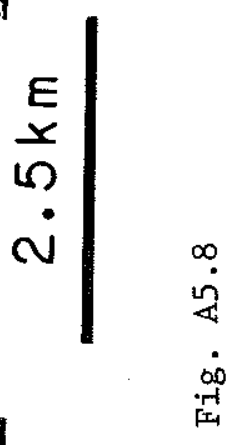




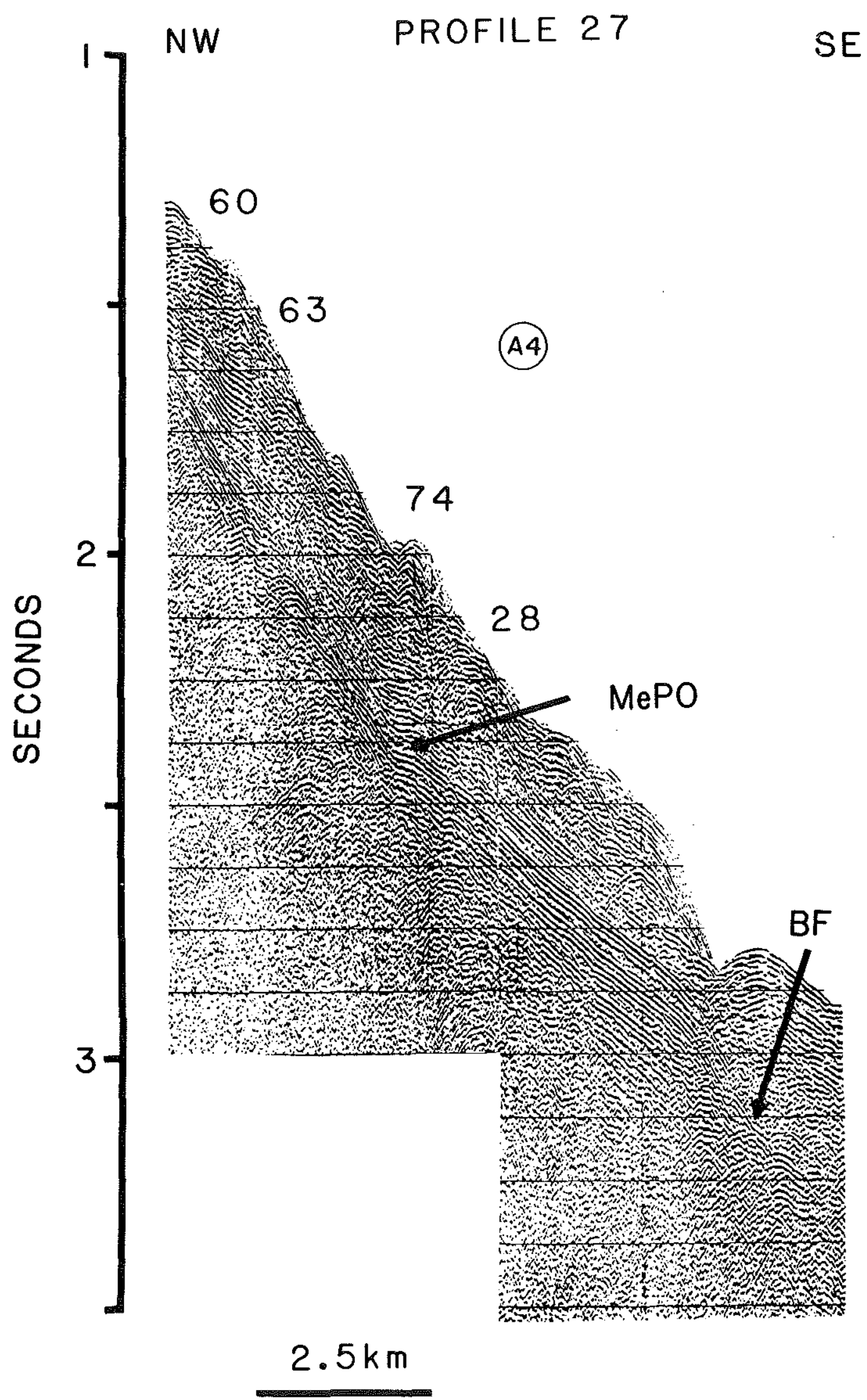

Fig. A5.9 
U

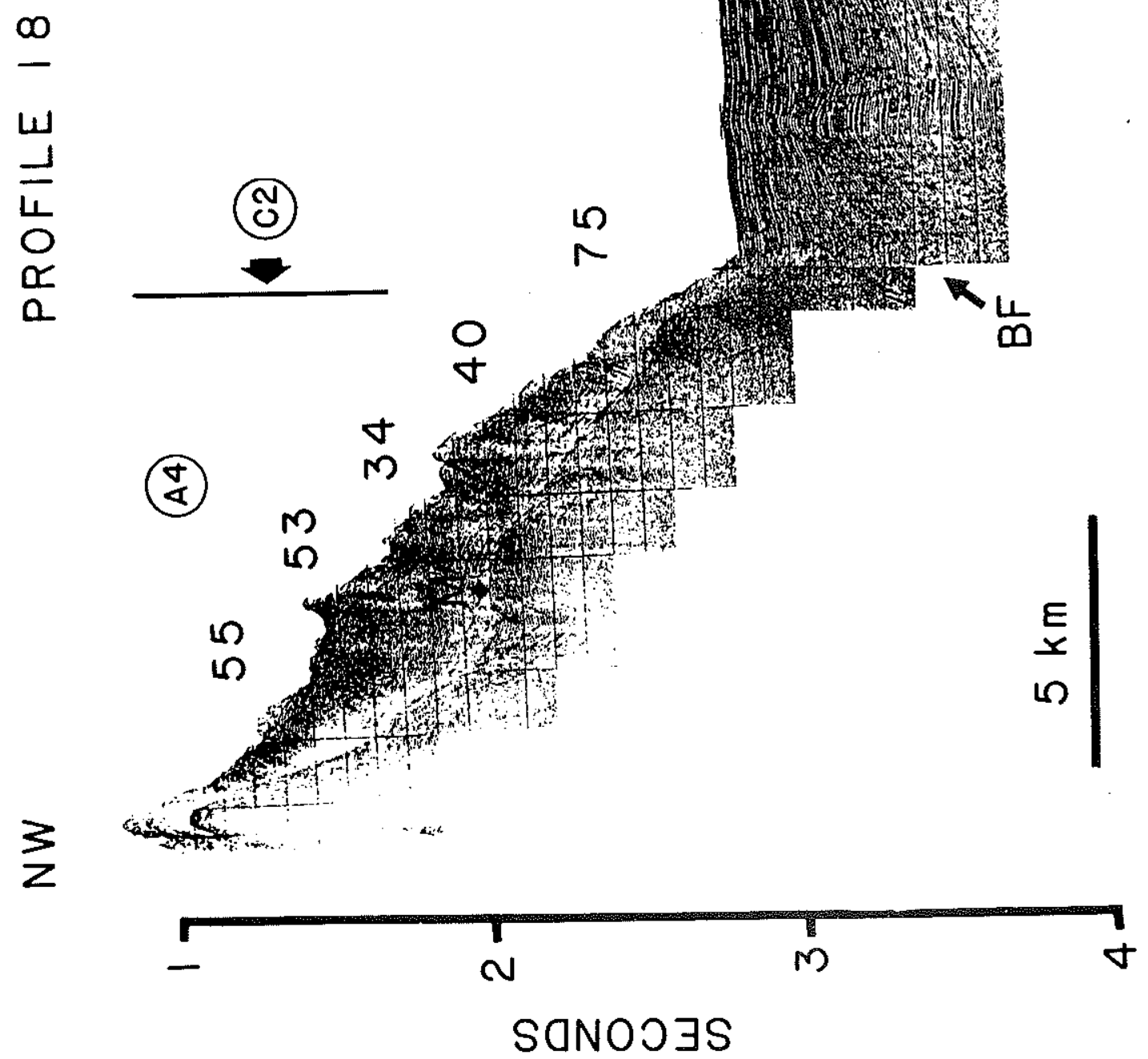

운 


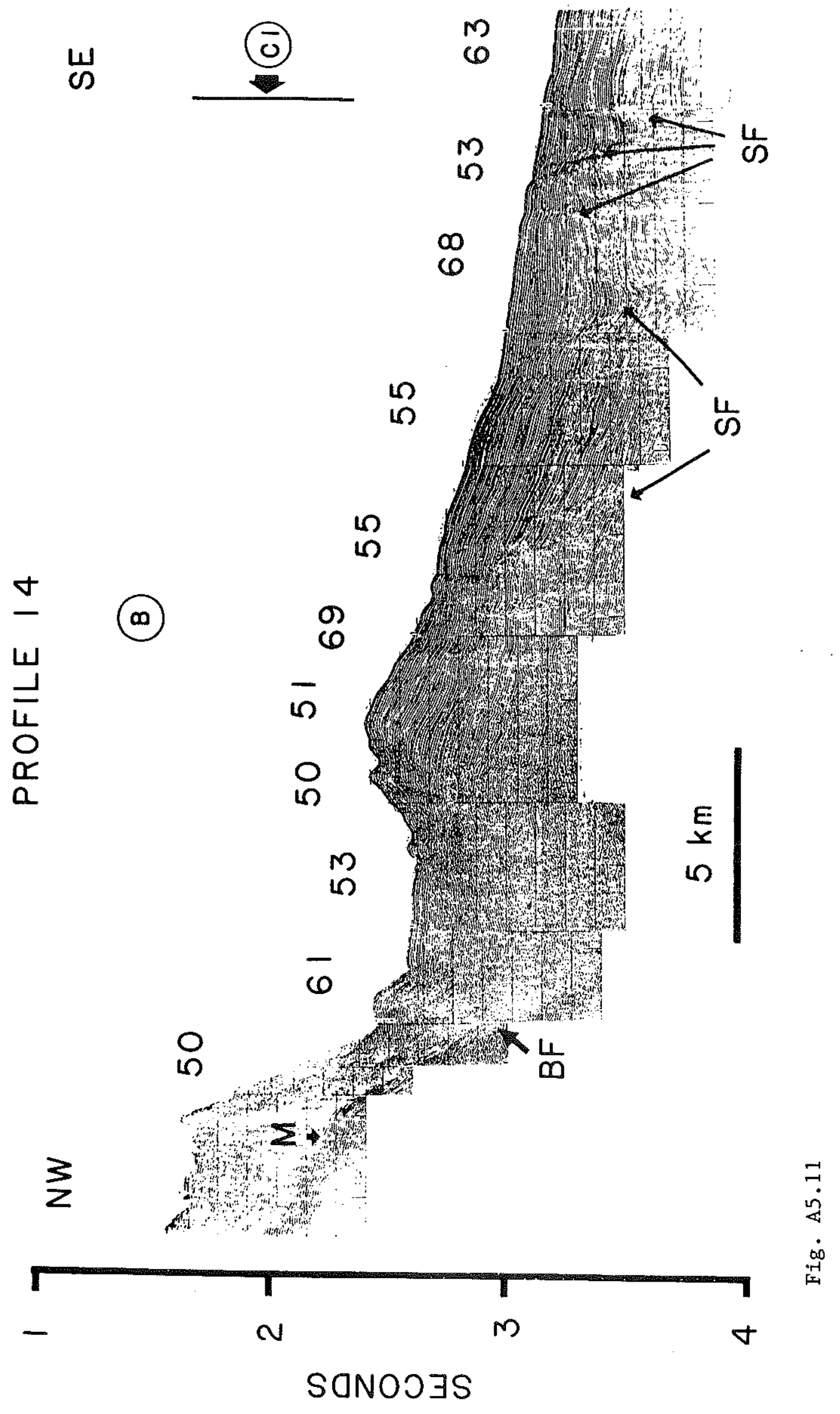




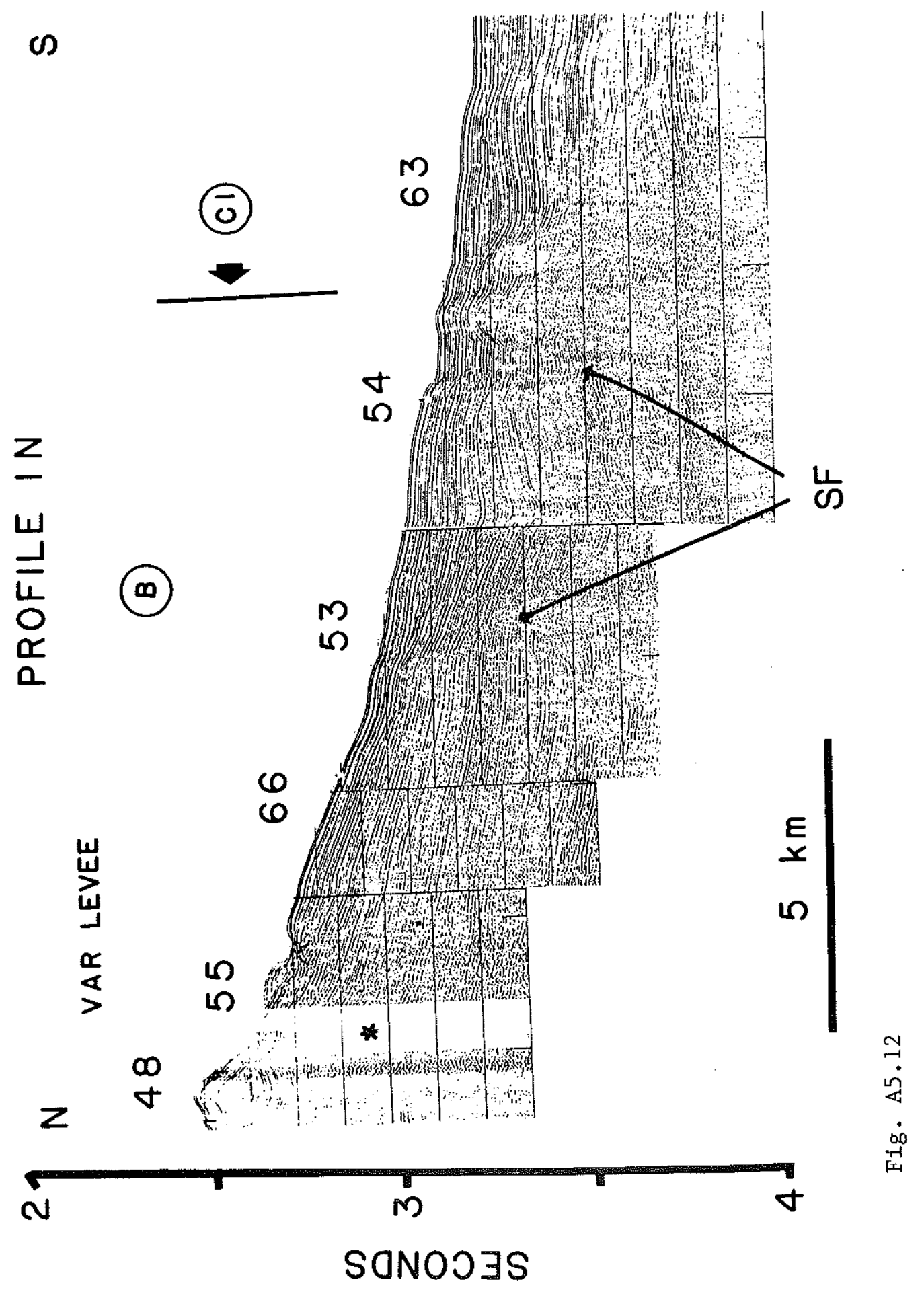


$-475-$

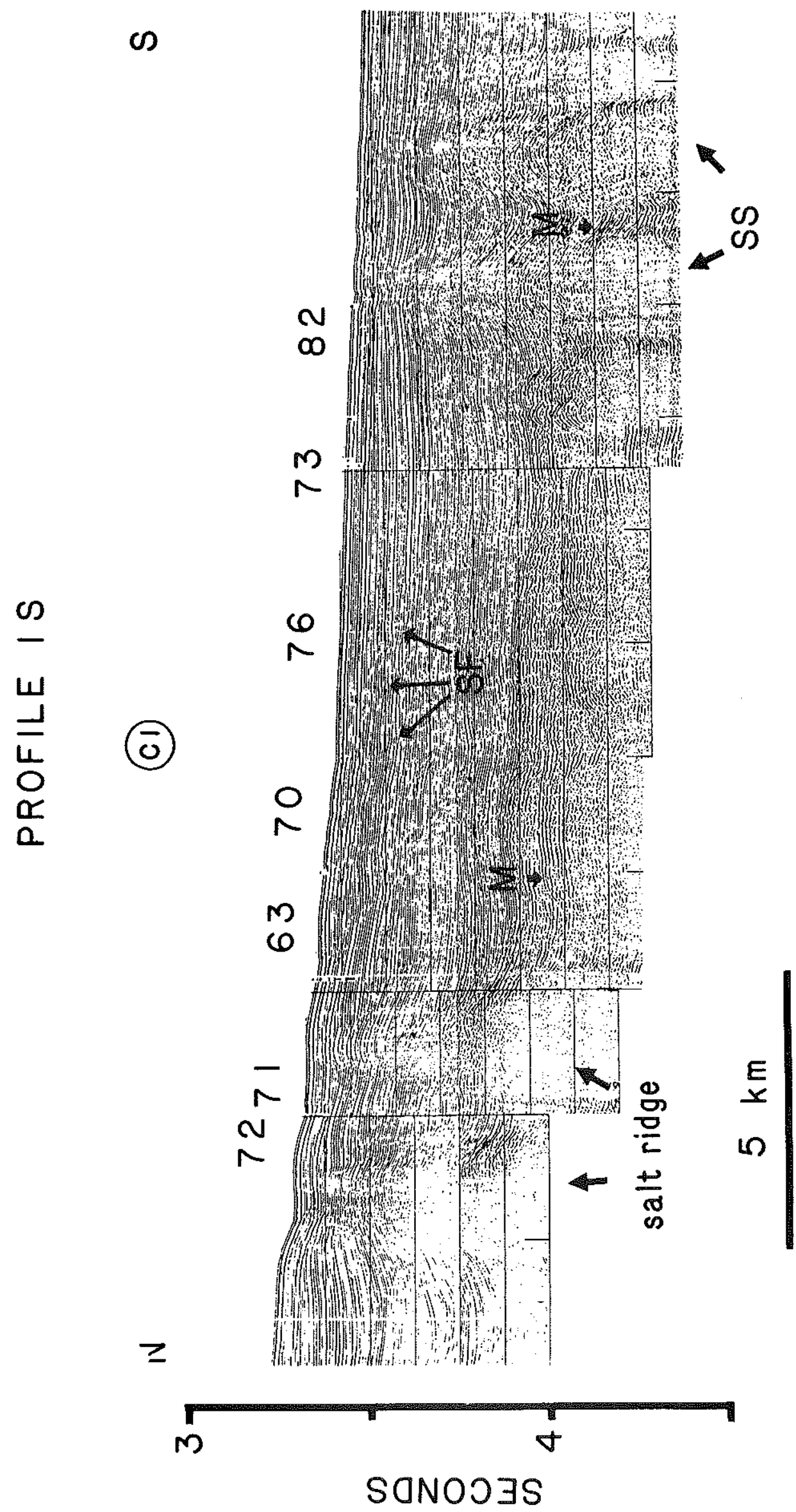

$m$
$n$
10
0
0
01
in 

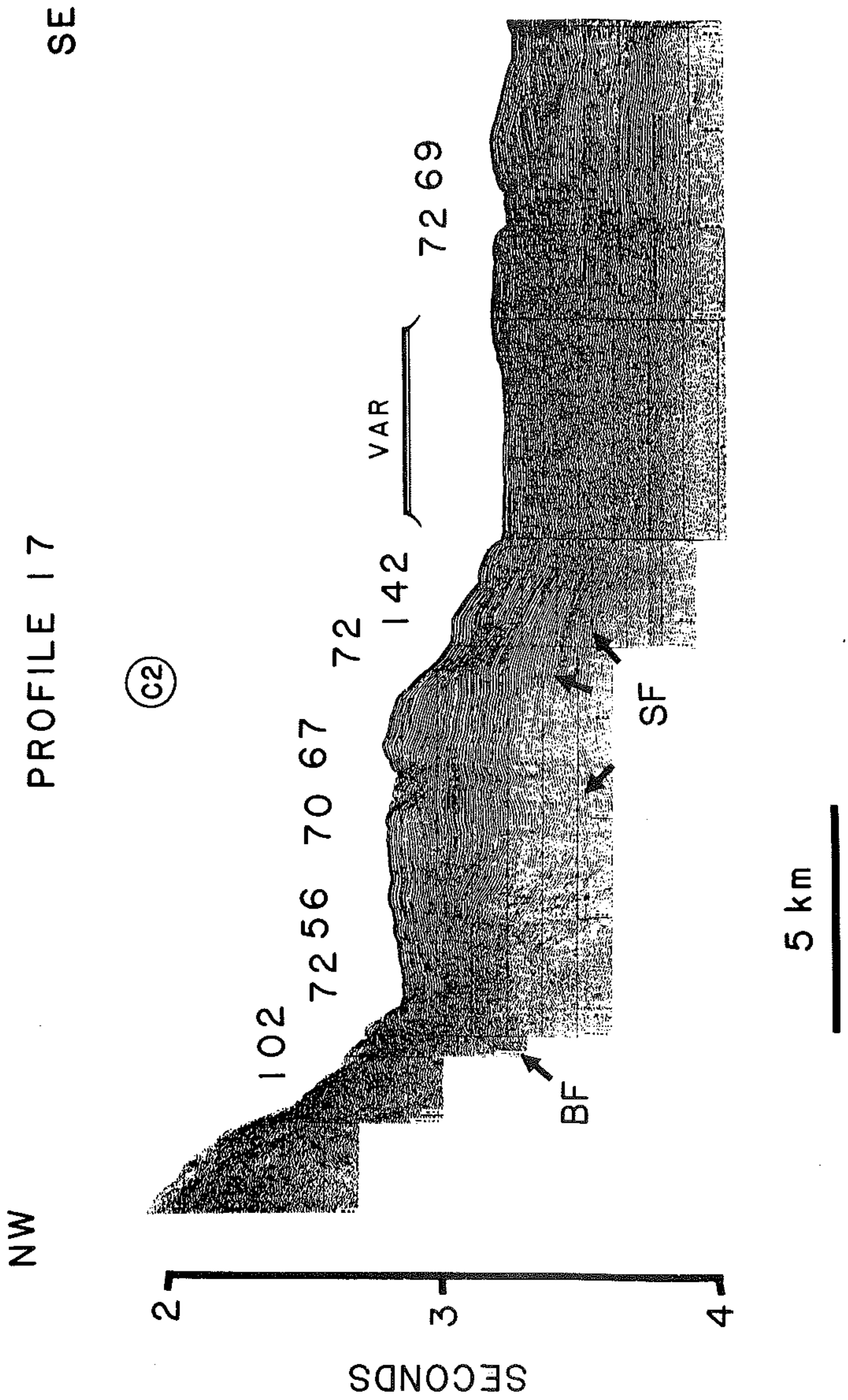

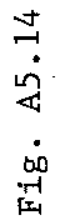




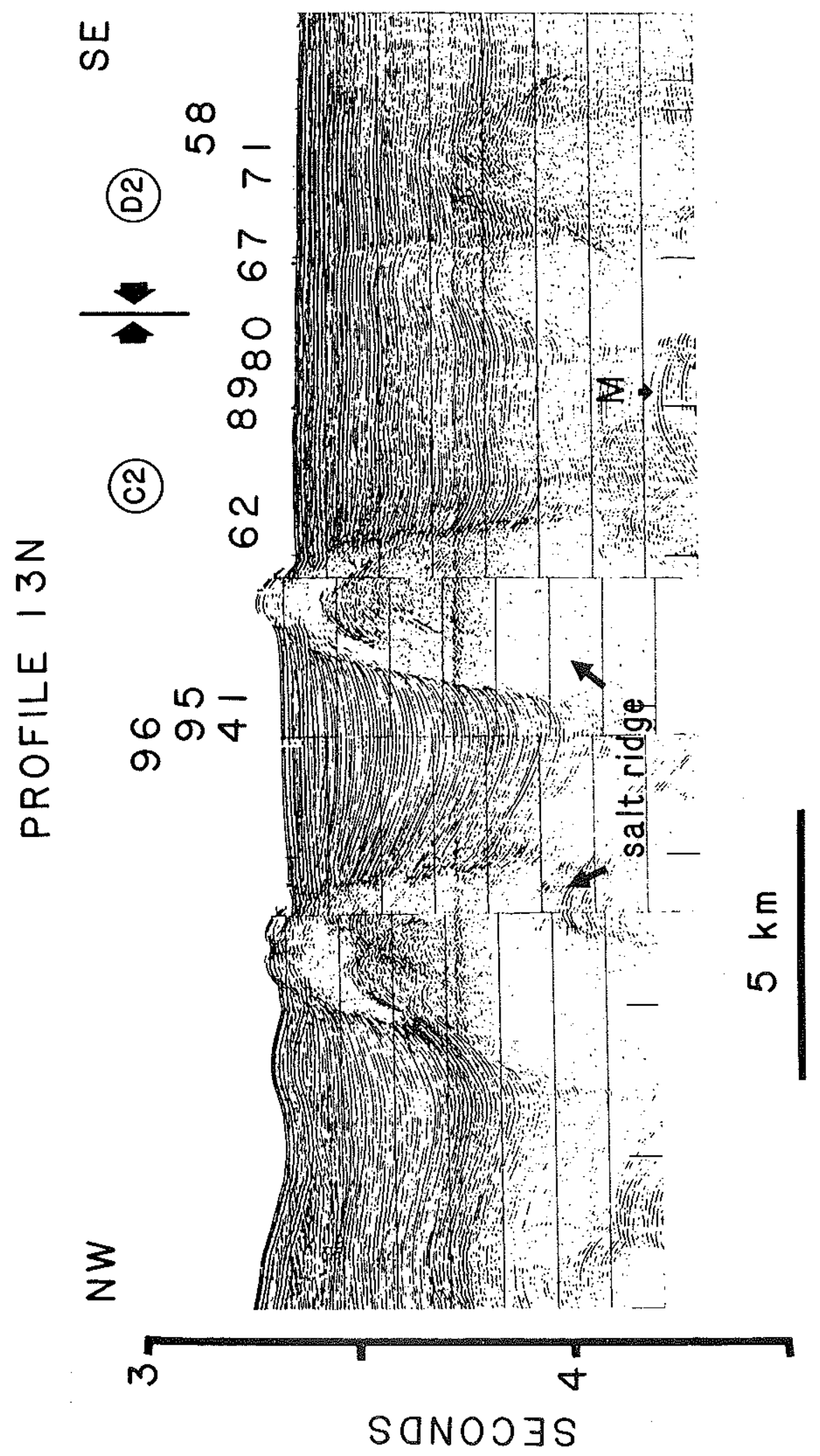

$n$
0
0
0
0
01
01 


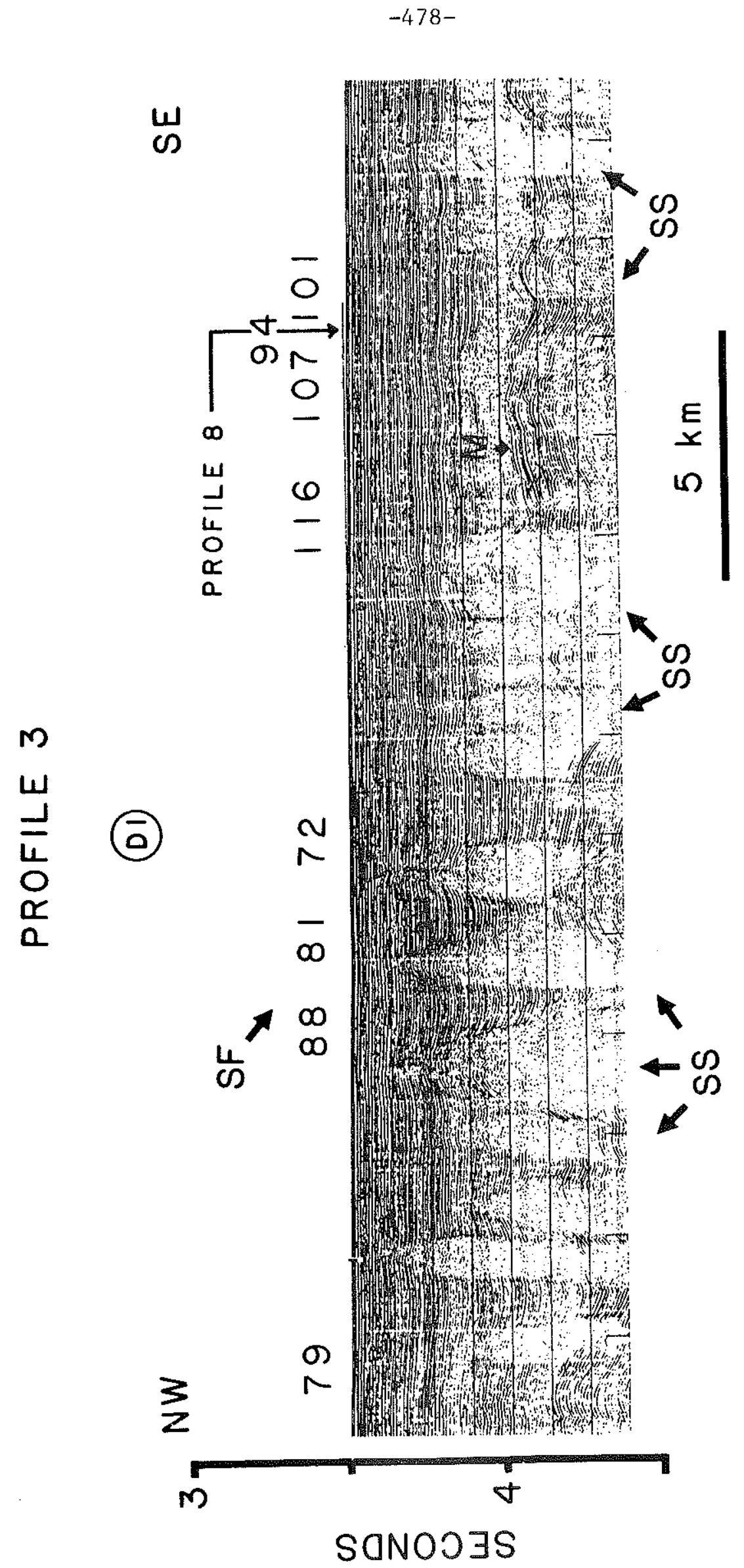

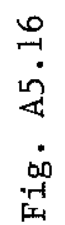




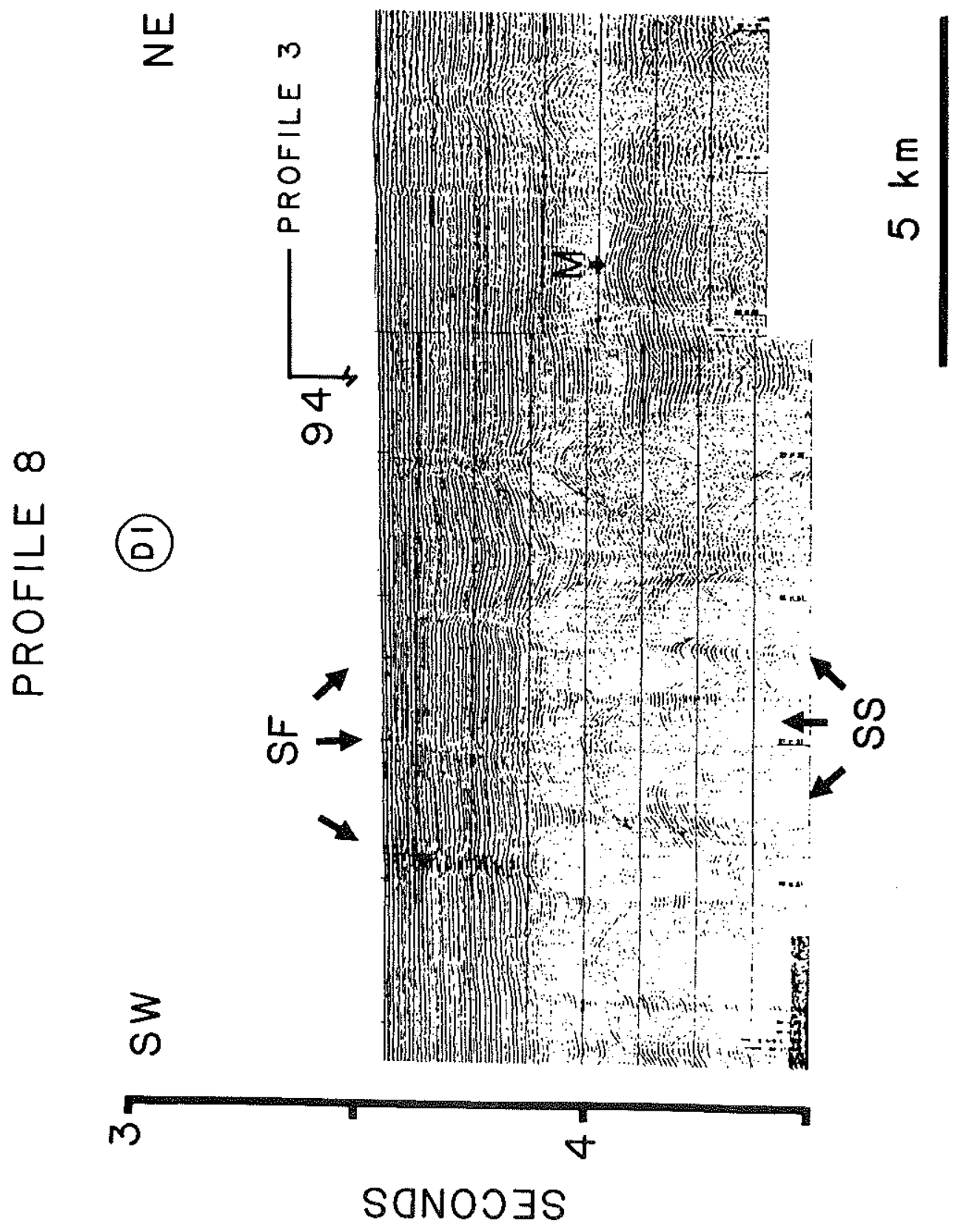

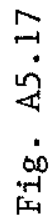




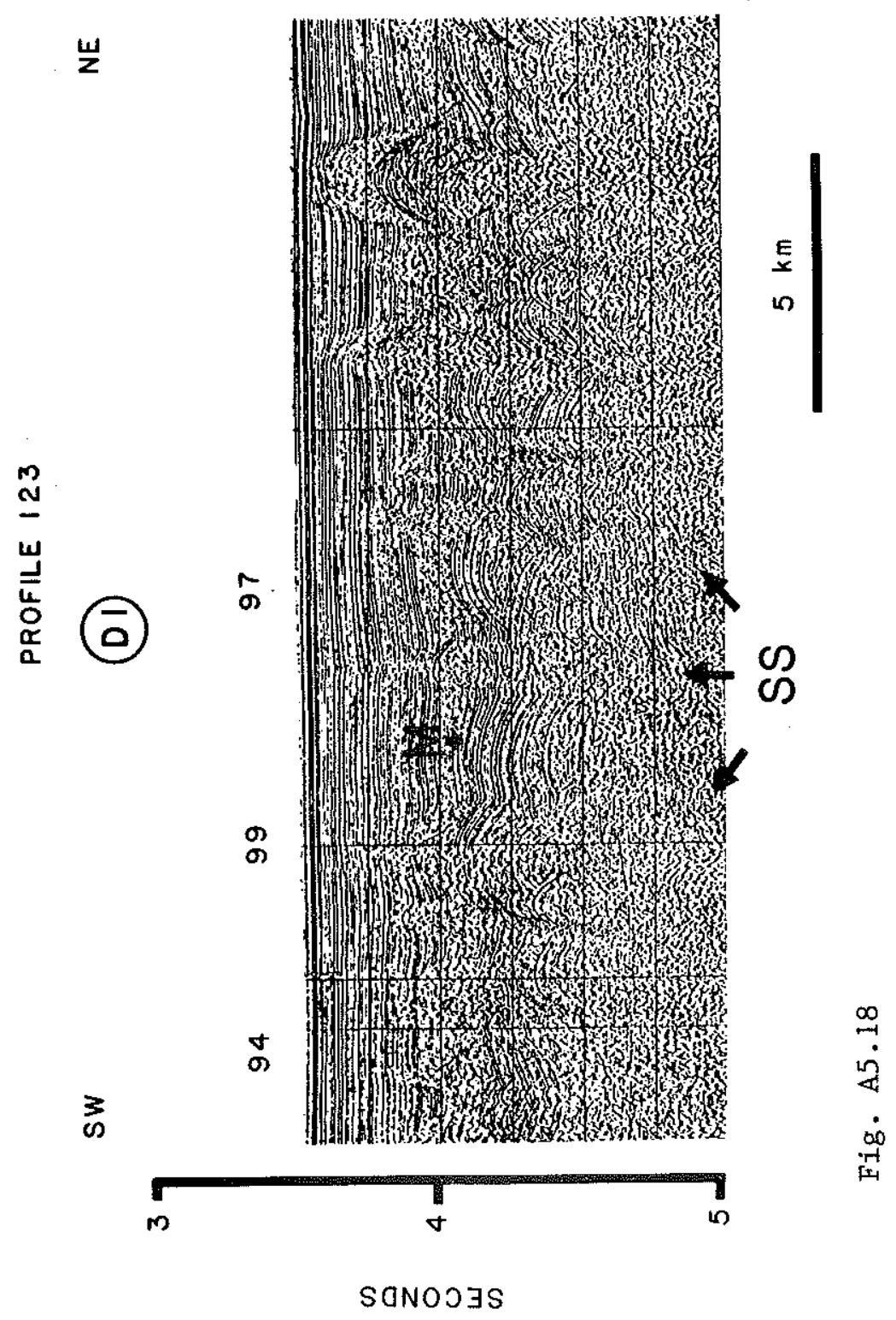




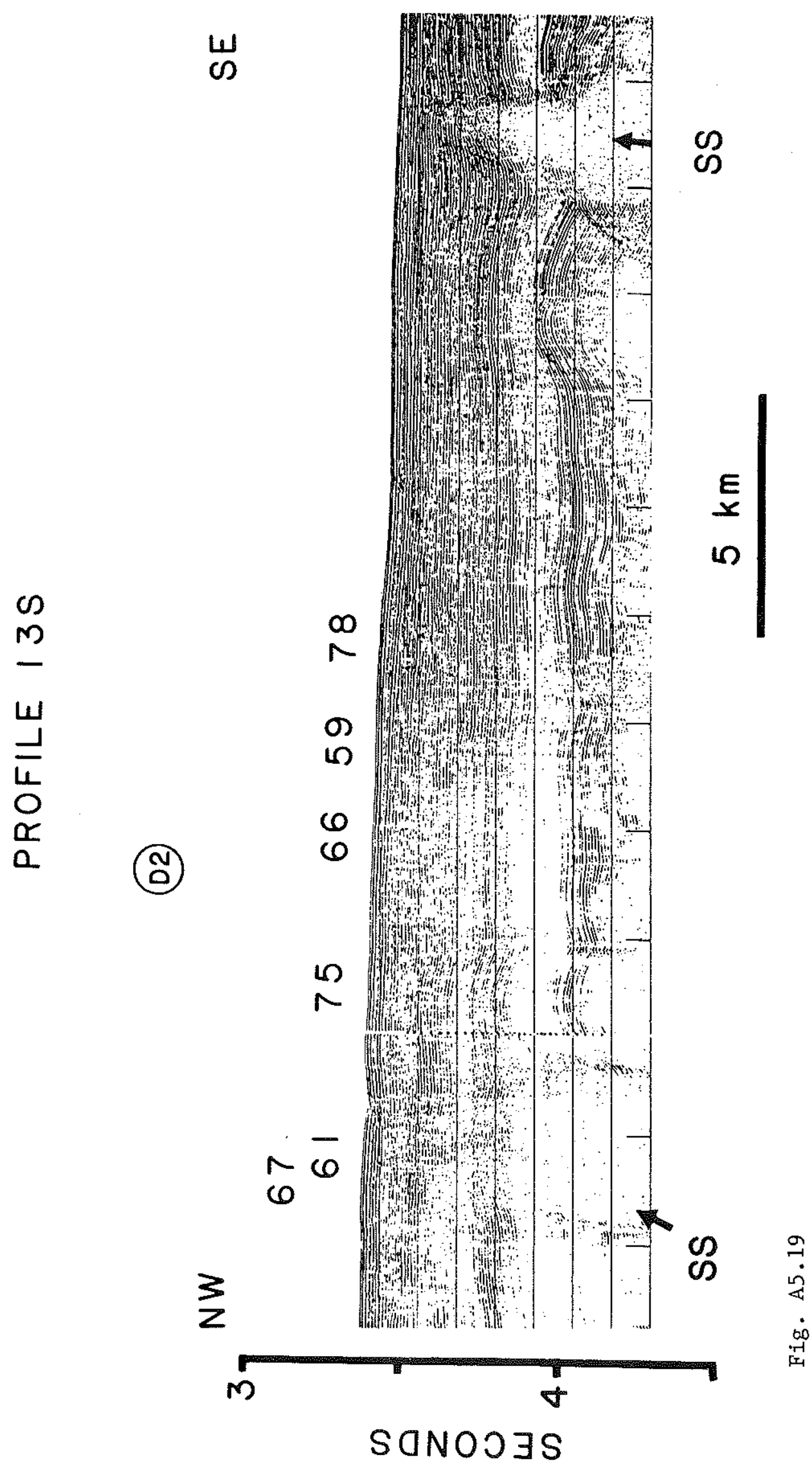




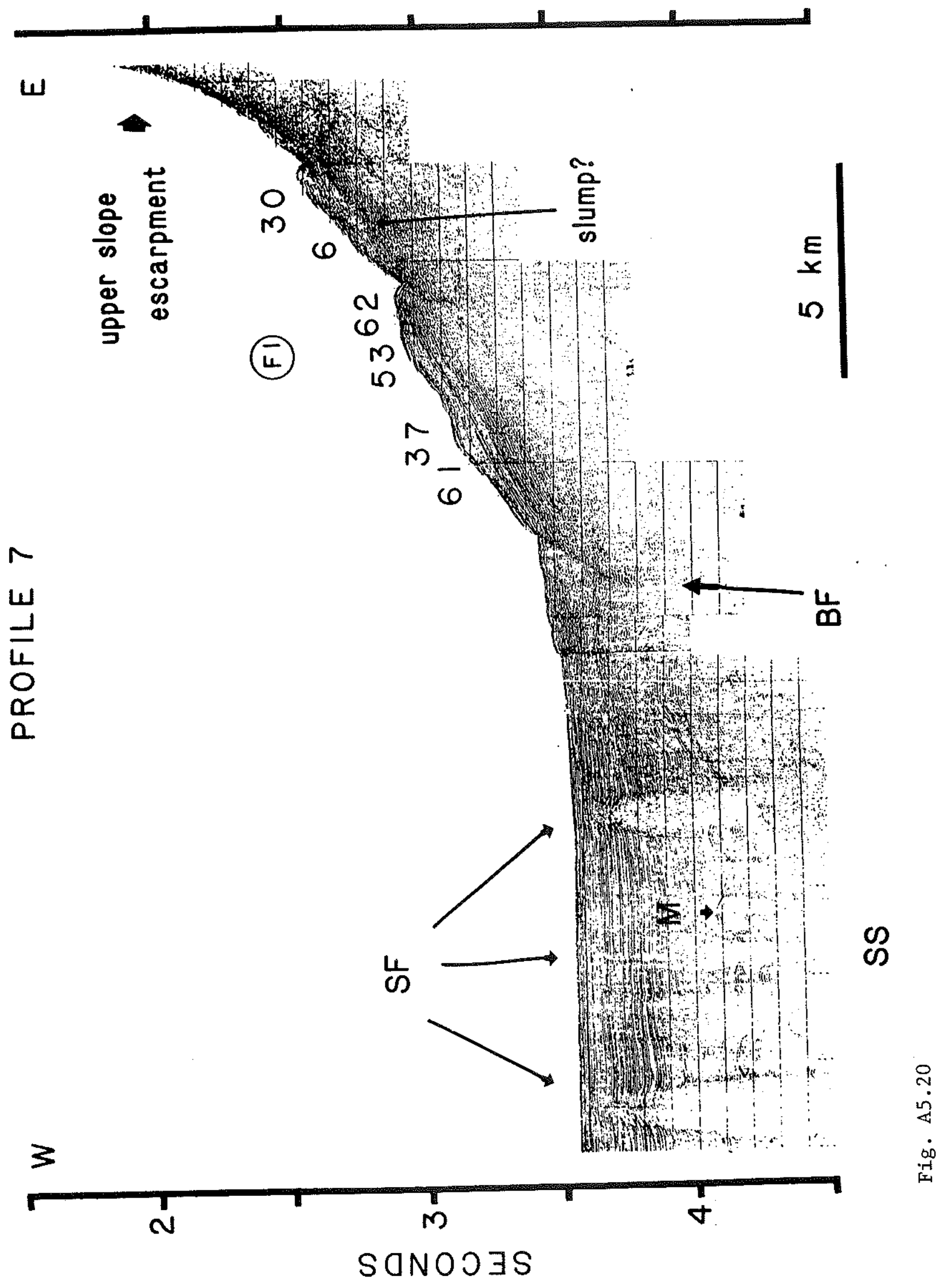




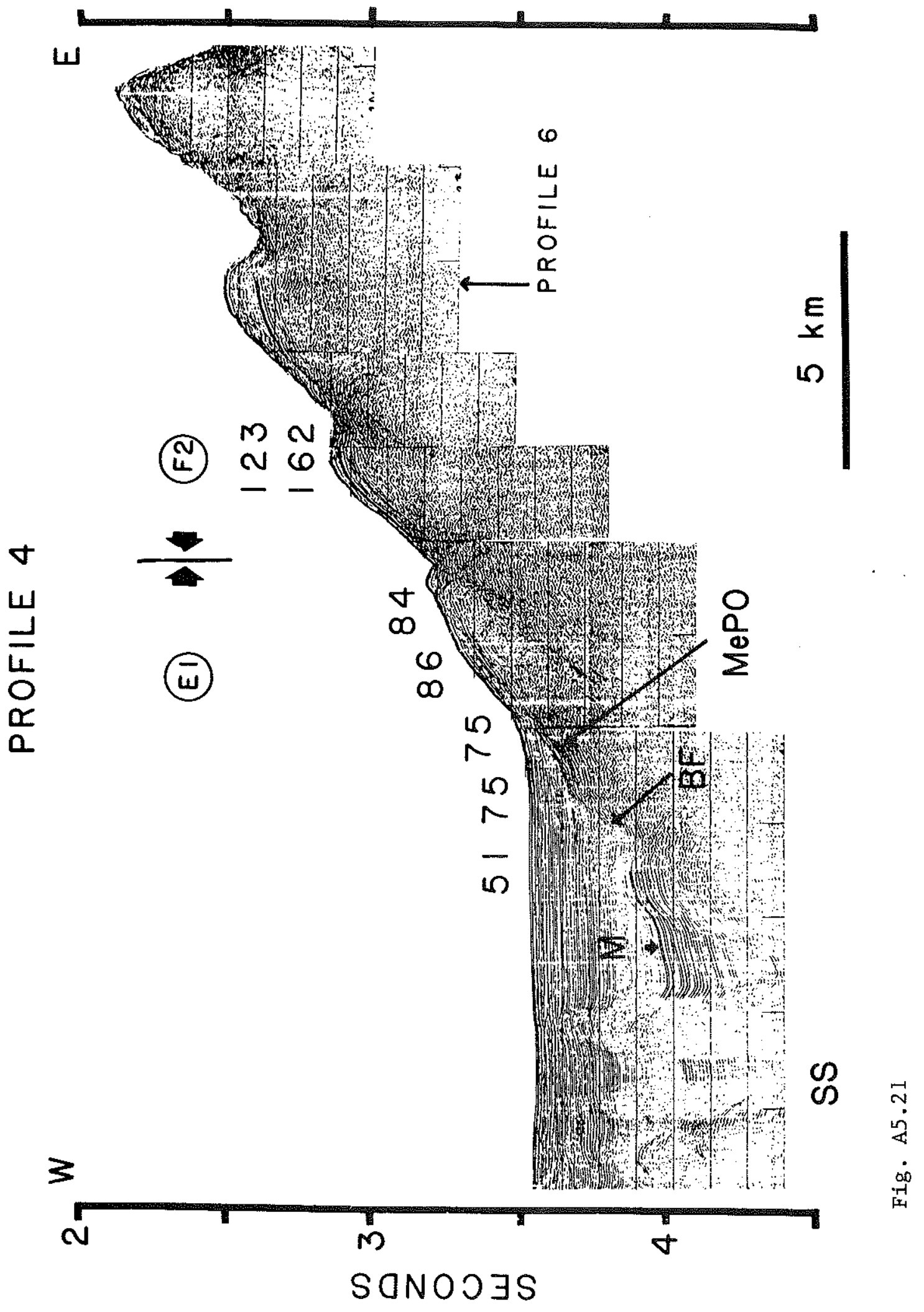




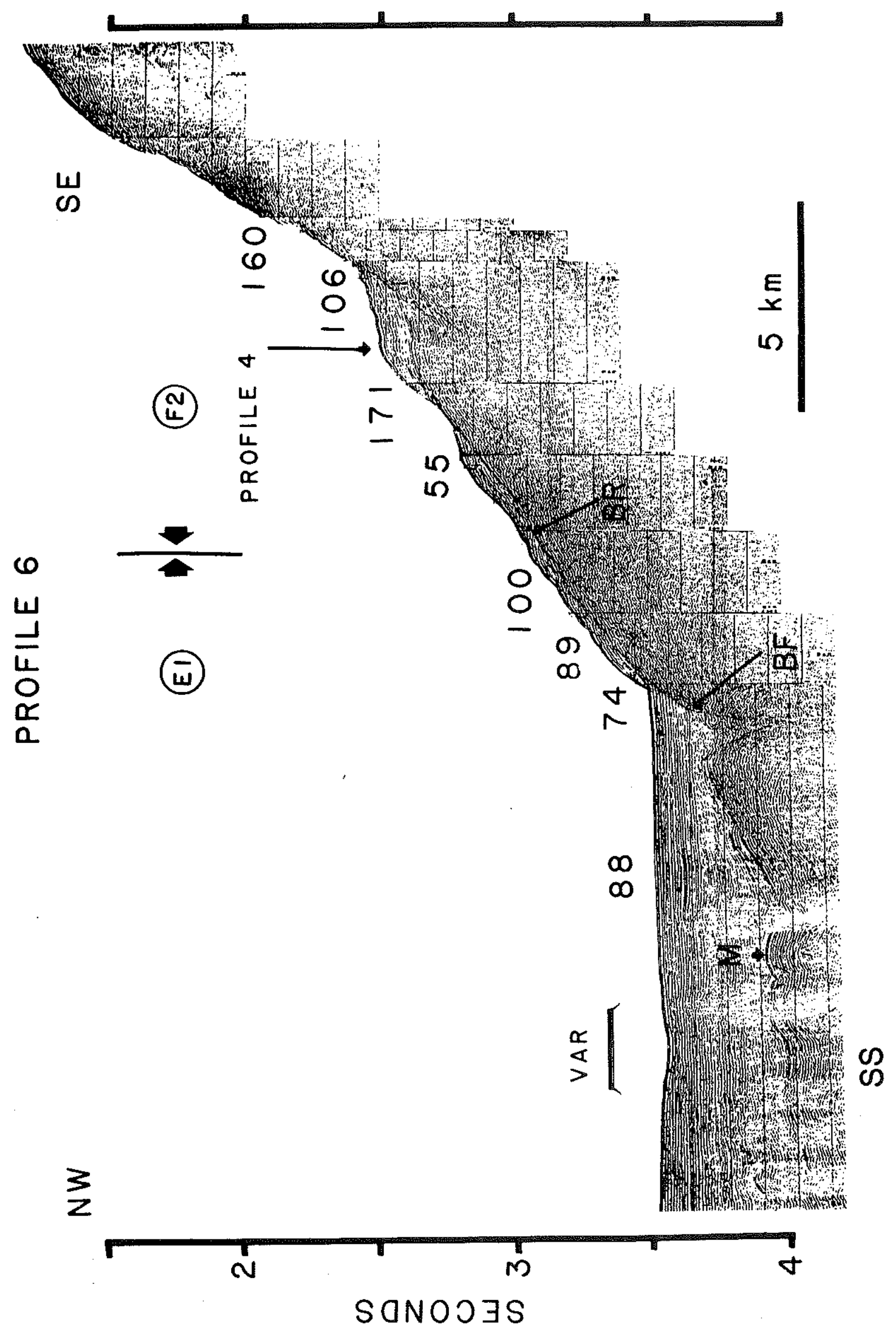

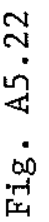




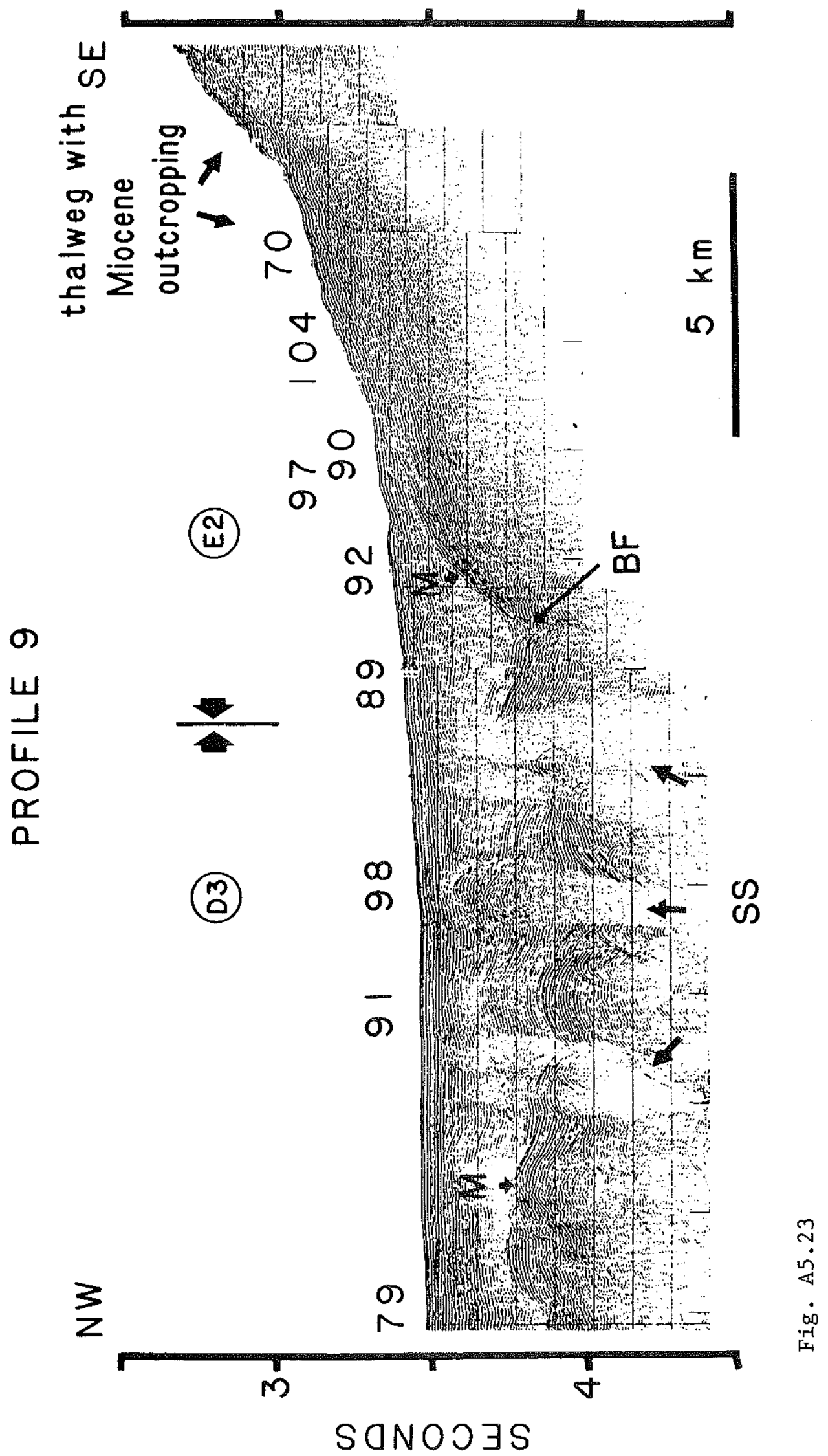




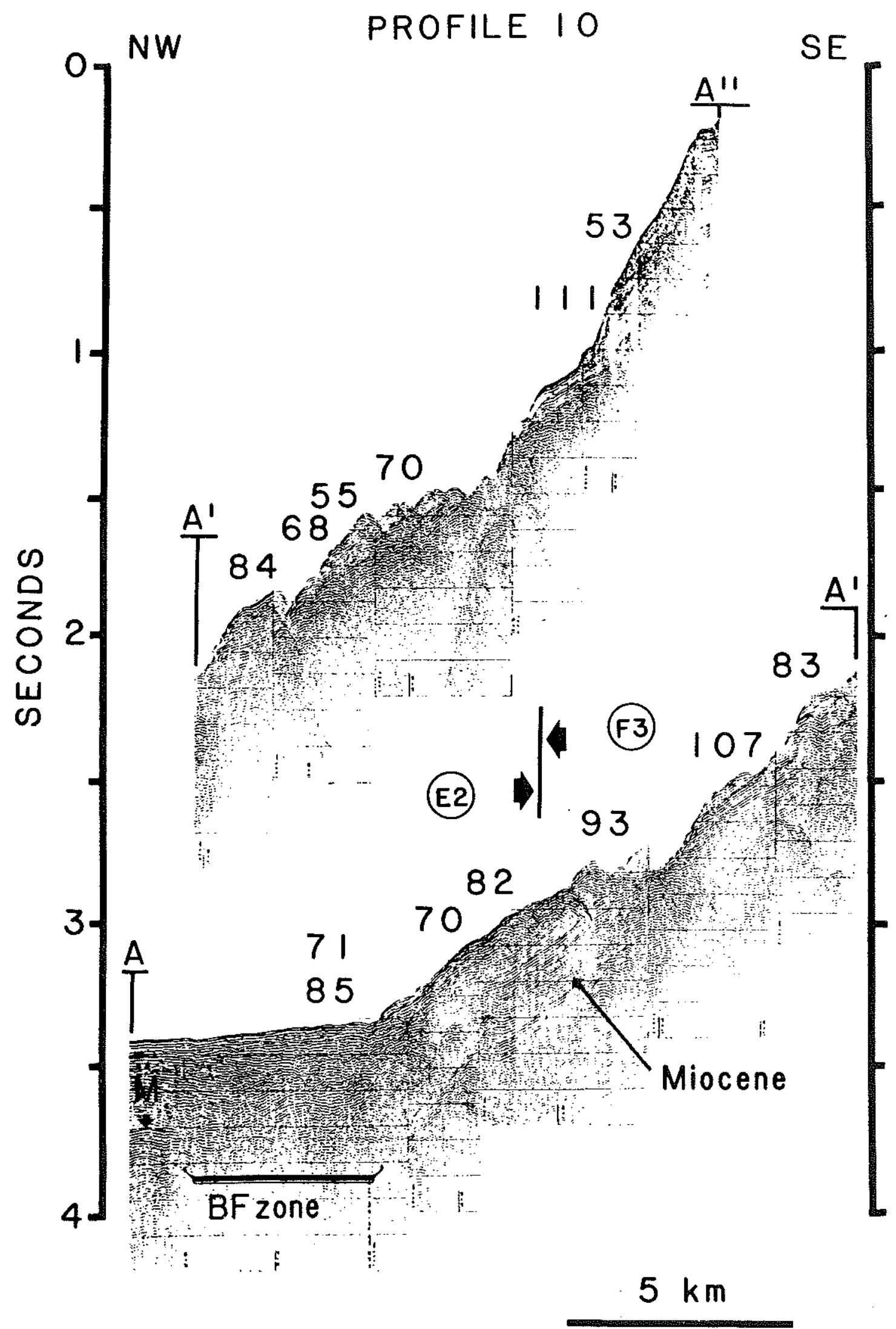

Fig. A5.24 


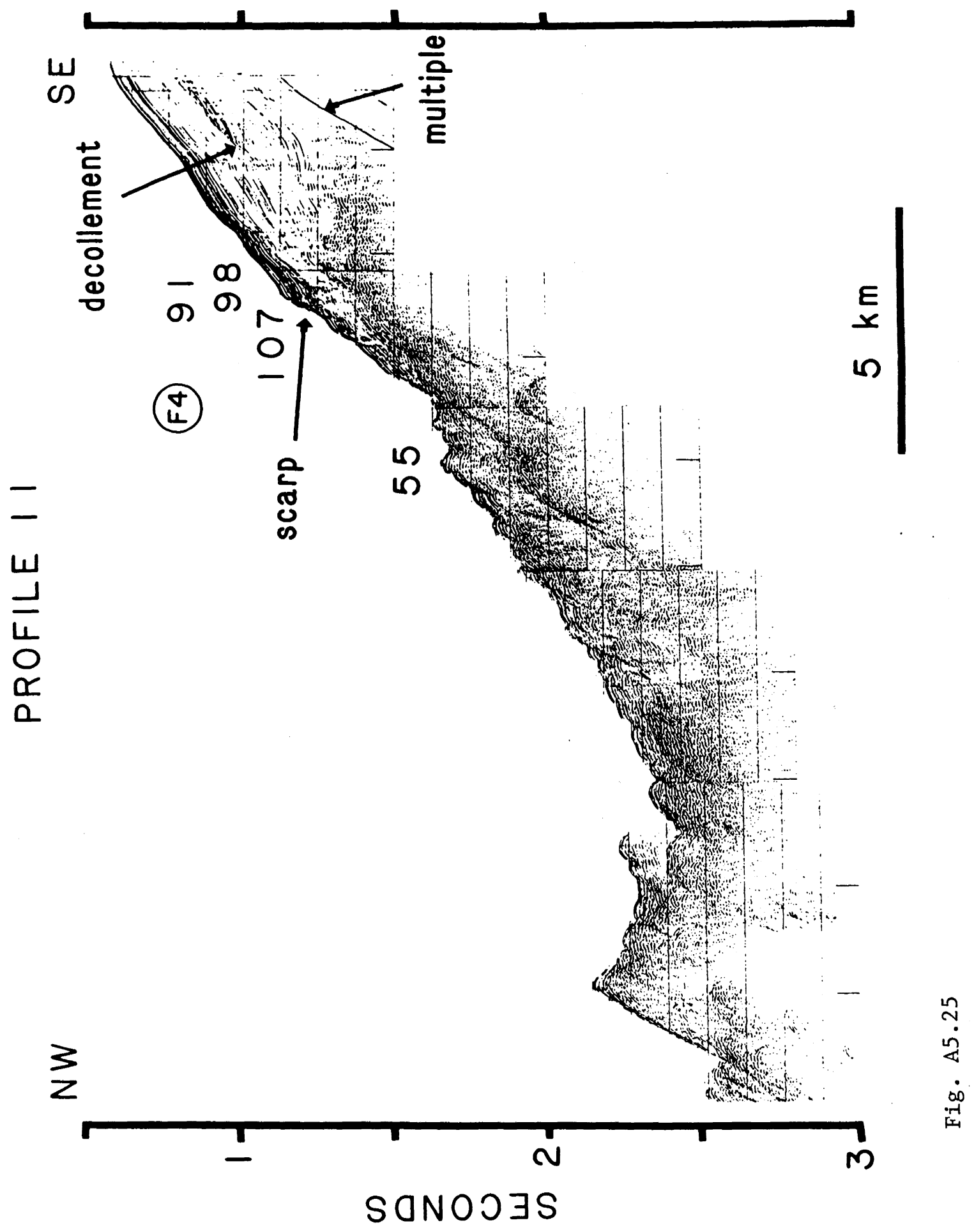




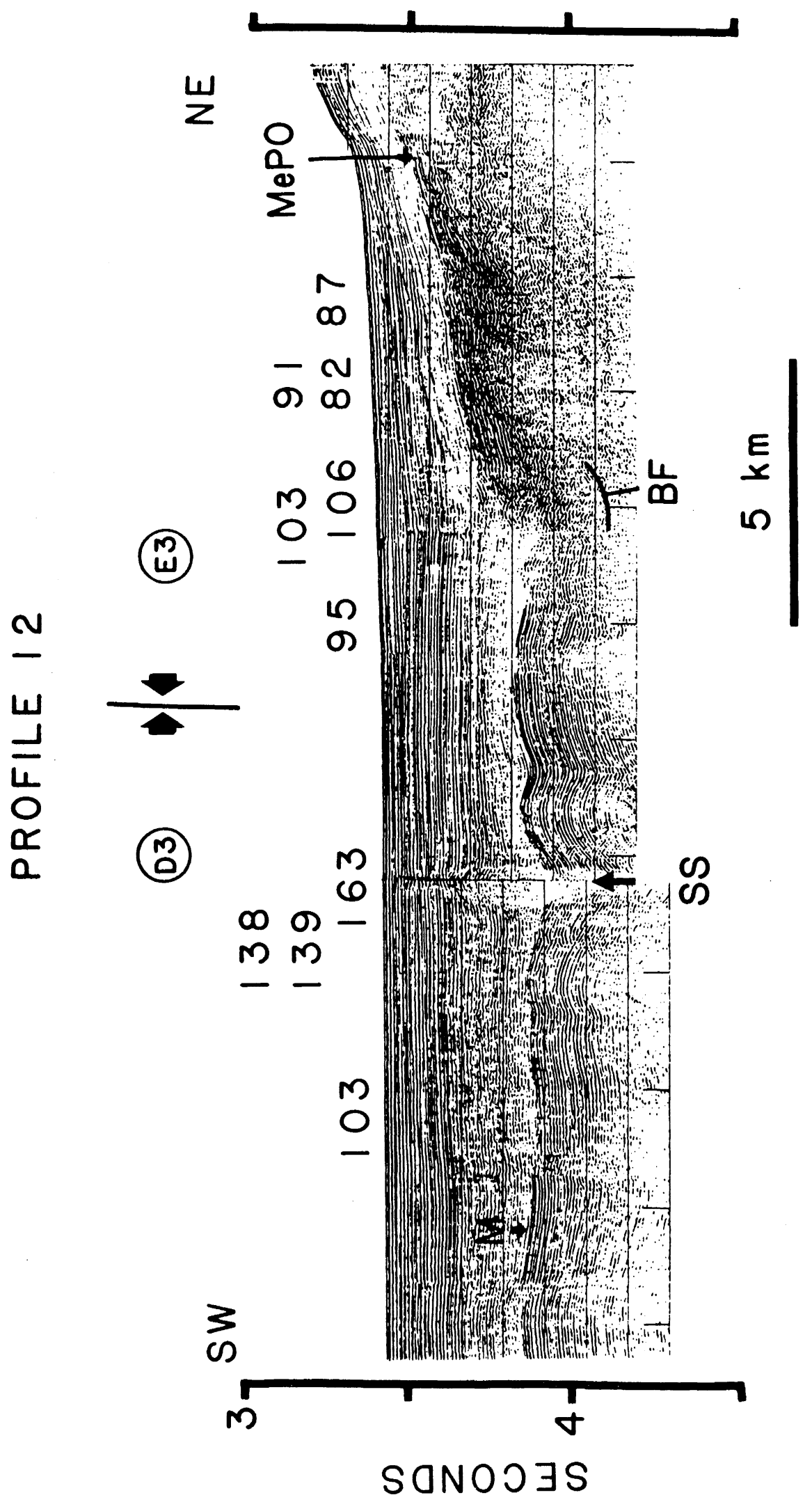

文 